\title{
ABHANDLUNGEN
}

DER AKADEMIE DER WISSENSCHAFTEN ZU GÖTTINGEN

NEUE FOLGE

\author{
Band 21
}

Homer,

\section{gedeutet durch ein großes Lexikon}

Herausgegeben von

Michael Meier-Brügger 
Homer, gedeutet durch ein großes Lexikon 


\section{Abhandlungen der Akademie der Wissenschaften zu Göttingen}

Neue Folge, Band 21

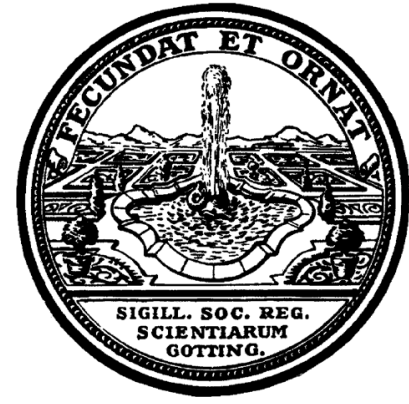

De Gruyter 


\title{
Homer, gedeutet durch ein großes Lexikon
}

\begin{abstract}
Akten des Hamburger Kolloquiums vom 6.-8. Oktober 2010 zum Abschluss des Lexikons des frühgriechischen Epos
\end{abstract}

Herausgegeben von

Michael Meier-Brügger

De Gruyter 


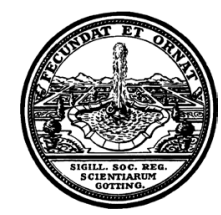

Vorgestellt von Christian Starck durch Rundschreiben vom 26. Juni 2012.

ISBN 978-3-11-028518-5

e-ISBN 978-3-11-029257-2

ISSN 0930-4304

Library of Congress Cataloging-in-Publication Data:

A CIP catalog record for this book has been applied for at the Library of Congress

Bibliografische Information der Deutschen Nationalbibliothek

Die Deutsche Nationalbibliothek verzeichnet diese Publikation in der Deutschen Nationalbibliografie; detaillierte bibliografische Daten sind im Internet über http://dnb.dnb.de abrufbar.

(C) 2012 Walter de Gruyter GmbH \& Co. KG, Berlin/Boston

Druck: Hubert \& Co. GmbH \& Co. KG, Göttingen

@ Gedruckt auf säurefreiem Papier

Printed in Germany

www.degruyter.com 


\title{
Geleitwort des Präsidenten der Akademie der Wissenschaften zu Göttingen
}

\author{
CHRISTIAN STARCK
}

I.

Das Vorhaben „Lexikon des frühgriechischen Epos“, dessen Abschluss heute mit einem Kolloquium gefeiert wird, ist seit 1980 im Rahmen des Akademienprogramms von der Akademie der Wissenschaften zu Göttingen betreut. Deshalb stehe ich als ihr derzeitiger Präsident hier, um in Form eines Grußwortes einiges zu dem Vorhaben und Worte des Dankes zu sagen.

Das Akademienprogramm, das seit 30 Jahren langfristig angelegte Forschungsvorhaben vor allem in den Geisteswissenschaften fördert, wird von Bund und Ländern gemeinsam finanziert. Die heute insgesamt über 160 Vorhaben stellen zusammengenommen das größte Forschungsprogramm in den Geisteswissenschaften dar, und zwar auch europaweit. Die einzelnen Forschungsvorhaben, die heute durch ein mehrstufiges Auslese- und Prüfungsverfahren gehen, erschließen und sichern kulturelle Wissensbestände, die zugleich vergegenwärtigt und für andere Wissenschaften nutzbar gemacht werden.

In dieses Programm ist das Hamburger Projekt „Lexikon des frühgriechischen Epos" 1980 aufgenommen worden, das schon vorher - auf Initiative von Bruno Snell - seit Ende des 2. Weltkrieges betrieben worden war. Der 1. Band, der fünf Lieferungen vereinigte - die erste 1955 erschienen - und ausschließlich den Buchstaben Alpha umfasste, lag 1979 gedruckt vor. Die Arbeitszeit von 25 Jahren für den Buchstaben Alpha hochgerechnet auf alle Buchstaben bis Omega hätte annähernd zweihundert Jahre erfordert.

Um eine Vollendung des Lexikons innerhalb eines überschaubaren Zeitraums möglich zu machen, wurde eine wesentliche Konzentration und Straffung des ursprünglichen Planes vereinbart. In sorgfältigen Beratungen der von der Akademie eingesetzten Kommission mit der Hamburger Redaktion wurde ein Plan für die zukünftige Arbeitsweise entwickelt, der die ursprüngliche Konzeption weitgehend bewahrte, zugleich aber wesentliche Einschnitte machen musste. So steht es in der Einleitung zur ersten Lieferung des 2. Bandes, erschienen 1982. Günther Patzig, von dem die Einleitung stammt, prognostizierte damals weitere 20 Jahre bis zum Ende des Jahrhunderts. Die 20 Jahre waren realistisch, wenn man das Erscheinen des gesamten 2. Bandes im Jahre 1991 zum Ausgangspunkt nimmt. Der 3. Band My bis Pi ist 2004 und der 4. Band von Rho bis Omega ist jetzt 2010 erschienen. 
II.

Die Idee für das Projekt kam, wie schon erwähnt, von Bruno Snell. Der Bildungsweg von Snell ging über Jurisprudenz und Volkswirtschaftslehre - studiert in Edinburg - zur antiken Philosophie und klassischen Philologie. In seiner Göttinger Dissertation (1922) über die Ausdrücke für den Begriff des Wissens in der vorplatonischen Philosophie behandelte er die allmähliche Entstehung der Begriffsbildung bei den Griechen. Bei Homer, so sagte er, sei es noch um sinnliche Wahrnehmung und handwerkliche Fähigkeiten gegangen. In Anknüpfung an seine Dissertation hat Snell später in seinem Aischylos-Buch die Ansicht vertreten, dass das Bewusstsein von eigenen Entscheidungen erst bei Aischylos auftrete, bei Homer dagegen noch fehle, wo die Menschen den Anstoß zu aktivem Handeln von den Göttern erhielten. So hat es Winfried Bühler in seinem Nachruf auf Snell formuliert (Jahrbuch der Akademie 1989, S. 111). In Snells Buch „Die Entdeckung des Geistes“, 1. Auflage 1946, steht der Satz, dass, was sich nicht in der Sprache artikuliert, auch nicht im Bewusstsein existiert.

Vieles hat Snell in den Jahren 1933-1945 erarbeiten können, in denen er mit Mut, Intelligenz und Witz sich nicht angepasst hat. 1936 veröffentlichte er einen kleinen Aufsatz über den goldenen Esel bei Apuleius, um mit der Bemerkung schließen zu können, dass im Gegensatz zu den griechischen Eseln, deren Laute mit dem auf die Negation oủ führenden Vokal o wiedergegeben würden, die deutschen Esel immer nur Ja sagten.

Zur Stützung seiner Sprachbeobachtungen (freilich nicht der Esel, sondern Homers) gründete er 1944 im Hamburger Seminar das Lexikon des frühgriechischen Epos, gewissermaßen ein Teil eines gedachten Thesaurus Linguae Graecae, für den Wortschatz von Homer und Hesiod. Damit sollten ältere Homerlexika, etwa von H. Ebeling (1885), die nicht mehr auf dem Stand der Homerforschung waren, von Grund auf ersetzt werden.

Wenn nun das Werk in vier großen stolzen Bänden vollendet vorliegt, wäre es interessant zu erfahren, ob die Arbeit am Lexikon die Aussagen von Bruno Snell über Sprache und Bewusstsein, über frühe sinnliche Wahrnehmung und spätere Begriffsbildung sowie über göttliche Anstöße und menschliches Bewusstsein von eigenen Entscheidungen sich bewahrheitet haben.

\section{III.}

Am Schluss noch Worte des Dankes:

Die Anfänge des Lexikons haben die Hamburger Wissenschaftliche Stiftung, die DFG und ihre Vorgängerin, die Notgemeinschaft der deutschen Wissenschaft, aber auch die Akademie der Wissenschaften zu Göttingen finanziell gefördert. Mit der Übernahme des Vorhabens ins Akademienprogramm war es - vorausgesetzt das Bestehen von Evaluationen - finanziell gesichert bis zum Abschluss.

Vielen Personen ist zu danken, den vielen sprachkundigen Mitarbeitern des ersten Vierteljahrhunderts: Walter Jens, Klaus Alpers, Thomas Galzer, 
Joachim Latacz, der sogleich über Homer und Europa sprechen wird, Klaus Nickau und Stephan Radt. Nach dem Erscheinen des 1. Bandes konnte die damalige Leiterin des Lexikons, Frau Eva Maria Voigt, der Göttinger Akademie ein konsequent durchdachtes, einheitliches und gestrafftes Konzept vorlegen, dessen Qualität so gut war, dass die Akademie von der Möglichkeit eines erfolgreichen Abschlusses in einer noch überschaubaren Zeit überzeugt werden konnte. Wir sind hier vor allem Günther Patzig zu großem Dank verpflichtet. Durch seine zweifache Kompetenz in der Philosophie und in der Klassischen Philologie konnte er dem ursprünglichen Anliegen Snells gerecht werden und es zugleich in eine neue, zielgerichtetere Arbeitsphase überführen.

Günther Patzig hatte von 1980 bis 1996 den Vorsitz der Leitungskommission der Akademie für das Lexikon des frühgriechischen Epos inne. Von seinem fachlichen Rat und seiner menschlichen Führung berichten die Mitarbeiter des Lexikons bis heute mit großer Begeisterung. Ihm folgten jeweils für sechs Jahre Ernst Heitsch und jetzt bis zum Schluss Arbogast Schmitt. Von der gemeinsamen Begeisterung für die Sache, die auf diese Weise entstand, zeugt auch, dass die zur Kerngruppe gehörenden Mitarbeiter auch nach ihrer Pensionierung dem Lexikon weiterhin ihre Arbeitskraft zur Verfügung stellten. Nur so konnte die große Masse der Artikel bewältigt und vor allem die Artikel mit schwierigen, komplexen Themen, deren Bearbeitung eine große Vertrautheit mit dem gesamten homerischen Text und der dazu gehörenden Forschungsliteratur voraussetzten, noch geschrieben werden. Im Namen der Akademie möchte ich ausdrücklich den Herren Langholf, Führer, Schmidt, Nordheider und Beck für ihren großen Einsatz danken.

Einen besonderen Dank richte ich auch an Michael Meier-Brügger, der in der Nachfolge von Eva Maria Voigt seit 1984, d.h. fast über die ganze Göttinger Zeit, das Lexikon als Redaktor betreute. Trotz eines Rufes an die Freie Universität Berlin führte auch er ohne offizielle Anstellung in idealistischem Engagement die Redaktionsarbeit am Lexikon weiter. Alle Lieferungen seit 1984 sind unter seiner Verantwortung entstanden.

Den letzten, aber keineswegs geringsten Dank möchte ich der Stadt und der Universität Hamburg aussprechen. Die Universität hat das Lexikon in ihren Räumen von der ersten Stunde an beherbergt, die Stadt Hamburg hat in allen Phasen der Geschichte des Lexikons ihre finanzielle und ideelle Unterstützung aufrecht erhalten. Für diese Hilfe sind wir dankbar. Daran wird das Lexikon dauerhaft erinnern.

Dem jetzt beginnenden Kolloquium wünsche ich Erfolg, Anregungen, Erkenntnisse und wissenschaftliche Gemeinschaft unter dem stark leuchtenden Stern Homers, der uns, wie Albrecht Dihle vor kurzem in Göttingen erläutert hat (A. Dihle, Hellas und der Orient. Phasen gegenseitiger Rezeption, Berlin, New York 2009), vieles vom Orient vermittelt hat. 
Bereitgestellt von | SUB Göttingen Angemeldet

Heruntergeladen am | 27.10.14 12:26 


\title{
Grußwort des Verlegers
}

\author{
DIETRICH RUPRECHT
}

Mit großer Freude und Genugtuung konnte der Verlag V\&R im Juli die beiden letzten Lieferungen des Homer-Lexikons ausliefern, so dass das vierbändige Werk von insgesamt fast 3.400 Seiten nunmehr vollständig vorliegt, 55 Jahre nach Beginn der Publikation. Bruno Snell hatte bereits 1949 die Verhandlungen mit meinem Vater über künftige Veröffentlichungen des "Thesaurus" aufgenommen. Bei seinem Besuch in Göttingen am 17. Oktober 1950 kamen die wichtigsten Vereinbarungen zur Sprache. Auch die Oxford University Press, berichtete er, habe bereits Interesse an dem Lexikon bekundet. Er neige indessen zu einem deutschen Verlag, zumal, wenn dieser wie V\&R über eine erfahrene Druckerei verfüge. Er äußerte die kühne Hoffnung, in den folgenden Jahren je ein Zwölftel des Gesamtumfangs im Manuskript vorzulegen. Eine Auflage von 1000 Exemplaren hielt er für angemessen. Man einigte sich schnell auf das große Format des Lexikons von Liddell-Scott (OUP), jedoch der bequemeren Lesbarkeit wegen auf eine größere Drucktype und weiteren Zeilenabstand. Bereits wenige Wochen später konnte der Verlag einen Probesatz der Druckerei Hubert \& Co. vorlegen, der von den Gutachtern gebilligt wurde. Zusätzlich wurde, anders als bei Liddell-Scott, um eine Zeilenzählung zwischen den beiden Satzspalten gebeten.

Übrigens teilte Snell um diese Zeit, damals noch Mitherausgeber der Vierteljahrsschrift "Philologus", dem 84-jährigen Herausgeber unserer "Glotta", Paul Kretschmer, mit, er werde das Engagement beim "Philologus« aufgeben, um künftig die "Glotta" mit herauszugeben. Er betrachte diese als Organ, in welchem über Erfahrungen und Ergebnisse im »Thesaurus « berichtet werden könne.

Im heutigen Rahmen möchte ich nun auf einige verlagsspezifische Gesichtspunkte eingehen.

In der langen Druckgeschichte dieses anspruchsvollen Lexikons spiegelt sich die in jenen Jahrzehnten rapide technische Entwicklung, vor allem der Satzverfahren wider. Bis zur zwölften Lieferung (1987) wurde noch der traditionelle Bleisatz auf der Monotype-Maschine benutzt, am Ende noch durch einen pensionierten, betagten Schriftsetzer. Wegen der davonlaufenden, nicht mehr finanzierbaren Satzkosten drängte der Verlag bei Lieferung 13 darauf, zu den noch in der Entwicklung begriffenen elektronischen Verfahren überzugehen. Die Manuskripte wurden fortan in der Hamburger Redaktion mit den 
erforderlichen Steuerungssymbolen erfasst, die so entstehenden Datenträger konnten dann elektronisch die Satzgeräte in der Druckerei steuern. Der Übergang auf dies Verfahren brachte zunächst Probleme mit sich und erforderte enge Zusammenarbeit zwischen Druckerei, Verlag und Redaktion, letztere erwies sich bei diesem neuen Gebiet als erfreulich lernfähig und flexibel. Wirtschaftlich würde das Lexikon von da an von Zuschüssen unabhängig; der Verlag konnte einen gewissen Beitrag zur Texterfassung beisteuern.

Die Verbindung zu dem ideenreichen Bruno Snell erwies sich für den Verlag als überaus fruchtbar. Bereits 1950 bei der Planung des Lexikons hatte Snell beabsichtigt, zu dessen Ergänzung noch einen archäologischen Band hinzuzufügen. Diesen Gedanken konkretisierte und erweiterte er zehn Jahre später: Zusammen mit dem Marburger Archäologen Friedrich Matz und in Verbindung mit dem Deutschen Archäologischen Institut (DAI) entstand der Plan eines umfangreichen Sammelwerks "Archaeologia Homerica. Die Denkmäler und das frühgriechische Epos", in 26 nach Sachgebieten eingeteilten Lieferungen. Das Werk begann $1967 \mathrm{zu}$ erscheinen. Nach dem Tode von Friedrich Matz übernahm Hans-Günter Buchholz die Herausgeberschaft. Nach längerer Unterbrechung kann in dieser Woche die vorletzte Lieferung "Kriegswesen, Teil 3 « vorgelegt werden; wir rechnen mit dem Abschluss des Werkes (3 reichlich bebilderte Bände) noch 2012 (Indices-Band voraussichtlich 2013), so dass auch dieses zweite Langzeitprojekt Snells nach über 50 Jahren vollendet wäre. - Nach Snells eigenem Bekunden betrachtete er als seine Hauptaufgabe eine umfassende Neuedition der Fragmente der griechischen Tragiker, unter Berücksichtigung der zahlreichen Papyrusfunde. Die von ihm selbst mit den »Tragici Minores" begonnene fünfbändige Edition wurde aufopferungsvoll von Stefan Radt (Aeschylus und Sophocles) und Richard Kannicht (Euripides) 2004 beendet.

Als eine Frucht des »Thesaurus" muss hier wenigstens erwähnt werden der "Index Hippocraticus« (zunächst als Lexikon geplant), mit den drei ergänzenden Testimonien-Bänden.

Über die weiterhin von Snell im Verlag angestoßene Reihe "Studienhefte zur Altertumswissenschaft" und "Hypomnemata. Untersuchungen zur Antike und ihrem Nachleben" zu sprechen, ist im heutigen Zusammenhang nicht möglich. Um diesen Untertitel zum Schluss aufzugreifen: Mein knapper Überblick sollte auch gezeigt haben, dass dem Nachleben der herausragenden Persönlichkeit Bruno Snells noch eine beträchtliche Dauer beschieden sein dürfte. 


\section{$\mathrm{Zu}$ diesem Band}

\section{MiCHAEL MEIER-BRÜGGER}

Das Lexikon des frühgriechischen Epos (LfgrE) ist nach einem halben Jahrhundert konzentrierter philologischer Arbeit vollendet. Es bietet dem Benutzer vielfache Information zum gesamten frühgriechischen Wortschatz, speziell semantisch. Die erste Lieferung datiert von 1955, die letzte Lieferung von 2010. Es ist gute Tradition, den Abschluss eines Langzeitunternehmens mit einem wissenschaftlichen Kolloquium zum Thema zu markieren und eine Bilanz mit Ausblick in die Zukunft zu ziehen.

Ich erlaube mir, das Programm hier abzudrucken:

\section{Veranstalter:}

Akademie der Wissenschaften zu Göttingen, Arbeitsstelle Hamburg

Lexikon des frühgriechischen Epos, Thesaurus Linguae Graecae, Universität Hamburg

Kolloquium zum Abschluss des LfgrE (1955-2010)

Mittwoch, 06. Oktober 2010, bis Freitag, 08. Oktober 2010

Thema: Homer, gedeutet durch ein großes Lexikon

Mittwoch, 06.10.2010

19 Uhr Eröffnung im Hörsaal C im Hauptgebäude der Universität Hamburg

Arbogast Schmitt, Vorsitzender der LfgrE-Leitungskommission der Akademie

Christian Starck, Präsident der Akademie

Dietrich Ruprecht, Verleger

Weitere Grußworte aus Göttingen und Hamburg

20 Uhr öffentlicher Abendvortrag

Joachim Latacz (Basel): Homer und Europa. Höhepunkte des Homerischen Einflusses auf die europäische Kulturentwicklung

\section{Uhr Empfang}

Donnerstag, 07.10.2010

$09.00-10.00$

M. Schmidt (Hamburg): Snells Erben: zur Geschichte des Lexikons

$10.00-10.30$ Kaffeepause

$10.30-12.30$

R. Führer (Hamburg): Worte im Kontext 
H. W. Nordheider (Hamburg): Patroklos und Phoinix in der Ilias (samt einem Anhang zu den Bremer Stadtmusikanten)

E. Tichy (Freiburg): Ilias diachronica: zur sprach- u. versgeschichtlichen Analyse des Ksi

12.30 - 14.00 Mittagspause

$14.00-15.00$

I. de Jong (Amsterdam): The interpretation of hode and houtos in Homeric speeches

$15.00-16.00$

H. Hettrich (Würzburg): Präpositionalausdrücke bei Homer

$16.00-16.30$ Kaffeepause

$16.30-17.30$

R. Scodel (Michigan): The language of Homeric Theory of Mind

$17.30-18.30$

A. Schmitt (Marburg): Vom Gliedergefüge zur handelnden Person. Snells entwicklungsgeschichtliche Homerdeutung und das Homerbild heute.

18.30 Kleines Buffet

20.00 öffentlicher Abendvortrag

W.-D. Niemeier (Athen): Griechenland und Kleinasien in der späten Bronzezeit: der historische Hintergrund der hom. Epen

\section{Freitag, 08.10.2010}

$09.00-10.00$

A. Rengakos (Thessaloniki): Der Antike Homertext. Versuch einer (vorläufigen) Bilanz

$10.00-10.30$ Kaffeepause

$10.30-11.30$

R. Nünlist (Köln): Aristarch und das LfgrE

$11.30-12.30$

F. Montanari (Genova): Glosse dialettali negli scholia all'Iliade

$12.30-14.00$ Mittagspause

$14: 00-15.00$

C. Calame (Lausanne / Paris): Die Homerischen Hymnen als musikalische Opfer: poetische und rituelle Beziehungen zu den Göttern

$15.00-15.30$ Kaffeepause

$15.30-16.30$

G. Uhlmann (Berlin): Nostos und Philoxenia: Zu Pattern, Normen und Charakter in den Apologoi der Odyssee

$16.30-17.30$

G. Danek (Wien): Homer und Avdo Međedović als „post-traditional singers“?

17.30 - 18.30 Abschlussvortrag

M. Meier-Brügger (Hamburg / Berlin): Zuerst in paar Worte zum Abschnitt E des LfgrE. Danach abschließend mehr subjektiv mit einem weinenden und einem lachenden Auge ein alphabetisch angeordnetes, bebildertes Dankeschön von Akademie bis V.Yntema.

20 Uhr Schlußbankett im Völkerkundemuseum 
In den hier vorgelegten Akten stehen die Grußworte des Präsidenten der Akademie und des Verlegers voran. Dann folgen zur besseren Handhabung die Vorträge in alphabetischer Reihenfolge. Herr Dr. Peter Busse (Berlin) hat mich bei der Redaktion mit großem Einsatz unterstützt. Dank sei F. von Sassen und J. Brauch vom Verlag.

Michael Meier-Brügger 
Bereitgestellt von | SUB Göttingen Angemeldet 


\section{Inhalt}

CHRISTIAN STARCK

Geleitwort des Präsidenten der Akademie

DIETRICH RUPRECHT

Grußwort des Verlegers

Michael MEIER-BRÜGGER

$\mathrm{Zu}$ diesem Band XI

Claude Calame

Die Homerischen Hymnen als poetische Opfergaben:

Musikalische und rituelle Beziehungen zu den Göttern

GEORG DANEK

Homer und Avdo Međedović als 'post-traditional singers'?

HEINRICH HETTRICH

Präpositionalausdrücke bei Homer

IRENE J.F. DE JONG

Double deixis in Homeric speech:

on the interpretation of ö $\delta \varepsilon$ and oũtos

RUDOLF FÜHRER

Wörter im Kontext

JOACHIM LATACZ

Homer und Europa. Höhepunkte Homerischen Einflusses auf

Europas Kulturentwicklung

MiCHAEL MEIER-BRÜGGER

Ein paar Worte zum Abschnitt E (= Etymologie) des LfgrE

FRANCO MONTANARI

Glosse Dialettali negli Scholia Omerici

WOLF-DIETRICH NIEMEIER

Griechenland und Kleinasien in der späten Bronzezeit.

Der historische Hintergrund der homerischen Epen

HANS-WILHELM NORDHEIDER

Patroklos und Phoinix in der Ilias

RENÉ NÜNLIST

Aristarch und das Lexikon des frühgriechischen Epos 
GYBURG RADKE-UHLMANN

Odysseus bei den Phäaken - Studien zur Heimkehrerhandlung

in den Apologoi der Odyssee

ANTONIOS RENGAKOS

Bemerkungen zum antiken Homertext

MARTIN SCHMIDT

Snells Erben: Zur Geschichte des Lexikons des frühgriechischen Epos

ARBOGAST SCHMITT

Vom Gliedergefüge zum handelnden Menschen.

Snells entwicklungsgeschichtliche Homerdeutung und ein mögliches

Homerbild heute 263

RUTH SCODEL

$\tilde{\eta}$ and Theory of Mind in the Iliad

EVA TICHY

Ilias diachronica:

Zur sprach- und versgeschichtlichen Analyse des $\Xi$

Kleines Sach- und Wortregister

373 


\title{
Die Homerischen Hymnen als poetische Opfergaben: Musikalische und rituelle Beziehungen zu den Göttern
}

\author{
Claude Calame \\ (übersetzt von Peter Busse)
}

Es ist schwer, im Korpus der Homerischen Hymnen einen kürzeren Text zu finden als das in drei Versen an Demeter gerichtete hymnische Gedicht. Dennoch zeigen diese Verse trotz ihrer extremen Knappheit nicht nur die dreiteilige Struktur, auf der jeder homerische Hymnus aufbaut; sie aktualisieren dabei auch noch die essentiellen pragmatischen Aspekte.

Es ist Demeter mit dem schönen Haupthaar, die ehrenwerte Göttin, die ich beginne zu besingen,

sie und ihre Tochter, die sehr schöne Persephone.

Freue Dich, Göttin, und nehme den Gruß dieser Stadt hier an; leite meinen Gesang.

Demeter wird zuerst in der dritten Person durch das Ich der persona cantans angerufen; dann wird die besungene Göttin sehr kurz durch ihre Verwandtschaftsbeziehung zu Persephone charakterisiert; schließlich wird sie direkt durch den Sprecher und Ich-Erzähler angerufen, der sie mit einem ausdrücklich Wunsch anspricht: evocatio, epica laus, preces, gemäß der dreiteiligen Struktur eines jeden homerischen Hymnus, aber ohne dass der zentrale, beschreibende und erzählende Teil hier durch das „hymnische Relativ“ eingeleitet wird; dieses Pronomen kann zur Rezitation mehrerer Dutzend Verse führen, wie es in den längsten homerischen Hymnen der Fall ist ${ }^{1}$. Von einem enunziativen Standpunkt aus gesehen wird das Gebet dieses sehr kurzen Hymnus mit der Formel eingeleitet, welche die meisten Anreden an die Götter beschließt: khaîre. Dieses klangvolle khaîre entspricht nicht einfach einer simplen Grußformel, sie bezieht vielmehr auf die vom Gott empfundene Freude beim Hören der gesungenen Eloge, die an ihn gerichtet ist ${ }^{2}$. In einem Spiel des do ut des

1 Vgl. Calame 1995/2005: 44-49, infolge zahlreicher Strukturrecherchen, darunter die wichtige Studie von Bremer, 1981: 195-203. Eine etwas verschiedene Version dieses Studiums wurde in A. Faulkner (Hrg.), The Homeric Hymns. Interpretative Essays, Oxford (Oxford University Press) 2011, veröffentlicht.

2 Vgl. Calame 1995/2005: 56-58, mit den bibliographischen Verweisen über die Bedeutung von khaírein, wie sie in Fußnote 57 angegeben sind; siehe auch unten (Fußnote 33) was den delischen Teil des Homerischen Hymnus an à Apollon betrifft. 
enthält der Wunsch ein Gebet zum Wohle der Stadt. Infolgedessen wird das Gedicht, durch die Reziprozität, die das Gebet durch die Beziehung mit dem Gott impliziert, als eine musikalische Opfergabe an die Gottheit präsentiert: diese erfreut sich daran und sichert im Gegenzug den Schutz der Stadt.

Aber wer Aussage oder Enunziation sagt, meint auch Pragmatismus, und wer Pragmatismus sagt, meint auch Ethnopoesie. Auf der einen Seite, im Hymnus 13, engagiert sich das poetische Ich in einem zweifachen Sprechakt: zuerst indem sie, in der Eigenschaft als Ich, den Beginn des Gesangs übernimmt (árkhom'aeídein: „,ich beginne zu singen“) und indem sie anschließend die am meisten performative der drei Formen von Anfängen in der homerischen Poesie wählt ${ }^{3}$; er verlangt von der Göttin, den Gesang selber zu beginnen (árkhe d'aoidếs), in einer Bitte, die auf den Wunsch antwortet, der an die Göttin gerichtet ist, sich am Gesang zu erfreuen. In dieser Passage bekräftigt diese zweite Bitte die Funktion der Einleitung bei aedischen Gesängen, weiter bei rhapsodischen Rezitationen, wie sie die homerischen Hymnen darstellen: zuerst die Anrufung des Gottes mit der Bitte, die an ihn gerichtet ist, dann der Gesang selbst, der unter die Inspiration und Autorität der in der Form des Präludiums besungenen Gottheit gestellt wird. Auf der anderen Seite wird die Forderung nach Heil für die Stadt von einer Geste der verbalen Deixis begleitet: es geht darum „diese Stadt hier zu retten“ (ténde sáou pólin). Auf sich selbst bezogen ist der Akt des Singens (aedisch, dann rhapsodisch) in der Zeit und im Raum geortet: er findet im Hier und Jetzt statt. Was die Länge anbetrifft, hat der homerische Hymnus, in seiner Eigenschaft als hymnischer, an eine Gottheit gerichteter Gesang und als musikalische Opfergabe, die Funktion, die rhapsodische Rezitation selbst in einer Reihe von rituellen Akten, die diese Gottheit ehren, einzuleiten. Der homerische Hymnus macht aus der Aufführung des rhapsodischen epischen Gesangs selbst eine rituelle und kultische Handlung ${ }^{4}$. Durch diese enunziativen Mittel nimmt die Erzählung, die oft im Mittelteil gegeben wird, eine ätiologische Funktion gegenüber dem Ritual an, zu dem es führt: vom „Mythos“ zum „Ritus“!

Durch seine einleitende Funktion mit einer kultischen Dimension verwandelt der homerische Hymnus auf eine gewisse Weise den erzählenden Gesang in einen melischen Gesang. Dieser epische Gesang in narrativer Ordnung wird manchmal am Ende des Hymnus selbst durch eine performative Formel angekündigt: seù d'egò arxámenos metabésomai állon es húmnon, „,nachdem ich mit Dir begonnen habe, will ich nun zu einem anderen Gesang übergehen“, und ich tue dies jetzt, hic et nunc. Man weiß nunmehr, dass die verschiedenen Formen

3 Vgl. Calame 2000: 59-69. Der Bezug zwischen der hymnischen Form und der des Gebets wird besonders von Aubriot-Sévin 1992: 172-193 erforscht.

4 Was den homerische Hymnus als rhapsodische Einleitung, wie er schon bei Thukydides 3, 104, beschrieben wird, angeht, siehe die Studien, die ich 1995/2005: 45 (zusammen mit Anmerkung 5) beschrieben und kommentiert habe. Zum Übergang von der aedischen gesungenen Schöpfung zur rhapsodischen Wiederholung, die eher rezitiert wird, siehe Nagy, 1990: 20-25. 
des melos reich an diesen performativen Futuren, die sich selbst auf den Akt des Singens beziehen, sind; es sind diese performativen Formen, die aus dem Homerischen Hymnus eine Form nahe der melischen Poesie macht und es dabei weit von unserem modernen Konzept von „Lyrik“ entfernt ${ }^{5}$.

Durch verschiedene Mittel der Aussage neigt der Homerische Hymnus dazu, mit der Gottheit, die der Aoidos und später Rhapsode besingt, eine praktische und reziproke Beziehung aufzubauen. Durch die gesungene Darbietung, wie sie auf diese Weise gegeben wird, wandelt sich das Gedicht in eine musikalische Opfergabe. Als Erstes ist es die Bestimmung des Homerischen Gedichtes, eine aedische und rhapsodische Rezitation durchzuführen, die eine Kulthandlung einleitet; diese poetische Rezitation wird in die verschiedenen rituellen Handlungen eingeschoben, die eine Gottheit anlässlich ihrer Feier in einer bestimmten Stadt und einem bestimmten Heiligtum ehren. Im Folgenden werden also von dieser ethnopoetischen Perspektive der ritualisierten musikalischen ,performance“ aus die poetischen Mittel untersucht, die in den Homerischen Hymnen eine kultische Beziehung zur besungenen Gottheit herstellen und unterhalten: Benennung und Definition der Gottheit in den einleitenden Versen der evocatio; erzählte musikalische Szenen im beschreibenden und narrativen Teil der epica laus; ,performative“ Enunziation in der abschlieBenden Sektion der preces.

\section{Die aedische und rhapsodische Benennung der Gottheit (evocationes)}

Ich besinge (aeído ) Hermes, den Kyllenier, den Töter des Argos,

Den Herrn des Berges Kyllenios und von Arkadien, reich an Schafen,

Den schnellen Boten der Unsterblichen, der Maia zeugen wird,

Die Tochter des Atlas, würdig des Respekts, die sich mit Zeus in Liebe vereinigen wird.

Jeder Homerische Hymnus beginnt mit der Benennung des angerufenen Gottes in einem Sprechakt, der die Form „Ich besinge“ annimmt (zuerst als Aoidos, dann als Rhapsode) ${ }^{6}$. Man wird sich erinnern, dass besonders für Herodot

5 Abschließend zu Aphr. 293, oder zum Hy. 9. 9 (Artemis), sowohl bei den langen als auch bei den kurzen Hymnen; siehe auch die häufige, abschließende Formel autàr egò kai seîo kaì álles mnésom' aoidês: Apoll. 546 oder der Hy. 6. 21 (Aphrodite), usw.: siehe unten Anmerkung 47. Was die Notwendigkeit betrifft, auf die einheimische Kategorie des mélos zurückzukommen, eine Dichtung, die fälschlich als „lyrisch“ bezeichnet wird, siehe meine Studie 2006a.

$6 \quad H y$. 18. 1-4 (Hermes); in Bezug auf die Formen des Präsens und des performativen Futurs, der generell aus den melischen Gedichten speech acts und als Konsequenz Akte des Gesangs macht, sei noch einmal auf die bibliographischen Angaben in Calame 1995/2005: 59 Anmerkung 25 verwiesen; hierzu auch noch die gute Studie von D'Alessio 2004: 274-284. 
das Benennen (onomázein) eines Gottes nicht einfach ein Akt war, ihm einen Namen zu geben, sondern ihm auch dadurch Qualitäten zuzusprechen; in einem polytheistischen System werden diese Qualitäten in Bezug zu Funktionen gesetzt, die in einem genau geregelten Tätigkeitsfeld ausgeübt werden. Allerdings würde der Name einer Gottheit in einer Perspektive, wie sie noch in Platons Kratylos zu finden ist, nicht von seiner Substanz unterschieden; ohne exakte Unterscheidung zwischen dem Bezeichnenden und dem Bezeichneten bezieht sich der Name des Gottes auf seine Essenz. Und in einer häufig ätiologischen Perspektive wird die Identifikation eines Gottes mit seinem Eigennamen generell begleitet von der Institution von Opferpraktiken oder sogar von der Begründung eines Heiligtums.

Nun entspricht dieser substantielle Benennungsprozess der Götter alles in allem demjenigen, für den mehrere Homerische Hymnen das Vehikel darstellen: der erzählerische Teil des hymnischen Gedichts besteht oft daraus, zu definieren und dem gelobten Gott seine timé zuzuordnen, das heißt der Teil, der ihm wirklich zukommt, im Kontrast zu den anderen Göttern des Pantheons einer bestimmten polis. Im alten Griechenland ist dieses Pantheon immer mobil und integriert verschiedene heroische Figuren und variiert in historischer Zeit und von einer Stadt zur anderen ${ }^{7}$. Auf diese Art, weit vor den Vorschlägen von Georges Dumézil zur Annäherung an die Götter in einem polytheistischen System, definieren sich die griechischen Götter auf einheimische Art und Weise durch einen Namen und ein Profil, das sie auf spezifische Funktionen und Interventionsmodi in einem bestimmten Bereich des sozialen Lebens der Sterblichen verweist ${ }^{8}$.

Aber die Namensgebung wird regelmäßig begleitet von Benennungen mit Termini, die schon bei jemandem wie Pausanias einfach als „Epiklesen“ identifiziert werden: einfache Beinamen, die im Falle der Götter oft von den Dichtern geschaffen werden können und teilweise lokalen Namen entsprechen oder epikléseis, die von allen geteilt werden'. Ohne jegliche Systematik zu haben, erlaubt die von Pausanias vorgeschlagene Unterscheidung im Bezug auf Poseidon, wie er in Achaia verehrt wird, eine operative Unterscheidung zwischen den wahren Theonymen, den poetischen Beinamen, den Epiklesen aus lokalen Kulten und den Epiklesen von „panhellenischer“" Verbreitung, in Kategorien, die sich oft überschneiden. Wegen ihres narrativen Charakters bieten

7 Vgl. Herodot 2, 49, 1-50, 2, mit den von mir gegebenen Verweisen in Hinsicht auf die Bedeutung der Denomination in meiner Studie von 2011; was den Prozess der Attribution der timaí betrifft, der in den Homerischen Hymnen stattfindet, siehe besonders Strauss Clay 1987: 15-16 et passim.

8 Zusammen mit den verschiedenen bibliographischen Referenzen habe ich diese Beziehung zwischen der indigenen Perspektive und den wissenschaftlichen Standpunkt über die Organisation des polytheistischen Systems im Beitrag 2006b: 210-225 ausgefuihrt.

9 Pausanias 7, 21, 7-8; hierzu siehe den guten Kommentar von Pirenne-Delforge 2008: 263-271. 
die Homerischen Hymnen eine Vielzahl an Benennungen poetischer Natur: der „schnelle Bote der Unsterblichen“, wie sich in Hymne 18 auf Hermes bezogen wird, in einer Benennung, die mittels eines „hymnischen Relativs“ angeschlossen wird, und die exakt den narrativen und mythischen Teil des Gedichtes einleitet; dies ist auch in der Einleitung zum langen Hymnus an Hermes der Fall, unter Verwendung desselben formelhaften Verses. Andererseits, wenn Argeiphontes generell in der homerischen Dichtung als alternativer Theonym für Hermes angesehen werden kann, bezieht sich die einleitende Benennung des Gottes, von dem erzählt und der besungen wird, oft auf seinen Ursprungsort oder auf seinen bevorzugten Wirkungsraum: Hermes der Kyllenier herrscht auf dem Berg Kyllenios in Arkadien, wo er geboren wurde (ebenso im langen Hymnus) ${ }^{10}$.

Dieser Parameter von geographischer Natur ist wichtig für die Beziehungen, welche die Bezeichnung und Benennung mit dem Gott herstellen, so dass er als tragendes Element der Erzählung gelten kann. Der Homerische Hymnus an Apollon stellt zum Beispiel die aufzählende und performative Frage, wie man weiß, wie man einen so berühmten Gott richtig besingen kann ( $p \underline{o} s$ t'ár s’humnéso pántos eúumnon eónta;); außer dieser rhetorischen Frage durchläuft der Bericht des Hymnus alle jene Orte, die als mögliche Geburtsorte in Frage kommen, um diese schließlich auf Delos zu lokalisieren, nach einer langen Liste von Städten im insularen und ägäischen Griechenland, dann in Delphi, am Ende einer neuen geographischen Strecke, die aber in Festlandgriechenland liegt ${ }^{11}$. Die aedische oder rhapsodische Erzählung wird so zum ätiologischen Mythos, er erklärt die musikalischen Ehren, die dem Gründergott in seinem Heiligtum von Delos zuteil werden, und die Kraft seiner Orakelstimme im Bereich von Delphi.

Diese Markierung örtlicher Natur, mit ihrer manchmal ätiologischen Funktion, wird normalerweise verdoppelt mittels einer Andeutung genealogischer Natur: Raum und Zeit. Es ist oft durch diese zeitliche Markierung, dass sich der Übergang von der evocatio zur epica pars mittels eines hymnischen Relativs vollzieht: der Übergang vom „Diskurs“ (markiert durch den Gebrauch der ersten Person im Präsens oder in einem performativen Futur, hier und jetzt) zur Form des „Berichts“ (dritte Person, Aorist und dort), um die zwei vom Linguisten Émile Benveniste vorgeschlagenen linguistischen Kategorien aufzunehmen $^{12}$. Es war auf dem Berg Kyllenios, wo Maia Hermes nach ihrer Vereinigung mit Zeus empfangen hat, wie es sowohl im kurzen als auch im

10 Dieser Befund gilt für die Form des Hymnus im Allgemeinen: vgl. Furley \& Bremer 2001: 52-56. Zu Argeiphontes als „Synonym“ für Hermes, siehe z. B. Homer, Ilias 2, 103-104 und Odyssee 1, 84, ebenso wie in den Hymnen selbst, Hy. 29. 7 (Hestia); vgl. Jaillard 2007: 211.

11 Apoll. 19; diese rhetorische Frage mit ihrer Form des performativen Futurs wird wiederaufgenommen am Übergang zu, delphischen Teil (Vers 207); vgl. Miller 1986: 2026 ebenso wie Nagy 2009: 17-19.

12 Vgl. Calame 1995/2005: 49-51. 
langen Hymnus steht. Ebensolches geschieht zum Beispiel auch an den Ausläufers des Taygetes, wo Leda die beiden Dioskuren gebiert, die beide als Tyndarides und Söhne des Zeus vorgestellt werden; genauso verhält es sich mit Asklepios, der als Sohn des Apollon von Koronis in der Ebene Dotion in Thessalien geboren wird; und es ist in den Talmulden des Berges Nysa (wo auch immer dieser genau lokalisiert wird), wo die Nymphen den kleinen Dionysos, der aus der Vereinigung des Zeus mit Semele hervorgegangen ist, aufziehen $^{13}$. Infolge dieser benennenden Bezeichnung, die mit einigen eher poetischen als kulturellen Charakteristika versehen wird, wird der Gott im einleitenden Teil der evocatio häufig mit einer geographisch-genealogischen Identität versehen.

Von einem syntaktischen Standpunkt aus gesehen ist die Aufzählung der poetischen Qualitäten und der etwaigen Epiklesen, die dem besungenen Gott zugeschrieben werden, aber charakterisiert durch einen parataktischen und asyndetischen Prozess. Obwohl das im Griechischen selten ist, wird dieser Prozess an den Ausdruck einer starken Emotion angeschlossen. Er markiert besonders die Aufrufe an die Gottheit, die die kultischen Hymnen einleiten und betonen, wie im Paian, das „Philodamos“ zugeschrieben wird: „Hier, oh Herr, Dithyrambos, Bakchos, Gott der Evoë, Stier gekrönt mit Efeu, Bromios, in dieser frühlingshaften Jahreszeit hier", dann in einem anderen metrischen Rhythmus: „Euoi, ô io Bacchos, ô ie Paian“. Weder die anfängliche Anrufung des Gottes noch der eingeschobene Refrain, der sich nach jeder Strophe dieses hymnischen Gesangs wiederholt weisen irgendeine Verbindungspartikel auf ${ }^{14}$. Invocatio (in der zweiten Person) und nicht einfach eine evocatio (in der dritten Person), die direkte Anrede an die Gottheit strebt mittels der musikalischen „performance“ des Gesangs deren Erscheinung an. Der Prozess wurde in den Orphischen Hymnen bis zum Extrem getrieben; der größter Teil besteht aus der Aufzählung der Qualitäten des besungenen Gottes in asyndetischen Parataxen. Der Prozess entspricht zugleich der Anrufungsopfergabe für die besungene Gottheit, die durch das hymnische, orphische Gedicht repräsentiert wird und des weiteren der eigentlichen theologischen Absicht der orphischen Bewegung, die Götter des traditionellen Pantheons zu überlagern, um sie zu einer Einheit mit Zeus zu verschmelzen ${ }^{15}$. Im Homerischen Hymnus im Allgemeinen verbindet sich die asyndetische Anrufung des Namens des Gottes und seiner

13 Hy 17. 1-6 (Dioskuren; vgl. auch 33, 1-5), Hy. 16. 1-3 (Asklepios), Hy. 26. 1-5 (Dionysos); vgl. Furley \& Bremer 2001: I, 54-55.

14 Paian 40. 1-5 Käppel; siehe hierzu den guten Kommentar von Furley \& Bremer, 2001: II, 58-60; zur Parataxe in der Definition des angerufenen oder heraufbeschworenen Gottes, vgl. I, 53-54.

15 Vgl. Hopman-Govers 2001: 37-49, und Morand 2001: 59-76. Es ist wegen dieses Versmaßes, dass der Homerische Hymnus 8 an Ares, der aus einer Ansammlung von asyndetischen Beinamen bestehet und der die hymnische Form des Gebets annimmt, als auf orphische Inspiration zurückgehend angesehen werden kann: vgl. Càssola 1975: 297-299. 
Qualitäten mit dem Akt des Singens, der durch die autoreferentiellen Formen in der ersten Person repräsentiert wird; die asyndetische Parataxe der Beinamen und die performativen Verbalformen geben der einleitenden Bezeichnung der Gottheit ihre pragmatische Dimension. Diese Anrufung zielt zweifellos nicht auf die Erscheinung der besungenen Gottheit, sondern in jedem Fall auf deren Lobpreisung. Es geht darum, die Gottheit mit einer musikalischen Opfergabe zu ehren, die in der aedischen und rhapsodischen Rezitation weitergeführt wird, die durch den Homerischen Hymnus als poetische Form und Genre eingeführt wird. Der Homerische Hymnus trägt dazu bei, die rhapsodische Rezitation zu ritualisieren ${ }^{16}$.

\section{Musikalische Beziehungen zwischen Menschen und Göttern (epicae laudes)}

Sowohl in den langen als auch in den kurzen Hymnen trägt der erzählerische Teil der aedisch-rhapsodischen Komposition generell dazu bei, die genealogische und geographische Identität des Gottes zu präzisieren; dadurch setzt das Gedicht den Gott in Beziehung zu den Menschen, manchmal durch das Medium der musikalischen Aufführung. Ein neuer Übergang vom „Mythos“ zum Ritual, generell in ätiologischer Form.

Wenn man die am weitesten entwickelten Erzählungen in den Homerischen Hymnen in Betracht zieht, wird erst Apollons Geburt auf Delos selbst erwähnt, wo die Ionier an ihn übereinstimmend musikalische Ehrungen richten, auf die wir noch zurückkommen werden; dann lokalisiert der Bericht den jungen Gott in Delphi, wo er sein Orakel, das die Pläne der Unsterblichen enthüllt, in einem Tempel einrichtet, wo er „,von allen Menschen verehrt wird“ (Vers 479). Zwischen dem Olymp und dem Hades bindet Demeter ihre Tochter Persephone kultisch in Eleusis, mit Hilfe von Zeus und der regierenden Familie; sie richtet dort, auf ätiologische Weise, die verschiedenen mystischen Riten ein, die den Menschen Wohlstand im Diesseits wie im Jenseits sichern. Wenn der Hymnus, der ihm gewidmet ist, den neugeborenen Hermes im Herz von Arkadien an den Ausläufern des Berges Kyllenios verortet, macht der Schluss des Gesanges aus ihm den Geleitboten zum Hades und den Boten der sterblichen Menschen, die er nicht müde wird zu täuschen. Schließlich der lange Hymnus, der an Aphrodite gerichtet ist und der die Göttin zwischen Zypern und Kythera ansiedelt, wie es ebenso in den beiden kurzen Hymnen der Fall ist, die ebenfalls der Göttin der Verführung gewidmet sind, um Schluss zu machen mit der definitiven Trennung zwischen Unsterblichen und Sterblichen. Mit der Ausnahme von Apollon in Delphi, entspricht der besungene Ort regelmäßig dem Geburtsort des Gottes, der in dem Hymnus besungen wird;

16 Siehe oben, Anmerkung 4 und, was die Hymnen allgemein angeht, Aubriot-Sévin 1992: 182-193. 
auf die eine oder andere Weise trägt die Gottheit dazu bei, die Beziehungen zwischen den unsterblichen Göttern und den sterblichen Menschen zu organisieren, zwischen dem Olymp und dem Hades. Von einem geographischen wie pragmatischen Punkt aus gesehen, kann nichts generelles über den Ort der Aufführung des Gedichtes gesagt werden, außer einigen sehr allgemeinen Angaben wie „diese Stadt hier" (tènde pólin) ${ }^{17}$. Diese räumliche Unbestimmtheit bei der Geste der verbalen Deixis lässt auf der pragmatischen Ebene die Wiederaufnahme des hymnischen Gedichts an verschiedenen Orten, unter verschiedenen rituellen Umständen der Anrufung offen; sie sichert ebenfalls wie bei den homerischen Epen, die vom hymnischen Präludium, bei dem rhapsodischen ,,reenactment“, eingeleitet werden, die Möglichkeit der ,panhellenischen" Verbreitung.

Wie besonders das Versprechen zeigt, das Persephone von Hades, Zeus' Bruder, gegeben wird, impliziert im Hymnus an Demeter die Vorstellung der timé die Beziehung zwischen den Göttern und den sterblichen Menschen. Die Tochter der Demeter, als die junge Braut des Gottes der Unterwelt, wird im Jenseits über alle sterblichen Wesen herrschen, aber sie wird unter den Sterblichen auch von den größten Ehren (timàs megístas) profitieren; wer das Unrecht begeht, nicht der Opfergabe zuzustimmen, welche die Einhaltung der heiligen Riten darstellt, wird unweigerlich bestraft werden ${ }^{18}$. Indem die Definition einer Handlungsart und die Begrenzung eines Interventionsfeldes impliziert wird, binden die timaí, welche die längsten Homerischen Hymnen durch die ätiologische Erzählung einrichten, die betreffende Gottheit ein in die schon erwähnte reziproke Beziehung zwischen Unsterblichen und Sterblichen: so ist die Pragmatik der fiktionalen Erzählung, die wir „Mythos“ nennen.

\subsection{Chorale Freudenbekundungen}

Wenn man die Argumentation berücksichtigt, die oft in der hymnischen Form eine erzählerische und deskriptive Entwicklung annimmt ${ }^{19}$, wird man die Aufmerksamkeit hier auf die Intervention der musischen Kunst richten, in der Zusprechung einer „Ehrung“ an einen Gott, und folglich einer bestimmten Qualität, Kompetenz und Funktion. Tatsächlich ist die Musik auf indigene

17 Vgl. Hy 13. 3; gerichtet an Hestia, der Hymnus 24 bittet die Göttin des Herdfeuers darum, ,in diesem Hause“ einzugreifen (érkheo tónde anà oîkon, Vers 4); dieser Typus der Geste der verbalen Deixis kommt häufig in der melischen Dichtung und in der Tragödie vor und wurde von mir in meiner Studie 2004a behandelt, die man zusammen mit den anderen Studien zu diesem Thema, die in der selben Sonderausgabe von Arethusa 37, 2004 gesammelt worden sind, lesen kann.

18 Dem. 345-369, zu lesen mit dem erschöpfenden Kommentar von Richardson 1974: 269-275, was die Anspielung angeht, die diese Verse über die Riten der Mysterien von Eleusis bieten, siehe auch Strauss Clay 1989: 251-254.

19 Gemäß dem pointierten Vorschlag, der formuliert und entwickelt wurde von Vamvouri-Ruffy 2004: 27-36. 
Weise als Verbindung des poetischen Gesangs, der Choreographie und der instrumentalen Melodie zu verstehen; als solche spielen sie eine zentrale Rolle bei der Etablierung und der Unterhaltung der rituellen Kommunikation zwischen den sterblichen Menschen und den unsterblichen Göttern. Die Inszenierung der verschiedenen musischen Künste im erzählenden Teil des Homerischen Hymnus nimmt folglich gegenüber der Funktion des Gedichtes selbst einen reflexiven Aspekt an, für den sie als erhellend gilt. Und es sind nicht nur die Gottheiten des polytheistischen Systems betroffen, welche durch ihre Qualitäten und ihre eigentlichen Kompetenzen im Handlungsfeld der Musik im griechischen Sinne intervenieren.

So ersetzt der Aoidos oder der homerische Rhapsode im Hymnus, den er der Erde widmet, den Bericht einer Episode aus der Biographie der Göttin durch eine Auflistung der Wohltaten, die die Sterblichen der Mutter aller Dinge verdanken: schöne Kinder, reiche Ernten, florierende Herden, ein Haus, das vor Reichtümern überquillt, eine Stadt mit schönen Frauen, die durch Gerechtigkeit und Wohlstand gekennzeichnet ist, in einem Wort das Leben (bíos) für die sterblichen Menschen. Für die Heranwachsenden bedeutet dies die Lobpreisung (euphrosúne), die auch diejenige der Götter ist, mit den Chortänzen, die die Heranwachsenden auf den blühenden Wiesen ausführen. Solcher Art sind die „Ehren“, welche, durch den Gebrauch des Verbs timân, das regelmäßig wiederholt wird, die erhabene Göttin den Sterblichen einräumt, besonders im Tausch gegen den Gesang als Geschen, der ihr als schlüssiger Teil der preces gegeben wird. So wird die Artikulation dieses abschließenden Gebets in der Form des do ut des mit dem zentralen Teil des Hymnus und der reziproke Zusammenhang zwischen der unsterblichen Gottheit und den sterblichen Menschen durch die zweite Person in der pars epica unterstrichen, obwohl sie regelmäßig durch einen hymnischen Relativ eingeleitet wird. Mittels des direkten Übergangs von sie, welche zum $D u$, und durch die Einführung einer Form des Makarismos (Seligpreisung; ,selig der, dem du dich bereitest, um einen wohltuenden Chor zu ehren“"), wird die Beziehung zwischen Unsterblichem und Sterblichem sofort auf einer benennenden Ebene lokalisiert; sofort trifft sie zusammen mit der Kommunikation, die der Aoidos-Rhapsode durch sein Gedicht selbst mit der besungenen Göttin herstellt, hic et nunc; diese lässt als Echo die Freudenbekundungen des Chores der Stadt, welche von dem von Gaia gewährten Wohlstand profitiert, auf sie widerhallen ${ }^{20}$.

Auf der anderen Seite, in jedem Falle bei zwei Reprisen, wird die musikalische Aufführung in der langen Erzählung, die dem essentiellen Teil des langen Hymnus der Aphrodite gewidmet ist, in Szene gesetzt. Beim ersten Mal, wenn die Göttin an Anchises herantritt, der seine Rinder am Berg Ida weidet, gibt sich dieser junge Heros in seiner göttlichen Schönheit der Musik hin; wie

20 Hy. 30 (Gaia); der Schlussteil des langen Hymnus an Demeter (480-482 und 486-489) ist im Bezug auf sie durch einen doppelten Makarismos markiert; vgl. Richardson 1974: 310-314 und 316-321, ebenso Calame 1997/2008: 68-71. 
Achilles in der Ilias spielt er die Lyra alleine, abseits von seinen Hirtenfreunden. Als eine Art Echo zeigt sich die Göttin ihrerseits dem jungen Hirten in der Identität eines ,jungen, ungebändigten Mädchens“ (parthénos admétess). Als Sterbliche behauptet sie, von Hermes entführt worden zu sein; wie die jungen Mädchen, die im Chor für Artemis in Karyai tanzen und vom spartanischen König Aristomenes entfuihrt wurden, hat sie im Chor der Artemis mit ihren Freundinnen, Nymphen und jungen Mädchen getanzt ${ }^{21}$. An diese beiden typischen Szenen, die dem Paradigma der musikalischen Aktivität, die den jungen Unverheirateten vorbehalten sind, auf der einen Seite junge Männer, auf der anderen junge Frauen, schließt sich die Anrufung Evokation des Kindes, das aus der Vereinigung der unsterblichen Göttin mit dem jungen sterblichen Heros hervorgeht an; sein Schicksal ist es, durch die Nymphen, die, weder sterblich noch unsterblich, mit den schönen Chortänzen der Götter assoziiert werden, auf den selben Berg Ida erhoben zu werden ${ }^{22}$. Folglich heißt die Teilnahme an der choralen Fröhlichkeit für die sterblichen Menschen teilzunehmen am Leben der Götter; die Hervorrufung der musikalischen Praxis impliziert die Überlagerung des „,mythischen“ Berichtes durch das Ritual.

Auch wenn die chorale Aktivität für Aphrodite nichts als ein Vorwand ist, die ihren Status als Frau bemäntelt, dessen sie sich bedient, um sich sogar mit einem Sterblichen zu vereinigen, verhält es sich mit Artemis völlig anders. Der Artemis gewidmete Homerische Hymnus, der gut zwanzig Verse umfasst, bestätigt die musikalischen Gaben, auf die der Aphrodite gewidmete Hymnus anspielt. Obwohl er in der dritten Person, allerdings im Präsens, die wahren Eigenschaften der jungfräulichen Göttin beschreibt, schließt sich der zentrale Teil des hymnischen Gedichtes, das der Artemis gewidmet ist, in einer doppelten Szene mit zwei der wichtigstes Aktivitäten der Schwester des Apollon an. Zuerst widmet sie sich auf den Berggipfeln der Jagd auf wilde Tiere, die im dunklen Wald. Dann senkt die Göttin der Bogenschützen ihren Bogen, um sich nach Delphi zu wenden, in die Nähe ihres Bruders Apollon; nachdem sie den Habitus der Grazie angelegt hat, führt sie nun die Spitze des schönen Chores an, der von den Musen und Chariten gebildet wird. Mit dieser Rolle als Choregin stimmt die Göttin die chorischen Gedichte an, die besingen, wie Leto ihre zwei Kinder Artemis und Apollon hervorbringen wird ${ }^{23}$. Man nimmt also bei der poetischen Rezitation an der Aufführung eines hymnischen chorischen Gedichtes teil: Mythos in Aktion in einem Mythos in Aktion! Dieser erzählerische Teil des Hymnus and Artemis macht durch den Gebrauch des Präsens aus der doppelten Identität der Göttin als Jägerin und Chorführerin

21 Aphr. 75-83 und 117-125 ; vgl. Calame 2001: 149-153, und Faulkner 2008:163-165 was den Status der parthénos im Gegensatz zu dem der Frau, die durch Aphrodite verkörpert wird und in die chorale Aktivität einbezogen ist.

22 Aphr. 256-263; zur Ambivalenz des Status der Nymphe, siehe den Kommentar von Faulkner 2008:185-186.

23 Hy. 27. 13-20 (Artemis); über diese Doppelfunktion der Artemis, vgl. Calame 2001: 52-53 und 91-101. 
eine dauerhafte Qualität; des weiteren wird die Genealogie der Göttin vom Homerischen Hymnus auf den chorischen Gesang der Musen und Chariten projiziert; geführt von Artemis nimmt dieser chorische Gesang einen reflexiven Charakter an, der die inkarnierte Dichtkunst bereichert, die sich häufig in den verschiedenen Formen der griechischen Gedichte manifestiert.

\subsection{Kunst der Musen und musikalische Erinnerungen}

Artemis tritt also in die Kategorie der Gottheiten ein, die in der Kunst der Musen aktiv sind. Ebenso geschieht dies natürlich mit Apollon, der besonders in einem sehr kurzen Hymnus von fünf Versen besungen wird ${ }^{24}$. Dieses Gedicht hat eine atypische aufzählende Form, die von dem Thema des Gesanges durchdrungen wird. Zuerst vergleicht die persona cantans in einer evocatio, die ausnahmsweise die Form eine direkten Anrufung des Phoibos annimmt, ebenfalls außergewöhnlich, ihre Stimme mit der des Flügelschlages des Schwans, und erinnert so folglich an den wahren Sinn der épea pteroénta, die ,geflügelten Worte“. Der Vogel wird beauftragt, den Gott zu besingen (aeídei), mit einer melodischen Stimme, am Ufer des Flusses Pinios in Thessalien. Dann, in einer zweiten Anrede mit $d u$ und in Gestalt der epica pars, richtet der Sprecher seinen Stimme an einen anonymen Sänger (aoidós) mit sanfter Stimme, der den Gott besingt (aeídei), im Präsens. Schließlich, wird im Vers der preces, der Sinn des traditionellen Anliegens an den Gott, sich am Gesang zu erfreuen (hoúto khaîre) verdeutlicht: „Durch meinen Gesang (aoidêii!) stimme ich dich günstig“. Der Gesang, der sich durch das ganze Gedicht hindurchzieht (und der das ganze Gedicht umfasst), wird so zur Opfergabe, die im Spiel des do ut des dazu bestimmt ist, sich der Gunst des besungenen Gottes zu versichern.

Um durch musikalische Aktivität zufrieden gestellt zu werden, gibt es natürlich auch den kurzen Hymnus, der zugleich an Apollon, die Musen und an Zeus gerichtet ist. Dieses hymnische Gedicht setzt in einer weitaus traditionelleren Form sogleich mit dem ich des Sprechers-Rhapsoden ein, der es mittels einer kurzen invocatio-Formel beginnt, um (in Gestalt der epica pars) die Abhängigkeit der Aoidoi und Kitharisten von Apollon und den Musen zu erwähnen; dies kontrastiert mit den Königen, die von Zeus abhängen (mit einer diskreten genealogischen Anspielung). Infolgedessen kann das Spiel des do ut des des anschließenden Gebetes sich nur auf den Gesang beziehen: im Austausch für die musikalische Freudenbekundung, die den Töchtern und Söhnen des Zeus angeboten wird, verlangt das poetische ich von diesen Göttern, sein eigenes Lied zu ehren. Schließlich endet das hymnische Gedicht mit der Formel, die

$24 H y$. 21 (Apollon): Càssola 1975: 375, äußert die Hypothese, dass diese fünf Verse tatsächlich nichts anderes sind als der Schussteil (preces) eines Hymnus, dessen Rest verloren gegangen ist; was die Qualitäten angeht, welche die Griechen dem Gesang des Schwanes zugeschrieben haben, vgl. ibid.: 578, mit dem Zeugnis des Alkman fr. 1, 101 Page-Davies. 
oft den rhapsodischen Gesang einleitet: „was mich betrifft, bereite ich mich vor, euch in einem anderen Gedenkgesang zu feiern (mnésomai)" (mit einem wahrscheinlichen etymologisierenden Spiel mit dem Namen der Musen; indem er dreimal in sechs Versen ausgerufen wird, erinnert dieser Name an Mnemosyne, ihre Mutter, die Inkarnation der poetischen Erinnerung) ${ }^{25}$. Das zufallige thematische Zusammentreffen zwischen den drei grundlegenden Teilen des Hymnus wird unterstrichen vom Standpunkt des Sprechers, nicht nur durch den Gebrauch des Präsens im Erzählteil, sondern vielmehr noch durch die Einleitung mit einer Makarismos-Formel: „Selig ist der, der die Musen liebt; aus seinem Munde perlt eine liebliche Stimme". Durch die Formulierung dieser vier Verse, die so in das lange Präludium zur Theogonie eingeschoben worden sind, und die ohne Zweifel von formelhafter Art sind, verschmilzt die Ebene des „Berichts“ mit der Ebene des „Diskurses“; somit wird der „Mythos" rituelle Realität ${ }^{26}$. Die Abhängigkeit des Aoidos und Kitharisten von den Musen und von Apollon und das Glück, das sie aus der Liebe der Musen empfangen können, sind in der Tat jene des poetischen ich, jene der persona cantans. Wenn sich das „Argument“, aus dem der erzählerische und beschreibende Teil des Hymnus besteht, sich auf den Gesang, den Aoidos und den Rhapsoden konzentriert, wird er durch den Gesang als musikalische Opfergabe zum Vermittler zwischen den Menschen und den Göttern; er wird zum direkten Protagonisten in der hymnischen Beziehung zwischen Sterblichen und Unsterblichen.

Aber, wie es sich für ein gutes polytheistisches System gehört, können mehrere Götter intervenieren, jeder nach seinen Qualitäten, seinen Kompetenzen und seinen eigentlichen Funktionen, in einem festgelegten Bereich. Dies wird im Korpus der Homerischen Hymnen, was den Bereich der musischen Künste angeht, gezeigt.

Im kürzesten der Hymnen, die ihm gewidmet sind, wird Dionysos gleich mit einem Beinamen (eríbromos) angerufen, der die schallenden Rufe, die sein Erscheinen kennzeichnen, bezeichnet. Deswegen schließt der Bericht der Erziehung (Kourotrophie) dieses Sohnes von Semele und Zeus durch die Heraufbeschwörung der Rufe (brómos), welche die Talmulden der Berges Nysa erfüllen; gefolgt von den Nymphen, wie es eine Gruppe Chortänzer tun würde; der junge Gott, der so oft besungen wird (polúumnos), durchschweift den

25 Hy. 25 (Musen, Apollon, Zeus); zur Möglichkeit der etymologischen Verwandtschaft zwischen Moûsa und Mnemosúne, siehe die Hinweise die unten in Anmerkung 47 gegeben werden.

26 Die Verse 2-5 des Hy. 25 korrespondieren mit Hesiod, Theogonie 94-97, in einer Beziehung, die nicht Abstammung ist: siehe die wichtigen Anmerkungen von Càssola 1975: 401-402 und 580, sowie im Bezug auf die Passage bei Hesiod, Brillante, 2009: 61-64, und Pucci, 2007: 111-121; über den Unterschied zwischen „Bericht“ und „Diskurs“ und den Gebrauch, den man davon in einer Studie über die Pragmatik der griechischen Poesie machen kann, siehe Calame 2005: 14-26 und 2008: 124-129 (mit Referenzen zu den Studien von Emile Benveniste). 
Wald; er erscheint als mit Efeu und Lorbeer gekrönter Chorege. Des weiteren wird die Mutter aller Götter und aller Menschen in verschiedenen Emanationen in den belegten Kulten in der Nähe von verschiedenen griechischen Städten Kleinasiens verehrt als Objekt eines sehr kurzen Hymnus; der zentrale Teil dieses Hymnus konzentriert sich völlig auf die musikalischen Aufführungen, welche die Präsenz der Göttin anzeigen: das Rasseln der Klappern und Tamburine, der Lärm der Oboen, das Schreien der Wölfe und der Löwen, die in den Talmulden der Berge widerhallen, in einem Zusammenhang zwischen dem Reich der Menschen, dem Reich der Tiere und dem der Pflanzen ${ }^{27}$.

Und es ist schließlich keine Überraschung, dass man Pan im epischen Teil des relativ langen Hymnus, der ihm gewidmet ist, in einer Landschaft mit hohen Gipfeln aufwachsen sieht; der Gott kehrt von der Jagd zurück und spielt dabei auf der Syrinx, die ihm zueigen ist, eine melodischere Weise als der süBeste der Gesänge der Vögel im Frühling. Sogleich wird der Gott als derjenige identifiziert, „der den Lärm des Rhythmus liebt“, vor dem Hintergrund eines hymnischen Relativs, der unter den Nymphen aufwächst, „die sich den Chortänzen hingeben“, und dabei die Gegenwart des Gottes hervorrufen. Es ist bei seiner Rückkehr von den beschneiten Gipfeln, dass die Bergnymphen mit dem Stampfen ihrer Füße und ihrer klare Stimme eine Wiese mit weichem Gras erschallen lassen; dort wachsen der Krokus und die Hyazinthe, wie auf der Liebeswiese, wo Persephone in der einleitenden Szene des Hymnus, der ihrer Mutter gewidmet ist, davongetragen wird; in diesen Chortänzen vereinigt sich der Gott, um dabei als Chorege zu wirken ${ }^{28}$. Außerdem steht es im zweiten Abschnitt dieses entwickelten deskriptiv-narrativen Teils den Göttern selber im Einklang mit dem Olymp zu, die Liebschaften des Hermes mit Kyllene und der Nymphentochter des Dryops zu besingen (humnêิsin), dann die Geburt des verwachsenen Gottes, der es schafft, sich den Unsterblichen, darunter Dionysos, hinzuzugesellen ${ }^{29}$.

\subsection{Die Götter und die musische Kunst: Hermes und Apollon}

Es bleiben die langen homerischen Hymnen, die einerseits von Hermes den Erfinder für Apollon auf der Lyra komponiert wurden und andererseits durch Apollon selbst, welche musikalisch in Delos, dann in Delphi verortet sind. Von

27 Siehe Hy. 26.1-10 (Dionysos, der sich selbst am Schluss des ihm selbst gewidmeten Hymnus als eríbromos bezeichnet: vgl. Hy 7.56, dann Hy. 14 (Mẹtềr theôn $n$ ); in seinem Kommentar erwähnt Càssola 1974: 327-330, die verschiedenen Orte, an denen die Mutter der Götter überall verehrt wurde, unter verschiedenen toponymischen Bezeichnungen.

28 Hy. 19. 2-5 und 12-26 (Pan); Die Konfigurationen und Funktionen der erotischen Wiesen werden durch Dem. 2-11 illustriert, mit den Parallelen und dem Kommentar von Calame 2002: 173-185.

29 Hy. 19. 27-47. 
diesen zwei Hymnen wird man für Hermes das erzählende, aufreihende Moment berücksichtigen, das den zentralen Teil des Gedichtes einnimmt. Am Anfang des Hymnus legt diese Erzählung die Herstellung der Lyra auf den gleichen Tag der Geburt des Gottes; im Folgenden erzählt sie lange die Übergabe des zauberischen Instruments an Apollon. Es gibt zwei musikalische Szenerien, von denen die erste unter die Kontrolle der Unsterblichen gestellt wird; sie lässt uns teilnehmen an der Herstellung der ,aedischen Schildkröte“ (chélus aoidós, Vers 25), welches die Lyra ist. Indem das Tier getötet wird, um seinen Panzer zu bekommen, macht der Gott auf eine Art und Weise die Schildkröte unsterblich; er macht aus ihr ein „Symbol“ (súmbolon, Vers 30) „von großer Nützlichkeit“, das mit einer schönen Stimme singt (aeídois, Vers 38). Dann bemächtigt sich Hermes des kaum fertig gestellten Instrumentes, mit seinen harmonisch gestimmten sieben Saiten, um darauf einige Akkorde anzuschlagen, die seinen schönen Gesang hervorrufen (hupò kalòn áeiden, Vers 54). Hermes wird also mit Heranwachsenden verglichen, die bei den festlichen Freudenbekundungen mit Poesie rivalisieren; der Gott singt von den Liebschaften von Zeus und Maia, deren Produkt er selber ist: ein neues Lied im hymnischen Gesang. Die Genealogie des Gottes wird dann dreimal erwähnt: in der einleitenden Anrufung an die Musen richtet er zuerst den hymnischen Gesang (húmnei, Vers 1) von der genealogischen Herkunft des Gottes, dann erwähnt er selber diese Genealogie am Anfang des erzählenden Teils mittels eine hymnischen Relativs, und schließlich vertraut der Sprecher-Erzähler schließlich dem Gott das gesungene Lob von jenem göttlichen Ursprung in den Bergen an. Diese aufzählende Polyphonie lässt auch an diejenige denken, die die melische Poesie charakterisiert, und von der die Epinikia des Pindar oft für uns zeugen ${ }^{30}$.

Was die Übergabe des wunderbaren Instrumentes an Apollon angeht, wird die lange Szene, die der Phase der erzählerischen Sanktion des langen Berichtes vorausgeht, mit musikalischen Momenten versehen. Diese Szene beginnt mit der Melodie, die Hermes auf der gerade geschaffenen Lyra spielt, um Apollon friedlich zu stimmen und in ihm das süße Verlangen zu wecken, das die Musik hervorruft (ab Vers 416). Dann ist es der Gesang, der von einer ebenso erotischen Stimme vorgetragen wird (eratè phoné, Vers 426); der Gott ruft damit die ursprünglichen Zeiten in Erinnerung, in denen jedem Unsterblichen seine Eigenschaft (moîra, Vers 429), die jedem von Ihnen zueigen ist, zugesprochen wurde, mit einer besonderen Erwähnung der Mnemosyne, der Mutter der Musen und die Inkarnation der aedischen Erinnerung. Es folgt die Befragung des Apollon über den Ursprung dieser musikalischen Technik (tékhne, moûsa, Vers 447), die eine unwiderstehliche Unruhe anregt, und die ebenfalls die Inspiration zum Jubel (euphrosúne, Vers 449) ist, sowie zum erotischen Verlan-

30 Herm. 1-5 et 24-64 ; vgl. Jaillard 2007 : 222-226, und Calame 2008b: 136-139, im Bezug auf die aufzählende Polyphonie der Epinikia des Pindar. Zur Struktur des Hymnus, vgl. Richardson 2010: 17-23. 
gen und zum Schlaf; sie ist noch viel mächtiger als die Chorgesänge, die der Gott mit den Musen des Olymps auf seiner Doppelflöte anstimmt. Es ist schließlich die Szene des Austauschs in der Hermes, entgegen seiner Funktion als glücklicher Bote, dem Apollon sein Instrument und die dazu gehörige Kunstfertigkeit überlässt; der Musikergott wird sie ausführen können beim reichhaltigen Festmahl, bei den Chortänzen und bei den rituellen Prozessionen, generell beim Jubel (euphrosúne, Vers 482). Folglich vergrößert Apollon mit der Lyra, derer er sich bedient, um mit Musik die von Hermes gestohlenen Rinder auf den Olymp zurückzuholen, sein eigenes musikalisches Kompetenzfeld, wogegen Hermes nun auch noch die Syrinx erfindet. Im Austausch erhält der Gott als Bote der Unsterblichen in Gestalt einer „Wertfunktion“ (timé, Vers 516) das Privileg, bei den Menschen das Handelswesen zu fördern; diese timé wird verkörpert durch den vergoldeten Stab, der Reichtum und Wohlstand symbolisiert, wie es auch der Äskulapstab tut. Apollon trägt so für Hermes zur Schaffung des Insigniums für diese spezielle Kompetenz bei; sie umfasst ebenfalls die Fähigkeit, die Grundprinzipien der gerechten Sprache zu erkennen, sowie die guten Taten. Der Merkursstab ist folglich ein súmbolon (Vers 527), das mit dem „Symbol“ übereinstimmt, welches die Lyra am Anfang des Gedichtes darstellt (Vers 30). Und ebenso wie die Mantik, für die Apollon für sich das Privileg vorbehält, kann der Gott die Sterblichen favorisieren oder sie fallen lassen, ebenso wird Hermes in der Zukunft „das Geblüt der sterblichen Menschen“ sichern oder im Gegenteil auch täuschen ${ }^{31}$. Die Erfindung der kitharís wie die Erfindung des Stabes tragen dazu bei, die verbale Kommunikation mit den Göttern zu bereichern, aber im Sinne der Interpretation und der Verführung; da sie dem gesungenen oder rezitierten Wort inhärent sind, können sie auch trügerisch sein.

Im Lob des langen homerischen Hymnus, das dem Gott der Bogenschützen gewidmet ist, wird Apollon offensichtlich mit den musikalischen Kräften und dann mit der Orakelstimme in Delos und in Delphi in Verbindung gebracht. Es ist bekannt, dass die duale Struktur dieses schönen Gedichtes sowie seine Geschichte die Objekte einer langen Kontroverse sind. Egal, ob es sich nun um eine echte rhapsodische Komposition handelt, die aus einer „Naht“ zwischen einem delischen und einem delphischen Teil besteht, oder ob es sich um ein einziges hymnisches Gedicht handelt, führt der doppelte Erzählteil des Gesangs die Biographie des Gottes von seiner Geburt auf Delos und seiner Niederlassung in einem Heiligtum, das durch chorale Musik charakterisiert ist, bis hin zu seiner Niederlassung in seinem Orakelheiligtum in Delphi.

Zuerst Delos, mit einem Bericht im Aorist, der aber von direkten Anreden der Mutter Leto und dann an den Gott selbst unterbrochen wird, und daher Verbformen in der zweiten Person aufweist. Gerade geboren und genährt von Nektar und Ambrosia, definiert Apollo selbst die Attribute entsprechend der

31 Herm. 416-578; vgl. Càssola 1975: 535-541 zu den Objekten des Austausches, deren Termini in der Studie von Leduc 2001 erforscht werden. 
Fähigkeiten, die seine eigenen sein werden: die kitharís, der Bogen und das Orakel, um den Menschen den Willen des Zeus zu offenbaren. Das Verfahren erinnert an Demeter, welche die wahren órgia einrichtete, am Ende des langen Hymnus, der ihr gewidmet ist, oder an Hermes, der seine eigene Genealogie zur Begleitung der Lyra singt. Es ist in dieser ätiologischen Perspektive, dass Apollon, der in Delos geboren wurde, sich auf seiner eigenen Insel niederlässt; am Berge Kynthos besucht der Gott die gymnastischen Wettkämpfe und die Gesangs- und Tanzwettbewerbe, welche die Menschen, die aus dem gegenüberliegenden Ionien gekommen sind, ihm zu Ehren veranstalten. Der Übergang der Erzählung vom Aorist zum Präsens, zusammen mit einer neuen direkten Anrede an Phoibos, lässt diese lange musikalische Szene mit dem nunc und eventuell mit dem hic der Rezitation des hymnischen Gedichts zusammentreffen. Insofern etabliert die Erzählung eine wechselseitige Beziehung zwischen dem Jubel des Gottes, der an den musikalischen Ehrungen teilnimmt, die an ihn gerichtet sind, und der Freude der Ionier an der Aufführung dieser musikalischen Darbietungen. Diese Gegenseitigkeit in der musikalischen Feier nimmt zwischen Gott und Menschen die Nähe vorweg, die infolge seiner hymnischen Komposition der Erzähler als Aoidos oder Rhapsode mit dem Gott schafft:

Und Du, folglich, freue Dich (khaîre), Sohn des Zeus und der Leto;

Was mich betrifft, werde ich deiner nachmals in einem anderen Lied gedenken (Vers 545-6).

Reziprozität ist um so wichtiger als die musikalische Aktivität und das Vergnügen des Chorsingens, welches die Ionierinnen und Ionier als Gleichberechtigte mit den Unsterblichen versammelt, befreit für immer von den Sorgen des Alterns; sie bedeutet die Überlagerung des Zustandes der Sterblichkeit mit dem Zustand der Göttlichkeit, des Rituals und des „Mythos“ ${ }^{\text {“32. }}$.

Währenddessen intervenieren die Deliaden, die jungen Diener des Gottes, der von weitem zuschlägt; die jungen Mädchen singen einen „Hymnus“ (humnésosin, Vers 158 ; húmnon aeídousin, Vers 161), der ein Loblied auf Apollon, Artemis und Leto ist, wie auch auf die Männer und Frauen aus der Zeit der Helden, so verzücken sie die menschlichen Rassen. Im Chor singen die jungen Mädchen von Delos im Dienst des Apollon das, was der Aoidos-Rhapsode in seiner hymnischen Komposition singt; der rhapsodische Gesang bekommt dann noch ein chorisches Echo ${ }^{33}$. Um zugleich diese starke Beziehung zwischen unsterblichen Gottheiten und sterblichen Menschen auf dem Umweg über die geteilte chorale Freude und die aufzählende Beziehung mit dem Ich-

32 Apoll. 127-132, dann 138-155. Aubriot-Sévin, 1992: 182-193, zeigt gut wie der Charakter des Opfernden den Jubel des Gottes hervorruft, den der Hymnus im Allgemeinen repräsentiert; was die Affinität zwischen Bogen und Lyra angeht, werden sie von einem anthropologischen Standpunkt aus in der Studie von Mombrun 2001 definiert.

33 Apoll. 156-164, zum Status der Chorgruppe der Deliaden, vgl. Calame 2001: 104-110; die Funktion ihres Gesangs wird neu definiert von Peponi 2009: 39-51. 
Erzähler und dem Ausführenden des homerischen Hymnus zu verstärken, werden anschließend die jungen Mädchen von Delos angesprochen. In einem bedeutenden Übergang von der dritten zur zweiten Person werden die Deliaden gebeten, sich zuerst zu freuen (khaírete, V. 166), dann ihrerseits die persona poetica selbst zu besingen (die sich als aoidós, Vers 169, bezeichnet: „der süßeste der Aoidoi“): wiederum ein Gesang im Gesang, aber in einer „performativen“ Art und Weise. In einer bemerkenswerten reflexiven Bewegung ist es dieses poetische Ich, das sich durch die bezaubernde Süße seiner Stimme auszeichnet, die das Objekt des Gesanges der Deliaden wird; durch diesen Prozess der Delegation seiner eigenen aedischen oder rhapsodischen Stimme auf die chorale Stimme der jungen Mädchen, die er selber in Szene gesetzt hat, führt die persona cantans, in der dritten Person und noch einmal unter dem Zeichen des poetischen térpein, eine Form von sphragís (Objekt zahlreicher gelehrter Diskussionen) ein: „Dies ist ein blinder Mann, der das felsige Chios bewohnt, alle seine Lieder (aoidaí, Vers 174) werden für immer die besten sein.“ - wie die Deliaden im Chor singen. Jenseits der Frage der Identität dieses Aoidos, der durch eine Blindheit gekennzeichnet ist, die auf die poetische Inspiration verweist, geschieht alles als ob die chorale Stimme der durch den Erzähler-Aoidos in Szene gesetzten jungen Mädchen seine eigene Stimme färben würde; tatsächlich geht infolge der gesungenen "Signatur" das Ich der persona cantans über in den Plural, in das Wir (Vers 174-175): dies ist das poetische Wir, welches in Reziprozität mit dem Lobpreis des Aoidos durch die jungen Tänzerinnen, sich in den Städten den kléos, d.h. den poetischen Ruhm des Ihr der Deliaden verbreiten wird ${ }^{34}$. Unterzeichnet vom Aoidos-Rhapsoden, transformiert sich der homerische Hymnus gewissermaßen in einen Chorgesang; jenseits des Geschlechtsunterschiedes wohnt man der ",choralen Projektion“ der einzelnen Stimme des „Homer“ in die kollektive Stimme der Deliaden bei.

Unabhängig von einer rhapsodischen Naht, die von einer großen textlichen Unsicherheit beherrscht wird, beginnt der delphische Teil des Homerischen Hymnus an Apollon zweifach mit Musik. In einer ersten Bewegung in Richtung auf das felsige Pythô (das im Präsens genannt wird), begleitet sich der Sohn der Leto, gekleidet in einen unvergänglichen Mantel der mit Weihrauch parfümiert ist, auf der phórmigx (Vers 184); er entlockt Klänge, die das Verlangen wecken. Der Gott selber ist der Aoidos. Dann, nach einer Reise auf den Olymp, wird er vom Gesang der Musen empfangen, zum Klang der kitharis (Vers 188); mit ihrer schönen Stimme, begleitet von den Tänzen der Grazien, der Horen, der Harmonie, der Hebe und von Aphrodite selbst, singen die Musen (humneûsin, Vers 190) von den Privilegien der Unsterblichen und dem Leid der Sterblichen, die vom Alter und vom Tod geschlagen werden. Von

34 Apoll. 165-176; wie es mimetisch durch die Inspiration des Aoidos von der Chorgruppe der Musen umgesetzt wird: vgl. Nagy, 2009: 19-30; über die Beziehung zum Ritual, vgl. Taddei, 2007: 89-93. Zur verfassertypischen Bedeutung der Prozedur der sphragis, siehe Calame 2004b: 13-19, mit vielen bibliographischen Hinweisen. 
Neuem wird die aedische Einzelleistung zu einer chorischen Leistung. Dann folgt Artemis auf die Musen, die ebenso wie ihr Bruder Apollon die kitharis spielt, begleitet von den Tanzschritten, die Ares und Hermes um reißen; Grund genug - noch einmal, Leto mit den goldenen Locken und den weisen Zeus zu erfreuen, die Eltern der jungen Gottheiten ${ }^{35}$. Als Reaktion wird der beispielhafte Gesang des jungen Apollon durch das poetische Ich wiederaufgenommen, das ebenso wie am Beginn des delischen Teils (Vers 19) die rhetorische Frage stellt: „Aber wie werde ich Dich besingen, Dich, der Du in jeder Hinsicht das Objekt der schönen Gesänge bist (eúumnos, Vers 207)?““. Der Gebrauch der Form des performativen Futurs humnés so (Vers 207) bekräftigt, dass diese rhetorische Frage tatsächlich zusammenfällt mit dem effektiven Beginn des erzählerischen Lobgesangs, der durch den Ich-Erzähler vorgeschlagen wird (in diesem Kontext verwendet er noch die Präsensform aeído $)^{36}$. Eine neue Übereinstimmung zwischen der gesungenen musikalischen ,performance“ bei den Göttern und der musikalischen Rezitation des sterblichen Aoidos, im Kontext einer rituellen und kultischen Sequenz, die an die Gottheit gerichtet ist.

Gemäß anderen Aussagemodalitäten wiederholt sich ein analoges Phänomen am Ende des delphischen Teils und damit am Schluss der langen hymnischen, Apollon gewidmeten Komposition. Der Gott trifft auf kretische Seeleute, die er veranlasst hat, zum Ort von Delphi zu reisen, welches er vom Ungeheuer Typhon befreit hat, um sie zu seinen ersten Priestern zu machen; der Gott ist gezwungen, seine Identität zu enthüllen: „Was mich betrifft, bin ich der Sohn des Zeus, und ich versichere, Apollon zu sein“ (Vers 480); was die Fremden aus Kreta angeht, werden sie die Wächter des Heiligtums des Gottes sein, geehrt von vielen Menschen. In einem Bericht, der sich sehr regelmäßig im Aorist und in der dritten Person entspinnt, gestattet die Intervention der autoritätsvollen Rede des Apollon in direkter Rede, im Präsens und im Futur der Willensäußerung, Zeit und Raum der heroischen Vergangenheit mit denen der Rezitation des hymnischen Gedichtes, hic et nunc, zusammentreffen zulassen. Durch die direkte Rede werden die verschiedenen Hinweise, die Apollon in Hinsicht auf die rituellen Gesten, welche die kretischen Seeleute ausführen müssen, bevor sie den Ort Delphi erreichen, gleichermaßen in Relation gesetzt (vom Standpunkt der Enunziation aus gesehen) mit dem hic et nunc der Aufführung des homerischen Hymnus; das gilt besonders für das Loblied, dass die Kreter singen (iepaiéon'aeídein, Vers 500), wobei sie sich dem Schritt des Gottes anpassen, der in Folge ihr Chorege wird. Wie es oft der Fall ist bei der epischen Erzählung, wird die Ausführung der verschiedenen rituellen Akte, die vom Gott in direkter Rede befohlen worden sind, anschließend

35 Apoll. 182-206; zur Frage der „Naht“, vgl. Miller, 1982: 66-69 und 111-117, ebenso Richardson 2010: 10-13 und 111-112.

36 Apoll. 207-215; vgl. Vers 19; die erzählerische Inkohärenz dieses Verses hat zum Vorschlag der Annahme einer Textlücke geführt: vgl. Càssola 1975: 499-501. 
im Aorist in den Bericht integriert. Die musikalische Szene nimmt dabei einen bevorzugten Platz ein, sie repräsentiert die musikalische Begleitung durch den Choregos Apollon auf der phorminx und den Marsch der kretischen Seeleute; sie singen eines der durch die Musen inspirierten Loblieder. Angekommen am Fuße des Parnass, muss Apollon nur noch den jungen Kretern die Verwaltung seines Heiligtums anvertrauen; sie werden zu den Vermittlern zwischen den Menschen, die sich in Delphi versammeln und dem Gott des Orakels und der Gerechtigkeit. Nach dem Willen des Gottes wird diese Funktion durch die „Übersetzer“ (semántores, Vers 542) übernommen, in Zusammenklang mit der Funktion, die Heraklit dem delphischen Orakel zuschreibt: weder zu ,sagen“" (légein), noch zu ,verschleiern“ (krúptein), aber ,,anzudeuten“ (sêmaínein). Die Kritiker haben die delphischen Übersetzer mit den Verwaltern des Heiligtums vom Delphi identifiziert, die zu Repräsentanten der Amphiktyonie geworden $\operatorname{sind}^{37}$. Auf eine ätiologische Art und Weise sichert der hymnische Bericht noch einmal den Übergang von der göttlichen und heroischen Vergangenheit zur rituellen Praxis in der Gegenwart.

\section{Poetische Verträge zwischen Sterblichen und Göttern (preces)}

Die oft formelhafte sprachliche Gestalt der abschließenden Verse jedes Homerischen Hymnus neigt dazu, in und durch das musikalische Gedicht selbst die Beziehung der Sterblichen mit den Göttern zu verwirklichen. In einer früheren morphologischen Studie habe ich versucht, die verschiedenen verbalen und poetischen Vorgänge aufzuzeigen, die im Homerischen Hymnus umgesetzt werden, um aus der hymnischen Komposition ein (musikalisches) Opfer an die angerufene Gottheit zu machen, und um die Götter in das Spiel der wahren Reziprozität des Gebetes einzubeziehen. Dieser poetische Vertrag des do ut des beginnt generell mit einer direkten Anrede der Gottheit: die evocatio des Anfangsteils wird zur invocatio, genauso wie in jeder anderen hymnischen Form. Durch die grammatische Form des $D u$ wird der Gott der Partner in einer direkten Beziehung, die im vorliegenden Gedicht repräsentiert ist, mit dem poetischen Ich, dem Ich des Aoidos und Rhapsoden; er ist der Vertreter der Öffentlichkeit, die an der kultischen Zeremonie teilnimmt und für die die homerische Rezitation bestimmt ist ${ }^{38}$.

37 Heraklit fr. 22 B 93 Diels-Kranz. Die rituellen Gesten, die von Apollon in direkter Rede angeordnet werden, in Vers 475-501 (siehe die anfängliche Anrede im Vokativ xeînoi) werden anschließend im erzählerischen Modus in den Versen 503-523 wiederaufgenommen; Detienne 1998: 134-144 und 169-172, lässt für uns en lebendigen Begriffen das Profil und die Funktionen dieses Gottes wiederauferstehen, als Sprecher und Interpret des Orakels. Zur Schaffung der Amphiktyonie und des Kreises der Verwalter des Heiligtums, vgl. Càssola 1975: 91-92 und 515-516.

38 Hier werden also die Hauptelemente der Morphologie des hymnischen Teiles der preces, wie sie in Calame 1995/2005: 53-63 vorgestellt wurden, wiederaufgenommen. 
In einem Großteil der homerischen Hymnen, die im Korpus der überlieferten Handschriftentradition enthalten sind, beginnt der besagte Schlussteil der preces mit einer „Gruß“-Formel; es ist angemessen, dieses khaîre, das den Teil des Gebets in 27 von 33 Hymnen eröffnet, im etymologischen Sinne zu verstehen, als eine Einladung an die Gottheit, sich $\mathrm{zu}$ freuen ${ }^{39}$. Wie es anfangs erwähnt worden ist, wird das Objekt der Freude in manchen Fällen erwähnt: es ist der Gesang. Anschließend, im kurzen Artemis gewidmeten Hymnus, wird die Göttin eingeladen, mit allen anderen weiblichen Göttinnen, ,sich am Gesang zu erfreuen“" (khaîre... aoidêi i); es ist eine Formulierung, wie man sie zum Beispiel am Ende des schon erwähnten Hymnus findet, der an die Mutter aller Götter und aller Menschen gerichtet ist ${ }^{40}$. Außerdem wird die Aufforderung khaîre in der Hälfte der hymnischen Gesänge, die mit dem Wunsch an die Gottheit, sich zu erfreuen, enden, begleitet vom Verbindungsglied hoútos, welches das erlebte Vergnügen des vorausgehenden preisenden Teils, ausdrückt. Der argumentative Charakter, den dieser zentrale beschreibende und erzählende Teil oft annimmt, wird dann bestätigt; auf diese Weise wird das deskriptive und narrative Lob in die Logik der Beziehung der Reziprozität zwischen dem Menschen und dem Gott eingeführt, in dem nunmehr bekannten Teil des göttlichen Berichts im hic et nunc der Handlung des Gesangs und des Kultes.

Außerdem mündet die abschließende Anrede an die Gottheit oft in ein Gebet, dessen Objekt explizit ist. So verlangt der Athene gewidmete Hymnus von der Göttin uns Glück und Wohlstand zuzubilligen (dòs ámmi), wogegen im sehr kurzen Hymnus an Aphrodite der Ich-Aoidos/Rhapsode von der Göttin verlangt, in ein Lied einzustimmen, das nur vom Zauber angefüllt werden kann, der das Liebesverlangen hervorruft (himeróessan aoidén). Dieser selbe Zusammenhang der Reziprozität wird klar und deutlich dargestellt im Hymnus an Gaia, schon zitiert im Bezug auf die jungen Mädchen, die an den choralen Freudenfeiern teilnehmen, sie bedeuten den Wohlstand, den die Erde der Stadt mit den schönen Gesetzen gewährt: „Freue Dich, Mutter der Götter, Gemahlin des besternten Himmels; gewähre mit Wohlwollen, im Gegenzug für meinen Gesang, den Wohlstand, der das Herz betört" ${ }^{\text {“41 }}$. Ebenso wie in einem Teil der epica laus werden die Schlussverse häufig auf den aedischen Gesang konzentriert. Des weiteren wird der Wunsch manchmal mit einer verbalen Geste der Deixis abgestimmt, die den Wunsch mit dem hic et nunc des hymnischen Gebets in Beziehung setzt, sei es, dass der Erzähler-Aoidos des sehr kurzen Hymnus an Demeter, der anfangs als Motto zitiert wurde, von der Göttin verlangt, das Wohl ,dieser Stadt hier“ (ténde pólin) zu sichern, direkt am Anfang des Gesangs (árkhe d'aoidêes), sei es, dass am Schluss des kurzen, Aphrodite gewidmeten Hymnus die poetische Person explizit die Göttin darum bit-

39 Man wird die bibliographischen Hinweise zur wörtlichen Bedeutung der Aufforderung zum khaírein in Anmerkung 2 finden.

40 Hy. 9.7 (Artemis), dann $H y$. 25. 6 (Mēter).

41 Hy. 11. 6 (Athene) und Hy. 10. 5 (Aphrodite), dann Hy. 30. 17-19 (Gaia). 
tet, nicht nur ihren Gesang anzustimmen, sondern ihm vor allen den Sieg in „diesem Kampf hier“ (en agôni tốide) zu gewähren; dieser Kampf kann nur einem der Musikwettstreite der rhapsodischen Rezitation entsprechen, wie sie einen integralen Bestandteil der Panathenäen ausmachten ${ }^{42}$.

Als drittes distinktives Merkmal des Schlussteiles bestimmter Homerischer Hymnen stellen mehrere dieser Schlusssequenzen folglich einen Vertrag zwischen dem Ich der persona cantans, mit denen für die er als Fürsprecher auftritt, und der Gottheit, die zuerst als er/sie angerufen, und dann mit Du angesprochen wird, dar. Indem er durch die Aufführung selbst ein musikalisches Opfer darstellt, ist der aedische und rhapsodische Hymnus mitunter auf der Ebene der musikalischen Freude an der vertraglichen reziproken Beziehung zwischen der Gottheit und dem poetischen Ich angesiedelt; dieses Ich des Erzählers wird oft zu einem Wir vergrößert, das sich auf die Gemeinschaft, die mit der kultischen Zeremonie verbunden ist, bezieht. Zum Beispiel wird Dionysos im Austausch für das Vergnügen, das durch den Gesang, der ihm gerade dargebracht wird, gebeten, dem Wir des Publikums den Jubel zu gewähren, der die regelmäßige Wiederkehr der Jahreszeiten hervorruft. Und es ist überhaupt keine Überraschung, die Musen und Apollon zu sehen, die gerade für die Hilfe, die die Gottheiten dem Aoidos und den Kitharaspielern gewähren, gepriesen worden sind, in ein Verhältnis der Reziprozität im poetischen Bereich eintreten: die Musen und Apollon werden eingeladen, sich an der Ehre zu erfreuen und als Austausch werden sie vom poetischen Ich gebeten, den Ruhm an dessen Gesang zu geben - an „meinem Lied“ (emèn timésat'aoidênn). Das Modell für diese reziproke Freude an der musikalischen Aktivität wird geliefert durch den Bericht der delischen Szene im ersten Teil des langen Homerischen Hymnus an Apollon ${ }^{43}$.

Auf der syntaktischen Ebene wird die Reziprozität, die so zwischen Göttern und Sterblichen etabliert wurde, vom Standpunkt der Aussage aus gesehen durch die Nähe der Formen des $d u$ und des $i c h$ unterstrichen, wie es zum Beispiel auch der Fall am Ende der Einleitung der Werke und Tage des Hesiod ist. Diese morphologische und syntaktische Nähe ist besonders wahrnehmbar in den Formeln, die eine bestimmte Anzahl von Hymnen beenden, indem sie auf eine darstellerische Art und Weise den Übergang zu einem anderen aedischen Gesang ankündigen: ,Was mich betrifft, so werde ich von Dir/ von euch in einem anderen Gedächtnisgesang eine Eloge machen (kai állẹs mnésom'aoídêss)“, solcherart sind die formelhaften Verse am Ende des Hymnus an Gaia oder wie man gesehen hat - des Hymnus an die Musen und an Apollon ${ }^{44}$. Genauso enden auch der lange Hymnus an Hermes, der lange Hymnus an Demeter, der

$42 H y .13 .3$ (Demeter) et 6, 20-22 (Aphrodite); zum agón als Wettstreit der rhapsodischen Rezitation, vgl. Shapiro, 1992.

43 Hy. 26. 11-13 (Dionysos) und Hy. 25. 6-7 (die Musen und Apollon).

$44 H y .30 .19$ (Gaia) und $H y$. 25. 7 (die Muse und Apollon); vgl. Hes. Op. 10 (ebenfalls bei Calame, 2005: 82). 
Kurze, Aphrodite gewidmete Hymnus, ganz zu schweigen vom Hymnus an Apollon selbst ${ }^{45}$.

Schließlich verweist die Form mnésomai auf die Funktion der Erinnerung, die in der mündlichen Tradition, alle rezitierte epische Poesie in homerischer Diktion begründet und dabei andere Dichtungsarten und poetische Genres belebt. Fleisch geworden in der Figur der Mnemosyne, der Mutter der Musen, und eingeschrieben in die Etymologie des Namens und der anderen, entspricht diese Funktion der Erinnerung der inspirierten Fähigkeit des Aoidos und auch des Rhapsoden, aus einer langen Tradition epischer Poesie die Quellen zu schöpfen, um die Heldentaten der Heroen, die noch den Göttern nahe sind, zu erzählen: Eine kreative Erinnerung, die von einer Tradition abhängt, die dazu bestimmt ist, in jeder poetischen Aufführung das Gedächtnis an eine heroische Gründervergangenheit zu schaffen und wiederzubeleben, und dabei eine ätiologische und pragmatische Beziehung zwischen „Mythos“ und „Ritu$\mathrm{al}^{\text {“ }} \mathrm{zu}$ umreißen ${ }^{46}$. Sie wird realisiert am Schluss mehrerer Homerischer Hymnen in dieser Form des performativen Futurs, der die Intention des poetischen Ichs bei der Realisierung seines Aktes des Singens selbst ausdrückt. Wie schon angedeutet, ist die Aufführung des vorliegenden Hymnus ein Akt des Lobpreises und des verbalen Opfers an die Gottheit, der dazu bestimmt ist, in einen neuen Akt der poetischen Erinnerung zu münden.

Der Prozess des performativen Übergangs zu einem anderen Gesang wird mittels einer anderen Schlussformel ausgedrückt, ebenfalls durch das Mittel einer Form des performativen Futurs: sề d'egọ arxámenos metabésomai állon es húmnon (,,durch Dich, was mich betrifft, habe ich begonnen und werde nun zu einem anderen Lied übergehen“") - so endet der lange, erzählende Hymnus an Aphrodite. Dies ist ebenso der Fall im kurzen Hymnus an Hermes, mit einer Wiederholung der Aufforderung sich zu freuen nach der Ankündigung des Überganges zu einem neuen Gesang; oder der eines noch kürzeren Hymnus, der ebenfalls an Artemis gerichtet ist, wo nach der Aufforderung an die Zuhörers des Gesangs (aoidê ), sich zu freuen, dem ersten Teil der Schlussformel ein Ausdruck vorangeht, der eine Anfangsformel wieder aufnimmt: ,für mich bist du es zuerst, und dank Dir, den ich zu singen beginne“" (aeídein) ${ }^{47}$. Neben der neuen formellen und syntaktischen Annäherung zwischen dem ich und dem $d u$, zusätzlich zum abschließenden Gebrauch einer Form des performativen Futurs, der die Funktion des Homerischen Hymnus als Einleitung bei der poetischen ,performance“ selbst, etabliert dieser Schlussvers die semantische

45 Herm. 589, Dem. 495, Hy. 6. 21 und Apoll. 546.

46 Diese poetische Funktion der aedischen Erinnerung wurde ausgiebig erforscht: siehe die Hinweise in Calame 1995/2005: 60 n. 26 (zusammen mit der Studie von Bouvier 1997), zu denen man Brillante, 2009: 43-46, hinzufügen muss.

47 Aphr. 293, Hy. 18, 11-12 (Hermes), Hy. 9, 7-9 (Artemis); andere Hymnen zeigen weitaus behutsamerer Interpretationsformeln: vgl. Calame 1995/2005: 62 Anmerkung 28. Zum Gebrauch der Formen des ,„performativen Futurs“, siehe oben Anmerkung 6. 
Gleichwertigkeit die oft zwischen den Termini húmnos und aoidé hergestellt wird.

Konzipiert als Gattung des Gesangs an sich, ist der homerische Hymnus eine musikalische und rituelle Opfergabe der Sterblichen and die Gottheit, die in ein anderes Opfer mündet, das ebenfalls poetisch ist. Im rituellen Spiel der Gabe und Gegengabe und auf dem Umweg des Arguments und des erzählenden Lobpreisens, stellt der homerische Hymnus einen poetischen Vertrag zwischen dem Gott und der Gemeinschaft der Sterblichen her, der auf der Aufführung des Gesangs als Opferritual beruht.

Der Kultur des griechischen Polytheismus ist dieser verbale und musikalische Vertrag zwischen dem Sterblichen und der Gottheit nicht alleine vorbehalten. Man findet eine analoge Form in biblischen Psalmen, wie dieser Beginn einer Anrufung:

Herr, ich rufe zu dir; eile zu mir;

vernimm meine Stimme, wenn ich dich anrufe.

Mein Gebet müsse vor dir taugen wie ein Rauchopfer,

mein Händeaufheben wie ein Abendopfer.

Psalm 141, 1-2 (Lutherbibel 1912)

\section{Bibliographie}

Aloni, A., L'aedo e il tiranno. Ricerche sull'Inno omerico a Apollo (Roma 1989).

Aubriot-Sévin, D., Prière et conceptions religieuses en Grèce ancienne jusqu'à la fin du Ve siècle av. J.-C. (Lyon 1992).

Bouvier, D., „Mnema. Le esperienze della memoria greca“, in S. Settis (éd.), I Greci 2. Una storia greca II: Definizione (Torino 1997) 1131-1146.

Bremer, J. M., „Greek Hymns“, in H. S. Versnel (éd.), Faith, Hope and Worship. Aspects of Religious Mentality in the Ancient World (Leiden 1981) 193-215.

Brillante, C., Il cantore e la Musa. Poesia e modelli culturali nella Grecia arcaica (Pisa 2009).

Calame, C., „Variations énonciatives, relations avec les dieux et fonctions poétiques dans les Hymnes homériques", Museum Helveticum 52, 1995: 1-19 (repris en 2005: 43-71).

—, „L'Hymne homérique à Déméter comme offrande: regard rétrospectif sur quelques catégories de l'anthropologie de la religion grecque“, Kernos 10 (1997) 111-133 (repris en 2008a: 63-83).

- Le récit en Grèce ancienne. Énonciations et représentations de poètes (Paris 2000), 2 éd.; trad. angl. par D. Collins et J. Orion: The Craft of Poetic Speech in Ancient Greece (Ithaca NY - London) 1995.

—, L'Éros dans la Grèce antique (Paris 2002), 2e éd.; trad. angl. par J. Lloyd: The Poetics of Eros in Ancient Greece (Princeton 1999)

- , „Deictic Ambiguity and Auto-Referentiality: Some Examples from Greek Poetics“, Arethusa 37 (2004a) 415-443. 
—, „Identités d'auteur à l'exemple de la Grèce classique: signatures, énonciations, citations", in C. Calame \& R. Chartier (éds), Identités d'auteur dans l'Antiquité et la tradition européenne (Grenoble 2004b) 11-39.

-, Masques d'autorité. Fiction et pragmatique dans la poétique grecque antique (Paris 2005), trad. angl. par P. Burke: Masks of Authority. Fiction and Pragmatics in Ancient Greek Poetics (Ithaca NY - London 2005).

-, „Identifications génériques entre marques discursives et pratiques énonciatives: pragmatique des genres ,lyriques'“, in R. Baroni et M. Macé (éds.), Le savoir des genres (Rennes 2006a) 35-55.

-, „L'histoire comparée des religions et la construction d'objets différenciés: entre polythéisme gréco-romain et protestantisme allemand", in M. Burger et C. Calame (éds.), Comparer les comparatismes. Perspectives sur l'histoire et les sciences des religions (Paris - Milan 2006b) 209-235.

- Sentiers transversaux. Entre poétiques grecques et politiques contemporaines (Grenoble 2008a).

—, „Entre récit héroïque et poésie rituelle: le sujet poétique qui chante le mythe“ in S. Parizet (éd.), Mythe et littérature (Poétiques comparatistes) (Paris 2008b) 123-141.

—, „Hérodote, précurseur du comparatisme en histoire des religions? Retour sur la dénomination et l'identification des dieux en régime polythéiste", in F. Prescendi \& Youri Volokhine (éds), Dans le laboratoire de l'historien des religions. Mélanges offerts à Philippe Borgeaud (Genève 2011) 263-274.

Càssola, F., Inni omerici (Milano 1975)

D'Alessio, G. B., „Past Future and Present Past: Temporal Deixis in Greek Archaic Lyric“, Arethusa 37 (2004) 267-294.

Detienne, M., Apollon le couteau à la main. Une approche expérimentale du polythéisme grec (Paris 1998).

Faulkner, A., The Homeric Hymn to Aphrodite. Introduction, Text, and Commentary (Oxford 2008).

Fränkel, H., Wege und Formen des frühgriechischen Denkens. Literarische und philosophiegeschichtliche Studien (München 1960).

Furley W. D. I Bremer, J. M., Greek Hymns. Selected Cult Songs from the Archaic to the Hellenistic period (Tübingen 2001).

Garcia, J.F., "Symbolic action in the Homeric Hymns: the theme of recognition", Classical Antiquity 21 (2002) 5-39.

Hopman-Govers, M., „Le jeu des épithètes dans les Hymnes orphiques“, Kernos 14 (2001) 35-49.

Jaillard, D., Configurations d'Hermès dans le polythéisme grec. Une théogonie hermaïque (Kernos Suppl. XVIII) (Liège 2007).

Leduc, C., „Cinquante vaches pour une lyre! Musique, échange et théologie dans l'Hymne à Hermès I", in P. Brulé et Ch. Vendriès (éds), Chanter les dieux. Musique et religion dans l'Antiquité grecque et romaine (Rennes 2001) 19-36.

Miller, A.M., From Delos to Delphi. A Literary Study of the Homeric Hymn to Apollo (Leiden 1986).

Mombrun, Ph., „Apollon: de l'arc à la lyre“, in P. Brulé et Ch. Vendriès (éds), Chanter les deiux. Musique et religion dans l'Antiquité grecque et romaine (Rennes 2001) 59-96. 
Morand, A.-F., Études sur les Hymnes orphiques (Leiden - Boston - Köln 2001).

Nagy, G., Pindars' Homer. The Lyric Possession of an Epic Past (Baltimore - London 1990).

—, „Perfecting the Hymn in the Homeric Hymn to Apollo“, in L. Athanassaki, R.P. Martin, and J.F. Miller (éds), Apolline Politics and Poetics (Athens 2009) 17-44.

Peponi, A.E., ,Choreia and Aesthetics in the Homeric Hymn to Apollo: The Performance of the Delian Maidens (Lines 156-64)“, Classical Antiquity 28, 2009, 39-70.

Pirenne-Delforge, V., Retour à la source. Pausanias et la religion grecque (Kernos Suppl. XX), (Liège 2008).

Richardson, N., The Homeric Hymn to Demeter (Oxford 1974).

-, Three Homeric Hymns: to Apollo, Hermes, and Aphrodite. Hymns 3, 4, and 5 (Cambridge 2010).

Pucci, P., Inno alle Muse (Esiodo, Teogonia, 1-115) (Pisa - Roma 2007).

Shapiro, H.A., “'Mousikoi Agones': Music and poetry at the Panathenaia”, in: J. Neils (hrsg.), Godesses and Polis: the Panathenaic Festival in ancient Athens (Princeton 1992) 53-75.

Strauss Clay, J., The Politics of Olympus. Form and Meaning in the Major Homeric Hymn (Princeton 1987).

Taddei, A. „Mmene e terpsis. Rammemorazione e rituale nell'Inno omerico ad Apollo", in L. Marrucci et Andrea Taddei (éds.), Polivalenze epiche. Contributi di antropologia storica (Pisa 2007) 79-93.

Vamvouri-Ruffy, M., La fabrique du divin. Les Hymnes de Callimaque à la lumière des Hymnes homériques et des hymnes épigraphiques. (Kernos Suppl. XIV) (Liège 2004). 
Bereitgestellt von | SUB Göttingen Angemeldet 


\title{
Homer und Avdo Međedović als 'post-traditional singers'?
}

\author{
GEORG DANEK
}

Am 27. Juni, unmittelbar nach seiner Ankunft in Bijelo Polje (Montenegro), der letzten Station vor seiner geplanten Rückkehr nach Amerika, stieß Milman Parry auf den über sechzig Jahre alten Sänger Avdo Međedović. Schon nach den ersten Aufnahmen waren sich Parry und sein engster kroatischer Mitarbeiter Nikola Vujnović dessen bewusst, dass sie es mit einem Ausnahmesänger zu tun hatten, dessen epische Erzählungen alles in den Schatten stellten, was sie bis dahin aufgenommen hatten oder aus publizierten Sammlungen kannten. Es folgte eine fieberhafte Tätigkeit: Während der nächsten 45 Tage diktierte oder sang Avdo Međedović epische Texte im Umfang von über 75.000 Versen. $^{2}$ Zusätzlich dokumentierten Parry und Vujnović lange Interviews mit dem Sänger, suchten währenddessen weiter nach anderen guten Sängern, ließen weitere Mitarbeiter auch mit diesen Aufnahmen machen, ersannen wissenschaftliche Experimente mit den Sängern, führten sie durch und werteten sie begleitend aus.

Parry war sich offenbar sofort sicher, dass er in Avdo Međedović endlich seinen 'jugoslawischen Homer' gefunden hatte, nämlich das bisher noch fehlende Analogon, das den Beweis erbringen sollte, dass Epen vom Umfang einer Ilias oder Odyssee ohne Hilfe der Schrift als Produkte einer rein mündlichen Erzähltradition entstanden sein konnten.

Als entscheidendes Beweisstück für diese These wählte Parry noch während seiner Arbeit mit Međedović dessen Epos „Die Hochzeit des Smailagić Meho“, das mit seinen 12.311 Versen fast an die Länge der Odyssee heran reicht und in seiner kontrollierten Diktion und präzisen Ausführung von Details unter allen dokumentierten Liedern dieses Sängers noch einmal hervorsticht. Es ist evident, dass Parry der akademischen Welt (oder jedenfalls seinen Arbeit- und Geldgebern an der Harvard University) dieses Epos als seinen Beweis für die Traditionalität und Mündlichkeit der homerischen Epen prä-

1 In memoriam Zlatan Čolaković (1955-2008).

2 Die Aufnahmen mit Međedović fanden vom 28. Juni bis zum 11. August 1935 statt, wobei Parry dem Sänger insgesamt höchstens vier, vielleicht sogar nur zwei Tage Pause gönnte: vgl. Bynum in SCHS 3 (1974), xx; Čolaković 2007/1, 497-499. 
sentieren wollte und dass seine gesamte Arbeit mit Međedović auf diesen Beweis abzielte. ${ }^{3}$

Milman Parry kehrte im August 1935 mit einer gewaltigen Menge von Ton- und Schriftaufnahmen sowie mit Vorarbeiten zu umfangreichen Studien, mit Notizen, Protokollen und Tagebüchern nach Amerika zurück, starb aber nur drei Monate später unter wenig geklärten Umständen, ohne eine Zeile zur Publikation freigegeben zu haben. Der Vergleich zwischen Međedović und Homer als entscheidendes Argument für eine Auffassung Homers als mündlich-traditioneller Dichter blieb somit Parrys Vermächtnis.

Letzte Spuren weisen aber darauf hin, dass Parry selbst sich noch keineswegs sicher war, in welcher Weise er Međedović in seine Gesamtthese einbauen solle: In einem Abstract für die American Philological Association, das er vor seinem Tod einreichte, verwendet Parry zwar die Länge von Međedovićs Epen (mit epischer Übertreibung) als Argument für die Vergleichbarkeit mit Homer, signalisiert aber deutlich, dass er als Comparandum nicht den singulären Ausnahmesänger, sondern die gesamte südslawische Epentradition sucht. ${ }^{4}$ Mit dem programmatischen Titel „Homer and Huso I“ verweist Parry auf die Person von Cor Huso, einen berühmten bosnischen Sänger der zweiten Hälfte des 19. Jahrhunderts, den nur mehr Parrys älteste Informanten persönlich erlebt hatten und der schon längst den Status eines sagenumwobenen, geradezu mythischen, nur mehr in seiner Nachwirkung greifbaren Sängers erlangt hatte. Parry hatte während seines Aufenthalts in Jugoslawien an einem Text mit dem Arbeitstitel „Ćor Huso. A Study of South Slavic Song“ zu schreiben begonnen; ${ }^{5}$ in seiner Arbeit mit den Sängern suchte er immer wieder herauszufinden, ob sie ihre Lieder direkt oder indirekt von diesem 'besten Sänger' (oder analogen 'mythischen' Sängern) gelernt hatten, da er auf diese Weise dessen Oeuvre erschließen, rekonstruieren und in seiner besonderen Qualität definieren wollte.

Parrys ursprüngliches Konzept speiste sich also aus dem (prae-)romantischen Homer-Konzept des 18. und frühen 19. Jh.s, dieser seltsamen Mi-

3 Parry begann noch vor seinem Tod mit einer Übersetzung dieses Epos, kam aber nur wenige hundert Verse weit. Lord $(1948,42)$ zitiert aus dieser Übersetzung und fügt hinzu: „I have continued the translation of this song as far as line 9000.“

4 Parry 1935 (= A. Parry 1971, 420): ,The traditional heroic songs which are still sung by the Bosnian Moslems, particularly by those on the old Montenegrin border (and of which I have made the first and only collection) commonly run in length to four or five thousand verses, and sometimes to as many as sixteen thousand verses. We thus have in them, for the first time, a body of songs, composed and transmitted orally, which generally equal in length the early Greek heroic songs, and so may be expected to throw much light upon them ..."

5 Dieser Text wurde von Parry nur auf Tonträger gesprochen. Er wurde nach Lords Tod (1991) von dessen engstem Mitarbeiter David Bynum publiziert (1995), ist aber weltweit in keinem Bibliothekskatalog sichtbar. Bynum hat ihn 1998 online gestellt (http://enargea.org). 
schung aus einander widersprechenden Elementen: einerseits dem Konzept eines individuellen 'Original-Genies', ${ }^{6}$ andererseits dem Herderschen 'Dichtenden Volksgeist' einer ständig im Fluss und Wandel befindlichen und letztlich anonymen mündlichen Tradition. ${ }^{7}$ Parry ging es daher auch in seiner Arbeit mit Međedović um die Frage, ob dieser Sänger trotz seiner unverkennbaren Sonderstellung im Vergleich zur übrigen Tradition trotzdem als Vertreter eben dieser Tradition verstanden werden könne. Parrys letzte Äußerung in dem APA-Abstract deutet darauf hin, dass er fest entschlossen war, diese Frage mit ,ja“ zu beantworten.

Nach Parrys Tod war es vordringlich, das umfangreiche Material für die Nachwelt zu sichern. Zu diesem Zweck wurde Nikola Vujnović nach Harvard geholt, wo er 1938-1940 sämtliche Tonaufnahmen Parrys transkribierte. ${ }^{8}$ Albert Lord, der seinem Lehrer Parry als frischer Studien-Absolvent nach Jugoslawien gefolgt war ${ }^{9}$ und dem bald die Aufgabe zufiel, Parrys Erbe anzutreten, versuchte darüber hinaus sehr früh, Parrys Feldforschungen auf dem Balkan fortzusetzen und auszuweiten. Die Auswertung von Parrys Material setzte demgegenüber nur zögernd und langsam ein. Erste Äußerungen Lords zeigen, dass er Parrys Doppelstrategie übernehmen wollte, indem er Međedović als „our Yugoslav Homer“, d.h. als die ideale Verkörperung der Tradition stilisierte, ${ }^{10}$ zugleich aber an dem Konzept „Homer and Huso“ festhielt. ${ }^{11}$ Dabei fällt auf, dass Lord von Anfang an Međedović als wichtiges Argument für die Analogie zwischen südslawischer und altgriechischer mündlicher Tradition verwendet, aber das hiefür herangezogene Material (Liedtexte in Übersetzung, Interviews mit Međedović) nur selektiv zitiert. Stattdessen publizierte Lord zunächst einen Band mit Texten und Übersetzungen von deutlich schwächeren Sängern (1953/54), sichtlich um die epische Tradition als breit angewendetes Handwerk zu dokumentieren. Eine Edition und Übersetzung von

6 Vgl. dazu Simonsuuri 1979.

7 In diesem Sinn deutet Foley (1998) sowohl Ćor Huso als auch Homer als Chiffren, deren legendäre Nachwirkung wenig oder nichts mit ihrem biographischen Werk zu tun habe.

8 Nikola Vujnović kehrte 1940 nach Jugoslawien zurück und ist im 2. Weltkrieg verschollen.

9 In der einzigen bislang publizierten Aussage Parrys über Lord nennt er ihn ,,my assistant" und zählt als seine Tätigkeiten das Katalogisieren von Material, das Abtippen einer Tonaufnahme und vor allem die technische Unterstützung bei den Tonaufnahmen mit den Sängern auf (Mitchell / Nagy 2000, xxiii f.). Lord war zu diesem Zeitpunkt 22 Jahre alt.

10 In einem unveröffentlichten Manuskript von 1937 (zitiert bei Mitchell / Nagy 2000, xi f.) beschreibt Lord die erste Begegnung Parrys mit Međedović in romantisch ausgeschmückter Weise, die nur bedingt mit den Dokumenten des Parry-Archivs in Einklang zu bringen ist, offenbar aus einer vagen, subjektiv gefärbten Erinnerung heraus.

11 Die Titel von Lord 1936, Lord 1938 und Lord 1948 greifen ausdrücklich auf Parrys Konzept „Homer and Huso“ zurück. 
Međedovićs Epen wurde schon früh und immer wieder angekündigt, aber immer wieder hinausgeschoben.

Auch noch in seinem zu Recht berühmten, fulminant formulierten Buch „The Singer of Tales“ (1960), das den endgültigen Durchbruch der oral theory bewirkte, zitiert Lord nur ausgewählte Passagen aus Međedovićs Liedern. So wird für die Leser nicht sichtbar, dass Međedović aufgrund des außergewöhnlichen Umfangs und der herausragenden ästhetischen Qualität seiner Lieder eine einzigartige Sonderstellung innerhalb seiner eigenen Tradition besaß.

Immerhin finden sich bei Lord Bemühungen, die poetische Qualität von Međedovićs Lieder zu beschreiben und damit zu erfassen, was Međedović für einen Vergleich mit Homer besonders fruchtbar macht. An einer Stelle fasst Lord die Analogie zwischen Avdo Međedović und Homer pointiert zusammen: „... The Song book version [sc. Avdos Vorlage, aus der er sein berühmtes Lied von Smailagić Meho gelernt hatte] left it to be taken for granted that all these details would have been worked out; Avdo has simply told in full what the other left to the imagination. Making the imagination articulate is one of Homer's secrets also." 12 An dieser und ähnlichen Stellen unterlässt Lord aber die naheliegende Schlussfolgerung, dass der Vergleich mit Međedović für ein Verständnis des Phänomens Homer vor allem dann fruchtbar wird, wenn man Međedović nicht als Verkörperung seiner eigenen Tradition, sondern im Kontrast zu eben dieser betrachtet, wenn man also danach fragt, inwiefern sich Međedović von seiner eigenen Tradition abhebt.

Lords Strategie, Međedović als idealtypische Verkörperung seiner eigenen Tradition zu präsentieren, hat sich allerdings rückblickend gesehen bewährt: Das Erscheinen von „The Singer of Tales“ bewirkte schlagartig den Durchbruch der oral theory (,Parry-Lord-Theorie“) in der Homerforschung. ${ }^{13}$ Übernommen wurde dabei aber nur Lords theoretisches Modell, das sofort für diverse Aspekte auf Homer angewendet und weiter entwickelt wurde. Die Oralisten der ersten Stunde (Kirk, Russo, Hainsworth, Hoekstra, Edwards, Fenik) diskutierten ihre aus Lords Buch abgeleiteten Kriterien aber ausschließlich am Homertext, ohne auf die Analogie zur südslawischen Tradition einzugehen. Lord hatte ein bestechendes Bild des traditionellen Sängers gezeichnet, der unter dem Ideal der 'historischen Wahrheit' bestrebt ist, jedes Lied in seiner inhaltlichen Struktur möglichst exakt so aufzunehmen, abzuspeichern und im Vortrag wiederzugeben, wie er es von einem anderen Sänger gehört hatte. Die Qualität des guten Sängers besteht bei diesem Modell lediglich darin, die einzelnen Handlungselemente einer vorgegebenen Geschichte (die als 'historisch wahr' betrachtet wird) möglichst stringent miteinander zu verknüpfen

12 Lord 2000 [1960], 107.

13 Bakker (2001) erklärt Lords Erfolg damit, dass sein Buch (1960) dem Zeitgeist der eben einsetzenden Postmoderne gewissermaßen zuvorkam (Marshall McLuhans „The Gutenberg Galaxy“ erschien 1962, Eric Havelocks „A Preface to Plato“ 1963, Umberto Ecos „L'opera aperta“ 1962, und Roland Barthes verkündete den „Tod des Autors" überhaupt erst 1968). 
und mithilfe der vorgegebenen Formelsprache möglichst glatt $\mathrm{zu}$ formulieren. Lords Modell erfasste die breite Masse der epischen Sänger in Jugoslawien sehr gut, und es ist kein Zufall, dass Lord zunächst nur mittelmäßige Sänger publiziert hatte.

Die Übertragung von Lords Modells auf Homer bewirkte automatisch, dass die erste Generation von Oralisten Homer ebenfalls zu einem ,,Singer of Tales“ stilisierte, der die Handlungsstruktur der Ilias bereits von seinen Vorläufern übernommen hatte und an seine Nachfolger weiterreichte, bis dieser Prozess der mündlichen Überlieferung durch einen punktuellen Eingriff von auBen schriftlich festgelegt wurde (,oral dictated text ${ }^{\text {“14 }}$ ). Konservative Homerforscher, vor allem in Europa, reagierten darauf mit dem Argument, dass die Analogie nicht die überragende Qualität der homerischen Epen erklären könne, für die man um die Annahme der Zuhilfenahme der Schrift nicht umhin komme. Auch wenn die Homerforscher in dieser Phase vor allem auf Lords theoretische Äußerungen reagierten, finden sich Hinweise auf die bescheidene ästhetische Qualität der von Lord publizierten Lieder. Milman Parrys Sohn, Adam Parry, stützte sich ausdrücklich auf dieses Argument, um Lord anzugreifen (und ihm implizit die Verfälschung des Vermächtnisses seines Vaters vorzuwerfen), und forderte als Beweis für die Gültigkeit der Analogie einen Text von vergleichbarer ästhetischer Qualität wie Homer; das heißt aber nichts anderes, als dass Adam Parry endlich eine Textedition und Übersetzung des so lange bereits als ,jugoslawischer Homer" angepriesenen Avdo Međedović einforderte. ${ }^{15}$

Als Lord 1974 endlich Avdo Međedovićs, „Hochzeit des Smailagić Meho“ (12.311 Verse) mit Text und Übersetzung publizierte, ${ }^{16}$ waren die Reaktionen von Seiten der Homerforscher jedoch erstaunlich gering. Man kann das damit erklären, dass die oralistische Homerforschung sich zu diesem Zeitpunkt längst

14 Das Konzept des diktierenden Homer in Analogie zu den besten Sängern Parrys (und Međedović) ist erstmals bei Lord (1953) formuliert.

15 Adam Parrys programmatischer Titel „Have We Homer's Iliad?“ (1966) und seine ausführliche, teils polemische Einleitung zu den gesammelten Schriften seines Vaters (1971) wurden von der europäischen Homerforschung als starke Entgegnung auf Lords Thesen wahrgenommen. Vgl. A. Parry 1971, xvi, Anm. 1: „... not the slightest proof has yet appeared that the texts of the Iliad and the Odyssey as we have them, or any substantial connected portion of these texts, were composed by oral improvisation of the kind observed and described by Parry and Lord and others in Jugoslavia and elsewhere." Vgl. dazu Mitchell / Nagy 2000, xvi.

16 Lord zeichnete für Übersetzung, Einleitung und Anmerkungen verantwortlich; Textedition und Übersetzung der (für nicht native speakers) sprachlich schwierigen Interviews mit Međedović stammen von Lords langjährigem Mitarbeiter David Bynum. Lord war zu diesem Zeitpunkt 61 Jahre alt und deutet an, dass er von Međedovićs schwieriger Sprache überfordert war (vii: ,... I sought long for the solution of such difficult passages. I fear that some of them still remain, and I have signalled them in the notes. Publication could not be delayed any longer."). Man mag das als Reaktion auf die Kritik durch Adam Parry deuten. Vgl. Anm. 3. 
verselbstständigt hatte und auf die Analogie mit der südslawischen Epik nicht mehr angewiesen zu sein schien; jene Homerforscher, die die Oral-poetryTheorie nach wie vor strikt ablehnten, waren zu dieser Zeit ohnehin längst in der Minderzahl, und auch unter ihnen setzte sich allmählich die Überzeugung durch, dass Homer jedenfalls eine lange mündliche Epen-Tradition voraussetze, auch wenn er sich selbst dank der neuen Technologie der Schrift über sie hinweggesetzt habe. So beschränkten sich die Reaktionen zu dem 'besten Epos' des 'jugoslawischen Homer' auf wenige Kommentare, die hervorhoben, dass auch Međedović nicht an die überragende künstlerische Qualität Homers herankomme und die Analogie daher ins Leere ziele.

Bald wurde auch angemerkt, dass die Länge des „Smailagić Meho“ in keinem Verhältnis zu seiner einfachen Erzählstruktur stehe und vor allem durch parataktische Aufschwemmung mittels Beschreibungen, exzessiven Wiederholungen und überlangen Katalogen erzielt sei. ${ }^{17}$ Man vermutete, dass Međedović sein langes Epos nicht unter 'natürlichen', d.h. traditionellen Bedingungen produziert habe, sondern weil Parry ihn dazu gedrängt habe, einen möglichst langen Text zu liefern, und ihn dafür gut bezahlt habe; ${ }^{18}$ wenn also schon der „Smailagić Meho“ kein mündlich-traditionelles Epos sei, treffe das noch viel weniger auf Homer zu. Im Übrigen wurde das Verhältnis von Međedović zu seiner eigenen Tradition nicht hinterfragt. Međedović erschien den meisten Homerforschern einfach nicht interessant genug, um für einen Vergleich mit Homer herangezogen zu werden. ${ }^{19}$

Als David Bynum 1980 einen Band mit zwei weiteren Epen des Međedović ohne Übersetzung herausgab (SCHS 6), ${ }^{20}$ wurde das von den meisten

17 Zuletzt hat Rainer Friedrich (2002) daraus abgeleitet, dass Homer im Gegensatz zu dem mündlich-traditionellen Međedović ein ,post-oral poet“ sei.

18 Lord bezieht in seinen Schriften zu diesem 'Vorwurf' nie Stellung, sagt aber in einem Interview (1986): „Von einigen Jugoslawen kann man hören, Parry habe die Sänger bezahlt, und das seien keine bona fide mündlich-traditionellen langen Lieder gewesen. Das ist, meine ich, eine unberechtigte Kritik. Parry hat die Sänger bezahlt. Sie haben für ihn gearbeitet, und er hat sie dafür bezahlt. Man kann einem Menschen zahlen, so viel man will, wenn er nicht die Gabe zur Produktion langer Lieder besitzt, wird das Geld gar keinen Unterschied bewirken.“ (Čolaković 2005, 44; Übersetzung aus dem Kroatischen: G.D.). Schon Parry schreibt in einem Rechenschaftsbericht an Harvard, dass er die Sänger nach Leistung und Wert bezahle.

19 Ein Grund dafür liegt darin, dass Lord mit seiner betont nüchtern prosaischen Übersetzung die poetischen Qualitäten des Međedović und seine Ausnahmestellung als Dichter innerhalb seiner eigenen Tradition nicht hinreichend erkennen ließ.

20 Im Klappentext des Bandes sind der Übersetzungsband und weitere Bände mit den restlichen Epen des Međedović angekündigt. Nichts davon ist je erschienen. Bynum veröffentlichte erst 1993, nach dem Tod von Albert Lord (1991), seine Übersetzung eines anderen, 1979 erschienenen Teilbandes und machte (nach 1998 ?) sämtliche Lieder des Međedović als Typoskripte auf seiner privaten Homepage zugänglich, jedoch ohne Übersetzung und Kommentar; das Milman Parry-Archiv in Harvard stellte später dasselbe Material als pdf-Files der handschriftlichen Transkripte von Nikola Vujnović 
Homerforschern nicht einmal registriert, obwohl die wenigen Kenner sich darin einig sind, dass das dort enthaltene Epos „Die Hochzeit des Vlahinjić Alija“ (5.883 Verse) viel besser gelungen ist als die berühmte „Hochzeit des Smailagić Meho“, vor allem weil die Erzählung hier nicht künstlich in die Länge gezogen wirkt und die Breite der Ausführung mit der Erzählstruktur harmoniert. Ich habe daher dieses Epos der Homerforschung zumindest in deutscher Übersetzung zugänglich gemacht (2002) und weitere Lieder anderer Sänger beigefügt, die die Sonderstellung des Međedović innerhalb seiner Tradition sichtbar machen sollen.

Međedović wird inzwischen von Homerforschern meist nur wegen der Länge seiner Lieder erwähnt. ${ }^{21}$ Gregory Nagy, der unter den heutigen Homerforschern sich am stärksten in die Nachfolge von Lord stellt und mit seinem „Evolutionary Model“ einer allmählichen Verfestigung des Homer-Textes zwischen ca. 750 und 550 v. Chr. in Amerika breiten Anklang findet, beschwört gelegentlich die sein Paradigma vermeintlich bestätigende Analogie der Südslawischen Epik, erwähnt aber in seinen Büchern Avdo Međedović nie. John Foley, der die „Vergleichende Epenforschung“ zu einer eigenständigen Disziplin erhoben hat, betont, dass Međedović (,this understudied poet“) alle Sänger seiner Tradition weit überrage, ${ }^{22}$ schränkt aber ein: „This situation is exactly what one would expect of poets, traditional or not, in any culture; most are workaday, a few are talented, fewer still are brilliant." ${ }^{\text {"23 }}$ Auch in der „Homer Encyclopedia“ (2011) ist der Vergleichswert Međedovićs für Homer auf die Formulierung reduziert: „... a worthy parallel to Homer, someone who, although illiterate, could perform extensive and elaborate epic songs in performance. " 24

Und doch ist es gerade die Sonderstellung des Međedović innerhalb seiner eigenen Tradition, die ihn für den Vergleich mit Homer besonders fruchtbar macht. Darauf habe ich in mehreren Detailstudien hingewiesen: Međedović verwendet die traditionelle Formelsprache flexibler, selbstständiger und kreativer als alle seine Kollegen (Danek 1991); er tendiert zu einer ähnlich streng limitierten Zeitbehandlung wie Homer ('Zielinskisches Gesetz'), im Gegensatz zu anderen Sängern (Danek 1998); er befragt traditionelle Motive und Werte auf ihre Gültigkeit (Danek 2006); seine Tendenz zur monumentalen Form verleiht seinen Epen den Anspruch auf universelle Welterklärung (Danek

online. Weiterhin nicht publiziert sind wichtige Gesprächstexte von Međedović sowie Protokolle und Korrespondenzen von Parry.

21 Die einzige mir bekannte Arbeit, in der Međedović auch im Vergleich zu Homer gebührend gewürdigt wird, ist der Aufsatz von Sale (1996).

22 Foley 1999, 43: „Exploring thoroughly mapped familiar territory with an even-handed combination of the singer's individual initiative and the rich implications in the poetic tradition, Medjedović paints a well-known picture in a familiar style, but does so on his own grand tableau."

23 Foley 1991, 9 Anm. 16.

24 J.M. Foley (s.v. Avdo Međedović), in Finkelberg 2011, 122. 
2007); er bezieht durch gezielte Anspielungen Teile des Mythos mit ein, die außerhalb der Handlung des Liedes liegen, so wie Homer in seinen mythologischen Exempla (Danek 2010); und er verleiht jedem Lied, egal aus welcher Art von Quelle er es übernommen hat, seinen unverwechselbaren großepischen Stil (Danek 2012).

In den zuletzt genannten Arbeiten profitierte ich wesentlich von neuen Anregungen durch den kroatischen Gelehrten Zlatan Čolaković, die ich sowohl aus seinen Schriften als auch aus der Korrespondenz mit ihm erhalten hatte. ${ }^{25}$

Zlatan Čolaković (1955-2008) arbeitete nach seinem Studienabschluss (PhD in Classics, Zagreb 1984) als Stipendiat unter Lord im Parry-Archiv an den Tonaufnahmen und Handschriften (1984-1988) und äußerte 1988 in einem Vortrag in Los Angeles scharfe Kritik an der sprachlichen Kompetenz aller Texteditionen der Parry-Sammlung. ${ }^{26}$ Zurück in Jugoslawien, nahm er 1989 zusammen mit seiner Frau den exzellenten bosnischen Sänger Murat Kurtagić auf (35.000 Verse), startete ein vom kroatischen Staat finanziertes Forschungsprojekt „Das Wesen bosnischer Epik“, ging aber in den Wirren des Jugoslawien-Krieges nach Kanada, wo er jahrelang als Übersetzer und Gerichtsdolmetsch lebte. Erst 2004 erschien sein Buch „Mrtva glava jezik progovara“ („Das tote Haupt lässt die Stimme vernehmen“), in dem er acht Lieder des Kurtagić und zwei bis dahin unveröffentlichte Lieder des Međedović edierte. ${ }^{27}$ In den Anmerkungen und ,Tagebuchnotizen“ zu den Tonaufnahmen finden sich zahllose scharfe Beobachtungen und Reflexionen zur Oralpoetry-Theorie und ihrem Wert für das Verständnis Homers. Schon hier lässt Colaković durchblicken, dass er Međedović nicht für einen traditionellen, sondern einen ,,post-traditionellen“ Sänger hält, der eben aus diesem Grund für einen Vergleich mit Homer besonders wertvoll sei.

2007 publizierte Čolaković eine zweibändige Textausgabe von Liedern des Međedović: eine Neuedition des „Smailagić Meho“ mit Texterklärungen und -verbesserungen gegenüber der Ausgabe von Lord/Bynum, und die Erstedition von vier weiteren Liedern. Hinzu kommen umfangreiche, bislang unveröffentlichte Handschriften Parrys und Gesprächsprotokolle mit Sängern, die dokumentieren, wie Parry mit Međedović gearbeitet hat: ${ }^{28}$ Parry plante die Gespräche, die sein Schreiber und Dolmetscher Nikola Vujnović mit dem Sänger führte, exakt im Voraus und fokussierte sie auf präzise Fragestellungen, die primär dem Ziel dienten, zu ergründen und dokumentieren, ob Međe-

25 Ich stütze mich auf meinen Email-Verkehr mit Zlatan Čolaković, der 2004 einsetzte und bis knapp vor seinem völlig unerwarteten und viel zu frühen Tod im Dezember 2008 andauerte.

26 Gedruckt in Čolaković 1992 (erweiterter Abdruck in Čolaković 2004, 569-606).

27 Vgl. dazu meine Besprechung in Danek 2005.

28 Die Fülle des hier publizierten Materials ist noch längst nicht ausgewertet; welche Aufschlüsse weitere unveröffentlichte Texte des Parry-Archivs bieten, lässt sich bestenfalls erahnen. 
dović, der sich in Länge, sprachlicher Qualität und Stil seiner Lieder so stark von allen anderen Sängern abhob, trotzdem als traditioneller Sänger bezeichnet werden könne. Parry ging es also in seinen Interviews (die gelegentlich wie Verhöre klingen $)^{29}$ um die Frage, ob Međedović dafür geeignet sei, den außergewöhnlichen Dichter Homer als mündlich-traditionellen Sänger zu erweisen.

Parry war zweifellos daran interessiert, diese Frage mit ,ja“ zu beantworten. Čolaković kommt bei einer kritischen Sichtung des Materials zur gegenteiligen Antwort. Er stützt sich dabei auf seine umfassende Kenntnis der gesamten Tradition, beruft sich aber vor allem auf Zeugnisse, die rund um die letzte Aufnahme Parrys mit Međedović (und seine letzte Lied-Aufnahme überhaupt) entstanden. Parry hatte sich vor seiner Abreise aus Bijelo Polje ein letztes Experiment ausgedacht: Er ließ den anerkannt guten alten Sänger $\mathrm{Mu}-$ min Ramadanović Vlahovljak, einen Schüler des berühmten Ćor Huso, ein Lied vortragen, das Međedović unbekannt war. Unmittelbar darauf forderte er Međedović auf, dieses Lied - das er zum ersten Mal gehört hatte - ebenfalls zu singen, und ließ auch Mumin zuhören. Međedović tat es, und der Umfang des Liedes wuchs in seiner Version von 2.294 auf 6.313 Verse, und zwar ohne dass Međedović substanzielle Änderungen an der Liedstruktur vorgenommen hätte.

Lord hat dieses Experiment ausführlich dokumentiert und im Detail gezeigt, wie Međedović seine Vorlage systematisch erweitert und vertieft hat. ${ }^{30}$ Erst Ćolaković weist aber darauf hin, dass Parry beide in das Experiment involvierten Sänger einer intensiven Befragung über ihr poetisches Selbstverständnis unterzogen hat: Međedović unmittelbar vor dem Beginn von Mumin Vlahovljaks Vortrag, ${ }^{31}$ Mumin nach der ersten Hälfte von Međedovićs Vortrag. ${ }^{32}$ Mumin war mit seinem Urteil über Međedović zunächst zurückhaltend, wurde aber auf Drängen von Parry und Vujnović deutlicher und gab zu verstehen, dass er Međedovics Vortrag für schlechter als seinen eigenen halte, gerade weil er um so viel länger sei. ${ }^{33}$ Seine Kritik kreist um das Konzept der

29 Vgl. Čolaković 2007/1, 361 (aus Parrys schriftlicher Anweisung zum Interview, das Nikola Vujnović mit Međedović am 5.8. 1935 führte; Übersetzung G.D.): „Wir haben dir so viele Tage zugehört, weil wir dachten, du sagst die Wahrheit über deine Lieder. Und jetzt versuchst du, uns zu betrügen, wie ein schlechter Sänger, der über seine Lieder lügen kann (Nikola: Sei recht wütend!)." [Unterstreichung im OriginalManuskript]

30 Lord 2000 (= 1960), 78-81; 102-105; 223-234. Für die einzige Erweiterung gegenüber der Vorlage, die in die Liedstruktur substanziell eingreift, vgl. Danek 2012, $117 \mathrm{f}$.

31 Das Gespräch mit Međedović (PN 12467), das wertvolle Einsichten in das poetische Selbstverständnis des Sängers bietet, ist jetzt publiziert bei Čolaković 2007/1, 395-428. Auch dieses Gespräch kreist lange um die Frage der „Ausschmückung“ und Länge der Lieder, also um ähnliche Vorwürfe, die Mumin später explizit erheben wird.

32 Das Gespräch mit Mumin Vlahovljak (PN 12472) ist publiziert in Čolaković 2007/1, 429-451 (bosnisch, zuvor schon 2004) und ausgewertet in Čolaković 2007/1, 47-90 (kroatisch) und Čolaković 2007/2, 567-597 (englisch).

33 Vlahovljaks Kritik ist verständlich, weil Međedović in diesem Vortrag auch nicht annähernd die Qualität seiner übrigen Aufnahmen erreichte. 
'Ausschmückung' (kita) eines Liedes, d.h. um die Technik der Ausweitung des Liedumfangs durch additive, deskriptive oder katalogische Elemente. Mumin streitet kategorisch ab, dass sein eigener Lehrer Ćor Huso die Lieder derart breit ,ausgeschmückt“ habe, und suggeriert damit, dass Međedović sich nicht mit „guten“ Sängern messen könne. Die konkreten Vorwürfe gegen Međedović lassen sich somit in drei Punkte zusammenfassen:

(1) Međedović habe seine Vorlage, Mumins Lied, unnötig gelängt;

(2) Er habe den Inhalt des Liedes in Details abgeändert, sei damit von der 'historischen Wahrheit' abgewichen und habe „Lügen“ eingeführt;

(3) Er habe Teile anderer Lieder in dieses eine Lied eingefuigt und somit mehrere Lieder unzulässig miteinander kombiniert.

Čolaković wertet die Kritik des Vlahovljak als Nachweis, dass Međedović von seinen eigenen Sänger-Kollegen nicht als traditioneller Sänger anerkannt gewesen sei. Er nimmt das als Ausgangspunkt für eine Auflistung aller Aspekte der Erzähltechnik, in denen Međedović von der breiten Masse der traditionellen Sänger abweiche, aber mit Homer übereinstimme. Daraus schließt er, dass beide Sänger als post-traditionelle Sänger betrachtet werden müssten, die durch intensive Verwendung untraditioneller Mittel, vor allem auch durch die schriftliche Fixierung ihrer Epen das Absterben der lebenden Tradition herbeigeführt hätten.

Gegen diese Argumentation hat David Elmer (ehemals Kurator des ParryArchivs), berechtigte Einwände erhoben. ${ }^{34}$ Elmer mahnt ein, dass die Äußerungen des Vlahovljak im Rahmen des Interview-Kontexts beurteilt werden müssen und dass die Abwertung der 'Ausschmückung' eines Liedes vor allem als Reaktion auf die außergewöhnliche Längung seines Liedes durch Međedović und nicht als allgemeingültiges poetologisches Konzept des Sängers zu verstehen ist. Elmer definiert dann anhand der entsprechenden Aussagen des Međedović die konträren Einstellungen der beiden Sänger zum Prinzip 'Ausschmückung', und damit zum Verhältnis zwischen historischer Wahrheit, Überlieferung und aktuellem Liedvortrag: Vlahovljak sieht als Ziel des Liedvortrags die exakte Wiedergabe der Handlungsstruktur und aller Details, die der Sänger von seinem 'Lehrer' übernommen habe; Ausschmückung ist für ihn eine ungebührliche Zutat zum überlieferten Stoff und verfälscht die Tradition. Međedović hingegen hat den Ehrgeiz, die Heldentaten der Vergangenheit möglichst so zu erzählen, wie sie tatsächlich stattgefunden hätten; dazu fühlt er sich verpflichtet, auch jene Details hinzuzufügen, die frühere Sänger ,ausgelassen" hätten, die aber die historische Plausibilität gebiete; Ausschmückung ist für ihn daher ein unabdingbares Gestaltungselement, um einer Erzählung innere Plausibilität zu verleihen. Elmer kann dabei zeigen, dass die Poetik des

34 Elmer 2010. 
Međedović sich in diesem Punkt eng mit dem homerischen Prinzip kósmos berührt. ${ }^{35}$

Auch Elmer erkennt an, dass Međedović mit seinem Konzept der selbstständigen 'Ausschmückung' der überlieferten Liedformen die üblichen Mittel der Tradition besonders stark ausgereizt habe. Elmer spricht sich aber gegen die Bezeichnung ,post-traditional“ aus und schlägt stattdessen vor, die Dichtkunst des Međedović als eine „hypertrophe“ Entwicklungsform der Tradition zu sehen, die die Tradition als solche nicht sprenge, aber nur marginal beeinflusse.

Sowohl Čolaković als auch Elmer weisen darauf hin, dass die 45 Tage Aufnahmetätigkeit mit Međedović als ein einziges umfassendes Experiment Parrys an einem außergewöhnlichen Sänger zu betrachten sind. Das betrifft nicht nur die Interviews, sondern schon die Inszenierungen der LiedAufnahmen, an denen sich zumindest die folgenden experimentellen Konstellationen deutlich ablesen lassen:

Parry fordert Međedović von Anfang an auf, sein „längstes Lied“ zu singen, wie er es auch bei anderen Sängern macht. Međedović ist der erste Sänger, der Parrys Hoffnungen erfüllt, und zwar in sukzessiver Steigerung: Gleich sein erstes, diktiertes Lied umfasst 7.621 Verse und ist damit deutlich länger als alles, wovon Parry bis dahin Kenntnis hatte; parallel zur Diktat-Aufnahme beweist Međedović, dass er auch im gesungenen Vortrag zu ähnlichen Dimensionen fähig ist (nach einem ersten Versuch mit 2.390 Versen singt er ein Lied mit 6.290 Versen). Unmittelbar nach Abschluss des ersten Diktats diktiert er tatsächlich sein „längstes Lied“ (12.311 Verse); später trägt er auch im gesungenen Vortrag ein „längstes Lied“ vor (13.326 Verse). Parry startet später noch einen dritten Anlauf und lässt Međedović sein endgültig „längstes“ Lied diktieren, bricht aber diesen Versuch nach zwei Tagen ab (3.738 Verse), wohl weil die Zeit immer mehr drängt und er vor seiner Abreise noch umfangreiche Interviews mit Međedović durchführen will; von diesem Zeitpunkt an lässt er Međedović nicht mehr diktieren, sondern nur mehr auf Schallplatte singen oder sprechen.

Parry lässt Međedović mehrfach ein Lied unterbrechen und später (nach dem Einschub anderer Lied-Vorträge oder Interviews) fortsetzen. Damit testet er, ob die Liedinhalte einander durch den eng vermischten Vortrag beeinflussen, und stellt fest, dass dies nicht der Fall ist: Für Međedović bilden die einzelnen Lieder voneinander unabhängige Einheiten. Parry will damit wohl Erklärungsmodelle für die Entstehung von Großepen ausschließen, die zu seiner Zeit in der Homerforschung noch aktuell sind: die Liedertheorie, und die Schichtentheorie.

35 Elmer 2010, 290-295. Zu kósmos als poetologischem Prinzip vgl. auch Od. 13, 362-

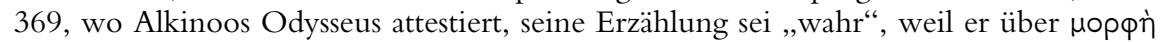
$\varepsilon \dot{\varepsilon} \dot{\varepsilon} \omega \nu$ verfüge. 
Im Rahmen dessen lässt Parry Međedović ein und dasselbe Epos zweimal vortragen, einmal im Diktat und einmal im Gesang, um festzustellen, bis zu welchem Grad Liedstruktur und Ausführung identisch bleibt. ${ }^{36}$ Aufgrund der ausgewogenen Dimensionen dieses Liedes möchte ich vermuten, dass Parrys Auftrag hier zusätzlich lautete, Međedović solle dieses Epos nicht so lang wie möglich, sondern in einem Umfang vortragen, der seiner üblichen Praxis entspreche.

Parry fordert Međedović knapp vor seiner Abreise auf, auch ein „kurzes Lied“ vorzutragen, offenbar zur Kontrolle, wie Međedović klingt, wenn er seine Liedeinheiten ähnlich kurz hält wie die meisten seiner Kollegen. Međedović erfuillt diese Erwartung zweimal hintereinander: ein erstes Lied mit 645 Versen, ${ }^{37}$ und ein nächster Versuch mit 1.302 Versen. Dieses zweite Lied sticht stilistisch kaum aus der Masse der Tradition hervor; Međedović beweist damit, dass er, wenn er will, auch banal traditionell singen kann, und es gibt von ihm auch einen Kommentar dazu: „Međedović sagte, wenn er wolle, könne er ein Lied, das er von 'schwachen' Sängern gelernt habe, genau so vortragen, wie sie es vorgetragen hätten! Doch das würde dann ein 'schwaches' Lied sein. “"38

Parry lässt als letztes Experiment Međedović ein ihm unbekanntes Lied eines anderen Sängers anhören und unmittelbar darauf selbst vortragen; auch dabei versucht er auszuschließen, dass Međedović die größere Länge durch Kontamination mit anderen Liedern erreicht hat.

Hier wird die Problematik von Parrys Experiment besonders deutlich,wie eine Stelle im Interview mit Mumin Vlahovljak zeigt: ${ }^{39}$ Der Sänger hat soeben betont, dass sein Lehrmeister Ćor Huso der beste Sänger gewesen sei, der weit und breit bekannt sei; Vujnović provoziert ihn daraufhin mit der Bemerkung: „Aber schau doch, Avdo hat gute Lieder, und er hat nichts von Ćor Huso gelernt!“ Mumin reagiert ironisch: ,Ja, Avdo hat gute Lieder! Gute Lieder hat der Avdo! Avdo schmückt aus, und jetzt meines, das ich kenne, er, er kann es noch ausschmücken, noch zweimal hinzufügen, und es wird noch mehr ausge-

36 Es handelt sich dabei um die „Hochzeit des Vlahinjić Alija“, dessen diktierte Version ich ins Deutsche übersetzt habe (Danek 2002) und die ich noch immer für das am besten gelungene Epos des Međedović halte. Međedović hat in der zweiten Version einen kleinen, aber signifikanten Eingriff in die Handlungsstruktur vorgenommen, der eindeutig als 'Korrektur' bzw. 'Verbesserung' klassifiziert werden kann: vgl. Danek 1998, 73-75.

37 Parry wollte mit diesem Lied testen, ob Međedović ein Lied über einen christlichen Helden in der für den christlichen Traditionszweig typischen Kurzliedform singe oder auch hier zur großepischen Form finde. Bynum (http://enargea.org/ue/texts/prizren0. html) kann immerhin zeigen, dass Međedović diesem Lied, das in allen erhaltenen christlichen Versionen als „Ballade“ zu bezeichnen ist, die Form eines - wenn auch kurzen - „Epos“ gegeben hat.

38 Čolaković 2007/1, 60, Anm. 23 (Übersetzung: G.D.).

39 Der Wortlaut in voller Länge bei Čolaković 2007/1, 442f.; englische Übersetzung und Interpretation bei Čolaković 2007/2, 571f. 
schmückt sein!“ Vujnović: „Ist das gut?“ Mumin: „Für den einen ja, für den anderen nein." Vujnović provoziert weiter, indem er wieder Ćor Huso ins Spiel bringt. Mumin reagiert gereizt: „Eh, der hat die Lieder nicht ausgeschmückt, was nicht das war, was gewesen ist [d.h., was nicht den Tatsachen entsprach], hat er nicht zusätzlich dazugetan.“ Vujnović: „Er hätte nur die Wahrheit gesungen, ha?“ Mumin: „Ha! Nur die Wahrheit!“ Vujnović: „Dann ist also keine Ausschmückung in dem Lied wahr?" Mumin: „Ja, bei Gott, genau!"

An dieser Stelle bricht der Dialog plötzlich zusammen. Vujnović fragt: „Warum lachst du jetzt? Sag!“ Mumin: „Wie soll ich nicht lachen, wo du es doch selbst siehst!“ Vujnović: „Was heißt, ich sehe es?“ Mumin: „Du weißt es selbst!“ Vujnović: „Inwiefern?““ Mumin: „Gut!“” Vujnović: „Bei Gott, wie soll ich es wissen, wenn ich nichts gesehen habe?“ Mumin: „Bei Gott, du weißt es mit Sicherheit, so wie ich. Sicher auch er, bei Gott, dein Herr Chef! Eeeeh!“

Vujnović beschließt daraufhin, das Geplänkel zu ignorieren, und das Gespräch läuft ruhig weiter.

Čolaković (572 Anm. 10) kommentiert diese Passage so: „Parry is nearby, recording this conversation with his apparatus. Vlahovljak uses fine irony in his conversation with Vujnović. He tells Vujnović that Parry is obviously his "boss", and that he realized Parry made an experiment consisting in recording his poem, and then Međedović's version of it." Ich glaube wir können noch weiter gehen: Vlahovljak, der schon vorher angemerkt hat, überflüssige Ausschmückung verfolge allein den Zweck, einem Lied „mehr Worte“ zu verleihen, signalisiert hier etwa diesen Gedanken: „Wir alle wissen, dass Međedović nur deshalb so lange Lieder singt, weil Parry ihn dazu aufgefordert hat und dafür bezahlt. Ich hingegen singe auch für Geld nicht länger, als es meinem Ehrenkodex als Sänger entspricht. Međedović tut es nur wegen des Geldes. Aber damit verstößt er gegen den tieferen Sinn des Heldenliedes, der darin besteht, die historische Wahrheit weiter zu transportieren."

Ich habe diese Deutung auch gegenüber Čolaković vorgeschlagen; er lehnte sie ab mit dem Argument, Međedović habe doch gewusst, dass Parry am übernächsten Tag aus Bijelo Polje abreisen werde, und habe daher von Parry keinen zusätzlichen Gewinn erwartet. ${ }^{40}$ An anderer Stelle unterstützt Čolaković jedoch meine Deutung: Međedović drückt im Interview am Vortag seine tiefe Dankbarkeit gegenüber Parry aus, weil ihn dieser aus einer ausweglosen Situation gerettet hatte: Kurz vor Parrys Ankunft in Bijelo Polje war das Familienhaus des Međedović abgebrannt. Die großzügige Bezahlung durch Parry ermöglichte es ihm, es wieder aufzubauen. ${ }^{41}$ Međedović war daher vielleicht mehr als andere Sänger bereit und gewillt, Parry jeden Wunsch zu erfüllen. Mumin Vlahovljak, der stolz darauf war, für seinen Gesang nie Geld genommen zu haben, musste das als Erniedrigung auffassen; Međedović, der auch

40 Emails vom 21. September und 10. Oktober 2006.

41 Čolaković 2007/1, 398-400. 
zuvor schon in der Lage war, längere Lieder zu singen als alle seine Kollegen, musste es hingegen auch aus künstlerischen Gründen geradezu begrüßen, wenn er sein Potenzial endlich einmal voll ausschöpfen konnte.

Međedović spürt den Druck, den Parry auf ihn ausübt, um zu optimalen Resultaten zu gelangen: Parry will einerseits unmissverständlich ein ,längstes Lied“, will aber andererseits ausschließen, dass dieses ,längste Lied“ auf untraditionelle Art zustande gekommen sei. Für Međedović reduziert sich das auf den Vorwurf, dass ein ,langes Lied“ grundsätzlich nur durch Betrug zustande gekommen sein könne. Trotzdem findet er zu einem eigenen Selbstbewusstsein, indem er auf seinem Sonderstatus als Qualitätsmerkmal beharrt: Er weist den Vorwurf der Kontamination zurück, und zwar zu Recht, gibt eigene Zutaten aber vorsichtig zu. ${ }^{42}$ Und trotz des Fehlens abstrakter Ausdruckskraft ${ }^{43}$ formuliert Međedović in nuce seine eigene ästhetische Theorie: Er ist besser als alle seine (ihm bekannten) Kollegen fähig, aus einem vorgegebenen Lied die Idee des Stoffes herauszuschälen bzw. dieser besonders nahezukommen, und zwar durch ein besonders hohes Maß an Anschaulichkeit, Präzision im Detail, vor allem aber auch durch eine Technik der „Auffüllung des bislang von allen Sängern Ausgelassenen“. ${ }^{44}$ Međedović hat das stolze Bewusstsein seiner eigener Überlegenheit gegenüber Vujnović so ausgedrückt: „Niemals wirst du mein Lied vortragen können so wie ich, auch nicht wenn du dein ganzes Leben daran lernst!“45

John Foley hat die Funktionsweise der südslawischen Epentradition als „traditional referentiality“ definiert, als eine „,pars pro toto“-Technik, in der jeder einzelne Liedvortrag auf die Tradition als Ganzes verweise. ${ }^{46}$ Međedović transzendiert jedoch diese „Immanent Art“, indem er das Implizite seiner Lieder explizit macht und dadurch zu einer Konkretisierung, Visualisierung, Vergegenwärtigung und Verlebendigung der Liedinhalte gelangt, die zumindest in den dokumentierten Liedern seiner eigenen Tradition ohne Beispiel ist ${ }^{47}$, die

42 Für einzelne kleinere Ergänzungen des Plots, vor allem gegen Ende der Lieder, zur Ergänzung von toten Enden, vgl. Danek 2012, 117-119.

43 Der Kontrast zwischen der Sprache der Interviews mit ihrem geradezu reduzierten Code und der Sprache der Epen ist allein schon ein schlagender Beweis furr die Traditionalität von Međedovićs Liedern: Ohne die Hilfe der traditionellen Formelsprache hätte Međedović keinen einzigen etwas komplexeren Gedanken formulieren könne.

44 Damit erinnert Međedović an das Prinzip der 'historischen Wahrscheinlichkeit', mit dem Thukydides in seinem berühmten Methoden-Kapitel $(1,22)$ seinen Gebrauch der direkten Reden rechtfertigt, oder einfach an Aristoteles (poet. 1451a), der es als Aufgabe des Dichters sieht, das Vergangene so zu beschreiben, „wie es gewesen sein könnte".

45 Čolaković 2007/1, 67.

46 Foley 1991 und 1999. Vgl. dazu Danek 2002a.

47 Ich bin davon überzeugt, das ein Ćor Huso, aber auch ein Mehmed Kolaković (siehe unten, Anm. 48) im mündlichen Vortrag (im Gegensatz zu der von ihm als Belastung empfundenen Diktat-Situation) ihre Lieder in ähnlicher Weise mit Leben erfüllen konnten. 
aber frappant an die markantesten Züge homerischer Darstellungskunst erinnert: Međedović füllt die Szenen mit konkreten narrativen Details auf und gestaltet sie mit lebendigen Dialogen aus; er erfüllt den Raum mittels Beschreibungen, so dass die Skizzenkarte seiner Vorlagen zu einer visualisierten Landschaft wird; und er füllt die erzählte Zeit auf zu einer von den Helden persönlich erlebten Zeitdauer und damit zu einem von den Hörern konkret nachempfindbaren Zeitablauf.

Welchen Wert hat also Međedović für einen Vergleich mit Homer? Međedović war als Ausnahmesänger nicht typisch für seine eigene Tradition, obwohl er ohne diese nicht vorstellbar ist. Milman Parry entdeckte ihn, während er nach den Spuren eines anderen Ausnahmesängers, Ćor Huso, suchte und feststellen musste, dass dessen Ausnahme-Qualität aus den Vorträgen seiner Epigonen nicht mehr rekonstruierbar und somit unwiderruflich verloren war. Im Gegensatz dazu konnte Parry etliche Epen des Međedović durch Aufnahmen fixieren und der Nachwelt überliefern. Da diese Aufzeichnungen aber so lange nicht publiziert wurden, lösten sie keine Rückwirkung auf die Tradition selbst aus: Die Sänger rund um Međedović konnten seine Lieder nicht aus schriftlich fixierten Texten (auswendig-)lernen, waren aber auch nicht imstande, nach einmaligem Anhören eines Vortrags die spezifische Qualität von Međedović zu reproduzieren oder auch nur nachzuahmen. Der einzige Sänger, von dem wir wissen, dass er die Tradition des Međedović bis zu einem gewissen Grad zu bewahren versuchte, war sein eigener Sohn Zaim, der in Anspruch nahm, die Lieder und auch den Vortragsstil von seinem Vater gelernt zu haben. Doch hielt offenbar niemand Zaim Međedović für einen überragenden Sänger. So hinterließ die besondere Qualität der Lieder des Međedović in der Tradition sonst keine tieferen Spuren.

Ähnliches können wir von einem anderen Ausnahmesänger behaupten, Mehmed Kolaković, dessen Lieder 1886-1888 aufgenommen wurden und der wahrscheinlich der kreativste Kopf unter den Epen-Sängern seiner Zeit war. Auch von seiner besonderen Qualität als Erzähler, die wir aus den veröffentlichten Texten ablesen können, war fünfzig Jahre später, als Milman Parry das Einzugsgebiet dieses Sängers in NW-Bosnien durchforschte, in der lebenden Tradition nichts mehr greifbar. Auch in diesem Fall versuchte nur Džafer Kolaković, der Sohn des Sängers, die besondere Form der Epen seines Vaters zu bewahren und weiter zu transportieren, aber ohne sichtbaren Erfolg. ${ }^{48}$

Auch Parrys verzweifelte Suche nach der Gestalt des Ćor Huso bestätigt dieses Bild: Nach einer einzigen (langen) Generation von Sängern, die den Ausnahmesänger Huso noch gehört hatten, konnte Parry die besondere Quali-

48 Zur innovativen Erzähltechnik des Mehmed Kolaković vgl. Schmaus 1971 [1953] und 1979 [1953], Danek 1998 und 2002, 275-303. Džafer Kolaković behauptete, die Akademie in Zagreb habe die Lieder seines Vaters bei den Diktat-Aufnahmen ,verkürzt“ und „,verfälscht“; laut Murko (1951, 279) waren die dokumentierten Versionen des Sohnes außergewöhnlich lang (bis zu 10.000 Verse), aber ästhetisch schwach. 
tät des mythischen Sängers in den Texten seiner Schüler nicht dingfest machen, da er sichtlich keinen gemeinsamen Nenner fand, mittels derer man die Vorträge der Epigonen definieren konnte. Međedović kommentierte das einmal treffend: „Was nutzt es, dass jemand ein Lied von Ćor Huso gelernt hat, wenn er selbst ein schwacher Sänger ist? “49

Vor allem für die frühe Überlieferung und die erstmalige Textfixierung der homerischen Epen lässt der Vergleich mit der südslawischen Tradition somit eindeutige Schlussfolgerungen zu: Parrys Modell eines Vergleichs zwischen Homer und dem legendären Ćor Huso zielt ins Leere, da die spezifische Qualität seines Vortrags schon nach einer einzigen Generation der mündlichen Weitergabe der Epen in den Liedern seiner Nachfolger nicht mehr sichtbar war. Damit scheidet das Modell von Nagy, nämlich die allmähliche Fixierung der Textgestalt über etliche Generationen der rein mündlichen Weitergabe, als wenig wahrscheinlich aus: Homers Text konnte in seiner überragenden Qualität nur erhalten bleiben, weil die nachfolgenden Sänger sich an der schriftlich fixierten Form orientieren konnten. Das Modell Međedović bietet hier ein besseres Analogon: Der Text Homers blieb sichtlich nur deshalb der Nachwelt erhalten, weil er in Buchform eingefroren war. Eine mögliche Erklärung für die erste Phase der Überlieferung der Homer-Texte könnte dahin gehen, dass die ersten Generationen der 'Homeriden' die Texte als oral poets anhand dieser schriftlichen Vorlage auswendig lernten, was dazu führte, dass ihre Vorträge durchaus etwas weiter vom Text abwichen, da es kein Konzept „Texttreue“ gab, sondern bestenfalls einen ästhetisch begründeten Qualitätswunsch nach „Textnähe“. Die Rekonstruktion der Textgeschichte Homers kann somit von dem konkreten Beispiel des Međedović wesentlich mehr profitieren als von der vagen Überlieferung zu Ćor Huso.

Avdo Međedović bleibt weiterhin ein „understudied poet“. In dieser Arbeit konnte nur angedeutet werden, dass die Homerforschung aus weiterer intensiver Arbeit an diesem ,jugoslawischen Homer“ wertvolle Erkenntnisse ziehen könnte. Zlatan Čolaković hat mit seinen Texteditionen von Liedern und Interviews, aber auch seinen zahlreichen wertvollen Beobachtungen und provokanten Thesen der Forschung ein weites Feld eröffnet. Um dieses Potenzial für unser Verständnis Homers fruchtbar zu machen, bleibt es notwendig, den Ausnahmesänger Međedović (so wie auch andere dokumentierte Ausnahmesänger) vor dem Hintergrund der gesamten südslawischen HeldenliedTradition zu studieren.

49 Čolaković 2007/2, 585 Anm. 38. 


\section{Bibliographie}

Bakker, E.J., „Homer, Hypertext, and the Web of Myth“, in: U. Schaefer / E. Spielmann (ed.), Formen und Folgen von Schriftlichkeit und Mündlichkeit (Tübingen 2001) 149-160.

Bynum, D.E., Serbo-Croatian Heroic Poems: Epics from Bihać, Cazin, and Kulen Vakuf (New York 1993).

Bynum, D.E. / Lord, A.B. / Lord, M.L. / Parry, M. (ed.), Cor Huso. A Study of the Southslavic Song (New York 1995, vgl. http://enargea.org).

Člaković, Z., ,South Slavic Muslim Epic Songs. Problems of Collecting, Editing and Publishing“", California Slavic Studies 14 (1992) 232-269.

Čolaković, Z., The Epics of Avdo Mededović. A Critical Edition. 1/2 (Podgorica 2007).

Čolaković, Z. / Rojc-Čolaković, M., Mrtva glava jezik progovara (Podgorica 2004).

Čolaković, Z. / Lord, A.B., „Nasljeđe Milmana Parrya (uz 70-godišnjicu smrti)“, Almanah 31/32 (2005 [1986]) 35-67.

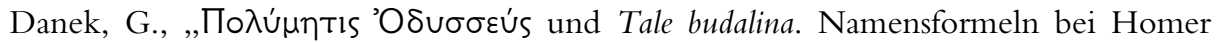
und im serbokroatischen Epos“, WS 104 (1991) 23-47.

Danek, G., ,'Literarische Qualität' bei Homer und im jugoslawischen Heldenlied“, WHB 34 (1992) 16-32.

Danek, G., „Darstellung verdeckter Handlung bei Homer und in der südslawischen Heldenlied-Tradition“, WS 111 (1998) 67-88.

Danek, G., Bosnische Heldenepen (Klagenfurt 2002).

Danek, G., „Traditional Referentiality and Homeric Intertextuality“, in: F. Montanari (ed.), Omero tremila anni dopo (Roma 2002a) 3-19.

Danek, G., Rez. zu Čolaković / Rojc-Čolaković 2004, WS 118 (2005) 278-282.

Danek, G., ,'Ein Bild von einem Helden'. Ekphrasis im bosnisch-muslimischen Heldenlied (Avdo Međedović, „Die Hochzeit des Vlahinjić Alija“"“, in: C. Ratkowitsch (ed.), Die poetische Ekphrasis von Kunstwerken. Eine literarische Tradition der Großdichtung in Antike, Mittelalter und früher Neuzeit (Wien 2006) 247-266.

Danek, G., „Developments of Traditional Narrative Techniques: Flashbacks in Homer and Avdo Međedović“", in: Čolaković 2007/2, 599-618.

Danek, G., „Agamemnon's Ancestors and Ruža’s Bridegroom (Iliad 2.99-109, and a Bosnian Parallel)“, in: C. Tsagalis (ed.), Homeric Hypertextuality, Trends in Classics 2, 2010, 225-238.

Danek, G., „The Doloneia Revisited“, in: Ø. Andersen / D.T.T. Haug (ed.), Relative Chronology in Early Greek Epic Poetry (Cambridge 2012) 106-121.

Finkelberg, M. (ed.), The Homer Encyclopedia (Malden MA / Oxford 2011).

Foley, J.M., Immanent Art. From Structure to Meaning in Traditional Oral Epic (Bloomington / Indianapolis 1991).

Foley, J.M., „Individual Poet and Epic Tradition: Homer as Legendary Singer“, Arethusa 31 (1998) 149-178.

Foley, J.M., Homer's Traditional Art (University Park PE 1999). 
Friedrich, R., ,Oral Composition-by-Theme and Homeric Narrative. The Exposition of the Epic Action in Avdo Medjedovic's Wedding of Meho and Homer's Iliad“, in: F. Montanari (ed.), Omero tremila anni dopo (Roma 2002) 41-71.

Lord, A.B., „Homer and Huso I: The Singer's Rests in Greek and Southslavic Heroic Song“, TAPA 67 (1936) 106-113.

Lord, A.B., „Homer and Huso II: Narrative Inconsistencies in Homer and Oral Poetry“, TAPA 69 (1938) 439-445.

Lord, A.B., „Homer, Parry, and Huso“, AJA 52 (1948) 34-44.

Lord, A.B., „Homer's Originality: Oral Dictated Texts“, TAPA 94 (1953) 124-134.

Lord, A.B., The Singer of Tales (Cambridge MA 2000 [1960]).

Mitchell, S. / Nagy, G., „Introduction to the Second Edition“, in: Lord 2000, viixxix.

Murko, M., Tragom srpsko-hrvatske narodne epike (Zagreb 1951).

Nagy, G., Homer the Preclassic (Berkeley 2010).

Parry, A., „Have We Homer's Iliad?“, YClS 20 (1966) 177-216.

Parry, A. (ed.), The Making of the Homeric Verse. The Collected Papers of Milman Parry (Oxford 1971).

Parry, M., „Homer and Huso: I. The Singer's Rests in Greek and Southslavic Heroic Songs“. Abstract in TAPA 66 (1935) xlvii.

Sale, W.M., „Homer and Avdo: Investigating Orality Through External Consistency“, in: I. Worthington (ed.), Voice into Text: Orality and Literacy in Ancient Greece (Leiden 1996) 21-42.

Schmaus, A., „Episierungsprozesse im Bereich der slavischen Volksdichtung“, in: Gesammelte Slavistische und Balkanologische Abhandlungen I (München 1971 [1953]) 194-219.

Schmaus, A., „Studije o krajinskoj epici“, in: Gesammelte Slavistische und Balkanologische Abhandlungen IV (München 1979 [1953]) 77-235.

SCHS = Serbo-Croatian Heroic Songs, ed. M. Parry, A.B. Lord, D.E. Bynum, Cambridge MA (/ Belgrad). 1/2, 1953/54; 3/4, 1974; 6, 1980; 14, 1979.

Simonsuuri, K., Homer's Original Genius. $18^{\text {th }}$-Century Notions of the Early Greek Epic (1688-1798), (Cambridge 1979).

http://chs119.chs.harvard.edu/mpc/index.html (Milman Parry Collection) 


\title{
Präpositionalausdrücke bei Homer ${ }^{\star}$
}

\author{
HEINRICH HETTRICH
}

Die Präpositionen und anderen sogenannten Formwörter mussten im LfgrE in äußerster Kürze behandelt werden. Deshalb soll in diesem Beitrag aufgezeigt werden, dass sich auch bei diesen Wortklassen interessante Forschungsperspektiven ergeben. Ich möchte zwei Komplexe herausgreifen: zum einen die Frage nach der Abgrenzung von Präposition, Präverb und Adverb bei Homer, ${ }^{1}$ zum anderen den Kasusgebrauch in Präpositionalphrasen.

Beginnen wir mit einem knappen Blick auf den Stand der Forschung: Über die Vorgeschichte der Präpositionen herrscht seit mehr als 100 Jahren grundsätzlich Übereinstimmung: In der Spätphase der indogermanischen Grundsprache, die wir um ca. 3000 v.Chr. ansetzen können, also nur ca. 1500 Jahre vor Linear B, - in dieser Spätphase entsprachen den nachmaligen Präpositionen und Präverbien meist selbständige Adverbien mit räumlicher, oft direktivischer Bedeutung. In der Indogermanistik spricht man von Lokalpartikeln (LPs).

In der Weiterentwicklung hin zum Griechischen schließen sich diese Partikeln zunehmend enger entweder an Nomina oder Verben an und werden so zu Prä- bzw. Adpositionen oder Präverbien. Bei Homer sind diese Entwicklungen noch nicht zum Abschluss gekommen, so dass - dies ist etwa die Position in der Grammaire homérique von Chantraine - ein und dieselbe LP Adverb, Adposition und Präverb sein kann. Äußeres Zeichen der noch nicht völlig aufgegebenen Selbständigkeit ist die gelegentliche Tmesis zwischen LP und zugeordnetem Bezugsnomen (BN) oder Verb. Unter Nr. 1-3 finden Sie jeweils ein Beispiel für die LP mpós im Sinne Chantraines als freies Adverb, Adposition und Präverb, die für sich sprechen und nicht weiter kommentiert werden müssen.

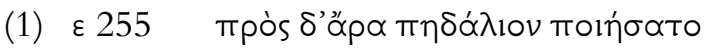

„Dazu machte er ein Steuerruder.“

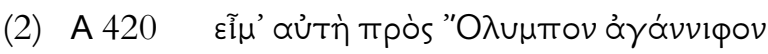

„Ich werde selbst zum schneebedeckten Olymp hingehen.“

^ Für klärende Hinweise danke ich Luz Conti.

1 Der Terminus ,Präposition“ ist in diesem Beitrag nur wegen seiner allgemeinen Verständlichkeit gebraucht; es ist damit nicht impliziert, dass der Übergang Adverb $\rightarrow$ Präposition bereits komplett vollzogen ist. 


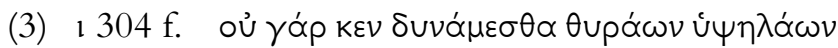

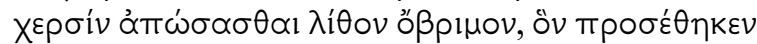
„,denn wir hätten von der hohen Öffnung nicht den wuchtigen Stein wegschieben können, den er dagegengelehnt hatte“"

In jüngerer Zeit wird jedoch über die grammatische Interpretation des homerischen Befunds wieder kontrovers diskutiert. Zur exemplarischen Verdeutlichung greife ich zwei einander wiedersprechende Ansätze heraus: die des englischen Gräzisten Geoffrey Horrocks und die des norwegischen Gräzisten und Sprachwissenschaftlers Dag Haug.

Horrocks setzt in seinem Buch von 1981 eine alles übergreifende Kategorie ,Partikel ${ }^{`}$ an, die etwa der gerade erwähnten ,LP` entspricht und wie diese entweder ein Nomen in einem obliquen Kasus oder ein Verb modifiziert, ohne sich bereits zu selbständigen und festen Kategorien ,Präposition“ oder ,Präverb“ differenziert zu haben. Es wird lediglich zwischen präpositionalem und adverbialem Gebrauch einer Partikel unterschieden.

Bei präpositionalem Gebrauch modifiziert die Partikel entweder ein explizit vorhandenes oder ein bloß implizites Nomen. Der erstere Fall liegt vor in

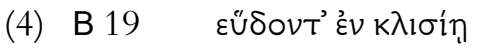
,schlafend im Zelt"“,

ebenso in

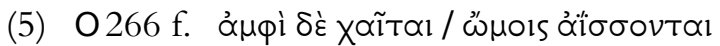

„Rings um die Schulter flattern die Mähnen.“

Die Sperrstellung von Partikel und BN in Beleg 5 kann so verstanden werden, daß die Partikel noch keine Präposition ist - eindeutig wäre diese bei Kontaktstellung. Wichtig ist weiter der Befund, dass die Partikel aber auch fehlen kann, wie in

(6) A 322 हैрX

„Gehet beide zum Zelt!“

Daraus schließt der Autor, dass in der Kombination von Partikel und BN das BN der Nukleus oder Kopf der Konstruktion und die Partikel der untergeordnete Modifikator ist.

Bei explizitem BN gibt es weiterhin verschiedene Konstruktionsalternativen: einerseits die Kontaktstellung von Partikel und Nomen wie oben in (4), ein weiterer der zahlreichen Belege ist

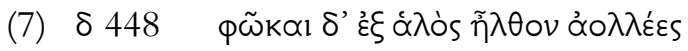

„Die Robben kamen dichtgedrängt aus dem Meer.“

und weiterhin möglich ist die Distanzstellung beider Konstituenten wie oben in (5). 
Dazu kommt als dritte Möglichkeit die präverbale Stellung der Partikel, wie $\varepsilon_{K}$ in

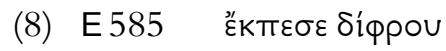

„Er stürzte aus dem Wagenkorb.“

oder koтó in

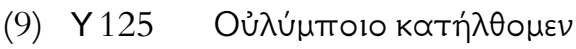

„Vom Olymp sind wir heruntergekommen“.

Ist dagegen das $\mathrm{BN}$ implizit, so steht die Partikel allein und verweist anaphorisch auf den lediglich vorausgesetzten Bezugsbegriff; so etwa ớp申í in (10) oder $\dot{\varepsilon} \mathrm{K}$ in (11)

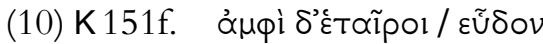

„Drumherum schliefen die Gefährten.“

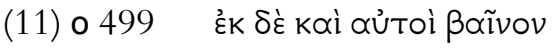

„Auch sie selbst traten [aus dem Schiff] heraus.“

Die zweite große Gruppe des Partikel-Gebrauchs, die adverbialen Partikeln, sind nach Horrocks dadurch definiert, dass sie weder ein explizites BN haben noch anaphorisch auf einen impliziten Begriff bezogen sind. Das gilt z.B. für ớmó in ớmó $\lambda \lambda u \mu l, z . B$. in

(12) E 758

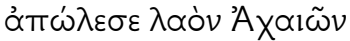

$$
\begin{aligned}
& \text { „Er vernichtete das Heer der Achaier“. }
\end{aligned}
$$

Soweit solche Verbalkomposita in Tmesis vorkommen können, gelten sie als

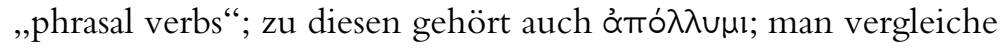

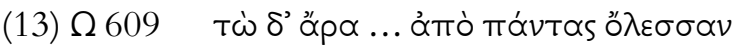

„Die beiden aber töteten alle“.

Ist dagegen Tmesis nicht belegt, handelt es sich um ein wirkliches Komposi-

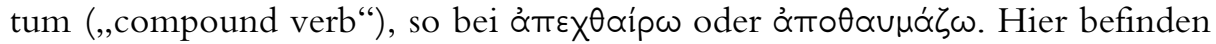
sich die Partikeln auf dem Weg zum Aktionsartmerkmal.

Mit dieser Klassifikation bewahrt, so Horrocks, Homer noch einen weit ins 2. Jahrtausend zurückreichenden Sprachzustand, wie die bei ihm noch lebendige Tmesis zeigt, für die es bereits in Linear B keinen Beleg mehr gibt.

Der Autor hat mit diesem Konzept zweifellos einen wichtigen Anstoß gegeben. Doch leidet es unter gewissen Inkonsequenzen, weil bei der Definition seiner Kategorien semantische und syntaktische Kriterien vermischt werden. So ist z.B. die Unterscheidung zwischen adverbialem und präpositionalem Gebrauch rein semantisch, ohne formales Kriterium, während diejenige zwischen ,phrasal verb' und ,compound verb' ganz auf der Ausdrucksseite verbleibt, ohne dass nach korrelierenden semantischen Unterschieden gesucht würde. 
Aber auch wenn diese und ähnliche Fragen gestellt werden müssen, zeigt das Buch von Horrocks deutlich, dass eine Überprüfung bisher eingeführter Kategorien notwendig ist.

In ganz anderer Weise weicht Dag Haug von der communis opinio ab. Er rechnet bereits bei Homer mit fest etablierten Präpositionen. So betrachtet er etwa das adverbiale $\varepsilon \dot{v}$ in

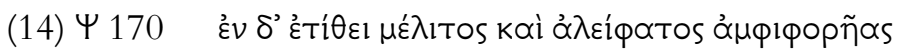

„Hinein aber stellte er Amphoren mit Honig und Salbe.“

trotz fehlendem BN ebenso als Präposition عُv wie in

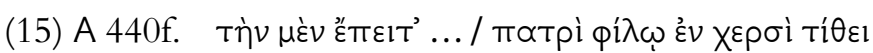

„Dann gab er sie dem lieben Vater in die Hände“

wo der Partikel ein BN zugeordnet ist. Zur Begründung weist er darauf hin, dass eine LP als freies Adverb in aller Regel anaphorisch ist, also auf einen vorerwähnten oder bekannten Begriff verweist. Für દ̉v in Beleg 14 ist dies das Totenlager des Patroklos auf dem Scheiterhaufen. Da also ein Bezugsbegriff der Partikel immerhin semantisch vorhanden ist, seien - ebenso wie diejenigen mit explizitem BN - auch diejenigen mit bloß implizitem als Präposition zu betrachten, und diese Präposition sei innerhalb der Präpositionalphrase (PP) bereits bei Homer wie später in klassischer Zeit die regierende Konstituente gegenüber dem untergeordneten $\mathrm{BN}$ - man sieht den diametralen Unterschied zu Horrocks. Die homerische Sprache unterscheide sich demnach von dem Klassischen Attischen lediglich durch die Möglichkeit der Sperrstellung von Präposition und BN sowie durch die große Häufigkeit der Fälle, in denen das BN einer Präposition implizit bzw. latent bleibt.

Es erscheint nicht einfach, bei einem derartigen Diskussionsstand auf Anhieb Klarheit bis ins Detail zu gewinnen. Machen wir deshalb einen Exkurs in das vedische Sanskrit als Vergleichshintergrund. Beide Sprachen stehen sich innerhalb der Indogermania ziemlich nahe, die vedische und die mykenische Überlieferung setzen in etwa gleichzeitig ein, und auch die Konstruktionsmöglichkeiten der LP's sind ähnlich, wenn auch im Vedischen etwas klarer und eindeutiger zu kategorisieren.

Wie in der homerischen Sprache bezeichnen auch im Vedischen die LP's lokale Relationen, darunter vielfach gerichtete Bewegungen, und auf diese wollen wir uns heute beschränken. ${ }^{2}$ Sie dienen damit vorwiegend der Präzisierung von Beziehungen, die bereits durch das Prädikatsverb in Verbindung mit einem Nomen in einem obliquen Kasus allein bezeichnet werden können. Dieses Nomen fungiert als BN der LP, in dem folgenden Beleg 16 vájram, der Akk. Sg. des Stammes vájra- „Keule“, verbunden mit der LP práti „,zu - hin,

2 Vergleiche allgemein zum Folgenden Hettrich-Casaretto-Schneider 2004 [2010]. 
gegen“, die etymologisch und weitgehend auch semantisch dem gr. Tpós entspricht: $^{3}$

(16) $8,96,9$ kás ta indra práti vájram dadharșa

„Wer hat je, Indra, deiner Keule getrotzt

(wörtl.: wer ist übermütig gegen deine Keule angegangen)?“

Hier steht das BN im A(kkusativ); es kommen aber auch andere oblique Kasus vor je nachdem, welchen Kasus das Verb vorgibt bzw. welcher Kasus der Aussageabsicht am besten entspricht:

(17) $1,118,8$ (BN im Dativ)

práti jánghām viśpálāyā adhattam

„Der Viśpalā verschafftet ihr ein Bein zurïck.“

(18) 10,64,13 (BN im Genitiv)

kuvíd angá práti yáthā cid asyá nạ

sajātyàsya maruto búbodhata

„Ob ihr, Marut, irgendwie auf diese Verwandtschaft mit uns achten werdet?"

(19) $10,167,4$ (BN im Lokativ)

suté sāténa yády àgamam vām

práti viśvāmitrajamadagnī damé

„Wenn ich mit Gewinn zum Soma, zu euch in das Haus,

o Viśvāmitra und Jamadagni, zurückgekehrt bin“

Unabhängig von der semantischen Beziehung zu einem Nomen kann die LP syntaktisch adnominal oder adverbal konstruiert werden. Bei adnominaler Konstruktion steht die LP in unmittelbarem Kontakt mit dem BN, also entweder prä- oder postpositiv, wie die LP ádhi „oben“, „hinauf“ in

(20) $8,23,26$ präpositiv

ágne ní șatsi ... ádhi barhís í

„Agni, setz dich nieder... auf die Opferstreu!“”

gegenüber

(21) $8,41,4$ postpositiv

yáh kakúbho nidhārayáh

prthivyām ádhi darśatáh

,,der die Bergspitzen befestigt hat oben auf der

Erde, der Ansehnliche“.

Die adverbale Konstruktion kennt ebenfalls zwei Varianten: die unmarkierte Kontaktstellung mit dem Verb, meist prä-, selten postverbal, sowie die mar-

3 Zu práti vgl. die Spezialuntersuchung von Casaretto 2010. - Alle vedischen Belege stammen, soweit nicht anders angegeben, aus dem Rgveda. 
kierte, hervorgehobene Stellung am Satzanfang, in Distanz zum Verb; die Entsprechung zur griechischen Tmesis; zu vergleichen sind u.a.

(22) 1,64,4 Kontaktstellung

vákșassu rukmā̀m ádhi yetire śubhé

„Auf der Brust haben sie Goldmünzen angelegt zum Prunke“

(23) 3,19,5 Distanzstellung

ádhi śrávāmsi dhehi nas tanúṣ̦u

„Lege Ruhm auf unsere Leiber!“”

Dies sind aber keine festen Regeln, sondern nur Tendenzen. Daneben kommen doppeldeutige Belege vor oder andere, die keinem dieser Muster entsprechen. Diese Abweichungen sind nicht selten und können je nach Partikel bis zu einem Viertel der Belege ausmachen; ein Fall ist

(24) 8,92,20 yásmin vísvāa ádhi śríyo

ránanti saptá samisádah

„,̈̈ber den sich alle Herrlichkeiten, die sieben

Opferversammlungen freuen!“

Werfen wir noch einen Blick auf die interne Struktur dieser Konstruktionen: In der adnominalen Konstruktion kann eine direktivische LP wegbleiben, ohne daß der Satz ungrammatisch wird. Er bezeichnet dann den gleichen SV, nur etwas weniger genau. Man vergleiche
(25) $5,33,3$
mit LP ádhi
tíșthā rátham ádhi tám vajrahasta
„Steig auf diesen Wagen hinauf, du mit der
Keule in der Hand."
(26) 6,18,9 ohne LP ádhi
vrtrahátyāya rátham indra tiștha
„Zur Vrtratötung steig auf den Wagen, Indra!“”

Wenn man einem Satz wie (25) die deutsche Wiedergabe gegenüberstellt, ist man versucht, die Wörter so einander zuzuordnen, wie durch die Hervorhebungen angegeben, also ádhi für eine Postposition zu halten. Diese Zuordnung wäre aber inkorrekt: Wir haben schon festgehalten, daß die LP im Vedischen wegbleiben kann, so in (26), während die Präposition auf im Deutschen grammatisch notwendig ist. Dann entspricht in (25) die dt. PP auf diesen Wagen als ganze dem vedischen Akkusativ rátham tám ohne ádhi, und ádhi selbst findet sein Gegenstück in dt. hinauf: Beide sind grammatisch entbehrlich und ergänzen lediglich als adverbiales Attribut oder Apposition ihr BN. Als Attribut/Apposition verhält sich ádhi ganz anders als eine Prä- oder Postposition, die ihren Kasus regiert, ihm also über-, nicht untergeordnet ist.

Ebensowenig kann adverbales ádhi in (22) und (23) als Präverb im strengen Sinne aufgefaßt werden, auch wenn es, wie in (22), mit dem Verb in Kontakt 
steht und mit ihm eine Akzenteinheit bildet. Seit Brugmann (1911: 759f.) ist anerkannt, daß von lexikalischer Univerbierung erst dann gesprochen werden kann, wenn eine gemeinsame semantische Weiterentwicklung der Kompositionsglieder vorliegt. Eine solche findet sich im RV nur relativ selten, z.B. in ádhi-ay / -gam/-gā, wörtlich „nach oben gehen“, weiterentwickelt zu ,achten auf, denken an". Würde man auf dieses semantische Kriterium verzichten, müßte man z.B. dt. anfangen in einem Satz wie Wann fangen wir denn endlich an? wegen der Distanzstellung als zwei lexikalische Wörter auffassen, was man kaum ernsthaft vertreten möchte. So wird man ádhi „oben“ in (22) trotz des intonatorischen Zusammenschlusses mit der unmittelbar folgenden Perfektform yetire nicht als Präverb, sondern als selbständiges Adverb verstehen.

Nur knapp sei noch darauf hingewiesen, daß eine LP auch ohne BN, dann als Adverb mit anaphorischer Funktion, gebraucht werden kann; man vgl. diesmal wieder mit práti - Beleg (27):

(27) 9,69,4 ukșá mimāti práti yanti dhenávah „Der Stier brüllt, [ihm] entgegen gehen die Kühe.“

Die grammatische Interpretation all dieser Befunde im Veda und bei Homer hat nach folgenden Alternativen zu erfolgen:

1) adpositionale Stellung:

Alternative a) Der Kasus des BN wird durch das Verb gesteuert, ganz so wie in Fällen, wo keine LP steht. Die LP tritt als attributiver oder appositiver Modifikator hinzu und stört den direkten Bezug des BN zum Verbum nicht.

Alternative b) Der Kasus des BN wird durch die LP gesteuert und ist in seiner autonomen Funktion beeinträchtigt (vgl. dt. mit dem Mantel /ohne den Mantel). Die Fügung aus LP und Kasus unterliegt als ganze der Rektion des Verbs (z.B. dt. warten + auf + Akk.; rechnen + mit + Dativ usw.).

2) adverbale Stellung:

Alternative a) LP und Verb bewahren ihre autonomen Bedeutungen und sind nicht voneinander abhängig (dt. die Tiere einfangen); die LP könnte auch wegbleiben.

Alternative b) LP und Verb entwickeln eine gemeinsame Sonderbedeutung (dt. mit dem Lesen anfangen).

Im Falle von 1a und 2a gilt die LP als Adverb, und ebenso, wenn kein näherer Bezug zu einem Nomen oder Verb vorliegt, wie in (27). Bei $1 \mathrm{~b}$ handelt es sich dagegen um eine Adposition, je nachdem um eine Prä- oder Postposition, bei $2 b$ um ein Präverb.

Wie verhalten sich nun die vedischen und homerischen Belege zu diesen Kriterien? 
a) Für die direktionalen LPs des Vedischen hat sich gezeigt, daß sie keine Einschränkungen auf die neben ihnen möglichen Kasus ausüben. ${ }^{4}$

Dagegen zeigen sich im Griechischen von Homer bis zum klassischen Attischen Einschränkungen der grundsätzlich möglichen Kombinationen bzw. semantische Weiterentwicklungen hin zu abstrakten Bezügen.

Weitgehend außer Gebrauch geraten:

ớpí + Gen./Dat.

ơvó + Dat.

$\mu \varepsilon \tau \propto \dot{\alpha}+$ Dat.

Automatische Folge ist eine stärkere Bindung von LP und BN in den Konstruktionen, die ,übrigbleiben“.
Abstrakte Bedeutungen nehmen an:
ơvtí + Gen.: $\quad$ gegenüber $\rightarrow$ anstatt

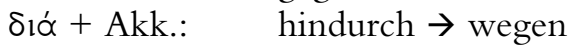
кœтó + Gen.: u.a. hinab zu $\rightarrow$ gegen

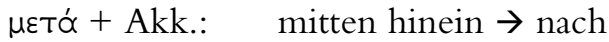

Während dies nachhomerische Entwicklungen sind, zeigt auch Homer schon einzelne Resultate ähnlicher Prozesse: Wie wir noch sehen werden, dürfte der von Chantraine so genannte génitif de but (1963: 113), wie er etwa vorliegt in

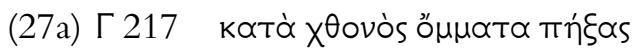

„,die Augen auf die Erde hingeheftet“,

einen vorher anzunehmenden Dativ verdrängt haben.

b) Im Veda ist eine LP, wie wir gesehen haben, in direktionalen Ausdrücken grundsätzlich optional. Diese Freiheit besteht bei Homer nicht mehr gleichermaßen. So ist der reine Akkusativ der Richtung $\left(A_{\text {ri }}\right)$ ohne

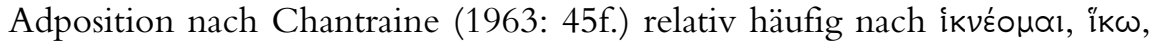

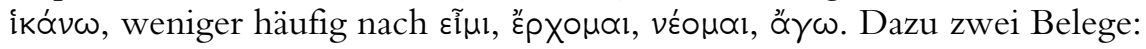
(28) T 307

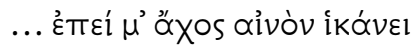
„da schrecklicher Kummer mich ankommt“
(29) H363

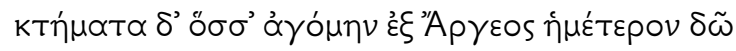 „die Schätze, die ich aus Argos nach Hause brachte.“

Bei den anderen Bewegungsverben steht neben dem Akkusativ regulär eine LP; z.B.
(29a) A366

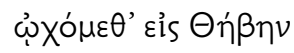
,wir eilten nach Theben“"

4 Die ved. Partikeln fallen weitestgehend unter Alternativen 1a und 2a und sind insoweit als Adverbien zu bewerten. 
LP und $\mathrm{A}_{\mathrm{ri}}$ sind also bei Homer stärker als im Veda aneinander gebunden, was auf eine Entwicklung hin zu PPs verweist.

c) Im Veda hat die adnominale oder adverbale Zuordnung einer direktionalen LP keine wesentlichen Folgen für die Bedeutung des ganzen Satzes; so erklärt sich die bemerkenswerte Anzahl nicht-regulärer Stellungen. Die ursprüngliche Funktion der LPs als selbständige Adverbien zeigt sich hier noch deutlich. Demgegenüber wird bei Homer die Kontaktstellung zu BN oder Prädikatsverb in viel deutlicherem $\mathrm{Maß}$ als im Vedischen als Regelfall erkennbar. Einige Stichproben im LfgrE zeigen folgendes:

$\propto)$ bei $\dot{\varepsilon} \lambda \theta \varepsilon \tilde{i} \nu+k \alpha T \alpha ́$ ist nur an einer (wiederholten) Stelle die LP nicht mit dem Verb zu einem Kompositum verbunden.

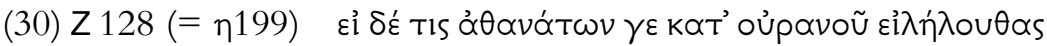
„,wenn du aber als einer der Unsterblichen vom Himmel herabgekommen bist"

Wir finden also diesen Beleg mit pränominaler Stellung und 12 weitere mit präverbaler Stellung vor; irreguläre oder doppeldeutige Fälle finden sich nicht.

ß) Kombinationen von LP und ő $\gamma \omega$ gibt es in großer Anzahl. In Sätzen mit diesem Verb ist - umgekehrt zu $\dot{\varepsilon} \lambda \theta \tilde{\varepsilon} \tilde{v}$ - die adnominale Stellung eindeutig in der Überzahl; z.B. in

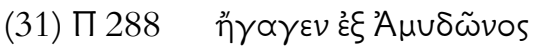

„Er führte [die Paionen] aus Amydon her.“

Der sehr seltene Ausnahmefall ist

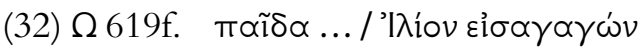

„nachdem du deinen Sohn nach Ilios gebracht hast",

der aber immer noch die reguläre Stellung für adverbale Konstruktion zeigt; man könnte sogar als Alternative postpositionale Stellung nach dem $A_{\mathrm{ri}}{ }^{\prime} \mid \lambda \lambda^{\prime}$ 'v erwägen. ${ }^{5}$

$\mathrm{Zu}$ diesem Befund paßt es, daß die Tmesis relativ selten vorkommt. Dag Haug hat auf 100 Verse der Ilias durchschnittlich 4,72, in der Odysee 5,55 Fälle von Tmesis ermittelt (Haug, o.J., 9). Diese und ähnliche Beispiele zeigen deutlich, daß zu den oben nach Beleg (24) formulierten Alternativen nicht nur klare ja-/nein-, sondern auch abgestufte Antworten möglich sind. Dabei ist klar erkennbar, daß bei Homer die LPs sich schon weiter auf Präverbien oder Adpositionen hin entwickelt haben als im RV. Für sich genommen sind die besprochenen griechischen Entwicklungen durchaus verschiedenartig, sie haben aber gemeinsam, daß sie den Abbau sowohl der Selbständigkeit der LPs als

5 Jedenfalls sind die LPs bei Homer stärker an ihr BN oder das Prädikatsverb gebunden als im Veda. 
auch der historischen Kasusbedeutungen begünstigen und umgekehrt die Uminterpretation von Kollokationen aus LP + Nomen als zusammengehörige Präpositionalphrase fördern. All das scheint schrittweise $\mathrm{zu}$ geschehen, und deshalb wäre es nicht sinnvoll, genau den einen Punkt der Entwicklung zu suchen, an dem die vorher attributiv-appositive Verbindung von LP und BN zur Präpositionalphrase hin sozusagen „umkippt“. Es wird eine Aufgabe weiterer Forschung sein, für die verschiedenen LPs diese Schritte im einzelnen über die soeben skizzierten Ansätze hinaus zu beschreiben. ${ }^{6}$

Aus der bis hierhin behandelten Thematik lassen sich nun verschiedene Einzelfragen zur weiteren Vertiefung herausgreifen; besonders interessant erscheint die folgende:

Wie erklärt sich der häufige Gebrauch des Genitivs neben Präpositionen und auch als adverbaler Kasus ohne Präposition? In der Häufigkeit dieses Genitiv-Gebrauchs übertrifft das Griechische alle anderen vorchristlich bezeugten idg. Sprachen deutlich. Dabei sind mehrere Gruppen zu unterscheiden:

a) Leicht erklärbar sind diejenigen Fälle, in denen der gr. Genitiv den idg. Ablativ fortsetzt, also die Verbindungen des Genitivs mit ởró, દ̇k, z.T.

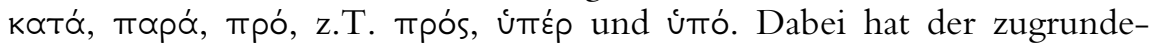
liegende Ablativ meist separativische Bedeutung, fungiert teilweise aber auch in Vergleichskonstruktionen als secundum comparationis.

b) Einen besonderen Fall bildet ởvtí. Diese Präposition stellt sprachhistorisch gesehen den Lok.Sg. eines idg. Wurzelnomens $\star_{2}$ ent- „Vorderseite, Stirn“ mit der L.Sg. Endung $-i$ dar. Der abhängige Genitiv ist also diachron ein Gen. possessivus - oder besser ein Genitiv der Zugehörigkeit -; die ursprüngliche Bedeutung war also ,auf der Vorderseite von, gegenüber von, gleichwertig mit" o.ä., noch greifbar in

(33) I 116f. $\quad$ ảvtí $v \cup \pi \circ \lambda \lambda \tilde{\omega} v$

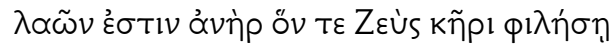

„Viele Krieger wiegt der Mann auf, den Zeus im Herzen liebgewonnen hat."

E.-M. Voigt hat dies im LfgrE unter dem Lemma ơvtí zutreffend beschrieben.

Für einen Teil der Belege von kató + Gen. ist eine ähnliche Lösung nicht a priori auszuschließen, wenn auch wenig wahrscheinlich. Gemeint sind Fälle wie

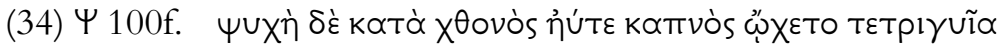
„Wie Rauch verschwand die Seele schwirrend unter der Erde."

6 Vgl. dazu bereits die Beiträge in Jacquinod 1994, außerdem Luraghi 2003 und Haug 2009. 
Eine ähnliche Konstruktion kennt das Althethitische vor der Mitte des 2. Jahrtausends. Dort ist das etymologisch verwandte kattan/katta , unten, unter, herunter“ mit Genitiv belegt, etwa in der Fügung nepisas kattan ,unter dem Himmel“". Da heth. katta(n) und andere funktional nahestehende Partikeln auf selbständige Nomina zurückgeführt werden, kann die heth. Fügung ursprünglich bedeutet haben ,auf/an der Unterseite des Himmels“, und auf eine

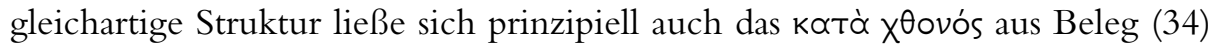
zurückfuihren, so daß wir hier einen weiteren ursprünglichen adnominalen Genitiv der Zugehörigkeit vor uns hätten.

Gegen diese Lösung im Falle von koтó - und damit gegen die Parallelität mit ớvтí + Gen. - spricht allerdings der funktionelle Gegensatz von kơ Genitiv und kató mit Akkusativ. Ein solcher Funktionsgegensatz ist typisch für adverbale Konstruktionen, während der adnominale Genitiv nicht in einem derartigen Oppositionsverhältnis zu den anderen Kasus steht.

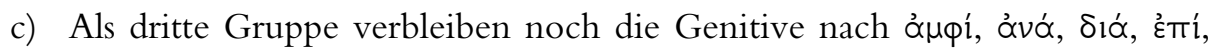

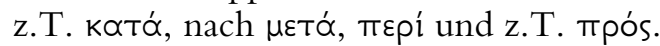

Hierzu wird in der Fachliteratur die Auffassung vertreten, diese Genitive seien als genitivi partitivi zu betrachten; ${ }^{8}$ Chantraine (1963:113) spricht neben kotó, wie bereits angedeutet, auch von einem daraus entwickelten génitif de but; so etwa in

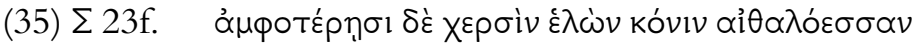
$\chi \varepsilon \cup \dot{\alpha} \alpha T$ Kòk $\kappa \varepsilon \phi \propto \lambda \tilde{\eta} s$

„mit beiden Händen schwarzen Staub ergreifend schüttete er ihn über sein Haupt".

Wir stoßen also auf den merkwürdigen Befund, daß ein und dieselbe grammatische Konstruktion, nämlich kotó + Gen., sowohl den Ausgangspunkt als auch das Ziel eines Sachverhaltes bezeichnen kann; letztlich eine Folge des Synkretismus von idg. Ablativ und Genitiv im Griechischen. Wenn wir nun die als partitiv verstandenen Genitive neben Präpositionen etwas näher betrachten und sie inhaltlich ähnlichen, aber mit einem anderen Kasus konstruierten Sätzen gegenüberstellen, fällt auf, daß der Gegensatz Genitiv vs. Akkusativ oder Genitiv vs. Dativ vielfach nicht oder zumindest nicht unmittelbar einen Teil-Ganzes-Kontrast bzw. einen Gegensatz ,indefinit' vs. ,definit' (Luraghi 2003: 60f.) bezeichnet. Einige Paare solcher Stellen:

(36 a): $\alpha \mu \varphi^{\prime}$

П 824f. (Genitiv)

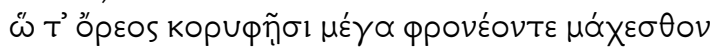

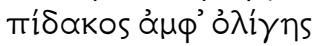

7 Vgl. Hoffner/Melchert 2008, 294ff., bes. 299.

8 Chantraine 1963, Kap. VI und VIII; Luraghi 2003, 329 f. 
„,die beide auf den Berggipfeln mutig gegeneinander kämpfen um eine schwach fließende Quelle“,

$\wedge$ 419f. (Akkusativ)

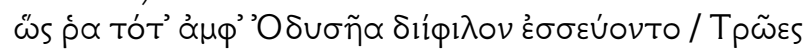

„So stürmten da die Troer um den zeusgeliebten Odysseus“

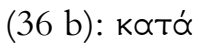

E 696 (Genitiv)

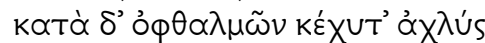

„Auf die Augen hatte sich Dunkel ergossen“,

$\wedge 108$ (Akkusativ)

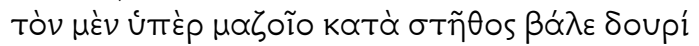

„,den traf er mit dem Speer über der Warze in die Brust“.

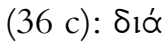

X327 (Genitiv)

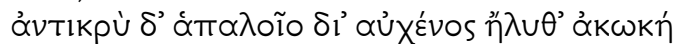

„Geradewegs durch den zarten Nacken fuhr die Speerspitze“,

$\wedge 118$ (Akkusativ)

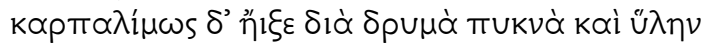

„Eilig rannte sie durch dichtes Gestrüpp und den Wald“.

(36 d): દ’mí

I 588f. (Genitiv)

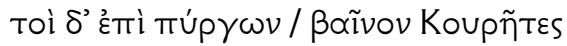

„Die Kureten aber stiegen auf die Wälle“,

Z 386 (Akkusativ)

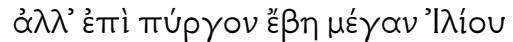

„Sondern sie ging hin zum großen Wall von Ilion“ (d.h. in

Richtung des...)

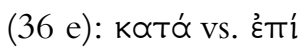

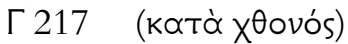

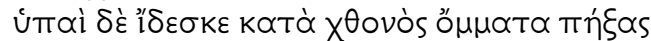

„,er schaute nach unten und heftete die Augen auf die Erde“,

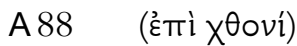

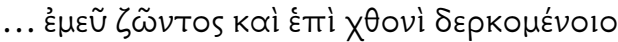

„während ich noch lebe und auf der Erde noch [das Licht] schaue“.

Daß an diesen Stellen durch die unterschiedlichen Kasus - Genitiv vs. Akkusativ - nicht ein Gegensatz von Teil und Ganzem bzw. von ,definit' vs. ,indefinit' bezeichnet wird, ist offensichtlich. Es scheinen aber andere semantische Nuancen zwischen den beteiligten Kasus vorzuliegen, die sich aus der Betrach- 
tung der Präpositionsbelege der Gruppe (c) in ihrer Gesamtheit ergeben, auch wenn sie nicht an jeder Einzelstelle in gleicher Eindeutigkeit beobachtet werden können, und zwar v.a.

1) Im Vergleich mit dem Akkusativ oder dem Dativ bezeichnet der Genitiv einen Begriff mit geringerer bzw. genauer abgrenzbarer räumlicher Ausdehnung; er gibt den entsprechenden räumlichen Bezug präziser wieder. ${ }^{9}$ Unter unseren Beispielen wird das besonders deutlich an den Stellen $36 \mathrm{~b}, \mathrm{c}$ und $\mathrm{d}$.

Bei kató: Der Genitiv in (36b) legt den SV auf Anhieb räumlich genau fest, während an der Folgestelle der weniger präzise Akkusativ $\sigma \tau \tilde{\eta} \theta$ os ne-

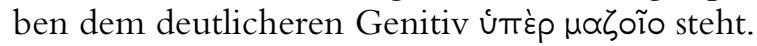

Neben Sıó (36c) bezeichnet der Genitiv aủXźvos einen genau begrenzten ,Ort' gegenüber den Akkusativen $\delta \rho u ́ \mu \alpha$ und ü $\lambda \eta v$, die als Akkusative der Erstreckung gelten können.

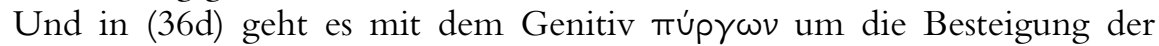
Stadtmauer im Kampf, die dadurch konkreter und eindeutiger in den Sachverhalt einbezogen ist als durch den Akkusativ múpyov. Dort kann die Dienerin Hektor lediglich sagen, daß Andromache in Richtung der Stadtmauer gegangen ist, ohne zu wissen, ob sie diese tatsächlich erreicht hat.

Demnach können die Genitive in unserer Gruppe c nur dann als auf den Genitivus partitivus zurückgehend verstanden werden, wenn sich Argumente finden lassen für eine entsprechende, zuvor eingetretene semantische Weiterentwicklung dieses Genitivs.

Die prototypischen Belege dieses Genitivs mit noch erhaltener partitiver Funktion erscheinen in 2 Varianten, auch wenn diese nicht immer eindeutig zu differenzieren sind: In der ersten Variante zielt der Agens nur auf einen Teil des fraglichen Begriffs, bekommt diesen Teil aber vollständig unter seine Kontrolle, man vgl. Schema I.

Schema I:

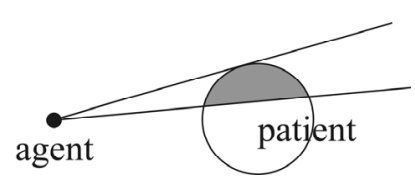

$\mathrm{Zu}$ dieser Variante gehören

(37) $\wedge 780$ ๔ủTà

„Aber als wir von Speise und Trank genossen hatten“,

9 Ähnlich Luraghi 2003, 329f. 
(38) $\times 11 \quad$ ö 1 p 1 míol olıvolo

„damit er vom Wein trinke“.

In der zweiten Variante der Belege mit Genitivus partitivus zielt der Agens zwar auf den abhängigen Begriff in seiner Vollständigkeit hin, bekommt ihn aber nur partiell unter seine Kontrolle, so z.B. in Schema II und den folgenden Belegen:

Schema II:

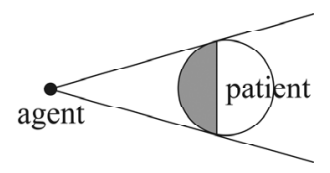

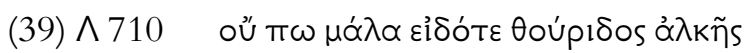

„beide den stürmischen Kampf noch nicht gut kennend“

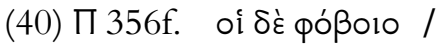

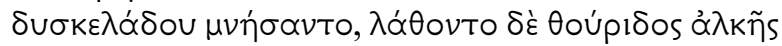

„Die aber dachten an lärmende Flucht und vergaßen der stürmischen Gegenwehr",

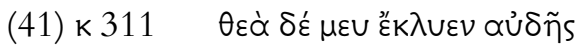

„Die Göttin aber hörte meine Stimme“.

Schwer einzuordnen ist z.B.

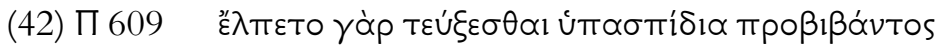
„,denn er hoffte, ihn zu treffen, der unter dem Schild voranschritt".

Belege der Art von 37-42 finden sich in unterschiedlichem Umfang in allen altindogermanischen Sprachen, v.a. auch im vedischen Sanskrit, das dem Griechischen strukturell besonders nahesteht.

Nun geht aber das Griechische über diesen Gebrauch des adverbalen Genitivs noch deutlich hinaus: Auffallig ist v.a., daß auch Verben der Bedeutungs-

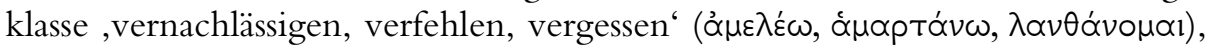
obwohl keine Partitivität vorliegt, den Genitiv regieren; sie dürften ihn übernommen haben von ihren Antonymika ,beachten, treffen' (s.o. $\mu \nu \alpha$ ó $\mu \alpha$ in 40 und TUYXóvw in 42). Im Veda sind dagegen die Konstruktionen beider Gruppen noch deutlich geschieden: Dort hat smar , sich erinnern' den Genitiv:

(43) AV 6,130,3 yáthā máma (G) smárād asáu „damit sich jener an mich erinnere“,

während das antonymische marșvergessen ' mit dem Akkusativ konstruiert wird:

(44) RV 1,145,2 ná mrssyate prathamám nāparam vácah (A) 
„Er vergi $\beta \boldsymbol{t}$ weder das erste noch das letzte Wort.“

Weitere Ausweitungen des Genitiv-Gebrauchs im Griechischen erscheinen nach den Verbgruppen ,berühren, erlangen' sowie als Genitiv des Körperteils nach Verben des Ergreifens, Fassens; vergleiche

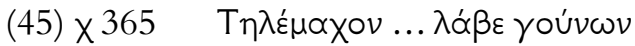

„Er faßte den Telemachos an den Knien.“

Nach dieser Ausweitung des Genitiv-Gebrauchs, ${ }^{10}$ besonders auf die antonymischen Verben ,vernachlässigen, verfehlen, vergessen', kann der Gebrauchstyp als ganzer nicht mehr als ,partitiv" verstanden werden; das hätte nach

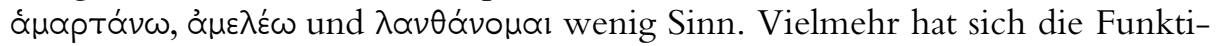
on nach diesen und ähnlichen Verben durch diese Ausweitung gewandelt, etwa in folgender Weise:

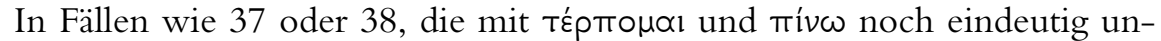
ter die Funktion ,Partitivität' fallen, bewirkt der Genitiv eine deutliche Markierung des abhängigen Begriffs im Kontrast zu anderen Kasus; man vergleiche nochmals oben Beleg (38) mit Genitiv olvoro, wo es um eine konkrete, bestimmte Menge Wein geht. Der Kontrast zum Akkusativ wird deutlich z.B. in

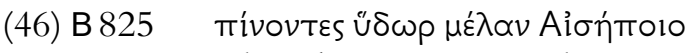
„das schwarze Wasser des Aisepos trinkend“.

Dort geht es um dieses Wasser schlechthin, im allgemeinen, nicht um eine konkrete, abgegrenzte Menge.

Dadurch, daß nun in Fällen wie etwa (37) oder (38) aus einem solchen allgemeinen, indeterminierten Ganzen eine konkrete, abgegrenzte Teilmenge gewissermaßen herausgetrennt wird, ist zugleich ein Zugewinn an klarer Begrenzung und herausgehobener Individualität impliziert. ${ }^{11}$

Es liegt nun nahe, in der Vorgeschichte der homerischen Sprache den angesprochenen leichten semantischen Wandel anzunehmen. Was anfänglich eine bloße Implikation von Partitivität war, eben dieses, abgegrenzt - individualisiert - herausgehoben', wird durch die Ausweitung des Genitivus partitivus über ,partitiv hinaus sozusagen , automatisch` zur Grundbedeutung. Das heißt, daß die bisherige Opposition ,partitiv' (G) vs. ,neutral' (Akk., Dat.) neu interpretiert wird als ,herausgegrenzt, markiert, individualisiert ${ }^{\circ}(G)$ vs. ,neutral' (Akk., Dat.).

10 Diese sekundäre Ausweitung findet sich in mehreren idg. Sprachen; vgl. Delbrück 1893, $310 \mathrm{ff}$.

11 Diese Funktion des Genitivs steht nur scheinbar im Widerspruch zu der vielfach vertretenen These, der gen.part. drücke Indefinitheit aus: Die klare Umgrenzung ergibt sich aus dem Kontrast des erfaßten Ausschnittes des Referenzbegriffes zu diesem Begriff als ganzem (Schemata I und II), die Indefinitheit daraus, daß eine exakte Position dieses Ausschnittes im Gesamtbegriff nicht festgelegt ist. Näheres dazu demnächst. 
In dieser veränderten Funktion kann sich der Genitiv über die in anderen idg. Sprachen bestehenden Grenzen weiter ausbreiten und schließlich auch auf die Präpositional-Phrasen übergreifen. So erhalten wir die genitivischen PPs, die funktional enger definiert sind als ihre Konkurrenten mit Dativ bzw. Akkusativ; ich verweise nochmals auf die oben unter (36) a - e besprochenen Paare mit Genitiv vs. Akkusativ oder Dativ. Wenn dies zutrifft, sind diese PPs (oben Gruppe c) jünger als diejenigen mit Akkusativ oder Dativ. Und in der Tat weisen auch einige Detailbeobachtungen chronologischer oder systematischer Art auf eine relativ späte Entstehung dieser genitivischen PPs hin:

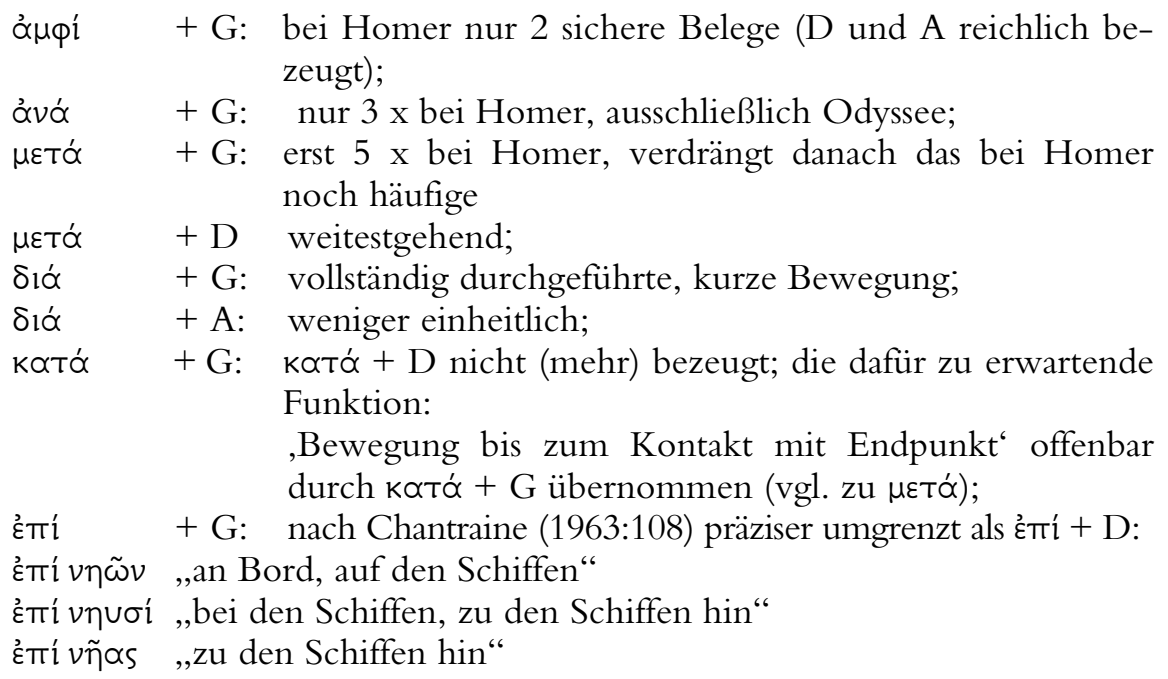

Die zuvor angestellten generellen Überlegungen und die soeben angeführten konkreten Indizien weisen also in dieselbe Richtung und sprechen dafür, daß der (ehemals) partitive Genitiv in homerischen Präpositionalausdrücken eine relativ junge Erscheinung ist. Damit ist aber die Entwicklung nicht zu Ende; das System des Klassischen Attischen zeigt wiederum ein anderes, erneut weiterentwickeltes Bild, das eine eigene Untersuchung erfordern würde.

\section{Bibliographie}

Brugmann, Karl, Vergleichende Laut-, Stammbildungs- und Flexionslehre nebst Lehre vom Gebrauch der Wortformen der indogermanischen Sprachen. 2. Bearbeitung, 2. Band, 2. Teil (Straßburg 1911).

Casaretto, Antje, Syntax und Wortarten der Lokalpartikeln des Rgveda VI: práti. IJDL 7 (2010) 1-53.

Chantraine, Pierre, Grammaire homérique. Tome II Syntaxe (Paris 1963).

Delbrück, Berthold, Vergleichende Syntax der indogermanischen Sprachen. 1. Theil (Straßburg 1893). 
Haug, Dag Trygve Truslew, ,Does Homeric Greek have prepositions? Or local adverbs? (And what's the difference anyway?)“, In: V. Bubenik and J. Hewson (eds.), Grammatical Change in Indo-European Languages (Amsterdam 2009) 103-120.

Haug, Dag Trygve Truslew, Tmesis in the epic tradition (Manuskript, ohne Jahr).

Hettrich, Heinrich; Casaretto, Antje; Schneider, Carolin. [2010], Syntax und Wortarten der Lokalpartikel im Rgveda IV: I. Allgemeines, II. úpa, III. áva. MSS 64 (2004) 17130 .

Hoffner, H.A. und H. C. Melchert, A Grammar of the Hittite Language. Part I-II (Warsaw IN 2008).

Horrocks, Geoffrey, Space and Time in Homer. Prepositional and adverbial particles in the Greek epic (New York 1981).

Jacquinod, Bernard (ed.), Cas et prépositions en Grec Ancien. Actes du colloque international de Saint-Étienne (3-5 juin 1993), (Saint-Étienne 1994)

Luraghi, Silvia, On the Meaning of Prepositions and Cases. The expression of semantic roles in Ancient Greek (Amsterdam-Philadelphia 2003). 
Bereitgestellt von | SUB Göttingen Angemeldet 


\title{
Double deixis in Homeric speech: on the interpretation of ö $\delta \varepsilon$ and oũTos ${ }^{1}$
}

\author{
IRENE J.F. DE JONG
}

The aim of the Lexikon des frühgriechischen Epos is to increase our understanding of Homer's world through a precise analysis of his words. The way to proceed was shown by the founder of the lexicon, Bruno Snell, who famously reconstructed the Homeric notion of self, or rather the lack thereof, on the basis of a set of words. At first sight, a contribution dealing with demonstrative pronouns may not seem appropriate to a volume celebrating the completion of the Lexikon: pronouns are virtually passed over in the Lexikon, as are most so-called 'Formwörter'. However, I hope to show that even words like ö $\delta \varepsilon$ and oũtos can tell us much about Homer, notably about an important aspect of his narrative art. I will start by establishing what in my view these pronouns do not do (section 1); I will then analyse in detail how they function within the fabric of Homer's narrative (sections 2-4), and end with an evaluation of the cumulative effect of their presence (section 5).

\section{Gestures of the aoidoi?}

The demonstrative pronouns ö $\delta \varepsilon$ and oũtos occur regularly in the Homeric text, almost exclusively in the speeches. ${ }^{2}$ Let us take a look at some examples:

(1) Iliad 3.191-2+199-200

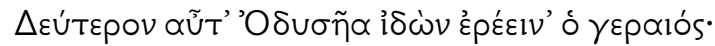

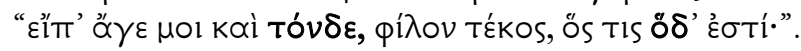

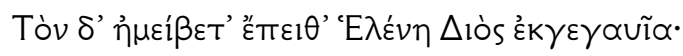

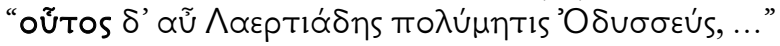

1 This contribution is a token of gratitude for the highly enjoyable and instructive year that I spent in Hamburg in 1984, on a stipendiary from the Netherland Organisation for Scientific Research (NWO).

2 For figures, see the Appendix. I do not discuss દ̇kદ̃̃vos (for which see Bonifazi 2009). For oữos in the narrator-text, see Bakker 1999. 
Looking secondly at Odysseus the old man [Priam] asked:

"Tell me now about this man, my dear child, who this is."

And him Helen, daughter of Zeus, answered:

"That man is the son of Laertes, clever Odysseus,..."3

(2) Iliad 22.38 (Priam is speaking)

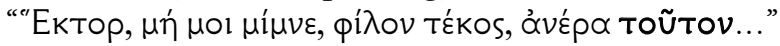

"Hector, do not wait, dear child, for that man [Achilles]..."

(3) Odyssey 13.344-51(Athena: Odysseus)

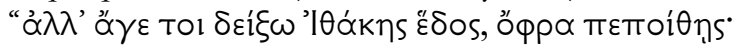

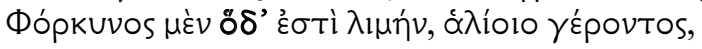

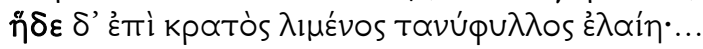

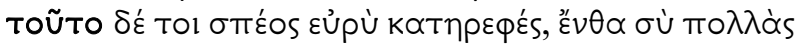

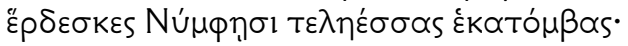

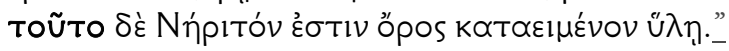

"But look now, I will show you the site of Ithaca, in order for you to be sure.

This here is the harbour named after Phorcys, the old man of the sea, and this the long-leaved olive tree at the head of the harbour.

And that is the wide arching cave, where you were wont to make your ample and perfect sacrifices to the nymphs.

And that is tree-clad mount Neriton."

With regard to such instances of ö $\delta \varepsilon$ and oũtos, commentators regularly refer to gestures: e.g. Ameis-Hentze (ad 1): 'beachte den regelmässigen Wechsel der Pronomina ő $\delta \varepsilon$ und oũtos in Frage und Antwort: Beide sind hinweisend'; scholia (ad 2): 'as if he points out Achilles to him [Hector]' (oiovei ...

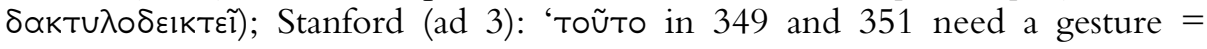
"over there",; de Jong (ad Od. 1.156-318): "the frequent use of deictic pronouns, which suggest gestures, lends it an air of drama'. ${ }^{4}$

In itself, this connection between demonstrative or deictic nouns and gestures is appropriate. The linguist Wackernagel, for instance, states:

Demonstrativa sind lautliche Fingerzeige, hörbare Winke, und enthalten eigentlich immer ein "sieh hin". Somit sind sie den hinweisenden Gebärden verwandt, die auch oft diese Pronomina begleiten. Am vollsten kommt ihre Funktion zum Ausdruck bei eigentlicher Deixis, wenn auf ein Stück des gegenwärtigen Wahrnehmungsbildes hingewiesen wird. ${ }^{5}$

3 Translations are my own. The texts are those of Monro-Allen for the Iliad, von der Mühl for the Odyssey.

4 Similar comments are found passim in these commentaries. They do not appear in the Iliad commentary of Kirk c.s, the Odyssey commentary of Heubeck c.s., or the recent Iliad commentary of Latacz c.s.

5 Wackernagel 1924, 101, my italics. Cf. also Diessel 1999, 94. 
The question I will address in the first part of my paper is: what exactly do commentators mean when they talk about gestures? Whose gestures are they referring to? This is rarely made explicit.

One exception is Victor Bérard, who is very explicit in a paper dating from 1918 with the speaking title 'Le geste de l'aède et le texte homérique'. In his view it is the aoidos (Homer) who makes gestures. He arrives at this conclusion after a fascinating parcours of academic reasoning:

"l'Iliade et l'Odyssée sont les formes premières du drame grec ... Les aèdes de l'ancien temps, puis les rhapsodes de l'âge classique "représentèrent" durant des siècles les poèmes homériques. (We know about the theatricality of the rhapsodes from Plato's $\operatorname{Ion}^{6}$ ) ... Avant ces représentations toutes théâtrales des rhapsodes classiques, avant leurs manières pompeuses, leurs grands gestes et leurs éclats de voix, nous ne savons rien de la récitation primitive des aèdes. Était-elle aussi animée et scénique? est-ce, au contraire, à l'imitation et à l'école des tragédiens et comédiens que les rhapsodes prirent leurs habitudes de déclamation gesticulante? et l'aède n'avait-il, auparavant, que le débit rituel et l'attitude quasi hiératique d'un officiant, d'un porte-parole du Dieu et de la Muse? ... L'antiquité ne nous ayant rien transmis là-dessus, toutes les hypothèses sont permises. (His hypothesis is that the aoidoi did gesticulate, and in support of his standpoint he points at the deictic pronouns). Tout au long des poèmes homériques ... il est des mots pareils qui non seulement appellent le geste, mais le nécessitent: on ne peut pas les comprendre sans lui. Il est même des tirades entières, semble-t-il, qui n'ont pas jamais pu être prononcées par l'auteur ou par ses interprètes, sans un commentaire perpétuel de la main, des yeux ou du visage. Aujourd'hui encore, il nous est impossible de les lire, même à voix basse, sans que le geste involontaire éclaire telle ou telle intention qui paraît évidente, mais que l'auteur n'a fait qu'indiquer par les mots." ${ }^{7}$

We see how Bérard reasons back from the rhapsodes to the aoidoi: we know that the former gesticulated and it is highly likely that the latter did so as well, especially since the deictic pronouns which are sprinkled throughout the poems need gestures. Indeed, by the end of his argument (and throughout the remainder of his paper), Bérard no longer distinguishes between aoidos and rhapsode but simply places them on a par: 'par l'auteur ou par ses interprètes'.

At times matters get even more complicated, when Bérard refers to charac-

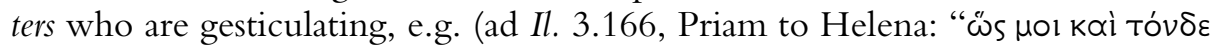

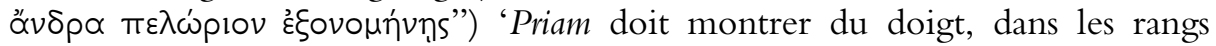
achéens, un guerrier qui domine la foule', or (ad Od. 15.174, Helen to Telem-

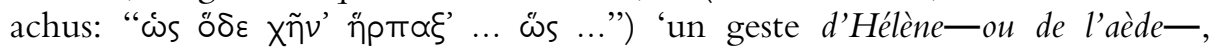

6 E.g. when they perform 'the lay of Odysseus leaping forth on the threshold, revealing himself to the suitors and pouring out the arrows before his feet, or of Achilles dashing at Hector' (Ion 535B). Note also that Socrates calls the rhapsode an actor (536A).

7 Bérard 1918, 1-5, my italics. Kühner-Gerth 1898, 641 also seem to connect the demonstratives with Homer the aoidos: 'Die Grundbedeutung der Demonstrativa tritt uns am deutlichsten und am häufigsten in den Homerischen Gedichten entgegen. Den sprechenden Homer muss man . . . sprechen nicht lesen.' 
montrant dans le ciel l'aigle qui s'enfuit, fait sans peine comprendre ce que désigne cet ő $\delta \varepsilon$ que n'accompagne aucun substantif. ${ }^{8}$ Chaos now is complete: who gesticulates? The aoidos, rhapsode, or one of the characters? I will turn to the option of characters gesticulating below, but for now focus on the aoidos and rhapsode.

Bérard's simple equation of aoidos and rhapsode is misleading, since a rhapsode recites while holding a rhabdos, or stick, in his hand, whereas an aoidos sings while holding a phorminx, or lyre, in one hand, and a plectrum in the other. ${ }^{9}$ A rhapsode had ample opportunity to gesticulate, but how much room to manoeuvre does a lyre leave the aoidos? I put this question to Martin West as expert on Greek music (amongst many other things). He replied:

I think the scope for gesticulation while holding a phorminx would be very limited, though one could imagine a measure of expressive movements of the upper body, and facial expression enhancing the vocal. All speculation really, as I think there is no external evidence, and I hardly think that deictic hode in speeches needed to be accompanied by gestures-especially as the things or persons referred to were not there to be pointed at. ${ }^{10}$

Leaving aside his last remark for the moment, I am inclined to concur with West in assuming that an aoidos would have his hands full with both lyre and plectrum and hence would find it difficult to make manual gestures.

It is as if Bérard has simply forgotten about this crucial difference between aoidos and rhapsode and, lumping them together, erroneously ascribes the gesturing that we can safely associate with the rhapsode to the aoidos as well. A similar equation of rhapsode and aoidos appears in a study by Boegehold on signs of gesticulation in Greek texts. While discussing the Homeric poems he says:

Consider now such a rhapsode who not only recites but also tells his story with motions of head and hand-indeed, acts out his song.... The poet himself (or in later generations, the rhapsode) acting as Agamemnon completes whatever sense is needed with a gesture. ${ }^{11}$

8 Bérard 1918, 5, 20, my italics.

9 For textual references to lyre cf. e.g. Od. 8.67, 261-2, 266, to lyre and plectrum, cf. e.g. HHHermes 418-19; HHApollo 184-5. For depictions on vases, see e.g. MaasMcIntosh Snyder 1989.

10 Personal communication via email. For discussions of the singing of Homer, see West 1981 and Danek-Hagel 1995.

11 Boegehold 1999, 36-42, my italics. Lateiner 1995, 20, referring to Bérard, also accepts bardic gesturing, but does not make clear whether he is talking about the aoidos or the rhapsode: 'Henceforth, the contribution of nonverbal behavior should be factored in as well, a highly affective and focused form of human expression allotted to persons in the text and presumably-but for us irretrievably-employed by the performers of the text. We can observe not only marked movements of face and hand but also expressive body tonus and orientation, whispers, pace, and posture.' (my italics). Herington 1985, 13 
Boegehold bases his claim that Homer gesticulated amongst other things on Plato Republic 393B, where the mimesis taking place in speeches is described as involving not only words but also some form of body-language:

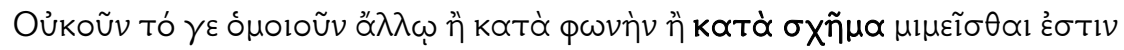

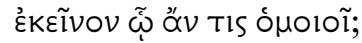

And is not likening one's self to another in speech or bodily bearing an imitation of him to whom one likens oneself?

The problem here is that Plato without doubt was thinking of the rhapsodic performance of the Homeric epics in his own times (as described by him in his Ion). So already at this stage there is a blurring of rhapsode and aoidos. ${ }^{12}$

I summarise my argument so far: it is unlikely that Homer would gesticulate while voicing deictic pronouns in speeches. Scholars who claim this are mixing up aoidoi with rhapsodes; only the latter, no longer holding lyre and plectrum, had the opportunity to gesticulate. The numerous demonstrative pronouns in Homeric speech are not some kind of script or score for the original performance.

\section{Gestures by characters}

Let us now turn to the interpretation of demonstrative pronouns as referring to gestures of the characters. There are some passages that explicitly confirm this

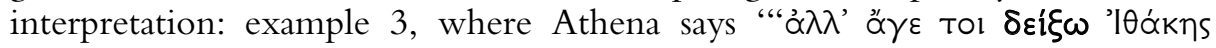
ह'ठos",, or

(4) Iliad 5.870-2

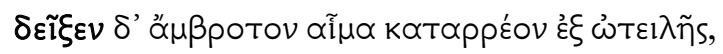

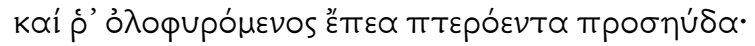

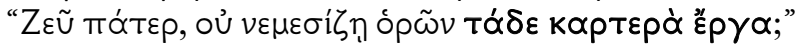

"and he [Ares] showed him the immortal blood dripping from his wound, and weeping spoke winged words to him:

'Father Zeus, are you not angry at the sight of this violence?", ${ }^{13}$

discusses the rhapsode, yet claims ' ...Homeric poetry seems to have been designed from the first to be acted. It demands impersonation; it demands skillful variations in tone, tempo, and dynamic; and there are some points, also, where it seems imperiously to exact from the speaker some form of physical gesture...'(my italics).

12 Note that Aristotle at Poetics $1462 \mathrm{a} 6$ explicitly and correctly connects gesturing with rhapsodes.

13 And cf. Il. 10.476-7. More in general, Homer often describes the nonverbal behaviour of his characters (smiling, scowling, taking someone's hand, etc.), for which see Lateiner 1995. 
Later narrators, too, sometimes explicitly note that characters gesticulate when they voice deictic pronouns, e.g.

(5) Herodotus Histories 5.49 (the Ionian Aristagoras: the Spartan king Cleomenes)

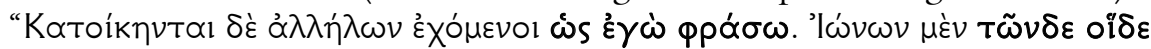

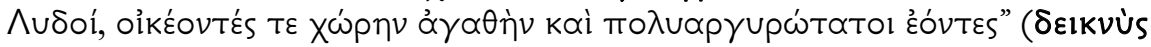

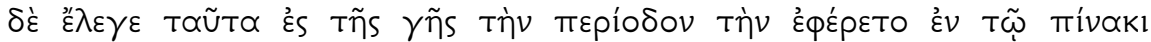

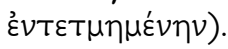

"They live close to each other as I will show. The Lydians here next to the Ionians there, inhabiting good land and being rich in silver." (He spoke while pointing out those things at the map of the earth which he carried with him engraved on the tablet). ${ }^{14}$

Herodotus' stress on Aristagoras' act of pointing out the countries on a map highlights the latter's rhetoric: the Ionian is using all available means to persuade his Spartan addressee to join in a revolt against the eastern oppressors.

Homeric characters making gestures is also obviously what Ameis-Hentze mean when they say 'hinweisend', as is evident from one of the few places where they are explicit:

(6) Iliad 5.214-16 (Pandarus: Aeneas)

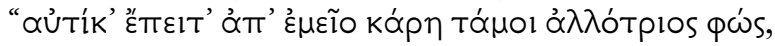

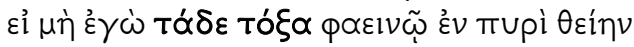

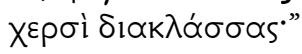

"Then let some strange man right away cut my head from my body, if I do not snap this bow into pieces with my hands and throw it in the blazing fire."

Ameis-Hentze: 'den Bogen hier, nachdrücklich hinweisend, um bei seiner Versicherung gleichsam keinen zweifel wegen des Objekts zu lassen' (my italics). As is clear from 'seiner', they take Pandarus to point at his bow. What they should have added is that we are only dealing with the suggestion of a gesture by Pandarus. ${ }^{15}$ My own formulation, quoted earlier, is better than that of AmeisHentze ('the frequent use of deictic pronouns, which suggest gestures, lends it an air of drama'), but for my commentary on Iliad 22 (ad 377-95) I have now chosen a very explicit formulation: "the deictic pronouns ... strewn over the speech evoke the gestures which the narratees are to imagine Achilles making while

14 Pelling 2007, 196, suggests that in his oral delivery Herodotus may have gesticulated. For an example from a modern novel, cf. Theodor Fontane, Effi Briest, p. 150 (Nach der Vorstellung aber sagte sie, während sie auf einen in der Nähe stehenden Stuhl mit hoher Lehne zuschritt: „Ich bitte sie nunmehr, gnädige Frau, die Bürden und Fährlichkeiten Ihres Amtes auf sich nehmen zu wollen. Denn von Fährlichkeiten - und sie wies auf das Sofa - würde sich in diesem Fall wohl sprechen lassen...").

15 Similarly too brief or not explicit enough is Bakker 1999, 7, ad Iliad 3.177: "with oũtos she [Helen] is actually pointing at the object of the reference, in the direct sense of "deixis." 
he speaks'. ${ }^{16}$ Thus a full, explicit and diachronically correct summing-up of the question of deictic pronouns and gestures in the Homeric epics would read: deictic pronouns evoke the gestures which the narratees are to imagine the characters making. When rhapsodes started to recite the Homeric poems, they could actually reproduce those gestures during their performance, unlike the aoidos who had his hands full holding and playing his lyre. ${ }^{17}$

\section{Double deixis}

Taking leave of the question of gestures imaginatively or actually

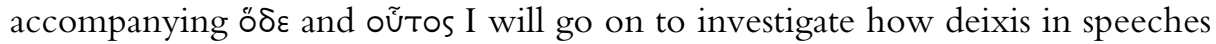
functions. In other words, I want to return to the remark by Martin West at the end of his email: how does deixis work when the things being pointed at are not there? In order to answer this question I must first introduce some linguistic theory on deixis. One first important distinction, which was already made in antiquity, is that between the deictic and the anaphorical or, in modern terminology, the exophoric and the endophoric use of demonstrative pronouns. $^{18}$ In the sentence 'that house belongs to me', 'that' is deictic/exophoric and refers to an object in the world of speaker and adressee; in 'There is a beautiful house in Amsterdam. That house belongs to me', 'that' refers back to an earlier textual element and is anaphoric/endophoric. I am interested only in the deictic or exophoric use of demonstrative pronouns. ${ }^{19}$

Within this category of the deictic or exophoric use we can further distinguish, as Bühler does, between deixis ad oculos and deixis am Phantasma:

16 Interestingly enough, this has been correctly assessed by Bérard, who, as we have seen, also refers to gestures by characters: cf. e.g. on p. 5 'même devant les yeux du lecteur d'aujourd'hui, le geste [of Helen at Il. 3.200] suit le mot' (my italics).

17 Cf. Stanford (ad oútws in Od. 17.442): " "so" with an indicatory gesture (presumably a repelling wave of the hand) as is often implied with such words in H. It could be reproduced by a reciting rhapsodist.' (my italics). Note that ad Od. 1.159 he makes the same mistake as Bérard and Boegehold: 'TaũTa: probably with an indicatory gesture (reproduced in recitation by the Bard or later rhapsodist)' (my italics). For the possible objection that for the rhapsodes too the referents of the deictic pronouns 'are not there' (see West's point), see Diessel 1999, 95, who observes that even when the referents of demonstratives are physically absent (but do exist in the universe of discourse), speakers may point to them as if they were there.

18 This modern terminology derives from Halliday-Hasan 1976, 57-76.

19 It will be clear that it is not always easy to determine whether a demonstrative pronoun is deictic or anaphoric. Take for example toútw at Iliad 4.415+417; this can be both deictic (Agamemnon is present at the dialogue between Diomedes and Sthenelus)

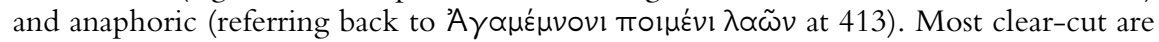
deictic pronouns at the opening of speeches or conversations, when they simply can-

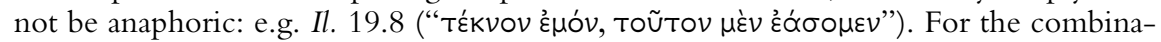
tion of the exophoric and the endophoric, see Lyons 1983, 67. 
whether a demonstrative pronoun refers to something that is visibly present in the context of speaker and addressee or something that is only mentally imagined by these interlocutors. ${ }^{20}$ These two types of deixis pertain not only to deictic pronouns but also to personal pronouns and temporal or spatial markers. The deixis of a narrative text such as the Homeric epics is typically am Phantasma: ${ }^{21}$ the temporal and spatial orientation (origo, base, anchorage) is not that of the narrator in the hic et nunc of narration, but that of the characters of the story in the past. ${ }^{22}$ The situation has been aptly described by Latacz:

Diese narrative Epik ... baute ... auf dem Fundament ausschliesslich der Deixis am Phantasma auf, sie war ein einziges 'Stellt euch vor!'. Vom Parisurteil auf dem Ida über das Schiffslager in Aulis bis zur Topographie des Stadt- und Kampsgeländes in der Troas, vom Kyklopen bis zur Zauberin Kirke, von Zeus und Hera auf dem Wolkenlager bis zu Apollons Schlag gegen Patroklos, wurde ja im Epos unaufhörlich an die Imaginationskraft des Hörers appelliert. Mit der errichtung Trojas (...) vor den geistigen Augen seines Publikums baute der epische Sänger bei jedem Vortrag aufs neue ein grosses wohlorganisiertes imaginäres Zeigfeld auf, mit 'oben' und 'unten' ..., mit 'links' und 'rechts' ..., ein Zeigfeld, in das sich jeder Hörer entsprechend seiner individuellen Rekonstruktionskraft hineinzusehen und hineinzutasten hatte, darin in nichts vom modernen Leser underschieden. ${ }^{23}$

If the Homeric epics as a whole are a form of deixis am Phantasma, then how do we analyse the deixis in the speeches that are embedded in them? How does the ő $\delta \varepsilon$ of example 1 function, where Homer tells his narratees that in the past, on the walls of Troy, Priam said to Helen 'who is this man?' The abundant linguistic literature on deixis is not very helpful in formulating an answer. $^{24}$

My suggestion would be to analyse deictic pronouns in Homeric speeches in terms of double deixis: first and foremost there is deixis ad oculos on the level of the communication between the characters: Helen can see the man Priam is pointing out to her. For the narrator and his narratees, however, there is no

20 Bühler [1934] 1965, 123.

21 Deixis am Phantasma is a form of what Lyons 1977, 579, calls 'deictic projection': 'shifting the deictic center from the speaker in the concrete speech situation to a person in a different situation that is evoked by the ongoing discourse'; see also Levinson 1983, 64, and Diessel 1999, 95. I have found only one study on deixis am Phantasma, Sitta 1991, who notes on p. 5 that 'die Deixis am Phantasma jedoch nach wie vor ein Mauerblümchendasein [führt]'.

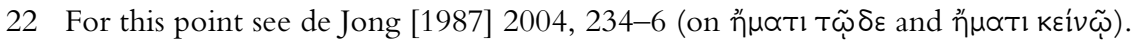

23 Latacz 1985, 69.

24 The chapter 'Deixis in Redewiedergaben' in Sitta 1991 does not provide an answer. Sennholz 1985, 232-3 suggests analysing deixis in speeches in novels as a form of 'deictic projection', thereby leaving unaddressed the point that a novel is itself a form of deictic projection (and hence the question of how these two projections relate to each other). 
more than a deixis am Phantasma, since they do not actually see the object or person referred to. My analysis closely resembles that of Latacz:

Es [das imaginäre Zeigfeld] schloss den Nachvollzug sogar mehrerer übereinandergetürmter Fiktionsschichten ein-etwa wenn der Sänger erzählt, wie Odysseus erzählt, wie der Kyklop erzählt, wie Telemos erzählt, dass einst ein Odysseus den Kyklopen blenden werde (Od. 9, 507-512) —, und es schloss damit zugleich innerhalb dieser je sekundären, tertiären usw. Fiktionsschicht auch wieder ein quasi-konkretes Hinzeigen fiktiver Figuren auf andere fiktive Figuren mittels sprachlich durch Zeigewörter signalisierter fiktiver Zeigegesten ein (also eine 'sekundäre', 'tertiäre' usw. Demonstratio ad oculos, z.B.: der Sänger imaginiert, wie

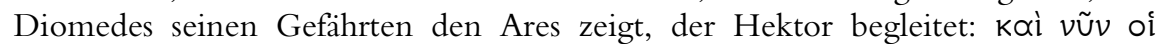

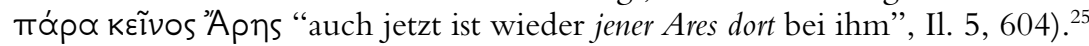

In the next section I will take a closer look at how double deixis actually works: how can narratees understand pronouns which refer to objects or persons which they cannot see but which they have to imagine? How can they understand in terms of deixis am Phantasma what for the characters is deixis ad oculos? How can they process, as Latacz calls it, 'sekundäre' or 'tertiäre' Demonstratio ad oculos?

\section{Double deixis in practice}

In discussing the function of ó $\delta \varepsilon$ and oútos within the fabric of Homer's narrative I will not go into the difference between these two demonstratives. ${ }^{26}$ What I am interested in here is the general question as to how narratees can tell what demonstrative pronouns refer to. The thesis I will defend is that the Homeric narrator virtually always takes care to provide his narratees with the information needed to understand and process the deictic pronouns in a speech, whether in the direct or in the larger context. I will argue my case by

25 Latacz 1985, 70. Note his correct 'fiktive Zeigegesten' and 'der Sänger imaginiert, wie Diomedes ... zeigt' (my italics).

26 For general discussions, see e.g. Martin Lopez 1994, Manolessou 2001, 130-9; for a discussion of these deictic pronouns in Homer, see Magnien 1922, and in Sophoclean drama Ruijgh 2006. Most scholars take ő $\delta \varepsilon$ as proximal and oútos as distal; from this basic opposition all other uses ('I' versus 'you'; 'new' versus 'given'; 'emotionally close' versus 'pejorative') can be derived. The Homeric corpus backs up this analysis, but there are some problematic instances, e.g. Il. 17.418 and 421, where the Greeks refer to Patroclus with toũtov, the Trojans with $\tau \tilde{\omega} \delta \varepsilon$, while the two parties are at exactly

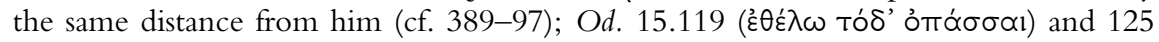

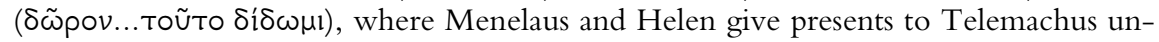
der identical circumstances. Could metre play a role here? See also note 29. 
means of a number of examples, which proceed from the simple to the more complex and even problematic. ${ }^{27}$

(7) Iliad 14.214-20

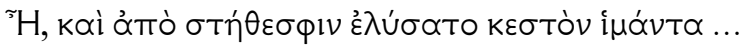

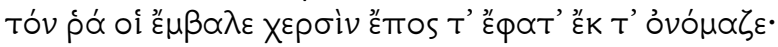

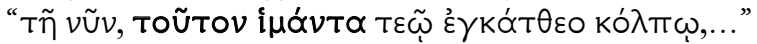

So she [Aphrodite] spoke, and untied from her breasts the embroidered band...

She put it in her [Hera's] hands and said:

"Here now, take that embroidered band and put it away in the bosom of your robe..."

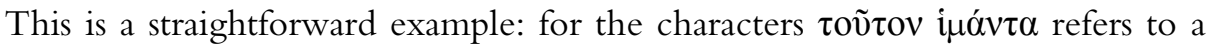
concrete referent present in the speech situation. Since the narrator has introduced the prop of the embroidered band just before the speech, it is also clear to the narratees what Aphrodite is talking about.

A somewhat larger context plays a role in:

(8) Iliad 5.159-75

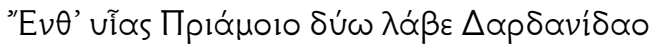

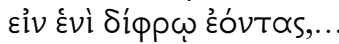

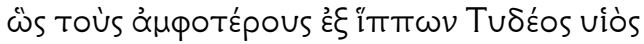

$\beta \tilde{\eta} \sigma \varepsilon \ldots$

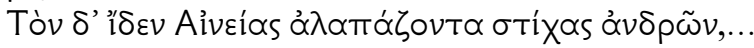

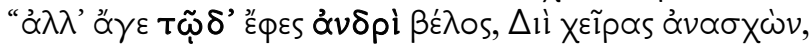

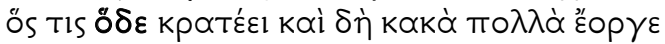

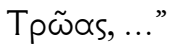

There he [Diomedes] took two sons of Priam, the son of Dardanus, who were standing on one and the same chariot...

So Tydeus' son sent the two from their chariot...

And Aeneas saw him working havoc in the ranks of men (and said to Pandarus:)

"Come then, raise your hands in prayer to Zeus, and send an arrow at this man,

whoever it is who is holding the field and has done much damage to the Trojans, ..."

For the characters $\tau \tilde{\omega} \delta$ ' $\alpha \dot{\nu} \delta \rho i$ and ő $\delta \varepsilon$ are clear examples of deixis ad oculos: Aeneas has seen a man 'working havoc in the ranks of men' and in his speech he points him out (and describes him) to Pandarus. ${ }^{28}$ The narratees also know who 'this man' is because of the anaphoric pronoun tòv in 172, which refers

27 I have made use of subdivisions of exophoric deictic pronouns in Fillmore 1997, 62-3, Levinson 1983, 65-8, and Diessel 1999, 94-5. Cf. also Bonifazi 2004 on deictic pronouns in Pindar.

28 Fillmore 1997, 62, calls this gestural deixis: 'By the gestural use of a deictic expression I mean that use by which it can be properly interpreted only by somebody who is monitoring some physical object of the communication situation'. 
back to the subject of the actions recounted in lines 159-65. Indeed, they know what Aeneas does not know, viz. that the man is Diomedes.

In the same way, Athena's speech at $\mathrm{Od}$. 13.344-51, example 3 above, was carefully prepared for by the narrator some two hundred lines earlier:

(9) Odyssey 13.96-112

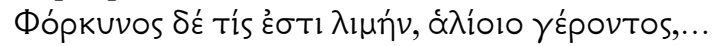

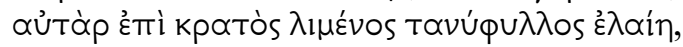

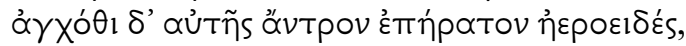

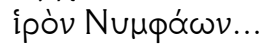

There is a harbour called after Phorcys, the old man of the sea,...

And at the head of the harbour there is a long-leafed olive-tree,

and near it a lovely misty cave,

sacred to the nymphs...

Cf. in Athena's speech:

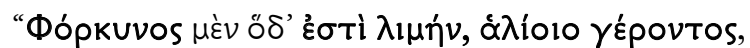

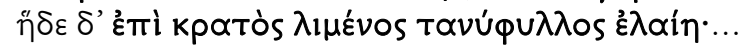

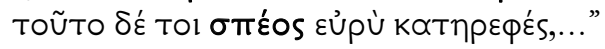

As a result of this careful preparation, not only Athena's addressee, Odysseus, but also the narratees can recognise the landmarks given by the goddess.

(10) Iliad 3.191-2

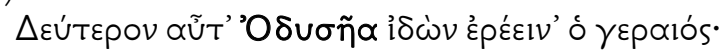

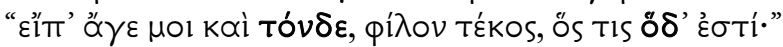

This example, which I earlier quoted as example 1, illustrates how anxious the Homeric narrator is to inform his narratees, so that they will not be puzzled. To that end, he is even prepared to be slightly illogical: Priam sees Odysseus and yet he asks who 'this man' is. The proper name 'Odysseus' instead of the more logical 'another man' is inserted for the benefit of the narratees. The narrator wants them to understand who Priam is referring to when he describes a man who is short but broad-shouldered and who patrols the ranks of his troops like a ram ranging through a flock of sheep. ${ }^{29}$

29 This passage, where we find the sequence 'proper name - reference with deictic ö $\delta \varepsilon-$ reference with (anaphorical) oũtos', conforms to the prototypical topic chain in narrative texts as described by linguists: 1) priming (bringing the referent within the mental horizon of the addressee, often via a proper name), 2) focussing (introducing the referent as an actively involved participant, often via a proximal demonstrative), 3) topicalizing (maintaining the referent as given topic, often via an anaphoric pronoun); see Kroon 2009, who discusses this phenomenon in Latin narrative texts. Cf also Od.

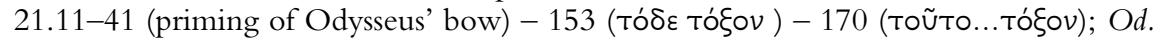

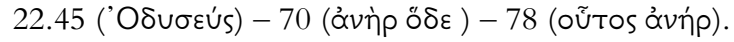


(11) Iliad 6.328-9 (Hector: Paris)

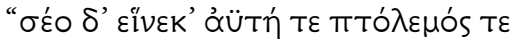

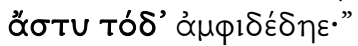

"because of you the clamour of war

is blazing around this city."

For the characters ớ $\sigma$ tu Tó $\delta$ ' is an instance of deixis ad oculos, more in particular of what Fillmore has called the symbolic use: ${ }^{30}$ when Hector says 'this city', he is not referring to something which is immediately visible in the speech situation; his addressee Paris, however, understands which city he is referring to. The same applies to the narratees: they too know, on account of the larger context of the speech-the Iliad as a whole-, that Hector is referring to Troy.

Odyssey 16.372-3 (Antinous: other suitors)

"oủ $\gamma$ àp ỏîw

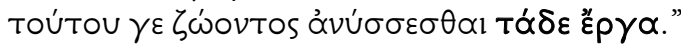

"For I do not think that

as long as that youth [Telemachus] is alive these things will be accomplished."

Here we have a demonstrative pronoun with an abstract referent. The suitors have just found out that the ambush they set for Telemachus has failed and that the youth has made it home safely. Antinous suggests a new scheme to kill him. For the suitors Tó $\delta \varepsilon$ ع́p $\propto \propto$ can be nothing else but the thing that has occupied their minds for three years now, viz. their wooing of Penelope. The narratees will likewise arrive at this interpretation on the basis of their knowledge of the Odyssey so far, although, to be on the safe side, some commentators provide a note. ${ }^{31}$

(13) Odyssey 8.403-406 (the Phaeacian youth Euryalus: Alcinous)

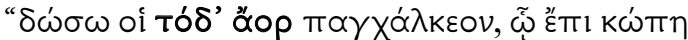

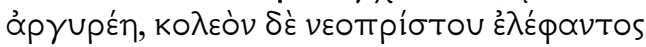

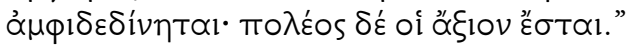

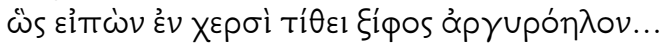

"I will give him [Odysseus] this bronze sword, with a silver hilt

and a scabbard of new-sawn ivory

around it. It will be a possession of great value to him."

Having so spoken he placed the silver-studded sword in his hand...

In this passage the narrator, by exception, had not introduced the prop referred to in the speech beforehand. But in a context where Alcinous refers to the fact

30 Fillmore 1997, 63: 'by the symbolic use of a deictic expression I mean that use whose interpretation involves merely knowing certain aspects of the speech communication situation, whether this knowledge comes by current perception or not'.

31 Ameis-Hentze-Cauer 1928 'dieses Vorhaben, die Werbung um Penelope'; Stanford 1958 “"our business here”, i.e. their wooing of Penelope'. 
that Euryalus must appease the guest (Odysseus) with words and a gift (396-7), the narratees will have no difficulty in mentally processing the reference to a sword. Indeed, this order of presentation is quite effective, in that it suggests the speed at which Euryalus is eager to make amends. While the other Phaeacians send heralds to fetch gifts from their homes (398-9), he gives his own, costly sword on the spot. ${ }^{32}$

The situation is slightly more complicated at another place where a prop is not introduced beforehand:

(14) Iliad 1.234-9+245-6

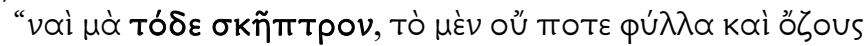

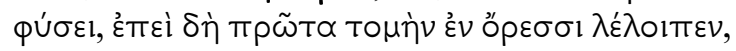

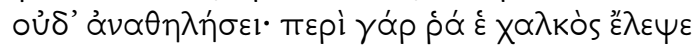

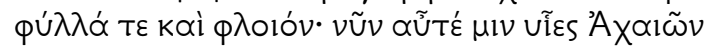

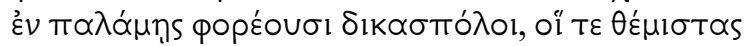

Tpòs $\Delta$ lòs Eipúatal."

$\ldots$

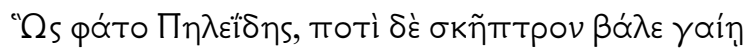

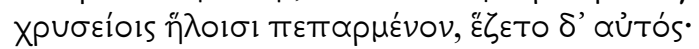

"By this sceptre, which will never grow leaves and branches, ever since it left its stump in the mountains, nor will sprout again. For the bronze stripped

its leaves and bark all round. Now the judgement-giving sons of the Achaeans

carry it in their hands, those who guard

justice given by Zeus."

Thus spoke Peleus' son, and he threw the sceptre,

studded with golden nails, against the ground, and himself sat down.

What can the narratees make of Achilles' unannounced reference to a sceptre? The discussion by Martin Schmidt in the LfgrE (s.v., 2co) is worth quoting in full:

Dass bei Hom. Sitte zugrundeliegt, wonach in öffentl. Versammlungen das Zepter von den Herolden dem gereicht wird, der damit das Wort erhält (...), ist mögl., aber nicht eindeutig. Contra: $\sigma$. nur bei wenigen Rednern erwähnt (...), noch seltener Herold, der $\sigma$. überreicht, nie Wiedergabe od. Rückgabe an Herold. Pro: auch wenn bei typ. Szenen Selbstverständliches oft übergangen wird (...), das Zepter nur bei "remarks of peculiar seriousness and importance"(...) erwähnt wird, erklärt die Annahme einer solchen Sitte die Verwendung von Zepter in Reden am besten (...). A 234 (...), nichts dazu, ob Ach. das $\sigma$. seit Beginn seiner Rede (nach-

32 Another example is Odyssey 10.287+302-6, where Hermes first refers to Tó $\delta \varepsilon$

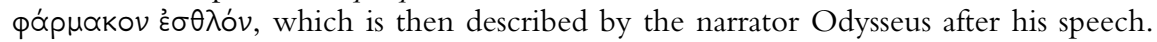
The order may be due to the fact that Odysseus is telling according to his experiencing focalization: he describes the herb at the moment when the god reveals to him its nature. 
dem er das Schwert in die Schiede gesteckt hat V. 220) in der Hand hält (...) od. es sich für den Eid nahm bzw. von Herold geben liess; auch nichts dazu, ob es sein $\sigma$. ist (...) od. e.m. Herold gehört.

The length of this discussion is an indication of what happens when the Homeric narrator leaves out his customary introduction. The sudden reference to the sceptre and Achilles' lengthy description of it do, however, enhance the impact of his solemn prediction (the Greeks will come to miss him dearly, as surely as the sceptre will never sprout leaves again) and - as in the previous example - the order is highly effective in terms of storytelling.

I will end with a passage where a deictic pronoun has presented genuine interpretative problems:

(15) Iliad 6.321-336

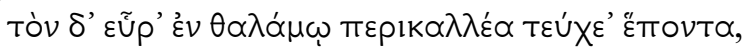

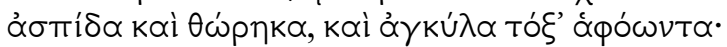

'Ap

$\tilde{\eta} \sigma \tau O \ldots$

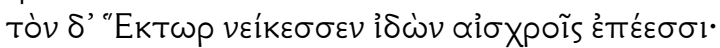

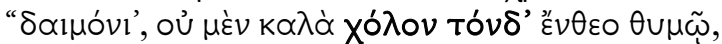

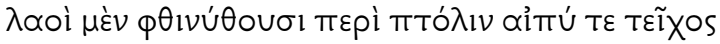

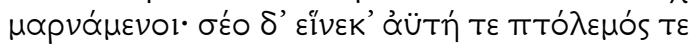

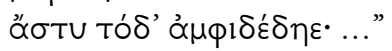

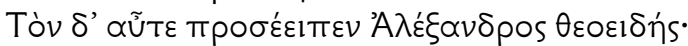

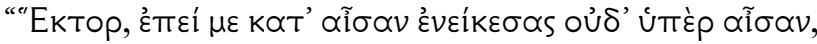

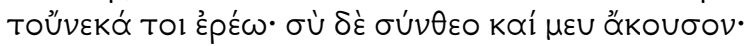

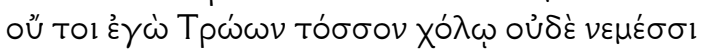

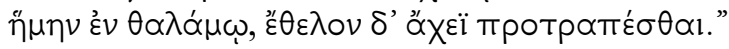

Him [Paris] he found in his bedroom, turning over his exquisite armour,

his shield and corselet, and fingering his curved bow.

And Argive Helen was sitting among her servant-women ...

When Hector saw him, he criticized him with reproachful words:

"Strange man, not appropriately have you conceived this anger in your heart.

The people are dying, fighting around the city and steep wall.

Because of you the clamour of war

is blazing around this city."

Godlike Alexander spoke to him in reply:

"Hector, since you deservedly and not undeservedly criticise me,

I will answer, and you give heed and listen to me.

It is not so much because of anger or resentment at the Trojans

that I am sitting in my bedroom, but I wanted to turn myself headlong to grief."

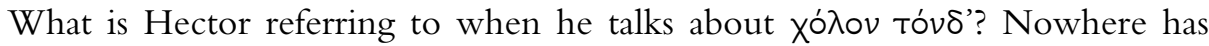
the narrator told the narratees that Paris is angry, and this question has puzzled 
critics from antiquity onwards. ${ }^{33}$ Let us start by examining Paris' anger more closely. Most scholars agree that Hector is sincere here and reject the suggestion, supported e.g. by Eustathius and Kirk, that rather than mentioning cowardice or slackness he assumes anger on the part of Paris, so as not to offend him. This suggestion is precluded by the manner in which Hector's speech is

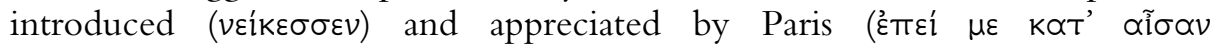

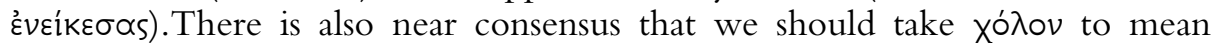
'you have conceived anger against the Trojans' rather than 'you have taken to heart the anger of the Trojans against you', though the two interpretations are closely related: Paris can be expected to be angry at the Trojans because he resents their indignation against him (which we hear about at 3.454; 6.524-5; and 7.390).

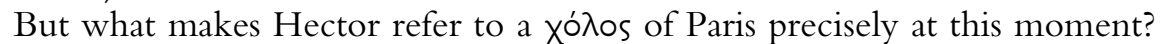
In other words, what is the force of tóvס'? Leaf, typically, comes up with an analytical solution: 'Tóvס' implies that some particular manifestation of Trojan resentment was immediately present to Hector and Paris'. Hence he assumes that a scene like 7.345-79, in which the Trojan Antenor suggests that Paris give Helen back, must originally have preceded the fraternal dialogue. Kirk calls the idea that 'Emphatic tóvס' might seem to suggest a more specific cause for resentment, like Antenor's proposal at 7.347-53' 'improbable' (without indicating why) but leaves Tóvo' unexplained.

Let us once more adopt the rule of thumb set out in this paper and comb out the direct and larger contexts in search of clues on how to understand

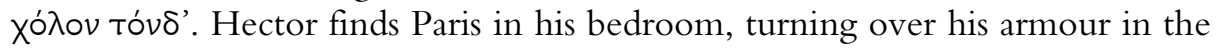
company of his wife and her maids. Paris' surroundings and actions are focalized by Hector, as witness the marker eũp'. It seems to be these perceptions-Paris finding himself in his bedroom instead of on the battlefield, together with his wife rather than his fellow-warriors, and turning over his weapons rather than using them ${ }^{34}$ - which lead Hector to conclude that Paris is angry. He may have thought of that hero of former times Meleager, who out

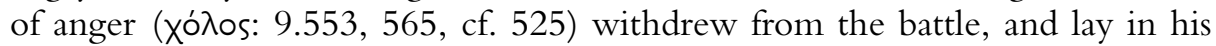
bedroom $(582,588)$, together with his wife $(556)$. The narratees may also recall the example of Achilles, who angrily (xwómevov/s: 1.429; 2.689) sits $(1.349)$ or lies $(2.688,772)$ inactively in his tent, in the company of his best friend Patroclus, and plays the lyre (9.186-9) rather than wielding his spear. In Hector's view, Paris' location and behaviour clearly suggest heroic anger (and

33 For doxography see Heitsch [1967] 2001, and Kirk 1990 and Stoevesandt 2009 ad 6.326, to which add Hijmans 1975.

34 Here I disagree with Hijmans 1975, 178, Kirk 1990, ad 6.321-4 and Stoevesandt 2009, ad 6.321-2, who take ह́то to battle, and concur with Leaf 1900-1902, ad 6.321: "the "dandy" Paris is turning over and admiring his fine armour with the same affection which Odysseus shews to his old bow' (Od. 21.393). 
concomitant inactivity), an interpretation which the narratees can understand. ${ }^{35}$

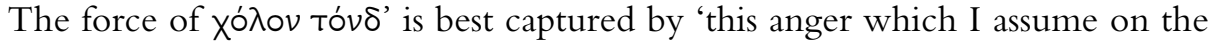
basis of what I see'. ${ }^{36}$

As plausible as Hector's interpretation may be, it is not the right one. Paris himself rejects it, maintaining that he is not angry at the Trojans but sad (obviously because he has lost his duel with Menelaus). The narratees know that this explanation is still far from the truth: Paris finds himself in his bedroom because Aphrodite, having saved him from certain death at the hands of Menelaus, placed him there, and because he took the initiative, cheering himself up-and appeasing a furious Helen-by making love to her.

\section{Conclusion. Deictic pronouns and Homeric realism}

This example brings me to the end of my paper. I have argued that deictic pronouns in Homeric speeches have a double function: they function as deixis ad oculos for the characters, as deixis am Phantasma for the narratees. The narratees must imagine that the characters are gesturing and pointing to places and characters which, again, they have to imagine. In the original performance situation, an aoidos like Homer, holding and playing the phorminx, could not reproduce those gestures, but later rhapsodes could. But even for rhapsodes and their audience the referents of the deictic pronouns remain a product of their Phantasma or imagination. In order to enable his narratees (and in their wake all his listeners and readers) to process this act of imagination, the narrator usually takes care to introduce and describe the objects or persons to be referred to in speeches beforehand, in the directly preceding context, or directly after the speech. Occasionally he trusts his narratees to make use of the context of the narrative as a whole.

I would like to conclude by asking one final question: why does Homer insert so many deictic pronouns in his speeches? One explanation, which I hint at in my narratological commentary (cf. quotation in section 1: 'the frequent use of deictic pronouns, which suggest gestures, lends it an air of drama'), is to

35 Schadewaldt 1959, 227, Fenik 1968, 122, and Stoevesandt 2009, ad 326, have all connected Paris' anger to that of Meleager and Achilles, without, however, explaining

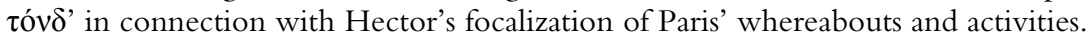

36 Ameiş-Hentze 1940, ad 326 ('den Groll hier, der sich jetzt in deinem Fernbleiben vom Kampfe zeigt') and O'Sullivan in the LfgrE s.v. 1bßbb ('anger of Paris at Tro. (assumed by Hector [app. on basis of Paris' absence from battle]...') are close but not specific enough. Stoevesandt 2009, ad 326, reverses the order: 'diesen Grimm da; sc. Grimm gegenüber den Troianern als Grund für Paris' Fernbleiben vom Kampf. Hijmans 1975, 180, gives the right translation ('that anger of yours that I apprehend') but the wrong interpretation (Hector, as often, is jumping to the wrong conclusion and misinterpreting Paris' activities, which he takes as signs of angry inactivity, while his brother is in fact preparing to return to battle). 
connect the frequent use of deictic pronouns to the theatrical quality of the Homeric epics, which has often been remarked upon, first by Plato, who called Homer 'the first of the tragedians' (Republic 607a). This suggestion is backed up by a comparison of the number of deictic pronouns in epic and drama (see the appendix). Homer aims at mimesis, at making his characters speak like real persons. A passage like Il. 1.275-84 reads like a dramatic script: Nestor first addresses Agamemnon and Achilles together as 'you' (257-74), and then turns to each separately: 'You [Agamemnon], powerful man though you are, do not take away the girl from this man (Tóv $\delta^{\prime}=$ Achilles) ... and you, Achilles, do not want to quarrel with the king... As truly as you are stronger and a divine mother bore you, this man (o $\delta \varepsilon=$ Agamemnon) is more powerful and rules over more men.' Nestor first looks at Agamemnon and points to Achilles; then he turns to Achilles, looks at him with a penetrating gaze and points to Agamemnon.

But I believe we can go one step further, by moving to a higher or more general level of Homeric literary criticism. Homer's narrative art is rightly celebrated for what has been variously referred to as energeia/enargeia, graphicness (Anschaulichkeit), and realism. ${ }^{37}$ He places the past before the eyes of his

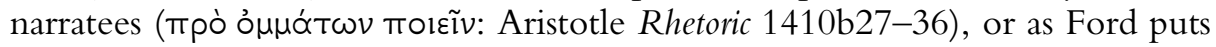
it:

The first words of each poem effect this appearance [of the past] by calling on the Muses: because we are granted their perspective, when the great speeches are given we seem to be on the edge of the assembly, and when the heroic actions are performed we seem to be present as onlookers. Though epic is by definition poetry of the past, it is poetry that claims to transport us to an au dela, not a beyond buried in the vault of recollection but a place as present as our own, though elsewhere. $^{38}$

It is important that this energeia/enargeia is not merely a matter of aesthetic principle, but also serves Homer's profound interest in narrative authority. In the Homeric epics, graphicness means credibility, as is clear from the narrator's emphatic enlisting of the Muses, eyewitnesses to world history (Il. 2.485), and from the compliment that Odysseus pays the Phaeacian singer Demodocus: 'I congratulate you above all mortal men...You sing with such truth about the fortunes of the Greeks, all they did and suffered and all the toils they went

37 See Ford 1992, 49-56, Bakker 1993, and de Jong 2005. Most scholars use enargeia in connection with Homer, but it seems better to talk in terms of energeia: he shows things in a state of actuality (as opposed to a mere potentiality). Homer devotes far less attention to the visual appearance of persons and things than to their working, dynamics, or effect (we do not know what Helen or Penelope looked like but we do hear about their effect on men; we hear more about the history of objects than about their appearance). See Otto 2009, esp. 71-6 and Uhlmann-Radke 2009.

38 Ford 1992, 55. 
through, as if you were there yourself or have heard from one who was' (Od. 8.48791).

The use of deictic pronouns clearly should be connected to this striving for realism by the Homeric narrator. Again and again the narratees are invited to activate their fantasy and mentally to imagine the events told. A final, highly cinematographic example will serve to illustrate this. The suitors have just heard that Telemachus has arrived home safely and they decide to send a ship with men to warn the suitors lying in an ambush that they can return home:

(16) Od. 16.349-55

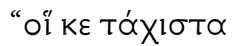

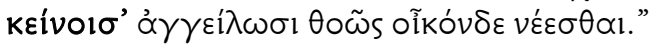

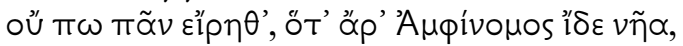

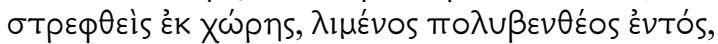

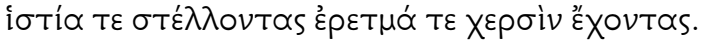

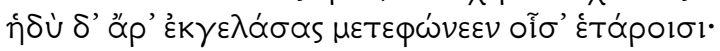

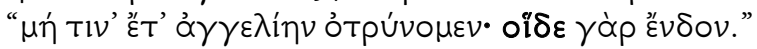

""who could let those over there

know that they should come home quickly."

He had not finished speaking when Amphinomus, turning round from his seat, saw the ship within the deep harbour, the men taking in the sails and holding the oars in their hands.

He laughed out heartily and said among his companions:

"No need to send a message. For here they are inside already."

The order of the deictic pronouns (first kzivolo', then oif $\delta \varepsilon$ ) helps us to visualise the scene, the return of the ship with suitors during the time that the other suitors on Ithaca are talking. The technique will later be exploited, e.g. by:

(17) Plato, Phaedrus 229 A-230 B

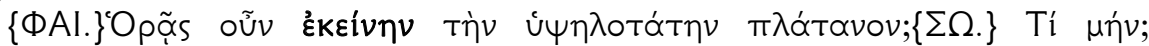

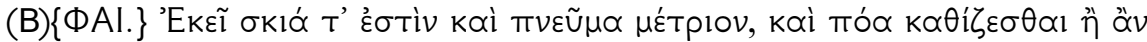

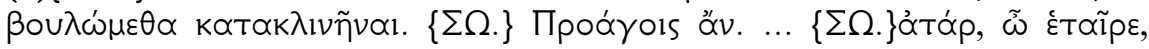

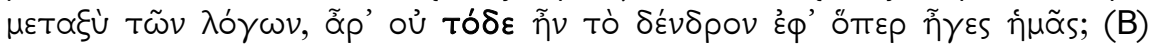

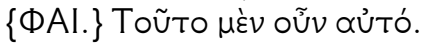

\{Phaedrus\} Do you see that very tall plane tree there? \{Socrates\} What about it? \{Phae.\} There is shade there and some breeze and grass to sit on or, if we want, to lie down on. $\{$ So. $\}$ Please lead the way. ... \{So.\} But, my friend, to interrupt our conversation, wasn't this the tree to which you were leading us? \{Phae.\} Yes, that is exactly the one (I was talking about).

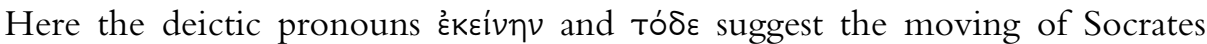
and Phaedrus and their arrival at the locus amoenus which will be the setting of their dialogue.

The constant use of deictic pronouns in Homeric speech, which refer to objects and persons that are visible to the characters and hence exist, serves to 
increase the narratees' belief in the existence of those objects and persons. In other words, the ad oculos status of the deictic pronouns helps to make the actual am Phantasma status of the epics less conspicuous. ${ }^{39}$

\section{Appendix}

1. őర $\varepsilon$ and oũtos in Homer ${ }^{40}$

\begin{tabular}{|c|c|c|c|c|}
\hline & ő $\delta \varepsilon$ & & oŨTOS & \\
\hline & speech & narrator-text & speech & narrator-text \\
\hline Iliad & 182 & 3 & 153 & 11 \\
\hline Odyssey & 277 & 0 & 160 & 7 \\
\hline
\end{tabular}

2. occurrences in 500 lines

\begin{tabular}{|c|c|c|c|}
\hline & total & ő $\delta \varepsilon$ & OŨTOS \\
\hline Iliad & 23 & 13 & 10 \\
\hline Odyssey & 42 & 16 & 26 \\
\hline S. Ajax & 77 & 52 & 25 \\
\hline Ap. R. Argonautica & 23 & 21 & 2 \\
\hline
\end{tabular}

\section{Bibliographie}

Ameis, K.F. / Hentze, C., Homers Ilias IV-VI (Leipzig-Berlin $\left.{ }^{9} 1940\right)$.

Ameis, K.F. / Hentze, C. / Cauer, P. Homers Odyssee XIII-XVIII (Leipzig-Berlin ${ }^{9}$ 1928).

Bakker, E.J., Poetry in Speech. Orality and Homeric Discourse (Ithaca-London 1993).

—, „Homeric HOUTOS and the Poetics of Deixis”, CP 94 (1999) 1-19.

Bérard, V., „Le geste de l'aède et le texte homérique“, REG 31 (1918) 1-38.

39 I wish to thank audiences in Amsterdam and Hamburg for commenting on this paper, S. R. van der Mije and A. Rijksbaron for reading through a written version, and Mrs. B. Fasting for correcting my English.

40 In compiling these figures I made use of the electronic Chicago Homer, which makes it possible to search for narrative or speech. I differ from this-very useful-program in

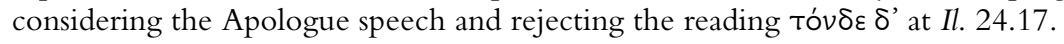


Boegehold, A.L., When a Gesture Was Expected: Selection of Examples from Archaic and Classical Greek Literature (Princeton 1999).

Bonifazi, A., „Communication in Pindar's Deictic Acts“, Arethusa 37 (2004) 391-414.

-, „Discourse Cohesion through Third-Person Pronouns. The Case of keivos and aủtós in Homer", in S. Bakker, G. Wakker (eds.) Discourse Cohesion in Ancient Greek (Leiden-Boston 2009) 1-19.

Brugmann, K., Die Demonstrativpronomina der indogermanischen Sprachen. Eine bedeutungsgeschichtliche Untersuchung (Leipzig 1904).

Bühler, K., Sprachtheorie: die Darstellungsfunktion der Sprache, (Stuttgart ${ }^{21965}$, first edition from 1934).

Danek, G. / Hagel, S., „Homer-Singen“, Wiener Humanistische Blätter 37 (1995) 5-20.

Diessel, H., Demonstratives:Form, Function, and Grammaticalization (Amsterdam 1999).

Fenik, B., Typical Battle Scenes in the Iliad. Studies in the Narrative Techniques of Homeric Battle Description (Wiesbaden 1968).

Fillmore, C.J., Lectures on Deixis (Stanford ${ }^{2} 1997$, first edition 1971).

Ford, A., Homer. The Poetry of the Past (Princeton 1992).

Halliday, M.A.K. / Hasan, R., Cohesion in English (London 1976).

Heitsch, E., „Der Zorn des Paris. Zur Deutungsgeschichte eines homerischen Zetemas", in Gesammelte Schriften I (München-Leipzig 2001) 178-209 (original from 1967).

Herington, J., Poetry into Drama. Early Tragedy and the Greek Poetic Tradition (Los Angeles-London 1985).

Hijmans, B.L., ,Alexandros and his Grief“, GB 3 (1975) 177-89.

de Jong, I.J.F., Narrators and Focalizers. The Presentation of the Story in the Iliad (London ${ }^{2} 2004$, first edition from 1987).

-, A Narratological Commentary to the Odyssey (Cambridge 2001).

—, „Convention versus Realism in the Homeric Epics“, Mnemosyne 58 (2005) 1-22.

- Homer Iliad XXII (Cambridge 2012).

Kirk, G., The Iliad: A Commentary, II, Books 5-8 (Cambridge 1990).

Kroon, C.H.M., „Text Structure and Referential Choice in Narrative. The Anaphoric Use of the Latin Demonstrative ille", Belgian Journal of Linguistics 23 (2009) 115-131.

Kühner, R. / Gerth, B., Ausführliche Grammatik der Griechischen Sprache II, 1 (HannoverLeipzig $\left.{ }^{3} 1898\right)$.

Latacz, J., „Realität und Imagination. Eine neue Lyrik-Theorie und Sapphos fainetai moi kēnos-Lied“", MH 42 (1985) 67-94.

Lateiner, D., Sardonic Smile. Nonverbal Behaviour in Homeric Epic (Ann Arbor 1995).

Leaf, W., The Iliad I, I-XII (London $\left.{ }^{2} 1900-2\right)$.

Levinson, S.C., Pragmatics (Cambridge 1983).

Lyons, J., Semantics 2 (Cambridge 1977).

Maas, M. / McIntosh Snyder, J., Stringed Instruments of Ancient Greece (New Haven 1989).

Magnien, V., „L'emploi des démonstratifs chez Homère“, BSL 23 (1922) 156-83. 
Manolessou, I., „The Evolution of the Demonstrative System in Greek“, Journal of Greek Linguistics 2 (2001) 119-48.

Martín López, I., „Deixis frente a anafora en griego antiguo“, Minerva 8 (1994) 11-41.

Otto, N., Enargeia. Untersuchung zur Charakteristik Alexandrinischer Dichtung (Stuttgart 2009).

Pelling, C.B.R., „Aristagoras (5.49-55, 97)“, in E. Irwin, E. Greenwood (eds.), Reading Herodotus. A Study of the Logoi in Book 5 of Herodotus Histories (Cambridge 2007) 179-201.

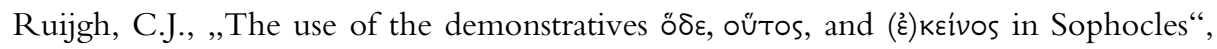
in I.J.F. de Jong, A. Rijksbaron (eds.), Sophocles and the Greek language. Aspects of Diction, Syntax, and Pragmatics (Leiden 2006) 151-61.

Schadewaldt, W., Von Homers Welt und Werk. Aufsätze und Auslegungen zur homerischen Frage (Stuttgart $\left.{ }^{3} 1959\right)$.

Sennholz, K., Grundzüge der Deixis (Bochum 1985).

Sitta, G., Deixis am Phantasma. Versuch einer Neubestimmung (Bochum 1991).

Stanford, W.B., The Odyssey of Homer (Hampshire-London $\left.{ }^{2} 1958\right)$.

Stoevesandt, M., Homers Ilias Gesamtkommentar IV, Sechster Gesang (Z) (Berlin-New York 2009).

Uhlmann-Radke, G., „Über eine vergessene Form der Anschaulichkeit in der Griechischen Dichtung“, Antike und Abendland 55 (2009) 1-61.

Wackernagel, J., Vorlesungen über Syntax mit besonderer Berücksichtigung von Griechisch, Lateinisch, und Deutsch, II (Basel 1924).

West, M.L., ,The Singing of Homer and the Modes of Early Greek Music“, JHS 101(1981) 113-29. 
Bereitgestellt von | SUB Göttingen Angemeldet

Heruntergeladen am | 27.10.14 12:33 


\title{
Wörter im Kontext
}

\author{
RUDOLF FÜHRER
}

Ich hatte das Privileg, neben und nach der Arbeit am LfgrE auch die Bände des Basler Kommentars noch vor der Drucklegung zu verfolgen. Dieser Perspektivenwechsel ist äußerst anregend und erhellend. Der Lexikograph bewegt sich auf der paradigmatischen Achse quer zum Text (nicht nur bei der Zusammenstellung des Flexionsparadigmas seines Lemmawortes in F), der Kommentator darf dem syntagmatischen Strom des Textes folgen.

Auch William C. Scott hat seinem paradigmatisch angelegten Buch The Oral Nature of the Homeric Simile von 1971 (Mnemosyne Suppl. 28) 2009 die syntagmatische Studie The Artistry of the Homeric Simile folgen lassen.

Aber nicht nur der erzählerische Kontext motiviert die Ersetzung von

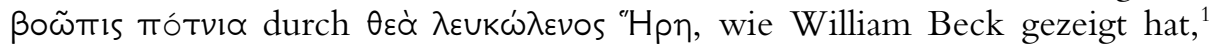

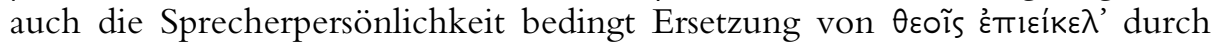

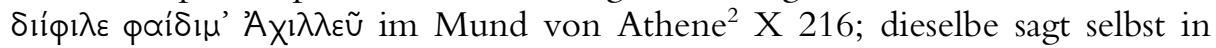
sterblicher Verkleidung nicht wie Nausikaa im sonst völlig gleichlautenden

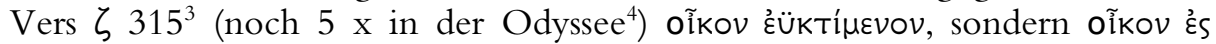

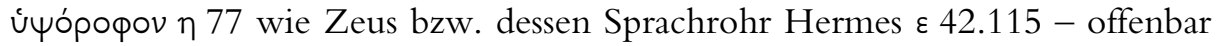
objektiv-distanzierter und weniger subjektiv-wertend.

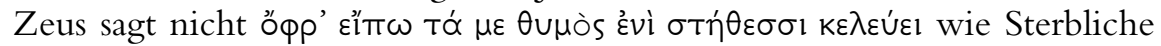

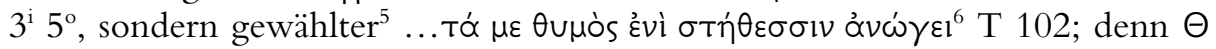

1 AJPh 107, 1986, 480 ff., von Sbardella, QUCC 43, 1993, $13^{22}$ ignoriert (vgl. QUCC 47, 1994, 21 ff.), aber von R.Friedrich, „Formular Economy in Homer“, Hermes Einzelschr. 100 (2007) 78 ff. rezipiert.

2 Friedrich a.O. 81.

3 Von vielen Handschriften und modernen Editionen ausgelassen bzw. getilgt als ,Wie-

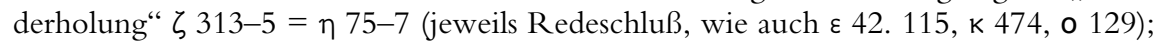
die variantenlose Differenz des Epithetons spricht für Echtheit.

$4 \delta 476$ (Proteus), 1533 (Polyphem), k 474 (Gefährten), o 129 (Helena), 4259 (Penelope), bis auf o 129 jeweils mit v.l. દ̇s úuópoфov.

5 und respektvoller: Zeus ist nie Objekt von $\kappa \varepsilon \lambda \varepsilon u ́ \omega$ im Gegensatz zu anderen Gottheiten (LfgrE II 1375, 13-21, 39-41, 61 f., 71. ff.).

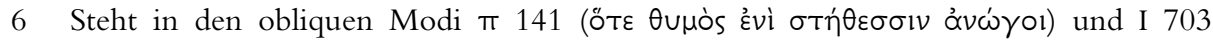

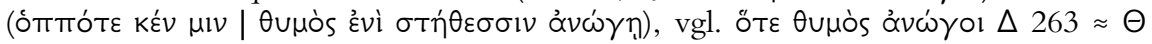

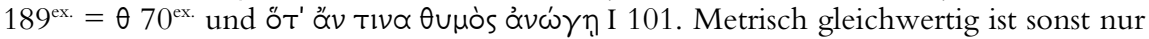

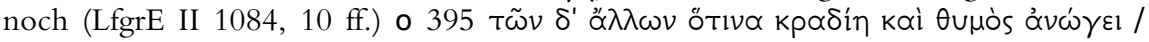

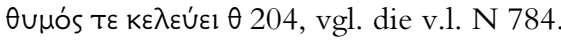




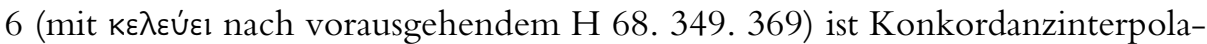

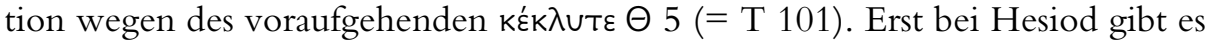
keinen Unterschied mehr zwischen Schoineus (fr. 75, 14) und Zeus (Th. 645).

Die folgende (durch den Basler Kommentar inspirierte) Betrachtung könnte man ,naming Patroclus' nennen im Anschluß an D.M. Shive's Naming Achilles (Oxford 1987), der jedoch paradigmatisch vorgeht, nicht syntagmatisch wie im folgenden, beschränkt auf das Buch T.

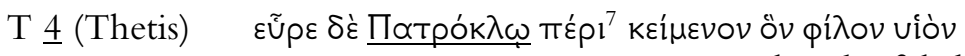

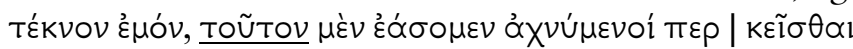
,den da“, distanziert im Ggs. zur Intimität Ach.Patr. 4 (so Ach. erst $\Psi$ 52, s.u. zu 225)

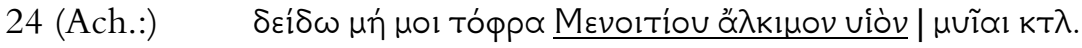
respektvolle patronymische Umschreibung des PN wie in dir. R. nur von Ach. $\Sigma 12$ ( sonst zeremonielle REinl. $\wedge$ 695. 814. 837, П 626, zus.fassender Szenenabschluß M 1 und Aristie $\Pi$ 278. 307. 665. 827.

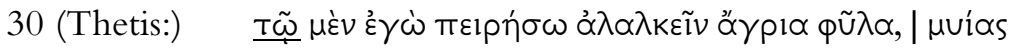

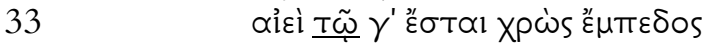
das Dem.Pron. (vgl. 8) zeigt "eine gewisse Distanziertheit gegenüber dem toten Patroklos", den Thetis "nie beim Namen nennt" (Coray, BK VI 2, 18) im Ggs. zum (noch) lebenden $\Sigma$ 451. 455 (s.o. zu 24)

$\underline{38}$

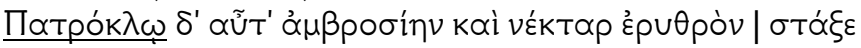

ringförmig die Szene abschließende Namensnennung im Erzähltext wie 4 (und später nur 283. 302)

Ach. erwähnt Patr. 56-71. 146-53 überhaupt nicht, nur seinen eigenen Kampfeswillen; erst

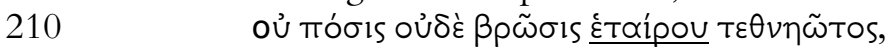

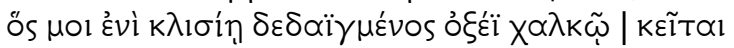

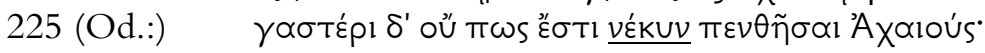
,den Toten' (Latacz, BK VI 1, 17), entsprechend 210 ,mein Gef.' : ,einen

7 Vgl. 284 (s.u.)! Das Postpositivum hebt die Zäsur nicht auf, s.West zu Th. 647 mit Verweis auf Bühlers Exkurs VI zur Europa des Moschos (Hermes Einzelschr. 13, 1960, 233 ff.). Der Lexikograph (LfgrE II 1363, 26 ff.) hängt von den Editionen ab, die zusammenschreiben (vgl. dazu die grundsätzliche Kritik GGA 253, 2001, 24), und rubri-

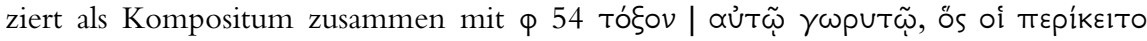

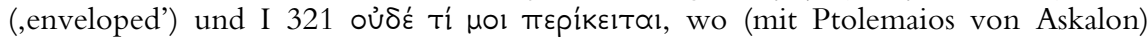

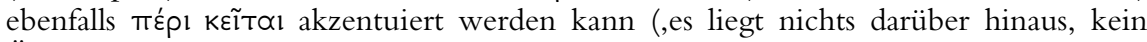
Überschuß vor' Ameis-H.). 
Toten' (Schadewaldt), vgl. $\Psi 50 \mathrm{f}$.

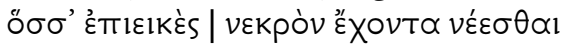

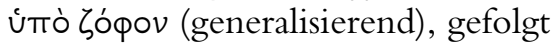
von 52 тои̃Tov $\mu \dot{v} \nu$ (spezifizierend)

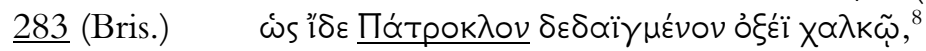

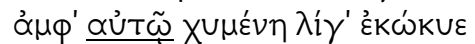

287

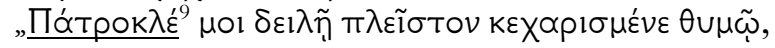

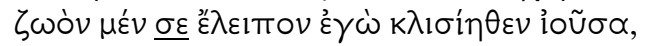

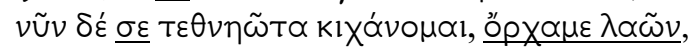

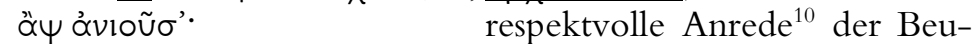
tesklavin an ihren liebenswürdigen ,Mentor', von Patr. nur hier

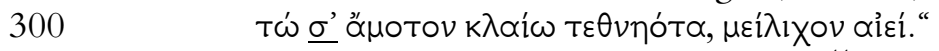

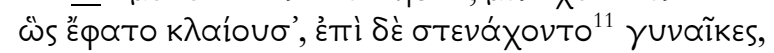

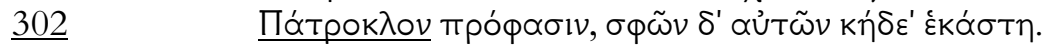

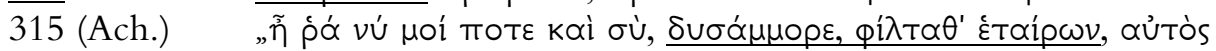

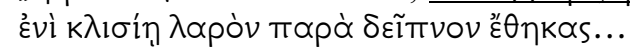

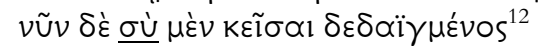

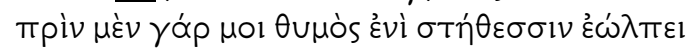

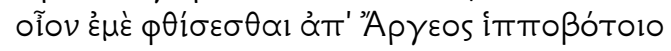

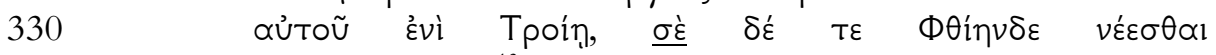
der Echo-Effekt ${ }^{13} \mathrm{zu} \dot{\varepsilon} \mu \dot{\varepsilon} \quad \phi \theta i-\quad \sigma \varepsilon \sigma \theta \propto l 329$ sichert sowohl $330 \delta \varepsilon$ ' $\tau \varepsilon$ gegen Ruijghs Konjektur $\delta$ ' auch $329 \phi \theta i ́-$ gegen Wests Orthographie $\phi \theta \varepsilon \dot{l}-$

$8=292^{\text {ex. }} \approx 211^{\text {ex. }}$

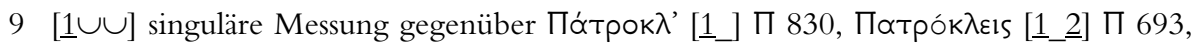
По́трок $\lambda \varepsilon$ [2__3] $\Omega 592$ (По́трок $\lambda \varepsilon\left[\_\underline{3}\right] 7^{\mathrm{i}}$ ), aber gerechtfertigt durch den Anklang von

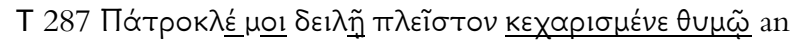

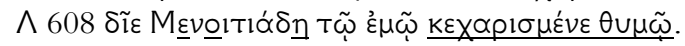

10 Vgl. $\Xi 102, \Phi 221$ (jeweils am Redeende).

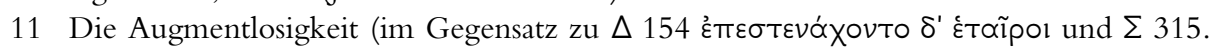

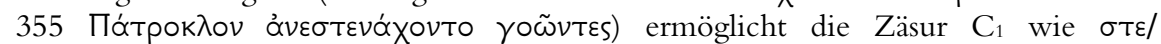

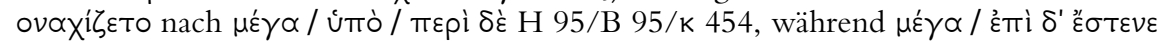

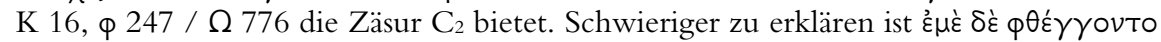

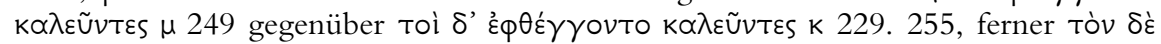

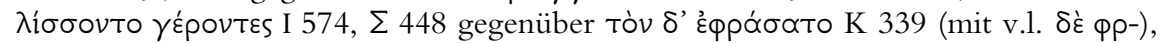
h. Merc. 354 (dazu Taida, Hermes 138, 2010, 254 f.), während das Augment den Ak-

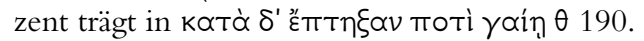

$12 \approx 203^{\text {in. med. }}$, vgl. $211\left(\approx 316^{\text {in. }}\right)$

$13[\cup \underline{2} 3 \cup] \approx[\cup \cup \underline{4}<\underline{5} \cup \cup>\underline{6} x]$, mit daktylischer Erweiterung' (à la Hainsworth, Flexibility 85 f.). S. auch Nagy, The Best of the Achaeans 185: „Coming home to Phthî̀e (XIX 330) is overtly contrasted with dying 'phthîsesthai' at Troy (XIX 329)" und Mackie, Colby Quarterly 38 (2002) $170 \mathrm{f}$.

14 Würde zwar mit 355 respondieren, aber die Verlagerung der inplizierten Negativität auf ein anderes (antithetisches) Subjekt macht Schwierigkeiten; als Parallele am nächsten käme 


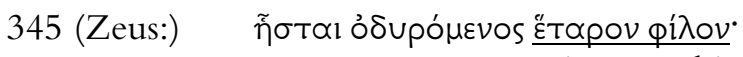

mit Empathie

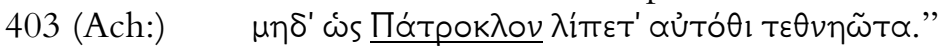
streng, tadelnd

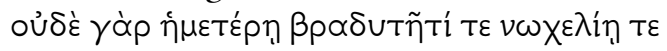

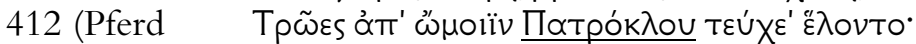

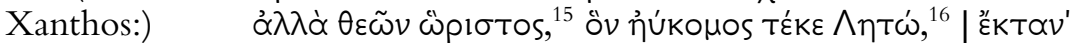

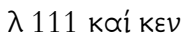

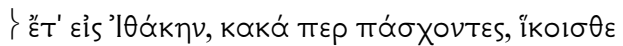

$\mu 138 \tilde{\eta} \tau^{\prime}$ ò̀

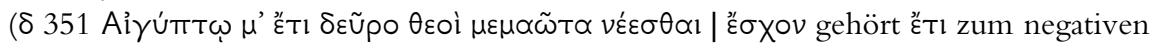
है०XOv).

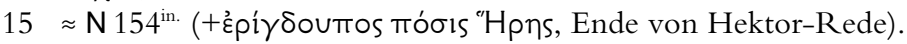

$16 \approx \lambda 318^{\text {ex. }}=$ h.Ap. $178^{\text {ex. }} \approx$ A $36^{\text {ex. }}$ „Die Füllung eines ganzen Verses mit der Benennung einer Person signalisiert deren Bedeutsamkeit für die Erzählung" (Coray, BK VI 2, 175 f.). 


\section{Homer und Europa. \\ Höhepunkte Homerischen Einflusses auf Europas Kulturentwicklung ${ }^{\star}$}

JOACHIM LATACZ

Das Lexikon des frühgriechischen Epos ist fertig! Eine Nachricht, die die ehemaligen Mitarbeiter - und so auch mich - mit ungläubigem Stolz erfuillt. Wer einmal, so wie ich, im Hamburger Philosophenturm im 8. Stock die 381 frühgriechischen Epos-Belege des Wortes đ̋ $v \theta p \omega \pi$ os, 'der Mensch', mit ihren Kontexten an die Wand gepinnt hat, wer wochenlang grübelnd vor den 381 Zettelchen gestanden hat, des Nachts mit plötzlichen Einordnungs-Ideen immer wieder aus dem Schlafe hochgeschreckt und rund ein Jahr lang mit öv $\theta$ p delt ist - der versteht die tiefe Freude derer, die das Werk nach 55 Jahren abgeschlossen haben, der Autoren ebenso wie der Sponsoren. Zumal und ganz besonders, wenn dieser Mensch sich jener Rezension des 5. Faszikels (erschie-

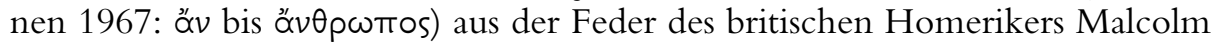
Willcock entsinnt, in der es über die zufällig kurz zuvor erschienene Dissertation des Artikel-Verfassers 'Zum Wortfeld Freude in der Sprache Homers' heißt: "Ich frage mich, ob nicht einer der Gründe für Dr. Latacz's Publikation seiner Forschungsergebnisse als separates Buch darin bestand, daß er das von ihm behandelte Lemma xaípw ['ich freue mich'] schwerlich noch während seiner Lebenszeit gedruckt sehen durfte"; ${ }^{2}$ denn, so Willcock weiter, beim bisherigen Tempo des Arbeitsfortschritts müsse man wohl mit etwa 175 Jahren bis zur Fertigstellung rechnen (und der Buchstabe Chi ist ja der drittletzte im griechischen Alphabet!). Daß ich Willcock doppelt widerlegt habe - ich lebe noch,

* Die Mündlichkeitsform ist bei diesem vor einem breiten Publikum gehaltenen Festvortrag bewußt beibehalten. Die Fußnoten sind auf Literatur-Angaben beschränkt.

1 J. Latacz, Zum Wortfeld 'Freude' in der Sprache Homers, Heidelberg : Winter Verlag 1966.

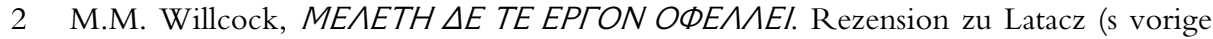
Anm.) und zur 5. Lieferung des LfgrE, in: The Classical Review 18, 1968, 271-273 (273: "I wonder whether one reason for Dr. Latacz's publishing his researches as a sep-

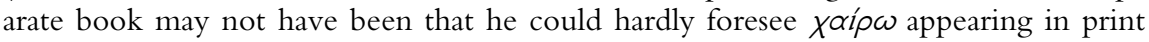
during his lifetime"). 
und es hat nicht 175, sondern 'nur' 55 Jahre gedauert -, dies, meine Damen und Herren, erfüllt mich heute mit wahrhaft diebischer Freude!

Wer aber - so müssen wir uns an diesem Festtag doch auch fragen -, wer außerhalb des Kreises der Mitarbeiter und Sponsoren (und außerhalb des esoterischen Zirkels der Altertumsforscher und Altertumsfreunde) - wer wird diese unsre Freude teilen? Und wer wird die Leistung, die mit diesem Werk erbracht ist, schätzen? Denn wie groß mag die Anzahl der europäischen und europäisch geprägten Erdenbürger sein, die mit dem Begriff 'frühgriechisches Epos' heute noch etwas zu verbinden wissen, und wie groß gar die Anzahl derer, die mit diesem Begriff, sofern sie seinen Inhalt mindestens erahnen, den Namen 'Homer' verknüpfen? Die Statistiken sagen uns: Die Anzahl dieser Hochgebildeten bewegt sich im untersten Promille-Bereich. Und selbst diese wenigen: was sagt ihnen denn der Name Homer? Vor drei Jahren stellte der amerikanische Kollege Seth Schein von der University of California in Davis in einem Sammelband mit dem Titel 'Homer in the Twentieth Century' lakonisch fest, an den Universitäten der USA würden zwar Jahr für Jahr rund 100.000 Studenten durch die dort beliebten 'Great Books'-Kurse hindurchgeschleust - also Kurse unter dem Thema 'Große Bücher der Menschheit' -, und diese Kurse begännen regelmäßig mit Homer - aber was in Ilias und Odyssee wirklich stehe, was dort wirklich verhandelt werde, worum es eigentlich dort gehe - und vor allem, warum Homer auch heute noch von Bedeutung sei - von alledem hätten am Ende der Homer-Behandlung (ein paar Stunden in 2 Wochen) nur die allerwenigsten Hörer auch nur eine entfernte Ahnung. ${ }^{3}$ Traurig, ohne Zweifel traurig. Aber darüber hier in Europa nun etwa den Kopf zu schütteln stünde uns schlecht an. Denn bei uns sieht es längst schon nicht viel anders aus. Immer wieder versuchen zwar besonders engagierte Kollegen an dieser oder jener Universität, wenigstens vergleichbare Vorlesungsreihen zustande zu bringen, doch das bleiben Ausnahmen, die im nächsten Semester schon wieder vergessen sind. Am Ende bleibt das alles Stückwerk.

Nun aber umgekehrt: Was zeigen denn diese immer wieder neu begonnenen Versuche der Massen-Homerisierung in der Tiefe an? Sind sie nicht der schlagendste Beweis dafür, daß man auf Homer jedenfalls nicht verzichten zu können glaubt, aus welchen Gründen auch immer - Beweis also dafür, daß Homer tatsächlich auch heute noch unter uns ist - daß er lebt? Und zwar das macht die Motiv-Analyse solcher Versuche deutlich - als Legitimation lebt? Als Legitimation - um es auf den Punkt zu bringen -, als Legitimation letztlich des 'Way of Western Civilization'?

Dies aber war Homers Schicksal von Anfang an - seit Ilias und Odyssee das Licht der Welt erblickten, um 700 v. Chr., durch rund 2700 Jahre hindurch mithin - das Schicksal nämlich, als Legitimationsinstrument für den

3 S. Schein, An American Homer for the Twentieth Century, in: B. Graziosi (Hrsg.), Homer in the Twentieth Century : between world literature and the western canon, Oxford : Oxford UP 2007, 268-285. 
Weg Europas zu fungieren, für Europas 'Sonderweg', wie man gesagt hat und zwar in allen nur möglichen Varianten, mit allen möglichen Akzentuierungen, mit allen möglichen ideologischen Zielen - guten wie schlechten -, aber stets als unbezweifelbare, autoritative Berufungsinstanz. Homer diente Europa und den europäisch geprägten Teilen der Welt nicht etwa nur als schöne Unterhaltungsliteratur - Belles Lettres -, sondern immer auch zugleich als Identifikations-, Integrations- und Vaterfigur - geliebt, gehaßt, vergöttert oder verworfen, aber stets präsent. Das war weder im Orient so noch in Afri$\mathrm{ka}$, weder in Indien, China noch in Indonesien. Es waren ausschließlich Europa und der europäische Kulturkreis, wo Homer diese Funktion besaß - und nach wie vor besitzt, wie gerade auch der heutige Anlaß zeigt.

Von einigen wenigen Stationen dieser europäischen Funktionalisierung Homers soll heute hier die Rede sein - für die Kenner als angenehme Erinnerung, für die Liebhaber als eine Art Perlenschnur zu weiteren Vertiefung ihrer Liebe. Von vier Höhepunkten der Homer-Wirkung soll gesprochen werden Höhepunkten im eigentlichsten Sinne dieses Wortes, denn der Strom der Homer-Wirkung floß durch die Jahrhunderte untergründig immer weiter und nur hier und da sprudelte er einmal ganz gewaltig auf und zeigte sich: 'Seht her! Eimi Homêros! Ich bin Homer! Ich bin noch da!'

Ein erster Höhepunkt lag in der zweiten Hälfte des 6. Jahrhunderts v. Chr. bei den Griechen selbst. In dieser Zeit scheint bei ihnen etwas begonnen zu haben, was man heute modisch als 'Homer-Diskurs' bezeichnen würde. Dieses öffentliche 'Reden über Homer' - und zwar erstmals mit expliziter Namensnennung: 'Hómeros', belegt in authentisch überlieferten, zeitlich nicht allzu weit von der Ilias- und Odyssee-Entstehung entfernten Dokumenten - dieses allgemeine Reden über Homer beginnt - jedenfalls für uns, die wir nur noch Trümmer der frühgriechischen Literatur haben - es beginnt genau dort, wo wir Homers Wirkungskreis aus vielen Gründen ohnedies lokalisieren müßten: im westkleinasiatischen Kolonialgebiet der Griechen, und noch genauer: im kleinasiatischen Ionien, auch Ostionien genannt. 


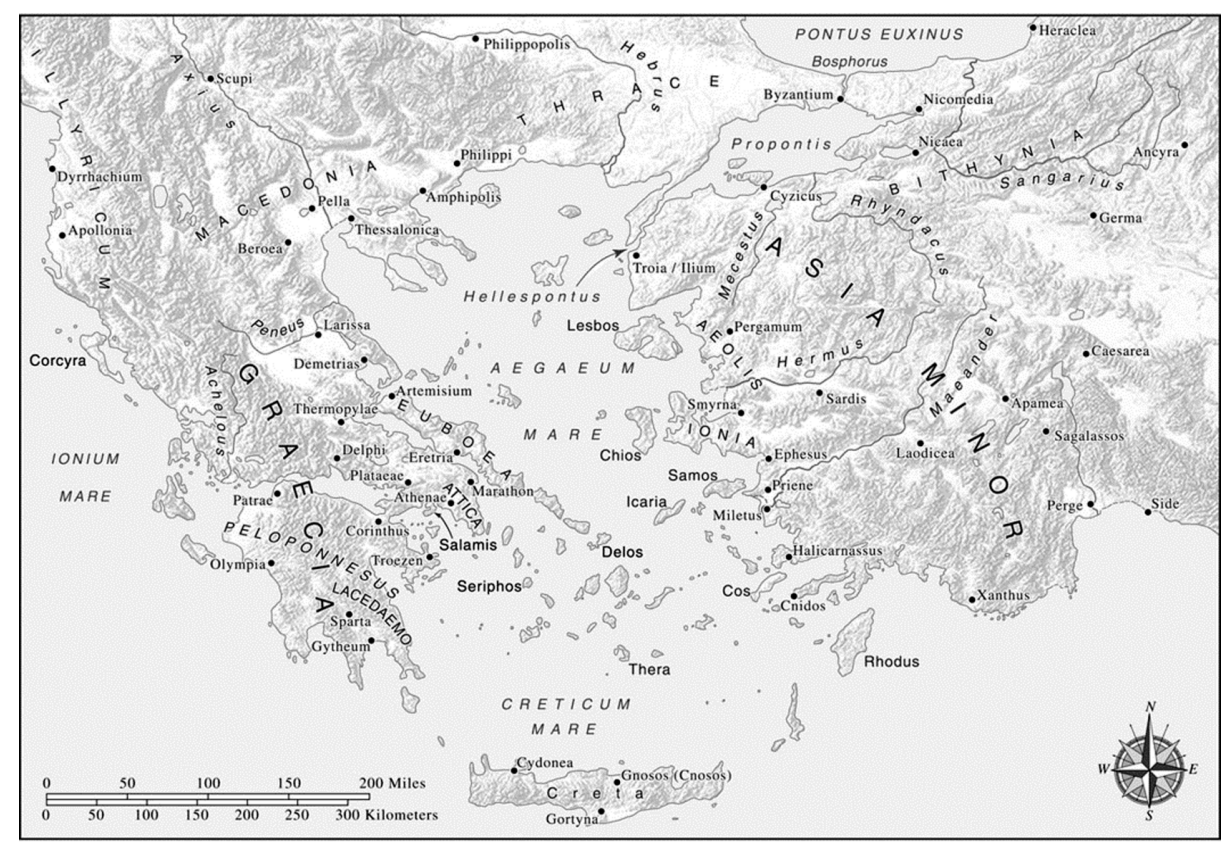

Abb. 1: Karte Griechenlands 


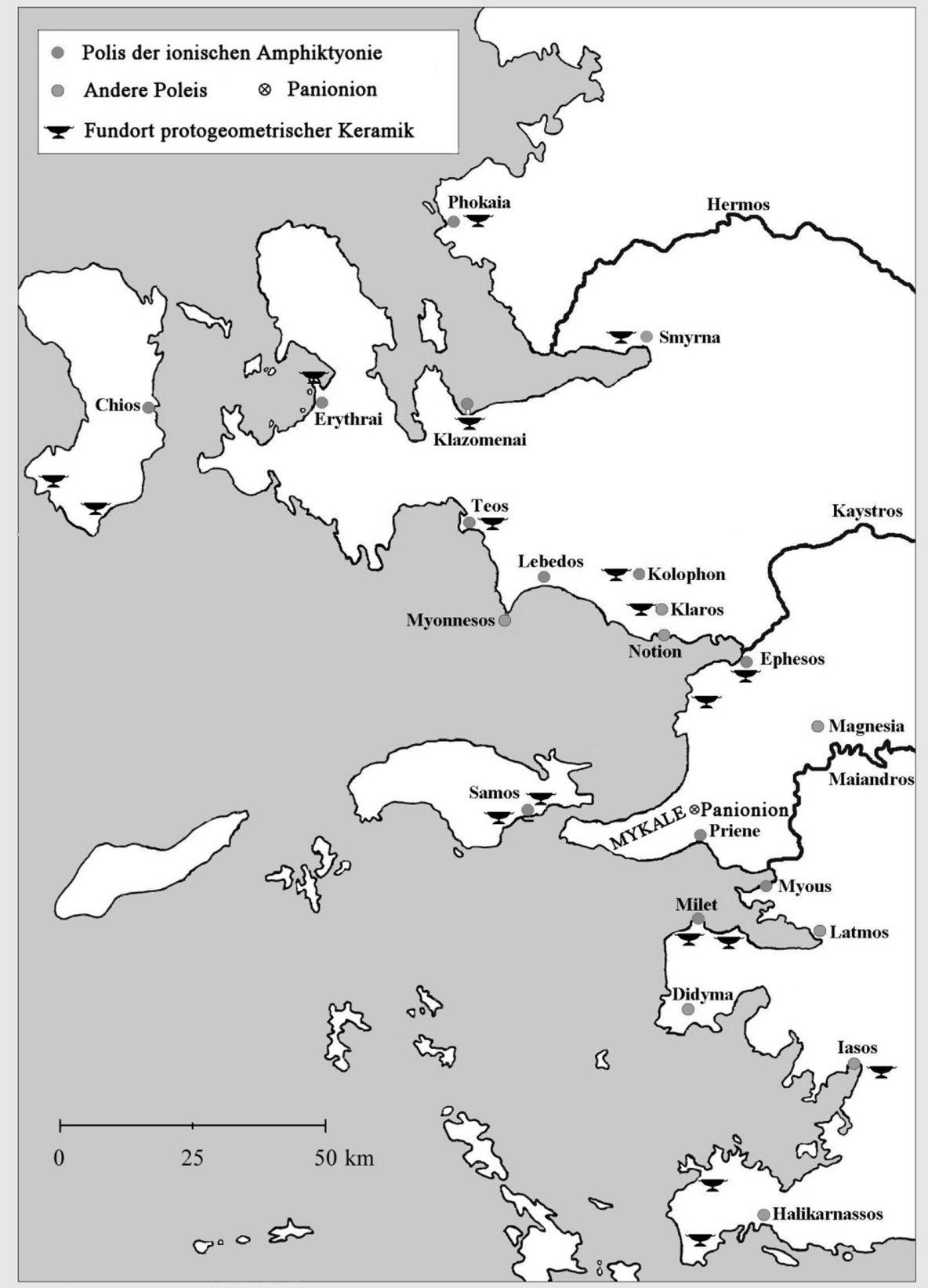

Abb. 2: Karte Ostioniens (Karten-Design: Claude Brügger, Basel) 


\begin{tabular}{|c|c|c|c|c|c|c|c|c|c|}
\hline & 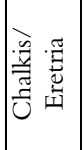 & 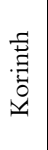 & $\begin{array}{l}\text { 荧 } \\
\text { 足 } \\
\sum^{\infty}\end{array}$ & . & 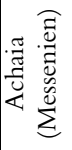 & 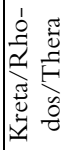 & 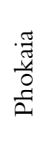 & $\frac{\vec{u}}{\dot{z}}$ & 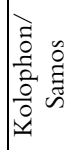 \\
\hline Al Mina [Levante] & 800 & & & & & & & & \\
\hline Pithekussai [Ischia] & 780 & & & & & & & & \\
\hline Kyme [Cumae, Nähe Cap Miseno] & 760 & & & & & & & & \\
\hline Megara (Hyblaia) [Sizilien, Nähe Syrakus] & & & $\begin{array}{c}75 \\
0\end{array}$ & & & & & & \\
\hline Naxos [Siz., Nähe Tauromenion $\sim$ Taormina] & 734 & & & & & & & & \\
\hline Syrakusai [Siracusa] & & $\begin{array}{c}73 \\
4 \\
\end{array}$ & & & & & & & \\
\hline Katane [Catania] & 733 & & & & & & & & \\
\hline Leontinoi [Lentini] & 733 & & & & & & & & \\
\hline Zankle ['Sichel'] / Messana [Messina] & 730 & & & & & & & & \\
\hline Rhegion [Reggio] & 728 & & & & & & & & \\
\hline Mylai [Milazzo] & 720 & & & & & & & & \\
\hline Sybaris [510 zerstört] & & & & & 720 & & & & \\
\hline Kroton [Crotone] & & & & & 710 & & & & \\
\hline Taras [Taranto/Tarent] & & & & $\begin{array}{c}71 \\
0 \\
\end{array}$ & & & & & \\
\hline Metapontion [Metaponto] & & & & & 700 & & & & \\
\hline Siris [Süditalien; urspr. von Kolophon] & & & & $\begin{array}{c}70 \\
0 \\
\end{array}$ & & & & & \\
\hline Lokroi [mit lokr. Beteiligung] & & & & $\begin{array}{c}70 \\
0 \\
\end{array}$ & & & & & \\
\hline Poseidonia [Paestum; von Sybaris?] & & & & & 700 & & & & \\
\hline Gela [Gela] & & & & & & 690 & & & \\
\hline Kalchedon [Kadıköy TR] & & & $\begin{array}{c}68 \\
0 \\
\end{array}$ & & & & & & \\
\hline Lampsakos [Lapseki TR] & & & & & & & $\begin{array}{c}68 \\
0 \\
\end{array}$ & & \\
\hline Abydos [Nähe Çanakkale TR] & & & & & & & & \begin{tabular}{|c|c}
67 \\
0 \\
\end{tabular} & \\
\hline Byzantion [Byzanz/Konstantinopel/Istanbul] & & & $\begin{array}{c}66 \\
0 \\
\end{array}$ & & & & & & \\
\hline Naukratis [Kom Gieif, Nildelta] & & & & & & & & $\begin{array}{c}65 \\
0\end{array}$ & \\
\hline Kyzikos [Belkıs TR] & & & & & & & & \begin{tabular}{|c|c}
65 \\
0 \\
\end{tabular} & \\
\hline Parion [gr. Kamares; heute Kemer TR] & & & & & & & & $\begin{array}{c}65 \\
0\end{array}$ & \\
\hline Sinope [Sinop TR] & & & & & & & & $\begin{array}{c}65 \\
0 \\
\end{array}$ & \\
\hline
\end{tabular}




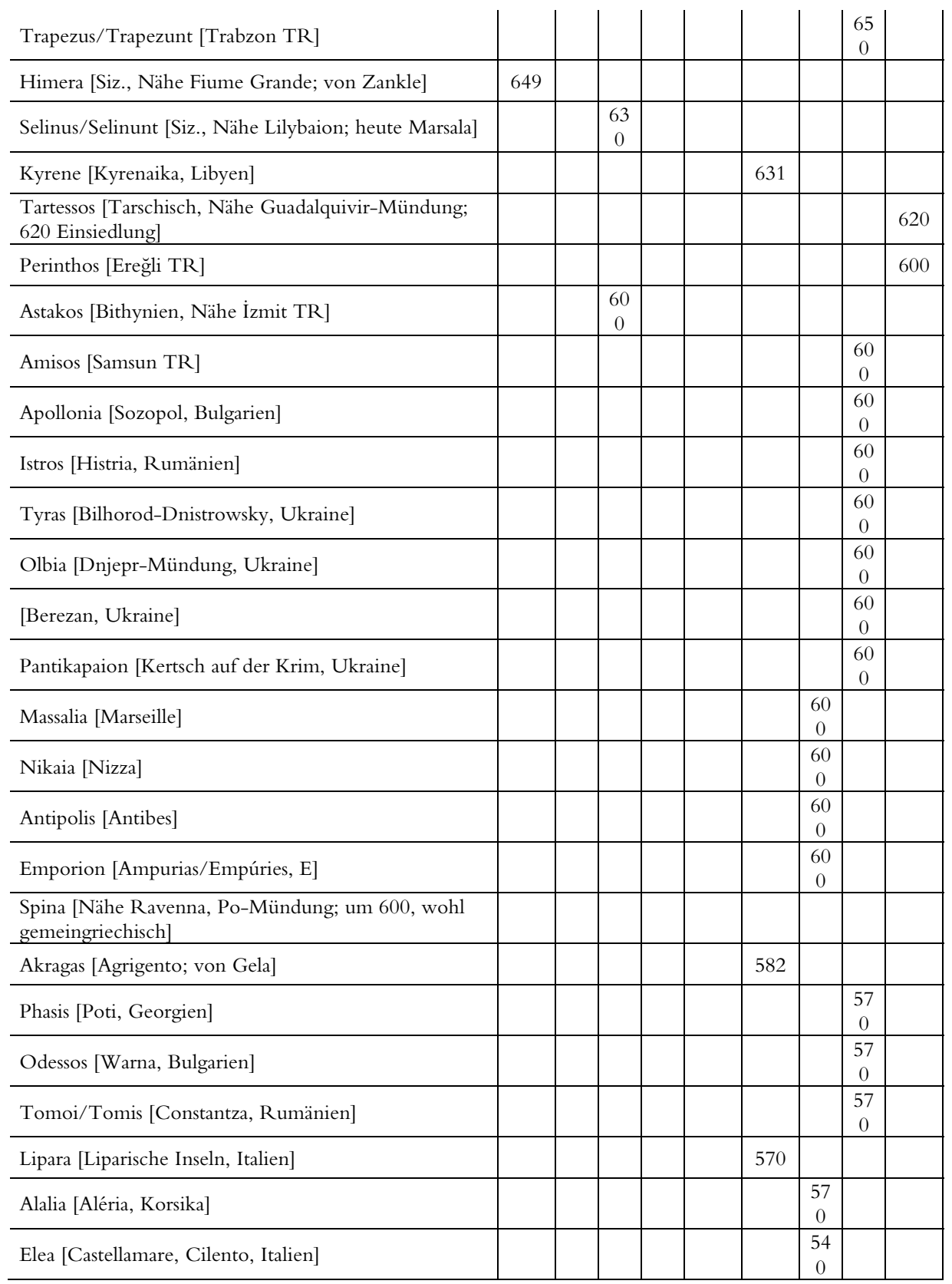

Abb. 3: Kolonien (Graphik: Joachim Latacz, Basel) 
Hier, in Ostionien, hatte um 600 in einem begrenzten Gebiet von etwa 150 km Nord-Süd-Ausdehnung (Phokaia bis Milet) jene Denkbewegung begonnen, die wir als 'Ionische Wende' bezeichnen können, nämlich: das systematische Faktensammeln und das auf dem gesammelten Faktenmaterial aufbauende logische Schlußfolgerungsdenken, in dem wir den Beginn der europäischen Wissenschaft und Philosophie erkennen. Es beginnt in der damals bedeutenden Hafenstadt Milet, einem uralten Wirtschafts- und Handelszentrum, das offensichtlich schon die minoischen Kreter im 2. Jahrtausend v. Chr. als 'Milatos' begründet hatten und das den allmählich zur kleinasiatischen Großmacht gewordenen Hethitern, die Milet in ihrer eigenen Sprache als 'Millawanda' kannten, über Jahrhunderte hinweg allerhand Probleme bereitete. Ende des 7./ Anfang des 6. Jh. wurde eben dieses Milet - damals seit rund 400 Jahren nicht mehr kretisch-minoisch, sondern griechisch - zum Sammelpunkt für all die vielen Auswanderungswilligen, die ionischen Geist in einer gewaltigen Kolonisationsbewegung in die Dardanellenregion und an die Küsten des Schwarzen Meeres exportierten: In nicht einmal 100 Jahren (ca. 650-570) gründeten die Ioner von Milet aus dort etwa 80 bis 90 neue griechische Städte - von denen viele unter kaum veränderten Namen in den Schwarzmeerländern Türkei, Rumänien, Bulgarien, Ukraine und Georgien heute noch fortleben.

Die ungeheure Informationsmenge, die durch die Kommunikation mit diesen vielen neuen Kolonialstädten nach Milet zurückfloß, zwang in Milet zur Ordnung und Kategorisierung, zum Rechnen und Messen, Planen und Entwerfen. Damit zog eine neue, präzisere, systematischere Art von Rationalisierung als zuvor in das Leben ein. Die alten Glaubenssätze gerieten ins Wanken: der alte Glaube an die Vorbestimmtheit des Lebens etwa, der ganze Götterglaube überhaupt, die zuvor selten befragte Hinnahme dessen, was ist, und vieles andere Traditionelle wurde nun fragwürdig, und statt dessen setzte folgerichtig nun das neue Fragen ein: 'Wo - wer - wie - warum? Wie ist die Welt beschaffen, wie der Mensch, wie kamen Welt und Mensch zustande?'und was der Fragen mehr waren. Alles wird bezweifelt, untersucht, diskutiert, neu definiert, kurzum: Es setzt das ein, was wir Forschung nennen - und damit auch das, was uns von damals bis zum heutigen Tag geblieben ist: der charakteristisch europäische Fortschrittsglaube. ${ }^{4}$

Diese ganze Bewegung beginnt mit Thales von Milet, Anaximander von Milet, Anaximenes von Milet, und sie breitet sich über die gesamte relativ kleinräumige ostionische Region aus. Es entsteht ein dichter, pulsierender Kulturraum, heute würde man wohl sagen: ein Denk-Cluster, in dem auch die kleineren Städte des Gebiets, neben Milet, ihren Beitrag zum neuen Denken leisten.

4 Ausführliche Darstellung: J. Latacz, Die griechische Literatur in Text und Darstellung. Band 1: Archaische Periode, Stuttgart : Reclam ${ }^{2} 1998,512-518$; dort auch die wichtigsten Fragmente der Schriften von Xenophanes und Heraklit in Griechisch und Deutsch, 542-583. 
Einer der ersten Denker dieser Gegend nun, von dem wir ein gesichertes Zeugnis über Homer haben, ist der Spötterphilosoph Xenophanes von Kolophôn (etwa 565-470). Im Zentrum seines Reflektierens steht der alte Götterglaube. Er wettert in vielen Werken, aus denen wir noch Fragmente besitzen, gegen die Generationen vor ihm, die noch glaubten, die Götter seien nur überdimensional vergrößerte Menschen. Was für ein Unsinn', sagt er, 'dann müßten sich ja Pferde ihre Götter wie Pferde vorstellen, und die Rinder ihre Götter als Rindvieh! Was hat denn dieser Anthropomorphismus für groteske Folgen?!', fragt er! 'Sehen wir uns das doch einmal an Beispielen an, die jeder kennt!', so fordert er. - Was für Beispiele sind das?

Xenophanes v. Kolophon, Fr. 11 DK

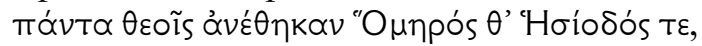

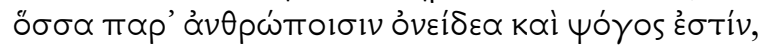

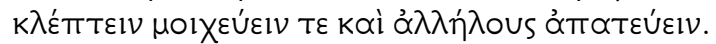

Alles das schrieben den Göttern Homeros und Hesiodos zu, was bei den Menschen zu Schande und Tadel nur gut ist:

stehlen und Ehebruch treiben und einer den andern betrügen!

Was lernen wir hier für Homer? Nun - wenn man zu dieser Zeit für oder gegen eine Sache argumentieren will, zieht man zuallererst Homer heran. Warum? Weil man davon ausgehen kann, daß diesen Dichter jeder kennt.

Das bestätigt sich in einem anderen Fragment desselben Xenophanes, aus einem Werk, das den Titel 'Sílloi' trug, 'Schieler'; gemeint ist damit etwas wie 'Spöttereien' oder auch 'Satirisches':

Xenophanes v. Kolophon, Fr. 10 DK

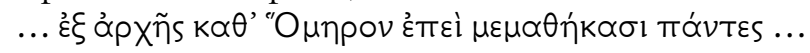

... haben von Anfang an nach dem Homeros gelernt doch sie alle ...

Dieser Hexameter ist ohne Kontext überliefert. Darum hat man viel gerätselt, wie es im Text wohl weitergegangen sein könnte, d.h. was denn genau nach Meinung des Spötters Xenophanes "alle nach Homer" gelernt haben. Am wahrscheinlichsten ist die Vermutung: Gelernt hatten sie, daß die Götter im Prinzip so seien wie sie selbst - ebenso wie im vorigen Fragment -, wogegen Xenophanes aber nun entschieden Einspruch erhebt, da Gott für ihn das ganz Andere und ein Eines ist. Doch das ist heute nicht unser Thema. Was wir hier lernen, ist etwas anderes: Daß in der 2. Hälfte des 6. Jh. v. Chr. ein bedeutender griechischer Denker ganz selbstverständlich davon ausgeht, alle, ausnahmslos alle, hätten zu ihrem Lehrer Homer gehabt - und darum könne, ja müsse man sich auf ihn berufen, ob nun in Zustimmung oder Ablehnung. Das hätte damals niemand sagen können, wenn es nicht den anerkannten Tatsachen entsprochen hätte. Was aber bedeutet hier dieses 'alle' genau? Offensichtlich nicht weniger, als daß jeder, der in Ostionien seit mindestens zwei bis drei 
Generationen zur geistigen Elite gehörte oder gehören wollte, durch die Schule Homers gegangen war!

Wir wissen nicht, in welchem Jahr genau Xenophanes diese beiden zitierten Aussprüche getan hat. Aber wir dürfen aus der Art der Berufung mit Sicherheit entnehmen, daß er und seine Leser in der Überzeugung lebten, Homer sei schon seit vielen Jahrzehnten - in unserer heutigen Rechnung: seit mindestens 600 oder gar 650 v. Chr. - die Grundlage der allgemeinen Geistesbildung gewesen: Schulstoff gewissermaßen, verbindende Denkgrundlage für alle Denker damals, eine unbestrittene Autorität mithin.

Das gleiche entnehmen wir einem Fragment des wenig später lebenden berühmten Philosophen Heraklit. Heraklit stammte ebenfalls aus diesem groBen ostionischen 'Brain Trust', aus Ephesos, einem anderen uralten Zentrum dieser Gegend, das die Hethiter als Apasas gekannt hatten.

Heraklit v. Ephesos, Fr. 56 DK

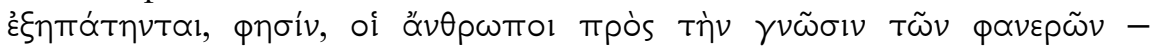

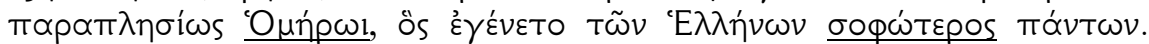

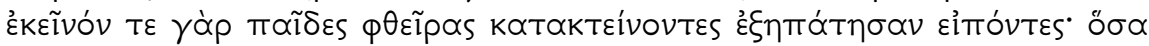

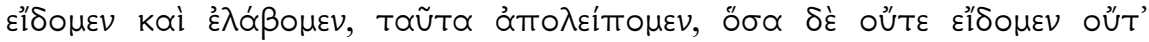

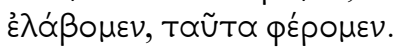

Vollständiger Täuschung unterliegen, sagt er, die Menschen beim Erkennen des vor Augen Liegenden - so wie Homer, der klüger war als alle Griechen miteinander: haben den doch läuseknickende [Fischer-]Knaben getäuscht, die sagten: "Was wir erspähten und fingen, das lassen wir hier, und was wir nicht erspähten und nicht fingen, das nehmen wir mit."

Heraklit ist unter den ionischen Philosophen der große Verwerfer. Alle Denker vor ihm finden bei ihm keine Gnade. Sie alle lebten im Irrtum. Die Wahrheit hat nur einer: er, Heraklit! (dieser Verwerfungsgestus, gepaart mit missionarischem Alleinseligmachungsanspruch, ist der europäischen Philosophie als gutgehütetes Erbe bekanntlich bis heute erhalten geblieben). Will man aber der Allerklügste sein, dann muß man denjenigen übertreffen, der bisher als Klügster galt: das wissen alle unsere Doktoranden und Habilitanden bis heute sehr genau. Wen glaubt nun Heraklit übertreffen zu müssen? Wer ist für ihn der Klügste? — Wiederum lautet die Antwort: Homer! - Man bedenke: Vor Heraklit hatten schon Thales und seine Schüler gesammelt, geforscht, kluge Theorien aufgestellt ... Die verwirft Heraklit natürlich ebenfalls. Aber der Allerklügste ist für ihn, aller dieser Denker ungeachtet, immer noch Homer. Für ihn, Heraklit, den Meisterdenker, ist diese Tatsache natürlich störend. Wie kann man sich dieses allseits anerkannten Hindernisses für den eigenen Geistesruhm am besten entledigen?

Heraklit v. Ephesos, Fr. 42 DK

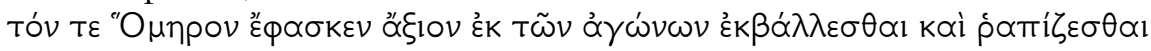

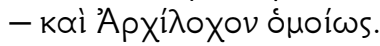


... und Homer, so äußerte er sich, sei wert, aus den Wettkämpfen verbannt und durchgeprügelt $\mathrm{zu}$ werden - und Archilochos genauso.

Eine klare Lösung! - Auf Archilochos gehen wir jetzt hier nicht ein. Wichtig für uns ist wieder nur: Heraklit hielt diesen Hómeros in gleicher Weise für 'die' Autorität wie Xenophanes. Und noch etwas lernen wir aus dem Fragment: In Agonen wurde Homer damals vorgetragen. Das bedeutet: in Rezitationswettbewerben. Um 500 v. Chr. war Homer also schon ein Klassiker.

Das bringt uns zu einer anderen Überlieferung aus der gleichen zweiten Hälfte des 6. Jh., über die wir hier reden. Diesmal aber stammt das Zeugnis nicht aus Ostionien, sondern aus dem griechischen Mutterland, und zwar aus Athen, das nicht nur ebenfalls ionisch, sondern sogar ur-ionisch war. Von dort ist überliefert, daß der Tyrannos ${ }^{5}$ Hípparchos, ein Sohn des berühmten Tyrannos Peisístratos, im Jahre 522 im Zuge der Neugestaltung des attischen Festwesens eine folgenreiche Neuerung einführte: Er ließ an den Großen Panathenäen, dem Hauptfest Athens für die Stadtgöttin Athenâ, das alle 4 Jahre stattfand, beide Homerischen Epen, Ilias ebenso wie Odyssee, durch einander ablösende Berufsrezitatoren, die Rhapsoden, in voller Länge als ein besonderes Kultur-Ereignis vortragen. Die beiden Epen waren also im Jahre 522 auch in Athen schon so berühmt, daß man eine solche Dauervorführung wagen konnte.

Nun wurde Athen bekanntlich im 5. Jh. zur Nachfolgerin Milets, d.h. zum Zentrum griechischer Dichtung, Wissenschaft, Philosophie und Kultur überhaupt. Die Wirkung dieser Neuerung des Hipparchos auf die allgemeine Bildung in ganz Griechenland war demgemäß enorm. Homer wurde buchstäblich zum obligatorischen Schulbuch. Kein griechischer Intellektueller, wo auch immer er in griechischen Landen zu Hause war, wuchs spätestens von jetzt an ohne Homer auf. Und so werden wir uns nicht darüber wundern, daß die Begründung z.B. auch des europäischen Theaters, die zur etwa gleichen Zeit in Athen stattfand, ebenfalls auf dem Nährboden Homers erfolgte. Allbekannt ist ja der kolportierte Ausspruch des ersten großen griechischen Tragödiendichters Aischylos, seine Stücke seien 'nur Scheibchen von den großen Mählern Homers'. ${ }^{6}$ Von Sophokles und Euripides sind Konfessionen dieser Art zwar nicht bekannt, aber wie stark auch ihre Stücke von Homer beeinflußt sind, ließe sich leicht zeigen. Klar würde dabei noch etwas andres werden, nämlich daß die Homer-Kenntnis zumindest dieser Intellektuellen damals beileibe nicht oberflächlich war, daß sie ganz im Gegenteil auch noch die kleinsten Einzelheiten in den beiden Werken umfaßte, daß also, kurz gesagt, schon damals, im 5. Jh. v. Chr., Homer nicht, wie manche Forscher zuweilen meinen, immer

5 Die übliche Wiedergabe des griechischen (Lehn-)Wortes тúpavvos, etwa 'Alleinherrscher', durch 'Tyrann' wird hier grundsätzlich vermieden, da sie falsche Assoziationen weckt.

6 Überliefert bei Athenaios (2. Jh. n. Chr.) in seinen 'Deipnosophistai' (etwa 'Die Gelehrten beim Bankett') 8. 347e. 
noch nur gehört, sondern daß Homer damals schon ausgiebig auch gelesen wurde, ganz gelesen wurde - daß also Ilias und Odyssee damals, wie wir heute sagen würden, bereits Dauer-Bestseller auf dem Buchmarkt waren.

Aber nicht nur die Dichtung, auch die Prosa des 5. Jahrhunderts steht auf dem Boden genauer Homer-Kenntnis. Man muß die großen Geschichtsschreiber des 5. Jh., Herodot und Thukydides - der eine beschreibt die Perserkriege, der andere analysiert den 30jährigen Krieg der Antike, den Peloponnesischen Krieg -, man muß sie nur auf dem Hintergrund eigener guter Homervertrautheit lesen, um die Einflüsse in inhaltlichen Anspielungen, erzähltechnischen Elementen, strukturellen Anleihen usw. im einzelnen zu erkennen.

Und wie es mit der Philosophie Athens steht, jener griechischen Welterklärungsbemühung, auf der unsere gesamte europäische Denktradition bis heute beruht, kann wegen der fast unübersehbaren Fülle der Homer-Bezüge in den Werken der führenden Denker dieser Zeit hier nur ganz kurz angedeutet werden. Bei Platon (427-347) ist Homer allgegenwärtig, als tief bewunderter Künstler einerseits, als systembedingt unter Qualen bekämpfter Seelenverführer andererseits -, und für Aristoteles (384-322) überragt Homer in jeglicher Hinsicht alle anderen Dichter, überragt sie so sehr, daß er nur 'göttlich' genannt werden kann. Zwei Sätze aus Aristoteles' Vorlesung über Dichtung, aus der 'Poetik' also, müssen hier reichen, um seine aus tiefgründiger vergleichender Analyse einer immensen Zahl von Dichtungen erwachsene unbeschränkte Hochschätzung für diesen Meister der Dichtkunst zu belegen:

Aristoteles, Poetik 1459 a30-37

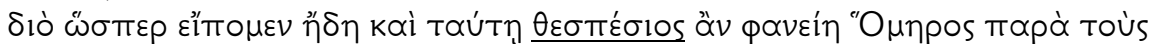

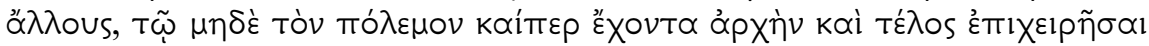

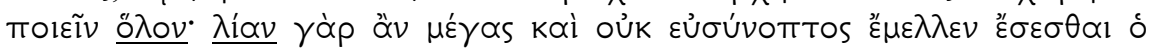

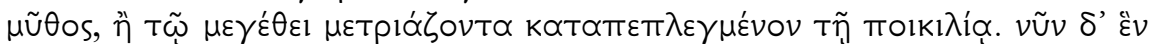

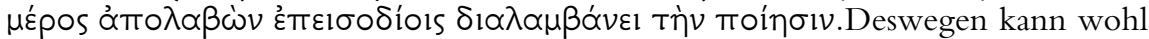
[...] Homer auch in derjenigen Hinsicht als gottbegnadet erscheinen [...], daß er den Troianischen Krieg [...] nicht in seiner Gänze zu dichten unternommen hat; die Fabel hätte dann nämlich allzu groß und nicht leicht überschaubar zu werden gedroht - oder, falls sie in der Ausdehnung Maß gehalten hätte, aufgrund der Buntheit [der Ereignisse] allzu verwickelt. So aber hat er einen einzigen Teil davon [nämlich den 'Groll des Achilleus'] beiseite genommen und die Dichtung mittels Einzelszenen gliedernd entfaltet.

Homer ist also für Aristoteles unerreichtes Vorbild aller Dichter - nicht nur der Epen-, sondern durchaus auch der Tragödiendichter - denn: 
Aristoteles, Poetik 1451a22-30

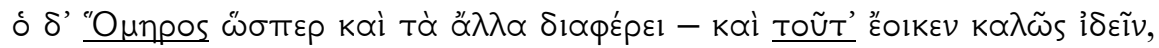

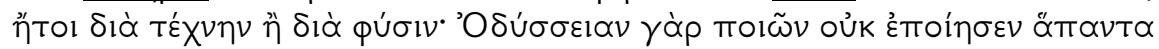

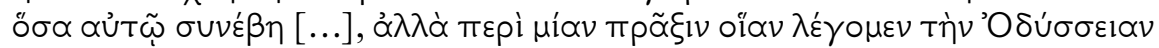

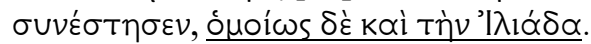

Homer aber - wie er denn auch in allem anderen herausragt - hat offensichtlich auch das erkannt (sei es aus technischer Kompetenz, sei es durch natürliche Intuition): Als er die Odyssee dichtete, hat er nicht alles dargestellt, was dem Odysseus [in seinem Leben] passierte [...], sondern er hat die Odyssee um nur eine einzige Handlung herum [...] komponiert, und ebenso auch die Ilias.

Damit hatte Aristoteles nicht nur die architektonische Einheit und damit den Sinn von Ilias und Odyssee wesentlich besser erkannt als Generationen moderner Homer-Philologen seit Friedrich August Wolf 1795 nach ihm, sondern damit hatte er auch die Grundvoraussetzung aller epischen und dramatischen Dichtung, die spannungsvoll und mitreißend sein will, benannt - die Einheit einer schrittweise sich steigernden Handlung. - Vor diesem Hintergrund analytisch erkannter Vorzüglichkeit der Homerischen Dichtung ist es nur selbstverständlich, daß Aristoteles als jahrelanger Hauslehrer Alexanders des Großen alles daransetzte, mit dem künftigen König immer wieder Homer zu lesen und zu interpretieren. Wenn Alexander sich später als neuen Achilleus sah und wenn seine Nachfolger im von ihm eroberten Ägypten, in der nach ihm benannten Stadt Alexandria, das dritte große Geisteszentrum der griechischen Antike, nach Milet und Athen, begründeten, das Museion, Sitz einer Bibliothek mit einem Endbestand von über 700.000 Rollen und Dichterwerkstatt für die neue experimentelle Dichtung der sogenannten 'Alexandriner' (wie etwa Kallimachos), Dichter, die ihre 'poésie nouvelle' aus dem bewußten Gegensatz zu Homer entwickelten - dann sind alle diese für Europas kulturgeschichtliche Entwicklung so wirkungsreichen Vorgänge letztlich die Konsequenzen der alles überstrahlenden Wertschätzung Homers in Athens großer Zeit des 5. und 4. Jh. v. Chr. Diese aber hatte ihre Wurzeln - das haben wir gesehen - in der zweiten Hälfte des 6. Jh. v. Chr. in Ionien an der westkleinasiatischen Küste - in Ionien, das bis 1922 griechisch war und heute zur Türkei gehört. 


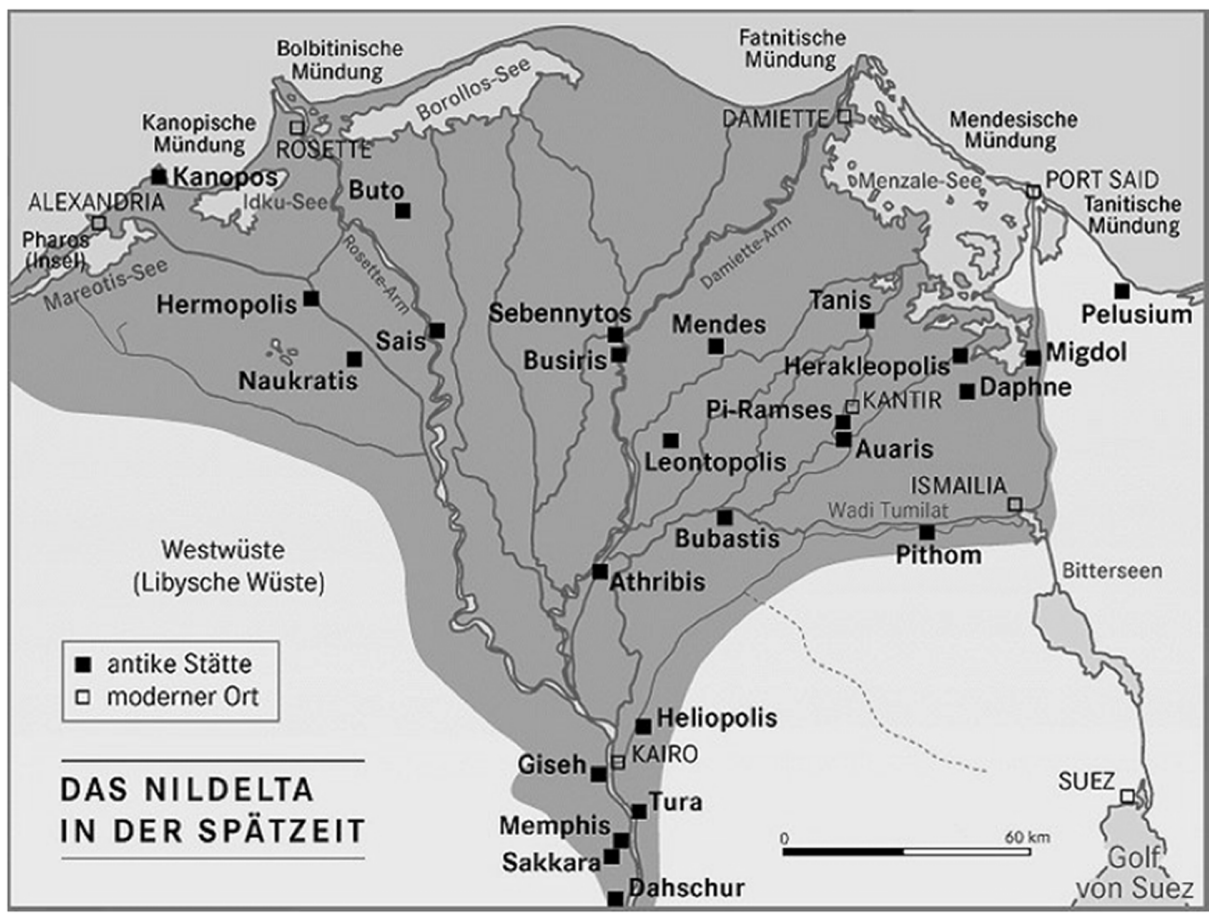

Abb. 4: Alexandreia im Nildelta (oben links)

Dies also war der erste Höhepunkt dessen, was man die 'Homerbestimmtheit' unserer westlichen Kultur genannt hat. ${ }^{7}$ Höhepunkt deshalb, weil es diese Zeit war, in der Homer das Denken der gesamten griechischen Geistes-Elite durchdrang und auf diese Weise die Grundlinien einer Denkstruktur formte und bestimmte, die in ihren tragenden Elementen trotz aller periodischen Ausbruchsversuche bis heute letztlich gleichgeblieben ist.

\section{II}

Wir kommen zum zweiten großen Höhepunkt der europäischen HomerBeeinflussung. Dieser hat sich in Rom ereignet. Das ist uns allen so geläufig, daß wir es für selbstverständlich halten. Das war es aber ganz und gar nicht. Rom hatte in den ersten Jahrhunderten seiner Existenz durchaus gewisse Anläufe zu einer eigenen Literatur gemacht. Mit dem Griechentum war Rom

7 So Walter Wimmel, Die Kultur holt uns ein. Die Bedeutung der Textualität für das geschichtliche Werden, Würzburg 1981, 23. Näheres dazu: J. Latacz, Homer. Der erste Dichter des Abendlands, Düsseldorf/Zürich : Artemis ${ }^{4} 2003,26-29$ ('Homer Begründer der abendländischen Textualität'). 
zwar bereits seit dem 7. Jh. über Unteritalien und Sizilien, das ja seit dem 7. Jh. griechisch besiedelt war, in vielfältige Berührung gekommen, hatte von dort auch das griechische Alphabet übernommen, wie es in der latinisierten Form auch wir noch benutzen, weitergehenden kulturellen Einflüssen durch Griechenland hätte es sich aber durchaus verschließen können - so wie es ja der Orient, die Levante oder Ägypten taten. Doch Rom reagierte anders. Es sah sofort, daß das Selbstentwickelte gegen das Griechische unendlich abfiel. In der Standard-Geschichte der römischen Literatur von Schanz-Hosius vom Jahre 1959 ist das so formuliert:

„In vier bis fünf Jahrhunderten einer stark hinausstrebenden Politik war Rom noch nicht dazu gekommen, sich im Reich des Schönen zu betätigen. “8

Rund 100 Jahre zuvor hatte sich Theodor Mommsen noch etwas drastischer ausgedrückt:

„Latium steht in der Dürftigkeit seiner künstlerischen Entwicklung fast auf der Stufe der culturlosen Völker."

In unserer Zeit drückt man sich gefälliger aus, aber auch die ausgesuchte Höflichkeit des bekannten Latinisten Manfred Fuhrmann in seiner 'Geschichte der römischen Literatur' von 1999 kann am Tatbestand nichts ändern:

„Quintilian vermerkt mit Stolz, die Satire sei eine Schöpfung der Römer; diese Feststellung setzt zutreffend voraus, daß alle übrigen Gattungen griechischer Import waren". ${ }^{10}$

Kulturelle Dürftigkeit also ... Aus ihr machte Rom jedoch das Beste, was es machen konnte: Es lernte. Zunächst übernahm man seit dem 3. Jh. v. Chr. von den Griechen das griechische Schulsystem, in seiner Dreistufung 'Elementarschule - Grammatiker-Unterweisung (d.h. Literaturkunde) - RhetorikUnterricht', und zwar übernahm man es im Verhältnis 1 : 1. Indes - ein Element fügte man hinzu, ein Element, das entscheidend für die europäische Kulturentwicklung werden sollte: Man ließ die fortgeschrittenen Knaben (etwa von 12 Jahren an) Literatur gleich zweisprachig lernen, griechisch und lateinisch. ${ }^{11}$ Die Folge war, daß der gebildete Römer von Jugend auf in der grie-

8 M. Schanz/C. Hosius, Geschichte der römischen Literatur bis zum Gesetzgebungswerk des Kaisers Justinian. Erster Teil: Die römische Literatur in der Zeit der Republik, in: Handbuch der Altertumswissenschaft, hrsg. v. W. Otto, Achte Abteilung. Erster Teil, München : Beck ${ }^{4} 1959,42$.

9 Th. Mommsen, Römische Geschichte, Erster Band: Bis zur Schlacht von Pydna, Berlin ${ }^{2} 1856,28$.

10 M. Fuhrmann, Geschichte der römischen Literatur, Stuttgart : Reclam 1999, 38 (Quintilian, Institutio oratoria 10.1.93).

11 J. Christes, Artikel 'Schule. III: Rom', in: Der Neue Pauly; F. Kühnert, Artikel 'Schulwesen', in: J. Irmscher/R. Johne (Hrsg.), Lexikon der Antike, Leipzig : Bibliographisches Institut ${ }^{9}$ 1987, 529-531. - Grundlegend: H. I. Marrou, Geschichte der Er- 
chischen Literatur einigermaßen zu Hause war - und daß er dadurch in ständigem Vergleichen die Entwicklung der eigenen, lateinischen Literatur qualitativ kontrollieren und befördern konnte.

Diesem Ziel diente bereits der erste Schritt: Im Jahre 240 v. Chr. ließ die Festverwaltung der ludi Romani, der 'Römischen Spiele', einen Kriegsgefangenen aus Tarent, Andrónikos - lateinisch Andronīcus -, der im römischen Patriziergeschlecht der Livii als Hauslehrer diente, sowohl eine Tragödie als auch eine Komödie in lateinischer Sprache aufführen - Stücke, die er nach griechischen Vorbildern gedichtet hatte. Die Titel dieser beiden Stücke kennen wir zwar nicht, wir wissen aber, daß Livius Andronicus später noch zahlreiche weitere Stücke aufführte, und darunter sind dann Titel wie 'Achilles', 'Equos Troianus' und 'Aiax'. Was da als allererstes Literaturgut nach Rom kam, war also wiederum - Homer! Und demselben produktiven Griechen verdankten die römischen Schüler ein paar Jahre später, gegen 200 v. Chr., auch ihr erstes Epos-Schulbuch auf lateinisch: die 'Odusia' oder 'Odyssia', eine OdysseeÜbersetzung im urrömischen Versmaß des Saturniers:

L. Livius Andronicus, Odyssia/Odusia, Vers 1:

Virum mihi, Camena, insece versutum ...

Das nahm sich zwar, wie Cicero später im 'Brutus' gespottet hat, wie eine Statue des Daedalus aus, ${ }^{12}$ also wie etwas archaisch Primitives, gegenüber dem perlenden griechischen

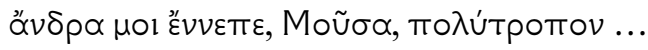

aber es war eben erneut Homer und niemand anders! Damit waren aber die zwei wichtigsten griechischen Literaturgattungen nach Rom verpflanzt: Epos und Tragödie. Sie entwickelten sich prächtig, und im 1. Jh. vor sowie im 1. Jh. nach Chr. erreichten sie beide ihren Höhepunkt: Das Epos in Vergils 'Aeneis' - die Tragödie in Senecas Dramen. Beide Dichter wandelten auf Homers Spuren: In der Aeneis fügte Vergil die 48 Gesänge der Homerischen Ilias und Odyssee zu jenen 12 Büchern zusammen, die nicht nur für alle künftige lateinische Epik zum Muster wurden, sondern die auch Homer endgültig romanisierten - die ferner die Römer zu den legitimen Erben des Homerischen Helden Aineias aus der troianischen Königssippe machten und damit Rom seine ersehnte nationale Identität verschafften (eine Identität, die also auf Homer basierte) - und die damit, schließlich, die griechische Literatur und ihren Gründervater Homer für alle Zeit, bis heute, in Europas geistigem Haushalt fest verankerten. Und Seneca hat etwas später mit mindestens zweien seiner neun Tragödien, dem 'Agamemnon' und den 'Troádes', sekundiert.

ziehung im klassischen Altertum, [Freiburg : Alber 1957] München : Deutscher Taschenbuch Verlag 1977 u.ö. (dtv. - Wissenschaftliche Reihe, 4275).

12 Cicero, Brutus 18, 71. 
Wie sich Homers Einfluß in diesen und weiteren Gattungen der gewaltig anwachsenden lateinischen Literatur ausbreitete, etwa in der römischen LiebesElegie oder später in der allegorischen Inbesitznahme Homers durch die christliche Kirche, das können wir in unserem Rahmen hier nicht weiterverfolgen. Im wissenschaftlichen Begleitband zur großen Homer-Ausstellung 2008/2009 in Basel und Mannheim ist das ausführlich dargestellt. ${ }^{13}$ Hier möchte ich nur das Fazit ziehen, das da lautet: In Rom erhielt Homer mit einer neuen Funktionalisierung, nämlich seiner Aneignung durch ein fremdes, nichtgriechisches Volk, das dann für mehr als das nächste halbe Jahrtausend zu Europas Führungsmacht werden sollte, sozusagen seinen gesamteuropäischen Ritterschlag. Von da an war er als der pater vatum, der 'Dichtervater', aus Westeuropas Geisteskultur, die ja bis weit ins 16 . Jh. hinein eine lateinische blieb, nicht mehr wegzudenken.

In den folgenden Jahrhunderten des kulturellen Niedergangs sowohl in Westrom wie in Ostrom (also in Byzanz/Konstantinopel) sind Höhepunkte der direkten Einflußnahme Homers zunächst allerdings nicht zu verzeichnen. In Byzanz entwickelt sich die griechische Sprache auf das Neugriechische hin, und die Kenntnis des Altgriechischen nimmt dort immer mehr ab, und im Westen hört sie so gut wie ganz auf. Homer wird in beiden Reichsteilen allmählich zu einem großen Schatten. Man weiß zwar noch, daß er der größte Dichter war, ja, sein Name wird geradezu zum Synonym für große Dichtung, man liest ihn auch noch in der Schule, zumindest in Byzanz - 30 Verse pro Tag, hören wir (heutigen Griechischlehrern dürften da die Augen übergehen!) -, aber das lebendige Verständnis, unterhalb der sprachlichen Oberfläche, wird auch hier in Byzanz schwächer und schwächer, und die kreative Rezeption mit neuen Nutzungsformen, die ja zu allen Zeiten auf gründlichste Textkenntnis angewiesen ist, hört hier allmählich auf. ${ }^{14}-\mathrm{Im}$ Westen geht es mit Homer zur gleichen Zeit zunächst noch viel reißender bergab: Hier, wo die geistige Elite auch nach dem Reichszusammenbruch nur auf lateinisch kommuniziert, entwickeln sich auf der Grundlage spätrömischer lateinischer Zusammenfassungen von Ilias, Odyssee und stofflich verwandten Erzählungen mangels Kenntnis der griechischen Originale die absonderlichsten Vorstellungen vom Inhalt der Homerischen Epen. Im 13. und 14. Jh. blüht eine unübersehbare Homeroder besser Troia-Literatur auf, in Versen und Romanen, sowohl lateinisch als auch allmählich schon in den Nationalsprachen, eine Literatur, die die originalen Werke nicht mehr kennt und die auf der Grundlage unsäglicher lateinischer Verhunzungen Homers aus den Homerischen Helden, deren Namen sogar oft nur noch in Verballhornung bekannt sind, mittelalterliche Ritter macht und die ganze mittelalterliche christlich-naive Wunderwelt an die Stelle

13 H. Harich-Schwarzbauer, Homer in der römischen Literatur, in: J. Latacz/Th. Greub/P. Blome/A. Wieczorek (Hrsg.), Homer. Der Mythos von Troia in Dichtung und Kunst, München : Hirmer Verlag 2008, 245-250.

14 C. Cupane, Die Homer-Rezeption in Byzanz, in: Homer (wie Anm. 13), 251-258. 
des Homerischen Originalgeschehens setzt. Ein klares historisches Bewußtsein ist ja nicht vorhanden, und so verschmelzen die Jahrhunderte zu einem einzigen großen zeitlosen Weltgemälde eigenen Rechts, das mit Homer nur noch ganz entfernt und in den alleräußerlichsten Fakten etwas zu tun hat. ${ }^{15}$

Ein Beispiel für diese mittelalterliche Verdrehungsliteratur muß hier genügen: Etwa im J. 1160 erscheint der nachmals einflußreichste Troia-Roman von Benoît de Sainte-Maure (auch: Sainte-More), in rund 30.000 altfranzösischen gereimten Achtsilblern. In ihm erscheint Achilleus, Homers Lieblingsheld, als Barbar, der die schöne Unschuld der Troianer, von denen sich der mittelalterliche Adel über Rom herleitete, unbeherrscht, unchristlich-sündhaft und verwerflich stört. Der im 22. Gesang der Ilias mit tiefster Menschlichkeit geschilderte Entscheidungszweikampf zwischen Hektor und Achilleus wird hier in völliger Verdrehung der Intention Homers zum Triumph des moralisch hoch überlegenen troianischen Hektor umgedeutet. Hektor redet Achilleus vor dem Zweikampf so an:

Benoît de Sainte-Maure, Roman de Troie, Verse 13178-13188 (Übers. J. Latacz):

Wenn du den Fehdehandschuh aufnimmst -

den großen Zorn, den du im Herzen hast,

kannst du dann rächen - und der Übel Last,

die, wie du sagst, ich dir so oft getan!

und auch den Schmerz um deinen liebsten Mann,

den ich dir nahm mit meinem Todesstreich -

und den du so oft fühltest weich

in deinen Armen, nackt an nackt,

und andre Spiele, lasterhaft und schambepackt,

die größtenteils sind tiefverhaßt

den Göttern, deren Strafe dich dafür erfaßt.

Achill der Lasterhafte also, dessen homosexuelle Verbindung mit Patroklos (von der Homer selbst gar nichts weiß) hier als der höchste Trumpf des reinen Hektor ausgespielt wird! Derartige Verfälschungen finden sich in dieser ZerrbildLiteratur auf Schritt und Tritt. Sie mögen uns traurig und wütend machen indessen: Vorsicht! Auch sie sind Stationen auf dem Wege der HomerRezeption, Stationen, die Neugier und ungebrochenes Interesse an diesem alten Stoff erweisen und so Homer, den wirklichen Homer, auf ihre Weise immerhin ebenfalls am Leben halten.

Mit der durch Petrarca und Boccaccio veranlaßten ersten, wenn auch rohen lateinischen Übersetzung der Ilias durch Leonzio Pilato ${ }^{16}$ um 1360 setzt dann endlich wieder eine Annäherung an den Original-Homer ein. Die Übersetzung weckt bei den führenden Geistern der Zeit neue hohe Ahnungen. Der

15 F. Montanari, Die Rezeption der Homerischen Dichtung im lateinischen Mittelalter, in: Homer (wie Anm. 13), 259-264.

16 Die Handschrift befindet sich heute in der Bibliothèque Nationale de France, Signatur: BNF ms lat. 7880(1) und 7880(2). 
Wunsch, den Original-Homer kennenzulernen, wird nun stärker und stärker. Man beginnt, zuerst in Italien, von byzantinischen Gelehrten-Immigranten allmählich etwas Altgriechisch zu lernen. Allzuviel wird allerdings noch nicht daraus. Dann aber, mit dem Erstdruck der Werke, 1488 in Florenz, ist die Zeit des Nichtwissens und der Sehnsucht nach dem authentischen Dichtervater Homer endgültig zu Ende.

\section{III}

Das führt zum dritten Höhepunkt. Die Bekanntschaft mit dem OriginalHomer bringt ja nun nicht nur Beglückung. Sie bringt auch Irritationen. Man war ja an Vergil gewöhnt, an den polierten, eleganten Römer. Nun aber dieser griechische Homer! Mit seiner Einfachheit, seinen scheinbar primitiven rohen Sitten, seiner unverhüllten Direktheit in den Reden der Figuren, seinen vermeintlich geschmacklosen Vergleichen, etwa des Aias mit einem Esel! ${ }^{17}$ - mit alledem wirkt Homer auf die galanten Höflinge der Zeit, allen voran in Frankreich, wie ein Holzklotz. Es kommt zu einem großen Streit: 'Was ist dieser Homer eigentlich wert? Und wer ist der größere Dichter? Homer oder Vergil? Und mehr noch: Kann man diesen alten Dichter Homer heute wirklich noch als Vorbild sehen? Ist die Gegenwart, die Zeit des 17. Jh., mit ihren ach so viel höher entwickelten Lebens- und Umgangsformen, mit ihren Fortschritten in den Wissenschaften und in der Aufgeklärtheit, der Antike nicht haushoch überlegen? Was soll uns also dieser alte Dichter heut noch sagen?' Diese Diskussion erfaßt, ausgehend von Frankreich, die Gebildetenschichten halb Europas. Heute ist sie bekannt unter der Bezeichnung 'Querelle des Anciens et des Modernes'. Sie begann offiziell vor der Académie Française im Jahre 1687 und ist verbunden mit Namen wie dem des Hauptangreifers Charles Perrault ${ }^{18}$ (der gar kein Griechisch konnte) und an ihrem Ende mit dem Namen der Hauptverteidigerin $\mathrm{M}^{\mathrm{me}}$ Anne Dacier, die 1699 eine nicht ganz unmögliche ProsaÜbersetzung der Ilias herausbrachte. ${ }^{19}$ - Der britische Historiker Macaulay hat den ganzen Streit im 19. Jh. rückblickend "verächtlich" genannt. ${ }^{20}$ Das ist er auch - aber auch er, das muß hervorgehoben werden, ist kulturgeschichtlich gesehen ein Höhepunkt der europäischen Homer-Beeinflussung, sogar ein

17 Ilias 11.556-565.

18 Charles Perrault: Parallèle des anciens et des modernes en ce qui regarde les arts et les sciences (Faksimiledruck der vierbändigen Originalausgabe Paris 1688-1696), hrsg. von H. R. Jauß, München: Eidos 1964 (der Beginn, Perraults Genesungsgedicht für Louis XIV, auf S. 165).

19 L'Iliade / Homère, trad. par $\mathrm{M}^{\mathrm{me}}$ Dacier, Paris 1699; L'Odyssée, Paris 1716.

20 Thomas Babington Macaulay (1800-1859), zitiert bei G. Finsler, Homer in der Neuzeit von Dante bis Goethe. Italien-Frankreich-England-Deutschland, Leipzig/Berlin 1912, 183. 304. 
äußerst wichtiger, denn er ist der Stimulus für das, was sich aus ihm entwickelte: die endliche und wirkliche Wiederentdeckung des griechischen Homer, mit allen ihren Folgen, in der deutschen Klassik! Insofern - als Humusboden verdiente auch die Querelle eine gründlichere Behandlung. Aber die Querelle ist schlicht zu umfangreich und kompliziert und letztlich aus unsrer heutigen Sicht im Argumentationsniveau doch auch zu unbedeutend, um hier genauer erörtert zu werden. Wir lassen sie darum liegen und wenden uns dem vierten, in unserem heutigen Rahmen letzten, unvergleichlich nachhaltigeren Höhepunkt der Homer-Rezeption zu: der strahlend aufgehenden Sonne Homers in der deutschen Klassik.

\section{IV}

Von 'deutscher Klassik' sprechen wir im Sinne eines Gegensatzes. Es ist der Gegensatz zum vornehmlich in England und Frankreich im 18. Jh. sich ausbreitenden Klassizismus. Dieser war eher etwas Äußerliches, eine mehr formale Nachahmung, besonders in der Architektur, der Möblierung, der Außen- und Innendekoration, der Mode usw. In Deutschland fand zwar auch dieses ÄuBerliche seine Imitatoren, weit bis ins 19. Jh. hinein, aber zum dominierenden Zug der Zeit wurde doch eine Variante, die auf das Innere zielte - eine, die zwar auch die Form, aber durch diese hindurchdringend das Wesen der Antike und ganz besonders der griechischen Antike zu erfassen suchte. Das äußerte sich seit etwa 1750 in einem immer drängenderen, immer sehnsuchtsvolleren Eindringenwollen, das sich bis zum 'Fieber' steigerte - wie Schiller das Phänomen in einem Xenion von 1796 nannte $^{21}$-, bis zur Graecomanie, zum Wahn, ja bis zu einer Art Zwangsneurose. Es gab keinen deutschen Intellektuellen in der Zeit von etwa 1770 bis 1830, der sich nicht mit den Griechen und besonders eben mit Homer beschäftigte, aber eben nicht nur beschäftigte, sondern sich für ihn begeisterte, ihn verehrte, ja anbetete - so wie Goethe es in einem Kurzgedicht ausgedrückt hat:

Johann Wolfgang v. Goethe, Künstlers Morgenlied (1774): ${ }^{22}$

Ich trete vor den Altar hier

Und lese, wie sich's ziemt,

Andacht liturg'scher Lektion

Im heiligen Homer.

Im heiligen Homer! Homer-Verehrung wurde hier zur Religion! Das war der Gipfel dessen, was Eliza M. Butler erstaunt und einigermaßen befremdet 1935

21 Xenion 320. Die zwei Fieber:

Kaum hat das kalte Fieber der Gallomanie uns verlassen,

Bricht in der Gräkomanie gar noch ein hitziger aus.

22 In: Weimarer Ausgabe (Goethes Werke, Weimar 1887-1919) I 2, 178. 
in ihrem Buch 'The Tyranny of Greece over Germany' geschildert hat. ${ }^{23}$ Hier - genau hier - wurde der Grund gelegt für das ganz besonders enge, sensible und nervös-gereizte Verhältnis zu Homer in Deutschland, das sich noch heute in den für Ausländer so verwunderlich erregten öffentlichen Homer-Debatten zeigt, die sich von Zeit zu Zeit in den deutschen Medien abspielen - gerade in den letzten Jahren in Form des kuriosen Schrott-Booms ${ }^{24}$ wieder abspielten -, in einer Zeit, die doch wahrlich in den Augen der Welt existentiellere Probleme zu lösen hatte als die Frage, wo Homer geboren wurde.

Lassen wir zunächst nur einmal die Namen derer an uns vorbeiziehen, die damals in der deutschen Klassik um Homer und mit Homer lebten und rangen: Winckelmann, Herder, Wieland, Lessing, Klopstock, Hölderlin, Voß, Goethe, Schiller, die Gebrüder Schlegel, Wilhelm von Humboldt, Schelling, Kleist ... - wir könnten noch viele andere hinzufügen. Besonders merkwürdig erscheint dabei auf den ersten Blick der Umstand, daß meines Wissens keiner von ihnen jemals den Boden Griechenlands physisch betreten hat. Aber gerade darin liegt ja eben der Kern dieser ungeheuren Faszination, nämlich in diesem 'das Land der Griechen mit der Seele suchen', wie Goethe seine Iphigenie im fremden, barbarischen Land der Taurer, auf der Krim also, klagen läßt $\mathrm{t}^{25}$. Ja mit der Seele eben wird gesucht, nicht mit dem Wanderstab! Denn es ist - das wissen die Suchenden selbst - es ist ein Traumland, in das man sich verliebt hat, ein Land der liebenden Humanität, der Menschheitsharmonie, und aus diesem Traum möchte man nicht herausgerissen werden durch eine vielfach, auch politisch, ernüchternde Realität. Die Liebe zu Homer als der Inkarnation eines ideal gesehenen vergangenen Menschheitszeitalters der harmonischen Verbundenheit mit dem Natürlichen, Einfachen, Schönen und Wahren weht uns aus allen Äußerungen der großen Geister jener Zeit an, und durch sie verwandelt sich die Sprache der Verliebten selbst in eine tief anrührende Einfachheit, etwa bei Hölderlin (für den nach der Sitte der Zeit, antikem Vorbild folgend, Homer der Mäonide war, der Dichter also aus Maionien, einer Landschaft Lydiens um [Sardes]/Smyrna, Homers vermuteten Geburtsort also):

23 Eliza M. Butler, The Tyranny of Greece over Germany, London : Cambridge UP 1935.

24 Siehe dazu J. Latacz, Troia und Homer. Der Weg zur Lösung eines alten Rätsels, Leipzig : Koehler \& Amelang ${ }^{6} 2010,156-159$ ('Der Fall Raoul Schrott'), mit besonderem Hinweis auf P. Dräger, Rezension zu Schrotts 'Homer. Ilias. Übertragen', München : Hanser 2008, und 'Homers Heimat', München : Hanser 2008, in: Göttingische Gelehrte Anzeigen 261, 2009, 1-27 (auch in: Bryn Mawr Classical Review [BMCR] 2009.08.30; Forum Classicum [FC] 52/3, 2009, 224-234; Die Alten Sprachen im Unterricht [DASIU] 57, 2009/3, 9-33; Langfassung [68 S.] in: <http://www.unituebingen.de/troia/deu/Rezension-Schrott-Homer.pdf $>$ ); s. zuvor bereits die Auseinandersetzung Schrott : Latacz über Übersetzungstheorie und -praxis in: Akzente. Zeitschrift für Literatur, hrsg. v. Michael Krüger, Nr. 53/3 (Juni 2006), Nr. 53/4 (August 2006) und Nr. 53/5 (Oktober 2006).

25 J.W.v. Goethe, Iphigenie auf Tauris (1787), Iphigeniens Eingangsmonolog ("... suchend"). 
Friedrich Hölderlin

Aus: Hymne an den Genius Griechenlands ${ }^{26}$

$[\ldots]$

Ha! Mäonide! wie du!

So liebte keiner, wie du!

Die Erd' und Ozean

Und die Riesengeister, die Helden der Erde

Umfaßte dein Herz!

Und die Himmel und alle die Himmlischen

Umfaßte dein Herz.

Auch die Blume, die Bien' auf der Blume

Umfaßte liebend dein Herz! -

Ach Ilion! Ilion!

Wie jammertest, hohe Gefallene, du

Im Blute der Kinder!

Nun bist du getröstet. Dir scholl

Groß und warm wie sein Herz,

Des Mäoniden Lied.

Hölderlins "Liebling unter den Helden" war Achilleus — Achilleus, über den er zu einem unendlich viel tieferen Verständnis der Ilias gelangte als viele Fachgelehrte heute noch:

Friedrich Hölderlin

Aus: Achill $^{27}$

Herrlicher Göttersohn! da du die Geliebte verloren,

Gingst du ans Meergestad, weintest hinaus in die Flut,

Weheklagend, - hinab verlangt in den heiligen Abgrund,

In die Stille dein Herz, wo, von der Schiffe Gelärm

Fern, tief unter den Wogen, in friedlicher Grotte die blaue

Thetis wohnte, die dich schützte, die Göttin des Meers.

Mutter war dem Jünglinge sie, die mächtige Göttin,

Hatte den Knaben einst liebend, am Felsengestad

Seiner Insel, gesäugt, ---- mit dem kräftigen Liede der Welle -

Und im stärkenden Bad' ihn zum Heroen genährt.

Und die Mutter vernahm die Weheklage des Jünglings,

Stieg vom Grunde der See, trauernd, wie Wölkchen, herauf,

Stillte mit zärtlich Umfangen die Schmerzen des Lieblings

Und er hörte, wie sie schmeichelnd zu helfen versprach.

Göttersohn!!! o wär ich wie du, so könnt' ich vertraulich $[\ldots]$

Einem der Himmlischen klagen mein heimliches Leid.

26 Exzentrische Bahnen. Friedrich Hölderlin, München : dtv 1993, 55f.

27 Exzentrische Bahnen. Friedrich Hölderlin, München : dtv 1993, 59. 
Die Sehnsucht nach der Verschmelzung mit dem "herrlichen" Göttersohn, der in jener alten idealen Zeit noch natürliche Zwiesprache halten konnte mit seiner göttlichen Mutter - und von ihr Trost empfing -, diese Sehnsucht ist unüberhörbar. Sie entspringt aus einer Nähe, einer Intimität, die unverkennbar aus tief sich einfühlender Homer-Lektüre kommt - in diesem Falle jener Szene aus dem ersten Gesang der Ilias, in der Achill am Meeresstrand unter Tränen seiner Mutter die Demütigung klagt, die ihm der Oberfeldherr Agamemnon öffentlich, unter den Augen des gesamten griechischen Heeres durch die Wegnahme der Briseïs zugefügt hat, aufgezwungen hat mit dem ganzen Zynismus großherrscherlicher Macht. Hölderlin hat mehrfach davon gesprochen, wie tief ihn diese Szene, diese Einfühlung Homers in die innersten Erregungen seiner selbstgeschaffenen poetischen Figuren gerüht hat. Und ich glaube, diese unverstellte, einfache Gerührtheit spüren auch wir noch, wenn wir aus seiner letzten Hymne, der 'Mnemosyne', diese Zeilen hören - diese zwei Zeilen nur:

\section{Friedrich Hölderlin}

Aus: Mnemosyne (letzte Fassung) ${ }^{28}$

Am Feigenbaum ist mein

Achilles mir gestorben ...

Nicht alle Zeitgenossen Hölderlins können oder wollen bis zu dieser Ungeschütztheit ihrer Griechen- und eben besonders Homer-Verinnerlichung vorstoßen. Aber bei allen schwingt sie in Äußerungen über Homer unüberhörbar mit - in Briefen, Gedichten, Nachahmungsversuchen wie etwa Goethes 'Achilleïs', die Fragment geblieben ist, in Vossens Übersetzungen, aber auch in Aufsätzen und Traktaten, wie z.B. in Herders 1794 erschienener Studie 'Über die Humanität Homers in seiner Iliade':

„O Homer - sooft ich von neuem deine Iliade lese, finde ich in ihr neue Züge der ordnenden Weisheit, Klugheit und Menschenliebe".29

Hier begreifen wir auch, wie diese Intimität mit Homer rein technisch zustande kommen konnte: "... sooft ich von neuem deine Iliade lese": das bedeutet ja eine Textlektüre von einer Intensität und Vollständigkeit, wie sie bis dahin bei den Nicht-Gelehrten kaum einmal stattgefunden haben dürfte. Sie vollzog sich zwar sicher nicht immer als Lektüre des Originals (Schiller etwa kam auch beim dritten Anlauf nicht über die griechische Elementargrammatik hinaus ${ }^{30}$ ), aber doch in den damals schon recht guten Übersetzungen (Graf Stolbergs Ilias

28 Friedrich Hölderlin. Gesammelte Werke, hrsg. v. Bernt von Heiseler, Gütersloh : Bertelsmann 1954, 285f.

29 Herders Sämmtliche Werke, hrsg. v. Bernhard Suphan (33 Bände), Berlin 1877-1909; hier: Band 17, 181.

30 J. Latacz, Schiller und die griechische Tragödie, in: H. Flashar (Hrsg.), Tragödie. Idee und Transformation (= Colloquium Rauricum, Band 5), Stuttgart/Leipzig : Teubner 1997, 235-257 (hier besonders: 235-238). 
erschien 1778, Vossens Odyssee 1781). Joachim Wohlleben, dem wir das schöne Büchlein 'Die Sonne Homers' von 1990 verdanken, hat für die damalige Homer-Lektüre den schönen Ausdruck "Leseversenkung" geprägt:

„Welche Leseversenkung schon um 1780 geherrscht haben muß, schließen wir aus dem Wort eines Spötters. Georg Christoph Lichtenbergs einschlägiges Bonmot aus den sog. Sudelbüchern ist berühmt: "Er las immer 'Agamemnon' statt 'angenommen'. so sehr hatte er den Homer gelesen “. ${ }^{31}$

Jetzt kann man, denke ich, wohl auch verstehen, welche Erschütterung jenes Ereignis für diese Zeit bedeuten mußte, das mit Friedrich August Wolfs 'Prolegomena ad Homerum' von 1795 über die schöne Homerische Welt hereinbrach. ${ }^{32}$ Zwar hatte man die in den 70er Jahren auch ins Deutsche übersetzten Bücher der Engländer gelesen, eines Thomas Blackwell ${ }^{33}$ und Robert Wood, ${ }^{34}$ in denen Homer erstmals konsequent in seinen Lebensraum, das kleinasiatische Ionien, und in seine vermutetete Lebenszeit hineinzusehen versucht wurde (bei Wood durch eigene Reise-Anschauung gestützt) — und bei denen (bei Wood unter Kombination der antiken Debatten) Homer als mündlich improvisierender Rhapsode in einer noch schriftlosen Zeit erschien. Gewiß, diese Anschauung war in Deutschland von damals einflußreichen Gelehrten wie Christian Gottlob Heyne in Rezensionen, Aufsätzen, Vorlesungen usw. sofort positiv aufgenommen worden, und als Friedrich August Wolf, seit 1777 Schüler Heynes an der Universität Göttingen, seine Arbeit am Homer begann, galt sie als die allgemein akzeptierte gängige Homer-Auffassung. ${ }^{35}$ Wolfs in nüchternem Latein systematisch aufgebaute These, die Ilias sei überhaupt nicht das Werk eines Mannes, sondern vieler, wirkte nun aber dennoch wie ein Denkmalsturz. Jeder war beeindruckt, doch in fast allen sträubte sich die dichterische Intuition gegen die verstandesmäßige Zerstückelung. Goethe etwa sprach zunächst von Wolf nur als von "Homers Vernichter". Zwischenzeitlich prostete er Wolf zwar zu, ${ }^{36}$ aber nur so lange, bis er die durch Wolf bewirkte vermeint-

31 J. Wohlleben, Die Sonne Homers. Zehn Kapitel deutscher Homer-Begeisterung. Von Winckelmann bis Schliemann, Göttingen 1990, 105. - Diesem Werk sind einige Zitate und Stellennachweise im Folgenden dankbar entnommen.

32 F.A. Wolf, Prolegomena ad Homerum [etc.], Halle 1795.

33 Th. Blackwell, Enquiry into the Life and Writings of Homer, London (1735) ${ }^{3} 1757$ (deutsche Übersetzung von J.H. Voß, Leipzig 1776).

34 R. Wood, Essay on the Original Genius and Writings of Homer, London 1769 (deutsche Übersetzung von C.F. Michaelis, Frankfurt/Main 1773).

$35 \mathrm{Zu}$ diesem ganzen Komplex s.. J. Latacz, 'Einführung' sowie 'Tradition und Neuerung in der Homer-Forschung. Zur Geschichte der Oral poetry-Theorie', in: J. Latacz (Hrsg.), Homer. Tradition und Neuerung (= Wege der Forschung, Bd. 463), Darmstadt : Wissenschaftliche Buchgesellschaft 1979, 1-23 und 24-44.

36 Weimarer Ausgabe I 1, 293f.: Erst die Gesundheit des Mannes, der, endlich vom Namen Homeros / Kühn uns befreiend, uns auch ruft in die vollere Bahn! / Denn wer wagte mit Göttern den Kampf? und wer mit dem Einen? / Doch Homeride zu sein, auch nur als letzter, ist schön. 
liche Befreiung von dem erdrückenden Übervater Homer, den es ja nun scheinbar nicht mehr gab, durch die Schaffung seiner eigenen homerisierenden Versuche 'Hermann und Dorothea' und 'Achilleïs' ausgekostet hatte. Danach, schon im Jahre 1800, als seine 'Achilleïs' gescheitert war, kehrte er zum alten Glauben an den einen Homer zurück. Sein Widerruf, die 'Palin-odie', klingt wie eine Erlösung:

Johann Wolfgang von Goethe

Homer wieder Homer ${ }^{37}$

Scharfsinnig habt ihr, wie ihr seid,

Von aller Verehrung uns befreit,

Und wir bekannten überfrei,

Daß Ilias nur ein Flickwerk sei.

Mög' unser Abfall Niemand kränken;

Denn Jugend weiß uns zu entzünden,

Daß wir Ihn lieber als Ganzes denken,

Als Ganzes freudig Ihn empfinden.

Dennoch: Die alte Sicherheit war bei den meisten dahin. Damit zugleich aber auch die spontane Versenkung und die Leidenschaft. Statt dessen bahnte sich ein wiederum anders gearteter Höhepunkt der Homer-Beeinflussung Europas an: Die Homer-Philologie. Als rationale, wissenschaftliche Analyse von Ilias und Odyssee sollte sie das ganze 19. und einen großen Teil auch noch des 20. Jahrhunderts hindurch an den Universitäten und auf den humanistischen Gymnasien speziell des deutschsprachigen Raums mehrere Generationen mit Homer aufwachsen lassen. Von der Humboldtschen Einführung des für alle verbindlichen Humanistischen Gymnasiums 1810 bis zur Preußischen Schulreform von 1900 - man bedenke: fast ein Jahrhundert lang! - war ein Hochschulzugang ohne Griechisch und damit ohne Homer in Preußen und in den meisten deutschsprachigen Ländern Europas nicht oder nur schwer möglich. Damit war zwar der ursprüngliche Zustand der Homer-Kenntnis im antiken Griechenland zumindest annähernd wieder erreicht. Damit zugleich trat aber auch etwas anderes wieder ein: Die Trennung von einfachem Genuß und tieferfragendem und forschendem Wissenwollen, anders gesagt: der unmittelbare, sich mitreißen lassende Zugang zu den Texten einerseits und der über alle Schichten des Werkes sich ersteckende punktuell analysierend eindringende wissenschaftliche Zugang andererseits. Diese Trennung hatte sich auch in der Antike schon einmal ereignet, damals, als in Alexandreia im 3. Jh. v. Chr. die Homer-Philologie begonnen hatte ${ }^{38}$ und dadurch zwischen allgemeinem Homer-Lesepublikum einerseits und Homer-Forschern andererseits ein Graben

37 Weimarer Ausgabe I 3, 159.

38 R. Pfeiffer, Geschichte der Klassischen Philologie. Von den Anfängen bis zum Ende des Hellenismus, Reinbek bei Hamburg : Rowohlt 1970, 114-337 (II 1: Die Entstehung der Philologie in Alexandria, 114-134). 
entstanden war. Das wiederholte sich nun in der Neuzeit. Hier, um 1800 herum, führte es zur Etablierung der Philologie als Wissenschaft, genannt 'Klassische Philologie', also 'Philologie der klassischen Sprachen', einer Wissenschaft, wie sie bis heute - und heute ausgebreiteter denn je - in rund 45 Kulturnationen der Welt an den Universitäten betrieben wird. ${ }^{39}$ Damit führte diese Trennung aber auch zum zwar ungewollten, jedoch unvermeidlichen Ende des schönen Dilettantentums, in dem Pastoren, Dichter, Philosophen, Staatsmänner, Lehrer und durchaus auch Professoren bis zu Wolfs Blitzstrahl vereint gewesen waren. Von nun an konnten Dichter und Literaten nicht mehr in gleicher Weise über Homer mitreden wie bisher. Die neue Wissenschaft von Homer entfernte sich im Streit um tausend Interpretationsprobleme und in der Entdeckung immer neuer historischer Voraussetzungen für ein angemessenes Verständnis der Homerischen Epen (Sprachwissenschaft, Archäologie, Oral poetry-Forschung, Linear B-Entschlüsselung u.v.a.m.) vom allgemeinen Publikum mit Siebenmeilenstiefeln. Aus der im 18. Jh. in der gebildeten Gesamtgesellschaft leidenschaftlich geführten Debatte um Homer und dann um Wolfs Homer-Thesen entwickelte sich im 19. Jh. eine ganze Bibliotheken füllende eigene Homer-Forschungsliteratur und eine entsprechende Spezialistenkaste. Und mehr noch: Aus der immer schärfer werdenden Argumentationstechnik in dieser speziellen Homer-Forschung ging ein neuer, rationalerer, selbstreflektierender Umgang mit den antiken Texten überhaupt und mit der ganzen Antike hervor. Es entstand die moderne Klassische Philologie - und in ihrem Gefolge bildeten sich die modernen Neuphilologien heraus. Die moderne Form der Philosophischen Fakultäten an den europäischen Universitäten entstand.

Dies war nun ein wiederum ganz anders gearteter Höhepunkt des HomerEinflusses auf Europa. Es war ein besonders raffinierter Sieg Homers. Und dieser Siegeszug, diese Homerisch-Odysseisch raffinierte Unterwanderung der europäischen Geisteskultur durch die Hintertür der Wissenschaft hält - das registrieren wir heute angesichts der Vollendung dieses Lexikons mit verhaltenem Triumph - sie hält, zum Glück, bis heute an! Entsprechend wird dieser Sieg Homers auch hier in Hamburg an den nächsten beiden Tagen in vielerlei Facetten ausgebreitet werden. Mir bleibt heute abend nur die Rolle des Hermes, mit der Botschaft: "Der Mäonide dankt! Er dankt allen, die aus der näheren und ferneren Umgebung herbeigeeilt sind, ihn zu ehren, und er dankt ganz besonders denen, die dieses große $\gamma$ źpas, dieses große Ehrengeschenk für ihn: das Lexikon und das Symposion, im Hintergrund ermöglicht haben: den

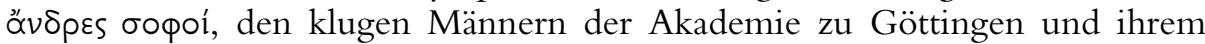
Präsidenten!

39 J. Latacz, Die Gräzistik der Gegenwart. Versuch einer Standortbestimmung, in: E.-R. Schwinge (Hrsg.), Die Wissenschaften vom Altertum am Ende des 2. Jahrtausends n. Chr., Stuttgart/Leipzig : Teubner 1995, 41-89. 


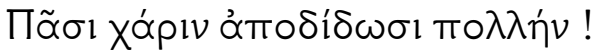

Lassen Sie uns hier innehalten und nach den Konsequenzen des vielfach differenzierten permanenten Homer-Einflusses auf Europa fragen!

Die erste Konsequenz ist jenes Phänomen, das wir schon eingangs einmal kurz berührten: Europa ist eindeutig - wenn auch weitgehend unbewußt 'homerbestimmt', und zwar irreversibel. Die Metamorphosen, die Homer im Laufe der europäischen Kulturgeschichte erlebt hat, die Funktionalisierungen, die Entstellungen, die Apotheosen und die Destruktionsversuche - sie alle haben nur Homers Unzerstörbarkeit befestigt.

Die zweite Konsequenz, die aus der ersten folgt, besteht in Homers unversiegter Inspirationskraft - heute wie seit jeher - und zwar nunmehr sowohl im allgemeinen Publikum als auch in der Wissenschaft, der Geisteswissenschaft. Literatur wie Literaturtheorie, Kunst wie Kunsttheorie, und auch moderne Medien wie der Film oder das Fernsehen - sie alle beziehen immer wieder neue Impulse aus Homer. Den ganzen großen Raum des gegenwärtigen Homer-Einflusses kann ich hier nicht ausschreiten. Die oft gehörten Namen zumindest der Dichter kann ich Ihnen aber auch hier nicht vorenthalten: James Joyce, Nikos Kazantzakis, Heiner Müller, Christa Wolf, Derek Walcott. Das sind indessen nur die Leuchttürme, die jeder kennt. Vielleicht nehmen Sie aber einmal Bernd Seidenstickers insel taschenbuch 'Unterm Sternbild des Hercules' zu Hand. ${ }^{40}$ Dort werden Sie ungeahnte Edelsteine der kleinen Form unter vielleicht ungeahnten Namen finden: Ingeborg Bachmann, Peter Huchel, Günter Kunert, Christoph Meckel, Ernst Jandl, Johannes Bobrowski, Peter Rühmkorf, Günter Eich und viele andere. Es sind unsre Zeitgenossen! Irgendwann hat er sie alle einmal erreicht und angerührt, der alte Mäonide! Und sie haben sich nicht widersetzt. Denn sie alle haben - auch ohne Spezialstudium - seine Qualität gespürt. Und seine Überzeitlichkeit - unter deren beruhigendem Dach in mancher guten oder schweren Stunde auch sie mit ihren heutigen Problemen sich schutzsuchend und für einmal unverhüllt ber-

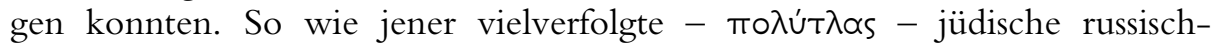
amerikanische Dichter und Literaturnobelpreisträger von 1987, mit dessen Selbsttrost durch Homer nach der Exilierung aus der Sowjetunion und der erzwungenen Trennung von seinem Sohn Andrej ich schließen möchte: ${ }^{41}$

40 B. Seidensticker/P. Habermehl (Hrsg.), Unterm Sternbild des Hercules. Antikes in der Lyrik der Gegenwart, Frankfurt a. M./Leipzig 1996 (insel taschenbuch 1789).

41 Übersetzung: J. Latacz. - Zu Palamēdes: Palamedes ('uralter Denker') war nach dem Mythos ein noch klügerer Grieche als Odysseus: Als Palamedes nach Ithaka kam, um Odysseus für den Troia-Feldzug zu werben, stellte sich der damals ganz junge Vater Odysseus, Sohn des Königs Laërtes von Ithaka, wahnsinnig und pflügte das Feld. Da legte ihm Palamedes den Säugling Telémachos, Odysseus' und Penélopes Baby, in die Furche vor den Pflug. Odysseus hielt ein - und war als Simulant entlarvt! 
Мой Телемах,

Троянская война

окончена. Кто победил - не помню.

Должно ьытъ, греки: столько мёртвецов

вне дома ьроситъ могут толъко греки .....

Und nun das ganze Gedicht in Deutsch:

Josef Brodsky (Iosif Brodskij, 1940 Leningrad -1996 New York)

Odysseus an Telemach $(1972)^{42}$

Mein Telemach,

der Krieg um Troia

ist aus. Wer ihn gewann - ich weiß nicht mehr.

Wahrscheinlich doch die Griechen: so viel Leichen

im Ausland lassen können nur die Griechen ...

Und doch - der Weg zurück nach Hause

hat sich als viel zu lang erwiesen.

Als ob Poseidon, während wir noch dort

die Zeit verloren, hätte ausgedehnt die Räume.

Mir ist ganz unbekannt, wo ich gelandet bin, was vor mir liegt — so eine schmutz'ge Insel,

Gebüsch, Gebäudeteile, ein Gegrunz von Schweinen, ein wilder Garten, irgendeine Zarin, und Gras und Steine ......

Liebster Telemach,

die Inseln sind sich alle ähnlich, eine wie die andre, wenn du so lang herumirrst - und das Hirn

ist schon ganz wirr vom Wellenzählen,

das Auge, zugeklebt vom Horizont, muß weinen, und Wasserfleisch trübt das Gehör.

Ich weiß nicht mehr, wie er geendet hat, der Krieg,

und wieviel Jahre du jetzt zählst - das weiß ich auch nicht.

Wachs' und werd' groß, mein Telemach, ja, wachse!

Allein die Götter wissen, ob wir uns noch wiedersehn.

Du bist ja jetzt schon nicht mehr jenes Kleinkind,

vor dem ich damals Halt gebot den Stieren.

Gäb' es nicht Palamedes, lebten wir zusammen.

42 Iosif Brodskij, Cast' reci. Stichotvorenija 1972-1976, Ann Arbor : Ardis Publishing Company 1977, 19. - Nur seutsche Übersetzung (ohne den russ. Originaltext) von Sylvia List in: Jossif Brodskij. Einem alten Architekten in Rom. Ausgewählte Gedichte. Aus dem Russischen von Karl Dedecius, Rolf Fieguth und Sylvia List. München/ Zürich: Piper (Serie Piper) 1986 (Neuausgabe), 109. In den ,Anmerkungen“ (116-120) nicht annotiert. 
Jedoch - kann sein, daß er auch recht tat: Ohne mich

bist du von Ödipuskomplexen frei geblieben -

und deine Träume, ja, mein Telemach, sind ohne Schuld.

\section{Bibliographie}

Blackwell, Th., Enquiry into the Life and Writings of Homer (London 1735, ${ }^{3} 1757$ ), (deutsche Übersetzung von J.H. Voß, Leipzig 1776).

Brodskij, Iosif, Cast' reci. Stichotvorenija 1972-1976 (Ann Arbor 1977).

Butler, E. M., The Tyranny of Greece over Germany (London 1935).

Christes, J., „Schule. III: Rom“, in: Der Neue Pauly

Cupane, C.,Die Homer-Rezeption in Byzanz“, J. Latacz/Th. Greub/P. Blome/A. Wieczorek (Hrsg.), Homer. Der Mythos von Troia in Dichtung und Kunst (München 2008), 251-258.

Dräger, P. Rezension zu Schrotts 'Homer. Ilias. Übertragen', München : Hanser 2008, und 'Homers Heimat', München : Hanser 2008, in: Göttingische Gelehrte Anzeigen 261 (2009) 1-27 (auch in: Bryn Mawr Classical Review [BMCR] 2009.08.30; Forum Classicum [FC] 52/3, 2009, 224-234; Die Alten Sprachen im Unterricht [DASIU] 57, 2009/3, 9-33; Langfassung [68 S.] in: <http://www.unituebingen.de/troia/deu/Rezension-Schrott-Homer.pdf $>$ )

Finsler, G., Homer in der Neuzeit von Dante bis Goethe. Italien-Frankreich-EnglandDeutschland (Leipzig/Berlin 1912).

Fuhrmann, M., Geschichte der römischen Literatur (Stuttgart 1999).

Goethe, J.W.v., Iphigenie auf Tauris (1787).

Harich-Schwarzbauer, H. „Homer in der römischen Literatur“, in: J. Latacz/Th. Greub/P. Blome/A. Wieczorek (Hrsg.), Homer. Der Mythos von Troia in Dichtung und Kunst (München 2008), 245-250.

Herders Sämmtliche Werke, hrsg. v. Bernhard Suphan (33 Bände), (Berlin 1877-1909).

Hölderlin, F., Exzentrische Bahnen (München 1993).

—, Gesammelte Werke, hrsg. v. Bernt von Heiseler (Gütersloh 1954).

Kühnert, F., „Schulwesen“, in: J. Irmscher/R. Johne (Hrsg.), Lexikon der Antike, (Leipzig $\left.{ }^{9} 1987\right), 529-531$.

L'Iliade / Homère, trad. par $\mathrm{M}^{\text {me }}$ Dacier (Paris 1699).

Latacz, J. „Schiller und die griechische Tragödie“, in: H. Flashar (Hrsg.), Tragödie. Idee und Transformation (= Colloquium Rauricum, Band 5), (Stuttgart/Leipzig 1997) 235-257.

—, Troia und Homer. Der Weg zur Lösung eines alten Rätsels (Leipzig ${ }^{6} 2010$ ),

—, „Die Gräzistik der Gegenwart. Versuch einer Standortbestimmung“, in: E.-R. Schwinge (Hrsg.), Die Wissenschaften vom Altertum am Ende des 2. Jahrtausends $n$. Chr. (Stuttgart/Leipzig 1995) 41-89.

-, Die griechische Literatur in Text und Darstellung. Band 1: Archaische Periode (Stuttgart $\left.{ }^{2} 1998\right)$.

—, Homer. Der erste Dichter des Abendlands (Düsseldorf/Zürich ${ }^{4} 2003$ ). 
-, Homer. Tradition und Neuerung (= Wege der Forschung, Bd. 463), (Darmstadt 1979).

—, Zum Wortfeld 'Freude' in der Sprache Homers (Heidelberg 1966).

Marrou, H.I. Geschichte der Erziehung im klassischen Altertum ([Freiburg : Alber 1957] München 1977).

Mommsen, Th., Römische Geschichte, Erster Band: Bis zur Schlacht von Pydna (Berlin $\left.{ }^{2} 1856\right)$.

Montanari, F., „Die Rezeption der Homerischen Dichtung im lateinischen Mittelalter", in: J. Latacz/Th. Greub/P. Blome/A. Wieczorek (Hrsg.), Homer. Der Mythos von Troia in Dichtung und Kunst (München 2008), 259-264.

Perrault, C., Parallèle des anciens et des modernes en ce qui regarde les arts et les sciences (Faksimiledruck der vierbändigen Originalausgabe Paris 1688-1696), hrsg. von H. R. Jauß (München 1964).

Pfeiffer, R. Geschichte der Klassischen Philologie. Von den Anfängen bis zum Ende des Hellenismus (Reinbek bei Hamburg 1970).

Schanz, M. / Hosius, C. „Geschichte der römischen Literatur bis zum Gesetzgebungswerk des Kaisers Justinian. Erster Teil: Die römische Literatur in der Zeit der Republik", in: Handbuch der Altertumswissenschaft, hrsg. v. W. Otto, Achte Abteilung. Erster Teil (München $\left.{ }^{4} 1959\right)$.

Schein, S., „An American Homer for the Twentieth Century“, in: B. Graziosi (Hrsg.), Homer in the Twentieth Century: between world literature and the western canon (Oxford 2007), 268-285.

Seidensticker, B. / Habermehl P. (Hrsg.), Unterm Sternbild des Hercules. Antikes in der Lyrik der Gegenwart, (Frankfurt a. M./Leipzig 1996).

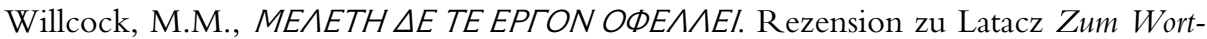
feld ,Freude' und zur 5. Lieferung des LfgrE, in: The Classical Review 18 (1968), 271-273.

Wimmel, W., Die Kultur holt uns ein. Die Bedeutung der Textualität für das geschichtliche Werden (Würzburg 1981)

Wohlleben, J. Die Sonne Homers. Zehn Kapitel deutscher Homer-Begeisterung. Von Winckelmann bis Schliemann (Göttingen 1990).

Wolf, F.A. Prolegomena ad Homerum [etc.] (Halle 1795).

Wood, R., Essay on the Original Genius and Writings of Homer, London 1769 (deutsche Übersetzung von C.F. Michaelis, Frankfurt/Main 1773). 


\title{
Ein paar Worte zum Abschnitt E (= Etymologie) des LfgrE
}

\author{
MICHAEL MEIER-BRÜGGER
}

1) Das ideale Lemma eines LfgrE-Artikels besteht aus den folgenden Informationsteilen:

- der Frequenzangabe $\left[\mathrm{x}^{\mathrm{i}}, \mathrm{x}^{\mathrm{o}}, \mathrm{x}^{\mathrm{H}}, \mathrm{x}^{\mathrm{h}}, \mathrm{x}^{\mathrm{e}}\right]$ und den Teilen E, F, M, $\Sigma \mathrm{X}, \mathrm{L}$, B, D, G.

- $\quad \mathrm{E}=$ "genet. Abdruck" = Nennung von Wortverband mit Ableitungen und Vorgeschichte,

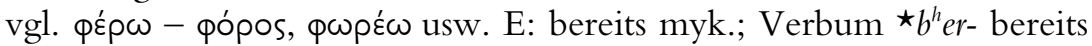
im Lexikon der urindogermanischen Grundsprache vorhanden $=$ ererbt

2) Ein Beispiel, um die Problematik von E zu verdeutlichen:

2a) Kriegsziel der Griechen vor Troia:

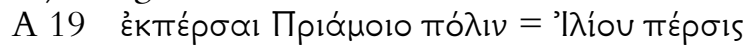

2b) Was bedeutet $\pi \dot{\varepsilon} \rho \theta \omega$ konkret? Welcher Aspekt ist herausgegriffen?

- wie dt. "erobern" i.e. "der Obere bleiben / Oberhand behalten"?

- wie dt. "einnehmen"

- wie dt. "plündern" i.e. "Plunder (Hausrat)" wegnehmen?

- wie dt. "zerstören" i.e. "zerstreuen / vernichten"?

2c) Antike Zerstörungen waren radikal: Städte wurden dem Erdboden gleichgemacht.

- vgl. Perserschutt auf der Akropolis

- vgl. die Zerstörung Milets durch die Perser (archaischer Schutt am Kalabaktepe)

2d) Neuer Vorschlag:

- die bis jetzt vorgelegten Analysen überzeugen nicht, auch nicht M. Janda, Eleusis, Innsbruck 2010, p. 230-241 $\left(<\star / b^{h} e r-d^{h} h_{1-} /\right.$ "das Davontragen")

- trotz der expliziten Ablehnung durch Frisk: $\pi \varepsilon \dot{p} \theta \omega$ ist gleich gebildet wie lat. perdere

- lat. per- + -dere aktiv "zu Grunde richten", "destroy", <*"hinüber machen" 
- pass. dazu per- + -ire "zu Grunde gehen", "disappear", < "hinüber gehen"

- per-dere wie con-dere "gründen"

- -dere zu -da- $<\star d^{h} h_{1}$ - i.S.v. "machen"

- $\quad \mathrm{zu}-d a-$ altes Perfekt $f \bar{e}-c_{-}<\star^{h} d^{h} h_{1^{-}}$, woraus neu lat. facere

- im Griech. *per $+d^{h} h_{1^{-}}>\pi \varepsilon \dot{\varepsilon}-\theta \omega /$ हैm $\pi \propto \theta \circ v$ "zu Grunde richten"

- vgl. है $\mu \alpha \theta \circ v(\mu \alpha v \theta \alpha \dot{\alpha} v \omega)<\star_{m}^{\circ} n s-d^{h} h_{1-}$ "in den Geist legen"

- dagegen ein Präsens wie $\pi \lambda \eta \dot{\theta} \omega \omega$ "bin voll" in Umkreis des pass. Aor.

2e) Quintessenz zum Abschnitt E

- Etymologien lassen sich nicht systematisch finden

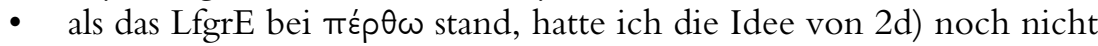

- wenn neue Etymologien auftauchen, brauchen sie Platz für eine überzeugende Argumentation und E gibt dafür den Raum nicht her

- Andeutungen allein sind zu vage, nur bereits vorliegende überzeugende Publikationen sind zitierfähig

3) Wie war der Umgang des LfgrE mit E?

3a) Phase I im Band I Alpha

- sehr ausführlich

3b) Phase II mit Beginn Beta

- radikale Kürzung ohne viele Verweise

3c) Phase III ab Lief. 13

- Neue Handbücher verfügbar: Chantraine, Dict.; Mayrhofer, EWAia, LIV $^{2}$

- Hinweis darauf genügt i.d.R.

- nur ganz selten spezieller Aufsatz genannt

4) Meine schönsten Erlebnisse beim Bearbeiten von Abschnitt $E$

4a) Die Diskussionen zu E beim Entstehen der Artikel:

- Bei der E-Arbeit immer wieder die folgenden Informationen zu finden: "unklar" (Frisk), "n'est pas claire" (Chantraine)

- Diskussionen mit den Mitarbeiter sehr fruchtbar

- Erkenntnisse: "vieles ist nur vorhistorisch, aber nicht homerisch nachweisbar", "Wörter haben meist bereits eine lange Vorgeschichte hinter sich", vgl. ícpós

- richtige Idee für eine Lösung kommt oft unerwartet, läßt sich nicht erzwingen

4b) Mein schönster Fund ist die Etymologie von żá $\phi \theta \eta 2^{\mathrm{i}}$

- publiziert in Münchener Studien zur Sprachwissenschaft 50, 1989, 9196

- hatte u.a. "im Hinterkopf gespeichert" żá $\phi \theta \eta=$ "unklar" 


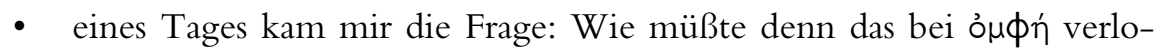
rene Verbum lauten?

- ̇uфń "Stimme" bekanntlich $<\star$ homp $p^{h} \bar{a}-<\star_{\text {song }} g^{w h} \bar{a}-$ "Gesang"

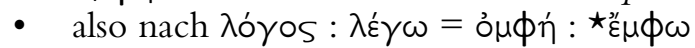

- AHA: źá $\phi \theta \eta$ ist der Aorist dazu!!!

- daher meine etymologische Lösung: $\dot{\varepsilon}-\alpha ́ \alpha-\theta \eta / e-a p^{h}-t^{h} \bar{e} /<\star / e-s^{0} n g^{w h}-$ $d^{h} \bar{e} /$

- $\quad \star /-s^{\circ} n g^{w h}-/ \mathrm{zu} \star / s e n g^{w h}-/$ "singen", belegt in ỏ $\mu \phi \eta ́$

- Lautlich: $\star /-s^{\circ} n g^{w h}-/$ wird frühgriech. zu /-hak $k^{w h}-/$ bzw. /-hap ${ }^{h}-/$ bzw. / $-a p^{h}-1$

- (im Frühgriechischen werden die Labiovelare beseitigt und werden vor dunklen Vokalen und Konsonanten zu Labialen; das neu entstandene $/-h-/$ ist wegen des folgenden $/-k^{w h}-/$ dissimiliert)

- Inhaltlich: źá $\phi \theta \eta=($ der Schild, der vom Speer getroffen zu Boden fällt) "wurde zum Singen/Klingen gebracht" 
Bereitgestellt von | SUB Göttingen Angemeldet

Heruntergeladen am | 27.10.14 12:34 


\title{
Glosse Dialettali negli Scholia Omerici
}

\author{
FRANCO MONTANARI
}

Lo studio delle glosse dialettali menzionate negli scholia omerici può essere visto in primo luogo entro un quadro di ricerca ben noto e frequentato, vale a dire quello degli studi degli antichi sulla dialettologia, e messo in connessione con la copiosa produzione lessicografica, nel cui alveo i materiali e le osservazioni di carattere dialettale costituiscono una presenza abbondante: nella lessicografia alessandrina il concetto di dialektos ha un chiaro valore geografico, a indicare le parlate locali di luoghi diversi e specifici, ${ }^{1}$ spesso chiamate in causa nello studio delle opere letterarie, in primis la poesia, come accade negli scholia

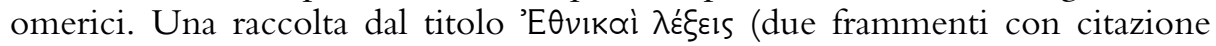
sicura in Galeno, uno possibile in Ateneo) è attribuita a Zenodoto, anche se non sono eliminati i dubbi se si tratti di Zenodoto di Efeso o di un altro Zenodoto e, nel caso di Zenodoto di Efeso, se si tratti di un'opera distinta dalle $\Gamma \lambda \tilde{\omega} \sigma \sigma \alpha$ l oppure no. Scrive K. Nickau: «Gehörte das Werk, wie unsere Vermutung lautet, dem Z(enodotos) von Ephesos und erklärte er sowhol Dialektwörter als auch homerische Glossen, so läßt sich seine Stellung in der Geschichte der Griechischen Lexikographie wie folgt verstehen: Philetas hatte die dunklen Wörter ... gesammelt, vielleicht auch, um den Schmuck des seltenen Ausdrucks (im Sinne von Aristot. poet. 22, 1545 a 9; vgl. Latte, Kl. Schriften 654) den Dichtern verfügbar zu machen, und $Z$ (enodotos) mag ihm darin gefolgt sein. Ebenso wie Philetas erklärte $Z$ (enodotos) Dialektwörter und Homerglossen, doch den Ephesier führten seine Homerstudien whol noch stärker zur Deutung schwer verständlicher Wörter in Ilias und Odyssee». ${ }^{2}$ Accostiamo una efficace sintesi di R. Pfeiffer: "There was hardly any following age in which the Greek mind was not attracted by this problem of explaining $\lambda \dot{\varepsilon} \xi \varepsilon 1 s$. Their origin and their changes, the differentiation of kindred words, the comparison between Greek dialects or between Greek and foreign words were discussed by the Sophists, by Democritus, and by the great Attic philosophers. In the new era the poets revived these studies with fervour, not only Philitas and Simias, but also Callimachus and Apollonius ... Whatever had been undertaken piecemal here and there in the course of time, was all now united into one great enterprise, the $\Lambda \dot{\varepsilon} \xi \varepsilon 15$ of Aristophanes. A collection of $\gamma \lambda \tilde{\omega} \sigma \sigma \propto l$ was

1 Cfr. Cassio 1993a, 1993b, pp. 79 sgg., 1997; Tosi 1994, partic. p. 209; Cassio 2008, pp. 3-8.

2 Nickau 1972, 40-42, cit. da col. 42. 
usually limited to obsolete and obscure terms; but under the neutral title $\Lambda \varepsilon ́ \xi \varepsilon 1 \varsigma$ every word which was peculiar in form or significance and therefore in need of explanation could be listed, whether it was out of date or still in use». ${ }^{3}$ Pfeiffer ricorda poi due punti a suo avviso centrali del lavoro di Aristofane: l'attenzione per lo sviluppo della lingua con la distinzione cronologica fra uso antico e moderno, con l'idea della possibile origine locale di quest'ultimo; un

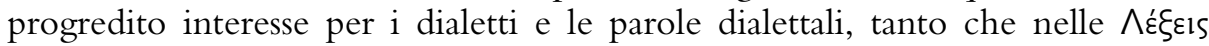

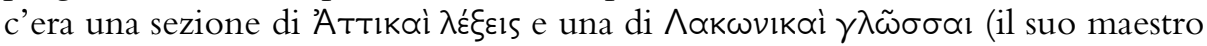

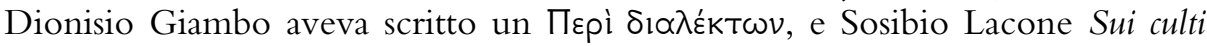
lacedemoni, con raccolta di glosse laconiche). ${ }^{4}$

Nell'ambito della filologia e della grammatica di età ellenistica e imperiale, gli studi dialettologici furono molto praticati e si svilupparono in connessione con problematiche quali la correttezza linguistica e la facies dialettale degli autori dei quali si doveva stabilire e interpretare il testo. Una figura importante in questo quadro è quella del grammatico Demetrio Issione, allievo di Aristarco

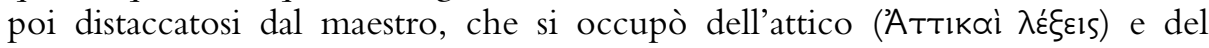

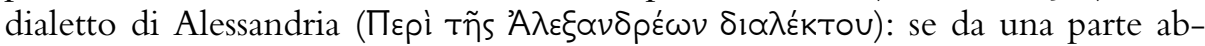
biamo un dialetto con il quale era impossibile non fare i conti, data la produzione letteraria interessata, dall'altra abbiamo con ogni probabilità uno sviluppo dell'interesse per la lingua parlata contemporanea. ${ }^{5}$ Oltre ai vari trattati o raccolte dedicati a singoli dialetti (fra cui un curioso 'I $\tau \propto \lambda_{1 \kappa} \propto \grave{l} \gamma \lambda \hat{\omega} \sigma \sigma \propto l$ di Diodo-

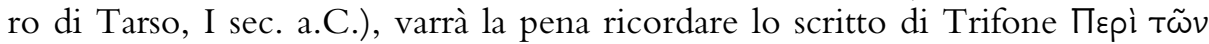

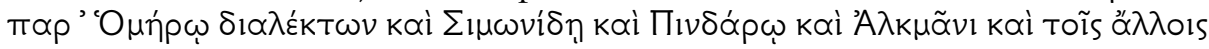
$\lambda$ ирıкоі̃s, dove spicca l'attenzione da una parte per Omero, dall'altra per i poeti lirici, la cui variegatezza e complicazione dialettale poneva problemi talvolta assai ardui. ${ }^{6}$ È una linea alla quale possiamo dedicare solo un breve cenno riassuntivo, sottolineando come essa dirami i suoi rivoli almeno in tre direzioni: la lessicografia, di cui già si è detto; lo studio linguistico-grammaticale, che, dopo le epocali sistemazioni di Apollonio Discolo ed Erodiano, per questo aspetto

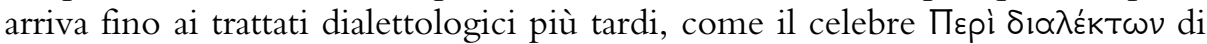
Gregorio di Corinto (X-XI sec.); la filologia e l'interpretazione dei testi, che è quello che ci interessa primariamente in questa sede.

3 Pfeiffer 1968, pp. $197 \mathrm{sg} .=$ pp. $311 \mathrm{sg}$.

4 Pfeiffer 1968, pp. 201 sg. = pp. 316 sg. Pfeiffer vede in Aristofane, oltre a una coscienza dello sviluppo diacronico della lingua, anche un interesse - evidentemente collegato - per la lingua parlata del suo tempo. Il problema nel suo insieme è stato discusso da Callanan 1987, pp. 75-82, da Ax 1990, pp. 13-15: Callanan nega recisamente la presenza in Aristofane di interessi per lo sviluppo diacronico della lingua, ma questa posizione è sembrata eccessiva e infondata ad Ax, anche sulla base di documentazione fornita dagli scholia omerici; si veda da ultimo Pagani 2011, pp. 37 e n. 81, 48 e n. 121.

5 Forse di ascendenza aristofanea, cfr. n. 4; su Demetrio Issione vedi Ascheri 2009 e Ascheri 2010, con utili sintesi e informazioni bibliografiche; sul dialetto di Alessandria vedi Fournet 2009.

6 Cfr. opp. citt. alla n. 1. 
Nella storia dell'interpretazione della poesia nel mondo antico, la Poetica di Aristotele è un testo chiave, nel quale si trova una riflessione su tutto il periodo precedente e si gettano decisive fondamenta per l'attività filologica ed ermeneutica dei secoli successivi. Prendiamo le mosse da ben noti passi della Poetica di Aristotele.

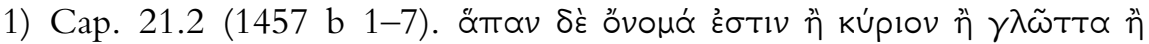

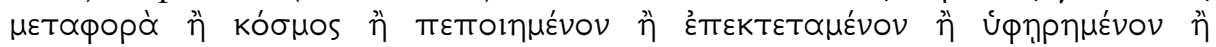

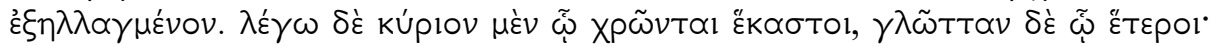

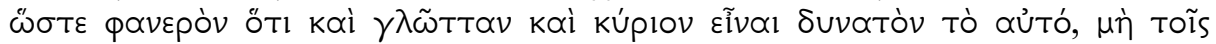

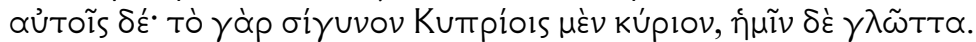

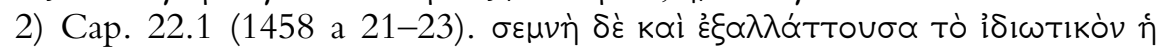

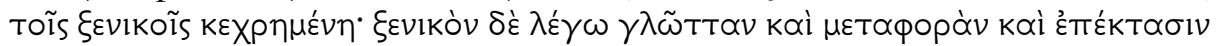

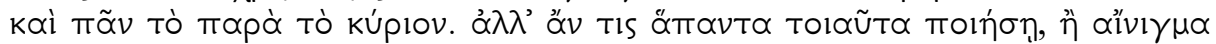

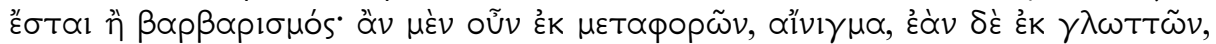

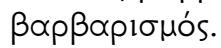

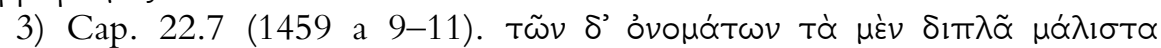

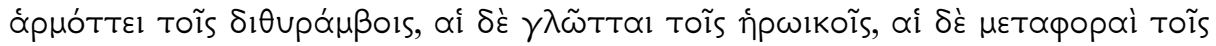
i̊ußzíors.

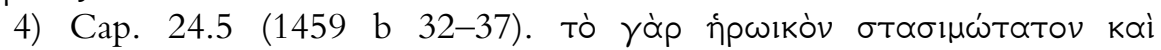

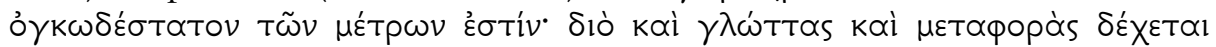

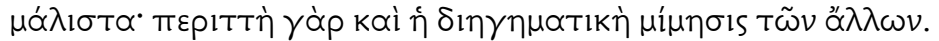

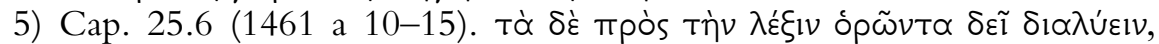

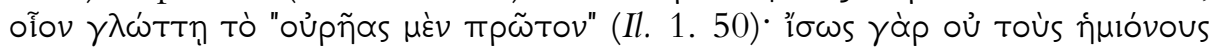

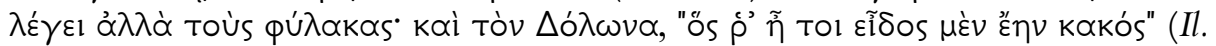

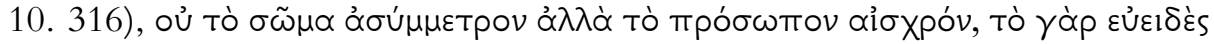

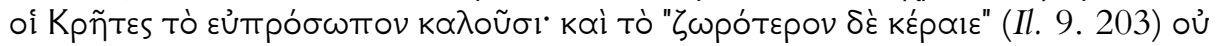

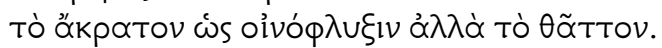

Alla fine del cap. 19 della Poetica, Aristotele introduce la trattazione della lexis (1456 b 9), che si sviluppa poi a partire dal cap. 20 (1456 b 20 sgg.). Nel cap. 21 (passo nr. 1) abbiamo la definizione generale del concetto linguisticolessicale di glossa: il termine designa un onoma usato da "altri" rispetto a quello di uso comune per tutti, cioè differente rispetto a ciò che è dominante. Nel passo nr. 2 la glossa è coerentemente inclusa in un insieme definito §ॄvikóv,

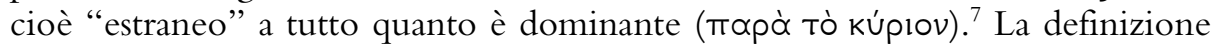
ha una portata del tutto generale e comprende vari tipi di "alterità", precisabili principalmente come di ordine temporale (una parola desueta rispetto al momento in cui viene usata) oppure geografico-dialettale (una parola di area geografica diversa rispetto a quella in cui viene usata): emergerà in seguito (passo nr. 5) che la glossa risulta un elemento oscuro del discorso e quindi ha bisogno di esegesi. Segue l'importante precisazione che lo stesso elemento lessicale può essere sia glossa sia dominante, ma non per le stesse persone, cioè non nello

7 Lucas 1972, p. 208, ad loc; Barabino 2010. 
stesso periodo e nello stesso luogo. L'esempio addotto si basa sull'aspetto geografico-dialettale e non su quello cronologico: la parola oíruvov appartiene al dialetto cipriota (nel senso di "lancia", come già si legge in Erodoto V 9. $3^{8}$ ), per cui a Cipro essa costituisce un elemento linguistico kúprov, mentre è glossa "per noi", scil. gli Attici.

Il cap. 22 è dedicato a definire i pregi del linguaggio poetico, che deve essere elevato e diverso dal linguaggio comune grazie all'uso di elementi estranei a quest'ultimo (cfr. sopra e passo nr. 2). Tutte le espressioni estranee al modo di parlare dominante conferiscono allo stile un carattere non comune e volgare, però non bisogna esagerare perché l'eccesso di glosse, metafore, abbellimenti vari può nuocere alla comprensione (mentre la parola comune è il fondamento della chiarezza: 22.2, 1458 a 34 e 1458 b 2-5), e addirittura condurre al ridicolo $(22.4,1458$ b 13-14): Aristotele invita a considerare l'epica come esempio di uso appropriato di tali pregi del linguaggio (1458 b 15-16). In seguito, nei passi nr. 3 e nr. 4 Aristotele afferma che l'uso di glosse è particolarmente adatto all'epica: nel nr. 3 si parla soltanto di glosse, nel nr. 4 di glosse e anche di metafore, che nel nr. 3 sono riservate alla poesia giambica, ma un collegamento specifico glosse - epica (tò ípwıkóv) è costante e ben sottolineato, anche se ovviamente in nessun modo esclusivo, dato che coinvolge fortemente anche lo stile della tragedia, come risulta tra l'altro dall'esemplificazione di 22.4-5 (1458 b $11-1459$ a 9 ).

Il cap. 25 illustra una serie di criteri esegetici, che possono essere utilizzati per interpretare le difficoltà dell'espressione poetica. All'inizio del cap. Aristotele anticipa che, poiché gli oggetti della mimesis vengono comunicati per mezzo del linguaggio, bisogna prendere in considerazione le glosse, le metafore e i $\pi \circ \lambda \lambda \grave{\alpha} \pi \alpha \dot{\alpha} \theta \eta$ Tñs $\lambda \varepsilon_{\varepsilon}^{\prime} \xi \varepsilon \omega s$. L'argomento è sviluppato poco più avanti (passo nr. 5), adducendo come esempi tre espressioni omeriche nelle quali un problema esegetico può essere risolto, secondo Aristotele, assumendo che una parola difficoltosa sia utilizzata in un senso obsoleto o dialettale: così si eliminano problemi di illogicità, di incongruenza o di sconvenienza. Non ci soffermiamo sulla validità dei problemi esegetici presentati e delle soluzioni avanzate. ${ }^{9}$ Per il nostro discorso serve osservare come la lysis del secondo esempio comporti il

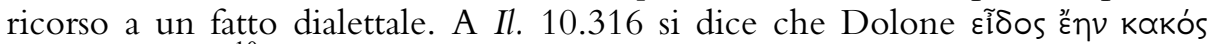

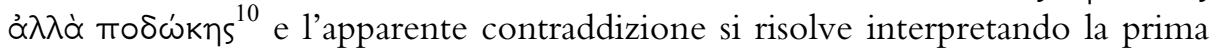
espressione non nel senso che Dolone fosse deforme nel corpo, che sarebbe in contraddizione con il fatto di essere un buon corridore, bensì nel senso che era brutto in viso: si tratta di un uso dialettale di Creta, sostiene Aristotele, dal

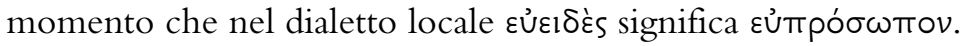

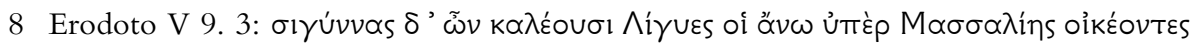

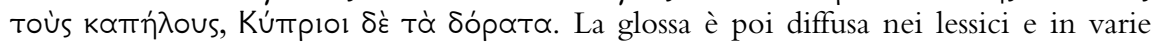
fonti erudite.

9 Vedi i comm. ad loc. di Bywater 1909, Gudeman 1934, Lucas 1972, Gallavotti 1974.

10 La clausola del verso non è riportata nel testo pervenuto della Poetica. 
Nell'ambito della trattazione sulla lexis, Aristotele definisce dunque la dottrina della "glossa", intesa come elemento stilistico proprio del linguaggio poetico, con particolare riferimento all'epica (e alla tragedia: cfr. cap. 25. 4-5, 1458 b 11 - 1459 a 3). ${ }^{11}$ Il tema si ritrova nella parte iniziale del III libro della Retorica (capp. 1-3), con dichiarati rimandi alla Poetica (1404 b 7, 1404 b 28, 1405 a 5). Nell'indicare in parallelo la diversità fra lo stile della prosa e quello della poesia, Aristotele chiarisce che gli ornamenti ottenuti grazie a elementi che si discostano dall'uso comune non sono in genere adatti al linguaggio pro-

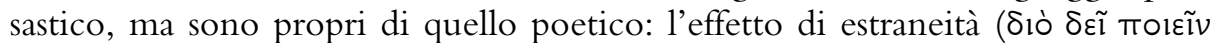

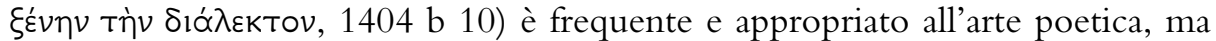
assai meno alla prosa, tanto più che una qualità essenziale dello stile è la chiarezza, che risulta soprattutto da ciò che è kúplov. ${ }^{12}$ Fra gli ornamenti del lin-

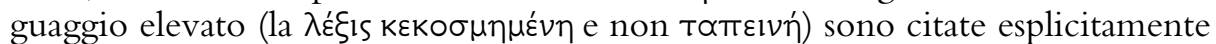
anche le glosse (il termine si trova in 1404 b 28, 1406 a 6, 1406 b 2). Aristotele evidenzia come ci sia stata un'evoluzione nello stile della prosa: «Nacque per primo uno stile poetico, come per esempio quello di Gorgia, e ancora oggi la maggior parte delle persone incolte ritiene che siano gli oratori di questo genere a parlare meglio, mentre non è così, e lo stile della prosa è diverso da quello della poesia»; anche nella tragedia si riscontra una tendenza nella direzione del discorso comune, sia nel passaggio dal tetrametro al giambo (più vicino alla lingua parlata), sia nel fatto che $\mathrm{i}$ tragediografi «hanno anche eliminato le parole

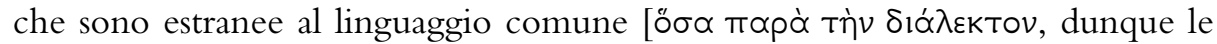
glosse], ${ }^{13}$ grazie alle quali i poeti precedenti abbellivano le loro opere e delle quali tuttora si servono i poeti che compongono esametri» (1404 a 25-35). Assieme all'aspetto di “arcaicità" dell'uso della glossa, ritorna il legame stretto (si direbbe in controtendenza rispetto alla linea prevalente) con la poesia epicoesametrica, legame ribadito a 1406 b 2 con l'affermazione che le glosse sono particolarmente adatte ai poeti epici (oí દ̇тотооюí).

Aristotele non inventa dal nulla il problema della necessità di spiegare le parole difficili nelle opere poetiche e neppure l'uso per esse del termine "glossa". Pfeiffer ha molto ben evidenziato i significativi precedenti della trattazione aristotelica, per cui basta qui un piccolo promemoria. Credo che egli abbia assolutamente ragione quando afferma che già i rapsodi, nel recitare i poemi, dovevano trovarsi nella necessità di offrire embrionali forme di interpretazione, fra cui la spiegazione delle parole difficili di uno stile certamente assai estraneo rispetto al linguaggio comune del loro pubblico, e che di questa più antica

11 Pfeiffer 1968, pp. 12, 75-79 = pp. 55, 142-147.

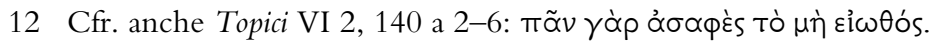

13 Poco più avanti dice che Euripide ha indicato la strada di utilizzare nella composizione poetica le parole della lingua corrente (1404 b 24-25). 
esegesi si trovano tracce nei poeti arcaici e classici. ${ }^{14}$ Pfeiffer mette in evidenza, da questo punto di vista, il significato dell'interesse dei Sofisti per la lingua e degli studi dedicati ai fenomeni linguistici. Fra questi, Prodico si distinse per le sue riflessioni su problemi della lingua e in particolare sui sinonimi e le distinzioni di significato, che - dice Pfeiffer - lo portarono «alla consapevolezza dell'uso diverso nelle diverse parti del paese», tanto che riteneva che Pittaco non sapesse ben distinguere le parole in quanto Lesbio e educato in una lingua straniera (Plat., Prot. $341 \mathrm{c}$ ); inoltre «Platone nel suo Cratilo [401 c] pare abbia

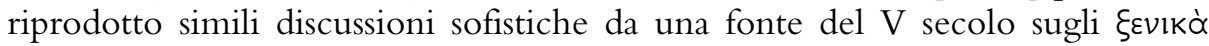
óvómata, quando egli riporta parole eoliche o doriche come 'straniere', cioè diverse dalla famigliare forma attica». ${ }^{15} \mathrm{Nel}$ dossier che stiamo evocando per

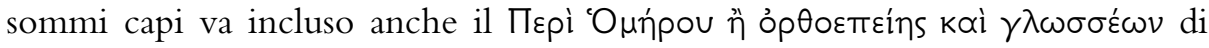
Democrito, opera di cui peraltro può essere dubitata anche la forma del titolo. ${ }^{16}$ Infine, è ben noto il fr. 233 PCG dei $\Delta \alpha \mathrm{l} \tau \alpha \lambda \tilde{n} s$ di Aristofane (commedia rappresentata nel 427 a.C.), ${ }^{17}$ nel quale si trova una delle più antiche testimonianze sull' esegesi omerica e in particolare sulla pratica di spiegare le parole difficili nell'ambito del sistema educativo ateniese del V secolo. Ci sono problemi di ricostruzione puntuale del frammento, ma il senso generale appare acquisito: a un giovane viene chiesto (a quanto pare dal padre) di spiegare e interpretare alcune "glosse" omeriche ( $\left.\lambda \varepsilon \dot{\varepsilon} \xi \circ v^{~ ' O \mu n ́ p o u ~} \gamma \lambda \omega^{\prime} \tau \tau \propto s\right)$; a questo segue la richiesta di spiegare una parola forse di Solone e poi un'altra da un'opera ignota. ${ }^{18}$ Abbiamo dunque due glosse omeriche e due di altra provenienza, per le quali si pone una questione di lessico arcaico e obsoleto.

In sostanza, ci sono tutti gli elementi per essere certi che Aristotele codifica come metodo esegetico e come criterio di analisi stilistica una prassi abbia variatamente diffusa, non solo a livello dell'educazione dei giovani, ma anche in ambiti culturali di diverso tipo, dall'attività dei rapsodi alle riflessioni linguistiche dei filosofi. Ma è importante sottolineare il fatto che lo strumento esegetico si basa, e non potrebbe essere altrimenti, sull'osservazione di una caratteristica essenziale e distintiva del linguaggio dell'epica omerica, e di conseguenza, anche se magari in misura diversa, di quello degli altri generi poetici "alti",

14 Pfeiffer 1968 , pp. $4-5,12,79=$ pp. 45-46, 55, 147; sulle più antiche tracce nei poeti di interpretazione di parole problematiche cfr. anche Montanari 1976, pp. 208-210, con bibliografia.

15 Pfeiffer 1968, pp. 37-43 = pp. 91-99: le citazioni sono a p. $41=96$, dove egli ricorda anche che Erodoto, I 142. 3-4, distingue varianti dello Ionico parlate in diverse città (vedi Asheri 1988, p. 348, ad loc.).

16 Pfeiffer 1968, pp. 42-43 e $79=$ pp. 97-99 e 147.

17 Cfr. Pfeiffer 1968, pp. 14-15 e 79 = pp. 59 e 147; Cassio 1977, pp. 75-77.

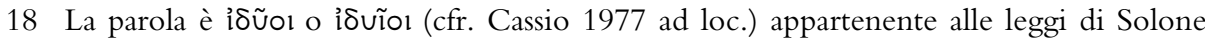
secondo Elio Dionisio 14 Erbse (citato da Eustazio 1158, 20): per la precisione Elio Dionisio la attribuisce a Dracone e a Solone, Fozio, Lex. 136 al solo Solone (fr. 41 b Ruschenbusch); si tratta evidentemente di un termine del linguaggio giuridico. Cfr. Montanari 2003. 
fino naturalmente alla tragedia. Anzi, poiché in ordine logico, e in base a una regola generale, l'osservazione del fenomeno è il fondamento da cui consegue la legittimità di uno strumento esegetico, è consentito chiamare in causa la glossa nell'interpretazione della poesia per il fatto che la glossa stessa è un riconosciuto elemento espressivo dello stile e del linguaggio poetico.

Proviamo ora a seguire specificamente la linea della glossa in quanto elemento estraneo per motivi dialettali, ricordando che Aristotele non ha mancato di precisare che lo stesso elemento lessicale può essere sia glossa sia dominante, ma non per le stesse persone, cioè non nello stesso periodo e nello stesso luogo. Fra gli esempi di glosse addotti da Aristotele nella Poetica, due sono chiaramente indicate come di carattere dialettale: 1) la parola oíruvov appartiene al dialetto cipriota, per cui a Cipro è un elemento linguistico kúpiov, mentre per gli Ateniesi è una glossa; 2) in Il. 10. 316 عĩoos kokós significa che Dolone era brutto in viso e non deforme nel corpo: si tratta di un uso dialettale di Creta,

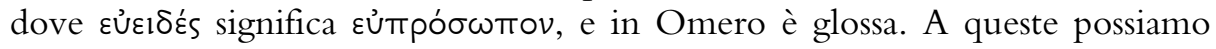
aggiungere la parola costituita da un triplice composto, citata all'inizio del cap. 21 (1457 a 35) come in uso a Marsiglia: le parole composte sono anch'esse un elemento del linguaggio poetico elevato e direi che qui possiamo parlare di una parola composta che è anche una glossa per motivi dialettali.

Se ci volgiamo ora finalmente agli scholia omerici, possiamo come primo passo provare a gettare uno sguardo, anche cursorio, all'Index V: Res potiores, imprimis grammatica et rhetorica dell'edizione degli Scholia in Iliadem di H. Erbse, s.v. Dialecti (vol. VII, pp. 84-88). La quantità di materiali elencata è assai grande e toglie subito l'illusione di analizzarla tutta per un'occasione come questa, specie se all' Iliade si volesse aggiungere anche l'Odissea. Alla ricerca di un punto di partenza nel mare magnum, un'indagine che possiamo fare è verificare se nella scoliografia omerica conservata troviamo la menzione di glosse dialettali attribuite alle due aree geografiche citate nella Poetica, vale a dire Cipro e Creta. L'avvio è un po' occasionale, ma il risultato mi pare di un certo interesse. Cominciamo dal fatto che negli scholia omerici ho trovato 13 glosse attribuite al dialetto cipriota: tutte riguardano l'Iliade.

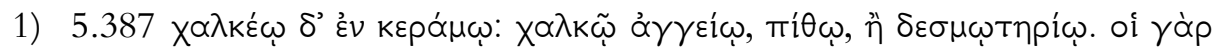

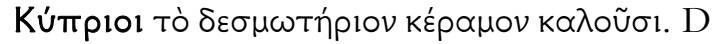

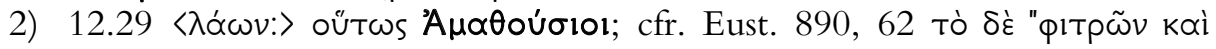

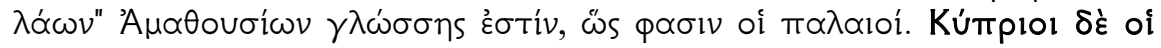

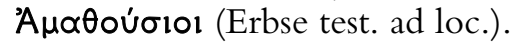

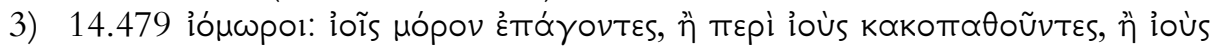

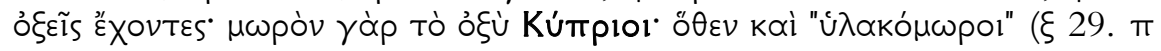
4).

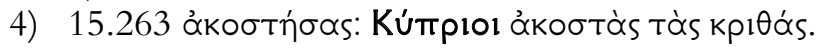

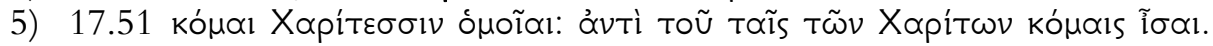

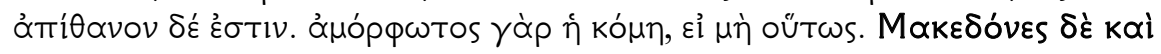

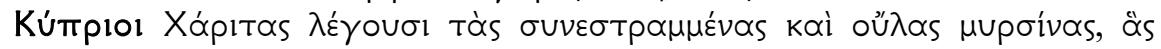


$\phi \propto \mu \dot{\varepsilon} v \sigma т \varepsilon \phi \propto v i ́ t 1 \delta \propto s . \mathrm{D}$

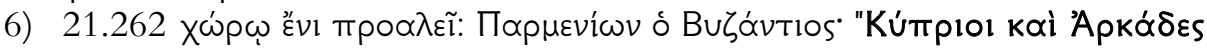

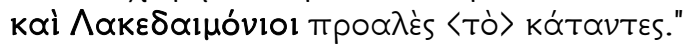

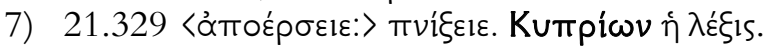

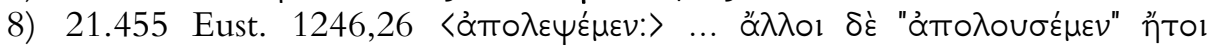

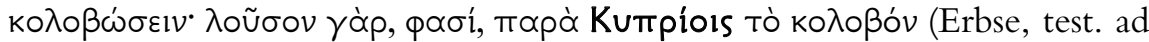
loc.).

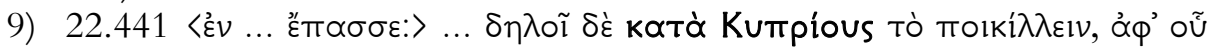

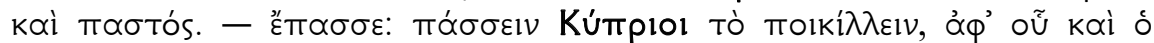
Tळótós. ${ }^{19}$

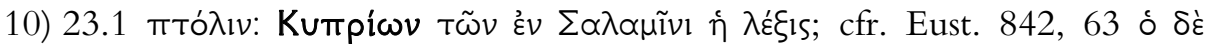

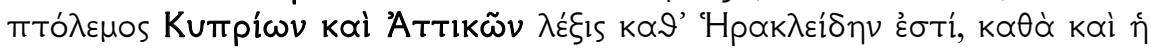
$\pi т \hat{\lambda}_{15}$ (Erbse test. ad loc.).

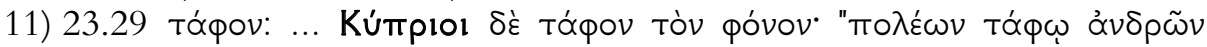

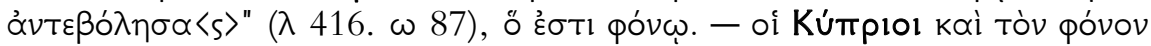

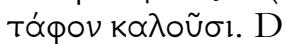

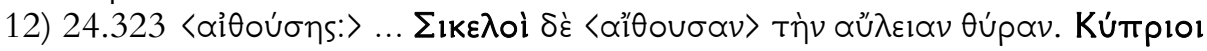

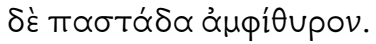

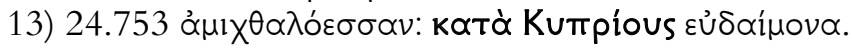

Non possiamo soffermarci su tutti questi casi, facciamo solo qualche osservazione sparsa. Nel nr. 1 la possibile glossa cipriota aggiunge una sfumatura al significato del passo: la straordinarietà dell'imprigionamento di Ares da parte degli Aloadi, Oto ed Efialte, dentro un grande vaso di bronzo ne risulta intensificata se la parola usata dal poeta per indicare il vaso, come glossa cipriota può significare anche $\delta \varepsilon \sigma \mu \omega t \eta \dot{p}$ iov, "prigione".

Nel nr. 2 osserviamo che il riferimento al dialetto cipriota è precisato con il rimando alla parlata specifica della città di Amatunte.

Nel nr. 3 ióuwpos viene comunque ricondotto a lós "dardo", ma per la se-

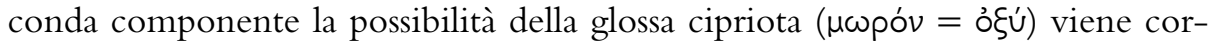
roborata con due rimandi interni all'epica, cioè a un aggettivo usato due volte nell'Odissea.

Nel nr. 4 il valore del verbo ớkoбтóc usato per il cavallo che si nutre alla greppia è interpretato sostenendo che ớkoбtń per "orzo" è parola cipriota. Altrove però la stessa parola è indicata come tessalica: in sch. 6.506-8 leggiamo

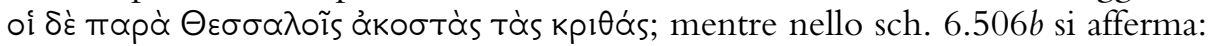

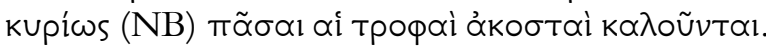

Nel nr. 8 la glossa cipriota è invocata per interpretare la variante

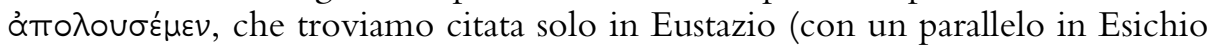
$\propto$ 6465), ma è del tutto assente nella tradizione diretta e anche negli scholia.

19 Nello stesso verso si trova la parola $\theta$ póva, per la quale lo sch. a Teocrito 2, 59-62,

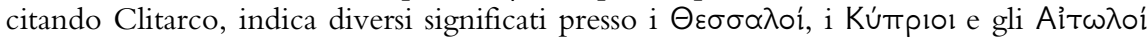
(cfr. Erbse, Sch. Iliad., test. ad loc.). 


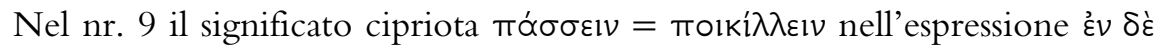

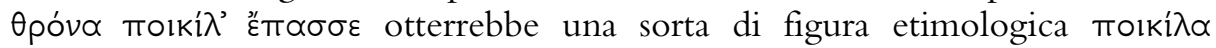

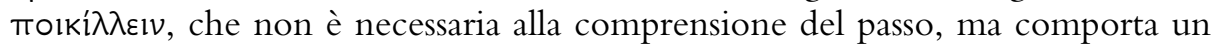
certo impreziosimento stilistico.

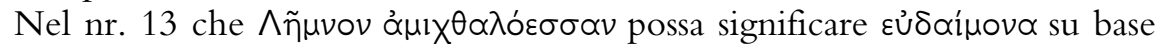
cipriota è una possibilità addotta per spiegare un epiteto di significato incerto (cfr. LfrE s.v.).

In quattro degli esempi citati, assieme al cipriota vengono chiamati in causa altri dialetti: nel nr. 5 il macedone, nel nr. 6 l'arcadico e il lacedemone, nel nr. 10 l'attico, nel nr. 12 il siciliano. Dell'attico avremo occasione di parlare più avanti, ora facciamo qualche rapida considerazione sugli altri dialetti menzionati.

Macedone. La parola ớtta è indicata come macedone nello sch. a Od. 16.31, come tessalica nello sch. D a Il. 9.607 (cfr. LfrE s.v.). Nello sch. Il. $20.404 c$ una parola macedone con vocalismo /a/ viene menzionata accanto a un gruppo di parole che si trovano Tapò $\Delta \omega p \_\varepsilon \tilde{\sigma} \sigma$.

Arcadico. Nello sch. Il. 13.390a per l'aggettivo omerico $\beta \lambda \omega \theta \rho \eta ́$ vengono elencati una serie di significati secondo diversi dialetti (cfr. LfrE s.v.): degli Arcadi, dei Beoti, di Magnesia (in Tessaglia, in Caria, in Lidia?), dei Driopi (popolazione di stirpe ionica: Erodoto I 146.1 ecc.), dei Tirreni, di Caristo (in Eubea). Nello sch. Il. 14.385 il significato della parola ơop presso gli Arcadi e gli Etoli viene distinto da quello omerico.

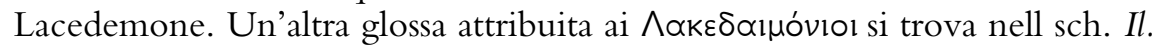

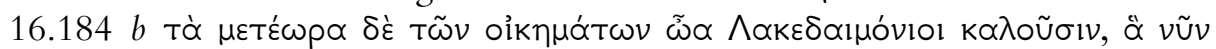

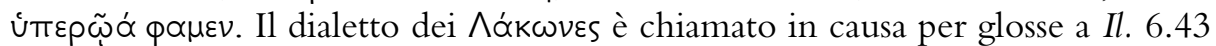

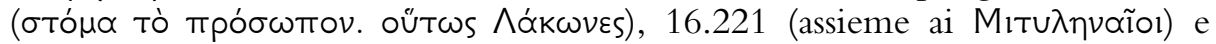
23.83 (^র́kw

Siciliano. Non ho trovato altri riferimenti al dialetto siciliano. Un'affermazione dello sch. Od. 20.383 potrebbe avere anche implicazioni

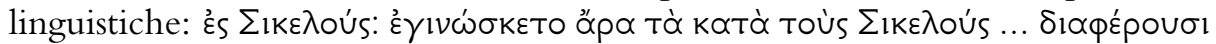

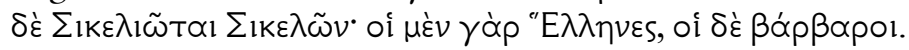

Passiamo ora al dialetto cretese, al quale troviamo riferite 5 glosse, quattro nell'Iliade e una nell'Odissea; non c'è traccia negli scholia della glossa a Il. 10. 316 discussa da Aristotele nella Poetica (cfr. sopra, passo nr. 5, 1461 a 10-15; vd. Erbse ad loc.).

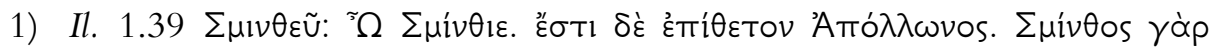

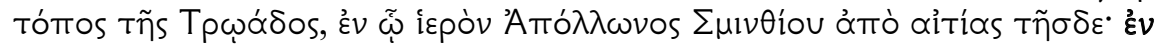

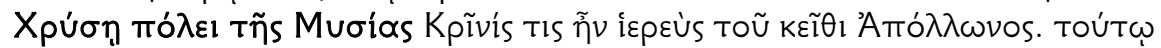

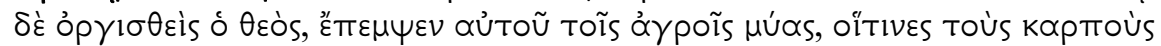

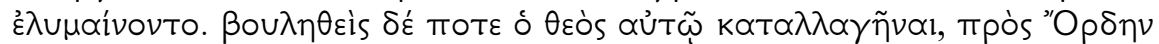

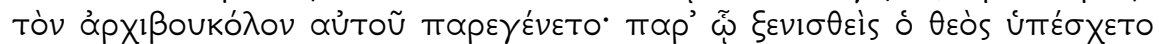

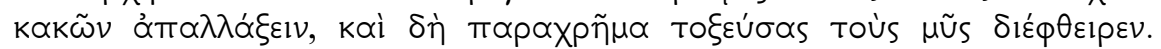

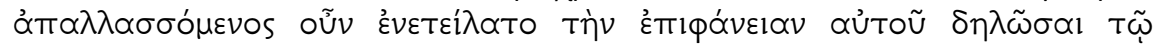




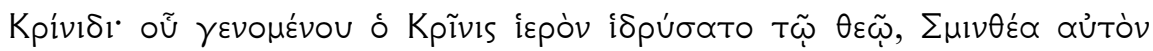

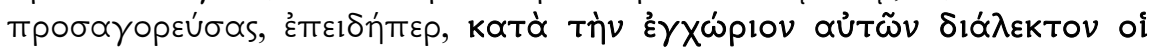

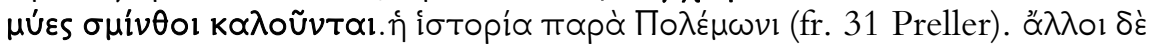
oÚt

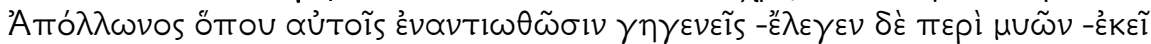

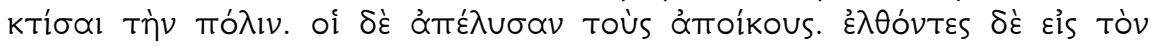

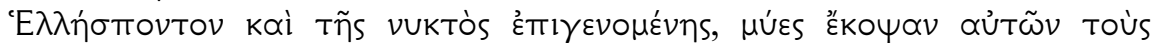

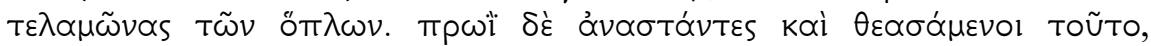

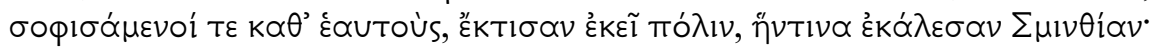

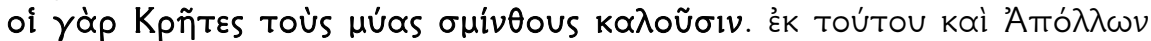

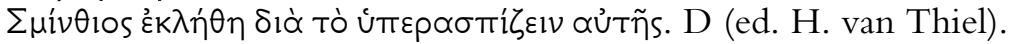

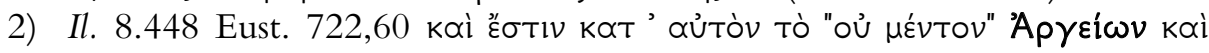

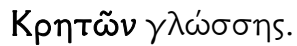

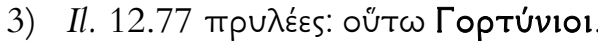

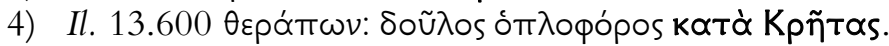

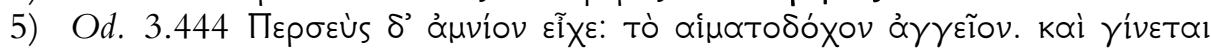

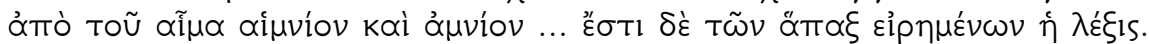

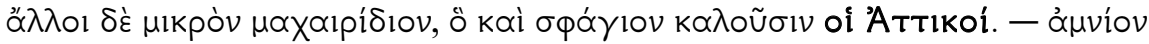

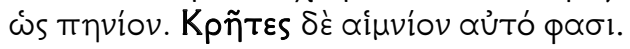

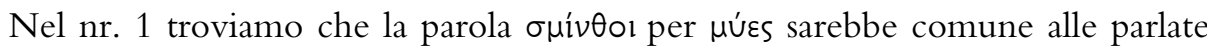
di Creta e della Misia: nel testo omerico essa rappresenta comunque una glossa dialettale, la cui conoscenza è essenziale per capire il significato dell'epiteto con il quale il sacerdote Crise si rivolge ad Apollo. È interessante osservare che, benché per la città della Misia e per Creta siano addotte due storie mitiche differenti, l'epiteto di Apollo viene ricondotto comunque al nome con il quale si indicano $i$ topi nei due dialetti.

Nr. 2: Eustazio (cfr. Erbse, test. ad loc.) è la sola fonte della variante $\mu \varepsilon ́ v$ Tov, risalente a Eraclide di Mileto, per il comunemente tràdito $\mu \varepsilon ́ v \theta \eta \eta$ : si tratterebbe di un'espressione appartenente ai dialetti argivo e cretese.

Nel nr. 3 si identifica una glossa cretese, per la quale si specifica l'appartenza al dialetto di Gortina (cfr. Eust. 893,32; Erbse, test. ad loc.).

Nel nr. 4, per áuvíov il primo significato è "vaso che raccoglie il sangue"

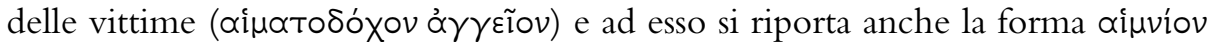

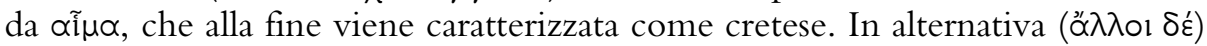
viene menzionato un altro possibile significato, secondo cui åxuviov sarebbe

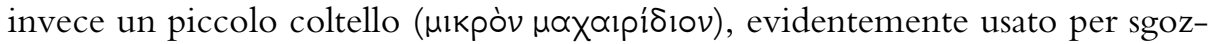
zare la vittima sacrificale; segue un riferimento all'attico, secondo cui questo

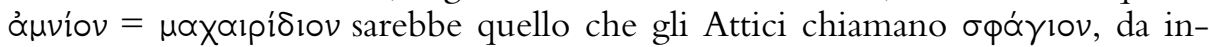

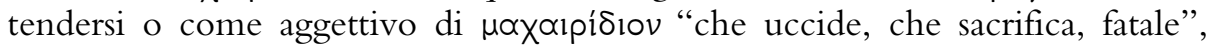
oppure anche come sostantivato "l'uccisore, il sacrificatore". Insomma, le due

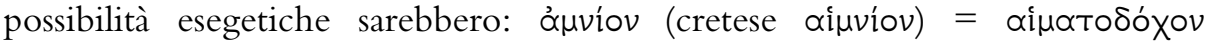

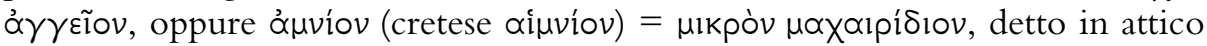
opóy lov. In ogni caso, è certo che questo scolio non parla di una glossa attica 
nella lingua omerica, bensì cita l'equivalente attico di uno dei possibili significati della parola omerica, caso mai molto vicina a un elemento lessicale cretese, utilizzando dunque l'attico come lingua di riferimento.

Questa rassegna è stata già troppo lunga per l'occasione: essa ovviamente non ha altro scopo se non quello di fornire una esemplificazione, che ormai mi pare abbastanza significativa, per quanto limitata. Abbiamo già incontrato per la lingua omerica svariati riferimenti a un notevole numero di "dialetti" appartenenti a diverse aree geografiche, più spesso identificati con il nome del popolo che li parla, più raramente con una indicazione geografica del luogo: cipriota

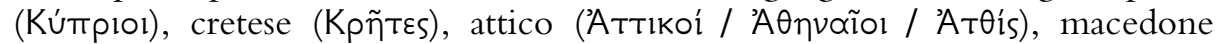

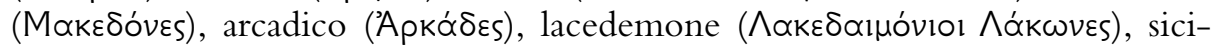

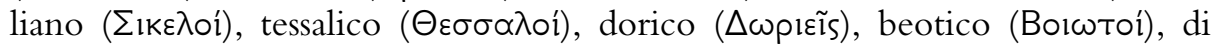
Magnesia (in Tessaglia, in Caria o in Lidia?), dei Driopi (popolazione di stirpe ionica, cfr. sopra), dei Tirreni, di Caristo (in Eubea), di Mitilene, della Misia. Nell'insieme, tenendo presente indici e ricerche operate con il TLG elettronico, vediamo intanto utilizzate denominazioni che vanno da quelle dei grandi

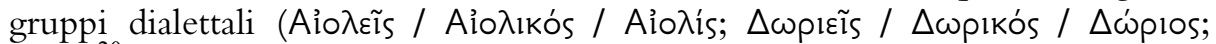

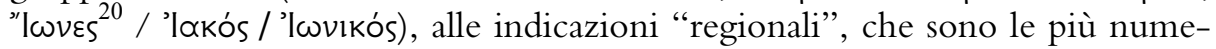
rose (Attica, Tessaglia, Beozia, Cipro, Creta, Macedonia, Etolia ecc.), fino all'individuazione di singole città, come Mitilene, Gortina di Creta o Amatunte di Cipro. Devo confessare che, pur avendo da molto tempo una certa percezione di quanto fosse ricco e variegato il quadro dei riferimenti ai "dialetti" della lingua greca negli scholia omerici e pur sapendo bene che per questo intervento non sarei certo riuscito a esaminare tutto il materiale, quando mi sono messo concretamente al lavoro la realtà si è rivelata ancora più sorprendente delle attese. Oltre a quello che abbiamo sotto gli occhi, dobbiamo considerare due fatti: 1) ciò che rimane nelle raccolte scoliografiche è una piccola parte di quanto fu prodotto dalla filologia antica; 2) la documentazione può essere arricchita da altre cospicue fonti, come il grande e importantissimo mare della lessicografia, Eustazio (che sopra abbiamo citato sporadicamente), altra saggistica omerica di vario genere. Ne risulta senza ombra di dubbio che la quantità e la varietà dei materiali dialettali chiamati in causa dalla critica omerica antica era ampia e abbondante, e porta alla nostra attenzione un fenomeno di straordinario interesse.

Mi limito a menzionare la prospettiva per cui sarebbe certamente interessante seguire e approfondire le possibili implicazioni delle notizie di contenuto dialettale della critica omerica antica a livello di geografia, usi e costumi dei popoli, mitologia. Per indicare un esempio, si può pensare al caso di Il. 1.39, con le due diverse vicende di Apollo collocate una in Misia e l'altra a Creta, e connesse all'epiteto del dio in base al comune nome dialettale dei topi ( $\sigma \mu i ́ v \theta_{0}$ $=\mu u ́ \varepsilon s)$ : Apollonio Sofista 143.9 ci informa che Aristarco collegava l'epiteto

20 lóoves in sch. Il. 13.685. 
con la città di Sminte, nella Troade (dove un culto di Apollo Sminteo esisteva, ma era diffuso anche fuori dalla Troade, peraltro non lontana dalla Misia), e che Apione chiamava in causa una processione Sminteia di Rodi, anch'essa collegata a un intervento di Apollo contro un'invasione di topi.

Lascio da parte la possibilità, o la tentazione, di affrontare questo insieme di dati dal punto di vista della dialettologia greca come è intesa e studiata dalla filologia e linguistica moderna: è un tipo di ricerca che comunque esula ampiamente dalle mie competenze e di cui al momento non mi sento in grado di immaginare le possibilità e i risultati.

Abbiamo evocato all'inizio in estrema sintesi gli elementi del vario e complesso quadro degli antichi studi dialettologici, al quale questi materiali si possono ricollegare. Torniamo ora al punto di vista dello stile e del linguaggio poetico. L'analisi degli antichi delle lingue letterarie dei diversi autori (o anche generi) è ancorata a un principio fondamentale: ogni autore scrive in una lingua essenzialmente e generalmente caratterizzata dall'ambito culturale e geografico principale in cui ha vissuto e operato, nella quale si registra l'innesto e la compresenza più o meno occasionale di elementi presi da dialetti diversi, riutilizzati all'interno di una lingua poetica entro la quale giocano quel ruolo di "glosse" che abbiamo descritto sulle orme di Aristotele: la glossa è un abbellimento dello stile per l'effetto di "estraneità" che comporta; la stessa parola è glossa se inserita in una base di altro dialetto, mentre non è glossa se utilizzata entro una base dello stesso dialetto. ${ }^{21}$

Le testimonianze mostrano che l'individuazione e spiegazione della glossa dialettale può offrire un elemento in più di comprensione del passo, oppure chiarire un aspetto non immediatamente o non del tutto comprensibile: lo sviluppo degli studi dialettologici e l'arricchimento di materiali a disposizione, nei trattati e nelle raccolte, offre al filologo esegeta una strumentazione che diventa sempre più ricca e potente. ${ }^{22}$ Tuttavia, se la base metodologica per l'uso del concetto e per la ricerca della glossa come strumento ermeneutico appare ben chiara, la sua applicazione, almeno in parte, rivela aspetti che lasciano abbastanza perplessi e che, mi pare, invitano a considerare il fenomeno anche da un altro punto di vista.

21 Per questi concetti cfr. da ultimo Cassio 1993a, 1993b, 1997, e le sintesi in Cassio 2008 (soprattutto cap. 3, pp. 70 sgg., e il contributo di C. Vessella, pp. 392-395).

22 Anche per questo aspetto degli sviluppi nell'ambito della filologia alessandrina deve esserci stato un impulso aristotelico-peripatetico. All'osservazione dei dialetti della Grecia e della loro diversificazione orientavano fattori quali: l'interesse per i vari usi e costumi (evidente per esempio nella raccolta delle Politeiai, ricche di dati materiali); lo studio del fatto linguistico in quanto tale e legato alla poesia (Retorica e Poetica); le ricerche, sviluppate dai peripatetici fino dalle prime generazioni, sulle personalità e le opere dei poeti, che portavano in evidenza la diversificazione dialettale. E uno degli aspetti da approfondire a proposito del rapporto tra Aristotele e scuola peripatetica e la filologia ed erudizione di età ellenistica: cfr. Montanari (cur.) 1994, 2000, 2001, 2008; Schironi 2009; Cadoni 2010; sintesi in Montanari, Peripatos, in corso di pubblicazione. 
Non intendo riprendere la discussione dei tre esempi di glosse omeriche addotti da Aristotele nel cap. 25 della Poetica, i cui elementi sono noti. Ricordiamo in breve solo il caso in cui viene menzionato un elemento dialettale,

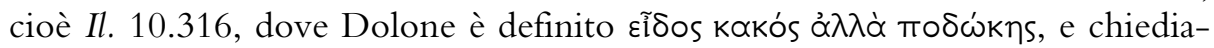

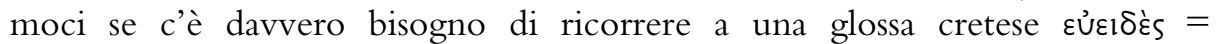
$\varepsilon \cup ̉ \pi p o ́ \sigma \omega \pi$ ov per spiegare come l'espressione non contenga una contraddizio-

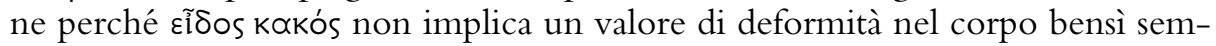
plicemente di bruttezza, che non contrasta per nulla con il fatto di essere un buon corridore.

Di quelli discussi sopra, riprendiamo per esempio il caso di Il. 17.51, dove

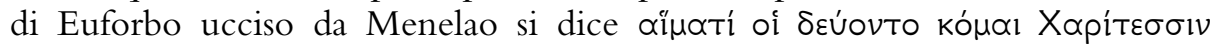

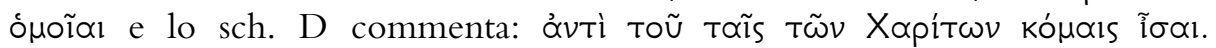

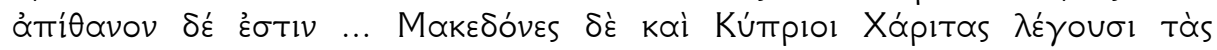

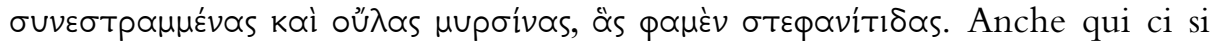
chiede quanto sia "inventato" il problema e il conseguente ricorso a una glossa

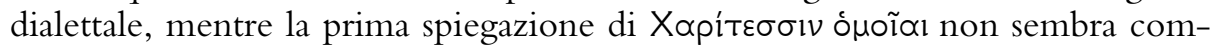
portare alcuna vera difficoltà.

Se l'interpretazione dell'epiteto di Apollo Smintio in Il. 1.39 si giova effettivamente degli elementi dialettali addotti, insieme al racconto delle vicende mitiche che vedono il dio protagonista, bisogna dire che in altri casi l'elemento dialettale invocato per fornire un'interpretazione non appare affatto strettamente o fondamentalmente necessario per capire il passo. Per essere forse un po' brutali, talvolta sembra che ci sia un interesse primario a "inventare" il problema esegetico, a "scoprire" per forza una glossa nel dettato poetico, allo scopo di utilizzare l'elemento dialettale essenzialmente per avere l'occassione di spiegarlo o almeno di arricchire le possibilità esegetiche (si pensi ai casi in cui viene elencata una serie di significati possibili a seconda del dialetto, come per esempio nello sch. Il. 13.390a, citato sopra per l'arcadico). Se talvolta l'elemento dialettale appare effettivamente utile per capire un passo oscuro caratterizzato da una glossa, altre volte esso sembra servire piuttosto per aggiungere al passo una sfumatura che in qualche modo conferisce maggior valore al significato del testo, oppure per offrire un'informazione che riveste essenzialmente un interesse erudito. Allo scopo di perseguire un elemento addizionale che risulta interessante essenzialmente dal punto di vista dell'interprete, sembra profilarsi una sorta di vera e propria "caccia alla glossa" per avere l'occasione di spiegarla, adducendo un dato dialettale con un suo portato di significati aggiuntivi e/o di particolari eruditi. Si direbbe insomma che si vede all'opera una precisa volontà di far emergere ed evidenziare un ricco e inusitato pluridialettalismo omerico, utile anche per quello che porta in più di contorno al testo. A questo fine, il metodo aristotelico della scoperta e analisi della glossa a scopi ermeneutici, lo strumento esegetico messo nelle mani di critici e filologi in base a una precisa analisi del linguaggio e dello stile, subisce un'applicazione indebitamente allargata e estensiva, con il risultato di arricchire il bottino dialettale di un considerevole numero di "scoperte" piuttosto discutibili per quanto riguarda la lingua 
omerica, il che non vuol dire - e questo è un altro aspetto del problema - che siano false o sbagliate sul piano puramente dialettologico in quanto tale. In fin dei conti, quell'idea di mescolanza dialettale nella lingua poetica di ogni autore, fatta di sporadici innesti su una base ben caratterizzata, per il caso particolarissimo di Omero sembra equivalere a una compresenza di tutti i dialetti conosciuti, che si risolve nel pervicace tentativo di ritrovarne ad ogni costo la testimonianza nei poemi. Un'idea che trova espressione in un passo dello ps.

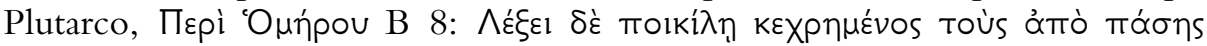

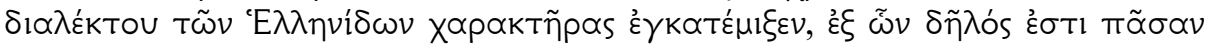

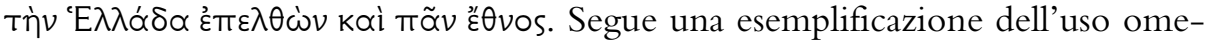
rico di dorico, eolico, ionico, per arrivare all'affermazione (cap. 12) $\mu \alpha^{\prime} \lambda_{l} \sigma \tau \alpha \delta \dot{\varepsilon}$

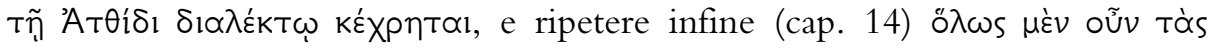

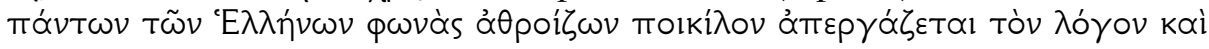

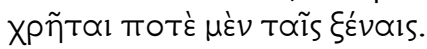

Era Aristarco il sostenitore dell'idea che Omero fosse di origine ateniese e che la lingua di Omero fosse una forma arcaica di Ionico, parlata anticamente in Attica, prima che si diffondesse nelle aree ioniche: nell'uso omerico essa poteva essersi arricchita di tratti dialettali appartenenti ad altre aree della Grecia, che il poeta avrebbe conosciuto nelle sue peregrinazioni. Con questa impostazione, il caso di Omero viene di fatto in qualche modo ricondotto al modello generale: una lingua base caratterizzata dall'ambito culturale e geografico principale in cui il poeta ha vissuto, nella quale si innestano elementi di altri dialetti che funzionano come "glosse". Si tratta peraltro, per il problema della lingua, di una visione coerente con l'impostazione storico-filologica aristarchea per gli altri aspetti e settori dell'omeristica: non si possono attribuire a Omero, per mezzo dell'allegoresi, visioni del mondo e ideologie a lui estranee o posteriori, né gli si possono attribuire conoscenze di qualunque tipo, che si sono manifestate o sono state scoperte in tempi posteriori. Un'analisi storico-filologica altrettanto rigorosa impedisce di attribuire alla lingua di Omero la commistione e la compresenza di tutti i dialetti del mondo greco, vale a dire l'utilizzazione di un impasto linguistico storicamente inspiegabile e inaccettabile. Al rifiuto alessandrino-aristarcheo dell'anacronismo e dell'incoerenza cronologica e storico-culturale si contrapponevano, come è ben noto, tendenze critiche ed ideologiche di segno opposto, capaci di attribuire ad Omero ogni filosofia e religione, e di farne l'origine e il serbatoio di tutte le conoscenze. Quest'ultima idea, nell'ambito della scoliografia, è ben rappresentata nel corpus dei cosiddetti scholia exegetica, mentre è assente negli scholia provenienti dalla linea genuinamente aristarchea del cosiddetto VMK (Viermännerkommentar: Didimo, Aristonico, Nicanore, Erodiano). Gli scholia con riferimenti a glosse dialettali che ho esaminato finora sono tutti scholia exegetica oppure scholia D o passi di Eustazio probabilmente riconducibili a scholia exegetica perduti; ${ }^{23}$ nessuno proviene da VMK.

23 Fenoglio 2009. 
Una diversa testimonianza, tuttavia, si aggiunge al quadro che abbiamo avuto davanti fino a questo punto. Nel suo intervento (pubblicato in questo volume) René Nünlist ha menzionato due scholia di Aristonico che offrono un'informazione dialettale interessante e che vale la pena esaminare.

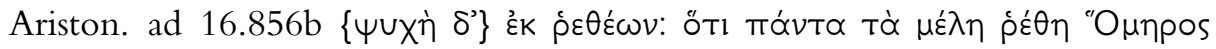

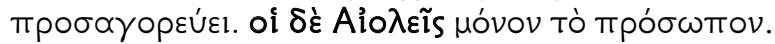

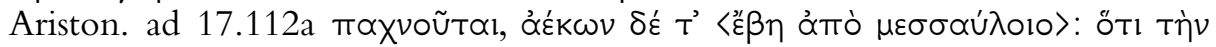

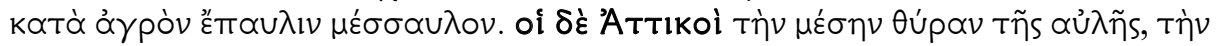

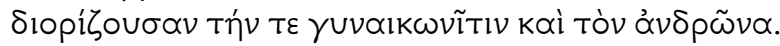

A proposito di 16.856 , si dice che $\rho \dot{\varepsilon} \theta 0$ in Omero indica tutti i $\mu \dot{\varepsilon} \lambda \eta$ del cor-

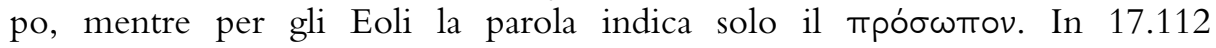
l'osservazione riguarda la diffenza di significato della parola $\mu \varepsilon ́ \sigma \propto v \lambda{ }^{\circ} v$ in Omero e nell'uso attico (scil. posteriore). Si tratta dunque chiaramente di due casi nei quali il dato dialettale non viene addotto per interpretare un qualsiasi aspetto del testo omerico, bensì come una considerazione aggiuntiva di carattere linguistico-lessicale, un'osservazione erudita che non risulta per nulla funzionale all'esegesi. Simili osservazioni possono rientrare nella prospettiva aristarchea, già ricordata sopra, cioè in sostanza risalire allo scopo di evidenziare che la lingua di Omero era una forma arcaica di ionico, parlata anticamente in Attica, diversa dunque per esempio dall'eolico (primo caso) e anche dall'attico (secondo caso). Il fatto che le si trovi in scholia di Aristonico, normalmente improntati a dottrina aristarchea, va in questa direzione, ed è importante proseguire e ampliare la ricerca per vedere se altre testimonianze dello stesso genere possono confortare questa idea.

Per tirare le somme, diremo che l'inusitata e particolare ricchezza di materiali dialettali nei resti della critica omerica antica (di cui quanto conservato non può che essere solo una parte, per di più assai parzialmente esaminata qui) costituisce un fenomeno di fronte al quale si delineano a mio avviso due possibilità interpretative, almeno per il momento.

1) Esso può rappresentare un altro settore che si aggiunge all'idea generale non aristarchea di Omero origine e serbatoio di tutte le conoscenze: anche per la lingua e per i dialetti in Omero si può trovare tutto, ogni cosa di ogni luogo e di ogni tempo, il che serve molto per chi lo interpreta, come in molte altre sfere del sapere.

2) Può trattarsi di tracce risalenti alla visione aristarchea: individuazione (anche grazie all'evidenziazione di differenze specifiche) della base della lingua omerica costituita da una forma arcaica di ionico dell'Attica, arricchita occasionalmente di elementi dialettali variegati e riconosciuti come glosse.

Se dovessi esprimere un'opinione a questo stadio della ricerca, direi che mi sembra più probabile la prima ipotesi per tutte le testimonianze la cui fonte scoliografica è costituita dagli scholia exegetica, mentre è verisimile che la seconda valga piuttosto per i materiali offerti da una fonte di derivazione aristarcheoalessandrina (scholia di VMK, come i due citati di Aristonico). Non mi sento 
affatto di escludere tuttavia che entrambi i fattori abbiano giocato un ruolo in momenti e stratificazioni diversi dell'erudizione omerica e che i loro effetti si siano mischiati nella composita tradizione di un materiale molto miscellaneo, nel quale le osmosi di contenuti non sono certo inusitate. Ciò di cui sono certo è che la ricerca è ben lungi dall'essere terminata: mi accontento di averne impostato $\mathrm{i}$ termini e individuato $\mathrm{i}$ binari sui quali camminare.

\section{Bibliografia}

Ascheri P., Demetrius [14] Ixion, 2009, in LGGA.

Ascheri P., Demetrio Issione "dialettologo": l'attico e il dialetto degli Alessandrini, in: Aner Polytropos. Ricerche di filologia greca antica dedicate dagli allievi a Franco Montanari, a cura di Fausto Montana, Roma 2010, pp. 125-152.

Asheri (cur.): Erodoto. Le storie. Libro I. La Lidia e la Persia, a cura di David Asheri, Milano 1988.

Ax W., Aristophanes von Byzanz als Analogist: zu Fragment 374 Slater (= Varro, de Lingua latina 9, 12), Glotta 68, 1990, pp. 4-18 (rist. in Lexis und Logos. Studien zur antiken Grammatik und Rhetorik, hrsg. von Farouk Grewing, Stuttgart 2000, pp. 116-127).

Barabino A., Una nota sul concetto aristotelico di $\gamma \lambda \tilde{\omega} \sigma \sigma \alpha$, in: Aner Polytropos. Ricerche di filologia greca antica dedicate dagli allievi a Franco Montanari, a cura di Fausto Montana, Roma 2010, pp. 163-170.

Bywater (cur.): Aristotle. On the Art of Poetry, rev. Text with Intr., Transl. Comm. by I. Bywater, Oxford 1909.

Cadoni, N., Aristotele e l'omeristica antica: sondaggi su j̃̈os, in: Aner Polytropos. Ricerche di filologia greca antica dedicate dagli allievi a Franco Montanari, a cura di Fausto Montana, Roma 2010, pp. 3-39.

Callanan C. K., Die Sprachbeschreibung bei Aristophanes von Byzanz, Hypomnemata 88, Göttingen 1987.

Cassio (cur.): Aristofane, Banchettanti, a cura di Albio Cesare Cassio, Pisa 1977.

Cassio (cur.): Storia delle lingue letterarie greche, a cura di Albio Cesare Cassio, Firenze 2008.

Cassio A. C., Alcmane, il dialetto di Cirene e la filologia alessandria, RFIC 121, 1993, pp. 24-36.

Cassio A. C., Parlate locali, dialetti delle stirpi e fonti letterarie nei grammatici greci, in: Emilio Crespo - José Luis García Ramón - Araceli Striano, Dialectologica Graeca. Actas del II coloquio internacional de dialectologia griega, Madrid 1993, pp. 73-90.

Cassio A. C., Futuri dorici, dialetto di Siracusa e testo antico dei lirici greci, AION(filol) 19, 1997, pp. 187-214.

Erbse (cur.): Scholia Graeca in Homeri Iliadem (Scholia Vetera), rec. H. Erbse, voll. I - VII, Berlin-New York, 1969-1988.

Fenoglio S., La riflessione sui dialetti nei Commentarii all'Odissea di Eustazio di Tessalonica, Quaderni del Dipartimento di Filologia, Linguistica e Tradizione Classica “A. Rostagni", n.s. 8, 2009, pp. 239-254. 
Fortenbaugh-Schütrumpf (cur.): Demetrius of Phalerum. Text, Translation and Discussion, Edited by William W. Fortenbaugh - Eckart Schütrumpf, Rutgers Univ. St. in Class. Humanit. (RUSCH), vol. IX, New Brunswich and London 2000.

Fournet J. L., Alexandrie: une communauté linguistique? ou la question du grec alexandrin, IFAO, Le Caire, 2009.

Gallavotti (cur.): Aristotele. Dell'arte poetica, a cura di Carlo Gallavotti, Milano 1974.

Gudeman (cur.): Aristoteles. Пврі поıптıкñs, hrsg. von Alfred Gudeman, Berlin 1934.

LGGA: Lessico dei Grammatici Greci Antichi, diretto da Franco Montanari, Walter Lapini, Fausto Montana, Lara Pagani: http://www.aristarchus.unige.it/lgga/index.php.

Lucas (cur.): Aristotle. Poetics, Introduction, Commentary and Appendixes by D. W. Lucas, Oxford 1968, 1972².

Montanari (cur.): La philologie grecque à l'époque hellénistique et romaine, Entretiens preparés et présidés par Franco Montanari, Entretiens sur l'antiquité classique, Tome XL, Fondation Hardt, Vandoeuvres-Genève, 1994.

Montanari F., Una glossa omerica pre-alessandrina? (Sch. Il. XVI 235 - Eubulo fr. 139 K.), "Rendiconti Istituto Lombardo - Classe di Lettere", 110 (1976), pp. 202-211.

Montanari F., Demetrius of Phalerum on Literature, in: Fortenbaugh-Schütrumpf 2000, pp. 391-411.

Montanari F., Gli studi omerici di Demetrio Falereo, SemRom 4, 2001, pp. 143-157.

Montanari F., I percorsi della glossa. Traduzioni e tradizioni omeriche dall'antichità alla cultura bizantina, in: Erudizione scolastico-grammaticale a Bisanzio, a cura di Paola Volpe Cacciatore, Napoli 2003, pp. 81-88.

Montanari F., Aristotele, Zenodoto, Aristarco e il serpente pietrificato di Iliade II 319, in: Studi offerti ad Alessandro Perutelli, Roma 2008, vol. II, pp. 237-244.

Montanari F., The Peripatos on Literature: Interpretation, Use and Abuse, Prolusione al Convegno "Filosofi della scuola di Aristotele - Cameleonte e Prassifane", Roma, Istituto Svizzero, 5-7 settembre 2007, in corso di pubblicazione nei Proceedings = RUSCH vol. XVIII, forthcoming.

Nickau K., Zenodotos, RE X A, 1972, 19-49.

Pagani L., Pioneers of Grammar. Hellenistic Scholarship and the Study of Language, in: From Scholars to Scholia. Chapters in the History of Ancient Greek Scholarship, Edited by Franco Montanari - Lara Pagani, Trends in Classics - Supplementary Volumes 9, Berlin - New York 2011, pp. 17-64.

Pfeiffer R., History of Classical Scholarship from the Beginnings to the End of the Hellenistic Age, Oxford 1968 = Storia della filologia classica. Dalle origini alla fine dell'età ellenistica, trad. it. Napoli 1973.

Schironi F., Theory into Practice: Aristotelian Principles in Aristarchean Philology, CPh 104, 2009, pp. 279-316.

Tosi R., La lessicografia e la paremiografia in età alessandrina e il loro sviluppo successivo, in Montanari (cur.) 1994, pp. 143-197 + 198-209. 
Bereitgestellt von | SUB Göttingen Angemeldet

Heruntergeladen am | 27.10.14 12:34 


\title{
Griechenland und Kleinasien in der späten Bronzezeit. Der historische Hintergrund der homerischen Epen
}

\author{
WOLF-DIETRICH NIEMEIER
}

1976 schrieb K. Bittel, der langjährige Ausgräber von Hattusa, der Hauptstadt des Hethiterreichs: ${ }^{1}$,„̈̈gäis ... einerseits und das westliche Vorderasien andererseits stehen im 2. Jahrtausend v.Chr. als Gebiete alter hoher Kultur nebeneinander. Aber die sich ihrer Erforschung widmen, arbeiten noch vielfach auf getrennten Bahnen. Die einen leiten sich von der Altorientalistik, die anderen von der klassischen Archäologie bzw. Alten Geschichte her, was immer noch durch die Wissenschaftstradition bedingte Distanzen mit sich bringt, sodaß man vom einen Gebiet ins andere mit einer gewissen Scheu zu blicken pflegt". So verlief auch schon die Entdeckung der bronzezeitlichen Hochkulturen in beiden Regionen im späten 19. und frühen 20. Jh. sehr unterschiedlich.

Es war das Interesse an den griechischen Mythen und insbesondere an den homerischen Epen, das die archäologische Erforschung der Bronzezeit Griechenlands, des heroischen Zeitalters der antiken Griechen, auslöste. Am Anfang stand Troia/Ilios, der Schauplatz der in der Ilias geschilderten heroischen Kämpfe und tragischen Geschicke voll menschlicher Tiefe.

Die antiken Griechen waren der Überzeugung, dass der Troianische Krieg tatsächlich stattgefunden hatte. Griechische Historiker gaben auf der Grundlage der Kalkulation von Genealogien eine Reihe von Daten für den Fall Troias an, die von 1334 v.Chr. (Douris von Samos) bis 1135 v.Chr. (Ephoros von Kyme) reichen, ${ }^{2}$ d.h. nach unser heutigen Terminologie alle in die Späte Bronzezeit Griechenlands fallen. Homer hat Troias Lage recht genau geschildert: es lag am Hellespont (den Dardanellen), mit dem Berg Ida im Südosten und den Inseln Tenedos und Imbros vor der Küste im Westen und - weiter entfernt - Samothrake, von dessen Höhen man nach Homer Troia sehen konnte. ${ }^{3}$ Bereits die ganze Antike hindurch wusste man daher, dass Troia im Nordwesten Kleinasiens, in der nach Troia benannten Landschaft Troas gelegen hatten. Hier zollten der Perserkönig Xerxes 480 v.Chr. ${ }^{4}$ und Alexander der Große

\footnotetext{
$1 \quad$ Bittel 1976a, 513.

2 Cancik 2001, 174 Schema 2.

3 Luce 1998, 21-53; Latacz 2010, 45ff.

4 Herodot 7, 43.
} 
334 v.Chr., ${ }^{5}$ der erste mit seinem Heer auf dem Weg von Ost nach West, der zweite auf dem Weg von West nach Ost, den homerischen Helden ihren Respekt. Alexanders Pläne zur Vergrößerung und Verschönerung der Kleinstadt führte sein Nachfolger Lysimachos (323-281 v.Chr.) aus. Er ließ einen prächtigen Marmortempel, ein beinahe 8000 Zuschauer fassendes Theater und eine Befestigungsmauer um die Unterstadt errichten. ${ }^{6}$

Für die Römer war Ilios/Ilium von großer Bedeutung als Herkunftsort des Aeneas, des Ahnherrn der Gens Iulia, der bei der Flucht aus seiner Heimatstadt das Palladion und die Laren mit nach Italien gebracht hatte. ${ }^{7}$ Iulius Caesar besuchte 48 v.Chr. die Stadt, gedachte dort seines Vorfahren, versprach den Wiederaufbau von Mauern und Burg und soll später sogar erwogen haben, die Reichshauptstadt hierher zu verlegen. ${ }^{8}$ Augustus hielt sich zwischen 21 und 19 v.Chr. längere Zeit in Ilios/Ilium auf, ließ Heiligtum und Tempel wiederherstellen und ein neues Odeion errichten, ${ }^{9}$ in dem 1997 sein MarmorPorträtkopf gefunden wurde. ${ }^{10}$ Weitere Kaiser, welche die wohlhabende Stadt besuchten, waren 124 n.Chr. Hadrian, 214 n.Chr. Caracalla und 324 n.Chr. Konstantin. ${ }^{11}$ Ähnlich wie Caesar soll letzerer erwogen haben, seine neue Hauptstadt hier zu errichten, bevor er sich für Byzanz entschied. ${ }^{12}$

So suchten auch die europäischen Reisenden seit dem Mittelalter im äuBersten Nordwesten Kleinasiens nach Troia. ${ }^{13}$ Im Dezember 2007 erfuhren aber die Leser der „Frankfurter Allgemeinen Zeitung“, dass der österreichische Schriftsteller R. Schrott Homers Geheimnis gelüftet habe, der Dichter der Ilias diese als Schreiber und Eunuch einer assyrischen Kanzlei 800 km südöstlich von Troia in Kilikien verfasst habe und das Troia Homers die Burg von Karatepe sei. ${ }^{14}$ Im Folgejahr veröffentlichte Schrott seine Thesen dann auch in Buchform. ${ }^{15}$ Weitere Verbreitung fanden sie außerdem durch einen Film der ZDF-Serie Terra X, in dem die Aussagen der aktuellen Troia-Mannschaft so entstellt wurden, dass diese beim ZDF protestierten. Schrotts jeglicher seriöswissenschaftlicher Grundlage entbehrenden Thesen wurden in mehren Beiträgen widerlegt. ${ }^{16}$ Bei einer 2008 in Innsbruck extra zu dem Thema veranstalte-

5 Plutarch, Alexandros 15; Arrian, Anabasis 1, 11,7-12,1.

6 Strabon 13, 593; Goethert - Schleif 1962; Rose 1991; 2001, 182-183; Korfmann 2001, 65 Abb. 66 (Rekonstruktion). 67 Abb. 69 (Plan); Rose 2006, 191-193.

7 Simon 2001, 159-170.

8 Lucanus, Pharsalia 9, 950-999; Sueton, Caesar 79,3; Mannsperger 2001, 104.

9 Strabon 13, 1,27; Rose 2006, 194-195.

10 Rose 1998, 93. 94 Abb. 20-21.

11 Rose 2006, 195-196.

12 Dagron 1974, 29-31.

13 Cook 1973, 14-51; Easton 1991; 2006, 107-110.

14 Schrott 2007.

15 Schrott 2008.

16 Jablonka 2008; Latacz 2008b; 2010, 156ff.; Rebenich 2008; Dräger 2009, 2f. $19 \mathrm{ff}$. 
ten Tagung folgte keiner der dort anwesenden Fachleute Schrott. ${ }^{17}$ Es ist auch nicht - wie manchmal behauptet wird - Schrotts Verdienst, die orientalischen Einflüsse in den homerischen Epen entdeckt zu haben. Diese waren längst bekannt. $^{18}$

Troia hat bedauerlicherweise immer wieder Dilettanten angelockt, sich mit abstrusen Thesen zu diesem ,Schicksalsberg der deutschen Archäologie' zu äußern. So machte in den 80er Jahren des 19. Jhs. ein gewisser Hauptmann a.D. E. Bötticher H. Schliemann mit großem Presserummel das Leben durch die Behauptung das Leben schwer, dieser habe die Grabungsergebnisse verfälscht, und bei Troia handele es sich in Wahrheit nicht um eine Siedlung, sondern um eine Feuernekropole, ${ }^{19}$ und seit 2001 polemisiert der Tübinger Althistoriker F. Kolb ohne archäologische Sachkenntnis gegen die Ergebnisse der neuen Troia-Grabung unter seinem Tübinger Kollegen M.O. Korfmann auch über dessen Tod hinaus, ja kriminalisiert Korfmann, dessen Mitarbeiter und Nachfolger und diffamiert die DFG-Gutachter, die ich für die Förderung des Troia-Projekts ausgesprochen haben, sogar in unglaublicher Weise in einem Buch, das bezeichnenderweise den Titel „Tatort ,Troia“" trägt. ${ }^{20}$ Schrotts und Kolbs inakzeptable Thesen werden bald in der Versenkung verschwunden sein wie jene des Böttichers. Es ist nur bedauerlich, dass seriöse Verlage so etwas publizieren. Doch kehren wir aus den Niederungen wissenschaftlicher Polemik zurück in die Forschungsgeschichte Troias in der zweiten Hälfte des 19. Jhs.

Anscheinend angeregt durch das 1863 erschiene Buch von C. MacLaren „The plain of Troy described“, in dem dieser Troia/Ilion auf dem Hügel von Hisarlik vermutete, ${ }^{21}$ begann der in der Troas ansässige britische Konsularbeamte und Amateurarchäologe F. Calvert im gleichen Jahr dort eine Ausgrabung und stieß auf den Tempel der Athena. ${ }^{22}$ Er verfuggte nicht über die notwendigen Mittel, um das Projekt weiter zu verfolgen und überließ die Grabungen auf Hisarlik H. Schliemann, der 1868 in die Troas kam. ${ }^{23}$ Dessen Ziel war es, ,der zivilisierten Welt den Beweis zu erbringen, dass die alte griechische Sage vom zehnjährigen Kampf um Troja Wahrheit sei und Homer treu und ehrlich die Königsburg des Priamos geschildert habe“". ${ }^{24}$ Nach ersten inoffiziellen Sondagen im Jahr 1870 führte er zwischen 1871 und 1890 sieben

17 publiziert in: Christoph - Rollinger (Hrsg.) 2011.

18 West 1997, 334-437.

19 Döhl 1981, 16-21; Zavadil 2009.

20 Kolb 2010. Zu einem am 3.2.2010 an der Universität Tübingen gehaltenen Vortrag, in dem Kolb die wesentlichen Aussagen seines Buchs vorstellte, hat Latacz 2010, $21 \mathrm{ff}$. treffend Stellung bezogen.

21 MacLaren 1863, 70-78.

22 Easton 1991, 122-125; 2006, 109-110.

23 Allen 1999, 110-127.

24 Schliemann 1892, 40. 
längere Grabungskampagnen in Troia durch. ${ }^{25} \mathrm{Da}$ er der Überzeugung war, dass das homerische Troia zuunterst im Hügel, auf dem „Urboden“ lag, ließ er zunächst von Norden nach Süden einen großen Suchschnitt graben. In $10 \mathrm{~m}$ Tiefe stieß er auf eine Brandzerstörungsschicht mit der Befestigungsmauer des späten Troia II mit Toren und einer Rampe, dahinter den Ruinen großer Gebäude. Für Schliemann bestand kein Zweifel, dass er er die legendäre Burg des Priamos vor sich hatte. Bestätigt sah er sich durch einen 1873 gemachten Fund Schatzfund: pfundschwere goldene Becher, große silberne Kannen, goldene Diademe, Armbänder, Halsketten, aus tausenden von Goldplättchen zusammengeheftet, die in einer Art Steinkiste direkt vor der Befestigungsmauer lagen. ${ }^{26}$ Das konnte für Schliemann nur der Schatz des Priamos sein, der in der Ilias 24,228ff. in Zusammenhang mit der Auslösung Hektors erwähnt wird. ${ }^{27}$

Bei seiner letzten Grabungskampagne in Troia, in seinem Todesjahr 1890, musste Schliemann dann aber noch erkennen, dass er sich geirrt hatte. Er und sein Mitarbeiter Wilhelm Dörpfeld stießen ca. $40 \mathrm{~m}$ südlich der Befestigungsmauer des vermeintlichen homerischen Troia auf einen jüngeren Befestigungsring, den von Troia VI, und zwei Gebäude. ${ }^{28}$ In den zugehörigen Schichten kamen erstmals in Troia Fragmente mykenischer Keramik des 14.-13. Jhs.v.Chr. zutage, ${ }^{29}$ wie Schliemann sie inzwischen selbst bei Grabungen in Mykene gefunden hatte. Troia II war demnach ein Jahrtausend zu früh, um die Szenerie des Troianischen Kriegs gebildet haben zu können. Heute wissen wir, dass es in die Frühe Bronzezeit, ca 2550-2250 v.Chr. zu datieren ist. ${ }^{30}$ Dörpfeld hat 45 Jahre später bei einem Besuch der amerikanischen Grabungen unter C.W. Blegen in Troia erzählt, wie Schliemann reagierte, als er seinen Fehler erkennen musste: ${ }^{31}$ Nachdem Dörpfeld mit ihm das Problem besprochen hatte, wobei Schliemann sorgfältig zuhörte, aber kaum etwas sagte, zog sich dieser in sein Zelt zurück und ließ sich vier Tage lang nicht ansprechen. Als er dann wieder herauskam, sagte er zu Dörpfeld: „Ich glaube, sie haben recht“. In einem Brief den Schliemann am 9. Oktober 1890, etwas mehr als zwei Monate vor seinem Tod, an R. Schöne, den Generaldirektor der Königlichen Museen zu Berlin, schrieb, räumte er ein, dass Troia VI mit der mykenischen Kultur gleichzeitig war. ${ }^{32}$

25 McDonald - Thomas 1990, 17-45; Easton 2006, 110-115.

26 Korfmann 2000; Korfmann 2001 b. Der Schatz kam am Ende des 2. Weltkrieges in das Puschkin-Museum in Moskau, s. Der Schatz aus Troia. Schliemann und der Mythos des Priamos-Goldes (Stuttgart \& Zürich 1996).

27 Schliemann 1990, $216 \mathrm{ff}$.

28 McDonald - Thomas 1990, 42-45; Easton 2006, 114-1115; s. den Plan Troia II, Vorsatz hinten.

29 Schmidt 1902, 163ff.; Mountjoy 2008.

30 Ünlüsoy 2006, 137-141.

31 Sperling 1986, 29-30.

32 Easton 1994, 174. 
Die Nachfolger Schliemanns in Troia, W. Dörpfeld, C.W. Blegen und M.O. Korfmann, haben mit ihren Grabungen gezeigt, dass Troia VI-VIIA im 13. bis zum Beginn des 12. Jh.v.Chr., der Zeit, in der nach der griechischen Tradition der Troianische Krieg stattfand, eine bedeutende Residenz mit einer Burg für die herrschende Elite und einer ebenfalls befestigten Unterstadt war. ${ }^{33}$ Die Siedlung war so groß wie die mykenischen Zentren, mittelgroße hethitische Städte und Orte wie Beycesultan und Ugarit. ${ }^{34}$ Die systematische Erforschung des Umlandes hat gezeigt, dass Troia VI-VIIA zu seiner Zeit mit weitem Abstand die größte Siedlung der Troas war und damit sicherlich deren Zentralort bildete. ${ }^{35}$

Doch noch einmal zurück zu Schliemann. Kaum hatte er 1873 die Arbeiten in Hissarlik/Troia fürs erste abgeschlossen, als es ihn, erfüllt von seiner Entdeckung der Wohnstätte des Priamos, drängte, auch den Sitz des in der Ilias mächtigsten Feindes Troias, Agamemnon, das von Homer als goldreich gepriesene Mykene, vom Schutt zu befreien. Im Gegensatz zu Troia musste Mykene nicht erst gesucht werden. Die starke Burg, mit ihren aus großen Blöcken errichteten kyklopischen Mauern und dem auch von Pausanias 2,16,6 erwähnten Löwentor mit seinem eindrucksvollen Relief waren immer sichtbar gewesen. ${ }^{36}$ Pausanias' Schilderung, nach der die Gräber des nach seiner Rückkehr aus Troia ermordeten Agamemnon und seiner Gefährten im Innern der Mauern liegen, veranlasste Schliemann, 1874 an verschiedenen Stellen innerhalb der Burg 34 Schächte graben zu lassen. ${ }^{37}$ Die Befunde in zwei Schächten ca. $40 \mathrm{~m}$ südlich des Löwentors waren vielversprechend. So setzten Schliemann und der griechische Archäologe P. Stamatakis hier am 7. August 1876 den Spaten an, und die mykenische Welt hätte kaum dramatischer wieder ans Licht treten können als durch die Funde dieser Grabung. Die 17 in den sechs Schachtgräbern bestatteten Toten waren mit Gold geradezu überhäuft waren: ${ }^{38}$ Goldene Masken bedeckten die Antlitze der Männer, goldene, reich mit Spiralen verzierte Platten bedeckten ihre Brüste; mit goldenen Scheiben übersät waren die Gewänder der Frauen, dazu hatten sie goldene Diademe, Ohrgehänge und Armreifen getragen. Für das jenseitige Leben hatte man den Tote kostbare Salben und Öl in bronzenen und silbernen Krügen, ihr goldenes und silbernes Trinkgeschirr sowie ihre Schwerter an goldenen Wehrgehängen in das Grab mitgegeben. Kampfszenen auf goldenen Siegelringen erinnerten Schliemann an Schilderungen in der Ilias. In der Darstellung auf einem golde-

33 McDonald - Thomas 1990, 83-86. 217-229; Thumm-Dograyan 2006; Becks 2006; Jablonka 2006.

34 Korfmann 1995, 179-180 Taf. 31.

35 Aslan u.a. 2003, 189.

36 s. z.B. die 1834-1837 durch Carl Rottmann gemalten Bilder von Mykene: Heilmann - Rödiger-Diruf 1998, 246-251, Taf. 111-115.

37 Schliemann 1878, 65-69.

38 Schliemann 1878, 175-380; Karo 1930/33. 
nen Siegel aus Schachtgrab III wollte er die Tötung Hektors durch Achilleus erkennen. ${ }^{39}$ Einen Turmschild, wie er in der Ilias beschrieben ist, erkannte er in der Kampfdarstellung auf einem Goldring aus Schachtgrab IV. ${ }^{40}$ Von 60 bearbeiteten Eberzähne, ebenfalls aus Schachtgrab IV, meinte er, sie stammten von Pferdegeschirr oder einem mit Eberzähnen besetzten Helm wie dem des Meriones. ${ }^{41}$ Schließlich verglich er einen goldenen Becher, auf dessen beiden Henkeln je ein plastischer Vogel angebracht war, mit dem in der Ilias geschilderten Becher des Nestor. ${ }^{42}$ Für Schliemann bestand kein Zweifel daran, dass er die Gräber des Agamemnon und seiner Gefährten aufgedeckt hatte ${ }^{43}$ und meldete dies in einem Telegramm an den König von Griechenland, Georg I. ${ }^{44}$ Aber auch hier irrte Schliemann, wie wir heute wissen: Die Schachtgräber von Mykene gehören ganz an den Anfang der mykenischen Kultur und sind mehrere Jahrhunderte älter als das traditionelle Datum des Troianischen Krieges.

Schliemanns Entdeckungen lösten eine Welle von Ausgrabungen an Fundplätzen der spätbronzezeitlichen Hochkultur des griechischen Festlandes aus, die bald nach dem ersten und bedeutendsten Fundort die mykenische genannt wurde. Bei diesen Grabungen zeigte sich bereits im frühen 20. Jh., dass der Bereich der mykenischen Kultur das griechische Festland von Messenien im Süden bis nach Thessalien im Norden umfasst hatte, außerdem auch auf die Kykladen und Inseln der Doodekanes ausgegriffen hatte. ${ }^{45}$ Bei den 1899 in Milet im Süden der Westküste Kleinasiens begonnenen Ausgrabungen der Berliner Museen zeigte sich, dass die Mykener außerdem auch dort Fuß gefasst hatten: Unter dem Athenatempels wurden die Ruinen einer spätbronzezeitlichen Siedlung mit mykenischer Keramik aufgedeckt, ${ }^{46}$ am Hügel Degirmentepe, 1,5 km südwestlich des Athenatempels 11 Felskammergräber mykenischen Typs mit charakteristischen mykenischen Beigaben ausgegraben. ${ }^{47}$ Dies sprach dafür, dass hier tatsächlich mykenische Griechen gesiedelt hatten ${ }^{48}$ während die mykenische Keramik in Troia Importgut war, das nur einen ganz geringen Anteil des in seiner großen Mehrzahl aus anderen Tonwaren, vor allem grauer Ware, bestehenden Keramikrepertoires stellte. ${ }^{49}$

39 Schliemann 1978, 202-204 Abb. 254; Marinatos - Hirmer 1973, Taf. 230 Mitte links.

40 Ilias 7, 219; 11, 485; 17, 128; Schliemann 1878, 259-261, Abb. 335; Marinatos Hirmer 1973, Taf. 230 oben .

41 Ilias 10, 261-265; Schliemann 1878, 312-314.

42 Ilias 11, 632-635; Schliemann 1878, 272-276 Abb. 346; Marinatos - Hirmer 1973, Taf. 210.

43 Schliemann 1878, 381-397.

44 Crepon - Bölke 1990, 260-261.

45 Fimmen 1924, 1-16.

46 Wiegand 1908, 7f.; von Gerkan 1925, $73 \mathrm{ff}$.

47 Fimmen 1924, 16; Niemeier - Niemeier 1997, 190-191; Niemeier 1998, 34-36.

48 Fimmen 1924, 16

49 Fimmen 1924, 95-96. 
Stellte die mykenische Kultur, das heroische Zeitalter der Griechen, am Ende des 19. Jhs. bereits keine Unbekannte mehr dar, so war die gleichzeitige spätbronzezeitliche Hochkultur Kleinasiens, die der Hethiter, durch die tiefgreifenden Kulturbrüche, die Kleinasien erlebt hatte, bereits in der Antike nahezu vollständig vergessen. Die Hittim, welche Martin Luther in seiner Bibelübersetzung in den heute üblichen Begriff Hethiter verdeutschte, wurden nur in einigen Passagen des Alten Testamentes erwähnt und schienen ein im frühen 1. Jts.v.Chr. in Südostanatolien und Nordsyrien ansässiges Volk zu sein, dass eine Reihe von Inschriften und Siegeln hinterlassen hatte. ${ }^{50}$ Als der französische Reisende Ch. Texier 1834 bei dem Dorf Bogazköy auf imposante Ruinen einer Stadt stieß, ahnte der nicht, dass er die Überreste von Hattusa, der Hauptstadt des Hethiterreiches, vor sich hatte, sondern schwankte in der Identifizierung zwischen Tavion, der Hauptstadt des trokmischen Stammes der Galater, und Pteria, einer kappadokischen Stadt, die nach Herodot 1,76 vom Lyderkönig Kroisos bei seinem unglückseligen Feldzug im Jahr 547 v.Chr. gegen das Perserreich zerstört wurde. ${ }^{51}$

Es waren der irische Missionar W. Wright und der britische Assyriologe A.H. Sayce, die in den 80er Jahren des 19. Jhs. das Fundament für die Wiederentdeckung der Hethiter legten. ${ }^{52}$ Sie fanden im Alten Testament Indizien dafür, dass die Hethiter einst eine bedeutende Macht gebildet hatten und vertraten die These, die Hethiter seien mit dem Volk identisch, das bei den Assyrern Hatti und bei den Ägyptern Heta hieß, das Hethiterreich hätte große Teile Kleinasiens umfaßt. ${ }^{53}$ Mit den Heta hatten die Ägypter feindliche Auseinandersetzungen, die schließlich 1275 v.Chr. in der berühmten Schlacht von Qadesch in Syrien kulminierten. ${ }^{54}$

Wright und Sayce stießen zunächst auf heftigen Widerstand in der Fachwelt, wurden aber bald durch einen spektakulären Fund in Ägypten bestätigt. 1887 kamen in Amarna, der von Pharao Amenophis IV. (Echnaton, 1358/1350-1341/1333 v.Chr. ${ }^{55}$ ) neu gegründeten Hauptstadt Ägyptens das königliche Archiv mit der außenpolitischen Korrespondenz des Pharaos zutage. ${ }^{56}$ Sayce reiste nach Ägypten um die ,Amarna-Briefe' zu studieren. ${ }^{57}$ Die Keilschrifttafeln waren zum allergrößten Teil in der Diplomatensprache des Alten Orients, dem bereits seit einiger Zeit entzifferten Babylonisch geschrieben. Unter ihnen fanden sich auch Briefe von hethitischen Herrschern an den

50 Ceram 1955, 31-33; Klengel 2008, 61.

51 Ceram 1955, 20-25; Bittel 1983, 10-12; Alaura 2006, 16-17.

52 Ceram 1955, 29-35.

53 Wright 1886; Sayce 1889.

54 Klengel 2002, 55-70.

55 von Beckerath 1997, $111 \mathrm{ff}$.

56 Ceram 1955, 35-39; Moran 1992.

57 Sayce 1888/89. 
Pharao. ${ }^{58}$ Zwei Briefe, die man nicht lesen konnte, wurden für die Hethiterforschung noch wichtiger. Man nannte sie ,Arzawa-Briefe' weil der eine von ihnen - zwar in lesbarer Keilschrift doch in unverständlicher Sprache - an den König eines Landes namens Arzawa gerichtet war. ${ }^{59}$ Der norwegische Gelehrte J. Knudtzon stellte 1902 die Hypothese auf, dass diese beiden Tafeln in einer indogermanischen Sprache verfasst waren. ${ }^{60}$

Seit den 80er Jahren gab es deutsche und britische Bemühungen, Ausgrabungen in Bogazköy zu beginnen. ${ }^{61}$ Von britischer Seite war der Protagonist Sayce, der versuchte, Schliemann für das Unternehmen zu gewinnen. ${ }^{62}$ Die ersten allerdings unsystematischen Ausgrabungen führte dann aber der französische Anthropologe und Archäologe E. Chantre in den Jahren 1893-1894 durch. ${ }^{63}$ Dabei kamen in der Königsburg Büyükkale auch Tontafelfragmente zutage. Sie zeigten eine enge Verwandtschaft zu den ,Arzawa-Briefen' aus Amarna, und der Keilschriftforscher J.-V. Scheil, der in das Museum in Konstantinopel gelangte Tafelfragmente untersuchte, vermutete erstmals, dass die Sprache dieser Fragmente und der ,Arzawa-Briefe' Hethitisch sei. ${ }^{64}$

Im Jahr 1905 hieß dann für den Berliner Assyriologen $\mathrm{H}$. Winckler die Losung „Nach Boghasköi““ ${ }^{65}$ Nachdem die englischen Konkurrenten um die Grabungslizenz durch das Eingreifen Kaiser Wilhemls II ausgeschaltet worden waren, ${ }^{66}$ führte Winckler im Herbst 1905 eine erste Testgrabung auf Büyükkale durch, bei der 34 Tafelfragmente zutage kamen. ${ }^{67}$ Winckler erkannte sofort die Ähnlichkeit zu den kurz zuvor von ihm selbst publizierten ,AmarnaBriefen'. ${ }^{68}$ In den Jahren 1906 und 1907 und dann noch einmal - bereits todkrank - in den Jahren 1911 und 1912 leitete Winckler dann umfangreiche Ausgrabungen in Bogazköy, bei denen fast 11.000 Tontafeln zutage kamen. ${ }^{69}$ Schon in der ersten Kampagne 1906 kam eine Tafel zutage, auf welcher der in babylonischer Sprache abgefassten Staatsvertrag zwischen dem hethitischen König Hattuschili III. und dem ägyptischen Pharao Ramses II. niedergeschrieben war, den man schon aus der an den Tempelwänden in Karnak festgehaltenen Version in ägyptischen Hieroglyphen kannte. ${ }^{70}$ Die Entdeckung erregte

58 Moran 1992, 114-117, EA 41-44.

59 Moran 1992, 101, EA 31.

60 Knudtzon 1902.

61 Alaura 2006, 20-32.

62 Alaura 2006, 25-26.

63 Alaura 2006, 43-50.

64 s. Chantre $1898,40.58$.

65 Titel des posthum veröffentlichten Berichts über die Tätigkeit im Jahr 1905: Winckler 1913.

66 Alaura 2006, 86-91, Klengel 2008, 63-64.

67 Alaura 2006, 91-92; Klengel 2008, 64-66 .

68 Winckler 1896.

69 Alaura 2006, 101-195; Klengel 2008.

70 Ceram 1955, 54-56; Alaura 2006, 104-105, zum Vertrag s. Klengel 2002, 75-93. 
überall großes Aufsehen. Nun bestand kein Zweifel mehr daran, dass die Tontafelarchive von Bogazköy jene der hethitischen Herrscher und die Ruinen jene von Hattusa, der Hauptstadt des Hethiterreiches waren. Der Klassische Archäologe Th. Wiegand, seinerzeit Abteilungsdirektor der Königlichen $\mathrm{Mu}-$ seen mit Sitz in Konstantinopel, den Winckler informierte, notierte am 8. Januar 1907 in seinem Tagebuch: ${ }^{71}$ „Nun dürfen wir große Ausblicke über die vorgriechische Zeit erwarten. Es ist eine höchst bedeutende Entdeckung“".

Die Entzifferung des Keilschrifthethtischen als indogermanische Sprache gelang mitten im ersten Weltkrieg, dem jungen tschechischen Gelehrten und Professor an der Universität Wien Friedrich (Bedrich) Hrozny. Vor der Deutschen Orientgesellschaft hielt er am 24. November 1915 den Vortrag, „Die Lösung des hethitischen Problems“, den der bekannten Assyriologe E. Weidner als die „eigentliche Geburtsstunde der Hethitologie“" bezeichnet hat. ${ }^{72}$ Zwei Jahre später folgte die gründliche Vorlage. ${ }^{73}$ In den Jahren 1916 und 1917 wurden die Tontafeln von Hattusa bis zur abschließenden Bearbeitung und Veröffentlichung in der Reihe „Keilschrifturkunden aus Boghazköi“ an das Vorderasiatische Museum in Berlin ausgeliehen, wo sie unbeschadet durch politische Umwälzungen und den 2. Weltkrieg bis zu ihrer Rückgabe im Jahr 1987 verblieben. ${ }^{74}$

$\mathrm{Zu}$ der Forschergruppe, die dort an den Hattusa-Tafeln arbeiteten, gehörte der junge Schweizer Assyriologe E.O. Forrer. Wie er später schrieb, war es seine wesentliche Hoffnung, ,dass diese am weitesten nach Westen vorgeschobenen Keilschrifttexte die Ethnologie Vorderasiens und damit auch Europas erhellen und eine Brücke bilden würden, die von der babylonischen Kultur hinüber zur Vorgeschichte Europas ... führt“, und „Es ist sehr zu bezweifeln, ob ich die Ausdauer gehabt hätte, all diese 11.000 Tafeln durchzusehen, wenn mich nicht die stille Hoffnung getrieben hätte, von Troja und Priamos einmal Näheres zu hören ". ${ }^{75}$ Am 3. Januar 1924 war es dann soweit: Forrer hielt vor der Vorderasiatisch-Ägyptischen Gesellschaft zu Berlin einen Vortrag mit dem Titel „Vorhomerische Griechen in den Keilschrifttexten von Bogazköy", den er noch im gleichen Jahr in zwei Aufsätzen veröffentlichte. ${ }^{76}$ Nach Forrer war das in den hethitischen Texten des 14. bis 13. Jhs.v.Chr. Ahhijawa genannte Land, eine Seemacht, die von den hethitischen Herrschern zeitweise als gleichberechtigtes Königtum anerkannt worden war, auf dem griechischen Festland zu lokalisieren, der Name Ahhijawa entsprach den Achaioi, Achäern, Homers, in der Ilias einer der drei alternativen Namen für die gegen Troia kämpfenden Griechen. Das Großkönigtum Ahhijawa - so Forrer - habe neben

71 zitiert von Alaura 2006, 104.

72 Hrozny 1915; Doblhofer 1990, 182-187; Klengel 2008, 68-69.

73 Hrozny 1917.

74 Klengel 2002, 67-72.

75 Forrer 1924a, 1f.

76 Forrer 1924a; 1924b. 
dem mykenischen Griechenland die ägäischen Inseln und Niederlassungen an der kleinasiatischen Küste umfasst. ${ }^{77}$ In Taruisa erkannte der Troia ${ }^{78}$ in Lazpa die Insel Lesbos, ${ }^{79}$ außerdem hethitisierte Formen von aus dem griechischen Mythos bekannten Personennamen wie Tawagalawa $=$ Eteokles, Attarasija $=$ Atreus und Antawara $=$ Andreus. ${ }^{80}$

Zunächst fand Forrer großen Anklang, so schrieben z.B. U. Wilcken: „Es scheint ein neues Licht über der griechischen Heroenzeit aufzugehen "81 und H. Schmid: „Die homerischen Helden dürfen wir nunmehr als historische Persönlichkeiten begrüßen“" ${ }^{82}$ Bald aber erfuhr Forrers „Griechenhypothese“, wie sie seine wissenschaftlichen Gegner nannten, vernichtende Kritik von anderen Vertretern der damals entstehenden Disziplin der Hethitologie, ${ }^{83} \mathrm{~J}$. Friedrich, ${ }^{84}$ A. Götze ${ }^{85}$ (der allerdings anfangs Forrer noch zugestimmt hatte ${ }^{86}$ ) vor allem von dem etablierten Indogermanisten Ferdinand Sommer.Dieser übte in seiner gewichtigen Publikation „Die Ahhijava-Urkunden“ von 1932 und nachfolgenden Schriften vernichtende und oft auch polemische Kritik an Forrer ${ }^{87}$ Götze und Sommer sahen in Ahhijawa ein autochthones kleinasiatisches Land, das der erste im Nordwesten ${ }^{88}$ der zweite in Kilikien ${ }^{89}$ lokalisieren wollte, beides allerdings ohne schlagende Argumente. ${ }^{90}$

Sommer forderte 1934, ,die Ahhijawa-Leute müssten durch andere Tatsachen als den Namensanklang nachweisen, dass sie wirklich Achäer sind". ${ }^{91}$ Solche Tatsachen brachte 1935 der Althistoriker F. Schachermeyr in die Debatte. Nach Sommers Lesungen einiger der Texte lag Ahhijawa am Meer. ${ }^{92}$ Die Aktivitäten Ahhijawas im östlichen Mittelmeer fanden im 14.-13.

77 Forrer 1924a, Karte zwischen S. 4 und 5.

78 Forrer 1924a, 7.

79 Forrer 1924a, 14.

80 Forrer 1924a, 9f. 14f. 21; 1924b, 114.

81 Wilcken 1924, 223.

82 Schmid 1924, 105; s. auch Schuchhardt 1924; Poisson 1925; Sayce 1925; Weber 1925, 22ff. $41 \mathrm{ff}$.

83 s. Schachermeyr 1935, $22 \mathrm{ff}$.

84 Friedrich 1927.

85 Götze 1928, 53ff.; 1930.

86 Oberheid 2007, 108f. Abb. 5.

87 Sommer 1932, 358f. 376ff.; 1934; 1937.

88 Götze 1928, 154. Später akzeptierte Götze 1933a, 171ff.; 1957, 183, dass es sich bei dem Volk von Ahhijawa um Achäer handele, lokalisierte Ahhijawa aber weiterhin im Nordwesten Kleinasiens. Dagegen argumentierte jedoch überzeugend bereits Schachermeyr 1935, 126ff. Gegen die Lokalisierung Ahhijawas in NordwestKleinasien s. auch Niemeier 1998, 20ff. 43ff.

89 Sommer 1932, 327. 358f. 374f.

90 Schachermeyr 1935, $79 \mathrm{ff}$.

91 Sommer 1934, $9 f$.

92 Sommer 1932, 376; Schachermeyr 1935, 50 f. 
Jhv.Chr. statt, zu derselben Zeit und in denselben Regionen wie die archäologisch nachweisbaren der Mykener, die mykenische und die hethitische Interessensphäre überschnitten sich im Südwesten und an der Südküste Kleinasien, auf Zypern und an der Levanteküste ${ }^{93}$ Schachermeyrs Schlußfolgerung war, dass eine Lokalisierung Ahhijawas in Kleinasien unwahrscheinlich sei, und dass man es mit Forrer eher in Griechenland zu suchen habe. ${ }^{94}$ Sommer attackierte auch Schachermeyr, räumte dann in seinem letzten Beitrag zum Thema von 1937 aber ein, dass die Diskussion an einem toten Punkt angelangt sei und schlug vor, sie einzustellen und ,....abzuwarten, ob die Zukunft einmal Besseres und Anderes, sei es in Richtung auf kleinasiatische Achäer, sei es auf die europäische Großmacht" beisteuere..$^{95}$

Kurz vor dem Erscheinen von Schachermeyrs Schrift veröffentlichte der große schwedische Altertumsforscher M.P. Nilsson zwei Bücher, die für die Frage nach möglichen bronzezeitlichen Wurzeln des Troia-Mythos von Bedeutung sind: im Jahr 1932 „The Mycenaean Origin of Greek Mythology“ und im Jahr 1933 „Homer and Mycenae“. Zusammen mit Forrer und Schachermeyr gehörte er zu jenen wenigen Gelehrten, die seinerzeit meinten, die Mykener hätten bereits Griechisch gesprochen. Im ersten Buch studierte Nilsson die geographischen Aspekte des griechischen Mythos. Er wies nach, dass viele Orte der Mythen, insbesondere die der großen Zyklen, sich durch die archäologischen Forschungen als wichtige mykenische Zentren erwiesen haben, was auch neuere Grabungen seit dem Erscheinen des Buchs weiter bestätigt haben, so für Mykene, die Residenz des Agamemnon ${ }^{96}$ und Tiryns ${ }^{97}$ in der Argolis, Theben ${ }^{98}$ und Orchomenos ${ }^{99}$ in Böotien und Iolkos in Thessalien. ${ }^{100}$ Neuere Ausgrabungen haben gezeigt, daß der Golf von Iolkos/Volos in der Tat ein wichtiges mykenisches Siedlungsgebiet war, ${ }^{101}$ in dem die mykenischen Siedlungen von Kastro-Palaia in Volos, ${ }^{102}$ aus der kürzlich eine Linear B-Tontafel identifiziert wurde, ${ }^{103}$ und Dimini ${ }^{104}$ Kandidaten für die Identifizierung als Iolkos sind. Dort, wo die archäologischen Indizien zu Nilssons Zeit noch relativ spärlich waren, wurde er durch spätere Entdeckungen bestätigt:

93 Schachermeyr 1935, 94ff. 119 Karte 4.

94 Schachermeyr 1935, 132ff. $156 \mathrm{ff}$.

95 Schachermeyr 1937, 287.

96 Nilsson 1932, 39ff. Zur Archäologie: Hope Simpson 1981, $11 \mathrm{ff}$. Mylonas 1983; French 2002; 2010.

97 Nilsson 1932, 50ff. Zur Archäologie: Jantzen 1975; Hope Simpson 1981, 20ff.; Maran 2010.

98 Nilsson 1932, 100ff. Zur Archäologie: Symeonoglou 1985; Dakouri-Hild 2010.

99 Nilsson 1932, 127ff. Zur Archäologie: Hope-Simpson 1981, 61. 211.

100 Nilsson 1932, $136 \mathrm{ff}$.

101 Stamatopoulou 2010/11, 77f.

102 Hope Simpson 1981, $161 \mathrm{ff}$.

103 Stamatopoulou 2010/11, 77. 78 Abb. 126f.

104 Adrimi-Sismani 2006. 
Der Palast von Pylos in Messenien, in der Ilias Sitz des Nestor, wurde erst 1939 entdeckt und in den 50er und 60 Jahren des 20. Jhs ausgegraben. ${ }^{105}$ Seine Identifizierung ist durch das Auftreten des Namens pu-ro = Pylos auf den Tontafeln des in ihm zutage gekommenen Tontafel-Archivs gesichert. ${ }^{106}$ In Lakonien, in der Ilias das Reich des Menelaos ${ }^{107}$ fehlte bisher ein mykenischer Palast. Die kürzlich erfolgten Funde von Linear B-Tafeln bei Agìos Vasileiòs bilden nun aber Indizien für die Existenz eines in unmittelbarer Nähe zu suchenden Palastes. ${ }^{108}$ Nilsson machte deutlich, dass die Erinnerung an die groBen mykenischen Zentren die sog. Dunklen Jahrhunderte zwischen dem Untergang der mykenischen Paläste und der Zeit Homers überlebt hatten, und dass die Geschichten, die von ihnen erzählt wurden, ihre Wurzeln in der mykenische Epoche haben.

Im zweiten Buch führte er dies für den Troianischen Mythenzyklus weiter aus und zeigte, dass die Ilias zweifelsohne Rückerinnerungen an die mykenische Periode enthält, neben den schon angesprochenen Waffen und anderen Objekten, ${ }^{109}$ das Fehlen der Dorer und die politische Geographie mit größeren Herrschaftsbereichen, wie es sie in mykenischer Zeit gab, nicht aber in der Zeit Homers, ${ }^{110}$ und insbesondere den Reichtum Mykenes (das zu Homers Zeit eine bescheidene kleine Landstadt in den alten kyklopischen Mauern war). ${ }^{111}$ Daneben aber erkannte Nilsson auch spätere Elemente, so u.a. das Auftreten der Phönizier als Seefahrer und Händler, ${ }^{112}$ Waffen aus Eisen ${ }^{113}$ und Brandbestattungen. ${ }^{114}$ Wie er feststellte, enthalten die homerischen Epen Elemente aus verschiedenen-Zeiten, die sich über einen Zeitraum von mindestens einem halben Jahrhundert von der mykenischen Periode bis zu Homers Zeit erstrecken. ${ }^{115}$ Nilsson akzeptierte Forrers These von der Gleichsetzung Ahhijawas der hethitischen Texte mit den Achäern Homers und der Existenz eines Großkönigtums Ahhijawa mit Zentrum auf dem griechischen Festland und

105 Nilsson 1932, 79ff. Zur Archäologie: McDonald - Thomas 1990, 229ff. 328ff.; Davis 2008; 2010.

106 Ventris - Chadwick 1973, 141f.

107 Nilsson 1932, 68ff.

108 Aravantinos - Vasilogamvroŭ.

109 Nilsson 1934, $137 \mathrm{ff}$.

110 Nilsson 1934, 157. Dazu, dass die Schilderung der Herrschaftsbereiche der gegen Troia ins Feld ziehenden Könige Rückerinnerungen an die mykenische Epoche enthält, insbesondere im sog. Schiffskatalog im 2. Buch der Ilias, und die politische Geographie Griechenlands zur Zeit Homers ganz anders aussah s. Niemeier 1991, insbesondere 141ff. Abb. 8f.; 2008, 77f. Abb. 9f.; Latacz 2010, 284ff.

111 Nilsson 1934, 158.

112 Nilsson 1934, $130 f f$.

113 Nilsson 1934, $139 f f$.

114 Nilsson 1934, $152 \mathrm{ff}$.

115 Nilsson 1934, $158 f$. 
Ausdehnung auf die Inseln der Ägäis und an die Küste Kleinasiens. ${ }^{116}$ Damit befand er sich aber in einer Minderheitsposition. Die letzte Stellungnahme Sommers, nach der man für eine Klärung des Ahhijawa-Problems neue Indizien abwarten solle, wurde von der Mehrzahl der Sprachwissenschaftler und Historiker, insbesondere im deutschen Sprachraum, ignoriert, Forrers These abgelehnt. ${ }^{117}$

Die Entzifferung der sog. Linear B-Schrift der Tontafeln aus den mykenischen Palästen als frühgriechisches Idiom, die 1952 dem britischen Forscher M. Ventris gelang, ${ }^{118}$ bestätigte dann aber die Ansicht Forrers, Nilssons und Schachermeyrs, nach der die Mykener bereits Griechisch gesprochen hatten. Außerdem zeigte sich, dass Sommers strikte Ablehnung der Identifizierung von in den hethitischen Keilschrifttexten genannten Eigennamen mit griechischen nicht richtig war. Wir haben zwei sichere Eigennamen von AhhijawaPersonen, den des Tawagalawa, des Bruders des Königs von Ahhijawa, im sog. Tawagalawa-Brief, ${ }^{119}$ und den des Attarasija, des Mannes von Ahhija (älterer Name von Ahhijawa) in der sog. Anklage gegen Madduwata. ${ }^{120}$ Forrer interpretierte Tawagalawa als hethitisierte Form des griechischen Namen Eteokles über eine für diesen angenommene ältere Form $\star$ Etewoklewes. ${ }^{121}$ Sommer lehnte diese Verbindung ab. ${ }^{122}$ Die von Forrer angenommene ältere Form wird aber durch das zweifach auf den Linear B-Tafeln aus Pylos auftretende Patronym E-te-wo-ke-re-we-i-jo $=$ Etewokleweios $=$ Sohn des Etewoklewes bestätigt. ${ }^{123}$ Die Verbindung Tawagalwa - Eteokles ist damit realistisch. ${ }^{124}$

Attarasija verband Forrer mit dem griechischen Namen Atreus. ${ }^{125}$ Auch dies wurde von Friedrich, Götze und Sommer strikt abgelehnt. ${ }^{126}$ Nach M.L. West stellt aber Atreus die jüngere Kurzform eines älteren mykenischen $\mathrm{Na}-$ mens dar, der als *Atresias, *Atersias, oder ${ }^{\star}$ Atarsias rekonstruiert und mit Attarasija verbunden werden kann. ${ }^{127}$

116 Nilsson 1934, $102 \mathrm{ff}$.

117 Heinhold-Krahmer 2003, 200.

118 Ventris - Chadwick 1956, 3ff; Chadwick 1967.

119 Sommer 1932, 191. Als Bruder des Königs von Ahhijawa wurde Tawagalawa zuerst von Forrer 1928a, 54 identifiziert. Dies wurde von Sommer 1932, 130 abgelehnt, aber von Güterbock 1990 bestätigt.

120 Götze 1927; Sommer 1932, 329ff.

121 Forrer 1924, 9f. 13f.; 1924b, 114.

122 Sommer 1932, $374 f$.

123 Ventris - Chadwick 1956, 138; 1973, 546.

124 Güterbock 1984, 120; 1990, 158; Starke 1990, 126 Anm. 766; Röllig 1992, 195f.; Starke 1997, 472 Anm. 61; Heinhold-Krahmer 2003, 201, Haas 2006, 6. Soweit ich sehe, hält allein Steiner 1998, 173 den Namen Tawagalawa für luwisch.

125 Forrer 1924a, 21; 1924b, 118; 1928b, 263.

126 Friedrich 1927, 102f.; Götze 1927, 41f.; Sommer 1932, 330. $372 f$.

127 West 2003. 
Nicht Forrer, sondern P. Kretschmer verband den Namen des Alaksandu, jenes Herrschers des Landes Wilusa, mit dem im frühen 13. Jh.v.Chr. der hethitische Großkönig Muwatalli II. einen Vasallenvertrag schloß, mit dem griechischen Namen Alexandros, dem in der Ilias alternativen Namen des Prinzen Paris von Troia. ${ }^{128}$ Sommers ablehnende Behauptung, ein Name auf -andros wie Alexandros sei vor dem Ende der mykenischen Periode nicht möglich gewesen, ${ }^{129}$ wurde durch die Identifizierung des weiblichen Pendants zu Alexandros auf einer Linear B-Tafel aus Mykene, a-re-ka-sa-da-ra = Alexandra, widerlegt. ${ }^{130}$ Die Gleichsetzung Alaksandu - Alexandros gewinnt damit eine große Wahrscheinlichkeit. ${ }^{131}$ Der griechische Ursprung des Namens eines Herrschers des zum luwischen Sprachgebiet gehörigen Wilusa ${ }^{132}$ ist möglicherweise so zu erklären, dass ein hervorragender Mann griechischer Abstammung von Kukunni, Alakasandus Vorfahre, adoptiert wurde, oder dass Alaksandu von einer griechischen Nebenfrau seines Vater Kukunni stammte. ${ }^{133}$

1983 rehabilitierte schließlich der renommierte Hethitologe H.G. Güterbock Forrer und gab der Diskussion um Ahhijawa neue Impulse. ${ }^{134}$ „Common Sense", so Güterbock, lege nahe, dass Hethiter und Mykener einander gekannt haben müssen. Für die Lage des Landes Ahhijawa in Kleinasien konnte er wie vor ihm Schachermeyr - keine Indizien erkennen. Nach den hethitischen Texten lag Ahhijawa jenseits des Meeres, höchstwahrscheinlich des Agäischen und sei daher in Griechenland zu suchen.

Die hethitischen Texte berichten über eine Reihe von Ereignissen im westlichen Kleinasien. Diese zu lokalisieren war aber lange Zeit unmöglich, da die in diesem Zusammenhang genannten geographischen Namen wie z.B. Lukka, Millawanda, Arzawa und Wilusa auf der Karte hin- und hergeschoben wurden wie Schachfiguren und es fast ebenso viele Kartierungen der spätbronzezeitlichen politischen Geographie des westlichen Kleinasien gab, wie sich Gelehrte mit dem Problem befassten. ${ }^{135} 1977$ sprach daher der britische Vorderasiatische Archäologe J. Mellaart ironisch von „the guessing game known as Hittite geography" ${ }^{136}$ ein Ratespiel, an dem er sich allerdings selbst rege beteiligte. ${ }^{137}$

128 Kretschmer 1924.

129 Sommer 1932, 366ff; 1934, 30ff.; 1937, $170 f f$.

130 My 303 = V 659: Sacconi 1974, 70 f.

131 Szemerenyi 1968, 725; Risch 1974, 227 mit Anm. 42; Szemerenyi 1988, 280ff., Starke 1999, 533; Heinhold-Krahmer 2003, 201.

132 Watkins 1986; Oettinger 2002, 52 mit Karte 2.

133 Latacz 2010, $173 f$.

134 Güterbock 1983.

135 s. z.B. die Karten in Macqueen 1986, 38f. Abb. 21f.

136 In seinem Vortrag „Troy - a re-assessment“ beim unpubliziert gebliebenen IVth International Colloquium on Aegean Prehistory, Sheffield University, Aprill $1977 \mathrm{~m}$ zitiert von Kosak, 1981, 12^; Bryce 1998, 45 mit Anm. 6.

137 Mellaart 1984, Karte S. 64f.; 1986a; 1986b; 1993. 


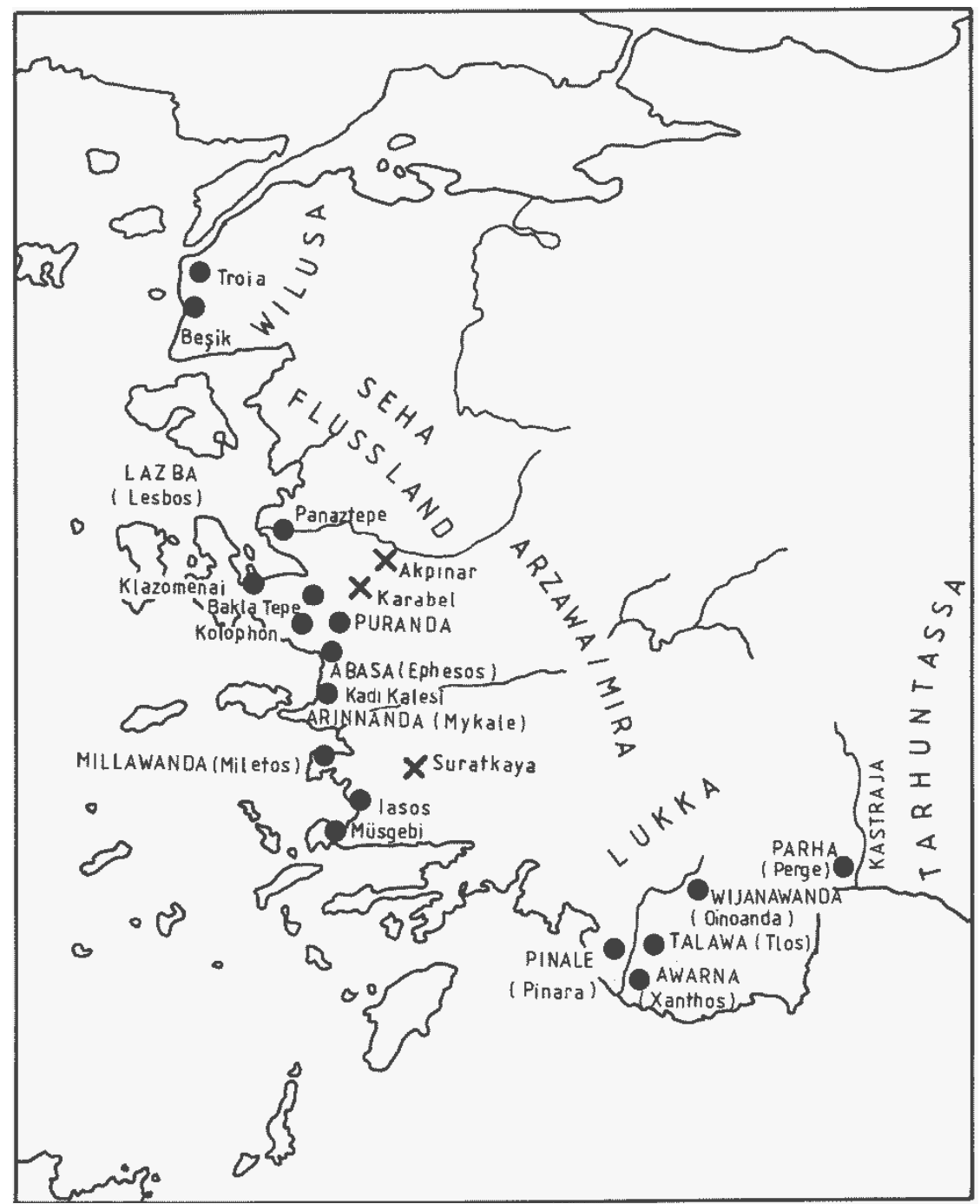

Abb. 1 Spätbronzezeitliche politische Geographie des westlichen Kleinasien, wichtige Orte und Fundplätze (Punkte) sowie Felsreliefs und -inschriften (Kreuze).

Neufunde von Inschriften in den 80er und 90er Jahren des 20. Jhs. sowie die Lesung einer lange bekannten, aber nicht entzifferten Inschrift haben aber inzwischen eine weitgehende Klärung der politischen Geographie des spätbronzezeitlichen Kleinasien ermöglicht (Abb. 1): ${ }^{138}$ In dem Vertrag zwischen

138 s. die unabhängig voneinander entstandenen Untersuchungen von Starke 1997; Haider 1997; 1999; Hawkins 1998; Niemeier 1998. 
Großkönig Tudhalija IV. (ca. 1240-1215 v.Chr.) und seinem Cousin Kurunta, König der Sekundogenitur Tarhuntassa, auf einer 1986 in Hattusa gefundenen Bronzetafe ${ }^{139}$ sind die Grenzen Tarhuntassas verzeichnet. Demnach lag es im Rauhen Kilikien und im östlichen Pamphylien, die Westgrenze bildete der Fluß Kastarajia mit der Stadt Parha, die als der in der Antike Kestros genannte Fluß Aksu und die Stadt Perge identifiziert werden. ${ }^{140}$ Auf der Akropolis von Perge sind kürzlich spätbronzezeitliche Siedlungsreste zutage gekommen. ${ }^{141}$ Weiter westlich lag feindliches Ausland. Im Süden der Westküste befand sich das Land Lukka, das spätere Lykien, wie die Schilderung eines Feldzuges des hethitischen Großkönigs Tudhalija IV. gegen Lukka in der hieroglyphenluwischen Inschrift auf einem Becken in Yalburt bei Konya zeigt, bei dem er die Städte Wijanawanda = Oinoanda, Pinala $=$ Pinara, Talawa $=$ Tlos, Awarna $=$ Arinna $=$ Xanthos eroberte und am heiligen Berg Patara opferte. ${ }^{142}$ Weiter nördlich lag das Land Arzawa mit der Hauptstadt Abasa, dem späteren Ephesos, wo bei neueren Grabungen auf dem Hügel von Ayasoluk eine bedeutende befestigte Anlage der späten Bronzezeit ans Licht tritt, wohl der Sitz der Könige von Arzawa. ${ }^{143}$ Die petrographische Analyse eines der beiden „ArzawaBriefe" aus Amarna, in welchem König Tarhuntaradu von Arzawa auf das Anliegen des ägyptischen Pharao Amenophis III. antwortet, eine seiner Töchter zu heiraten, ${ }^{144}$ ergab, dass der Brief aus der Region von Ephesos stammt. ${ }^{145}$

Millawanda ist nach seinen in den hethitischen Texten bezeugten geographischen Verbindungen mit Lukka einerseits und Arzawa andererseits ${ }^{146}$ in der Küstenzone zwischen Lukka im Süden und Arzawa im Norden anzusetzen, d.h. zwischen dem Latmischen Meerbusen und dem südlichen Karien. ${ }^{147}$ Die zuerst 1929 von B. Hrozny, dem Entzifferer der hethitischen Keilschrift, vorgeschlagene Identifizierung von Millawanda mit dem ionischen Milet gewinnt damit große Wahrscheinlichkeit. ${ }^{148}$ Auf die archäologischen Befunde unserer neuen Grabungen in Milet, die diese Identifizierung stützen, werde ich noch eingehen. Nördlich von Arzawa/Mira folgte an der Küste eine Gruppe von drei Ländern, die durch Verflechtungen und Verbindungen in den hethitischen Quellen folgendermaßen zu lokalisieren sind: ${ }^{149}$ das Seha-Flußland in den Tälern des Hermos und wohl auch des Kaikos, Lazpa - wie schon von

139 Neve 1987, 405ff; 1922, 19ff. Publikation der Inschrift: Otten 1988.

140 Otten 1988, 13 S 8 Zeilen 60f. S. 37f.; Gurney 1992, 2f; Houwink ten Cate 1992, 255; Hawkins 1995, 52; Starke 1997, 450; Yakar u.a. 2001, 715.

141 Martini 2010, 21ff.

142 Niemeier 2008, 298ff.

143 Büyükkolanci 2007; Niemeier 2008, $300 f f$.

144 Moran 1992, 103, EA 32 (Übersezung V. Haas).

145 Goren u.a. 2004, 45ff.

146 Heinhold-Krahmer 1993-97, 188.

147 Haider 1999a, 674f; Heinhold-Krahmer 2003, 202ff.

148 Hrozny 1929, $329 f$.

149 Starke 1997, 451ff.; Hawkins 1998, 29; 2002, 98ff.; Niemeier 2007, 65. 
Forrer postuliert - auf der Insel Lesbos und Wilusa in der Troas. Die Ähnlichkeiten zwischen topographischen Namen des 2. und des 1. vorchristlichen Jahrtausends sind frappierend: ${ }^{150}$ u.a. Lukka $=$ Lykia, Millawanda $=$ Millatos (Milet), ${ }^{151}$ Abasa $=$ Ephesos; Wilusa $=\star$ Wilios $/$ Ilios.

Angesichts der besprochenen Lokalisierungen von Ländern an der Südund Westküste Kleinasiens steht dort endgültig kein Platz mehr für Ahhijawa zur Verfügung. ${ }^{152}$ Wie schon 1935 Schachermeyr festgestellt hat, war Ahhijawa für die Hethiter ein fernes, weitgehend unbekanntes Land, dem man die bei sich geübten völkerrechtlichen Gebräuche erklären musste. ${ }^{153} \mathrm{Im}$ Gegensatz zu den anderen im Zusammenhang mit den Auseinandersetzungen im westlichen Kleinasien genannten und auch dort lokalisierten Ländern, Lukka, Millawanda, Arzawa, Seha-Flußland und Wilusa berichten die hethitischen Texte nie, dass ein Hethiterkönig nach Ahhijawa gezogen wäre. ${ }^{154}$ Ahhijawa unterstützt immer wieder Gegner der Hethiter im westlichen Kleinasien und nahm vor den Hethitern über See geflohene Gegner auf. ${ }^{155}$ Die zahlreichen Vorschläge, die im Lauf der Jahrzehnte von Befürwortern und Gegnern von Forrers AchäerTheorie für die Lokalisierung von Ahhijawa vorgeschlagen worden sind, habe ich 1998 in einem Ausschlussverfahren einer gründlichen Untersuchung unterzogen und bin zu dem Ergebnis gekommen, dass Ahhijawa auf dem griechischen Festland gelegen haben muß. ${ }^{156}$ Dort kommen zwei mykenische Residenzen als Zentrum von Ahhijawa in Frage: Mykene, an das man natürlich zuerst denkt, ${ }^{157}$ aber auch Theben, ${ }^{158}$ für das neben den reichen Funden, die Beziehungen zum Vorderen Orient bezeugen, und dem wichtigen Mythenzyklus auch die Tatsache spricht, dass das Toponym Achaia in ZentralGriechenland beheimatet ist und erst spät auf die Peloponnes kam. ${ }^{159}$ Der bedeutende amerikanische Archäologe C.W. Blegen, Ausgräber des ,NestorPalastes' von Pylos, schätzte Theben so wichtig ein, das es ein Rivale Mykenes um die Vorherrschaft in Griechenland gewesen sein muß. ${ }^{160} \mathrm{~J}$. Latacz meint, die Identifizierung von Theben als Haupstadt von Ahhijawa könne das alte Rätsel lösen, warum der Schiffskatalog im 2. Buch der Ilias mit Böotien be-

150 Niemeier 2008, 303.

$151 \mathrm{Zu}$ der zu rekonstruierenden mykenisch-griechischen Namensform Millatos s. Heubeck 1985, 132, zur Umwandlung von griechisch Millatos zu hethitisch Millawanda (oder umgekehrt?) s. Niemeier 2007, 67f.

152 so auch Hawkins 1998, 30.

153 Schachermeyr 1935, 51.

154 Wie schon Schachermeyr 1935, 51 festgestellt hat.

155 Easton 1984, 29; Heinhold-Krahmer 2003, 206.

156 Niemeier 1998, 20ff. 43ff. 20 Karte Abb. 3. 22 Karte Abb. 4.

157 s. z.B. Schachermeyr 1935, 132ff. 156ff.; 1986, 44ff.; Garstang - Gurney 1959, 81; Bryce 1989, 5; Niemeier 1989, 44; Hope Simpson 2003, $233 \mathrm{ff}$.

158 Niemeier 2008, 304ff.

159 Toepffer 1894, 157f.; Lehmann 1985, 52f.; 1991, 112; Niemeier 2008, $304 f f$.

160 Blegen 1975, 76. 
ginnt, und warum die Flotte der Griechen sich in Aulis sammelt, dem Hafen von Theben. ${ }^{161}$

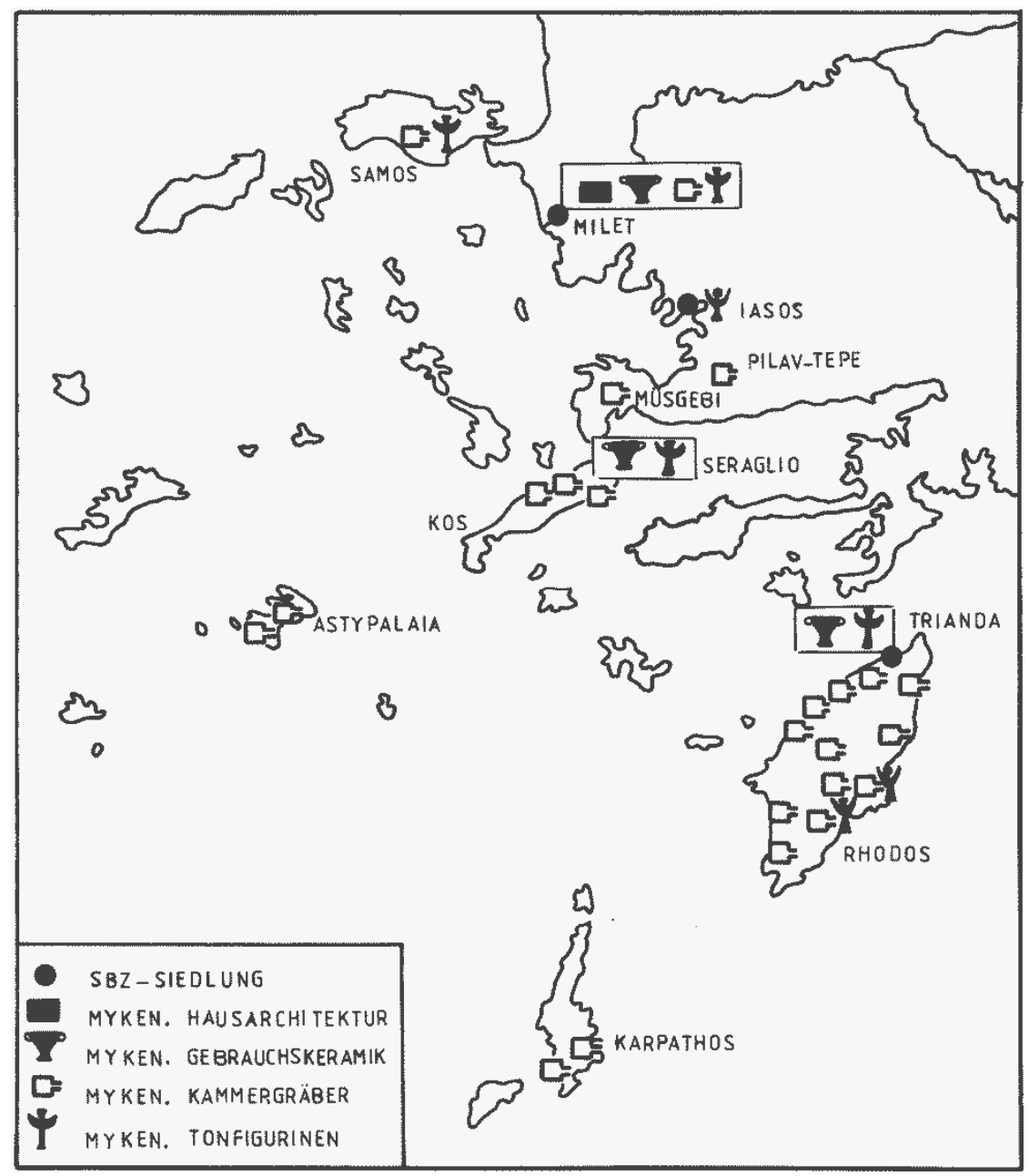

Abb. 2 Indizien für Präsenz von Mykenern in der SO-Ägäis während der späten Bronzezeit.

Wo auch das Zentrum Ahhijawas gelegen hat, in Mykene oder in Theben, mit seiner Lokalisierung auf dem griechischen Festland stimmt überein, dass sich Milet, welches - wie besprochen - als das von Untertanen des Königs von Ahhijawa bewohnte Millawanda identifizieren ist, nach den Ergebnissen der neuen, 1994-2004 durch meine Frau und mich in den bronzezeitlichen Schichten Milets durchgeführten Grabungen in den Siedlungsperioden Milet

161 Latacz 2010, 184. 
V und VI (letztes Viertel des 15. Bis Ende des 13. Jhs.v.Chr.) als eine rein mykenische Siedlung darstellt - gleichgültig wie groß der Anteil des Bevölkerungssegmentes war, das tatsächlich aus Griechenland stammte, und wie groß der des lokalen Bevölkerungssegmentes, das die mykenische Kultur vollkommen adaptierte. ${ }^{162}$ Es gibt charakteristisch mykenische Hausarchitektur; ${ }^{163}$ die Keramik ist nahezu ausschließlich mykenisch, wobei die lokal hergestellte undekorierte Haushaltsware in diesem Zusammenhang von größerer Bedeutung ist als die zum großen Teil importierte dekorierte. ${ }^{164}$ Vorratsgefäße mit vor dem Brand eingeritzten Linear B-Zeichen ${ }^{165}$ und ein mykenisches Siegel ${ }^{166}$ bezeugen mykenische Administration, Terrakotta-Figurinen von Stieren und Frauen mykenischen Kult, ${ }^{167}$ die schon angesprochenen Felskammergräber mykenischen Typs mit charakteristischen Beigaben mykenische Bestattungssitten. ${ }^{168}$

Entsprechende Funde in lasos (Terrakotta-Figurinen), Pilavtepe (mykenisches Kammergrab mit Beigaben mykenischer Art), Müsgebi (Nekropole mit Kammergräbern und Beigaben mykenischer Art) zeigen an, dass sich das Land Millawanda von Milet anscheinend nach Süden bis zur Halbinsel von Halikarnassos/Bodrum erstreckte (Abb. 2). ${ }^{169}$ An diesen Fundorten kam auch dekorierte mykenische Keramik zutage, außerdem bei neueren Grabungen innerhalb der Johanniter-Festung auf der Zephyrion- Halbinsel von Halikarnassos/Bodrum neben einer ,kyklopischen' Mauer. ${ }^{170}$ Bei den Inseln von Samos im Norden bis Rhodos im Süden mit entsprechenden mykenischen Befunden und Funden ${ }^{171}$ muß es sich um die immer wieder in den hethitischen Texten erwähnten Inseln im Machtbereich des Königs von Ahhijawa handeln, auf die Gegner der Hethiter flohen.

162 Niemeier - Niemeier 1997, 219ff.; Niemeier 1996, 1998, 300ff.; 2005, 10ff.; 2007a, $13 \mathrm{ff}$.

163 Niemeier - Niemeier 1997, 197f,; Niemeier 1998, 30f. 35f.

164 Niemeier 2007a, 15 Taf. 5,3; 2008, 307. 308 Abb. 4.

165 Niemeier 1998, 37 Fotos $13 f$.

166 Niemeier 2004, 686 Nr. 481; Niemeier 2008, 307f. Abb. 4.

167 Niemeier - Niemeier 1997, 218. 217 Abb. 31; Niemeier 2007a, 14 Taf. 5,2; Niemeier 2008, 309 Abb. 6.

168 s. oben mit Anm. 47.

169 Für Nachweise s. Niemeier 2007b, 53 Anm. 182ff. Für das mykenische Kammergrab am Pilavtepe s. jetzt Benter 2009.

170 Zur Fundsituation s. Pedersen 2009, 324 Abb. 11f. Ich danke P. Pedersen und M. Berg-Brise, die mir diese Keramik gezeigt und außerdem gestattet haben, sie hier zu erwähnen.

171 Für Nachweise s. Niemeier 2007b, 54 Anm. 192ff. 


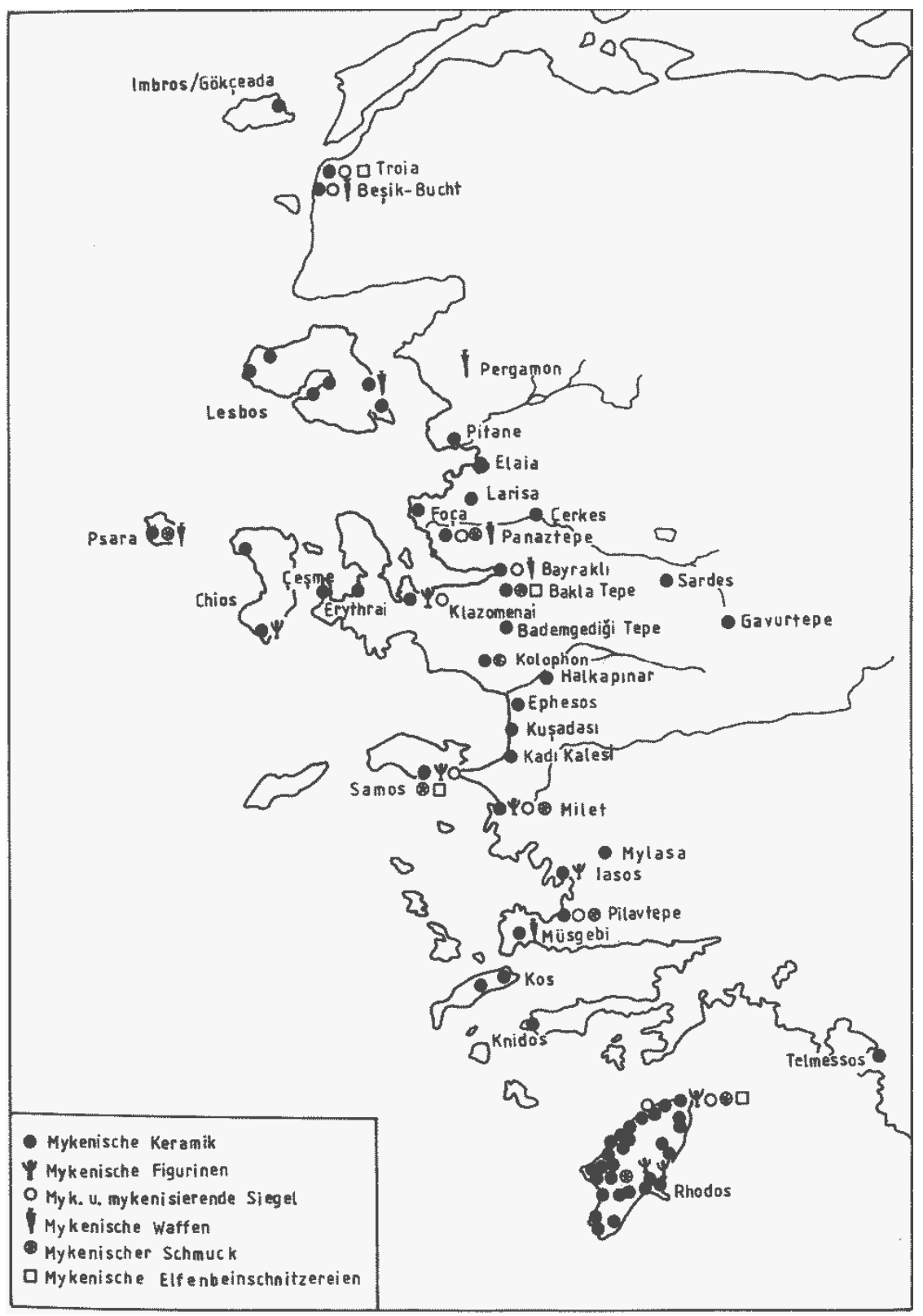

Abb. 3 Mykenische Objekte in der östlichen Ägäis

Weiter nördlich gibt es sowohl an der Westküste als auch auf den ihr vorgelagerten Inseln ebenfalls Importe mykenischer Keramik und anderer Objekte, diese sind jedoch in nur geringer Anzahl in Siedlungen und Nekropolen ganz 
überwiegend lokalen Charakters zutage gekommen (Abb. 3) ${ }^{172}$ Hier lebten in den luwischen Ländern Arzawa/Mira, Seha-Flußland und Wilusa wohl kleinere Gruppen mykenischer Griechen, Kaufleute, Töpfer und andere Handwerker mit der überwiegenden einheimischen, luwisch sprechenden Bevölkerung.

Über Jahrhunderte hinweg lag das westliche Kleinasien im Spannungsfeld zwischen Ahhijawa und dem Hethiterreich, dem Ahhijawa mit seinen westkleinasiatischen Verbündeten immer wieder Probleme bereitete. Die älteste erhaltene Erwähnung von Ahhijawa (in der älteren Form Ahhija) finden wir in der schon erwähnten sog. Anklage gegen Maduwatta, einem Brief, den Arnuwanda I. (ca. 1400-1375 v.Chr.) an Madduwata, einen untreuen hethitischen Vasallen im westlichen Kleinasien schrieb und sich darin über dessen Missetaten zur Zeit Tudhalijas I. (ca. 1420-1400 v.Chr.) des Vaters Arnuwandas und Begründers des neuhethitischen Reiches beklagte. ${ }^{173}$ Die militärischen Fähigkeiten des Madduwata scheinen nicht glänzend gewesen zu sein. Erst wurde er bei einem Angriff gegen Arzawa vernichtend geschlagen, sein Land von Arzawa okkupiert, und mußte von einer hethitischen Armee wieder befreit werden, dann griff ihn der schon erwähnte Attarasija, der Mann aus Ahhija, an. Madduwata leistete keinen Widerstand, sondern floh. Wiederum mussten die Hethiter eingreifen. Ein hethitisches Heer schlug Attarisijas Armee, zu der einhundert Streitwagen gehörten. Attarasija operierte mit seinen einhundert Streitwagen wohl kaum von Schiffen aus, sondern von einer mykenischen Siedlung im Süden der Westküste Kleinasiens. ${ }^{174}$ Madduwata erwies sich den Hethitern gegenüber als undankbar und machte gemeinsame Sache mit deren Feinden, u.a. verbündete er sich mit Arzawa und unternahm gemeinsam mit seinem vormaligen Feind Attarasija einen Raubzug gegen das zur hethitischen Interessensphäre gehörigen Alasija/Zypern. ${ }^{175}$ Bei Attarasija handelte es sich wohl nicht um einen König von Ahhijawa, sondern um einen mykenischen Aristokraten, der in jener Zeit der Auseinandersetzungen in Griechenland, die zur Herausbildung der mykenischen Palastzentren führten, an die Westküste Kleinasiens emigriert war und sich dort eine neue Basis geschaffen hatte. ${ }^{176}$ Diese kann sehr gut Milet/Millawanda gewesen sein, da dort die archäologischen Indizien - wie besprochen - für mykenische Präsenz bis in die zweite Hälfte des 15. Jhs.v.Chr. zurückreichen.

172 Für Nachweise s. Niemeier 2007b, 54ff. Anm. 200ff.

173 Götze 1928; Beckmann 1996, 144ff.; s. auch de Martino 1996, 47ff.; Bryce 1998, 140ff.; Klengel 1999, $115 f$.

174 So auch Güterbock 1984, 119; Mountjoy 1998, 47; Benzi 2002, 361.

175 s. Bryce 1998, 144ff.; Klengel 1999, 121ff. Die früher immer wieder umstrittene Lokalisierung des Königreichs Alasija auf Zypern ist nun durch die Analyse des Tons von Tontafelbriefen des Königs von Alasija and den ägyptischen Pharao Amenophis IV. aus dem Archiv von Amarna gesichert, s. Goren u.a. 2003, 233ff.; 2004, 48ff. Zu den Beziehungen zwischen dem Hethiterreich und Zypern s. de Martino 2008.

176 Mellink 1983, 139; Bryce 1998, 140; Niemeier 2007b, 74f. 
Tudhalija I. selbst zog - wie wir aus seinen Annalen erfahren - gegen die Arzawa-Länder (u.a. Arzawa und das Seha-Flußland) zu Felde und führte aus den besiegten Ländern zahlreiche Gefangene und Streitwagen nach Hattusa. ${ }^{177}$ Auf dem Rückweg wurde er angegriffen. ${ }^{178}$ Die Angreifer gehörten zu ca. 20 namentlich genannten Ländern, darunter Wilusa, die in der wissenschaftlichen Literatur oft als „Assuwa-Koalition" bezeichnet werden, bei denen es sich aber wahrscheinlich um „gliedstaatähnliche Teilgebiete des Landes Assuwa“ handelt, das im äußersten Nordwesten Kleinasiens zu lokalieren ist. ${ }^{179}$ Tudhalija schlug Assuwa vernichtend und kehrte mit vielen Gefangenen, darunter der königlichen Familie, und Beute nach Hattusa zurück. ${ }^{180}$ Danach verschwindet der Name Aussawa aus den hethitischen Dokumenten, an seine Stelle tritt Wilusa.

Einige Indizien sprechen dafür, dass Ahhijawa in den Assuwa-Konflikt verwickelt war. F. Starke konnte kürzlich nachweisen, dass es sich bei einem in Hattusa gefundenen Tontafelbrief um ein Schreiben des Königs von Ahhijawa an den hetitischen Großkönig Hattusili III (ca. 1265-1240 v.Chr.) handelt. ${ }^{181}$ In den ersten elf Zeilen geht es um einen Streit zwischen dem König von Ahhijawa und dem von Hattusa um Inseln, die einst zu Assuwa gehörten, aber einem Vorfahren des Briefschreibers vom König von Assuwa, der desssen Tochter heiratete, als Mitgift gegeben wurde. Da Assuwa nach der Unterwerfung durch Tudhalija 1. im späten 15. Jh.v.Chr. nicht mehr existierte, müssen die Inseln noch im 15. Jh.v.Chr. in den Besitz des damaligen Königs von Ahhijawa gekommen sein, und es muß sich um Inseln in der der NO-Ägäis nahe der Troas wie Lemnos und Imbros gehandelt haben, auf denen kürzlich spätbronzezeitliche Siedlungsreste mit mykenischer Keramik zutage gekommen sind. ${ }^{182}$ Die dynastische Heirat spricht für enge Beziehungen zwischen Assuwa und Ahhijawa. Zwei Funde in Hattusa aus der zweiten Hälfte des 15. Jhs. v.Chr. sind in diesem Zusammenhang von großem Interesse, da sie anscheinend kriegerische Aktionen durch Mykener in Kleinasien widerspiegeln. Das Fragment einer hethitischen Schale zeigt die eingeritzte Darstellung eines Kriegers dessen Ausrüstung, insbesondere der .Zonenhelm mit Roßhaarbusch,

177 Garstang - Gurney 1959, 121ff.; Bryce 1998, 134f.; Klengel 1999, 111.

178 de Martino 1996, 15.

179 Starke 1997, 455f.

180 de Martino 1996, 18; Bryce 1998, $135 f$.

181 Bei dem internationalen Workshop „Mycenaeans and Anatolians in the Late Bronze Age“ in Montréal, dessen Publikation durch A. Teffeteller in Vorbereitung ist. Es handelt sich um den Brief KUB (Keilschrifturkunden aus Boghazköi) 26.91. Die hier wiedergebenen Ergebnisse Starkes wurden von den anwesenden Fachleuten akzeptiert, nicht aber seine Lesung des Namens Kadmos. s. auch Latacz 2010, $311 \mathrm{ff}$.

182 Lemnos: Boulotis 1997, 267 (Koukonisis); Neufunde mykenischer Keramik aus einer spätbronzezeitlichen Siedlungsschicht in Hephaistia konnte ich 2005 dank der freundlichen Einladung des Grabungsleiters E. Greco sehen. Imbros: Davis u.a. 2001, 86 mit Literaturangeben in Anm. 328. 
nicht hethitisch ist (Abb. 4). Wie K. Bittel gezeigt hat, trägt der Krieger der Schale einen Zonenhelm, möglicherweise einen Eberzahnhelm, minoischmykenischen Typs. ${ }^{183}$ Wir haben also auf dem Schalenfragment die hethitische Darstellung eines mykenischen Kriegers der Zeit Attarasijas und Tudhalijas I. vor uns. Ein Bronzeschwert trägt die sekundär eingravierte akkadische Weihinschrift „Als Tudhalija, der Großkönig, das Land Assuwa zerstörte, weihte er diese Schwerter dem Wettergott, seinem Herrn“. ${ }^{184}$ Demnach gehörte das Schwert zur Beute Tudhalijas 1. aus dem Assuwa-Krieg. Es handelt sich um ein mykenisches Schwert des sog. Typs B, möglicherweise aus einer mykenischen Waffenschmiede im westlichen Kleinasien. ${ }^{185}$ Wahrscheinlich kämpften also Ahhijawa-Krieger auf Seiten Assuwas gegen die Hethiter.

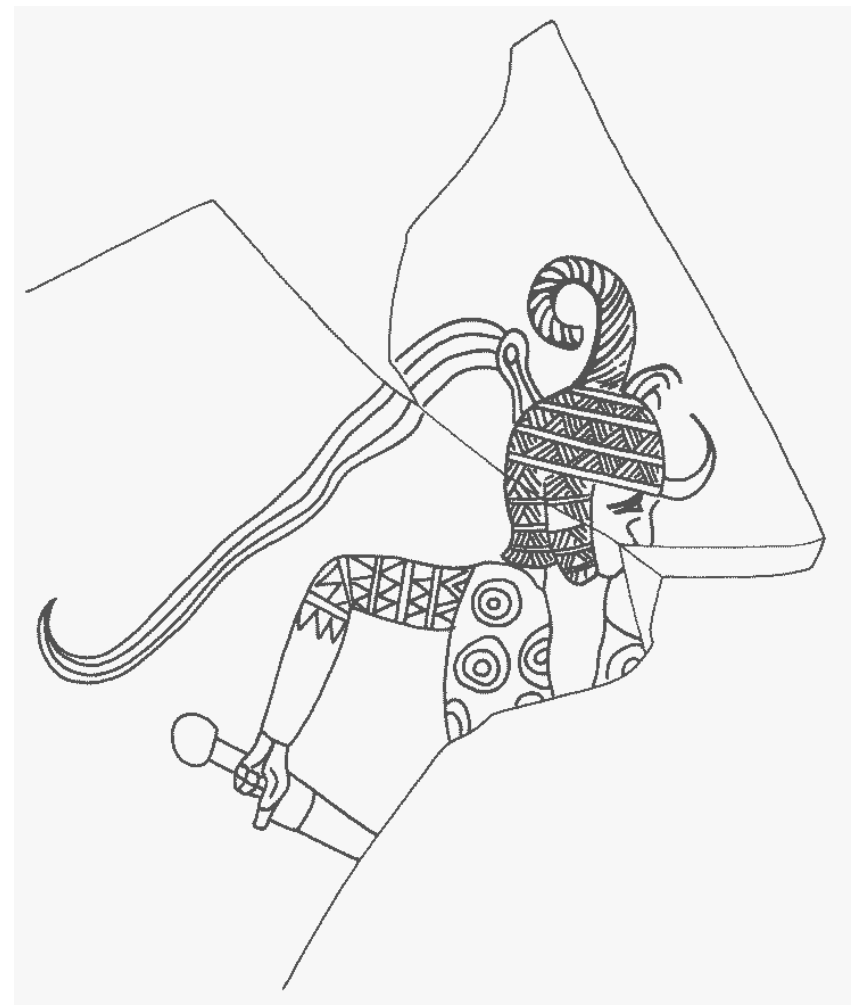

Abb. 4 Hattusa, Schalenfragment mit eingeritzter Darstellung eines mykenischen Kriegers, 2. Hälfte des 15. Jhs. v.Chr.

183 Bittel 1976b; s. auch Gütebock 1984, 115; Macqueen 1986, 63; Cline 1996; Niemeier 1998, 42; zu den minoisch-mykenischen Zonenhelmen s. Borchardt 1972, $16 \mathrm{ff}$.

184 Salvini - Vagnetti 1994; Niemeier 2002, 297 Abb. 2. 355 Nr. 153.

185 Niemeier 2008, 314. 
In der Regierungzeit Tudhalijas III. (ca. 1375 - 1355 v.Chr) eroberten die Kaskäer, die kriegerische Feinde der Hethiter im Pontos-Gebiet, die Hauptstadt Hattusa und größere Teile des Landes. Diese Schwächung des Hethiterreiches ausnutzend, griff Arzawa von Westen her an und brachte das Untere Land, die sich südwestlich an das hethitische Kernland anschließende Provinz im späteren Lyakonien an sich. ${ }^{186}$ Das Hethiterreich schien am Ende, und Arzawa auf dem Weg zur führenden Macht Kleinasiens. Der ägyptische Pharao Amenophis III. suchte das Bündnis mit Arzawa und strebte die dynastische Heirat mit einer Tochter des Königs Tarhuntaradu von Arzawa an, die möglicherweise tatsächlich stattfand. ${ }^{187}$ In dem im Archiv von Amarna erhaltenen Brief Amenophis III. heißt es: „Ich habe gehört, daß alles beendet ist und daß das Land Hatti zerschmettert ist“. Dies traf aber keineswegs zu. Tudhalija III. sandte seinen Sohn Suppiluliuma gegen Arzawa. Dieser errang einen glänzenden Sieg und vertrieb die Truppen Arzawas aus dem Unteren Land. ${ }^{188}$ Als Großkönig gelang es Suppiluliuma dann, das Mitanni-Reich im Osten zu zerstören und Hatti zum mächtigsten Reich des Vorderen Orients zu machen. ${ }^{189}$

Kurz darauf geriet das Hethiterreich aber wieder in eine Krise. Ca. 1318 v.Chr. starb nach kurzer Regierungszeit König Arnuwanda IL, sein jüngerer Bruder Mursili II. bestieg den Thron und war sogleich mit Angriffen von allen Seiten konfrontiert, da die Feinde der Hethiter glaubten, die Unerfahrenheit des jungen Königs ausnutzen zu können. ${ }^{190} \mathrm{Im}$ Westen formierte sich eine feindliche Allianz, zu der Arzawa, Ahhijawa und Millawanda gehörten, wie aus einer leider unvollständigen Passage der Annalen Mursilis II. zu erschließen ist. ${ }^{191}$ Der Großkönig sandte Truppen nach Westen gegen Millawanda, die dieses eroberten und zerstörten. ${ }^{192}$ Die Periode V der Siedlung am Athenatempel in Milet endete nach der Fundkeramik um diese Zeit in einer Brandzerstörung, die wahrscheinlich durch die Truppen Mursilis II. verursacht wurde. ${ }^{193}$

Noch in demselben Jahr führte Mursili II. selbst ein Heer gegen Arzawa und marschierte in Abasa/Ephesos ein. ${ }^{194}$ König Uhhazidi von Arzawa floh über See ,auf die Inseln“, sicherlich Inseln die zu Ahhijawa gehörten, wie Samos, Kos und Rhodos. Im folgenden Jahr vernichtete Mursili die letzten

186 Bryce 1998, 158ff.; 2003, 55f.; Hawkins 1998, 10 mit Anm. 31; Klengel 1999, $132 \mathrm{ff}$.

187 Moran 1992, 101ff. (Übersetzung von V. Haas). s. von Schuler 1965, 36ff.. 50ff.; Kühne 1973, 95ff.; Heinhold-Krahmer 1977, 50ff.; Haider 1999, 208ff; Klengel 1999, $131 \mathrm{f}$.

188 Bryce 1998, 163ff.; Klengel 1999, $149 f f$.

189 Bryce 1998, 174ff.; Klengel 1999, $155 f f$.

190 Götze 1933b, 14ff.; Bryce 1998, 206ff.; Klengel 1999, $178 f f$.

191 Götze 1933b, 37f.; zum Erhaltungszustande und zum Problem der Ergänzung Heinhold-Krahmer 1977, 97ff.; Güterbock 1983, $134 f$.

192 Götze 1933b, 37f.; Güterbock 1983, 134f.; Bryce 1998, 207.

193 Mellink 1983, 140; Niemeier - Niemeier 1997, 201ff.; Niemeier 2007b, 77.

194 Götze 1933b, 47ff.; Bryce 1998, 210f.; Klengel 1999, $189 f$. 
Widerstandsnester in Arzawa. ${ }^{195}$ Arzawa wurde in die Vasallenstaaten Mira und Haballa aufgelöst, auch das Seha-Flußland wurde in einen Vasallenstaat umgewandelt. ${ }^{196}$

Wilusa hatte sich aus diesem Konflikt herausgehalten. In der Präambel des schon erwähnten Alaksandu-Vertrages heißt es: ${ }^{197}$ „Als Tudhalija gegen Arzawa zog, betrat er Wilusa nicht, denn es war mit ihm befreundet und schickte ihm regelmäßig Gesandte". Für den Rest der Regierungszeit Mursilis II., die ca. 1290 v.Chr. endete, hatten die Hethiter Ruhe im westlichen Kleinasien. Das von hethitischen Truppen eroberte Millawanda kam wieder unter die Kontrolle von Ahhijawa, spätestens in der Regierungszeit des Sohnes und Nachfolgers Mursilis II., Muwatalli II. (ca. 1290-1272 v.Chr.). Dies geht aus einem Brief des Königs Manabatarhunta des Seha-Flußlandes an Muwatalli II. hervor. ${ }^{198}$ Die Rückgabe erfolgte möglicherweise im Rahmen eines Vertrages, mit dem die Hethiter angesichts der Konfrontation mit den Ägyptern in Syrien, die - wie schon erwähnt - schließlich 1275 v.Chr. in der Schlacht von Qadesch kulminierte - durch die Befriedigung der territorialen Ambitionen Ahhijawas auf kleinasiatischem Boden die Kooperation des Königs von Ahhijawa für die Aufrechterhaltung der Stabilität im westlichen Kleinasien zu erreichen versucht haben könnten. ${ }^{199}$

Ahhijawa sorgte über Millawanda aber weiter für Unruhe im westlichen Kleinasien. Bereits während der Regierungszeit Muwatallis II. operierte von Millawanda aus ein gewisser Pijamaradu, der über Jahrzehnte hinweg der provokanteste Feind der Hethiter im westlichen Kleinasien blieb und von Wilusa im Norden bis Lukka im Süden agierte. ${ }^{200}$ Aus dem bereits erwähnten Brief des Manabatarhunta geht hervor, dass Pijamaradu zu Beginn der Regierungszeit Muwatallis II. Wilusa okkupiert hatte. ${ }^{201}$ Manabatarhunta hatte militärisch gegen Pijamaradu eingegriffen, aber anscheinend eine schwere Niederlage erlitten. Pijamaradu hatte auch Lazpa/Lesbos angegriffen und von dort vor dem Eintreffen der zu Hilfe gerufenen hethitischen Armee eine Anzahl von Sarapitu (religiöses Personal im Dienst des hethitischen Königs und des Königs des Seha-Flußlandes) nach Millawanda verschleppt, wo Atpa, Schwiegervater des Pijamaradu, Vasall des Königs von Ahhijawa war. Nach der Vertreibung des Pijamaradu aus Wilusa schloß Muwatalli II. mit Alaksandu von Wilusa den schon erwähnten Vasallenvertrag, der Wilusa einerseits Schutz garantierte, es anderseits aber auch zur Heerfolge gegenüber den Hethitern verpflichtete. ${ }^{202}$

195 Niemeier 2008, 316f.

196 Starke 1997, 452f.

197 Latacz 2010, 162, \ 2 (B I 9-14) (Neuübersetzung F. Starke).

198 Houwink ten Cate 1983/84, 46.

199 Bryce 1998, 244f.

200 Heinhold-Krahmer 1983; 1986.

201 Houwink ten Cate 1983/84, 33ff.; Starke 1997, 453f.; Bryce 1998, 245.

202 Latacz 2010, 159ff. (Neuübersetzung F. Starke). 
Und in der Tat nennt Ramses II. in seinem Bericht über die Schlacht bei Qadesch unter den Hilfstruppen der Hethiter Krieger aus Dardanija. Es besteht kein Zweifel daran, dass dieser Name mit den Dardanoi zu verbinden ist, die in der Ilias eine alternative Bezeichnung für die Troianer, sind, und von denen der Name der Dardanellen abgeleitet ist. ${ }^{203}$

Über Pijamaradus weiteren Aktivitäten im westlichen Kleinasien erfahren wir vor allem im sog. Tawagalawa-Brief, den Hattusili III. (ca. 1265-1240 v.Chr.) an den König von Ahhijawa schrieb und von dem nur die dritte Tafel erhalten ist. ${ }^{204}$ Hattusili beklagt sich über Pijamaradus feindselige Handlungen und dessen Protektion durch den König von Ahhijawa. Die Operationsbasis des im Brief auftretenden Tawagalawa/Eteokles, eines Bruders des Königs von Ahhijawa, ${ }^{205}$ der dessen Repräsentant im westlichen Kleinasien war, befand sich allem Anschein nach in Millawanda/Milet. Als Hattusili mit einer Armee gegen Pijamaradu nach Westen zog, täuschte dieser vor, sich unterwerfen zu wollen, lockte aber die Hethiter bei Ijalanda, dem späteren Alinda ${ }^{206}$ in einen Hinterhalt. Hattusili stürmte Ijalanda, Pijamaradu floh nachMillawanda/Milet. Der König von Ahhijawa sagte die Auslieferung Pijamaradus zu. Als Hattusili an die Grenze von Millawanda zog, um Pijamaradu in Empfang zu nehmen, war dieser aber bereits über See nach Ahhijawa geflohen.In Hinsicht auf Wilusa ist eine Stelle des Tawagalawa-Briefes von Interesse, in der Hattusili den König von Ahhijawa darum bittet, eine dritte Person daran zu erinnern, dass die beiden Könige Frieden in der Angelegenheit Wilusas gemacht hätten, in der sie einander bekämpft hatten.

Die letzten erhaltenen Quellen zur spätbronzezeitlichen Geschichte WestKleinasiens, zu Ahhijawa und Millawanda, bilden Keilschriftdokumente Tudhalijas IV. (ca. 1240-1215 v.Chr.). Als Masturi, der den Hethitern treue Vasallenkönig des Seha-Flußlandes kinderlos starb, ursupierte ein gewisser Tarhunnaradu den dortigen Thron. ${ }^{207}$ Auf einem fragmentarisch erhaltenen Dokument, wohl der historischen Einleitung eines Vertrages oder eines königlichen Erlasses erfahren wir, dass Tarhunnaradu gegen die Hethiter rebellierte und dabei auf die Unterstützung des Königs von Ahhijawa vertraute. Diese kam aber nicht oder war ungenügend, denn Tudhalija gelang es, die Rebellion niederzuwerfen. ${ }^{208}$

Die letzte Erwähnung Millawandas findet sich im sog. Millawata-Brief, den Tudhalija IV. an einen von ihm als „mein Sohn“ angesprochenen Vasall

203 Haider 1997, 117f. Gegen Haiders These, dass Wilusa nicht an den Dardenellen lag, s. Niemeier 2007b, 65f.

204 Sommer 1932, 2ff.; zum Tawagalawa-Brief s. Singer 1983, 209ff.; Starke 1997, 453ff.; Bryce 1998, 320ff.; Klengel 1999, 264ff.; Niemeier 2008, $320 f f$.

205 s. oben mit Anm. 119.

206 Garstang - Gurney 1959, 78.

207 Singer 1983, 203; Bryce 1998, 338.

208 Güterbock 1992; Bryce 1998, 338ff. 
im westlichen Kleinasien richtete, dessen Namen im erhaltenen Teil nicht genannt ist. ${ }^{209} \mathrm{Im}$ Dokument ist davon die Rede, dass der Absender und der Empfänger des Briefes die Grenzen von Millawanda neu festgelegt haben. Gleichgültig, ob der Empfänger in Mira oder Millawanda/Milet residierte, was beides vorgeschlagen worden ist, ${ }^{210}$ zeigt der Millawata-Brief einen Machtwechsel in Millawanda/Milet und die Verdrängung des Einflusses von Ahhijawa an. ${ }^{211}$ Für einen solchen Machtwechsel sprechen auch archäologische Indizien: Um 1200 v.Chr., also nach diesem Machtwechsel, ist nach dem Ergebnis unserer neuen Ausgrabungen die Befestigungsmauer von Milet VI zu datieren, die mit ihren in regelmäßigen Abständen vorspringenden, rechteckigen Bastionen keinen mykenischen sondern einen anatolisch-hethitischen Typus zeigt. ${ }^{212}$ Unter den Beigaben in den späten Kammergräbern der Nekropole am Degirmentepe gibt es hethitische Schwerter. ${ }^{213}$ Das Fragment eines um 1200 v.Chr. zu datierenden mykenischen Kraters lokaler Produktion zeigt ein konisches Objekt mit Hörnern, eine Hörnerkrone, ${ }^{214}$ wie sie von hethitischen Göttern, seit dem mittleren 13. Jh.v.Chr. auch von hethitischen Großkönigen getragen wurde. ${ }^{215}$ Der der Hörnerkrone zugewandte Vogelkopf am rechten Rand des Fragmentes bildet möglicherweise den Rest der Kopie einerhieroglyphen-luwischen Inschrift. In entsprechender Position findet sich ein Vogel in der Inschrift des Reliefs Karabel A vor der Figur des Königs Tarkasnawa von Mira. ${ }^{216}$ In jedem Fall stellt die zu ergänzende Darstellung eines hethitischen Gottes oder Großkönigs auf einem in Milet hergestellten mykenischen Krater ein starkes Zeichen hethitischen Einflusses dar. Hauptthema des sog. Milawata-Briefes ist aber nicht - wie die Bezeichnung in der neuzeitlichen Forschung annehmen lassen könnte - Millawata/Millawanda, sondern Wilusa. Tudhalija wollte Walmu, den vertriebene hethitischen Vasallenkönig von Wilusa, der in Millawanda Zuflucht gefunden hatte, wieder in Wilusa einsetzen.

Was sagen die hethitischen Quellen zu der in den letzten Jahre so umstrittenen Frage nach einem möglichen historischen Hintergrund der Überlieferung vom Troianischen Krieg aus? Wie besprochen, berichten sie von mehreren Angriffen gegen Wilusa/Troia, den Vasallen des Hethiterreiches, Angriffen, in die Ahhijawa und dessen Vasall Millawanda verwickelt waren.

209 Hoffner 1982; Singer 1983, 214ff.; Bryce 1985; 1999, 339ff.; Niemeier 2008, $323 f$.

210 Millawanda: Hoffner 1982, 133; Lehmann 1991, 113; Gurney 1992, 220f. Anm. 58; Bryce 1998, 340ff. Mira: Starke 1997, 454; Hawkins 1998, 19. 28. Singer 1983, $215 f$. identifizierte den Empfänger des Briefes zunächst als den Vasellankönig des SehaFlußlandes, hat sich aber inzwischen der Meinung von Starke und Hawkins angeschlossen (mündliche Mitteilung).

211 Güterbock 1986, 38.

212 Niemeier 1998, 38; Buchholz 1999, 177.

213 Niemeier 2002, 298. 297 Abb. 4.

214 Niemeier 2002, 298.299 Abb. 7; 2008, 324f. Ab. 11.

215 Zur Hörnerkrone s. Boehmer 1972-75, van den Hout 1995, 545ff.

216 Hawkins 1998, 5 Abb. 3b.d. S. 7 Abb. 5. 
Der Troianische Krieg ist nicht direkt in den hethitischen Quellen zu finden, die zudem vor dem Untergang des Hethiterreichs um 1200 v.Chr. sehr lückenhaft sind. Die in den hethitischen Quellen geschilderten Konflikte im westlichen Kleinasien bilden aber ein historisches Gesamtbild, in den sich ein Angriff mykenischer Griechen, der zur Eroberung und Zerstörung Troias führte, gut einfügt. In diesem Zusammenhang interessant erscheint auch die Tatsache, dass Personennamen von Troianern in der Ilias wie Paris und Priamos, die sich einer Etymologie aus dem Griechischen entziehen, problemlos aus dem luwischen Sprachgut abgeleitet werden können. ${ }^{217}$

Für die Existenz mykenischer Dichtung gibt es keine direkten Beweise. Bei einer Hochkultur von ihrem Niveau, die Kontakte zum Vorderen Orient und Ägypten unterhielt, ${ }^{218}$ ist jedoch kaum denkbar, dass sie im Gegensatz zu jenen keine Literatur und Dichtung kannte. Die zufällig bei den Brandzerstörungen der Residenzen gebrannten und dadurch erhaltenenTontafeln mit den Verwaltungstexten sind die einzigen mykenischen Schriftzeugnisse, die auf uns gekommen sind. Die Mykener verwendeten aber sicherlich auch andere Schriftträger aus organischem, inzwischen längst vergangenem Material, wie Leder oder Pergament. ${ }^{219}$ In den Silbenschriften des alten Vorderen Orients und Ägyptens, die einen ähnlichen Charakter haben wie die mykenische Linear B-Schrift, wurden auch Literatur und Dichtung festgehalten. Ich halte es daher für gut möglich, dass in mykenischer Zeit Dichtung schriftlich fixiert wurde und die ,Oral Poetry' ${ }^{220}$ erst richtig nach dem Untergang der mykenischen Paläste um 1200 v.Chr.v.Chr. und dem damit verbundenen Verlust der Schrift für mehr als drei Jahrhunderte einsetzte.

Die Schlachtengemälde, welche sich die mykenischen Herrscher an die Wände ihrer Paläste malen ließen und die u.a. Kämpfe um Städte zeigten, ${ }^{221}$ feierten sicherlich bestimmte Siege, die auch an den Höfen besungen wurden. ${ }^{22}$ Von besonderem Interesse in diesem Zusammenhang ist ein Fresko aus Halle 64 des Palastes von Pylos in Messenien mit der Darstellung des Kampfes zwischen zwei deutlich unterschiedenen Parteien, auf der einen Seite mykenische Kriegern mit Eberzahnhelmen und Beinschienen, auf der anderen deren mit Tierfellen bekleidete Gegner (Abb. 5). ${ }^{223}$ N. Yalouris hat dieses Fresko mit einer Stelle in der Ilias $(7,133 \mathrm{ff}$.) in Verbindung gebracht, in der Nestor von Pylos sein Heldentum als Sieger über die Arkader in Erinnerung ruft. ${ }^{224}$

217 Haas 2006, 5 f.

218 Cline 1994.

219 Leder oder Pergament als Schriftträger sind im minoischen Kreta durch die Abdrücke zusammengefalteter Schriftstücke auf den Rückseiten tönerner ,Päckchenplomben' nachgewiesen - s. Müller 1999, $349 f f$.

220 s. Latacz 2008a, 66ff.; Deger-Jalkotzy 2008.

221 Immerwahr 1990, $122 \mathrm{ff}$.

222 Zu mykenischen Darstellungen von Sängern s. Hagel 2008.

223 Lang 1969, 71f. Nr. 22 H 64, Taf. 16. 117. A. M.

224 Yalouris 1989. 


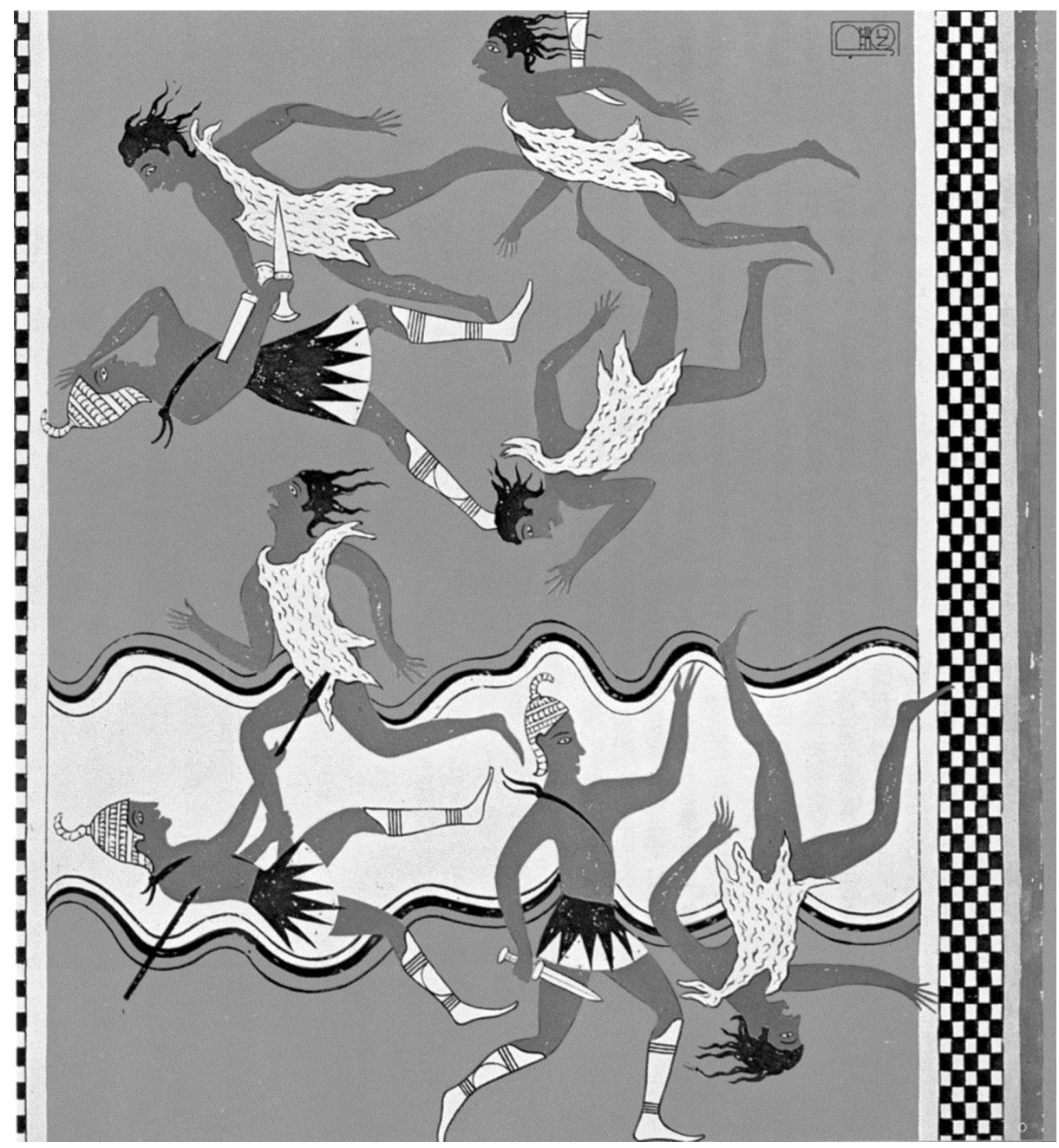

Abb. 5 Pylos (Messenien), Fresko mit Kampfdarstellung aus Halle 64 des Palastes, 13. Jh.v.Chr., Rekonstruktion P. de Jong

Die Arkader aber waren die ganze Antike hindurch dafür bekannt, dass sie sich mit Schafsfellen kleideten. So war nach Yalouris' Interpretation diese berühmte Schlacht dargestellt und jeder, der das Fresko sah, wurde an diese erinnert, die in den Epen gepriesen und von der auf allen Festen im Lande erzählt wurde.

Das Versmaß der homerischen Epen, der Hexameter, ist mykenischen Ursprungs und eine Reihe von formelhaft Versen der Ilias stammen nachweislich aus mykenischer Zeit, teilweise sogar aus der frühmykenischen Zeit der 
Schachtgräber von Mykene. ${ }^{225}$ So wurden die Geschichten um den Troianischen Krieg über die Generationen weiter vermittelt, aber von den Sängern der schriftlosen Zeit nach dem Untergang der mykenischen Paläste immer wieder den Zeitumständen angepasst, durch Neusetzung von Akzenten, Neuzeichnung der handelnden Figuren, Neumotivierung der Handlungen, Aufnahme neuer Realien etc. ${ }^{226}$ A. Lesky hat in Hinsicht auf die homerischen Epen treffend als einem Amalgam gesprochen ${ }^{227}$ und festgestellt: ${ }^{228}, \ldots$ die verschiedenen Epochen angehörigen Elemente treten in einer innigen, mechanisch nicht aufzulösenden Verbindung auf". Der Kern der Geschichte, der zur Zeit Homers lang zurückliegende Kampf um Troia, blieb aber der gleiche. Der Dichter verwendete ihn als Hintergrund für seine Geschichte, die des Konfliktes zwischen Achilleus und Agamemon, welche ihrerseits die Stasis, die Auseinandersetzungen des aufstrebenden Adels seiner Zeit, der zweiten Hälfte des 8. Jhs.v.Chr., widerspiegelt. ${ }^{229}$ Dabei überhöhte Homer den Zug gegen Troia in legitimer dichterischer Freiheit zu einem panhellenischen Unternehmen unter Beteiligung der berühmtesten Helden Griechenlands. So schuf er etwas ganz Neues, das erste große Epos des Abendlandes, das einen festen Bestandteil des kulturellen Erbes Europas bildet.

\title{
Bibliographie
}

\begin{abstract}
Abkürzungen:
Hattusa Wilhelm, G. (Hrsg.), Hattusa - Bogazköy. Das Hethiterreich im Spannungsfeld des Alten Orients, Colloquien der Deutschen Orientgesellschaft 6 (Wiesbaden 2008).

Homer Latacz, J. / Greub, Th. / Wieczorek, A. (Hrsg.), Homer - Der Mythos von Troia in Dichtung und Kunst (München 2008).

Ionien Cobet, J. / von Graeve, V. / Niemeier, W.-D./ Zimmermann K. (Hrsg.), Frühes Ionien: eine Bestandsaufnahme, Panionion-Kolloquium Güzelcamli, 26. September - 1. Oktober 1999, Milesische Forschungen 5 (Mainz 2007).

Troia I Troia: Traum und Wirklichkeit (Stuttgart 2001).

Troia II Korfmann, M.O. (Hrsg.), Troia: Archäologie eines Siedlungshügels und seiner Landschaft (Mainz 2006).
\end{abstract}

225 Latacz 1998; 2010, 332ff. 379ff.; Hiller 1999.

226 Sherratt 1990; Latacz 2010, 337ff.

227 Lesky 1968, 717. 719.

228 Lesky 1968, 749.

229 Latacz 1997, $10 f f$. 
Adrimi-Sismani, V., "The palace of Iolkos and its end", in: S. Deger-Jalkotzy - I. Lemos (Hrs.), Ancient Greece: from the Mycenaean palaces to the age of Homer (Edinburgh 2006) 465ff.

Alaura, S., „Nach Boghasköi!“, zur Vorgeschichte der Ausgrabungen in Bogazköy-Hattusa und zu den archäologischen Forschungen bis zum Ersten Weltkrieg, 13. Sendschrift der Deutschen Orient-Gesellschaft (Münsterschwarzach Abtei 2006).

Allen, S.H., Finding the walls of Troy. Frank Calvert and Heinrich Schliemann at Hisarlik (Berkeley 1999).

Aravantinos, V. - Vasilogamvrou, A., ,The first Linear B Documents from Ayios Vasileios (Laconia)“, in P. Carlier, Ch. de Lamberterie, M. Egetmeyer, N. Guilleux, Fr. Rougemont, J. Zurbach (Hrsg.), Études mycéniennes 2010. Actes du XIIIe colloque international sur les textes égéens, Sèvres, Paris, Nanterre, 20-23 septembre 2010, (Pisa - Roma 2012) 41-54.

Aslan, R. - Bieg, G. - Jablonka, P. - Krönneck, P., „,Die mittel- bis spätbronzezeitliche Besiedlung (Troia VI und Troia VIIA) der Troas und der GeliboluHalbinsel“", Studia Troica 13 (2003) 165ff.

Beckerath, J. von, „Chronologie des pharaonischen Ägpten“, Münchner Ägyptologische Studien 46 (Mainz 1997).

Beckmann, G., Hittite diplomatic texts (Atlanta 1996).

Becks, R, ,Troia in der späten Bronzezeit - Troia VI und Troia VIIa“, in: Troia II, $155 \mathrm{ff}$.

Benter, M., „Das mykenische Kammergrab vom Pilavtepe“, in: F. Rumscheid (Hrsg.), Die Karer und die Anderen, Internationales Kolloquium an der Freien Universität Berlin, 13.-15. Oktober 2005 (Bonn 2009), 349ff.

Bittel, K., „Das zweite vorchristliche Jahrtausend im östlichen Mittelmeer und im Vorderen Orient: Anatolien und Ägäis“, Gymnasium 83 (1976) 513ff.

—, „Tonschale mit Ritzverzierung aus Bogazköy“, Revue Archéologique (1976) 9ff.

- Hattusa, Hauptstadt der Hethiter. Geschichte und Kultur einer altorientalischen Großmacht (Köln 1983).

Blegen, C.W., „Chapter XXIII(a): The expansion of the Mycenaean civilisation“, in: The Cambridge Ancient History, third edition II.2 (Cambridge 1975), 165ff.

Boehmer, „Hörnerkrone“, in: Reallexikon der Assyriologie und Vorderasiatischen Archäologie 4 (Berlin 1972-75), $431 \mathrm{ff}$.

Borchardt, J., Homerische Helme. Helmformen der Ägäis in ihren Beziehungen zu orientalischen und europäischen Helmen in der Bronze- und frühen Eisenzeit ( Mainz 1972)

Boulotis, Ch., „Koukonisi Lemnou, tessera chronia anaskafikes erevnes: theseis kai ypotheseis“", in: Ch. Doumas - V. La Rosa (Hrsg.), He Poliochne kai he proime epoche tou chalkou sto Boreio Aigaio, Diethnes Synedrio, Athena, 22-25 Apriliou 1996 (Athen 1997), 230ff.

Bryce, T.R., „A reinterpretation of the Milawata letter in the light of a new join piece“, Anatolian Studies 35 (1985) 13ff.

-, „The Nature of Mycenaean Involvement in Western Anatolia“ Historia 38 (1989) $1 \mathrm{ff}$.

-, The Kingdom of the Hittites (Oxford 1998). 
-, „History“, in: H.C. Melchert (Hrsg.), The Luwians. Handbuch der Orientalistik 68 (Leiden - Boston 2003), $27 \mathrm{ff}$.

Buchholz, H.G., Ugarit, Zypern und Ägäis. Kulturbeziehungen im zweiten Jahrtausend v. Chr., Alter Orient und Altes Testament 261 (Münster 1999).

Büyükkolonci, M., „Apasa, das alte Ephesos und Ayasoluk“, in: Ionien, $21 \mathrm{ff}$.

Cancik, H., „Der Troianische Krieg: seine Bedeutung für das Geschichtsbild der Griechen und Römer", in: Troia I, 174-179.

Ceram, C.W., Enge Schlucht und schwarzer Berg. Entdeckung des Hethiterreiches (Hamburg 1955).

Chadwick, J., The Decipherment of Linear B (Cambridge $\left.{ }^{2} 1967\right)$.

Chantre, E., Recherches archéologiques dans l'Asie occidental. Mission scientifique en Cappadoce, 1893-1894 (Paris 1898).

Cline, E. H., Sailing the wine-dark sea: international trade and the Late Bronze Age Aegean (Oxford 1994).

-, „Assuwa and the Achaeans: The ,Mycenaean' Sword at Hattusa and its possible implication", Annual of the British School at Athens 91 (1996) 137ff.

Cook, J.M., The Troad: An archaeological and topographical study (Oxford 1973).

Dagron, G., Naissance d'une capitale, Bibliothèque Byzantine 7 (Paris 1974).

Dakouri-Hild, A. „Thebes“, in: E. Cline (Hrsg.), The Oxford Handbook of the Bronze Age Aegean (ca. 3000-1000 BC) (Oxford 2010), 690ff.

Davis, J.L. (Hrsg.), Sandy Pylos (Princeton ${ }^{2} 2008$ ).

-, „Pylos“, in: E. Cline (Hrsg.), The Oxford Handbook of the Bronze Age in the Aegean (ca. 3000-1000 BC) (Oxford 2010), 680ff.

Davis, J.L. - Tzonou-Herbst, I. - Wolpert, A.D., „The Islands of the Aegean, Addendum: 1992-1999“, in: T. Cullen (Hrsg.), Aegean Prehistory: A Review (Boston 2001), 77ff.

Deger-Jalkotzy, S., „Die vorhomerische Epik - Indizien und Wahrscheinlichkeiten", in: Homer, 99ff.

Doblhofer, E., Zeichen und Wunder. Geschichte und Entzifferung verschollener Schriften und Sprachen (Augsburg 1990).

Döhl, H., Heinrich Schliemann: Mythos und Ärgernis (München und Luzern 1981).

Dräger, P., Rezension von: R. Schrott, Homers Ilias. Übertragung (München 2008), unter Einbeziehung von: R. Schrott, Homers Heimat. Der Kampf um Troia und seine realen Hintergründe (München 2008), Göttingische Gelehrte Anzeigen 261 (2009) $1 \mathrm{ff}$.

Easton, D.F. „The Hittites and the Trojan War“, in: L. Foxhall - J.K. Davies (Hrsg.), The Trojan War: its historicity and context, Papers of the First Greenbank Colloquium, Liverpool 1981 (Bristol 1984), 23ff.

—, , Troy before Schliemann“, Studia Troica 1 (1991) $111 \mathrm{ff}$.

—, "Schliemann did admit the Mycenaean date of Troia VI", Studia Troica 4 (1994) $173 \mathrm{ff}$.

—, „Mit der Ilias im Gepäck - Die Erforschung Troias bis 1890“, in: Troia II, $107 \mathrm{ff}$.

Fimmen, D., Die kretisch-mykenische Kultur (Leipzig \& Berlin 1924). 
Forrer, E.O., „Vorhomerische Griechen in den Keilschrifttexten von Bogazköi“, Mitteilungen der Deutschen Orient-Gesellschaft zu Berlin 63 (1924) 1ff.

-, „Die Griechen in den Boghazköi-Texten“, Orientalische Literaturzeitung 27 (1924) 113ff.

—, „Ahhijava“, in: Reallexikon der Assyriologie 1 (Berlin 1928), 53ff.

-, „Für die Griechen in den Boghazköi-Texten“, in: F. Sommer - H. Ehelolf (Hrsg.), Kleinasiatische Forschungen I/2 (Berlin 1928), $252 \mathrm{ff.}$

French, E., Mycenae: Agamemnon's capital, the site in its setting (Stroud 2002).

-, „Mycenae“, in: E. Cline (Hrsg.), The Oxford Handbook of the Bronze Age Aegean (ca. 3000-1000 BC) (Oxford 2010), 671ff.

Friedrich, J., „Werden in den Keilschrifttexten die Griechen erwähnt?“, in: F. Sommer - H. Ehelolf (Hrsg.), Kleinasiatische Forschungen I.1 (Berlin 1927), 87ff.

Garstang, J. - Gurney, O.R., The geography of the Hittite empire (London 1959).

Gerkan, A. von, Kalabaktepe, Athenatempel und Umgebung, Milet I. 8 (Berlin 1925).

Goethert, F.W. -Schleif, H., Der Athenatempel von Ilion (Berlin 1962).

Goren Y. -Bunimowitz, S. -Finkelstein, I.- Na'aman, N., ,, The location of Alashiya: new evidence from petrographic investigation of Alashiyan tablets from ElAmarna and Ugarit“, American Journal of Archaeology 107 (2003) 233ff.

-, Inscribed in clay: provenance study of the Amarna Tablets and other Near Eastern texts (Tel Aviv 2004).

Götze, A., Kleinasien zur Hethiterzeit, Orient und Antike I (Heidelberg 1924).

—, Madduwatas, Mitteilungen der Vorderasiatischen-Aegyptischen Gesellschaft 32.1 (Leipzig 1927).

-, Rezension zu E.O. Forrer, Die Nachbarländer des Hatti-Reiches von Arzaova bis Griechenland (Berlin 1929), Orientalische Literaturzeitung 33 (1930) $285 \mathrm{ff}$.

—, Kulturgeschichte des Alten Orients III.1: Kleinasien (München 1933).

-, Die Annalen Mursilis II., Mitteilungen der Vorderasiatisch-Aegyptischen Gesellschaft Leipzig 38 (Leipzig 1933).

-, Hethiter, Churriter und Assyrer. Hauptlinien der vorderasiatischen Kulturentwicklung im II. Jahrtausend v. Chr. Geb. (Oslo 1936).

—, Kulturgeschichte des Alten Orients III.1: Kleinasien (München ${ }^{2} 1957$ ).

Gurney, O.R., „Hittite Geography: thirty years after“, in: H. Otten - E. Akurgal H. Ertem (Hrsg.), Hittite and other Anatolian and Near Eastern studies in honour of Sedat Alp (Ankara 1992), 213ff.

Güterbock, H.G., ,The Ahhiyawa problem reconsidered“, American Journal of Archaeology 87 (1983) 133ff.

-, „Hittites and Akhaeans: a new look“, Proceedings of the American Philosophical Society 128 (1984) 114ff.

—, „Wer war Tawagalawa?“, Orientalia 59 (1990) 157ff.

-, „A new look at one Ahhiyawa text“, in: H. Otten - E. Akurgal - H. Ertem (Hrsg.), Hittite and other Anatolian and Near Eastern studies in honour of Sedat Alp (Ankara 1992), 235ff.

Haas, V., Die hethitische Literatur: Texte, Stilistik, Motive (Berlin 2006). 
Hagel, S., „Die Sänger aus musikarchäologischer Perspektive“, in: Homer, $106 \mathrm{ff}$.

Haider, P.W., „Troia zwischen Hethitern, Mykenern und Mysern - besitzt der Troianische Krieg einen historischen Hintergrund?“, in: H.D. Galter (Hrsg.), Troia: Mythen und Geschichte. Grazer Morgenländische Studien 4 (Graz 1997), 97ff.

—, „Zur historischen Geographie Westkleinasiens im 13. Jh. v.Chr.“, in: H. Friesinger - F. Krinzinger (Hrsg.), 100 Jahre österreichische Forschungen in Ephesos, Akten des Symposion in Wien 1995. Archäologische Forschungen 4 (Wien 1999), $665 \mathrm{ff}$.

—, „Die Beziehungen zwischen dem Pharaonenhof und dem Königreich Arzawa in Westkleinasien“, in: P. Scherrer - H. Täuber - H. Thür (Hrsg.), Steine und Wege, Festschrift für Dieter Knibbe (Wien 1999), $205 \mathrm{ff}$.

Hawkins, J.D., The Hieroglyphic Inscription of the sacred Pool Complex at Hattusa (SÜDBURG). Studien zu den Bogazköy-Texten Beih.3 (Wiesbaden 1995).

-, „Tarkasnawa King of Mira, Tarkondemos, Bogazköy sealings and Karabel“, Anatolian Studies 48 (1998) 1ff.

-, ,The historical geography of Western Anatolia according to the Hittite texts“, Anatolian Studies 52 (2002) 93ff.

-, „Anatolia: The end of the Hittite empire and after“, in: E.A. Braun-Holzinger - H. Matthäus (Hrsg.), Die nahöstlichen Kulturen und Griechenland an der Wende vom 2. Zum 1. Jahrtausend v. Chr. Kontinuität und Wandel von Strukturen und Mechanismen kultureller Interaktion (Möhnesee-Wamel 2002), $143 \mathrm{ff}$.

Heilmann, Ch. -Rödiger-Diruf, E. (Hrsg.), Landschaft als Geschichte: Carl Rottmann 1797 - 1850, Hofmaler Ludwigs I. (München 1998).

Heinhold-Kramer, S. Arzawa. Untersuchungen zu seiner Geschichte nach den hethitischen Quellen. Texte der Hethiter 11 (Heidelberg 1977).

—, „Untersuchungen zu Piyamaradu I“, Orientalia 52 (1983) 81ff.

—, „Untersuchungen zu Piyamaradu II“, Orientalia 55 (1986) $47 \mathrm{ff}$.

-, ,Milawa(nd)da“, in: Reallexikon der Assyriologie und Vorderasiatischen Archäologie 8 (Berlin - New York 1993-97), 188ff.

-, „Ahhiyawa - Land der homerischen Achäer im Kampf mit Wilusa?“, in: Ch. Ulf (Hrsg.), Der neue Streit um Troia: eine Bilanz (München 2003) $193 \mathrm{ff}$.

Heubeck, A., „Zu einigen kleinasiatischen Ortsnamen“, Glotta 63 (1985) $115 \mathrm{ff}$.

Hiller, S., „Homerische und mykenische Phrasen“, in: S. Deger-Jalkotzy - S. Hiller - O. Panagl (Hrsg.), Floreant Studia Mycenaea. Akten des X. Internationalen Mykenologischen Colloquiums in Salzburg, 1.-5. Mai 1995 (Wien 1999), $289 \mathrm{ff}$.

Hoffner, H.A., „The Milawata Letter augmented and reinterpreted“. in: Vorträge gehalten auf der 29. Rencontre Assyriologique Internationale in Wien, 6.-10. Juli 1981, Archiv für Orientforschung, Beih. 19 (Horn 1982), $130 \mathrm{ff}$.

Hout, T.P.J. van den, ,Tuthalija IV. und die Ikonographie der hethitischen Großreichszeit", Bibliotheca Orientalis 52 (1995) 545ff.

Hrozny, F. (B.), „Die Lösung des hethitischen Problems“, Mitteilungen der Deutschen Orient-Gesellschaft zu Berlin 56 (1915) 17ff. 
- Die Sprache der Hethiter, ihr Bau und ihre Zugehörigkeit zum indogermanischen Sprachstamm (Leipzig 1917).

—, „Hethiter und Griechen“, Archiv Orientální 1 (1929) 323ff.

Hope Simpson, R., Mycenaean Greece (Park Ridge 1981).

-, „The Dodecanese and the Ahhiyawa Question“, Annual of the British School at Athens 98 (2003) 203ff.

Houwink ten Cate, $\mathrm{Ph}$. „Sidelights on the Ahhiyawa question from Hittite vasall and royal correspondance“", Jaarbericht van het Vooraziatisch-Egyptisch Genootschap „Ex Oriente Lux" 28 (1983/84) 33ff.

-, , The bronze tablet of Tudhaliyas IV and its geographical and historical relations“", Zeitschrift für Assyriologie und Vorderasiatische Archäologie 82 (1992) 233ff.

Jablonka, P., „Leben außerhalb der Burg - Die Unterstadt von Troia“, in: Troia II, $167 \mathrm{ff}$.

—, „Homer ist, wenn man trotzdem lacht“, Literaturen (2008.4) 76-82.

Jantzen, U.(Hrsg.), Führer durch Tiryns (Athen 1975).

Immerwahr, S.A., Aegean Painting in the Bronze Age (University Park - London, 1990).

Karo, G., Die Schachtgräber von Mykenai (München 1930/33)

Klengel, H., Geschichte des hethitischen Reiches, Handbuch der Orientalistik I. 34 (Leiden 1999).

-, Hatuschili und Ramses. Hethiter und Ägypter - ihr langer Weg zum Frieden (Mainz 2002).

—, „Bogazköy - Berlin: zur frühen Geschichte der Hethitologie“, in: Hattusa 6172.

Knudtzon, J.A., Die zwei Arzawa Briefe (Leipzig 1902).

Kolb, F., Tatort „Troia“: Geschichte, Mythen, Politik (Paderborn 2010).

Korfmann, M., „Troia: a residential and trading city at the Dardenelles“, in R. Laffineur - W.-D. Niemeier (Hrsg.), Politeia: society and state in the Late Bronze Age Aegean, Proceedings of the 5th International Aegean Conference, University of Heidelberg, Archäologisches Institut, 10-13 April 1994, Aegaeum 12 (Liège \& Austin 1995), $173 \mathrm{ff}$.

—, „Der „Schatz A“ und seine Fundsituation. Bemerkungen zum historischen und chronologischen Umfeld des ,Schatzfundhorizontes' in Troia“, in: J.-W. Meyer (Hrsg.), Beiträge zur vorderasiatischen Archäologie, Winfried Orthmann gewidmet (Frankfurt/Main 2000), 212ff.

—, ,Wilusa/(W)Ilios ca. 1200 v.Chr. - Ilion ca. 700 v.Chr.“, in Troia I, 64ff.

—, „Neue Aspekte zum ,Schatz des Priamos’: Der Schatz A von Troia, sein Auffindungsort und seine Datierung“, in: Troia I, $373 \mathrm{ff}$.

Kosak, S., ,The western neighbours of the Hittites“. Eretz-Israel 15 (1981) 12^ff.

Kretschmer, P., „Alaksandus, König von Wilusa“, Glotta 13 (1924) $205 \mathrm{ff}$.

Kühne, C., Die Chronologie der internationalen Korrespondenz von El-Amarna, Alter Orient und Altes Testament 17 (Kevelaer - Neukirchen-Vluyn 1973).

Lang, M.L., The frescoes, The Palace of Nestor at Pylos in southern Messenia II (Princeton 1969). 
Latacz, J., „Troia und Homer“, in: H.D. Galter (Hrsg.), Troia: Mythen und Archäologie, Grazer Morgenländische Studien 4 (Graz 1997) 1ff.

—, „Epos. II. Klassische Antike“, in: Der Neue Pauly, Band 4 (Stuttgart 1998), $12 \mathrm{ff}$.

—, „Der Beginn von Schriftlichkeit und Literatur“, in: Homer 62ff.

—, „Poeten wissen, was man mit dem Material alles anstellen kann“, Süddeutsche Zeitung, 3.1.2008.

—, Troia und Homer: der Weg zur Lösung eines alten Rätsels (Leipzig ${ }^{6} 2010$ )

Lehmann, G.A., Die mykenisch-frühgriechische Welt und der östliche Mittelmeerraum in der Zeit der Seevölker-Invasion um 1200 v.Chr. (Opladen 1985).

—, „Die politisch-historischen Beziehungen der Ägäis-Welt des 15.-13 .Jhs.v.Chr. zu Ägypten und Vorderasien: einige Hinweise“, in: J. Latacz (Hrsg.), Zweihundert Jahre Homer-Forschung: Rückblick und Ausblick, Colloquium Rauricum Bd. II (Stuttgart und Leipzig 1991) 105ff.

Lesky, A., „Homeros“, in: Paulys Realencyclopädie der klassischen Altertumswissenschaft, Supplement-Band IX (Stuttgart 1968) 687ff.

Luce, J.V., Homer's landscapes (Yale 1998).

Macqueen, J.G., The Hittites and their contemporaries in Asia Minor (London ${ }^{2} 1986$ ).

Mannsperger, D., „Mythen, Machtpolitik und Münzpropaganda: Die Troiatradition von Xerxes bis Mehmet dem Eroberer", in: Troia I, $103 \mathrm{ff}$.

Maran, J., „Tiryns“, in: E.H. Cline (Hrsg.), The Oxford Handbook of the the Bronze Age Aegean (ca. 3000-1000 BC) (Oxford 2010) 722ff.

Marinatos, S. / Hirmer, M., Kreta, Thera und das mykenische Hellas (München 1973).

Martini, W., Die Akropolis von Perge in Pamphylien vom Siedlungsplatz zur Akropolis, Sitzungsberichte der Wissenschaftlichen Gesellschaft der Johann Wolfgang Goethe-Universität Frankfurt am Main, Bd. XLVIII Nr. 1 (Stuttgart 2010).

de Martino, S., L'Anatolia occidentale nel medio regno ittita, Eothen 5 (Firenze 1996).

de Martino, S., „Relations between Hatti and Alasiya according to textual and archaeological evidence", in: Hattusa, 247ff.

McDonald, W.A. / Thomas, C.G., Progress into the past: the rediscovery of Mycenaean civilization (Bloomington \& Indianapolis 1990).

Mellaart, J., „Troy VIIA in Anatolian Perspective“, in: L. Foxhall / J.K. Davies (Hrsg.), The Trojan War, its history and context, Papers of the First Greenbank Colloquium, Liverpool 1981 (Bristol 1984), 64ff.

-, „Hatti, Arzawa and Ahhiyawa: a review of the present stalemate in historical and geographical studies“, in: Philia Epe eis Georgion E. Mylonan (Festschrift für G.E. Mylonas), Bd. I (Athen 1986) 74ff.

-, ,Some reflections on the history and geography of Western Anatolia in the late 14th and 13th Centuries B.C.“, Anadolu 10 (1986) $215 \mathrm{ff}$.

-, „, The present State of Hittite geography“, in: M.J. Mellink / E. Porada / T. Özgüc (Hrsg.), Aspects of art and iconography: Anatolia and its neighbours, Studies in Honour of Nimet Özgüc (Ankara 1993) 415ff.

Mellink, M.J., „Archaeological comments on Ahhiyawa-Achaians in Western Anatolia“, American Journal of Archaeology 87 (1983) 138ff. 
The Amarna letters, edited and transcribed by W.L. Moran (Baltimore \& London 1992).

Mountjoy, P.A., ,The East Aegean-West Anatolian Interface in the Late Bronze Age: Mycenaeans and the kingdom of Ahhiyawa“, Anatolian Studies 48 (1998) $33 \mathrm{ff}$.

-, „The Mycenaean pottery from Troy in the Berlin Schliemann collection“, in: M. Wemhoff / D. Hertel / A. Hänsel (Hrsg.), Heinrich Schliemanns Sammlung Troianischer Altertümer - Neuvorlage (Berlin 2008), $29 \mathrm{ff.}$

Müller, W., „Die Tonplomben und andere gestempelte Tonobjekte“, in: Iraklion, Archäologisches Museum Teil 6: Die Siegelabdrücke von Aj. Triada and anderen zentral-und ostkretischen Fundorten, Corpus der minoischen und mykenischen Siegel II.6 (Berlin 1999) 339ff.

Mylonas, G.E., Mycenae rich in gold (Athen 1983).

Neve, P., „Die Ausgrabungen in Bogazköy-Hattusa 1986“, Archäologischer Anzeiger (1987) 381ff.

Neve, P., Hattusa - Stadt der Tempel und der Götter, (Mainz 1992).

Niemeier, W.-D., „La struttura territoriale della Grecia micene“, in: F. Prontera (Hrsg.), Geografia storica della Grecia antica (Roma - Bari 1991) $123 \mathrm{ff}$.

-, „The Mycenaean Potters' Quarter at Miletus“, in Ph.P. Betancourt / R. Laffineur (Hrsg.), Techne: Craftsmen, Craftswomen and Craftsmenship in the Aegean Bronze Age, Proceedings of the 6th International Aegean Conference, Philadelphia, Temple University, 18-21 April 1996, Aegaeum 16, (Liège - Austin 1996) 347ff.

-, ,The Mycenaeans in Western Asia Minor and the problem of the origins of the Sea Peoples“, in: S. Gitin - A. Mazar - E. Stern, Mediterranean peoples in transition, thirteenth to early tenth centuries BCE, in honor of Trude Dothan (Jerusalem 1998), 17-65.

-, „Hattusa und Ahhijawa im Konflikt um Millawanda/Milet: Die politische und kulturelle Rolle des mykenischen Griechenland in Westkleinasien“, in: Die Hethiter und ihr Reich. Das Volk der 1000 Götter (Stuttgart 2002) 294ff.

-, „Milet“, in: I. Pini (Hrsg.), Corpus der minoischen und mykenischen Siegel V, Supplement 3,2 (Mainz 2004) 677ff.

-, ,Minoans, Mycenaeans, Hittites and Ionians in Western Asia Minor: New Excavations in Bronze Age Miletus/Millawanda“, in: A. Villing (Hrsg.) The Greeks in the East (London 2005), $1 \mathrm{ff}$.

-, „Milet von den Anfängen menschlicher Besiedlung bis zur Ionischen Wanderung“, in: Ionien, $3 \mathrm{ff}$.

-, Westkleinasien und Ägäis von den Anfängen bis zur Ionischen Wanderung: Topographie, Geschichte und Beziehungen nach dem archäologischen Befund und den hethitischen Quellen, in: Ionien, 37ff.

-, „Hattusas Beziehungen zum westlichen Kleinasien und dem mykenischen Griechenland nach den neuesten Forschungen“, in: Hattusa, 291ff.

—, „Griechenland, die Ägäis und das westliche Kleinasien in der Bronzezeit, in: Homer, $72 \mathrm{ff}$. 
Niemeier, B. / Niemeier, W.-D., „Milet 1994-1995. Projekt ,Minoischmykenisches bis protogeometrisches Milet': Zielsetzung und Grabungen auf dem Stadionhügel und am Athenatempel“, Archäologischer Anzeiger (1997) 189ff.

Nilsson, M.P., The Mycenaean origin of Greek mythology (Berkeley 1932).

Nilsson, M.P., Homer and Mycenae (London 1934).

Oberheid, R., Emil O. Forrer und die Anfänge der Hethitologie. Eine wissenschaftstheoretische Studie (Berlin \& New York 2007).

Oettinger, N., „Indogermanische Sprachträger lebten schon im 3. Jahrtausend v.Chr. in Kleinasien: die Ausbildung der anatolischen Sprachen“, in: Die Hethiter und ihr Reich: das Volk der 1000 Götter (Stuttgart 2002) 50ff.

Otten, H., „Die Bronzetafel aus Bogazköy: ein Staatsvertrag Tuthalijas IV.“ Studien zu Bogazköy-Texten, Beiheft 1 (Wiesbaden 1988).

Pedersen, P., ,The palace of Maussolos in Halikarnassos and some thoughts on its Karian and international context", in: F. Rumscheid (Hrsg.), Die Karer und die Anderen, Internationales Kolloquium an der Freien Universität Berlin, 13.-15. Oktober 2005 (Bonn 2009) 315ff.

Poisson, G., „Tantale, roi des Hittittes“, Revue Archéologique 22.2 (1925) 75ff.

Rebenich, S., „Ein ehrgeiziges Migrantenkind, leider kastriert“, Neue Zürcher Zeitung, 15.3.2008.

Risch, E., Wortbildung der homerischen Sprache (Berlin $\left.{ }^{2} 1974\right)$.

Röllig, W., „Achäer und Trojaner in den hethitischen Texten“, in: I. GamerWallert (Hrsg.), Troia - Brücke zwischen Orient und Okzident (Tübingen 1992), $183 \mathrm{ff}$.

Rose, C.B., „The theater of Ilion“, Studia Troica 1 (1991) $69 \mathrm{ff}$.

Rose, C.B., „The 1997 post-Bronze Age excavations at Troia“, Studia Troica 8 (1998) $71 \mathrm{ff}$.

Rose, C.B., „Ilion in griechischer und römischer Zeit“, in: Troia I, $180 \mathrm{ff}$.

Rose, C.B., ,Auf mythengetränktem Boden - Ilion in griechischer, römischer und byzantinischer Zeit", in: Troia II, $189 \mathrm{ff}$.

Salvini, M./ Vagnetti, L., „Una spada di tipo egeo da Bogazköy“, La Parola del Passato 276 (1994) $215 \mathrm{ff}$.

Sayce, A.H., „The cuneiform tablets of El-Amarna, now preserved in the Boulaq Museum“", Proceedings of the Society of Biblical Archaeology 11 (1888/89).

- The Hittites (London 1889).

—, „Perseus and the Achaeans in the Hittite texts“, Journal of Hellenic Studies 45 (1925) $161 \mathrm{ff}$.

Schachermeyr, F., Hethiter und Achäer (Leipzig 1935).

Sherratt, E.S., ,,Reading the texts': archaeology and the Homeric question”, Antiquity 64 (1990) 807ff.

Schliemann, H., Mykenae. Bericht über meine Forschungen und Entdeckungen in Mykenae und Tiryns (Leipzig 1878).

Schliemann, H., Selbstbiographie (Leipzig 1892).

Schliemann, H. Bericht über die Ausgrabungen in Troia in den Jahren 1871 bis 1873, Nachdruck der Erstausgabe 1874 (München 1990). 
Schmid, H., Vorgeschichte Europas (Leipzig - Berlin 1924).

Schmidt, H., Heinrich Schliemanns Sammlung troianischer Alterthümer (Berlin 1902).

Schrott, R., „Homer hat endlich ein Zuhause - in der Türkei“, Frankfurter Allgemeine Zeitung, 22.12.2007.

Schrott, R., Homers Heimat. Der Kampf um Troia und seine realen Hintergründe (München 2008).

Schuchardt, C. „Nachwort“, Mitteilungen des Deutschen Archäologischen Instituts, Athenische Abteilung 47 (1922) 122f.

Schuler, E. von, Die Kaskäer. Ein Beitrag zur Ethnographie des alten Kleinasien, Untersuchungen zur Assyriologie und Vorderasiatischen Archäologie 3 (Berlin 1965).

Simon, E., „Rom und Troia: der Mythos von den Anfängen bis in die römische Kaiserzeit", in: Troia I, 154-173.

Singer, I., ,Western Anatolia in the thirteenth century B.C. according to the Hittite texts." Anatolian Studies 33 (1983) $205 \mathrm{ff}$.

Sommer, F., Die Ahhijava-Urkunden (München 1932).

-, Ahhijavafrage und Sprachwissenschaft (München 1934).

—, „Ahhijava und kein Ende“, Indogermanische Forschungen 55 (1937) 169ff.

Sperling, J., „Reminiscences of Troy“, in: M.J. Mellink (Hrsg.), Troy and the Trojan War, a Symposium held at Bryn Mawr College, October 1984 (Bryn Mawr 1986) $29 \mathrm{ff}$.

Stamatopoulou, M., „Thessaly (Archaic to Roman)“, Archaeological Reports (20102011) $73 \mathrm{ff}$.

Starke, F., Untersuchungen zur Stammbildung des keilschrift-luwischen Nomens, Studien zu den Bogazköy-Texten 31 (Wiesbaden 1990).

- , ,Troia im Kontext des historisch-politischen und sprachlichen Umfeldes Kleinasiens im 2. Jahrtausend“, Studia Troica 7 (1997) 447ff.

—, „Luwisch“, in: Der Neue Pauly 7 (Stuttgart - Weimar 1999), 528ff.

Steiner, G. „,Großkönige' in Anatolien von Labarna-Hattusili I. bis zu den Achaimeniden“", in: S. de Martino / F. Imparati (Hrsg.), Studi e testi I, Eothen 9 (Firenze 1998) $151 \mathrm{ff}$.

Symeonoglou, S., The topography of Thebes from the Bronze Age to modern times (Princeton 1985).

Szemerenyi, O., „Mycenaean: a milestone between Indo-European and historical Greek", in: Atti e Memorie del Primo Congresso Internazionale di Micenologia, Roma, 27 Settembre - 2 Ottobre 1967 (Roma 1968) 715ff.

-, „Hounded out of Academe ...: the sad fate of a genius“, in: Studi di storia e filologia anatolica dedicati a Giovanni Pugliese Carratelli, Eothen 1 (Firenze 1988), 257ff.

Thumm-Dograyan, D. „Und doch war alles anders ...Wilhelm Dörpfeld und Carl Blegen“, in: Troia II, 117ff.

Toepffer, R., „Achaia“, in: Paulys Realencyklopädie der Classischen Altertumswissenschaft I.1 (Stuttgart 1894), $155 \mathrm{ff}$.

Ulf, C. / Rollinger, R. (Hrsg.), Lag Troia in Kilikien? Der aktuelle Streit um Homers Ilias (Darmstadt 2011).

Ünlüsay, S., „Vom Reihenhaus zum Megaron - Troia I bis Troia III“, in: Troia I, $133 \mathrm{ff}$. 
Ventris, M. / Chadwick, J., Documents in Mycenaean Greek (Cambridge 1956).

Ventris, M. / Chadwick, J., Documents in Mycenaean, (Cambridge ${ }^{2} 1973$ ).

West, M.L., „Atreus and Attarasiyas“, Glotta 77 (2003) $262 \mathrm{ff}$.

- The east face of Helikon: west Asiatic elements in Greek poetry and myth (Oxford 2011).

Weber, W., Die Staatenwelt des Mittelmeers in der Frühzeit der Griechen (Stuttgart 1925).

Wiegand, Th., Sechster vorläufiger Bericht über die von den Königlichen Museen in Milet und Didyma unternommenen Ausgrabungen (Berlin 1908).

Wilcken, U., Griechische Geschichte (München - Berlin 1924).

Winckler, H., Die Thontafeln vom Tell-el-Amarna, Keilinschriftliche Bibliothek 3 (Berlin 1896).

—, Nach Boghasköi! Ein nachgelassenes Fragment, Der Alte Orient XIV/3 (Leipzig 1913).

Wright, W., The empire of the Hittites (London 1886).

Yalouris, N., „Ein Schlachtengemälde im Palast des Nestor“, Mitteilungen des Deutschen Archäologischen Instituts, Athenische Abteilung 104 (1989) 41ff.

Zavadil, M., Ein trojanischer Federkrieg: Die Auseinandersetzungen zwischen Ernst Boetticher und Heinrich Schliemann (Wien 2009). 


\title{
Patroklos und Phoinix in der Ilias
}

\author{
HANS-WILHELM NORDHEIDER
}

Meine Damen und Herren, liebe Kolleginnen und Kollegen.

Was ich hier sagen möchte, basiert auf drei Artikeln, die ich für unser Lexikon gemacht habe: Das sind die Artikel Achilleus, Patroklos und Phoinix. Der erste ist eine Jugendsünde, wo ich mehr oder weniger leichtfüßig über die Probleme hinweggehuscht bin; die beiden anderen Artikel - Patroklos und Phoinix kommen, hoffe ich, der Sache näher. In diesen Artikeln finden Sie Stellenangaben, Einzeldiskussionen und Literatur, worauf ich im Folgenden aus Zeitgründen weitgehend verzichte.

Nun zur Sache:

Bekanntlich schildert die Ilias nicht den ganzen 10 Jahre dauernden Kampf um Troia, sondern nur eine Episode von einigen Dutzend Tagen Dauer gegen Ende des Krieges, nämlich den Zorn des von Agamemnon beleidigten Achill -

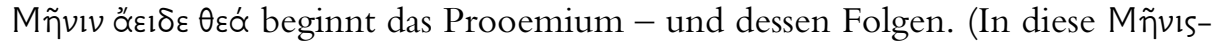
Dichtung wird dann aber der Gesamtkrieg kunstvoll hineingespiegelt, so daß man am Ende doch den Eindruck hat, den ganzen Krieg - und nicht etwa nur eine Achilleis - erlebt zu haben). Dieser Zorn nun wirkt im Hinblick auf das in der Sage vorgegebene Handlungsziel, die Eroberung Troias, als Retardation (und eigentlich ist die ganze Ilias im Rahmen des Gesamtkriegs eine Retardation, die aber natürlich nicht etwa überflüssig ist, sondern das ganze Geschehen in bedeutsamer Verdichtung enthält).

Der beleidigte Achill weigert sich, weiter am Kampf teilzunehmen, spinnt aber nun nicht etwa eine Racheintrige (wie Kriemhild im Nibelungenlied) und konspiriert auch nicht etwa mit den Gegnern (wie das später in historischer Zeit der aus Athen verbannte Alkibiades oder der eine oder andere spartanische König mit den Persern taten), sondern er wartet ab, daß die Griechen ohne seine Mitwirkung scheitern und so die Verkehrtheit ihres Tuns und seinen, Achills, Wert erkennen werden. Seine einzige Gegenaktion besteht darin, seine göttliche Mutter Thetis um Intervention bei Zeus zu bitten, daß der bis auf weiteres den Troern den Sieg verleihe. Er legt die Revanche, die Wieder-

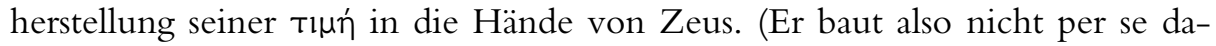
rauf, daß es ohne seine Mitwirkung nicht klappen werde, sondern hilft ein bißchen nach, indem er, salopp ausgedrückt, um den Sieg der Gegner betet). 
Der Dichter steht also vor der Aufgabe, eine Handlung zu bauen, in der der Hauptheld der einen Partei über weite Strecken passiv ist (man könnte dabei an andere Helden des Nichthandelns wie Hamlet oder Wallenstein denken, bei denen aber das Handeln / Nichthandeln als solches problematisiert wird), wo dieser Hauptheld aber andererseits - im Hinblick auf das vorgegebene Handlungsziel - schließlich wieder in den Kampf zurückgeführt werden soll.

Wie geht er dabei vor?

Zum einen, indem er schildert, wie die Griechen ohne Achills Mithilfe nun tatsächlich in sich steigernder Bedrängnis die von diesem angekündigten Mißerfolge erleiden, die in der Erstürmung des Schiffslagers durch die Troer und in Agamemnons defätistischem Vorschlag, den Kriegszug abzubrechen und die Flucht zu ergreifen, gipfeln. Dabei gewinnen - als Ersatz für den abwesenden Achill - andere Helden an Bedeutung: z.B. auf griechischer Seite Diomedes und bei den Troern Hektor.

Zum andern ist aber im Streit zwischen Achill und Agamemnon im Alpha, der Achills Streik verursacht, bereits als Keim der Handlungsstrang der Versöhnung angelegt, und zwar in der Person NESTORS, der als altersweiser, erfahrener Ratgeber sozusagen ein wandelnder Vermittlungsausschuß ist. Er versucht sofort, vermittelnd einzugreifen und die drohende Polarisierung durch eine Kompromißformel, die beiden recht gibt, aber auch beide in ihre Schranken weist, zu überbrücken, dringt aber angesichts des Starrsinns und der zugespitzten Ichbezogenheit, der $\propto \cup ่ \theta \alpha ́ \delta \varepsilon ı$ der Kontrahenten nicht durch.

Nestor bedient sich aber im folgenden nacheinander zweier Akteure, um seinen Vermittlungsversuch fortzusetzen: Das sind PHOINIX und PATROKLOS. Ich gehe jetzt ausdrücklich nicht auf die Frage ein, woher diese Figuren stammen, ob der Dichter, wie nicht unwahrscheinlich, sie bereits in der Tradition vorgefunden hat - dazu finden Sie einiges in den erwähnten Lexikonartikeln. Es geht mir vielmehr um ihre Funktion in der Mñvıs-Handlung der Ilias, zu der sie wesentlich gehören; darum, wie der Dichter sie in die Handlung eingebaut, an die Handlung adaptiert hat und welche Rolle sie dort spielen.

Phoinix tritt zum erstenmal und hauptsächlich nur im Iota auf, ist also wesentlich eine Episodenfigur (auch wenn er außerdem später - im $\Pi, P, T$ und $\Psi$ - noch gelegentlich im Umkreis Achills erwähnt wird). Patroklos dagegen wird - nach unscheinbaren Anfangsnennungen - immer mehr ins Handlungszentrum gerückt und wird zeitweise zum Vertreter Achills und so zu einer im Handeln und Erleiden für den Fortgang der Handlung bestimmenden Zentralfigur.

Auffällig ist nun die Weise, wie beide bei ihrer ERSTNENNUNG unbestimmt und unerklärt aus dem Off auftauchen. Patroklos ist zunächst nur stumme Begleitfigur, wird bei seiner Erstnennung beiläufig nur mit seinem Patronymikon genannt (A 307 verläßt der zornige Achill die Versammlung 


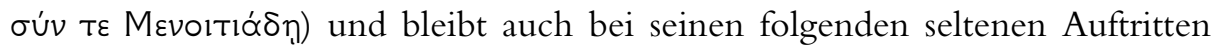
(bei der Übergabe der Briseis sowie bei der Bittgesandtschaft im Iota) stumm im Hintergrund, wobei man mutmaßen kann, daß er dabei die von den Parteien ausgetauschten Argumente hören und auf sich wirken lassen konnte. Und Phoinix wird erstmals - ohne Erklärung des Wer und Woher - von Nestor genannt, als der im Iota in der ởopí vorschlägt, eine Bittgesandtschaft zu Achill zu schicken, um ihn in den Kampf zurückzuführen.

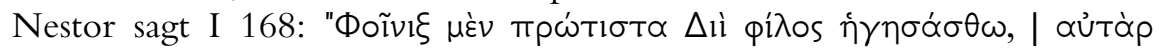

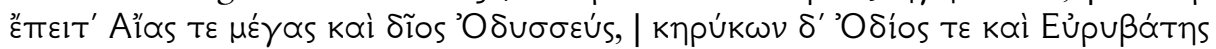
$\alpha^{\prime \prime} \mu^{\prime} \dot{\varepsilon} \pi \varepsilon \dot{\varepsilon} \sigma \omega \nu$." Phoinix ist hier also der erste von fünf Personen in sorgfältig gestaffeltem Nacheinander. - (Das erinnert an die Staffelung von drei Personen

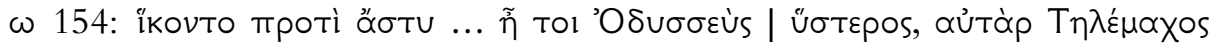

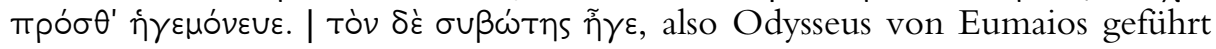
hinterher und Telemach voran).

Die folgende Aktion der Bittgesandten - wie sie zu Achill gehen - wird dann über 30 Verse ausschließlich in Dualen geschildert ('die beiden gingen' usw.), als ob nur zwei Personen statt der zunächst genannten fünf tätig wären. - Diese DUALE sind, wie Sie wissen, eines der meistdikutierten Probleme der Homerphilologie. Die Erklärungsversuche reichen von der Deutung, die schon Aristarch und dann z.B. Von der Mühll u.a. vertraten, daß die Duale sich auf die beiden Hauptgesandten Odysseus und Aias bezögen, wobei

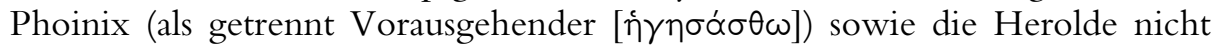
mitgezählt seien, bis zu Wests u.a. Annahme, sie seien die stehengebliebenen Reste einer ursprünglichen Zweiergesandtschaft, in die Phoinix sekundär interpoliert worden sei, und seien mithin auch ein Indiz für die schriftliche Abfassung der Ilias, weil ein mündlicher Dichter solche Unebenheiten wohl harmonisierend ausgeglichen hätte. - Dazu hier nur soviel, daß ich Aristarchs Übersetzung zuneige (Phoinix geht voraus - Odysseus und Aias folgen im Dual); weitere Vorschläge und Diskussion finden Sie samt Literatur im Artikel Phoinix.

Auffällig ist nun, daß Phoinix unvermittelt aus dem Off auftaucht: Weder erfahren wir zunächst, wer er ist, noch, wo er sich zum Zeitpunkt der Versammlung aufhält - jedenfalls ist er nicht bei Achill (zu dessen Entourage er eigentlich gehört, wie wir später erfahren), sondern nimmt offenbar an der Versammlung teil, weil aus dem Folgenden hervorgeht, daß er in Nestors Absicht, Achill zum Mitkämpfen zu überreden, eingeweiht ist.

Erinnern wir uns: Auch Patroklos blieb bei seiner Erstnennung (mit blo-

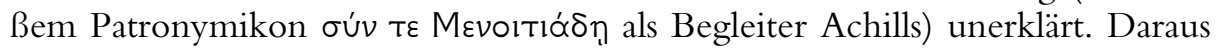
könnte man schließen, daß Patroklos wie Phoinix beide in der der Ilias vorangehenden Sage irgendwie bekannt gewesen sein müssen; darüber lassen sich nur Vermutungen anstellen (dazu Literatur in meinen Artikeln). Und dazu nur die ANMERKUNG, daß wir die Informationen so annehmen müssen - und nur so annehmen können - wie der Dichter sie uns gibt. Und daß ein Epos wie die Ilias - damals wie heute - selten (und vielleicht nur bei philologischen 
Fachtagungen wie der heutigen) auf ein homogenes Publikum von Rezipienten (Hörern / Lesern) mit dem immer gleichen Wissensstand traf und trifft sondern die einen wissen mehr, die anderen weniger von der Vorgeschichte, aber die Dichtung soll auf beide wirken.

Gestatten Sie mir - und entschuldigen Sie bitte - dazu einen kurzen EXKURS, den meine Kollegen sich schon öfter haben anhören müssen: Man könnte das mit der - immer nur stückweisen, nicht ganzheitlichen - Rezeption eines heutigen Kino-Großepos vergleichen - ich meine den Filmmehrteiler 'STAR WARS', der nacheinander in mehreren Teilen - und nicht etwa in der Reihenfolge der Handlungschronologie - veröffentlicht wurde, d.h. in die Kinos kam. (Die Filmemacher begannen vielmehr mit einer Episode aus der Mitte, ließen dann das Happy End mit dem Sieg der Guten folgen und zeigten

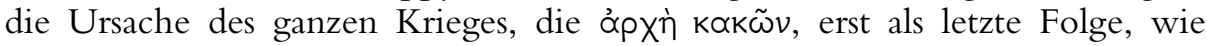
nämlich die Demokratie umkippte zur Tyrannei des, dann durch die ganze Episodenfolge hindurch wirkmächtigen, bösen Imperiums - was sich aber erst am Schluß der Serie aufklärte, zumal es auch keinen den Filmen vorausgehenden Roman gab). Dabei habe ich selber erlebt, daß ich über die Vorgeschichte und Voraussetzungen der Handlung und ihrer Protagonisten viel weniger oder gar nicht - informiert war als meine das Ganze überblickenden Söhne, aber trotzdem das Spiel genossen habe. Das heißt: Die dichterische Schilderung wirkt auch auf Hörer / Leser, die zunächst nicht wissen, wer Patroklos oder Phoinix waren.

Zurück zur Ilias: Wichtiger als Ihr Vorkommen in älterer Sage ist, was der Dichter aus den beiden Figuren macht und wie er sie, auch wenn sie schon in der Tradition vorgegeben gewesen sein sollten, an seine Mñvis-Dichtung adaptiert und wie er uns die Vorgeschichte und Voraussetzungen der beiden Figuren erst dann mitteilt, wenn er sie für ihre Interaktion mit Achill braucht.

Das heißt, die jew. Person wird nicht bei ihrem ersten Auftritt erklärt, indem der Dichter sich informierend an den Hörer / Leser / Rezipienten als Adressaten wendet - wie wir das vom klassischen autonomen / autarken Roman gewohnt sind oder auch vom historischen Sachbuch - sondern die Vorgeschichten von Patroklos und Phoinix werden jeweils als Argumente eingebaut in den Appell, mit dem Phoinix bzw. Patroklos auf Achill einzuwirken versuchen (wobei wir Hörer / Leser sozusagen zu Zeugen eines Bühnendialogs werden - das ist die Technik des Dramas).

Als eines von vielen Gegenbeispielen - nämlich für das Verfahren, eine Person jew. sofort bei ihrem ersten Auftritt dem Leser vorzustellen - nenne ich nur die verdienstvolle und materialreiche Mozart-Biographie von Schenk, der sich die Aufgabe gestellt hat, jede recherchierbare Person zu ermitteln, die Mozart in seinem kurzen Leben getroffen hat. Dabei bringt er es, indem er Mozarts Leben chronologisch nacherzählt, pro Seite auf bis zu sechs in den Handlungsverlauf eingestreute Kurzbiographien, was den Lesetext manchmal zu einem Katalog macht, und erwartet, daß der Leser die jew. einmal vorgestellten Personen dann bei ihren späteren Auftritten im Buch wiedererkennt - 
was schwerfällt und nur mit Hilfe eines Personenregisters gelingt. So geht Homer in der Regel nicht vor. (Höchstens erhält der eine oder andere 'Kleine Kämpfer' bei seinem einmaligen Auftritt angesichts seines Todes mal solch eine Kurzbiographie).

Wer Phoinix ist und welche Vorgeschichte er hat, erfahren wir erst, wenn er - in seiner Rede an Achill - mit Hilfe eben dieser Vorgeschichte und der Hervorhebung bestimmter biographischer Details auf Achill einzuwirken versucht, wieder am Kampf teilzunehmen. Diese Rede steht zwischen den Reden des Odysseus und Aias: ist der Mittelteil und auch der Höhepunkt des 'Redetriptychons' der Bittgesandtschaft (wie Wilamowitz das ausdrückt) und ist besonders reich an erzählerischen Elementen: Zunächst zwei Geschichten von fruchtlosem / kontraproduktivem Zorn - die eine aus Phoinix' eigener biographischer Vorgeschichte, wie er, von seinem Vater zur Kinderlosigkeit verflucht, daran gehindert werden mußte, diesen umzubringen (ebenso mußte Achill von Athene zurückgehalten werden, im Affekt Agamemnon umzubringen); - dann die Geschichte vom fruchtlosen Zorn des Meleager als epische Einlage. Beide Zornesgeschichten sind - vom Dichter an die Situation adaptierte - Exempla, die Achill die Fruchtlosigkeit seines eigenen Zornes vor Augen führen und ihn zur Umkehr bewegen sollen. Schließlich die Allegorie von den Nı̊á, den 'Bitten' - als personifizierten Zeustöchtern - denen Achill sich nicht verweigern dürfe. Darein verwoben als Erinnerung, die die Nähe und Vertrautheit des Sprechers evozieren soll, wie Phoinix als íḱtᄁns an den Hof von Achills Vater Peleus kam, Achills Erzieher wurde und diesen als Kleinkind auf seinem $\mathrm{Schoß}$ fütterte.

Lassen Sie mich en passant nur auf ein Detail in Phoinix' Biographie hinweisen: Wie er, von seiner eifersüchtigen Mutter überredet, mit der $\pi \propto \lambda \lambda \propto$ кís, der Konkubine seines Vaters, schläft, um diese dem Alten abspenstig zu machen, und daraufhin von dem erzürnten Vater zur Kinderlosigkeit verflucht, also gleichsam kastriert wird. Das klingt wie eine Herodot-Novelle mit nahöstlicher Färbung und hat direkte Parallelen im Alten Testament (worauf schon Brown, Israel und Hellas und St. West hingewiesen haben): Da 'geht' (2 Samuel) der rebellische Absalom - in einem auf dem Dach des väterlichen Palastes erbauten Zelt - 'vor allem Volk' zu den Frauen seines von ihm vertriebenen Vaters David 'ein', damit Israel erkenne, daß er der neue König ist; er nimmt also zum Zeichen des Machtwechsels den väterlichen Harem in Besitz. - Hinter Phoinix' Beischlaf mit der väterlichen Konkubine scheint also, ins privat Monogame einer persönlichen Intrige umgebogen, ein nahöstlicher Königssturz zu stehen. - Andere Versionen, wo Phoinix fälschlich von der Frau des Vaters des Beischlafs beschuldigt wird - also das alttestamentarische Potiphar-Motiv (wie bei Hippolytos und Phaidra) - findet man bei Apollodor und fand man wohl auch im verlorenen Phoinix des Euripides. (Dazu weiteres im Artikel Phoinix). - Jedenfalls scheint solch ein nahöstlicher Zug zu 'Homer als Dichter der orientalisierenden Epoche' (wie Walter Burkert formuliert) zu passen. Und vergessen wir dabei nicht, daß Фoĩvı - trotz mancher von Müh- 
lestein probierter ingeniöser Assoziationen - zunächst 'der Phöniker' heißt, der - vom Vater gleichsam kastriert - den kleinen Achill auf seinem Schoß füttert

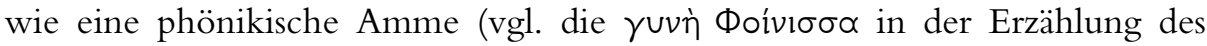
Eumaios; und vgl. andererseits als weiteren nahöstlichen Personennamen noch den Greis namens Aiyúntıos, der in der Volksversammlung auf Ithaka auftritt).

Phoinix' Rede bleibt nicht ohne Wirkung auf Achill: Er schwächt die zuvor geäußerte Absicht, heimzufahren, jetzt ab zur möglichen Alternative (I 619

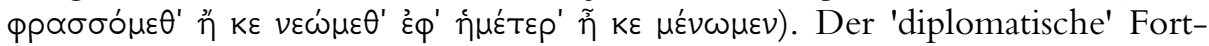
schritt der Verhandlungen mit Achill ist also wesentlich dem Appell von Achills väterlichem Freund und Vertrauten Phoinix zu verdanken. Insofern ist die von Nestor initiierte Bittgesandtschaft - die eigentlich eine Kombination aus zwei formal und grammatisch unterschiedenen Aktionen war: nämlich der (durch den Dual ausgedrückten) Aktion der beiden 'offiziellen Botschafter' Odysseus und Aias einerseits und des Appells des vertrauten Freundes andererseits - nicht ganz fruchtlos geblieben. Im übrigen bleibt Phoinix, während die beiden anderen zu den Griechen zurückkehren, jetzt bei Achill - ist gleichsam zu diesem zurückgeführt - wohin er gehört.

War Phoinix von Nestor - und vom Dichter - unvermittelt und unerklärt als Vermittler ins Spiel gebracht worden, so wird das Eingreifen des PATROKLOS gründlicher motiviert. Beidemale spielt der Dichter ein ähnliches The$\mathrm{ma}$ - das des von Nestor beauftragten Vermittlers zwischen Achill und den Griechen - durch, aber das zweitemal, bei Patroklos, hat er mit seinem Vermittler mehr vor und bemüht sich, dessen Eintritt aus der Latenzphase in die aktive Phase sorgfailtiger zu motivieren.

(Man könnte an Goethes Bemerkung anläßlich der Theaterauffuihrungen von Schillerschen Dramen denken, Schiller in seinem ungeduldigen geistigen Höhenflug sei manchmal etwas großzügig oder nachlässig im Motivieren von Bühnenaktionen gewesen, so daß er manchmal im Interesse des kritischen Publikums habe nachmotivieren müssen). - Hierzu noch ein iliadisches Beispiel für eine solche HARMONISIERENDE NACHMOTIVIERUNG: $\Lambda$ 771, als - in Nestors Erzählung - Nestor und Odysseus zur Anwerbung der Kriegsteilnehmer zu Peleus nach Phthia kommen, läßt der Dichter sie dort auch Menoitios antreffen - nicht, weil der mit seinem Sohn dauernd vom heimischen Opous zu Peleus nach Phthia emigriert wäre (wie Leaf im Kommentar zu meinen scheint), sondern weil der Dichter ihn dort braucht, damit Nestor im folgenden die Mahnungen beider Väter an ihre Söhne zitieren und damit jetzt ad hoc Patroklos beeinflussen kann. (Ebenso ist auch die Mutter Thetis mal von Peleus getrennt, mal sind sie und der Vater als gemeinsam auf den Sohn Achill wartendes Elternpaar gedacht). - Eine ähnliche, wenn auch oberflächliche, Motivierung - richtiger Behauptung - von Phoinix' Anwesenheit bei der Heeresversammlung - also etwa die Einfügung: 'Phoinix, der gerade hier ist, soll vorausgehen' - würde uns beruhigen und uns viele philologische Erörterungen ersparen. 
Entsprechend der bedeutsameren Rolle, die Patroklos in der Ilias spielt, hatte bereits $\Theta 475$ Zeus prophetisch Patroklos' Tod mit Achills Kampfeintritt und Hektors Ende zusammengesehen; eine zweite Prophezeiung folgt O 63ff. - Patroklos' zukünftiger Tod wird also - wie der nachiliadische Tod Achills $\mathrm{zu}$ einem der strukturierenden Fernbezüge, die das Epos durchorganisieren und verklammern. Es ist aber tragische Ironie, daß Patroklos' Tod zwar uns, dem Publikum, mitgeteilt wird, aber - anders als der des Achill - weder ihm selber noch Achill bewußt ist.

Patroklos' Eintritt in die aktive Phase wird vom Dichter prophetisch mit einer Unheilsüberschrift angekündigt. Angesichts der von den Troern verfolgten zurückflutenden Griechen schickt Achill Patroklos aus, sich nach einem Verwundeten zu erkundigen; der - Patroklos - ( 1604$)$ : है

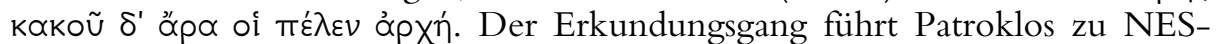
TOR - wieder ist Nestor der Iniator der Gegenaktion - wo aber die Erkundigung nach dem Verwundeten bald zu der Nebensache wird, die sie von Anfang an war. Vielmehr versucht Nestor erneut - diesmal durch eine längere Rede an Patroklos, in der er auch Ermahnungen der Väter Menoitios und Peleus zitiert, also die Situation des Kriegsanfangs evoziert - Achill in den Kampf zurückzuführen, und gibt dann als Alternative Patroklos den entscheidenden Plan ein, in den Waffen Achills und an dessen Stelle in den Kampf einzugreifen - wobei die Troer durch den Anschein, Achill kämpfe wieder mit, getäuscht und in Schrecken versetzt werden sollen. Wie wir wissen, funktioniert dieser Plan radikaler, als es sich die Initiatoren vorstellen konnten. Achill läßt Patroklos an seiner statt in den Kampf ziehen; der bekommt seine Aristie, wie sie nur erstrangigen Helden zukommt, überschreitet dabei aber auch seine ihm von Achill gesetzte Grenze, rechtzeitig umzukehren, und fällt in Parallele und Vorwegnahme von Achills eigenem Tod - durch Apoll, Hektor und Euphorbos - dessen Beteiligung die direkte Rache durch Menelaos ermöglicht - wobei Euphorbos' Hirtenname und seine charitinnengleichen, reichgeschmückten Haare (P 51) an Paris, den Achilltöter der Aithiopis, erinnern.

Durch Patroklos' Tod verwandelt sich der Zorn der beleidigten Ehre bei Achill in Rachezorn gegen Hektor und treibt ihn wieder in den Kampf.

Patroklos hat nach seinem Tod noch einen letzten Auftritt: $\Psi$ 65ff. erscheint Patroklos' Totengeist (seine $\left.\psi \cup \times \eta^{\prime}\right)$ dem Achill, kündigt diesem dessen eigenen bevorstehenden Tod an und bittet um gemeinsame Bestattung - eine Szene, die an die Erscheinung des toten Enkiddu im Gilgamesch-Epos denken läßt. Zur Motivierung dieses Wunsches erinnert er Achill an ihre gemeinsame Verbundenheit - erst hier erfahren wir den Anfang ihrer beider Vertrautheit, wie er wegen eines Totschlags als íḱ́tns an den Hof des Peleus kam und von diesem zu Achills $\theta \varepsilon p o ́ n t \omega v$ gemacht wurde.

FASSEN WIR ZUSAMMEN: Phoinix und Patroklos sind Akteure innerhalb des Mñvıs-Themas der Ilias. Sie sind in ihrer Funktion Parallelfiguren, insofern beide im Auftrag Nestors den erzürnten Achill wieder in den Kampf 
zurückführen sollen. Zu diesem Zweck appellieren sie nicht spontan an Achill, wie es ihnen bei ihrer Vertrautheit und Zugehörigkeit zum Haushalt Achills möglich wäre (I 190 sitzt Patroklos schweigend bei Achill und hört seinem Gesang zu); der Dichter läßt sie vielmehr jeweils den Umweg über Nestor den iliadischen Prototyp des Vermittlers - nehmen, mit dessen Instruktionen ausgerüstet sie dann Achill zu beeinflussen suchen, wobei sie Nestors Argumente zusätzlich durch die Schilderung menschlicher Vertrautheit und Nähe bereichern und emotional verlebendigen. Erst im Fortgang dieser Handlung werden ihre Vorgeschichten, Rollen und Charaktere sukzessiv entfaltet, d.h. auf verschiedene Teile der Handlung verteilt und in den Reden der Beteiligten enthüllt, wo sie jeweils argumentativ und emotional auf Achill einwirken sollen.

Beider Aktionen sind sozusagen - musikalisch - die zweimalige Durchführung eines ähnlichen Themas. Beide sind ältere Vertraute und Erzieher Achills - und ersetzen insofern bei Achill, der ja nach Thetis' Weggehen mutterlos ist, den vor- und außeriliadischen Kentauren Cheiron als Erzieher. Dabei bleibt Phoinix in der Ilias episodisch, Patroklos dagegen wächst über die Rolle des bloßen Vermittlers, wie es Phoinix ist, hinaus; er wird handelnd und erleidend zum Vertreter Achills und nimmt auch dessen nachiliadischen Tod vorwegwie er auch den nachiliadischen Tod des anderen Achillfreundes Antilochos vorwegnimmt (worüber W. Kullmann Wichtiges gezeigt hat). Mithin verwendet der Dichter auf seine Integration in die Handlung mehr Sorgfalt, kündigt auch seinen Tod durch leitmotivische Prophezeiungen an.

Die Schilderung der menschlichen Beziehungen, vorwiegend durch die Reden, die Phoinix und Patroklos an Achill richten und wie sie nur von vertrauten Freunden kommen können, gehört - neben solchen Höhepunkten wie Hektors Abschied von Andromache oder Achills und Priamos' Begegnung im $\Omega$ - zum seelisch Reichsten, was die Ilias zu bieten hat.

\section{Als Anhang \\ Zur Genese der „Bremer Stadtmusikanten“ \\ Ein analytisch-neoanalytisch-strukturalistisch-allegoretischer Beitrag zur Homerischen Frage}

Hans-Wilhelm Nordheider

Vier unter dem gebräuchlichen, wenn auch nicht wissenschaftlich exakten Begriff „Haustiere“ subsumierbare Wirbeltiere, davon drei zu den Säugern (Mammalia), eines zu den Vögeln (Aves) gehörig, gelangen, jeweils durch ein

* Der folgende Beitrag desselben Autors, schon 1983 im Privatdruck einer Festschrift für Eva-Maria Voigt erschienen, steht hier noch einmal, um zu demonstrieren, daß Lexikonarbeit auch Spaß machen kann. 
ähnliches Schicksal aus ihren Behausungen vertrieben, auf dem Weg nach Bremen, wo sie Stadtmusikanten werden wollen, in ein Räuberhaus inmitten eines dunklen Waldes, vertreiben die dort Befindlichen und bleiben dort.

Diese scheinbar so einfache und schlüssige, weil seit den Brüdern Grimm vertraute Geschichte verbirgt unter ihrer Oberfläche kindlicher Harmlosigkeit mancherlei Probleme.

\section{Die Personen der Handlung}

1. Wie verträgt sich zunächst die Eigenart der vier Tiergestalten mit ihrem Plan, Stadtmusikanten zu werden? Schon auf den ersten Blick erkennt man, daß Esel und Katze typologisch hervorragend in die Kategorie der musikantischen Tiere passen (erinnert sei nur an das bekannte Volkslied vom Sängerwettstreit zwischen Kuckuck und Esel oder an den mit leidvoller Erfahrung gestörter Nachtruhe verbundenen Begriff der Katzenmusik); dagegen kommen Hund und Hahn, wenn auch wie viele andere Tiere mit charakteristischen Stimmen begabt, wohl eher aus einem anderen Zusammenhang (s.u. I 2, II 3).

2. Esel und Katze, ersterer schon in Apuleius' Metamorphosen und in mittelalterlichen Schwänken fahrender Scholaren mit häufigem Schauplatzwechsel auftretend, letztere bekannt für charakterliche Unabhängigkeit und Distanziertheit, gehören zum Typ der vagantischen Tiere; wohingegen der treue Hund und der wachsame Hahn geradezu Symbole haus- und hofverbundener Beständigkeit und Immobilität darstellen.

3. Der Repräsentant der sprichwörtlichen Eselsdummheit und die listig geschmeidige Katze bilden ein konträres, in gegenstrebiger Fügung verbundenes Paar nach Art von Wolf und Fuchs, Kain und Abel, David und Goliath, Faust und Mephisto, Adam und Eva, Don Quijote und Sancho Pansa oder Sherlock Holmes und Doktor Watson, das man sich gut als Helden einer abenteuerlichen Vagantengeschichte nach Art pikaresker Romane vorstellen kann; wobei die beiden anderen, Hund und Hahn, nur schwer integrierbar wären.

4. Bisher ergibt sich also: Esel und Katze eignen sich typologisch gesehen sowohl als Freundespaar wie für das unserer Geschichte zugrundeliegende Musikanten- und Vagantenmotiv bestens, während Hund und Hahn in diesem Zusammenhang anscheinend sekundär sind.

\section{Die Handlungsstränge}

1. Jedem unvoreingenommenen Leser muß der Widerspruch auffallen, der zwischen dem die erste Hälfte der Erzählung beherrschenden (auch titelgebenden) Plan, nach Bremen zu gehen (B) und dort Stadtmusikant zu werden (M) - im folgenden ,Ziel': $Z^{\mathrm{B}+\mathrm{M}}$ genannt - und dem Ende der Geschichte besteht, wo dieser Plan von den Tieren völlig vergessen zu sein, oder besser: überhaupt 
nicht existiert zu haben scheint. Stattdessen ist nun ein ,hellerleuchtetes Räuberhaus" $(\mathrm{H})$, in das die Tiere unter Vertreibung der dort schmausenden Räuber eindringen, Mittelpunkt und Ziel der Handlung $\left(\mathrm{Z}^{\mathrm{H}}\right)$.

2. Die Vertreibung der Räuber aus dem Haus nun, in der traditionellen Lesart als Vertreibung aus dem Räuberhaus, oder marxistisch als Expropriation der Exproprieteure dargestellt, ist ihrerseits als Motiv nicht unproblematisch: Wieder sei an das gesunde Volksempfinden des unvoreingenommenen Lesers appelliert, der sich unter einer Vertreibung von Räubern zunächst einmal die Vertreibung aus dem geraubten, d. h. gewaltsam und widerrechtlich besetzten Eigentum anderer, vorstellt. An unsere Erzählung ist also die Frage zu richten: Wie sind die Räuber in das sog. Räuberhaus gekommen, in dem sie als festlich Tafelnde (,Schmausende' und nicht ,Hausende') geschildert werden.

3. Hier sei nun an den oben (I 2) mitgeteilten Gedanken angeknüpft, daß Hund und Hahn ihrem Typus nach keine vagantischen Musikanten, sondern Wächter sind, die man sich, wie durch unzählige Literaturbeispiele zu belegen, am besten als Hüter und Bewohner von Haus und Gehöft vorstellen kann. Es scheint nun sehr plausibel, diese Hüterfunktion in irgendeiner Weise auf das sog. Räuberhaus, d. h. das von den Räubern besetzte Haus, zu beziehen. Dann läßt sich folgende ursprüngliche Version erschließen: Hund und Hahn nehmen an der Rückeroberung ihres von Räubern besetzten Hauses teil.

\section{Die Genese}

Fassen wir zusammen:

1. Wir haben es mit zwei verschiedenartigen Tierpaaren zu tun, dem musikantisch-vagantischen Duo Esel-Katze und dem wächterisch-bodenständigen Paar Hund-Hahn.

Beide Paare sind in ihrer Gegensätzlichkeit zunächst kaum in einer gemeinsamen Handlung vorstellbar, fügen sich aber jeweils sehr gut in die beiden Hälften unserer Geschichte: Esel und Katze in die Wanderung nach Bremen samt Musikantenprojekt, Hund und Hahn in die Rückeroberung der Hausherrnschaft.

2. Die Diskrepanzen lassen sich am besten erklären, wenn man folgende Genese für unsere Geschichte annimmt:

a) Am Anfang steht die abenteuerliche, pikareske Vagantengeschichte vom gegensätzlichen Freundespaar Esel und Katze $\left(\mathrm{V}^{\mathrm{Es}+\mathrm{Ka}}\right)$, die nach Bremen wandern, um dort Stadtmusikanten zu werden, und - so darf man vermuten - auf dieser Wanderung allerlei (leider nicht überlieferte) Abenteuer (Episoden: $\mathrm{E}^{\mathrm{XY}}$ ) erleben.

b) Daneben steht, zunächst selbständig, die Hausgeschichte von Hund und Hahn $\left(\mathrm{H}^{\mathrm{Hu}+\mathrm{Ha}}\right)$, die ihrem (ebenfalls der Überlieferung zum Opfer gefallenen) Herrn (Dom.) helfen, die eingedrungenen Räuber zu vertreiben und die Hausherrnschaft zurückzuerobern. - Die Parallele zur Odyssee ist hier unüber- 
sehbar, der Rückschluß auf eine evtl. ursprüngliche Teilnahme des Hundes Argos an Odysseus' Kampf gegen die Freier erlaubt. - Diese Rückeroberung erscheint in unserer Geschichte aufgespalten und umgeformt in zwei Aktionen: einerseits als Vertreibung der schmausenden Räuber, andererseits als Zurückschlagung des Räuberspähers am Schluß (ein an die Dolonie der Ilias erinnerndes Nocturno), wobei Einzelheiten noch die offenbar kakophone Drastik der Vorlage (z.B. die in , abenteuerlichem Stil' geschilderten Verwundungen des Spähers durch die Tiere oder deren Stimmengeheul) aufblitzen lassen.

c) Aus diesen beiden selbständigen Geschichten V und $\mathrm{H}$ schuf ein Erzähler die seit den Brüdern Grimm geläufige Fassung der „Bremer Stadtmusikanten" (BM), indem er, vielleicht unter dem Einfluß bildlich dargestellter Tierpyramiden (erinnert sei an nahöstliche Kompositpfeiler aus Tierfiguren, südindische Tempeltürme und indianische Totempfähle), das ursprüngliche Vagantenpaar Es + Ka durch Hinzufügung der ursprünglichen Wächter $\mathrm{Hu}+$ $\mathrm{Ha}$ zum Quartett Es $+\mathrm{Ka}+\mathrm{Hu}+\mathrm{Ha}$ erweiterte (also die seither berühmte und als Denkmal am Bremer Rathaus aufgestellte Tierpyramide schuf) und andererseits die Hausgeschichte $\mathrm{H}$ (unter Verkürzung auf die Räubervertreibung $\mathrm{R}$ ) in die Vagantengeschichte $\mathrm{V}$ einschaltete, wobei diese (R) andere Abenteuerepisoden $\left(\mathrm{E}^{\mathrm{XY}}\right)$ und auch das Handlungsziel $\left(\mathrm{Z}^{\mathrm{B}+\mathrm{M}}\right)$ verdrängte und so aus einer, ursprünglich vielleicht beabsichtigten, Episode $\left(\mathrm{E}^{\mathrm{H}}\right)$ selber zum Handlungsziel $\left(\mathrm{Z}^{\mathrm{H}}\right)$ wurde. Es ergibt sich also:

$$
\mathrm{V}^{\mathrm{Es}+\mathrm{Ka}}+\mathrm{H}^{\mathrm{Hu}+\mathrm{Ha}}=\mathrm{BM}^{\mathrm{Es}+\mathrm{Ka}+\mathrm{Hu}+\mathrm{Ha}}
$$

oder genauer:

$$
\mathrm{V}^{\mathrm{Es}+\mathrm{Ka}}-\left(\mathrm{E}^{\mathrm{XY}}+\mathrm{Z}^{\mathrm{B}+\mathrm{M}}\right)+\mathrm{R}\left(=\mathrm{H}^{\mathrm{Hu}+\mathrm{Ha}}-\mathrm{X}^{\text {Dom.etc. }}\right)=\mathrm{BM}^{\mathrm{Es}+\mathrm{Ka}+\mathrm{Hu}+\mathrm{Ha}}
$$

wobei $\mathrm{X}$ und $\mathrm{Y}$ verlorengegangene Teile (Episoden: E, Figur des Hausherrn: Dom. usw.) bezeichnen sollen.

\section{Der Dichter}

Abschließend noch ein Wort über die Weise dieser Verknüpfung:

Die Brücke oder Kompositionsfuge zwischen der Vagentengeschichte (V) und der Rückeroberung (R) bildet der berühmte, an kafkaeske Frustrationsobsessionen erinnernde Satz: „Sie konnten aber die Stadt Bremen an diesem Tage nicht erreichen und übernachteten deshalb in einem dunklen Wald“. Hier ist einerseits das im folgenden verdrängte Handlungsziel Bremen $\left(Z^{\mathrm{B}+\mathrm{M}}\right)$ ein letztes Mal genannt, andererseits die ab jetzt dominierende Räubervertreibung $\left(Z^{\mathrm{H}}\right)$ eingeleitet; die Passage muß also dem vereinigenden Dichter der Endfassung gehören.

An dieser kompositionell höchst empfindlichen Stelle nun steht der Hinweis auf den ,dunklen Wald', der blitzartig klarmacht, von welcher Absicht sich der Erzähler von BM leiten ließ: Unüberhörbar ist hier das Zitat des Eingangs von Dantes Divina Commedia: 
Nel mezzo del cammin di nostra vita mi ritrovai per una selva oscura

wodurch sich der 'dunkle Wald', in dem sich unsere vier Vaganten, die Vertreter kraftvoller Dummheit (Es), listiger Geschmeidigkeit (Ka), Treue (Hu) und Wachsamkeit $(\mathrm{Ha})$, verirrt haben, als der den Menschen umstrickende Bereich von Irrtümern und Leidenschaften erweist.

In diesem Wald nun sieht der Hahn, Vogel der Wachsamkeit, in der Ferne das Licht des Räuberhauses brennen, das für die Vier zum Ort der Bewährung und schließlich nach der Inbesitznahme zum himmlischen Jerusalem wird, neben dem das irdische Ziel einer Beamtung in Bremen keinen Bestand hat.

Es war also kein bloßer kompilierender Redaktor, sondern ein komponierender Dichter und tiefer Denker, in dessen Weltbild der dunkle Wald der Verstrickung wie das helle Licht der Gnade ihren Platz haben, und zudem, wie die monumentale Idee der Tierpyramide zeigt, ein Visonär von grandioser Gestaltungskraft, der aus den handfesten Abenteuer- und Kampfgeschichten V und H die „Bremer Stadtmusikanten“ schuf und damit das zeitlose Thema der peregrinatio, des Weges der Seele durch Verstrickung und Bewährung zur leuchtenden Himmelsstadt, neu und eindrucksvoll gestaltete.

Nachtrag: Wieweit bei unserer Geschichte noch das Thema der retardierten Heimkehr, also eine Nostendichtung, als Vorlage eine Rolle spielte, als deren Helden man sich am liebsten eine Brieftaube vorstellen würde, muß weiterer Forschung vorbehalten bleiben. 


\title{
Aristarch und das Lexikon des frühgriechischen Epos
}

\author{
RENÉ NÜNLIST
}

\begin{abstract}
Als die Stadt London zu Beginn des 19. Jahrhunderts als erste die damals bahnbrechende Neuerung einer öffentlichen Gaslichtbeleuchtung einführte, war die (zweifellos unbeabsichtigte) Folge die, daß die Stadt erst relativ spät auf die modernere Strombeleuchtung umgerüstet wurde. Dieses sogenannte 'Law of the Retarding Lead' läßt sich auch in der Wissenschaft beobachten. ${ }^{1}$ Ebenfalls im frühen 19. Jahrhundert schrieb Karl Lehrs sein inzwischen klassisches Buch De Aristarchi studiis Homericis. Die erste Auflage erschien 1833, die zweite 1865, die dritte postum 1882 (besorgt von A. Ludwich). In der zweiten von insgesamt fünf 'dissertationes' legte Lehrs auf gut 120 Seiten das Material zu Aristarchs Worterklärungen vor (1882, 36-161). Was seither auf diesem Gebiet geleistet wurde, ist vergleichsweise schnell erzählt. ${ }^{2}$ Die in den 1880er-Jahren entstandenen Arbeiten von Max Hecht gehen von Lehrs aus und behandeln ein Dutzend Wörter, bei deren Erklärung Aristarch sich geirrt haben soll. ${ }^{3}$ Auch in seinen Studien zu Aristarchs Worterklärungen begeht Adolf Römer den gleichen Grundfehler wie in all seinen Arbeiten zur antiken Homerexegese: Praktisch unabhängig von der tatsächlichen Überlieferungslage reklamiert Römer all das für Aristarch, was sich besonders gut mit seinen eigenen Auffassungen verträgt. ${ }^{4}$ Die exakt 100 Jahre alte Dissertation von Christoph Dimpfl (1911) ist, obwohl nicht unter Römers Ägide entstanden, vor dessen methodischen Fehlern nicht gefeit und wiederholt in den zuverlässigeren Teilen nicht selten Dinge, die bereits bei Lehrs stehen. Immerhin steuert Dimpfl zwei wichtige Erkenntnisse bei, was Aristarchs Methode betrifft. Zum einen vergleicht Aristarch die Sprache Homers auch in semasiologischer Hinsicht mit der $\sigma u v \eta \dot{\theta} \theta \varepsilon ı \alpha$, dem zeitgenössischen (also hellenistischen) Sprachgebrauch. ${ }^{5}$ Zum anderen steht Aristarch dem Wortgebrauch der nachhomerischen Auto-
\end{abstract}

1 Rijksbaron $(1997,1)$, der als Beispiel das Standardwerk von Denniston, The Greek Particles $\left({ }^{1} 1934,{ }^{2} 1954\right)$, nennt.

2 Zu vergleichen ist auch der Forschungsüberblick zum Thema 'Worterklärung' von Schmidt (1976, 25-26).

3 Hecht $(1882,1884,1888)$.

4 Römer (1885, 1911, 1924, 1-44); zur Einschätzung Schmidt (1976, 25).

5 Dimpfl (1911, 19-38), wobei im einzelnen aus den genannten Gründen vieles zu beanstanden ist. Zum Verhältnis zwischen Homers Sprache und der $\sigma u v \eta \dot{\theta} \theta \varepsilon l \propto$ s.u. 


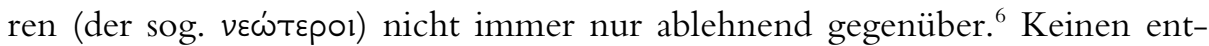
scheidenden Fortschritt bringt der Abschnitt über die Semantik im Aristarchbuch von Albert Severyns (1928, 103-119), der auf den Spuren Römers wandelt. Seinem unmittelbaren Beweisziel entsprechend, beschränkt Marchinus van der Valk sich auf die Nennung einiger Beispiele dafür, daß die bTScholien mit Aristarchs (Wort-)Erklärung übereinstimmen (1963, 460-462) bzw. von ihr abweichen (463-464). Aristarchs Leistungen auf diesem Gebiet werden von Rudolf Pfeiffer (1968, 227-228) primär mit Blick auf ihre textkritischen Auswirkungen kurz gewürdigt. Andrew Dyck (1987, v.a. 128) zeichnet die kritische Auseinandersetzung mit den Glossographen nach. Zusätzlich zu den bereits genannten Arbeiten gibt es eine Reihe von verstreuten Einzelbeobachtungen, aber, soweit ersichtlich, keine systematische Untersuchung. ${ }^{7}$ Man wird vermuten dürfen, daß die Meinung vorherrschte, Lehrs habe zu diesem Thema bereits das Nötige gesagt. ${ }^{8}$

Auch wenn Lehrs' Leistung nicht im geringsten geschmälert werden soll, ist der Zeitpunkt doch gekommen, um ernsthaft über die Einführung einer elektrischen Straßenbeleuchtung nachzudenken. Der erfolgreiche Abschluß des Lexikon des frühgriechischen Epos ist ein besonders passender Anlaß, um sich grundsätzliche Gedanken zu Aristarchs semasiologischen Studien zu machen. Ausgangspunkt der folgenden Überlegungen ist selbstverständlich Lehrs' Buch (1882), von dem zunächst einmal gezeigt werden muß, daß es tatsächlich übertroffen werden kann. Von Einzelheiten abgesehen, lassen sich aus heutiger Sicht im wesentlichen drei Defizite feststellen.

(1) Lehrs beschäftigt sich vornehmlich mit der Frage, welche Bedeutung Aristarch den jeweiligen Wörtern oder Wortfeldern zugeschrieben hat. Dagegen spricht er fast nie über Aristarchs Methode. Wie ist dieser bei der Ermittlung einer Wortbedeutung vorgegangen? Von welchen Prinzipien wurde er geleitet? Welche Erklärungsmuster schwebten ihm vor? Auf Fragen dieser Art geht Lehrs so gut wie gar nicht ein. Der Grund dürfte darin zu suchen sein, daß Lehrs wie viele seiner Zeitgenossen in Aristarch einfach den antiken Meister ihrer eigenen Wissenschaft erkannte, der im wesentlichen nach den gleichen Prinzipien vorging wie sie selbst. In einer Zeit, die der expliziten Methodenreflexion ohnehin nicht viel abzugewinnen vermochte, schien es überflüssig oder zumindest nicht unmittelbar zwingend, sich Rechenschaft über die Methoden seiner antiken Vorgänger abzulegen. ${ }^{9}$ Ein äußeres Indiz für

6 Dimpfl (1911, 39-45), mit der gleichen Einschränkung wie in Anm. 5. Zum Thema selbst s.u.

7 Solche Einzelbeobachtungen finden sich etwa in Aufsätzen (z.B. Schmidt 1979, 177178 ) und inbesondere im ersten Band des LfgrE (nach der Neuorientierung des Projekts ab dem Buchstaben $\beta$ nur noch vereinzelt, z.B. s.v. kpó $\sigma \propto \mathrm{l})$.

8 Derjenige, der das auch explizit sagt, ist Römer (1912, 1) - freilich mit unverhohlen polemischem Unterton.

9 Die kurze Würdigung, die Lehrs der Einzelbesprechung vorausschickt, operiert vor allem negativ und unterstreicht, in welch desolatem Zustand sich die Worterklärung 
diese affirmative Grundhaltung ist u.a. darin zu erkennen, daß Aristarchs Behandlung eines Wortes regelmäßig diejenige der zeitgenössischen Sekundärliteratur an die Seite gestellt wird. Die dadurch implizierte Zustimmung kommt in einem vielsagenden Addendum zur ersten Auflage zum Ausdruck (zitiert 1882, 51 Anm. 30a): de dissertatione secunda non superfluum fuerit monere, me singulas voces ab Aristarcho tractatas explorasse et probari mihi nisi quid in contrariam partem additum sit.

Der vorliegende Beitrag verfolgt in erster Linie das Ziel, die methodologische Lücke in Lehrs' Darstellung wenigstens ansatzweise zu schließen. Eine Gewichtung zugunsten des Methodischen drängt sich auch deshalb auf, weil sie sich gut mit den äußeren Vorgaben eines Aufsatzes vereinbaren läßt, in dem nur ausgewählte Beispiele vorgeführt werden können. Der Ausgleich der beiden übrigen Defizite erfordert eine umfangreichere Studie:

(2) Lehrs hat das Material zu Aristarchs semasiologischen Studien zwar mit einem beachtlichen Grad an Vollständigkeit gesammelt, ist aber nicht wirklich dazu gekommen, alles von Grund auf durchzuarbeiten. Zumal der hintere Teil seiner zweiten 'dissertatio' ist vielfach nicht mehr als eine minimal kommentierte Stellen- bzw. Wörterliste, die weder nach einem erkennbaren Muster gegliedert ist noch das gesammelte Material durchinterpretiert. Die eigentliche Arbeit des Sichtens, Deutens und Ordnens muß hier noch geleistet werden. In der Ausgabe der Iliasscholien von Erbse (1969-1988) schlägt sich dieser Umstand dadurch indirekt nieder, daß im Testimonienapparat vielfach gar nicht erst auf Lehrs' Behandlung verwiesen wird. ${ }^{10}$ Nach einer groben Schätzung muß ungefähr die Hälfte der von Lehrs gesammelten Worterklärungen noch durchgearbeitet werden.

(3) Wie bereits angedeutet, ist Lehrs' Sammlung nicht vollständig. Die Komplettierung ist somit ein drittes Ziel, das ebenfalls mit einer vorläufigen Angabe beziffert werden kann. Lehrs hat etwas mehr als dreihundert Homerische Wörter identifiziert, zu deren Semantik Aristarch sich in irgendeiner Weise geäußert hat. ${ }^{11}$ Die aktuelle Fassung meiner Materialsammlung enthält annähernd sechshundert Einträge, also fast doppelt so viele wie Lehrs.

Um eine allgemeine Vorstellung vom Umfang von Aristarchs semasiologischen Studien zu bekommen, bietet sich ein Vergleich mit dem Homerlexikon von Apollonios Sophistes an, das ungefähr 3000 Lemmata umfaßt, also fünf Mal mehr. ${ }^{12}$ Die Differenz begründet sich ohne Zweifel in den je unterschiedlichen Zielsetzungen eines Lexikons und eines Kommentars.

vor Aristarch befunden habe. Auf der positiven Seite wird immerhin die Konzentration speziell auf den Homerischen Wortgebrauch erwähnt $(1882,46)$.

10 Das gilt z.B. für die unten in Anm. 28, 35 und 41 aufgeführten Belege.

11 Die Erfassung dieser Wörter ist mit den derzeit zur Verfügung stehenden Mitteln nicht einfach, weil der 'index rerum et verborum' (1882, 477-487) nicht differenziert, unter welchem Gesichtspunkt Lehrs die darin aufgeführten Wörter besprochen hat.

12 Zum Vergleich: Das LfgrE, in dem freilich auch Hesiod usw. erfaßt sind, besteht aus ungefähr 10.000 Lemmata (W. Beck, per litt.). 
Als Ausgangspunkt für eine Rekonstruktion von Aristarchs Arbeitsweise eignet sich seine Besprechung eines Homerischen Ausdrucks, an der sich mehrere Aspekte nachweisen lassen, die für seine Methode repräsentativ sind. Ge-

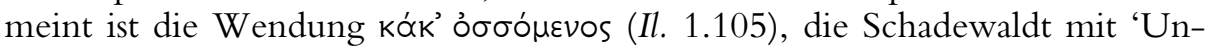
heil blickend' übersetzt. Sie steht in der Einleitung zu der Rede, in der ein wutentbrannter Agamemnon den Seher Kalchas anfährt (1.106-120), weil dieser ihn für das Ausbrechen der Seuche verantwortlich erklärt hat (1.93-

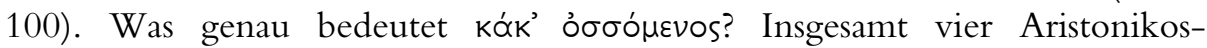
Scholien zur Ilias nehmen auf diese Frage Bezug. ${ }^{13}$ Am wichtigsten ist das Scholion zur Stelle selbst.

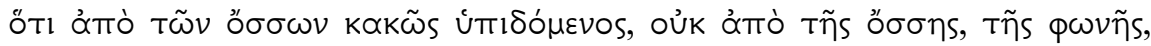

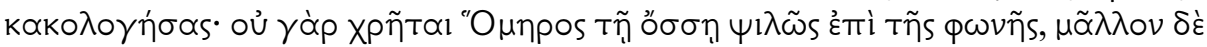

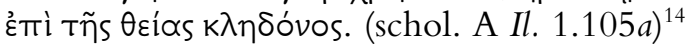

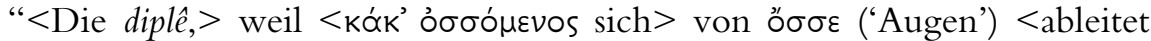
und $>$ 'böse von unten anblickend' < bedeutet>, nicht von ő $\sigma \sigma \alpha$, 'Stimme', $<$ in der Bedeutung $>$ 'beschimpfend'. Denn Homer verwendet ö $\sigma \sigma \alpha$ nicht allgemein für die Stimme, sondern < speziell> für das göttliche Gerücht." ${ }^{15}$

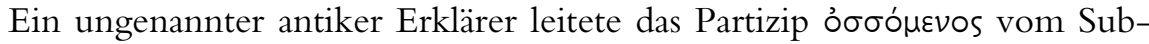
stantiv ő $\sigma \propto \alpha$ ('Gerücht' und dann allgemeiner 'Stimme') ab und gab die ganze

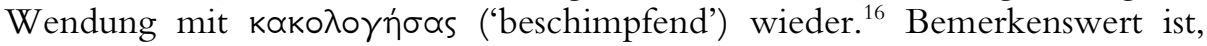
daß Aristarch sich nicht einfach darauf beschränkt, die vorgeschlagene Deutung zurückzuweisen und statt dessen eine andere Etymologie vorzuschlagen. Er legt eine aufschlußreiche Begründung vor. Homer verwende das Wort ő $\sigma \sigma \alpha$ nicht allgemein für jede Art von Stimme, sondern eingeschränkter für ein Gerücht göttlichen Ursprungs. ${ }^{17}$ Dies - so wird man den Argumentationsgang fortsetzen dürfen - paßt hier nicht, weil Agamemnon keine göttliche Figur ist und es an der vorliegenden Stelle auch nicht um ein Gerücht geht. Mit anderen Worten: Um die andere Erklärung zu widerlegen, untersuchte Aristarch die Homerische Verwendung des angeblich zugrundeliegenden

13 Bekanntlich sind Aristarchs Kommentare verloren. Zu ihrer Rekonstruktion aus den Exzerpten, die in augusteischer Zeit (Aristonikos, Didymos) bzw. im 2. Jh. n. Chr. (Nikanor, Herodian) gemacht wurden, s. z.B. Dickey (2007, 18-19). Sofern nicht anders vermerkt, können alle in diesem Beitrag genannten A-Scholien zur Ilias Aristonikos zugeschrieben werden.

14 Lehrs (1882, 88), Dimpfl (1911, 17).

15 Durch den Überlieferungsprozeß sind Scholien oft stark verkürzt und setzen vieles stillschweigend voraus, das in der Übersetzung als Verständnishilfe in spitzen Klammern ergänzt ist.

16 Offensichtlich besteht eine methodische Verwandtschaft mit dem Abschnitt E(tymologie) im LfgrE; s. Meier-Brügger in diesem Band.

17 Der positive Teil der Erklärung kehrt im (Vulgat-)Scholion DEHJM ${ }^{a} V$ Od. 1.282g wieder, das deshalb spätestens seit Carnuth $(1869,12)$ Aristonikos zugeschrieben wird (zuletzt in der neuen Ausgabe der Odysseescholien von Pontani 2007, z.St.); ähnlich schol. H Od. 24.413 (Carnuth 1869, 164). 
Wortes ö $\sigma \sigma \propto$ und kam zum Schluß, daß diese die vorgeschlagene Deutung nicht zu stützen vermag. Er lehnte sie deshalb ab und zog es statt dessen vor, das Partizip von ő $\sigma ఠ \varepsilon$ ('Augen') abzuleiten. ${ }^{18}$

Was den Wortgebrauch von ö $\sigma \sigma \alpha$ betrifft, steuert ein zweites Scholion (schol. A Il. 2.93b) eine wichtige Ergänzung bei. Die Verwendung des Worts

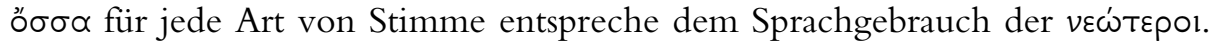
Homer selbst verwende es ausschließlich für das göttliche Gerücht (i $\theta$ zía $\kappa \lambda \eta \delta \omega \dot{v})$. Hier sieht man die Methode am Werk, die unter dem Schlagwort

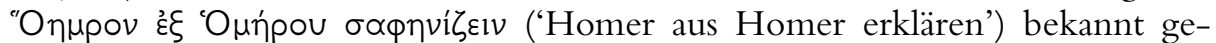
worden ist. ${ }^{19}$ Aus Sicht eines heutigen Lexikographen mag es offensichtlich sein, daß die Bedeutung eines Wortes in erster Linie aus den Belegen beim fraglichen Autor abgeleitet werden muß. Die Diskussion im oben zitierten Scholion zeigt aber, daß dieses Grundprinzip damals zumindest nicht als selbstverständlich vorausgesetzt werden konnte.

Aristarch stellte bei der Verwendung von ö $\sigma \sigma \propto$ einen Unterschied zwi-

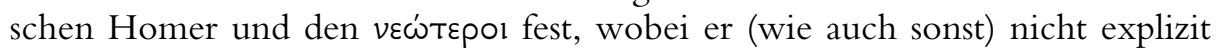
macht, wer mit dieser Kollektivbezeichnung gemeint ist. Immerhin erwähnt Erbse im Testimonienapparat (z.St.) einen Vers aus Hesiods Theogonie (832), in dem ő $\sigma \sigma \alpha$ im allgemeineren Sinn von 'Stimme' verwendet wird. Die Parallele

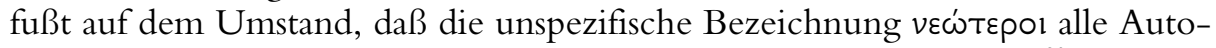
ren bezeichnet, die jünger sind als Homer - einschließlich Hesiods. ${ }^{20}$ Im übrigen darf an dieser Stelle nicht mit Stillschweigen übergegangen werden, daß der von Aristarch festgestellte Unterschied zwischen Homer und den Späteren auch im LfgrE verfochten wird. Der Artikel ő $\sigma \propto \alpha$ unterscheidet im Abschnitt B zwischen: 1. Homer und 2. Außerhalb Homers.

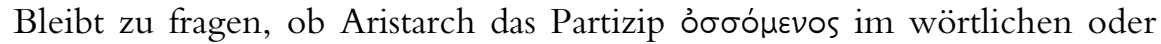
im übertragenen Sinn verstanden hat. Vorausgeschickt sei, daß das LfgrE in dieser Frage Uneinigkeit zeigt. Während im Artikel kakós eine wörtliche Auslegung vorgeschlagen wird ('drohend blicken'), favorisiert der Artikel ő $\sigma \circ \propto \mu \propto l$ die übertragene Bedeutung 'im Geist vor sich sehen' bzw. in bezug auf Ilias 1.105 'schlimme Aussichten vor Augen'. Das zitierte Scholion übersetzt die

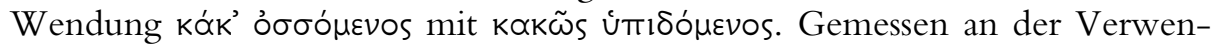
dung von úpopócw spricht das eher dafür, daß Aristarch der Wendung in Ilias

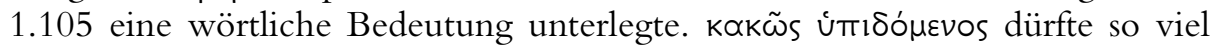
wie 'böse von unten (also argwöhnisch) anblickend' bedeuten. Freilich macht ein anderes Scholion (schol. A Il. 22.356a) deutlich, daß Aristarch auch die

18 Das zitierte Scholion zeigt auch, daß es bereits in der Antike Versuche gegeben hat, zwischen 'richtigen' und 'falschen' Etymologien zu unterscheiden. Die gleiche Etymologie wird auch in schol. A Il. $24.172 a$ verfochten.

$19 \mathrm{Ob}$ Aristarch selbst diesen Ausdruck verwendet hat, ist im vorliegenden Zusammenhang unwichtig. Zur Maxime Montanari (1997, 285-286, mit Lit.).

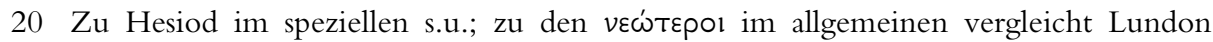
(2001, 835 Anm. 30) passend die Alternativbezeichnung oi $\mu \varepsilon \theta^{\text {' 'O } \mu \eta p o v ~(z . B . ~ s c h o l . ~ A ~}$ Il. $2.2 b)$. 


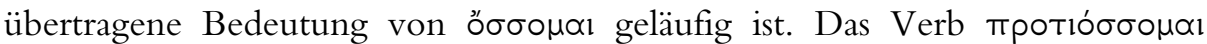

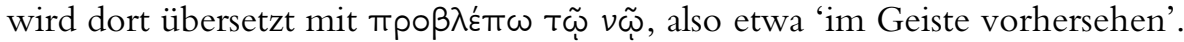

$\mathrm{Da}$ bestimmte Wörter je nach Kontext wörtlich oder übertragen verwendet werden können, ist für Aristarch also selbstverständlich. Das ist, wenn man etwa an die Metapherndiskussion von Aristoteles denkt, nicht weiter erstaunlich. ${ }^{21}$ Entsprechende Deutungen tauchen in Aristarchs Worterklärungen immer wieder auf. Dabei wird die wörtliche oder 'eigentliche' Bedeutung meist mit dem Adverb kupíws bezeichnet. ${ }^{22}$ Bei der übertragenen Bedeutung ist die

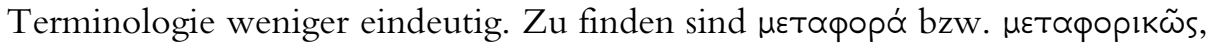
wobei der Begriff (wie bei den antiken Erklärern üblich) weiter gefaßt ist als die moderne Verwendung des Worts 'Metapher'. ${ }^{23}$ Daneben findet sich auch der Begriff тротюки̃s, dem man am besten englisch 'figuratively' an die Seite stellt, weil darin das lateinische Wort figura (für griechisch трóтоos) steckt. ${ }^{24} \mathrm{Zu}$

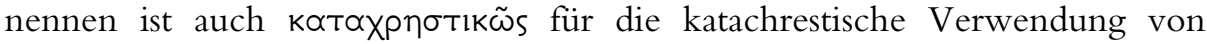

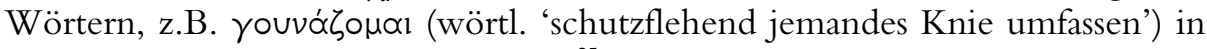
der Bedeutung íkєтєú $\omega$ ('anflehen'). ${ }^{25} \mathrm{Zu}$ betonen ist an dieser Stelle, daß Aristarch wiederholt von wörtlicher bzw. übertragener Bedeutung handelt, ohne daß er dafür einen bestimmten Terminus verwendet. ${ }^{26}$ Dieses für die antike Philologie charakteristische Phänomen ist für die moderne Forschung deshalb relevant, weil es bedeutet, daß die Scholien Stück für Stück durchgearbeitet werden müssen. Wenn man - z.B. mit Hilfe des elektronischen TLG - nur nach bestimmten Begriffen sucht, entgeht einem wichtiges Material. ${ }^{27}$

Ein Bewußtsein für die mögliche Bedeutungsvielfalt von Wörtern kommt auch in anderer Form zum Ausdruck. So stellt Aristarch in bezug auf das Verb

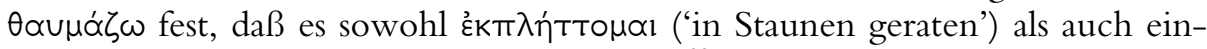
fach $\theta$ cóoual ('betrachten') bedeuten kann. ${ }^{28}$ Nun mag man in den beiden vorgeschlagenen Bedeutungen immer noch einen gemeinsamen Nenner erkennen und sie als zwei Formen einer sinnlichen, primär visuellen Wahrneh-

21 Aristoteles, Poetik Kap. 21-22, Rhetorik 3. Buch, Kap. 2, 4 und 10-11.

22 Schol. A Il. 2.670, 4.141a, 5.266b usw.

23 Schol. A Il. 1.37e, 1.51c, $2.49 b$ usw.

24 Schol. A Il. 4.343a.

25 Schol. A Il. 11.130a. Die Behandlung von Aristarchs Katachresendeutung durch Lotz (1909) krankt an den methodischen Schwächen des Doktorvaters (Römer); vgl. Schmidt $(1976,25)$.

26 Ein gutes Beispiel ist die Diskussion der Bedeutung von фú $\propto \alpha$ in schol. A Il. 9.2b

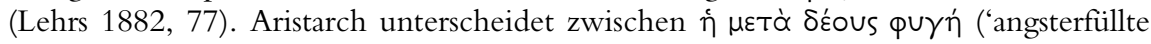
Flucht') und हैא $\pi \lambda \eta \xi 15$ ('Bestürzung'). Das eine ist die wörtliche Grundbedeutung, das andere eine übertragene Bedeutung, ohne daß dies im Scholion ausdrücklich gesagt würde; ähnlich schol. A Il. 6.400 a (zur Bedeutung von kó $\lambda$ mos). Auch metonymische Verwendung kann einfach umschrieben werden (z.B. schol. A Il. 21.502b).

27 Zum Methodenproblem Nünlist $(2009,3)$.

28 Schol. A Il. 2.320a, vgl. 13.11a, 18.496a, 24.394; Lehrs (1882, 146). 


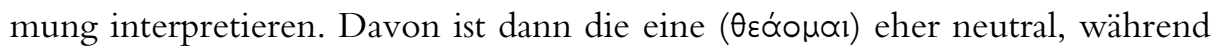

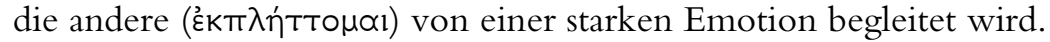

Dieses Festhalten an der Vorstellung eines gemeinsamen Nenners gestaltet sich schon schwieriger bei der Erklärung des Verbs ő $\gamma \propto \mu \propto$ l. Aristarch zufolge

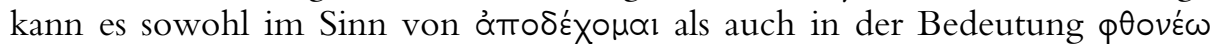
verwendet werden. ${ }^{29}$ Letzteres bedeutet sicher 'mißgönnen', während

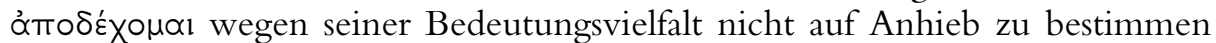
ist. Da aber ein zweites Scholion (schol. A Il. 17.71) eine Unterscheidung trifft

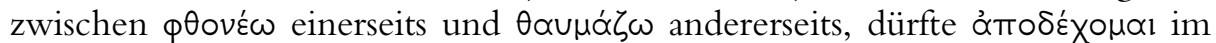
ersten Fall wohl ebenfalls im Sinn von 'bewundern' aufzufassen sein. ${ }^{30}$ Aristarchs Beschreibung von ơ $\gamma \propto \mu \propto l$ als 'bewundern' vs. 'mißgönnen' nähert sich schon stark der Situation, die man durch die tägliche Arbeit mit Wörterbüchern nur zu leicht für selbstverständlich hält: Die Bedeutungsvielfalt eines bestimmten Wortes wird dadurch zum Ausdruck gebracht, daß das Wörterbuch die voneinander abgrenzbaren Bedeutungen unter 1., 2., 3. usw. aufschlüsselt.

Das gleiche gilt auch für Aristarchs Behandlung des Verbs $\mu \varepsilon v \varepsilon \propto \alpha^{\prime} v \omega .{ }^{31}$ Auffällig ist hier zum einen, daß das Bedeutungsspektrum besonders groß ist. Es

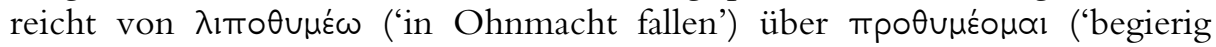

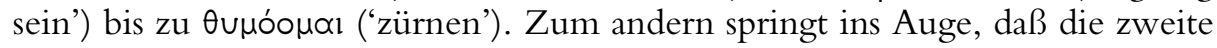
Bedeutung mit einer Parallelstelle (Il. 21.543) belegt wird. Auch dieses Vorgehen, das Anführen von Belegen und Parallelstellen, mag aus heutiger Sicht selbstverständlich sein. Es verdient aber betont zu werden, weil es in der antiken Diskussion oft genug unterbleibt.

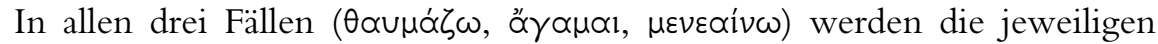
Bedeutungen einfach voneinander abgegrenzt, ohne daß das zusätzlich erläu-

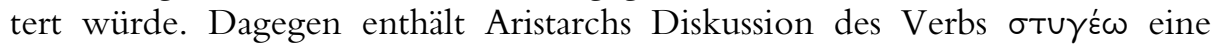
zusätzliche Bemerkung, die für seine Arbeitsweise aufschlußreich ist. ${ }^{32}$ Den Anlaß bildet der Schluß der Rede, in der Iris Poseidon wissen läßt, daß er sich nach Zeus' Willen aus dem Kampfgeschehen zurückziehen soll (Il. 15.174-

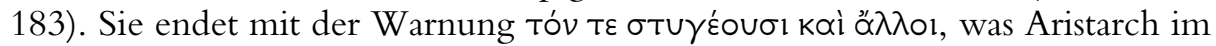
Sinn von 'denn diesen (Zeus) fürchten auch andere' verstanden wissen will.

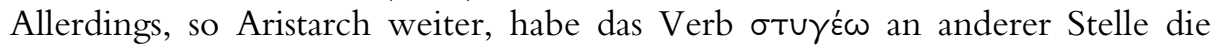

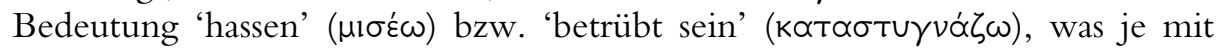
einer Homerstelle belegt wird (Il. 20.65, 17.694). All das veranlaßt ihn zu der Bemerkung, mit der das Scholion beginnt. Die Stelle ist mit einer diplê mar-

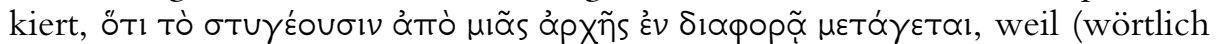
übersetzt) 'das Wort $\sigma \tau \cup \gamma \varepsilon \dot{\varepsilon} \omega$ aus einem einzigen Ursprung aus verschiedenen

29 Schol. A Il. 7.41a; Lehrs $(1882,146)$.

30 Anders van der Valk (1963, 592), dem zufolge ein Widerspruch zwischen den beiden Scholien besteht.

31 Schol. A Il. 16.491a, vgl. 19.68b, 19.365-8a $a^{1}, 24.54 d$.

32 Schol. A Il. 15.183; Lehrs (1882, 147). 
Gründen abgeleitet wird'. Der Text des Scholions und seine Auslegung sind nicht ganz einfach. ${ }^{33}$ Der zugrundeliegende Gedanke wird dennoch klar. Es

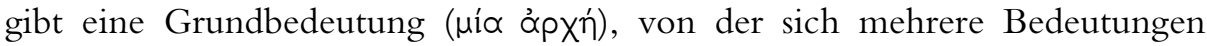
herleiten. Bedauerlicherweise geht aus dem Scholion nicht eindeutig hervor, was Aristarch zufolge die Grundbedeutung von $\sigma \tau \cup \gamma \varepsilon \dot{\epsilon} \omega$ ist. Aber die Aussage als solche ist bemerkenswert und steht im Einklang mit der Grundstruktur eines Artikels im LfgrE (und anderen Wörterbüchern): Ausgehend von einer Grundbedeutung werden die verschiedenen Nuancen nacheinander durchgesprochen.

Aristarch äußert sich noch in einer weiteren Hinsicht zur Bedeutungsvielfalt von Wörtern. Dem entsprechenden Nachweis muß zunächst die Klärung einer Vorfrage vorausgeschickt werden. Wie gesehen, leitet Aristarch die Bedeutung eines Wortes in erster Linie aus dem Wortgebrauch des betreffenden

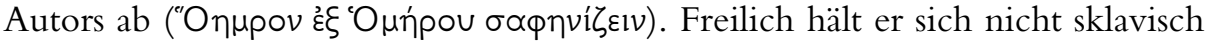
an dieses Prinzip. Zumal bei der Erklärung von hapax legomena führt eine streng textimmanente Betrachtungsweise oft nicht weiter, weil das nötige Vergleichsmaterial fehlt. ${ }^{34}$ In Il. 11.155 beginnt ein Homerisches Gleichnis damit,

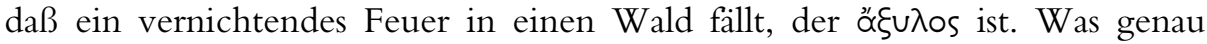
bedeutet dieses hapax? Das Scholion zur Stelle referiert drei Deutungen, die

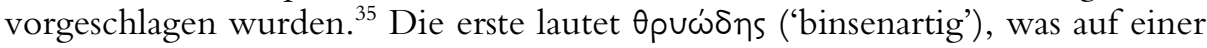

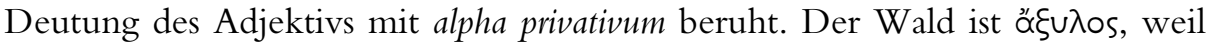
er nicht aus Holz, sondern aus Binsen besteht. Die zweite Erklärung lautet

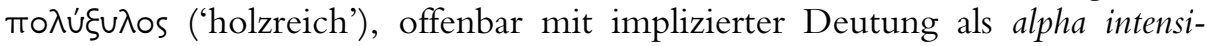
vum. ${ }^{36}$ Die dritte, von Aristarch favorisierte Erklärung kommt auf eine ähnliche Bedeutung wie die zweite, basiert aber wiederum auf einer Etymologie mit alpha privativum. Der Wald ist reich an Holz, weil keiner darin Holz geschlagen

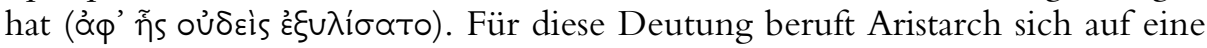

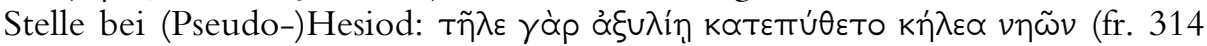
$\mathrm{M}-\mathrm{W})$. Was die Einzelheiten betrifft, stellen sich mehrere Probleme, weil das Hesiodfragment nur aus diesem Scholion bekannt und seine Bedeutung nicht zweifelsfrei gesichert ist. ${ }^{37}$ Immerhin wird man vermuten dürfen, daß das Adverb Tก̃ $\lambda \varepsilon$ ('fern') mit ein Grund dafür war, warum Aristarch auf seine Deutung von Il. $11.155 \mathrm{kam}$. Der Wald ist so weit entfernt, daß keiner ihn wirt-

33 Lehrs (ap. Friedländer 1853, 244, wiederholt Lehrs 1882, 147 Anm. 87a und bei Erbse

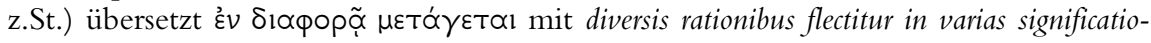
nes.

34 Hier und im folgenden ist hapax legomenon so gemeint, daß das jeweilige Wort nur einmal beim betreffenden Autor belegt ist.

35 Schol. A Il. 11.155b; Lehrs $(1882,153)$.

36 Ein ausdrücklicher Hinweis auf alpha intensivum findet sich in der Besprechung der

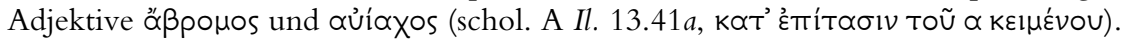

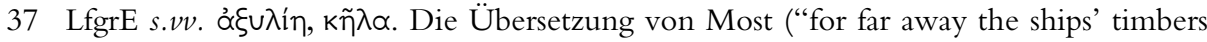
were rotting for lack of wood") ist nicht mit dem Inhalt des Scholions vereinbar und setzt voraus, daß Aristarch die Hesiodstelle falsch verstanden hat. 
schaftlich genutzt hat. In erster Linie soll das Beispiel lediglich illustrieren, daß Aristarch bei der Deutung eines hapax legomenon Hesiod heranzieht.

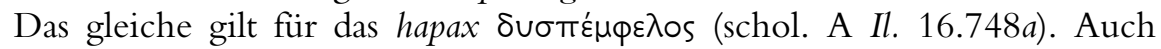
hier verwendet Aristarch eine Hesiodparallele (Th. 440), um Zenodot entgegenzuhalten, das Wort sei auf das 'Meer' zu beziehen und nicht auf die 'Män-

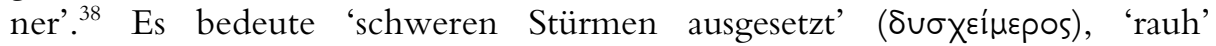
(тpaxús). Aus mehreren Quellen ist bekannt, daß Aristarch Hesiod für jünger hielt als Homer ${ }^{39}$ Allerdings hielt er ihn wohl nicht für viel jünger, sonst hätte er sich kaum zur relativen Chronologie zu äußern brauchen. Durch die zeitliche und gattungsbezogene Nähe zu Homer bot Hesiod sich besonders zum Vergleich an. Daß die zeitliche Abfolge dabei nicht einfach in Vergessenheit geriet, zeigt die Erklärung des Wortes $\mu \propto x \lambda \circ \sigma u ́ v \eta$ ('Geilheit'). ${ }^{40}$ Aristarch zufolge war Hesiod der erste, der dieses Wort benutzt hat, was ihm ein weiteres Argument für seine Auffassung liefert, daß der Passus - und damit das Parisurteil insgesamt - nicht Homerisch sein kann. Die zeitliche Abfolge bleibt ihm bei seinen Worterklärungen also durchaus präsent. Freilich ist er u.U. bereit, in der Zeit sogar weiter hinunterzugehen als bis zu Hesiod. So wird die Bedeu-

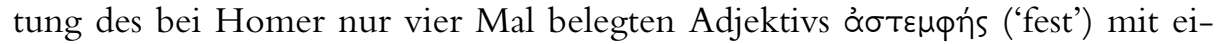
ner Parallele aus Anakreon (fr. 367 PMG) untermauert. ${ }^{41} \mathrm{Da}$ die Präposition Úmó gelegentlich mit $\mu \varepsilon т \alpha ́$ gleichbedeutend ist, wird mit einer Archilochosstelle (fr. 58.12 West) belegt. ${ }^{42}$ Und wenn Aristarch im Text von Il. 5.31 die Form von Ares' Epitheton $\tau \varepsilon 1 \chi \varepsilon \sigma ı \pi \lambda \lambda \tilde{\eta} \tau \alpha$ gegen Zenodots Änderung $(\tau \varepsilon 1 \chi \varepsilon \sigma i \beta \lambda \tilde{\eta} T \alpha)$ verteidigt, stützt er sich auch auf Stesichoros (fr. $242 \mathrm{PMG}){ }^{43}$ Die Beispielreihe zeigt, daß Aristarch sich durchaus nicht immer darauf beschränkt, 'Homer aus Homer' zu erklären. Eine ausdrückliche Begründung für dieses Abweichen von seiner Erklärungsmaxime ist nicht erhalten. Man wird aber wohl vermuten dürfen, Aristarch habe seine Maxime zumal dann nicht stur umgesetzt, wenn der Homerische Befund selbst nichts oder zu wenig hergab. In solchen Fällen hätte ein Festhalten an streng textimmanenter Interpretation zu einem Verlust von unentbehrlichem Vergleichsmaterial geführt. Auf dieses $\mathrm{zu}$ verzichten wäre einer letztlich sachfremden Selbstbeschneidung gleichgekommen. ${ }^{44}$

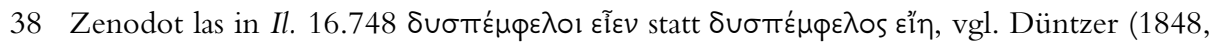
95).

39 Nünlist (2012, 123-124, mit Lit. in Anm. 42 und 51).

40 Schol. A Il. 24.25-30, Dimpfl (1911, 19); ähnlich schol. A Il. 24.304a (zu X'́pvıßov). Beide Wörter sind Homerische hapax legomena.

41 Schol. A Il. 3.219a; Lehrs $(1882,152)$.

42 Schol. A Il. $18.492 b=$ fr. 189 Matthaios.

43 Schol. A Il. 5.31d. Alle drei Beispiele (Anakreon, Archilochos, Stesichoros) sind aufgeführt bei Dimpfl $(1911,44)$.

$44 \mathrm{Im}$ übrigen zeigt die Diskussion etwa von geographischen Fragen (z.B. schol. A Il. 15.518a, Lehrs 1882, 226), daß Aristarch auch in anderen Zusammenhängen nicht ausschließlich textimmanent vorging. 
Ein weiteres selten belegtes Wort verdient an dieser Stelle erwähnt zu werden, weil seine Behandlung deutlich über den Bereich der semantischen Analyse hinausweist. Gemeint ist das Wort $\delta i \delta \cup \mu o$, das kein richtiges hapax ist. In dieser Form kommt es in beiden Epen je einmal vor und ist außerdem in

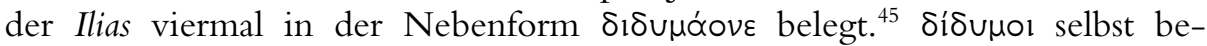
schreibt in der Ilias (23.641) die beiden Aktorsöhne, Antimachos und Thalpios, die auch unter dem Namen Molione bekannt sind. Was bedeutet es, daß sie

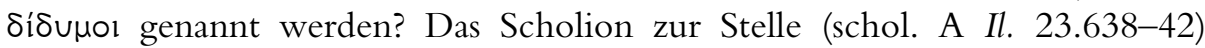
macht deutlich, daß Aristarch das Wort nicht wie andere im Sinn von 'Zwil-

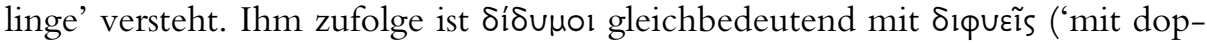
peltem Körper'), wobei die Körper zusammengewachsen sind - siamesische Zwillinge also. Als 'Zeugen' ( )Hesiod heran (fr. $18 \mathrm{M}-\mathrm{W}$ ). Aristarchs Argumentationsweise bleibt in methodischer Hinsicht bemerkenswert, auch wenn die meisten modernen Homererklärer ihm, was die konkrete Deutung betrifft, die Gefolgschaft verweigern (z.B. LfgrE s.v.). Im übrigen ist es natürlich so, daß er Hesiod nicht blindlings folgt. Denn dieser wird an anderer Stelle in bezug auf die Genealogie des gleichen Brüderpaars dafür gerügt, daß er aus Homers Bezeichnung Moגíove die

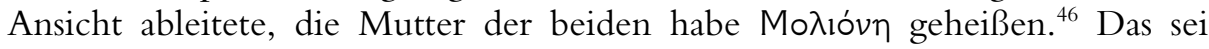
falsch, argumentiert Aristarch, weil es bei Homer keine Metronymika gebe. Er führt auf diese Weise vor, daß man jeden Fall bzw. Aspekt einzeln für sich betrachten muß und nicht mechanisch Prinzipien umsetzen kann.

Ein letztes Wort zu den hapax legomena. Die Zahl der einschlägigen Scholien läßt den Schluß zu, daß Aristarch sie systematisch gesammelt und als solche markiert hat. ${ }^{47}$ Das LfgrE tut das auch und differenziert folgendermaßen. Die dem Lemma nachgestellte Angabe 'hapax' bezeichnet absolute hapax legomena, während das einmalige Vorkommen eines Wortes bei Homer implizit deutlich wird. Seit dem Buchstaben $\mu$ wird das Auffinden dadurch erleichtert, daß die Anzahl Stellen auch bei selten belegten Wörtern nach dem Lemma angegeben wird (in eckigen Klammern, aufgeschlüsselt nach Ilias, Odyssee

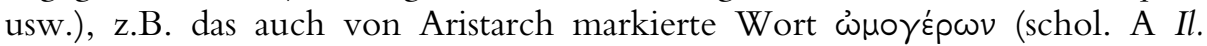
23.791).

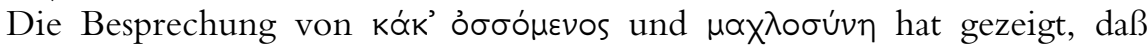
Aristarch auch bei der Untersuchung des Sprachgebrauchs sauber zwischen den Gepflogenheiten Homers und denjenigen seiner Nachfolger differenziert hat. Abgesehen von einem Plädoyer dafür, den Wortgebrauch möglichst aus dem Werk des betreffenden Autors abzuleiten, enthält dieser methodische Ansatz auch ein Bewußtsein dafür, daß die Bedeutung von Wörtern sich im Lauf der

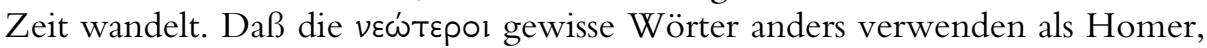
ist ein untrügliches Indiz für die historische Bedeutungsentwicklung von Wör-

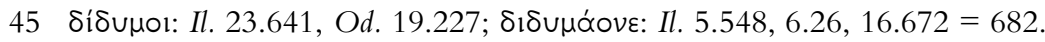

46 Schol. A Il. 11.750 (= fr. 26B Matthaios); Lehrs $(1882,175)$.

47 Lehrs $(1882,12)$, Stellensammlung bei Erbse (zu 1.106c). 
tern. Das mag aus heutiger Sicht eine selbstverständliche Erkenntnis sein. Sie verdient aber, an dieser Stelle hervorgehoben zu werden, weil die jüngere Forschung den griechischen Grammatikern keinen oder einen nur sehr schwach entwickelten Sinn für Sprachgeschichte attestiert (zuletzt Lallot 2011). Eine eingehende Auseinandersetzung mit dieser Auffassung soll an anderer Stelle erfolgen (Nünlist im Druck). Im vorliegenden Zusammenhang muß die Feststellung genügen, daß die weitgehende Indifferenz gegenüber historischer Sprachentwicklung für Aristarch in dieser Form nicht gilt. Dabei geht es nicht nur um die Entwicklung von Wortbedeutungen, sondern erstreckt sich, wie zu zeigen sein wird, auch auf die Bereiche Morphologie und Syntax. Der vorliegende Beitrag richtet sein Augenmerk auf die historische Entwicklung von Bedeutungen. Aristarch setzt nämlich den Wortgebrauch Homers nicht nur von dem der $v \varepsilon \omega ́ t \varepsilon \rho o l ~ a b$, sondern grenzt ihn - wo nötig - auch vom zeitgenössischen Sprachgebrauch, der sogenannten $\sigma u v \eta \dot{n} \theta \varepsilon ı \alpha, a b .{ }^{48}$

$\mathrm{Da}$ hier ein echtes Verständnisproblem lauert, wird unmittelbar klar, wenn man z.B. mit Schülern einen älteren Text liest. Wenn in einem 1828 geschriebenen Theaterstück ein Soldat zu einem anderen sagt "[ich will] ein wenig mit euch kosen", dann ist das Gepruste unter den Schülern wohl unvermeidlich. ${ }^{49}$ Das Beispiel ist insofern schlecht gewählt, als dem (muttersprachlichen) Leser auf Anhieb klar werden dürfte, daß der Soldat schwerlich einen homoerotischen Annäherungsversuch unternimmt. Die Sache ist hinterhältiger, wenn die zeitgenössische Bedeutung nicht a priori ausgeschlossen ist. In dem Fall ist die Gefahr größer, daß man aufgrund des eigenen Sprachgebrauchs in die Irre geführt wird und zu einer Fehldeutung gelangt. (Vergleichbar sind die faux amis beim Lesen einer Fremdsprache.) Auf diesem Hintergrund erschließt sich einem die didaktisch inspirierte Funktion einer ganzen Reihe von Scholien, in denen Aristarch erklärt, daß Homer das Wort 'nicht wie wir' (oủX ஸ́s ìneĩs), also nicht wie ein Grieche des 2. Jahrhunderts v. Chr. verwendet. Das gilt zum Beispiel für das Adverb $\sigma \chi \varepsilon \delta o ́ v$, das Homer lokal im Sinne von દ̇ $\gamma \gamma$ ús ('nahe') verwendet, 'nicht wie wir', die damit einen Zweifel zum Ausdruck bringen ('beinahe, fast')..$^{50}$

Besonders interessant wird es, wenn Aristarch sich in dieser Frage mit anderen Erklärern auseinandersetzt. Zum Beispiel verwirft er Zenodots Textän-

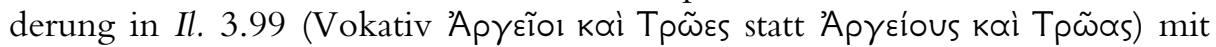

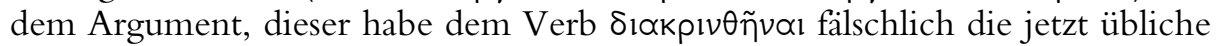
Bedeutung gegeben (also 'entschieden werden'). ${ }^{51}$ In Wahrheit bedeute es bei

48 Dimpfl (1911, 19-38), vgl. Anm. 5.

49 Aus der Anfangsszene des Trauerspiels König Yngurd von A. Müllner (1828), zitiert nach Weimar $(1993,168)$.

50 Schol. A Il. 17.202a (= fr. 160 Matthaios), Lehrs (1882, 91), Dimpfl (1911, 20); vgl.

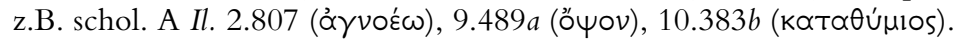

51 Schol. A Il. 3.99a; Lehrs (1882, 148), Dimpfl (1911, 9). 
Homer aber 'getrennt werden'. Zenodot hätte demzufolge übersehen, daß das Verb eine signifikante Bedeutungsentwicklung hinter sich hat. ${ }^{52}$

Damit ist geklärt, daß Aristarch ein Bewußtsein für die historische Bedeutungsentwicklung hatte. ${ }^{53}$ Er grenzte die Sprache Homers regelmäßig von derjenigen der $v \varepsilon \omega ́ \tau \varepsilon p o l$ oder der hellenistischen Zeitgenossen ab. ${ }^{54}$ Somit ist eine Rückkehr zum Thema möglich, das oben bereits mit Verben wie $\theta \propto u \mu \alpha ́ \zeta \omega$ oder $\sigma \tau \cup \gamma \varepsilon \dot{\epsilon} \omega$ illustriert wurde, deren Bedeutungsvielfalt Aristarch erkannte und beschrieb. Dazu treten jetzt Beispiele, wo er nicht nur innerhalb des gleichen Wortes einen signifikanten Bedeutungsunterschied ausmachte, sondern diesen gewissermaßen in einen sprachhistorischen Rahmen stellte. Bei der

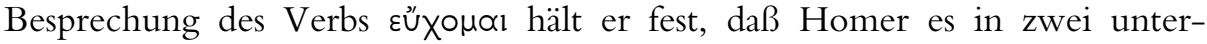

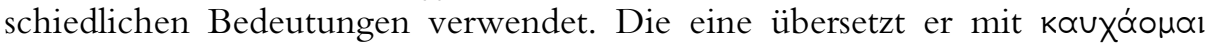

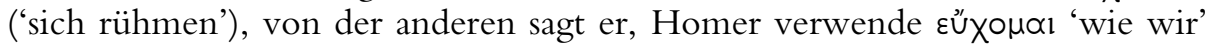

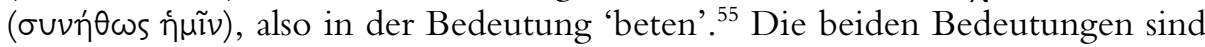
insofern nicht gleichwertig, als die eine nach wie vor gebräuchlich ist, während die andere inzwischen obsolet ist. Hier liegt der Keim zu einem Wörterbuchartikel, der sowohl inhaltlich als auch chronologisch gegliedert ist, wobei in dem Fall eher an ein Lexikon wie das von Liddell-Scott-Jones zu denken ist. Das gleiche gilt letztlich auch für Aristarchs Kommentar zur Verwendung von óm $\pi \varepsilon \lambda \varepsilon^{\prime} \omega$ in Il. 9.682. ${ }^{56}$ Wenn er betont, daß Homer 'an dieser Stelle' (vũv) das

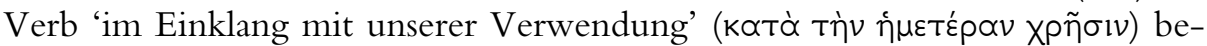
nutzt (also im Sinn von 'drohen'), ist damit impliziert, daß er das gleiche Verb auch anders verwendet. Die Bestätigung liefern zwei weitere Scholien. ${ }^{57}$ Das

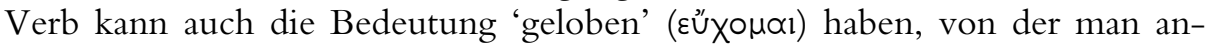
nehmen darf, daß sie im 2. Jahrhundert nicht mehr gebräuchlich war.

Wie schon mehrfach deutlich wurde, kommen Aristarchs Deutungskategorien immer wieder nur implizit zum Ausdruck. Das gilt auch für die historische Bedeutungsentwicklung. Nach dem Zeugnis von Apollonios Sophistes (131.6-7, 165.9-10) vertrat Aristarch die Ansicht, Homer habe das

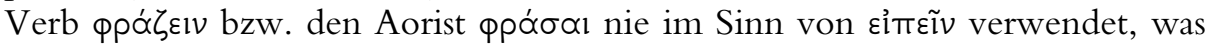
bedeuten muß, daß andere Autoren das tun. An der zweitgenannten Stelle

52 Das ist Aristarch zufolge die eigentliche Ursache für Zenodots Textänderung. Von der hellenistischen Bedeutung des Verbs ausgehend, vermochte er die Akkusative nicht als Subjekt einer AcI-Konstruktion zu erkennen.

53 Er teilt dieses Interesse mit seinem Vorgänger Aristophanes von Byzanz (Pfeiffer 1968, 198-200). Beim Versuch, gewisse Übertreibungen zurechtzurücken, schießt Callanan (1987, 79-82) seinerseits übers Ziel hinaus, wenn er Aristophanes jegliches Bewußtsein für Diachronie abspricht; s. z.B. fr. 368 Slater.

$54 \mathrm{Daß}$ die Sprache der $v \varepsilon \omega ́ t \varepsilon p o l$ nicht einfach mit der der hellenistischen Zeitgenossen gleichgesetzt wird, zeigen Kommentare wie schol. A Il. 9.219b, 16.336a ${ }^{1}$.

55 Schol. A Il. $21.183 b$ und 10.461c, vgl. 5.121, 8.526a, 19.100a, 21.183b, 21.501b; Lehrs (1882, 146).

56 Schol. A Il. 9.682; Lehrs $(1882,146)$.

57 Schol. A Il. $23.863 b$ und 23.872 . 
wird deutlich, daß Aristarch deswegen einen Vers athetierte. ${ }^{58}$ Der chronologische Aspekt des Arguments bleibt implizit.

Als ergänzende Anmerkung sei erwähnt, daß selbst dann Mißverständnisse auftreten können, wenn Aristarch diesen Aspekt ausdrücklich erwähnt. So

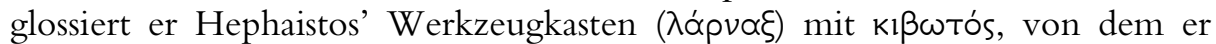

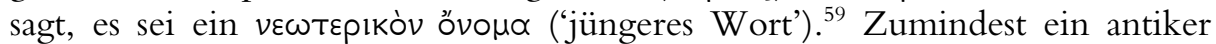
Erklärer hat diese Erklärung mißverstanden (schol. T Il. 24.228b ${ }^{1}$ ex.). Er rügt Aristarch dafür, übersehen zu haben, daß sowohl Simonides (fr. 623 PMG) als auch Hekataios (FGrH 1 F 368) das Wort verwendeten. Die Kritik schießt

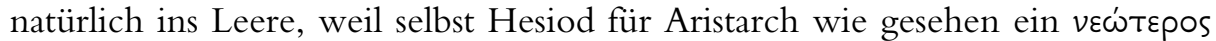
ist. Gleichzeitig ist sie ein Indiz dafür, daß der Begriff mit der Zeit eine Bedeutungsänderung erfahren hat.

Als weiteres, wenn auch sehr selten benutztes Unterscheidungskriterium läßt sich in Aristarchs Worterklärungen auch die Kategorie 'Dialekt' nachwei-

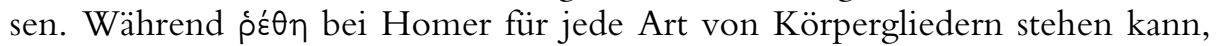

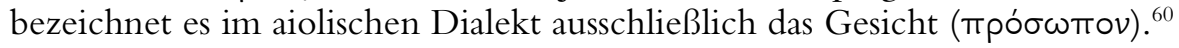

Eine dieser auf den Dialekt bezogenen Erklärungen gibt ein kleines Rätsel auf. Aristarch (schol. A Il. 17.112a) zufolge verwendet Homer das Wort $\mu \varepsilon ́ \sigma \sigma \alpha \cup \lambda o s$ anders als of Atтıкоí, d.h., anders als im attischen Dialekt üblich. Dort bezeichnet es die Tür, die vom Innenhof in die inneren Gemächer führt. Die festgestellte Diskrepanz ist insofern merkwürdig, als Aristarch Homer ja für einen Athener hielt, was er in erster Linie aus dessen Sprache (Formen und Wörtern) ableitete (Pfeiffer 1968, 228). Einen möglichen Ausweg aus dem Dilemma bietet eine Übernahme von Lehrs' Kommentar $(1882,100) \mathrm{zu}$ Aristarchs Erklärung von $\gamma \varepsilon \gamma \omega v \varepsilon$ é (schol. A Il. 8.223). Demnach hätte Aristarch erkannt, daß die attische Tragödie das Verb fast durchweg in der Bedeutung 'sprechen' verwendet (Wackernagel 1916, 156), während es bei Homer noch 'sich durch lautes Rufen vernehmbar machen' bedeutet. In Analogie dazu hätte Aristarch aufgrund von Stellen bei Euripides (Alc. 549) oder

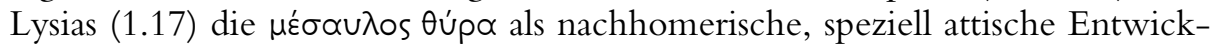
lung empfunden. Die Deutung muß natürlich Hypothese bleiben, zumal das Beispiel isoliert dasteht. Insgesamt bleibt das Feststellen einer nicht-attischen Verwendung beim 'Athener' Homer seltsam.

In seinen Studien zum Homerischen Vokabular wurde Aristarch notgedrungen auch mit der Frage konfrontiert, inwiefern sich die Bedeutungen von Wörtern überschneiden. Sie kommt in mindestens zwei Erklärungstypen zum Ausdruck. Zum einen betreibt Aristarch gewissermaßen Wortfeldunter-

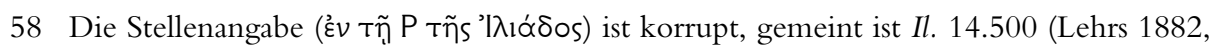
84). Auffällig ist, daß das Scholion zur Stelle diesen Athetesengrund nicht ausdrücklich erwähnt, sondern lediglich die (angebliche) Tautologie moniert, was von schol. A Il. 18.253 ex. zurückgewiesen wird (Erbse z.St.).

59 Schol. A Il. 18.413a; Lehrs $(1882,149)$.

60 Schol. A Il. 16.856b, vgl. 22.68a und Montanari in diesem Band. 
suchungen. So unterscheidet er beispielsweise zwei Arten, einen Menschen zu verfolgen. Wenn der Verfolgte weiß, daß er jemanden im Nacken hat, benutzt

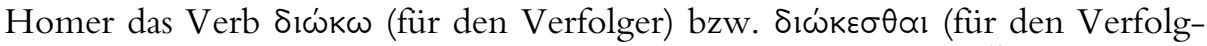

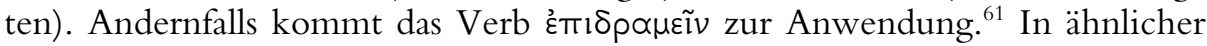

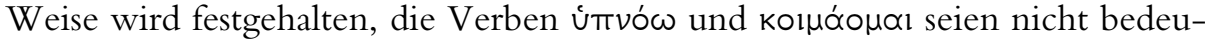
tungsgleich. Das eine bedeute 'schlafen', das andere 'sich schlafen legen' (ohne dabei notwendig den Schlaf zu finden). ${ }^{62}$ Besonders komplex sind seine Ausführungen zum vielleicht wichtigsten Wort der Ilias überhaupt, $\mu \tilde{\eta} v ı$. Die Komplexität resultiert daraus, daß Aristarch an einigen Stellen einen Unterschied zwischen $\mu \tilde{\eta} v 1 s$ und Xódos erkennen will, an anderen dagegen von Synonymie spricht. ${ }^{63}$ Das Rätsel harrt noch einer überzeugenden Lösung. ${ }^{64}$

Zumindest eine der fraglichen Stellen kann befriedigend erklärt werden und enthält gleichzeitig den zweiten Erklärungstyp. Die für die Homerische Sprache typische Verbindung zweier sinnverwandter Wörter, hier xó

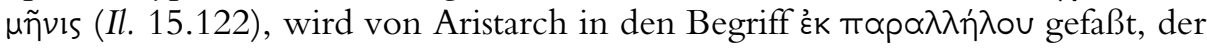
hier und anderswo das beschreibt, was wir im Basler Kommentar "synonymische Doppelung" nennen. ${ }^{65}$

Bis hierher ist in erster Linie davon die Rede gewesen, nach welchen Kriterien Aristarch das Wortmaterial untersucht hat. Nicht weniger wichtig ist die Frage, wie er konkret vorgegangen ist, wenn er die Bedeutung eines Wortes zu ermitteln suchte. Plakativ ausgedrückt: Woher weiß er, daß das Wort sound-so $X$ bedeutet? Es wird sich von selbst verstehen, daß diese Frage mit den zur Verfügung stehenden Mitteln nicht abschließend beantwortet werden kann. Dennoch können zumindest Hypothesen aus dem vorhandenen Material abgeleitet werden.

$\mathrm{Da} \beta$ Aristarch als Muttersprachler grundsätzlich in einer besseren Position war als ein heutiger Homerleser, versteht sich von selbst. Freilich haben die bereits besprochenen Beispiele gezeigt, daß das nicht immer weiterhalf oder gelegentlich sogar von Nachteil sein konnte.

Bereits dokumentiert ist der Versuch, die Bedeutung eines Wortes aus der Etymologie abzuleiten und/oder eine Grundbedeutung zu eruieren.

Außerdem spricht einiges dafür, daß Aristarch das entsprechende Wortmaterial systematisch, in bestimmten Fällen vielleicht sogar vollständig durchgearbeitet hat. Ein erstes Indiz ist die Häufigkeit, mit der die Bedeutung bestimm-

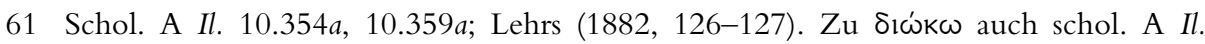
$8.439 a, 22.158 a$.

62 Schol. A Il. 7.482a; Lehrs $(1882,114)$.

63 Unterschied: schol. A Il. 4.513a (mit ausdrücklichem Bezug speziell auf Achill), 9.261b, 19.67b, 24.395. Synonymie: schol. A Il. 15.122a, 16.30b, 16.62a, 23.543b.

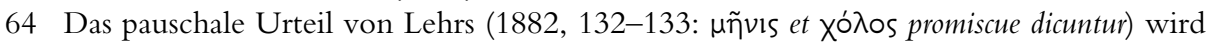
den Stellen, die einen Bedeutungsunterschied postulieren (und ihm durchaus bekannt sind), kaum gerecht.

65 Schol. A Il. 15.122a, vgl. 1.99a (mit Stellensammlung im Testimonienapparat). Synonymische Doppelung: BK zu Il. 1.160. 
ter Wörter im Lauf des Kommentars in Erinnerung gerufen wird. Ein paar konkrete Zahlen mögen das belegen. Die Bedeutung des Worts móvos ('Mühe, Arbeit, Mühsal') bzw. des Verbs по véoual wird in den erhaltenen Aristonikos-Scholien zur Ilias mindestens $17 \mathrm{Mal}$ kommentiert. Das Verb $\mu \dot{\varepsilon} \lambda \lambda \omega$ ('alles deutet darauf hin, daß ich...') $20 \mathrm{Mal}$, das Substantiv póßos (Aristarch zufolge 'Flucht') $37 \mathrm{Mal}$, das Verb $\beta \alpha \dot{\alpha} \lambda \lambda \omega$ ('werfen, treffen') sogar ungefähr 60 Mal. ${ }^{66}$ Selbstverständlich sind die jeweiligen Wörter noch häufiger belegt. Aber die Anzahl der einschlägigen Scholien spricht doch sehr für die Annahme einer systematischen Untersuchung. In dem Zusammenhang ist daran zu erinnern, daß Aristarch auch andere Phänomene systematisch gesammelt hat: hapax legomena; Stellen, an denen der Name Ilios ein Femininum sein muß; Stellen, aus denen hervorgeht, daß der Olymp ein Berg ist; gleichnamige Figuren wie Eurybates, usw. ${ }^{67}$ Bei diesem Vorgehen konnte es nicht ausbleiben, daß Aristarch bei der Erklärung von Wörtern auch auf Ausnahmen (tatsächliche und scheinbare) stieß ${ }^{68}$

Die Systematik seiner Arbeitsweise läßt sich nicht nur an der Häufigkeit der einschlägigen Notate ablesen, sondern auch an ihrer Dichte. Diese kann wiederum am Beispiel Tóvos/Trovéoual dokumentiert werden, das wie erwähnt 17 Mal kommentiert wird. Eines davon ist das Scholion zum Vers Il.

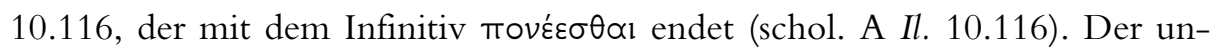

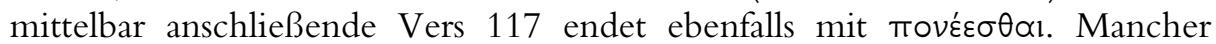
Kommentator dürfte versucht sein, in einem solchen Fall auf die inferentiellen Fähigkeiten der Leser zu setzen und das Wort kein zweites Mal zu kommentieren. Nicht so Aristarch, der auch Vers 117 mit einer diplê markierte. Allerdings schreibt Aristonikos (schol. A Il. 10.117) schlicht 'aus dem gleichen

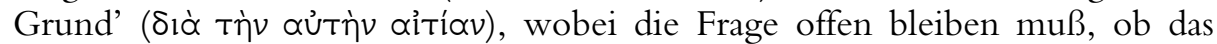
bereits in Aristarchs Kommentar so stand. ${ }^{69}$ Die Kommentierungsdichte deutet also ebenfalls auf vollständige Stellenerfassung, die wiederum das Vertrauen der

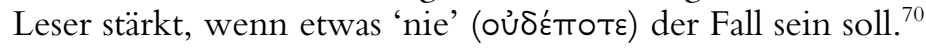

Beim Durcharbeiten dieses Materials scheint Aristarch besonders auf Stellen geachtet zu haben, aus denen die Bedeutung des untersuchten Wortes zweifelsfrei hervorgeht. Zur Illustration sei für einmal ein Beispiel gewählt, wo

66 Sämtliche Belege aufzuführen führte an dieser Stelle zu weit, weshalb nur auf die einschlägigen (wenn auch nicht ganz vollständigen) Stellensammlungen bei Erbse hinge-

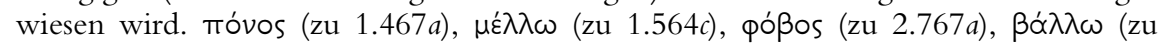
4.540).

67 hapax legomena: s. Anm. 47; Ilios: schol. A Il. 3.305 b (mit Stellensammlung); Olymp: Nünlist (2011, 113, mit Lit.); gleichnamige Figuren: Nünlist (2009, 240-242).

68 Schol. A Il. 16.467b; Lehrs (1882, 53-54).

69 Vergleichbar ist זpòs tò aủTó in schol. A Il. 22.239 mit Bezug auf den Kommentar zu

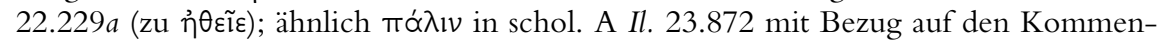

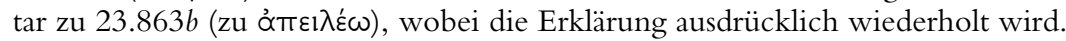

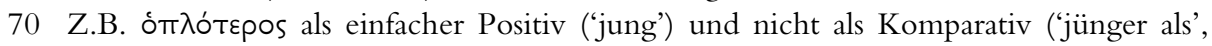
schol. A Il. 4.324-5; Lehrs $(1882,179)$. 
er sich nach moderner Auffassung geirrt hat. Das Verb $\chi \omega \dot{\circ} \mu \propto \propto \mathbf{l}$ wird heute im allgemeinen als 'in Zorn geraten' gedeutet (LfgrE s.v.). Aristarch dagegen glos-

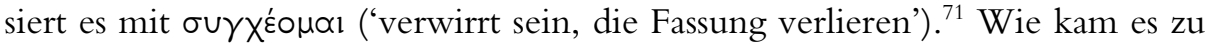
dieser Fehldeutung? Lehrs $(1882,144)$ vermutet, Aristarch sei das Opfer einer falschen Etymologie. Gemessen an Aristarchs gut dokumentiertem Interesse an Etymologie ist das plausibel. Freilich wird in keinem der insgesamt sieben Aristonikos-Scholien ausdrücklich darauf verwiesen. Es ist somit berechtigt, eine andere Erklärung in Erwägung zu ziehen. In einem der fraglichen Scholien (schol. A Il. 21.519a) findet sich das Wort $\sigma \alpha \phi \tilde{\omega} s$ ('klärlich, offensichtlich'). Zumindest an dieser Stelle scheint die Bedeutung, Aristarch zufolge, unzweifelhaft zu sein. Im Homertext wird hier der Götterkampf abgeschlossen. Apollon geht nach Troia, die anderen Götter zurück auf den Olymp: oi $\mu \dot{v} v$

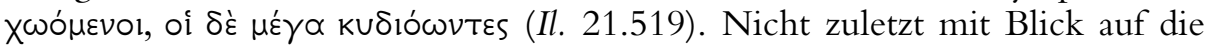
$\mu \varepsilon^{\prime} \nu$ - $\delta$-́-Konstruktion könnte Aristarch hierin einen Gegensatz gesehen haben. Die siegreichen Götter sonnen sich in ihrem Erfolg, die anderen sind konsterniert. Damit war für ihn die Bedeutung des Wortes gesichert und konnte auf die anderen Stellen übertragen werden. Mit anderen Worten: In Ilias 21.519 glaubte Aristarch das zu erkennen, was er anderswo einen tótтos $\delta 1 \delta \propto \sigma \kappa \propto \lambda$ lkós nennt. Die Stelle lehrt, wie die zur Diskussion stehende Frage gedeutet werden muß. Ausdrückliche Hinweise auf den тóтоos $\delta_{1} \delta \propto \sigma \kappa \propto \lambda_{\mathfrak{l}}$ ós sind sehr selten. Die Vorgehensweise als solche findet sich dagegen immer wieder und kann u.a. durch $\sigma \propto \phi \tilde{\omega} s$ angezeigt werden. ${ }^{72}$

Dafür noch ein zusätzliches Beispiel, an dem sich zwei weitere Aspekte von Aristarchs Methode aufzeigen lassen. Bei der Besprechung von móvos in Il. 22.11 argumentiert er (schol. A Il. 22.11a), die Bedeutung ơ $\lambda \gamma \eta \delta \omega \nu$ ('Schmerz') passe an dieser Stelle $\sigma \alpha \phi \tilde{\omega} s$ nicht. Er unterstreicht das dadurch, daß er die beiden Varianten ausführlich paraphrasiert. Apollon könne hier doch nicht zu Achill sagen 'du kümmerst dich nicht um den Schmerz der

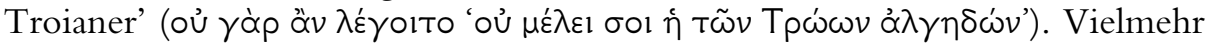
sage er 'du kümmerst dich nicht darum, dich hinsichtlich der Troianer anzu-

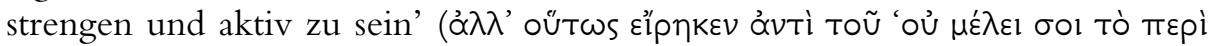

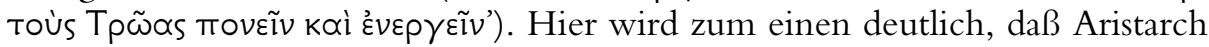
genau auf den jeweiligen Kontext achtet und diesen bei seiner semasiologischen Analyse stark einbezieht. ${ }^{73}$ Besonders klar tritt dieses Prinzip in seiner Aufforderung zum 'close reading' hervor (schol. A Il. 14.84a: દis тฑ่v

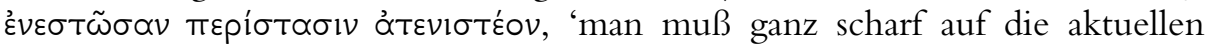
Umstände [sc. der beschriebenen Szene] achten'). Zum anderen kommt in der Paraphrase auch ein didaktischer Impetus zum Ausdruck. Durch die direkte Gegenüberstellung der beiden 'Übersetzungen' wird besonders anschaulich

71 Schol. A Il. 13.165a (mit Erbses Stellensammlung).

72 Dazu und allgemein zum tómos $\delta ı \propto \alpha \kappa \propto \lambda ı$ ı́s Nünlist (2012).

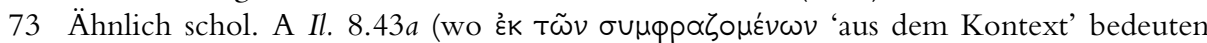
dürfte, vgl. schol. A Il. 19.149a). 
vorgeführt, welcher von beiden der Vorzug zu geben ist. Einer ähnlichen Intention dürften auch einige der zahlreichen Erklärungen zuzuschreiben sein, die dem Muster 'das Wort so-und-so bedeutet nicht X, sondern Y' folgen. ${ }^{74}$ Man braucht daraus nicht immer den Schluß zu ziehen, daß jemand die abgelehnte Bedeutung tatsächlich verfochten hat und die Erklärung somit polemisch ist. Zumal wenn keine Gewährsperson wie Zenodot oder die Glossographen genannt ist, sollte man zumindest die Möglichkeit erwägen, daß es sich einfach um eine didaktische Präsentationsweise handelt. 'Das Wort sound-so bedeutet nicht, wie man vielleicht denken könnte, X, sondern Y. ${ }^{75}$

Dieses Verfahren des Nebeneinanderstellens findet sich z.B. auch dann, wenn Aristarch semantisch verwandte Wörter zueinander in Beziehung setzt bzw. voneinander abgrenzt wie in den bereits besprochenen Wortfeldanalysen. Leicht anders gestaltet es sich bei den Wörtern, deren Bedeutung zweifelhaft

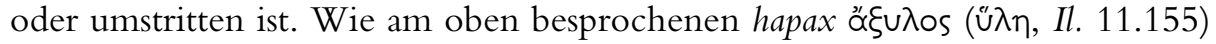
ersichtlich, werden die zur Verfügung stehenden Deutungsmöglichkeiten nacheinander durchgesprochen. Als letzte folgt diejenige, der Aristarch den Vorzug gibt (eingeleitet durch $\beta \hat{\varepsilon} \lambda{ }_{T 10 v}$ ). Daneben gibt es auch mehrere Fälle, wo es bei der Aufzählung von Möglichkeiten bleibt und Aristarch offenbar auf eine Entscheidung verzichtet hat. ${ }^{76}$

Eine weitere Gegenüberstellung kann sich aus konträren Konnotationen ergeben, die das gleiche Wort haben kann. So kommt es, daß das Wort

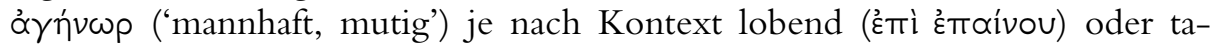

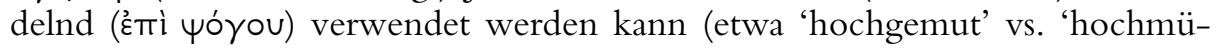
tig'). ${ }^{77}$

Eine andere Zweiteilung betrifft die aktivische oder passivische Deutung von Adjektiven wie ơ $\mu \eta \dot{x} \propto$ vos als 'der kein Mittel findet' bzw. 'gegen den man

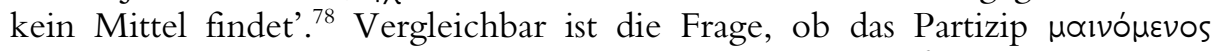
kausativ ist oder nicht ('in Rasen versetzend' oder 'rasend'). ${ }^{79}$

Das Ziel, seinen Lesern den Homertext so gut wie möglich zu erschließen, brachte es mit sich, daß Aristarch sich auch dem Problem der Homonymie stellen mußte. Das vielleicht eindrücklichste Beispiel sind die Einträge, die sich

74 Z.B. schol. A Il. 3.395a, 4.232, 8.223, 8.239a.

75 Anders sieht es aus, wenn Aristarch eine bestimmte Bedeutung ablehnt, weil sie dem Homerischen Gebrauch widerspricht und somit einen Athetesengrund liefert, z.B. schol. A Il. 2.597 (mit Stellensammlung im Testimonienapparat), 7.161a (dito).

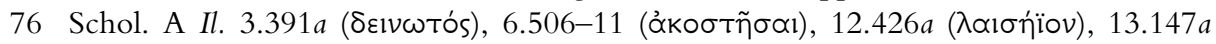

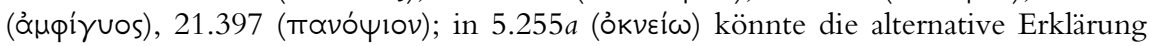
ein späterer Zusatz sein. Durch die genannten Beispiele wird die Auffassung von Römer (1924, 11, ähnlich 54-56) stark erschüttert, Aristarch habe "immer, wenn nur irgend möglich, entschieden".

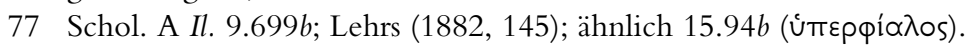

78 Schol. A Il. 15.14b, 16.29a; Lehrs (1882, 145-146). Der Text eines dritten Scholions (A Il. 10.167a) ist korrupt (Erbse im app. crit.).

79 Schol. A Il. 6.132a, 21.5b. 


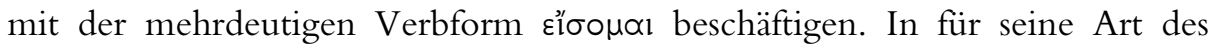
Kommentierens charakteristischer Weise erklärt Aristarch zum einen, daß

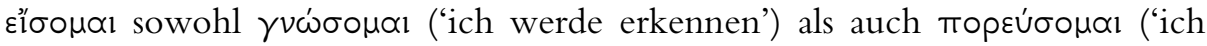
werde gehen') bedeuten kann, wobei klar wird, daß er Homonymie meint (und nicht Polysemie). ${ }^{80} \mathrm{Im}$ gleichen Scholion macht er darauf aufmerksam, daß die mit einem gewissen Verwechslungpotential ausgestattete Form عlø $\sigma$ To

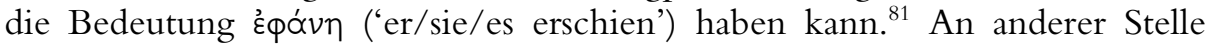

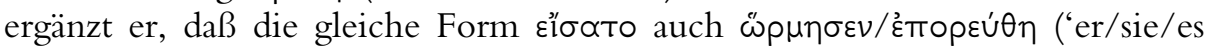
ging') bedeuten kann. ${ }^{82}$ Man sieht, wie Aristarch sich bemüht, die Verwechslungsgefahr nach Möglichkeit auszuschließen.

Das andauernde, zähe Ringen um das bestmögliche Textverständnis führte auch dazu, daß Aristarch sich gelegentlich veranlaßt sah, seine Meinung zu revidieren. Hatte er das Wort kpó $\sigma \propto \alpha$ (Bedeutung unsicher) im Kommentar noch mit $\kappa \varepsilon \phi \propto \lambda i \delta \varepsilon \varepsilon$ ('Zinnen') wiedergegeben, entschied er sich in der später

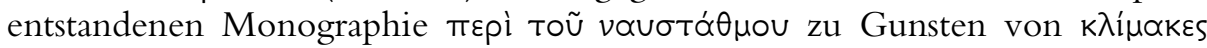
('Leitern'). ${ }^{83}$

Bekanntlich bekämpfte Aristarch die Auffassung der Chorizonten, wonach die Ilias und die Odyssee nicht vom gleichen Dichter stammten. Das hindert ihn aber nicht daran, auch Unterschiede zwischen den beiden Epen festzustellen. So hält er z.B. fest (schol. A Il. 10.338), ö $\mu$ ı入os bezeichne in Il. 10.338 die

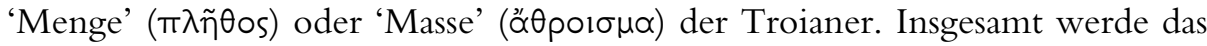
Wort in der Ilias aber häufiger für den 'Kampf ( $\mu$ óx $\chi)$ verwendet, in der Odyssee dagegen für die 'Menge'. Zwei Scholien zum verwandten Verb ó $\mu \lambda \lambda \dot{\varepsilon} \omega$ liefern eine Etymologie (ómoũ tòs ỉ $\lambda \propto s, \sigma v \mu \beta a ́ \lambda \lambda \lambda \varepsilon ı$, 'die Kampfhaufen zusam-

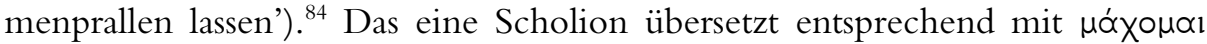
('kämpfen'). Das andere erwähnt, daß die Verwendung von ó $\mu \imath \lambda \varepsilon \dot{\varepsilon} \omega$ an dieser Stelle 'wörtlich' (kupíws) ist. Den Gedanken wird man so ergänzen dürfen, daß

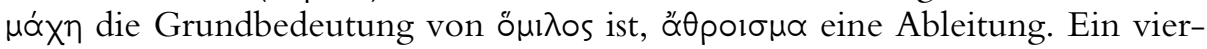

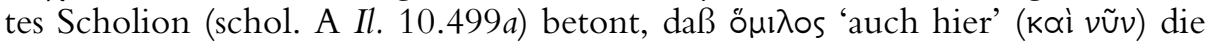
(wie gesehen ungewöhnliche) Bedeutung $\alpha^{\prime} \theta$ poı $\sigma \mu \alpha$ hat. Die Rede ist von Il. 10.499, weshalb 'auch hier' sicher auf den zuvor kommentierten Vers 10.338 $\mathrm{zu}$ beziehen ist. Wie dem modernen Homeriker kaum entgehen wird, sagt Aristarch offenbar nichts zum Umstand, daß die semantisch außergewöhnlichen Iliasstellen beide aus der 'Dolonie' stammen. Das LfgrE nennt die von Aristarch propagierte Etymologie als eine von zwei Möglichkeiten und enthält im Teil B eine vergleichbare Zweiteilung. Unter 1 sind die nicht-militärischen

80 Schol. A Il. 8.532; Lehrs $(1882,147)$. In schol. A Il. 21.335c wird Zenodot vorgewor-

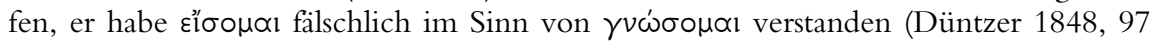
Anm. 19 meint, zu Unrecht).

81 Vgl. schol. A Il. 13.191a.

82 Schol. A Il. 12.118a, vgl. 15.544b (wo die Frage unentschieden bleibt), 21.424a, auch 13.45 c.

83 Schol. A Il. 12.258a, vgl. 12.375, 14.35a (= fr. 41 Schironi).

84 Schol. A Il. 11.502, 11.523. 
Verwendungen aufgeführt, unter 2 die militärischen, die weitestgehend von Belegen aus der Ilias dominiert werden.

Anzufügen ist eine weitere Beobachtung Aristarchs, die letztlich auf seinen Worterklärungen basiert. Er hat gesehen, daß scheinbar unpassende Epitheta (z.B. die 'glänzende' Kleidung, die Nausikaa waschen will, Od. 6.74) mit der Annahme verteidigt werden können, sie brächten eine allgemeine oder permanente Qualität zum Ausdruck und nicht die im gegenwärtigen Augenblick

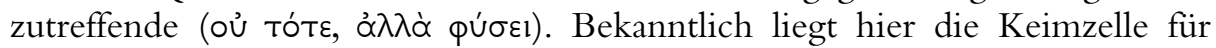
Parrys 'generic epithets'. ${ }^{85}$

Der vorliegende Beitrag geht im Einklang mit der communis opinio davon aus, daß Aristarchs Worterklärungen nicht im Rahmen eines lexikographischen Projekts entstanden sind. Aristarch schrieb kein Homerlexikon (Pfeiffer 1968, 220). Freilich gibt es ein Indiz, das dafür sprechen könnte, daß er über eine Art von 'index verborum' verfügte. In Ilias 10.226 verwendet

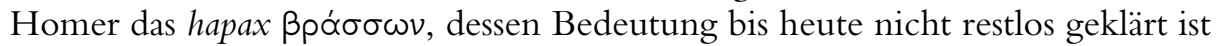
(LfgrE s.v.). In der Diskussion (schol. A Il. 10.226) setzt Aristarch sich kritisch mit der Deutung der Glossographen (fr. 7 Dyck) auseinander. Sie übersetzten

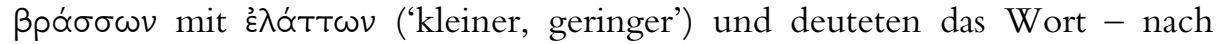
einer schlagenden Ergänzung Friedländers - als Komparativ von ßpaxús ('kurz'). Aristarch widersetzte sich dieser Deutung mit dem Argument, das Wort Bpaxús sei bei Homer nicht belegt. Davon einmal abgesehen, ob Aristarchs Argument als solches durchschlägt, ist er offenbar dazu in der Lage, korrekt darüber Auskunft zu geben, daß ein bestimmtes Wort bei Homer nicht belegt ist. ${ }^{86}$ Die übliche Erklärung lautet so, daß die alexandrinischen Gelehrten solche Angaben aufgrund ihrer profunden Kenntnis des Homertexts aus dem Gedächtnis zu machen imstande waren. ${ }^{87}$ Gewaltige Gedächtnisleistung und stupende Textkenntnis unterliegen keinem Zweifel, aber schließen sie tatsächlich mit ein, daß man auch die Wörter zu nennen vermochte, die bei Homer nicht belegt sind? Mit einer solchen Annahme stößt man an die Grenzen der Plausibilität. Umgekehrt ist die Vorstellung eines vollständigen 'index verborum' im Zeitalter der Buchrolle ebenfalls nicht unproblematisch. ${ }^{88}$ Als Kompromiß könnte man vielleicht an eine Spezialliste von bei Homer nicht belegten Wörtern denken, wofür es zwei indirekte Parallelen gibt. Die eine ist die mit Aristophanes' von Byzanz Namen verbundene Liste von Wörtern, die

85 Nünlist (2009, 300-301, mit Lit.).

86 Wenn Erbse (zu 3.36b) mit seiner Vermutung recht hat, daß Ep. Hom. $\propto 163$ Dyck und Hesych $\propto 462$ via Apollonios Sophistes von Aristonikos abhängen, hielt Aristarch den Glossgraphen (fr. 1 Dyck) das gleiche Argument in bezug auf óxí (= трофи́) entgegen.

87 Z.B. in der Diskussion im Anschluß an den Vortrag, der diesem Aufsatz zugrunde liegt.

88 In dem Zusammenhang ist immerhin anzumerken, daß die antike Verwendung von 'Zetteln' als zwischenzeitlichen Textträgern außer Frage steht (Dorandi 2000, 5-25). 
'im Verdacht stehen, bei den Alten nicht belegt zu sein' ${ }^{89}$ Die andere die später für Porphyrios nachweisbare Liste von Namen, die bei Homer fehlen. ${ }^{90}$

Angesichts der im vorstehenden dokumentierten Systematik, Sorgfalt und Scharfsinnigkeit von Aristarchs semasiologischen Untersuchungen (Lehrs 1882, 52) ist es kaum verwunderlich, daß seinen Erklärungen zum Teil eine beträchtliche Nachwirkung beschieden war. Besonders berühmt ist seine Feststellung, Homer verwende das Wort $\sigma \tilde{\omega} \mu \alpha$ ausschließlich für den toten Körper (Ap. Soph. 148.23-26). Bekanntlich liegt hier einer der Ausgangspunkte für Snells Auffassung vom Menschenbild Homers. ${ }^{91}$ Diese wird im Beitrag von A. Schmitt kritisch gewürdigt, weshalb an dieser Stelle nur zwei kleine Ergänzungen anzubringen sind. Zum einen hat Snell übersehen, daß bereits in der Antike Kritik an Aristarchs Auffassung geäußert und Homerstellen vorgelegt wurden, an denen $\sigma \tilde{\omega} \mu \alpha$ einen lebendigen Körper bezeichnet. ${ }^{92}$ Entscheidend jedoch ist das zweite Versäumnis. Zwei Aristonikos-Scholien machen deutlich, daß das von Snell angewandte Erklärungsprinzip quod non est in verbo, non est in mundo durchaus nicht Aristarchs Zustimmung gefunden hätte. In beiden Scholien geht es um das gleiche Phänomen. ${ }^{93}$ Im Homertext ist jeweils davon die Rede, daß eine Göttin, Hera bzw. Aphrodite, sich bei der Toilette mit duftendem Öl einreibt (Il. 14.170-172, 23.186-187). Homer, so argumentiert

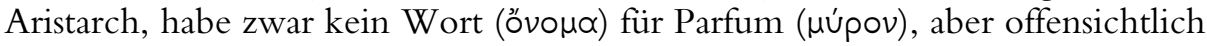
kenne er dessen Gebrauch ( $\chi p \tilde{\eta} \sigma ı)$ ). Inhaltlich ist hier von einer Trivialität die Rede, aber methodisch gesehen sind die beiden Scholien von großer Bedeutung. Nur weil ein Autor ein bestimmtes Wort nicht benutzt, muß das noch lange nicht bedeuten, daß er die dahinterstehende Konzeption nicht kennt.

Zusammenfassend kann man sagen, daß Aristarch bei seinen Worterklärungen systematisch vorging. Er versuchte - gegebenenfalls unter Einbezug der Etymologie und/oder in Auseinandersetzung mit anderslautenden Erklärungen - eine Grundbedeutung zu eruieren. Diese hatte sich, je nachdem, in verschiedene Richtungen weiterentwickelt, denen er ebenfalls nachging. Ungeachtet der Annahme einer Grundbedeutung kam dem jeweiligen Kontext der zur Diskussion stehenden Belegstelle eine wichtige Rolle zu. Das Studium der Bedeutungsvielfalt schloß auch Fälle von Synonymie (Wortfelduntersuchung) und Homonymie ein. Das Resultat der Untersuchungen wurde gegebenenfalls begründet und mit Parallelen gestützt. Ausschlaggebend war in erster Linie der Gebrauch des fraglichen Autors, wobei Aristarch auch den von anderen Autoren einbezog und sei es nur, um die Unterschiede herauszustreichen. Dabei

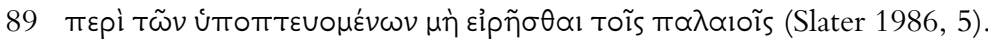

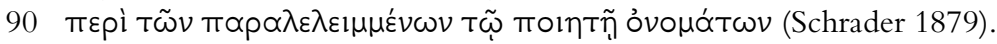

91 Snell $(1986,16)$. Ein gleichartiges Argument bildet die Basis für die berühmte Debatte um den Text von Il. 1.5 (Lehrs 1882, 87).

92 Erbse im Testimonienapparat zu Il. 3.23. Ein Reflex der Debatte findet sich auch in schol. A. PV 351b, das betont, 'dieser Dichter' verwende $\delta$ '́uas für den unbelebten Körper (gemeint ist: anders als Homer).

93 Schol. A Il. 14.172 $c^{1}, 23.186 a$. 
waren auch sprachhistorische Erwägungen von Belang, die bis in seine eigene Zeit hinunterführten. Namentlich machte er die zeitgenössischen Leser auf Übereinstimmungen mit und Abweichungen von ihrem eigenen Sprachgebrauch aufmerksam. In schwierigen oder strittigen Fällen studierte er nicht nur wie sonst eine möglichst große Anzahl von Belegen, sondern richtete sein Augenmerk auf die Stellen, aus denen die (Grund-)Bedeutung sich zweifelsfrei ableiten ließ. Die Sichtung sämtlicher Belege förderte auch die eine oder andere Ausnahme zutage. In einigen schwierigen Fällen verzichtete Aristarch auf eine Entscheidung und beschränkte sich auf die Aufzählung von möglichen Erklärungen. Aristarch ging also vielfach nach ähnlichen Prinzipien vor wie die moderne Lexikographie, ohne deshalb immer zum gleichen Resultat zu gelangen. Somit wird man sich am Ende die Frage stellen müssen, ob man am gleichen Punkt gelandet ist, an dem Lehrs sich bereits vor fast 180 Jahren befand. Die Antwort lautet 'nicht ganz'. Anders als bei Lehrs sind Aristarchs Prinzipien nicht mehr oder weniger stillschweigend vorausgesetzt worden. Statt dessen ist der Versuch unternommen worden, Belege anzuführen, aus denen sich seine Arbeitsweise bei der Erklärung von Wörtern ableiten läßt.

\section{Bibliographie}

Callanan, Ch.K., Die Sprachbeschreibung bei Aristophanes von Byzanz (Göttingen 1987).

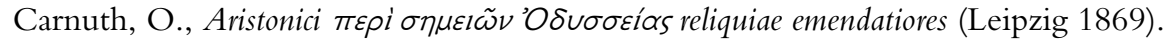

Denniston, J.D., The Greek Particles (Oxford $\left.{ }^{2} 1954\right)$.

Dickey, E., Ancient Greek Scholarship: A Guide to Finding, Reading, and Understanding Scholia, Commentaries, Lexica, and Grammatical Treatises, from Their Beginnings to the Byzantine Period (Oxford 2007).

Dimpfl, Ch., Beiträge zu Aristarchs homerischer Wortforschung (Eichstätt 1911).

Dorandi, T., Le stylet et la tablette: Dans le secret des auteurs antiques (Paris 2000).

Düntzer, H., De Zenodoti studiis Homericis (Göttingen 1848).

Dyck, A., „The Glossographoi“, in: HSCPh 91, 1987, 119-160.

Erbse, H., Scholia Graeca in Homeri Iliadem, 7 Bde. (Berlin-New York 1969-1988).

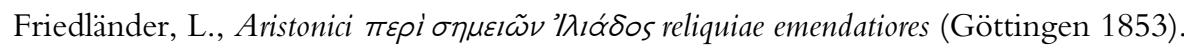

Hecht, M., Quaestiones Homericae (Königsberg 1882).

—, Zur Homerischen Semasiologie (Königsberg 1884).

—, „Zu Aristarchs Erklärung Homerischer Wortbedeutungen“, in: Philologus 46, 1888, 434-444.

Lallot, J., „Did the Alexandrian Grammarians have a Sense of History?“, in: S. Matthaios et al. (Hrsgg.), Ancient Scholarship and Grammar: Archetypes, Concepts and Contexts (Berlin-New York 2011) 241-250.

Lehrs, K., De Aristarchi studiis Homericis (Leipzig ${ }^{3} 1882$ ).

Lotz, E., Auf den Spuren Aristarchs (Erlangen 1909). 
Lundon, J., „POxy 1086 e Aristarco“, in: Atti del XXII congresso internazionale di papriologia, Firenze, 23-29 agosto 1998, Florenz 2001, 827-839.

Montanari, F., „The Fragments of Hellenistic Scholarship“, in: G.W. Most (Hrsg.), Collecting Fragments - Fragmente sammeln (Göttingen 1997) 273-288.

Nünlist, R., The Ancient Critic at Work: Terms and Concepts of Literary Criticism in Greek Scholia (Cambridge 2009).

-, „Aristarchus and Allegorical Interpretation“, in: S. Matthaios et al. (Hrsgg.), Ancient Scholarship and Grammar: Archetypes, Concepts and Contexts (Berlin-New York 2011) 107-119.

-, ,Topos didaskalikos and anaphora - two interrelated principles in Aristarchus' Commentaries", in: M.R. Niehoff (Hrsg.), Homer and the Bible in the Eyes of Ancient Interpreters (Leiden 2012) 113-126.

-, „A chapter in the history of Greek linguistics - Aristarchus' interest in language development", in: RhM 155, 2012 (im Druck).

Pfeiffer, R., History of Classical Scholarship: From the Beginning to the End of the Hellenistic Age (Oxford 1968).

Pontani, F., Scholia Graeca in Odysseam, vol. I: scholia ad libros $\alpha-\beta$ (Rom 2007).

Rijksbaron, A. (Hrsg.), New Approaches to Greek Particles (Amsterdam 1997).

Römer, A., „Zu Aristarch und den Aristonicusscholien der Odyssee“, in: Bayerische Blätter für das Gymnasialschulwesen 21, 1885, 273-293 u. 369-399.

-, ,Der angebliche Einheitlichkeits- und Gleichheitsfanatismus in der Homerexegese Aristarchs“, in: RhM 66, 1911, 275-317 u. 321-355.

—, Aristarchs Athetesen in der Homerkritik (wirkliche und angebliche) (Leipzig 1912).

—, Die Homerexegese Aristarchs in ihren Grundzügen, hg. v. E. Belzner (Paderborn 1924).

Schmidt, M., Die Erklärungen zum Weltbild Homers und zur Kultur der Heroenzeit in den bT-Scholien zur Ilias (München 1976).

—, „Hom. $\mu \tilde{\eta} \lambda \alpha$ und die antiken Erklärungen“, in: Glotta 57, 1979, 174-182.

Schrader, H., „Porphyrios bei Eustathios zur BOISTIA“, in: Hermes 14, 1879, 231-252.

Severyns, A., Le cycle épique dans l'école d'Aristarque (Liège 1928).

Slater, W., Aristophanis Byzantii fragmenta (Berlin-New York 1986).

Snell, B., Die Entdeckung des Geistes: Studien zur Entstehung des europäischen Denkens bei den Griechen (Göttingen ${ }^{6} 1986$ ).

van der Valk, M., Researches on the Text and Scholia of the Iliad, 2 Bde. (Leiden 19631964).

Wackernagel, J., Sprachliche Untersuchungen zu Homer (Göttingen 1916).

Weimar, K., Enzyklopädie der Literaturwissenschaft (Tübingen-Basel ${ }^{2} 1993$ ). 


\title{
Odysseus bei den Phäaken - Studien zur Heimkehrerhandlung in den Apologoi der Odyssee
}

\author{
GYBURG RADKE-UHLMANN
}

\section{Die Heimkehr des Odysseus und die Einheit der Handlung}

Die Erzählung vom Aufenthalt des Odysseus auf der Insel der märchenhaften Phäaken nimmt nicht weniger als sieben Gesänge, also mehr als ein Viertel des gesamten Epos ein. Die Erzählungen des Odysseus am Hof des Alkinoos wiederum umfassen insgesamt mehr als 1400 Verse. Die Episode aber ist freilich nicht nur quantitativ für das Gesamtepos von Bedeutung und Wichtigkeit, sondern auch qualitativ. Denn Odysseus' Aufenthalt auf Scheria ist eine Schlüsselstation für das Ziel seines Handelns: Hier entscheidet es sich endgültig, ob und wie bald der ewige Heimkehrer Odysseus nach Ithaka zurückkehren wird, ob er zurückkehren kann und ob er noch rechtzeitig zurückkehren kann, um die Situation, die sich auf Ithaka drastisch zugespitzt hat, aufklären und zu einem glücklichen Ende führen zu können.

Wie der von Rudolf Führer besorgte Artikel im Lexikon des frühgriechischen Epos ${ }^{1}$ klar herausarbeitet, ist der Nostos, die glückliche, gelingende Heimkehr, in der Odyssee nicht nur ein Gegenstand, über den als Teil der Handlung gesprochen wird, sondern mehr noch ein Gegenstand, über den nachgedacht, der erhofft, ersehnt und betrauert wird, der die Gedanken der Handelnden und ihre Absichten und Ziele beherrscht. Ich erinnere an die Verse, in denen der Zuhörer Odysseus zum ersten Mal in der Odyssee begegnet:

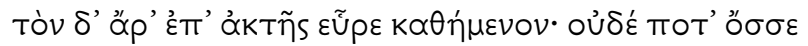

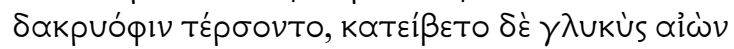

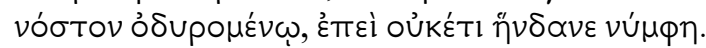

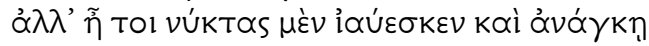

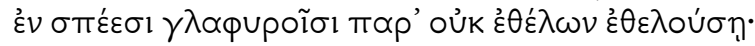

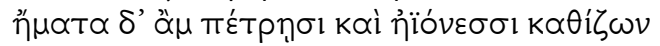

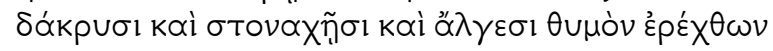

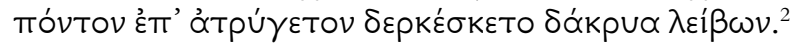

1 Rudolf Führer, Art. ,Nostos', begr. von Bruno Snell und hrsg. vom Thesaurus Linguae Graecae, in: LfrE, 2004, Sp. 432-435.

2 Der griechische Text folgt der von Thomas W. Allen besorgten OCT-Ausgabe. 
Den fand sie am Gestade sitzend, und niemals wurden ihm die beiden Augen von Tränen trocken, und es verrann sein süßes Leben, während er um die Heimkehr jammerte. Denn es gefiel ihm die Nymphe nicht mehr,

sondern wahrhaftig, er ruhte die Nächte nur gezwungen in den gewölbten Höhlen, ohne Wollen bei ihr, der Wollenden.

Die Tage aber saß er auf den Steinen und an dem Strande, mit Tränen und Seufzern und Schmerzen sein Herz zerreißend, und blickte auf das unfruchtbare Meer, Tränen vergießend.

(Od. 5.151-158) Übersetzung hier und im folgenden von Wolfgang Schadewaldt

Kalypso findet Odysseus am Strand sitzend. Seine Augen sind feucht von Tränen. Er betrauert die Heimkehr. Seine Gedanken sind so beherrscht von dem Gedanken an den Nostos, daß er die Gegenwart nicht mehr wahrnehmen, nicht mehr Freude an ihr finden kann. Diese Szene ist - wie alle Einführungsszenen bei Homer - markant und charakterisierend. Sie sagt etwas über den Charakter des Odysseus aus und führt die Handlungsfäden, die seit dem Proömium vom Erzähler gesponnen worden waren, zu einem Gesamtbild zusammen: Alles drängt auf Odysseus' Heimkehr und bangt um sie: während die einen sie fürchten und $\mathrm{zu}$ verhindern oder ihr zuvorzukommen suchen, sehnen sich die anderen Tag für Tag, Nacht für Nacht nach ihr, Odysseus selbst aber betreibt sie in jeder einzelnen seiner Handlungen von seinem ersten Auftritt an bis zur Bestrafung der Freier und Mägde und der Vergewisserung seiner Identität Penelope gegenüber. Die Nostos ist das innere Handlungsziel der Odyssee und vom Proömium angefangen ihr eigentliches, Einheit stiftendes Thema: Wie wird der ewige Irrfahrer Odysseus dieses schwierige Unterfangen bewältigen? Wie kann er vor und nach dem Erreichen der Küsten von Ithaka dafür Sorge tragen, daß seine Heimkehr anders als die Agamemnons gelingt und zu Glück und dauerhafter Freude führt?

Unter allen Gesängen und Handlungsteilen der Odyssee scheinen nun die einzelnen Irrfahrtenerzählungen (in ihrer individuellen Gestalt betrachtet), die Odysseus auf Scheria am Hof des Phäakenkönigs Alkinoos vorträgt, den geringsten Bezug und Beitrag zur Heimkehrerhandlung, zum Gelingen einer schwierigen Rückkehr, zu leisten, ja auf den ersten Blick scheinen sie ganz anderen erzählerischen Zielen und Zwecken zu dienen. Solche werden gewöhnlich vor allem auf der Ebene des epischen Erzählers gesucht, der mit dem Ich-Erzähler Odysseus ein Forum gewinnt, um seine Erzählkunst zu präsentieren, oder der in und mit dem Erzähler Odysseus ein Medium zur Reflexion auf das eigene Singen und Dichten entworfen hat. Derartige Interpretationen, die sich nicht mit der Erzählung als Darstellung einer Handlung befassen, sondern eine Reflexion auf das Erzählen im Erzählen implizieren, sind nicht selten von dem Bestreben geleitet, die Erzähltechnik der Odyssee als fortschrittlich oder ,bereits“ modern avant la lettre zu erweisen.

Bedenkt man allerdings die Präsenz des Nostos-Motivs und des Nostos als Gegenstands des Denkens und Strebens der handelnden Personen auch inner- 
halb der Scheria-Episode, sieht sich jede Interpretation, die die Apologoi des Odysseus primär als künstlerische Demonstration des Autors erweisen möchte, in der Erklärungspflicht. Denn Odysseus betreibt gegenüber Arete und Alkinoos von Beginn seines Aufenthalts im Palast des Phäakenkönigs an konsequent und hartnäckig seine Heimkehr, von der er seine Gedanken nicht abwenden kann. Ich zitiere beispielhaft die Anrede, die Odysseus bei seiner Ankunft an Arete richtet:

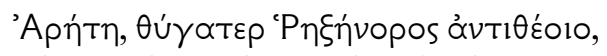

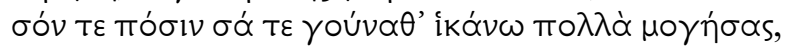

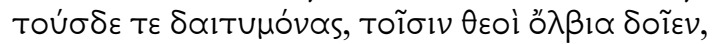

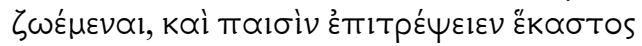

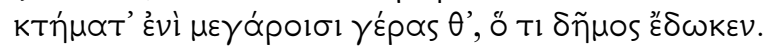

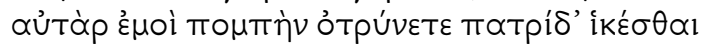

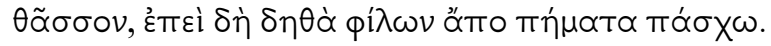

„Arete, Tochter des gottgleichen Rexenor!

$\mathrm{Zu}$ deinem Gatten und zu deinen Knien komme ich, nachdem ich vieles ausgestanden, und zu diesen Tischgesellen, denen die Götter Segen geben mögen, daß sie leben und ein jeglicher den Söhnen den Besitz in den Hallen überlassen möge und das Amt, das ihm das Volk gegeben.

Doch mir betreibt ein Geleit, daß ich ins Vaterland gelange, eilends, da ich schon lange fern den Meinen Leiden leide." (7.146-152)

Auch der Beginn seiner Irrfahrergeschichten steht im Zeichen des Versprechens, bei der Heimkehr zu helfen, das Alkinoos Odysseus bereits mehrfach und noch einmal unmittelbar vor den Erzählungen gegeben hatte (8.555-561). Die Heimkehrerhandlung, die das ganze Epos umspannt, wird von Odysseus also auch in seinen Erzählungen fortgesetzt und an einer Schlüsselstelle der Handlung vorangetrieben.

Angesichts dieses Befundes, erstaunt die - anderweitig freilich erklärbare Beobachtung, in welcher Weise die Scheria-Handlung von der Forschung primär behandelt wurde: So wie die im eigentlichen Sinn dichtungsreflexiven Ansätze, liegen auch die vielen motivischen und strukturellen Gemeinsamkeiten und Affinitäten, die in der Forschung zwischen den Erzählungen der Odyssee bzw. des Erzählers der Odyssee und dem Erzähler Odysseus beschrieben wurden, oft auf einer Metaebene jenseits des Handlungszusammenhangs und fassen die Erzählungen nicht als Teile einer Gesamthandlung, sondern als Akte sui generis auf.

Insbesondere die strukturalistische und poststrukturalistische Forschung hat sich hierzu hervorgetan. Zu diesen zählt auch - verflochten mit der Idee des autoreferentiellen Erzählens - die Suche nach Ansätzen zu einer Kunst des Fiktionalen oder des Phantastischen, das in den märchenhaften Erzählungen des Odysseus erstmals in der abendländischen Literatur entwickelt und kunst- 
theoretisch affirmativ entworfen worden sei. ${ }^{3}$ Aber auch weniger theoriegeleitete Forschungsansätze der Pattern- und Strukturforschung neigen, sobald die Apologoi betroffen sind, dazu, die mit den Mitteln der Oral-Poetry-Forschung erschlossenen Handlungsmuster vor allem motivisch und sangestechnisch für relevant zu halten, wohingegen ihre Bedeutung für die individuelle Heimkehrerhandlung in den Hintergrund tritt und nicht oder weniger reflektiert wird.

Gerade die Pattern- und Strukturforschung unitarischer Ausrichtung eignet sich dazu, einen wichtigen Unterschied herauszuarbeiten und zu betonen: Die Forschung - hervorzuheben ist hier die frühe Arbeit von Wilhelm Mattes, ${ }^{4}$ aber auch die Beiträge von Rutherford $-^{5}$ hat die erstaunlichen Bezüge, die zwischen den Großteilen auf Makro- und Mikroebene bestehen, hervorgehoben und die engen motivischen Parallelen zwischen weit auseinanderliegenden Episoden der Odyssee-Erzählung als Argumente gegen Analyse und Neoanalyse verwendet. Die Struktur- und Motivverwandtschaften ${ }^{6}$ deuten auf eine einzige Hand, die den Zusammenhang hergestellt hat, und ihre kompositorische Fähigkeiten hin. Diese Ergebnisse sind von herausragender Bedeutung und fußen zudem auf der von der Oral-Poetry-Forschung und deren kontinentalen analytischen Vorgängern bzw. Analogien erarbeiteten Einsicht in Produktionsweise und Binnenstruktur der beiden großen homerischen Epen. Sie zeigen, daß es einen bestimmten Zusammenhang zwischen den großen Handlungsstationen und -teilen in der Odyssee gibt. Davon hat zweifellos auch die Erforschung der Apologoi profitiert.

Das wesentliche Charakteristikum dieser Beiträge und Argumente für die Einheit der Odyssee liegt gleichwohl in der Suche nach einer Ordnung und Ordnungsstrukturen und -zusammenhängen, die sich vornehmlich aus Motiven, Bildern, Mustern, intertextuellen Bezügen ${ }^{7}$ und Handlungselementen

3 Uvo Hölscher, Die Odyssee. Epos zwischen Märchen und Roman, München ${ }^{2} 1989$, passim und bes. 26-33.

4 Wilhelm Mattes, Odysseus bei den Phäaken. Kritisches zur Homeranalyse, Diss. Frankfurt, Würzburg 1958, der eine scharfsinnige Abrechnung mit der Homeranalyse mit Bezug auf die Phaeakis vorlegt.

5 S. Richard B. Rutherford, At Home and Abroad: Aspects of the Structure of the Odyssey, in: Proceedings of the Cambridge Philological Society 211: N.S. 31, 1985, 13350, Richard B. Rutherford, Homer. Odyssey, Books XIX and XX., Cambridge 1992, bes. 11-16, 38-47, der auch auf Alex F. Garvie, Homer. Odyssey, Books VI - VIII, Cambridge 1994, 25f. verweist.

6 Motivgeschichtlich hat vor allem die Neoanalyse gearbeitet. S. zusammenfassend Antonios Rengakos, Narrativität, Intertextualität, Selbstreferetialität. Die neue Deutung der Odyssee, in: M. Reichel und A. Rengakos (Hgg.), Epea pteroenta. Beiträge zur Homerforschung, Stuttgart 2002, 173-191, 182-184; grundlegende Arbeiten stammen von Wolfgang Kullmann (s. den Ergebnisbericht in Wolfgang Kullmann, Ergebnisse der motivgeschichtlichen Forschung zu Homer (Neoanalyse), in: ders., Homerische Motive, Stuttgart 1992, 100-134) sowie der epenvergleichenden Homerforschung.

7 Geleitet von modernen Strömungen der Intertexualitätsanalyse sind die Studien von Pietro Pucci (Pietro Pucci, The Proem of the Odyssey, in: Arethusa 15, 1982, 39-62; 
speisen. Alle diese ranken sich zwar um die eine Erzählung von der Heimkehr des Odysseus, sie lassen sich aber nicht als Handlungszusammenhang bestimmter, aus dem Charakter des Helden und seiner individuellen Handlungssituation ableitbarer, notwendiger und unverrückbarer Handlungsteile in dem Sinn erweisen, wie es Arbogast Schmitt in seinem Beitrag in diesem Band für die Ilias gezeigt hat. ${ }^{8}$ Für die Odyssee wurde der Nachweis einer solchen inneren Handlungseinheit, wie sie in der Ilias bereits durch das erste Wort und das Proömium nahegelegt wird und für das Gesamtepos als innere, aus dem Charakter Achills abgeleitete Handlungseinheit erwiesen werden konnte, noch nicht erbracht. Ja, die Odyssee scheint sich einem solchen Nachweis auf den ersten Blick zu entziehen und eine eher äußere Ordnungsform ihrer Erzählstrukturen zu präsentieren. Joachim Latacz hat auf diesen Eindruck der geringen inneren Verbundenheit und - freilich nur scheinbaren - Unordnung, wie sie der Odyssee-Dichter am Ende des Proömiums bekennt, ${ }^{9}$ vor dem Hintergrund seiner die Einheit der Handlung und deren innere, psychologische Motivation in den Vordergrund rückenden Deutung zu Recht hingewiesen. ${ }^{10}$

Kein Zweifel: der Dichter der Odyssee ruft diesen Eindruck ausdrücklich hervor. Er insinuiert seinen Zuhörern und späteren Lesern eine Leichtigkeit und Spontaneität der Erzählung, die der Odyssee ihr besonderes narratives Gepräge verleihen. Und doch scheint dieser Eindruck der Leichtigkeit nicht auf Kosten einer eigentlichen, inneren Handlungseinheit $\mathrm{zu}$ gehen, sondern scheint diese vielmehr in einem strengen Sinn und mit der erstaunlichen Komplexität, die mit mehrfachen Handlungsebenen, einem gekonnten Umgang mit Zeitstrukturen, ${ }^{11}$ Rückblenden und Vorausblenden sowie den ver-

Pietro Pucci, Odysseus Polutropos. Intertextual Readings in the Odyssey and the Iliad, Ithaca: Pietro Pucci, 1987 (Cornell studies in classical philology. The Townsend lectures 46)), die zwischen Ilias und Odyssee einen dimensionalen Unterschied in der „Stellung des Gedankens“ annehmen und dies als Fundament einer dekonstruktivistischen Analyse in den Heldentypen Achill und Odysseus nachzuweisen suchen.

8 S. A. Schmitt (in diesem Band), Vom Gliedergefüge zum handelnden Menschen. Snells entwicklungsgeschichtliche Homerdeutung und ein mögliches Homerbild heute, S. 263-317 und Arbogast Schmitt, Teleologie und Geschichte bei Aristoteles oder Wie kommen nach Aristoteles Anfang, Mitte und Ende in die Geschichte?, in: Karlheinz Stierle und Rainer Warning (Hgg.), Das Ende. Figuren einer Denkform, München 1996 (Poetik und Hermeneutik 16), 528-563; Arbogast Schmitt, Homer, Ilias ein Meisterwerk der Literatur?, in: Reinhardt Brandt (Hg.), Meisterwerke der Literatur von Homer bis Musil, Leipzig 2001, 9-52.

91.9.

10 Joachim Latacz, Homer. Der erste Dichter des Abendlands, Düsseldorf 2003 (4. überarb. und durchgehend aktualisierte Aufl.) 170-175.

11 Wie man gegen Zielinski zeigen könnte: Thaddaeus Zielinski, Die Behandlung gleichzeitiger Ereignisse im antiken Epos, in: Philologus Suppl. 8, 1899-1901, 405-449; dazu auch Gustav Adolf Seeck, Homerisches Erzählen und das Problem der Gleichzeitigkeit, in: Hermes 126, 1988, 131-144; Odysseus Tsagarakis, On Simultaneous Actions 
schiedenen Erzählern und Erzählperspektiven spielt, ${ }^{12}$ als innere Handlungseinheit, die um die Sehnsucht nach Frau und Heimat des ewigen Heimkehrers Odysseus komponiert ist, entwickelt zu haben. Diese innere Einheit setzt sich nicht zusammen aus einer Vielzahl von assoziativen, motivischen Parallelen und der Handlung äußerlichen Ordnungsstrukturen, sondern erschließt sich im Nachvollzug des inneren Wollens, Strebens und Erreichens des Ziels dieses Strebens durch den Helden Odysseus, das im Rahmen der Möglichkeiten epischen Dichtens flankiert ist durch das komplementäre Sehnen und Bangen seiner Frau Penelope, das suchende Fragen und Hoffen seines Sohnes Telemach, die Angst der den Palast verwüstenden und aufzehrenden zügellosen Freier Penelopes auf Ithaka sowie aller weiteren für die Handlung zentralen Figuren wie Kalypso, Nausikaa, Alkinoos und viele andere.

Dieser dem ersten Blick verborgenen und vom Dichter kunstvoll verhüllten inneren Handlungseinheit nachzugehen, ist die Absicht der folgenden Skizze.

\section{Die Apologoi als Teil der Heimkehrerhandlung}

Für die Ich-Erzählung der Apologoi, die eine Erzählung vor einem bestimmten, definierten Publikum ist, von dessen Reaktionen auch berichtet wird, wurden neben den erwähnten dichtungstheoretischen und metapoetischen Ansätzen - wiederum als ein Mittel der Analyse der Erzählerebene (der Rolle des Erzählers, die Reflexionen auf das Erzählen usw.) - Impulse der sog. Rezeptionsästhetik und reader-response-theory aufgegriffen. Eine Ausnahme bilden in deren Umfeld solche Beiträge, die versuchen, die Erzählungen der Apologoi auf den Handlungsverlauf der Odyssee zu beziehen. Glenn Most arbeitete in einem wichtigen, in der Tradition strukturalistischer PatternForschung stehenden Aufsatz ${ }^{13}$ heraus, daß alle Erklärungsversuche der Erzählungen des Odysseus auf Scheria solange unspezifisch und unzufriedenstellend bleiben, solange sie nicht die unmittelbare Handlungssituation und die Intention des Heimkehrers Odysseus bedenken, der gerade acht Jahre von der schönen Nymphe Kalypso am Weiterziehen gehindert worden war und nun im am Ende der Welt lebenden Volk der Phäaken seine einzige mögliche Hoffnung auf Heimkehr erkennt.

in Homer, in: M. Païsi-Apostolopoulou (Hg.), Proceedings of the 9th International Symposium on the Odyssey (2-7 September 2000), Ithaca 2001, 355-366.

12 S. die mit den Mitteln der modernen Narratologie vorgenommenen Analysen von Irene de Jong, bes. Irene F. de Jong, A narratological commentary on the Odyssey, Cambridge 2001, passim.

13 Glenn Most, The Structure and Function of Odysseus' Apologoi, in: Transactions of the American Philological Association 119, 1989, 15-30. 
Most grenzt diese Strategie nachdrücklich gegenüber der Annahme ab, die Erzählungen des Odysseus dienten einfach der Unterhaltung seines Publikums. Viele Geschichten könnten diese Funktion erfüllen. Warum Odysseus gerade diese erzählt, bliebe unklar. Demgegenüber schlägt Most vor, in den Apologoi Erzählungen von (überzeichnet) schlechten Gastgebern in märchenhafter Form zu sehen (von den Kikonen über die Lotophagen, die Kyklopen, die Laistrygonen, bis hin zu Kirke (inklusive der Nekyia), den Sirenen, Skylla und Charybdis und schließlich Kalypso), die mit dem Skopos erzählt werden, die Phäaken an ihre Pflichten als Gastgeber zu erinnern und so seine Heimfahrt in einer grundsätzlich schwierigen und prekären Situation zu erwirken. ${ }^{14}$ Die Erzählungen hätten, so Most, darin ihren Skopos, daß Odysseus die Phäaken vor einem ungastlichen Verhalten warnt, um damit der Gefahr zu entgehen, die nahe vor Augen stehende Chance auf Heimkehr zu verlieren. Die Geschichten kämen vor diesem Hintergrund mit der einfachen Lehre daher: „Let me go home now“. ${ }^{15}$ Diese werde in unterschiedlichen Beispielen strukturell analog vermittelt.

Die Fokussierung auf die Apologoi als Handlung ist zweifellos ein wichtiger Fortschritt für das Verständnis des Aufbaus der Odyssee und ein Beitrag zur notwendigen Rückkehr von den mehrfach reflexiven dichtungstheoretischen Deutungen zurück zur Odyssee als einer bestimmten Erzählung von einer bestimmten Handlung, die gemäß den Gattungsmöglichkeiten eine Vielzahl von miteinander verflochtenen Unter-, Neben- und Teilhandlungen umfaßt. Nicht eine abstrakte Struktur des Erzählens als solche oder der Umgang mit dem Erzählen, nicht eine generelle Sangestechnik, nicht allein der Nachweis, daß in der Odyssee auch über große Strecken hin durch motivische Wiederholungen oder Pattern-Analogien Verbund und Einheit hergestellt werden, befriedigt mit Blick auf die Frage, in welchem Sinn alle Teile der Odyssee und so auch die Scheria-Handlung mit den Ich-Erzählungen des Odysseus Teile einer bestimmten, zusammengehörenden Handlung und ihrer Erzählung sind. ${ }^{16}$

Die Notwendigkeit eines solchen konkreten Handlungsbezugs hat Most bereits konstatiert. Die schlichte Annahme, die Apologoi-Erzählungen, könnten hinreichend differenzierend, als Warnung vor schlechten Gastgebern verstanden werden und erhielten daraus ihre Funktion in der Heimkehrerhandlung des Odysseus, scheint jedoch diese Forderung nicht hinreichend erfüllen zu können. Eine Revision dieser Antwort (,Warum erzählt Odysseus seine Abenteuergeschichten und warum gerade diese?") muß zuerst noch einmal bei der Situation auf Scheria, wie sie in den Büchern 6ff. geschildert wird, anset-

14 Dies erarbeitet Most in Auseinandersetzung mit Forschern wie Charles Segal, die die Situation bei den Phäaken einseitig als harmonisch und unproblematisch beschreiben.Vgl. Charles Paul Segal, The Phaeacians and the Symbolism of Odysseus' Return, in: Arion 1.4, 1962, 17-64, bes. 59. Laut Segal erreichte Odysseus ,, a haven where uncertainty and hostility are suspended“; Segal spricht von der „,calm and perfect safety Odysseus finds among them".

15 Most, The Structure and Function of Odysseus' Apologoi, 30.

16 S. Rutherford, At Home and Abroad: Aspects of the Structure of the Odyssey. 
zen. In einem zweiten Schritt soll dann die Polyphem-Episode als Kern und Schlüssel für die Lösung der Frage skizziert werden.

\subsection{Die Apologoi als Erzählungen für die Phäaken}

Auf Scheria gerät Odysseus in eine Reihe von Situationen, die seiner Klugheit im Handeln, seiner Phronesis, viel abverlangt. Schon Nausikaa, die Königs-

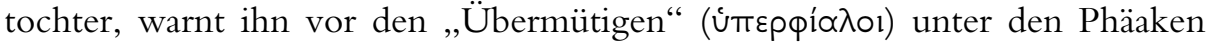
(6.274), Athene umgibt ihn auf dem Weg zum Palast des Alkinoos mit einem dichten Nebel, ,damit ihn keiner der übermütigen Phäaken sehen und fragen solle, wer er denn sei und ihn mit Worten verletzen solle“ (7.16-17), warnt ihn auch selbst noch einmal vor der Abneigung, die die Phäaken gegenüber Fremden hegen (ebenda 31-33) und fordert ihn ausdrücklich dazu auf, all seinen Mut und seine Beherrschtheit aufzubieten (50f.). ${ }^{17} \mathrm{Zu}$ bedenken ist dabei freilich, daß Athenes Rede Odysseus gegenüber auch als Prüfung verstanden werden kann, um Odysseus' von Athene später auf Ithaka hochgelobte Zurückhaltung und sein notorisches Mißtrauen (13.291ff.) zu reizen. Tatsächlich gibt es in der folgenden Erzählung keinen oder doch nur wenig Anlaß für diese starken Vorbehalte. Selbst die Reizungen und Kränkungen des Euryalos während der Wettspiele müssen nicht, ja, sie dürfen nicht als Charakteristikum der Phäaken gewertet werden. Einzelnes abweichendes Verhalten gibt es schließlich auch bei den Griechen selbst oder bei anderen Gruppen, ohne daß dies zur Verallgemeinerung berechtigte. Man denke etwa an die Szene des Wettrennens während der Leichenspiele für Patroklos in der Ilias, als Menelaos von dem übermütigen Antilochos gereizt wird.

Es sind aber reale Handlungssituationen, reale Herausforderungen, vor die sich Odysseus auf Scheria gestellt sieht. Die von der Forschung aufgedeckten Parallelen, die es zu Odysseus' Ankunft auf Ithaka handlungsmotivisch und in bezug auf die Struktur der Handlung gibt, belegen den Eindruck noch einmal, daß Odysseus sich auf Scheria nicht in einer paradiesischen Heilslandschaft befindet, wo alle Sorgen und Aufgaben - am Rande der Oikoumene - märchenhaft suspendiert sind, ${ }^{18}$ bevor ihm zuhause schwere Prüfungen bevorstehen. ${ }^{19}$ Scheria ist eine Herausforderung, für die Athene Odysseus ebenso stärken, ihm raten und ihn unterstützen muß wie auf Ithaka (z. B. 8.15-22).

17 Zur Ungastlichkeit der Phäaken: G.P. Rose, Unfriendly Phaeacians, in: TAPA 100, 1969, 387-406.

18 Segal, The Phaeacians and the Symbolism of Odysseus' Return, passim. Vgl. die in der (freilich nachhomerischen) Antike sprichwörtliche Gastfreundchaft der Phäaken, wie bei Dio Chrysostomos, der die Phäaken gegenüber denjenigen verteidigt, die deren Gastfreundschaft in Zweifel ziehen. Dio. Chrys. Orat. 7.90; Heracleides Ponticus Fr. 175 (Wehrli).

19 Gut herausgearbeitet wird dieser Charakter einer Herausforderung auch von Mattes, Odysseus bei den Phäaken, 110ff. und $123 \mathrm{ff}$. 
Eine Schwarz-Weiß-Zeichnung verbietet sich zur Charakterisierung der Situation in beide Richtungen: Odysseus kommt nicht in ein Schlaraffenland, aber auch wahrlich nicht zu Barbaren, denen er rechte, nämlich griechische Manieren und Sitten beibringen müßte. Er kommt zu einem kultivierten, fabelhaft reichen, von Athene in der Kunst der Seefahrt geschulten Volk (7.108-132) mit einer umsichtigen und klugen Königin (7.69-74), die sich mit Geschick und klugen Worten gewinnen läßt (7.75-77), und einem gutherzigen (7.309f.) und mitleidigen (8.93-96, 532-535) König, der sein Angebot, Odysseus nach Hause zu geleiten, mehrfach vorträgt (7.189-198; 7.317-328; 8.28-36) und der Rücksicht zu nehmen weiß auf die besondere Geschichte und Vergangenheit seines Gastes. ${ }^{20}$

Einen Schlüssel zu einem differenzierten Verständnis der Handlung bietet der Artikel ,Xenos‘ von Martin Schmidt im Lexikon des frühgriechischen Epos. ${ }^{21}$ Der Artikel arbeitet klar heraus, daß Odysseus auf Scheria sich den Status und die Gunst, die ein Gastfreund genießt, erst erarbeiten muß. Er muß vom Fremden zum geehrten Gast werden. ${ }^{22}$ Das Bedeutungsspektrum des Wortes „Xenos“ bedarf daher, so zeigt es der Artikel, der feinsinnigen Ausdeutung, die davon geleitet werden kann, daß die Phäaken immer wieder von der Notwendigkeit sprechen, den Fremden so, wie es sich gehört, als Gastfreund zu behandeln, ihn zu einem Gastfreund zu machen - durch die angemessene

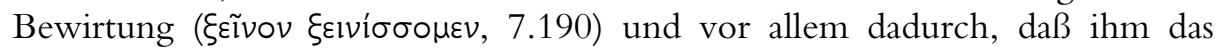
Geleit für die Heimfahrt gegeben wird (z. B. 7.227).

Die Phäaken sind nicht nur ein hochkultiviertes Volk, sie wissen auch insbesondere sehr genau um die Pflichten des guten Gastgebers und rühmen sich, sie immer zu erfüllen (7.190-196; 8.30-43), ihr Ruhm besteht gerade in ihrer freundschaftlichen Hilfsbereitschaft Fremden gegenüber (7.555-563). ${ }^{23}$ Odysseus muß sich also auf eine Weise verhalten, die ihn von einem Fremden in den Status eines rechtmäßigen Gastfreundes erhebt.

Es gibt in diesem Sinn keine generelle charakteristische „Fragilität“ der Gastfreundschaft bei den Phäaken. ${ }^{24}$ Alkinoos sagt gleich zu Beginn die Hilfe

20 Z.B. wechselt er das Thema, als er Odysseus' Tränen bemerkt: 8.94-103; 532ff.

21 Martin Schmidt, Art. ,Xenos', in: LfgrE, Bd. 3, 16, 1996, Sp. 463-469.

22 Stationen dieses Gewinnens von Vertrauen und Kleos sind: die Rede gegenüber den Phäaken: 7.226-227; gegenüber Arete 7.237ff.; gegenüber Alkinoos 7.299-301; Odysseus' Reaktion auf die Beleidigungen des jungen Phäaken Euryalos: 8.158-165; Alkinoos läßt für Odysseus das Bad richten: 8.426f.

23 Schöne Beobachtungen dazu von G. J. de Vries, Phaeacian Manners, in: Mnemosyne 30, 1977, 113-121 (als Antwort auf Rose, Unfriendly Phaeacians).

24 So läßt sich beispielsweise die Tatsache, daß sich Alkinoos angesichts des staunenerregenden Auftritts des Odysseus dazu hinreißen läßt, entgegen den Geboten der Gastlichkeit gleich nach dem Namen des Fremden zu fragen (7.215), nicht als Indiz für eine mangelhafte phäakische Gastlichkeit werten. Vielmehr erweist sich in der Szene Homers feiner Blick für individuelle Charaktere und ihre individuellen Neigungen und Schwächen (vgl. den Rat des Echeneos 7.159-166 und Alkinoos eilfertige Reak- 
bei der Heimkehr zu und hält sich im Laufe der weiteren Handlung auch an dieses Versprechen, den - noch namenlosen - Fremden „morgen“ nach Hause zu geleiten (7.317f.). ${ }^{25}$ Es bedarf keiner Moralpredigt, keiner Sittenlehre durch erbauliche oder monströse und dadurch abschreckende Beispiele. Odysseus kann und muß nicht als Lehrmeister von unartigen, ungesitteten Schülern auftreten. Er muß zeigen, daß er nicht nur ein unbekannter Fremder ist, dessen Auftreten und plötzliches Erscheinen Staunen und ängstliche Vorbehalte erzeugt. ${ }^{26}$ Die Situation, in der Odysseus auf Scheria ist, erweist sich in dieser Perspektive als die für ihn in der gesamten Odyssee charakteristische. Er ist immer der Fremde, der Gastfreund werden will oder der allgemeiner gesprochen: das Vertrauen und das Gefühl der (wechselseitigen) Verpflichtung mit denjenigen aufbauen will und muß, die ihn aufnehmen, die Xenodokoi sind. Odysseus wird von Nausikaa, von Alkinoos, aber auch von Eumaios, von Telemach, von Eurymachos und schließlich von Laertes als „Xenos“ addressiert. Es ist die Rolle des zuerst unerkannten Heimkehrers, aus der sich seine Aufgabe ergibt, bei den Phäaken wie auf Ithaka. Er muß sich als Xenos im Sinne eines rechtmäßigen Gastfreundes empfehlen.

Wenn die Erzählungen des Odysseus also auf diese Situation und diese Aufgabe reagieren, dann ist es unwahrscheinlich, daß sie dies mit extremen, abschreckenden Bildern tun könnten. Denn die Schwierigkeit liegt nicht einseitig bei den Phäaken, die ihre vermeintlich barbarischen Tendenzen kontrollieren sollen. Der fremde Odysseus muß sich als würdiger Gastfreund, als jemand, der die bevorzugte Behandlung als Gastfreund verdient, erweisen. Damit aber scheitert eine Strategie zur Erklärung der oft als märchenhaft oder fiktional bezeichneten Geschichten von der Zauberin Kirke, vom Riesen Polyphem usw., die auf das Bizarre und Extreme der Geschichten blickt und in diesem die Abschreckungsqualität der Erzählungen ausmacht.

Ein alternativer Erklärungsversuch, den ich im folgenden skizzieren möchte, knüpft an solche Deutungen an, die sich mit den sog. Lügengeschichten des Odysseus auf Ithaka beschäftigt und herausgearbeitet haben, daß es nicht die konkreten Namen von Orten oder Personen, nicht die genauen Verwandtschaftsbeziehungen und materiellen Details sind, die den Charakter und die Aussage dieser Geschichten prägen, sondern der sich in diesen Handlungen ganz wahrheitsgemäß - offenbarende des Ich-Erzählers Odysseus. ${ }^{27}$

tion: 167-171). Allzu scharf urteilt Most, The Structure and Function of Odysseus' Apologoi, 30 über Alkinoos.

25 S. die schöne Interpretation und Widerlegung der analyischen Phäakis-Interpretation von Wilhelm Mattes (Mattes, Odysseus bei den Phäaken, passim), der eng am Text und mit überzeugenden Belegen die Zusammengehörigkeit der drei Tage des Aufenthalts bei den Phäaken und ihrer inneren Handlung, die von der Sehnsucht des Odysseus nach Heimkehr geprägt ist, aufzeigt.

26 7.139-145.

27 Vgl. Bernard Fenik, Studies in the Odyssey, Wiesbaden 1974 (Hermes-Einzelschriften 30), 167-171. 
Wenn Odysseus sogar gegenüber Athene seine Irrfahrergeschichte mit Namen und Orten schmückt, die erfunden und verschieden von seinen tatsächlichen Erlebnissen sind, dann erzählt er gleichwohl viel und Individuelles von sich selbst: Er schildert seine Leiden, seine Heimatlosigkeit, seine Findigkeit und Fähigkeit, auch schwierige Situationen zu meistern usw. Die Verschleierung, die die Geschichte zu einer Lügengeschichte macht, betrifft nicht den Kern dessen, was ein hellhöriger Zuhörer aus der Geschichte über sein Gegenüber erfahren kann; sie betrifft nur unwichtige Details, Motive und Daten, die der Zuhörer, wenn er wissen möchte, was für ein Mensch das ist, mit dem er es da zu tun bekommt, getrost überhören oder vergessen kann. Von dieser Perpektive aus eröffnet sich auch ein neuer Blick auf die ApologoiErzählungen, der weniger auf die sog. Märchenatmosphäre oder das Wunderbare gelenkt wird, sondern mehr auf die Art des Handelns, auf das, was die Handlungsentscheidungen und das Erzählen als Handeln über den Protagonisten aussagen.

Denn die Opposition Realität vs. märchenhafte Phantasiewelt ist nur eine weitere unter den abstrakten Struktur-Oppositionen wie Grieche vs. Barbar oder Kultur vs. Natur, mit denen Homers literarische Kunst nicht hinreichend erfaßt werden kann. Wenn Odysseus hingegen die Geschichten von den Lotophagen, von der Zauberin Kirke und den Kyklopen ebenso wie die „Lügengeschichte" von dem Kreter, der nach einer Bluttat aus Selbstschutz auf der Flucht gewesen sei, dazu benutzt, um etwas über sich zu verstehen zu geben, über das, was er kann und was er erlitten hat, warum er sich nach nichts stärker sehnt als nach der Heimkehr und warum er diese verdient, dann erkennt man das Wesen der Apologoi nicht mehr in ihrer märchenhaften Suspension der historischen Wirklichkeit, sondern in einem bestimmten Beitrag zur individuellen Heimkehrerhandlung, zur gelingenden Nostos-Handlung, um die Odysseus' ganzes Denken kreist.

Odysseus' Probleme sind individuellerer Art als das Bezwingen eines unkultivierten Volkes am Rande der bekannten Welt. Sie haben vielmehr etwas mit ihm selbst, mit seinem Auftreten und seiner individuellen Geschichte als Irrfahrer und ewigem Heimkehrer zu tun. Einerseits erweckt der - von Athene mit Schönheit und Kraft gestählte - Fremde die Bewunderung der Phäaken und empfiehlt ihn Alkinoos als potentiellen Schwiegersohn, eine Gedankenrichtung, die Odysseus' Heimkehrplänen naturgemäß entgegengesetzt ist (7.311-315). Andererseits ist Odysseus, der von Poseidon gehaßte und verfolgte Irrfahrer, kein an sich gern gesehener Fremder oder gar Gastfreund in einem Haus, dessen Herrscher beide Nachkommen Poseidons sind, ${ }^{28}$ und in einem Volk, das als Seefahrernation ganz besonders unter dem Schutz und der Aufsicht des Meeresgottes steht.

28 Odysseus erfährt davon in den Versen 7.54-59. 
Eine Warnung, die Poseidon einst den Phäaken gegenüber ausgesprochen hatte und die sie im Gedächtnis bewahren, erscheint angesichts der Irrfahrten des Odysseus noch einmal in einem anderen, gleichsam grelleren Licht:

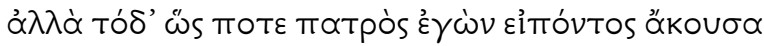

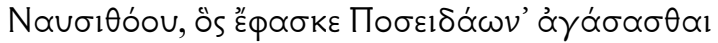

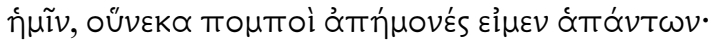

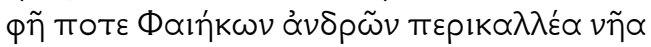

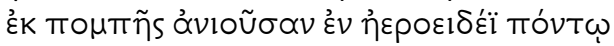

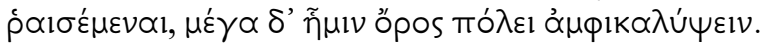

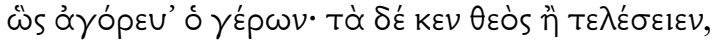

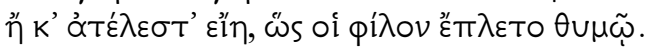

„Freilich hörte ich einst oftmals meinen Vater Nausithoos sagen,

Poseidon verarge es uns,

daß wir allen sicheres Geleit geben.

Er werde einst ein herrliches Schiff der Phäaken,

wenn es zurückkehrt von gegebenem Geleit, im dunstigen Meer

zerstören, groß werde der Berg sein, der uns die Stadt verbirgt.

So erzählte der Alte. Ein Gott mag das alles erfüllen,

oder es mag auch unerfuillt bleiben, wie es ihm im Herzen beliebt.“ (8.564-571)

Alkinoos erzählt diese Geschichte jedoch eher als Beiwerk denn als etwas, das im Zentrum seiner Gedanken einen Platz hat. Viel mehr ist sein Denken von der Vorstellung eingenommen, daß die Phäaken unendlichen Ruhm verdienen durch ihre große Seefahrerkunst, die sie anderen zur Hilfe anbieten.

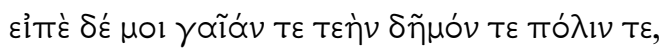

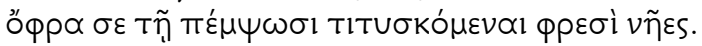

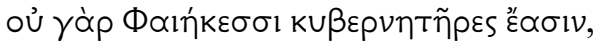

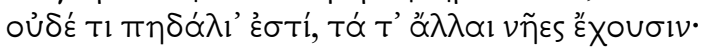

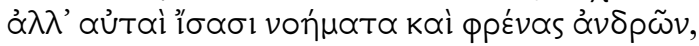

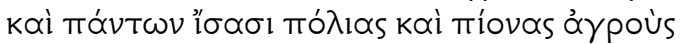

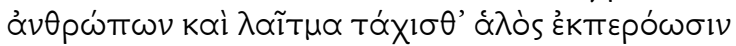

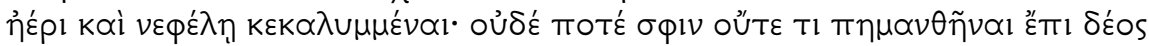

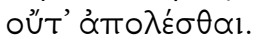

„Aber nenne mir das Land, das Volk, die Stadt, aus der du kommst, so daß dich die Schiffe dorthin geleiten, sie kennen ihr Ziel ganz von selbst.

Denn wir Phäaken haben keine Schiffsführer auch kein Steuer, wie es andere Schiffe haben.

Von selbst wissen sie die Gedanken und den Sinn der Männer, und kennen aller Menschen Städte und fruchtbare Länder, schnell durchfahren sie das gefahrvolle Meer, ganz von dunstigem Nebel eingehüllt. Niemals empfinden sie Furcht, daß ihnen ein Leid zustieße oder Vernichtung. Freilich hörte ich einst...." (8.555-564) 
Ruhm und Stolz auf die eigene, die Seefahrerkunst zur Vollendung führende Fähigkeit sind es, die Alkinoos umtreiben, nicht die Sorge vor dem großen zornigen Gott. Dies ist ein Anknüpfungspunkt für den sehnsüchtigen Heimkehrer. Hier wird er versuchen müssen, Alkinoos, Arete und die Phäaken zu packen.

Und so hatte Odysseus seit seiner Ankunft im Palast zwar nicht verschwiegen oder geleugnet, daß Poseidon ihm grollt und schlimme Leiden auferlegte (7.270-274). Doch macht er diesen Zwist nicht zum beherrschenden Thema seiner Irrfahrergeschichten: nicht das, was er erleidet, das, was er tut, was er kann und leistet, ist der Gegenstand seiner Erzählungen. ${ }^{29}$ Dieses Selbstbewußtsein ist als solches noch ganz abstrakt und ohne Begründung und Beleg. Es ist die Aufgabe der Irrfahrererzählungen, aus dem abstrakten Begriff konkrete Vorstellungen werden zu lassen. Sie lenken die Aufmerksamkeit auf den umsichtigen Seefahrer, den mutigen Eroberer und demonstrieren, ein welch ungewöhnlich vorausschauender, sorgsam planender, rechtgesinnter Mann er ist, ein Mann würdig freigiebiger Gastfreundschaft.

\subsection{Eine Hamartia in den Apologoi? - Odysseus und die Peira bei den Kyklopen}

Unter den Irrfahrergeschichten, die Odysseus erzählt, fällt eine unter den übrigen Erzählungen auf - und auch mit Blick auf dieses die Heimkehr im Sinn habende Handlungsziel - aus dem Rahmen: die Geschichte von der Blendung des Polyphem.

Odysseus' Kyklopengeschichte ist das Staunenswerteste, was sich in der ganzen Odyssee findet. Der Grund dafür ist nicht etwa der vermeintlich prominenteste märchenhafte Charakter. Denn wenn Odysseus von dem PoseidonSohn Polyphem erzählt, dann ist dies für seine Zuhörer keine Geschichte aus unwirklichen, phantastischen Gefilden, sondern etwas, das ihnen als Nachkommen Poseidons wenn nicht naheliegt, so doch Momente der Bekanntheit aufweist. Die Geschichte ist staunenswert, weil sie inkonsistent zu sein scheint. Odysseus' Handeln ist in ihr problematisch, ja fehlerhaft und nur partiell erfolgreich und scheinbar wenig geeignet, Vertrauen zu schaffen oder ein Paradebeispiel für den Polytropos Odysseus und seine Fähigkeit zu sein, mit Notsituationen umzugehen. Denn er gerät nicht in diese Not, er schafft sie sich selbst und erweist sich als für sein Handeln voll und ganz selbst verantwortlich, ein Handeln, daß ihm den Zorn des großen Gottes einbringt. Trotzdem gilt auch Odysseus selbst diese Episode im Rückblick als Inbegriff seines Durchhaltevermögens und seiner Klugheit, die sich gegen alle Widrigkeiten durchsetzt.

29 Diese beginnen gleich programmatisch mit einem Bekenntnis und einer Selbstdarstellung: „Ich bin Odysseus, der Sohn des Laertes, dessen/ Listen bei den Menschen bekannt sind, mein Ruhm dringt empor bis zum Himmel.“ (9.19-20) 
Er verwendet sie als ein solches Exempel etwa in der Rede, die er zu Beginn des Skylla-Charybdis-Abenteuers hält (12.208-212). Es ist dies die Krisensituation eines Seefahrers schlechthin. Die Gefährten sind in Furcht, weil das Meer vor ihnen dampft und wogt. Odysseus erinnert sie, um ihnen Mut zu machen, an seine Taten auf der Kyklopeninsel. Inhalt dieser Erinnerung ist die Arete, die Boule und der Noos des Odysseus; diese hätten sich vor allem und exemplarisch in der Kyklopen-Episode verwirklicht und bewährt. Denn dort gab es die gefahrvollste Situation, gegen die sogar alle Gefahren der größten Naturgewalten als gering erscheinen. Die Gefahren, die Odysseus nicht schafft, sondern die traditionell und bekannt sind, sind also nichts im Vergleich mit der Polyphem-Gefahr. Sie können Odysseus nicht reizen, und sie können nicht konkurrieren mit der Gefahr, die Odysseus als Erzähler und Handelnder selbst geschaffen hat.

Auch später auf Ithaka hat sein Polyphem-Abenteuer für Odysseus selbst diese Bedeutung: Kurz vor der größten Krise seiner Selbstbeherrschung angesichts des frevelhaften Treibens der Freier und Dienerinnen erinnert sich Odysseus im Selbstgespräch daran, und zwar als Beispiel für seine große Fähigkeit, auszuharren, den Thymos zurückzuhalten und damit ein größeres Gut, eine größere zu erwartende Lust zu erstreben, anstatt dem augenblicklichen Ärger zu folgen und damit das größere Handlungsziel zu gefährden: ${ }^{30}$ als Paradigma seines Noos, seiner Klugheit gegen vorschnelle Rachegelüste. ${ }^{31}$ Dieser Rückblick bezieht sich unmittelbar auf die Verse 9.299ff.

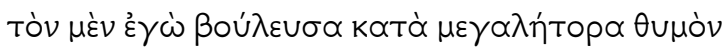

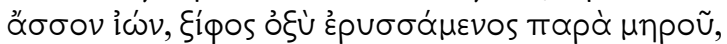

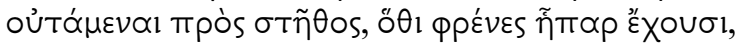

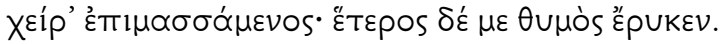

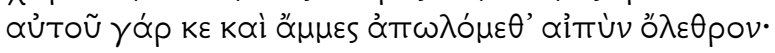

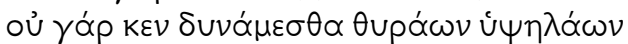

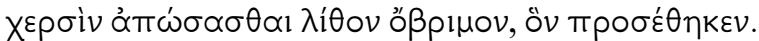

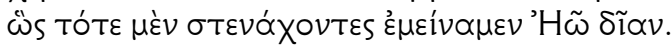

„Da gedachte ich in meinem großherzigen Mute, an ihn heranzutreten und, das scharfe Schwert gezogen von der Hüfte, es ihm in die Brust zu stoßen, da wo das Zwerchfell die Leber umschlossen hält, nachdem ich die Stelle mit der Hand ertastet. Doch eine andere Regung hielt mich. Denn auch wir waren dort in jähem Verderben umgekommen:

30 20.19-22: „Halt aus, mein Herz. Schon Hündischeres hast du einst ertragen, an dem Tag, als der ungestüme Kyklop mir die wackeren Gefährten fraß. Du aber hieltest es aus, bis dein Noos dich aus der Höhle herausbrachte, obwohl du doch meintest, es nicht zu überleben.“

31 Damit ist nicht ausgemacht, daß Odysseus in der gesamten Polyphem-Geschichte dem Noos folgt. Das tut er, wie unten zu zeigen sein wird, ausdrücklich nicht. Die Lösung der Krise allerdings gelingt Odysseus durch seine Schlauheit und sein besonnenes Planen. 
vermochten wir doch nicht, von den hohen Türen den gewaltigen

Stein mit den Handen hinwegzustoßen, den er vorgesetzt. So warteten

wir da seufzend auf das göttliche Frühlicht.“ (8.299-306)

Odysseus hatte also auch in der Situation größter Bedrängnis beim Riesen Polyphem ausgehalten, hatte sich zurückgehalten und kluge Besonnenheit gezeigt. Das ist der Vergleichspunkt. Und doch erscheint die Erinnerung an die Polyphem-Episode damit seltsam fragmentarisch und selektiv. Denn sie ist die einzige Episode, in der Odysseus' Thymos sich nach eigenem Bekunden zum einzigen Mal gegen das, was besser gewesen wäre, gegen den Rat des umsichtigen Noos durchgesetzt hatte.

Eine Analyse der Polyphemgeschichte, die dieses Staunen produktiv macht und daraus auch Erkenntnisse für die spezifische Literarizität der Odyssee gewinnt, soll daher hier unternommen werden: Die Erzählung beginnt mit der Schilderung der barbarischen Gesellschaft und Sitten der Kyklopen (9.106-115 und 125-129). Zu dieser fügt sich eine geographische Beschreibung der Unkultiviertheit und Unberührtheit einer kleinen dem Festland vorgelagerten Insel, auf der wilde Ziegen grasen. Der Erzähler exponiert die Landschaft so, daß sie für die Geschichte, die er erzählen will, den Hintergrund bilden kann und seinen Erzählzielen dient. Erst nach dieser negativen Exposition (9.118124) geht das Bild von der Insel in die Darstellung eines Paradieses über, in dem sich die Natur sua sponte in reicher Fülle mit ihren Gaben darbietet (9.130-140). Danach folgt die Schilderung der Landung von Odysseus mit seinen Gefährten auf der Insel (9.142ff.). ${ }^{32}$ Mit dem Anbrechen des nächsten Tages beginnt dann die eigentliche Erzählung.

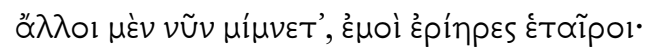

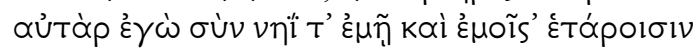

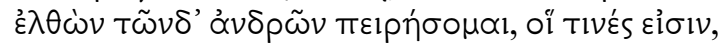

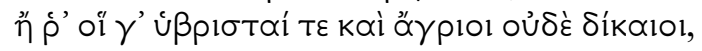

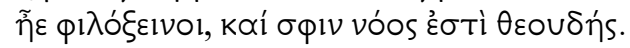

„Ihr andern bleibt jetzt hier, meine geschätzten Gefährten!

Ich aber will mit meinem Schiff und meinen eigenen Gefährten

hingehen und diese Männer erkunden, wer sie sind:

ob sie Unbändige sind und Wilde und nicht Gerechte,

oder gastfreundlich und einen Sinn haben, der die Götter scheut.“ (9.172-176)

Der Seefahrer Odysseus spricht selbst: er nennt seinen Plan. Es ist eine Peira, eine Probe, ob die Bewohner dieses Landes kultivierte und gottesfürchtige Menschen sind: der Zuhörer weiß nach der Exposition des Erzählers Odysseus,

32 Alles liegt im Dunkeln, kein Blick in das Innere der Insel ist möglich. Das schafft Spannung und steigert im Rückblick die Leistung dessen, der so geistesgegenwärtig ohne längere Vorbereitung handeln konnte. Erst am nächsten Morgen können sie die Insel erkunden. Sie jagen Ziegen und sättigen sich an ihrer Beute. Alles endet in einem üppigen Gelage (9.162). 
daß diese Peira von vorneherein zum Scheitern verurteilt ist. Denn es kann kein sinnvolles Ziel sein, die Kultiviertheit des schlechthin Unkultivierten erproben zu wollen. Der Fokus wird damit auf Odysseus selbst gelenkt. Die Episode wird zu einer Peira für ihn selbst: einer Probe des Mutes und der Klugheit.

Als Odysseus mit seinen ausgewählten Gefährten das Land erreicht, ist es wiederum nicht mehr der Seefahrer Odysseus, der beschreibt, was er sieht; sondern wieder exponiert der Erzähler die Situation: Sie sehen eine Grotte, deren Ausstattung beschrieben wird. Doch dann wird nicht mehr die Umgebung, sondern das, was zu dieser Grotte gehört, aber aktuell nicht sichtbar ist, beschrieben (9.187-194), nämlich die Lebensweise und Gewohnheiten Polyphems. Die Perspektivenvermischung geht so weit, daß der Handelnde Odysseus aus dem, was der Erzähler Odysseus aus seinem nachträglichen Wissen heraus geschildert hat, einen Schluß für sein Handeln zieht: Er wählt auf der Basis des gerade geschilderten Wissens noch einmal aus seinen Gefährten aus. ${ }^{33}$ Odysseus nimmt einen besonderen, besonders starken Wein mit, dessen Herkunft und Beschaffenheit in nicht weniger als 15 Versen beschrieben wird (9.196-212); und er wappnet sich noch mehr: er sorgt auch noch für Proviant:

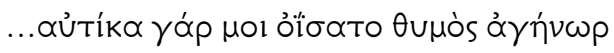

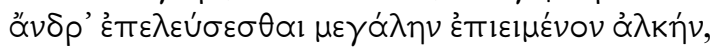

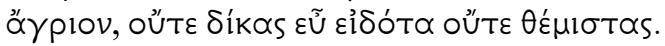

„Denn mir ahnete schon im starken Gemüt, wir würden

Einen Mann besuchen, mit großer Stärke gerüstet,

Grausam und ungerecht, und durch keine Gesetze gebändigt.“ (9.213-215)

Betont wird damit, daß Odysseus sich wissentlich und willentlich in ein großes Abenteuer, in sein größtes Abenteuer begibt, und daß diese Peira eine Peira des Odysseus (gen. obj.) sein wird. Der Blick richtet sich also nur scheinbar auf die Kyklopen und erprobt deren Menschlichkeit. Sie sind vielmehr der Anlaß für eine Selbstinszenierung und einen Selbsttest des Odysseus. Die Phäaken hören zwar eine Geschichte über ihre (entfernten) Verwandten - doch diese werden zu Beginn so eindeutig von ihnen selbst abgerückt, daß es zu einem Vergleich gar nicht kommen kann - oder daß ein Vergleich vom Erzähler nicht intendiert sein könnte. Auch Polyphem selbst ist keine potentielle Identifikationsfigur; er bleibt als individuell Handelnder „,blaß“ und wird bloß generisch als - allerdings fürsorglicher - Hirte charakterisiert. Allein die von ihm nach der Provokation von Odysseus ausgelebte Roheit wird anschaulich vorgeführt und bis ins Extreme gesteigert.

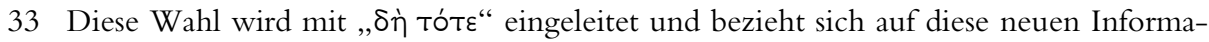
tionen (194f.: „Also befahl ich den anderen treuen Gefährten, beim Schiff zu bleiben und das Schiff an Land zu ziehen. Ich selbst aber ging los, nachdem ich zwölf Gefährten, meine besten, ausgewählt hatte."). 
Damit gerät die Geschichte an den Rand des Märchenhaften: aber nur an den Rand, nicht in ein Märchen hinein. Denn immer noch ist die Geschichte fest an ein Individuum, an Odysseus, den Städtezerstörer und epischen Helden par excellence gebunden. Märchen hingegen lassen sich deshalb so gut als Beispiel für strukturalistische Typologien verwenden, ${ }^{34}$ weil sie nicht primär an der Darstellung eines Individuums, sondern mehr an Konstellationen von Handlungen und oft gattungshaft bezeichneten Personen interessiert sind. Auch dort, wo die Schicksalsfälle eines einzelnen Helden mit einem Namen verbunden und ins alleinige Zentrum gerückt erscheinen, ist dieser Protagonist doch als Exemplum konstruiert, dessen Erlebnisse sich an vielen Orten, zu vielen Zeiten so oder ähnlich wieder ereignen können. „Es war einmal..“ und kann auch wieder so oder ähnlich sein. ${ }^{35}$

So wie in den Apologoi überhaupt so ist es auch in der Polyphemepisode im Unterschied zu solchen märchenhaften Strukturen dieser außergewöhnliche und einmalige Odysseus, dessen Verhalten auch im weiteren Verlauf der Erzählung differenzierend beschrieben und bewertet wird.

Als Odysseus mit seinen Gefährten die Höhle betritt, finden sie die Höhle zwar ohne ihren Bewohner vor, aber die Gefährten bekommen es mit der Angst zu tun und bitten Odysseus, zum Schiff zurückzukehren. Doch Odysseus lehnt ab. Der Erzähler Odysseus legt die Motive und Gründe dafür schonungslos, oder scheinbar schonungslos - offen dar (9.228-230): Noch einmal beharrt Odysseus darauf, er wolle die Gastfreundschaft des Kyklopen testen. Dieses Mal aber wird dieses Verhalten direkt als unvorteilhaft bewertet. Es ist eine sinnlose, unnötige Peira, die lediglich mehreren Gefährten das Leben kosten wird; und wenn Odysseus die anderen sechs schließlich retten kann, dann aber doch als der, der sie erst - unnötigerweise - in diese von ihm

34 Wie von V. Propp in seiner klassischen Studie paradigmatisch vorgeführt: Vladimir Propp, Morphologie des Märchens, dt. von Christel Wendt, hg. von Karl Eisenmacher, München 1972.

35 Einen anderen Ansatz verfolgt Hölscher, Die Odyssee, bes. 29 mit Verweis auf Ludwig Radermacher, Die Erzählungen der Odyssee, in: Sitzungsberichte der Österreichischen Akademie der Wissenschaften Wien / Philosophisch-Historische Klasse 185, 1915. Hölschers Definition der Odyssee als „Epos zwischen Märchen und Roman“ arbeitet mit geistesgeschichtlich problematischen Konstrukten und Vorstellungen, die der Odyssee den Status eines Produkts einer „ursprünglichen erzählenden Phantasie“ (ebenda, s. auch Norman Austin, Archery at the Dark of the Moon. Poetic Problems in Homer's Odyssey, Berkeley 1975, z.B. 88, 104, 115 u.ö.) zuweisen und sie entwicklungs- und bewußtseinsgeschichtlich an einem Anfang oder frühen Stadium des abendländischen Erzählens und der Fiktion verorten. Eine Auseinandersetzung mit analogen hermeneutischen Vorgaben leistet Arbogast Schmitt, Selbständigkeit und Abhängigkeit menschlichen Handelns bei Homer. Hermeneutische Untersuchungen zur Psychologie Homers, Abhandlungen der Geistes- und Sozialwissenschaftlichen Klasse / Akademie der Wissenschaften und der Literatur 5, Stuttgart 1990, passim und bes. 1271; s. außerdem Gyburg Radke, Die poetische Souveränität des homerischen Erzählers, in: Rheinisches Museum 150, 2007, 8-66. 
selbst geschaffene Lage gebracht hat. Odysseus handelt wider das, was das Vor-

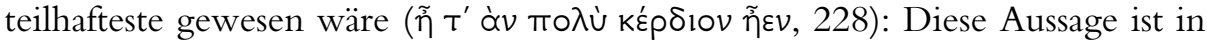
der Odyssee einmalig. Nur als er sich am Ende Polyphem als Odysseus zu erkennen gibt, bekennt der Erzähler noch einmal, daß sich bei ihm nicht die Vernunft durchgesetzt habe (9.491-501). Odysseus gesteht ein, daß er sogar entgegen expliziter Warnungen seinem Thymos freien Lauf gelassen habe: daß es der Thymos, nicht der Noos war, der ihn dazu trieb, sich noch einmal an Polyphem zu wenden und seinen Namen zu verkünden.

Die ganze Geschichte über gibt es diese Konzession der Unvernunft sowohl des Erzählers als auch des Handelnden: Doch sie wird - als etwas Negatives, als eine Konzession, als Geständnis eines Fehlers - dadurch ausbalanciert, daß sich Odysseus, dessen Thymos ihn in diese Lage gebracht hat, durch seinen ungewöhnlich scharf- und umsichtigen Noos aus eben dieser Lage auf eine außergewöhnliche Weise wieder befreien kann. Dadurch wandelt sich die Aussage vollständig ins Gegenteil: Die Polyphemgeschichte gerät dadurch wir hatten dies an den nachträglichen Bewertungen innerhalb der Odyssee schon sehen können - zu einer Demonstration der Schlauheit des Odysseus, seiner Phronesis, jede Situation, und sei sie auch noch so unüberwindbar durch kluges Nachdenken und nicht durch körperliche Stärke, lösen und bewältigen zu können.

Man muß diesen Exempelstatus noch genauer bestimmen: Wir hatten zu Beginn der Schilderung der Verhältnisse bei den Kyklopen eine Diskrepanz zwischen dem beobachtet, was der Erzähler Odysseus und dem, was der Seefahrer Odysseus weiß. In der Forschung wurde schon oftmals Verwunderung darüber zum Ausdruck gebracht, daß Homer die Chancen einer perspektivischen Ich-Erzählung in den Apologoi nicht genutzt ${ }^{36}$ und den Ich-Erzähler entgegen der Erzählsituation und also vermeintlich fälschlich quasi als allwissenden Erzähler komponiert habe.

Die Verwunderung läßt sich aufheben, wenn man die Erzählung als Handlung begreift: Die Beschreibung des Soziallebens der Kyklopen ist Teil der fiktiven Konstruktion und Teil des Bekenntnisses dieser Fiktion, genauer: dieser Eigenproduktion der Gefahr. Sie ist damit ein Baustein der konkreten Veranschaulichung der Klugheit des Odysseus, für den und auf den zugeschnitten sowohl der Seefahrer als auch der Erzähler eine Situation selbst erschafft, die ihm alles abverlangt, die das ist, was diese Klugheit des Odysseus benötigt, um sich voll entfalten, um voll praktisch verwirklicht werden zu können. Ein vernunftgemäßes Abwägen und vorsichtiges Vermeiden des Unvernünftigen genügt dafür nicht mehr.

36 Werner Suerbaum, Die Ich-Erzählungen des Odysseus. Überlegungen zur epischen Technik der Odyssee, in: Poetica 2, 1968, 150-177, 153-164; s. auch die positivere und differenziertere Analyse von de Jong, A narratological commentary on the Odyssey, bes. 223-227. 
Die Geschichte ist ein Konstrukt, aber eines, das nicht in der Innerlichkeit verbleibt, sondern das zur Handlung wird. Nicht nur der Erzähler Odysseus erschafft etwas poietisch, sondern auch der Handelnde Odysseus: er erschafft seine ihm eigentümliche Peira. ${ }^{37}$

Sie ist also keine erzählinterne Fiktion in dem Sinn, daß etwas erzählt wird, was Odysseus gar nicht erlebt hat, sondern sie ist eine Handlungs-Fiktion, in der eine Situation dazu benutzt und dafür gestaltet wird, das Paradebeispiel der Findigkeit des Odysseus zu werden. Deshalb ist diese Geschichte sowohl auf der Erzähl- als auch auf der Handlungsebene nicht einfach abgespiegelte Wirklichkeit, sondern etwas poietisch Geschaffenes, eine Handlung, ,wie sie wohl

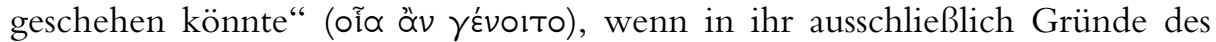
Charakters handlungsrelevant werden. ${ }^{38}$

Handelnder und Erzähler Odysseus zeigen, welchen Ruhm es schafft, seine Tugend $\mathrm{zu}$ beweisen und dabei seine eigene Identität nicht nur $\mathrm{zu}$ wahren, sondern sogar zu vollenden. Odysseus bleibt alle Erzählungen über bei dem, was er ist. Und er inszeniert sich darin, daß er sich selbst zu dem macht, der er ist.

Er tut dies aber nicht als Selbstzweck, sondern um die Phäaken zu einem Handeln zu reizen, mit dem sie sich über den Willen des Poseidon hinwegsetzen. Deshalb demonstriert er, wie er selbst dem großen Gott getrotzt hat und daraus zwar Leid, aber zum doppelten und dreifachen Ausgleich auch ewigen Ruhm erworben hat. In dieser Perspektive wird verständlich, warum Odysseus diese Episode positiv als Paradigma für sich verwenden kann, aber vor allem auch, warum und daß er damit bei den Phäaken Erfolg hat.

Um diesen Erfolg bei den Phäaken zu erklären, müssen wir den Aspekt fokussieren, daß sich für das Eingehen des Wagnisses, dafür, die Höhle des Polyphem zu betreten, der Thymos, der nach Ehre und Verwirklichung des eigenen Könnens strebt, durchsetzt. Nicht der Weitblick, der darauf sieht, was wirklich und unter Berücksichtigung aller Gefahren und möglicher Konsequenzen besser und richtig ist, bestimmt bei dem Eingehen der Peira Odysseus' Handeln - und soll aktuell ebenso nicht bei den Phäaken ihre Entscheidung für oder wider die Hilfe bei der Heimkehr bestimmen. Denn wenn Alkinoos und die Seinen zu Ende gedacht hätten, was das warnende Orakel sagt, wenn sie dieses allgemeine Wissen richtig und dem Noos gemäß aktualisiert hätten mit Bezug auf den Wunsch des irrfahrenden und von Poseidon gehaßten Odysseus, dann hätten sie ihm die Heimfahrt nicht gewähren können und mit Blick auf das für sie wahrhaft Gute nicht gewähren dürfen.

37 Diese poietische Erschaffung wird zum eigenen Handeln des Odysseus; deshalb wird sie vom epischen Erzähler ebenso wie die anderen Geschichten der Apologoi auch an keiner Stelle als Lüge, als Unwahres bezeichnet, während die kretischen Geschichten, die Odysseus auf Ithaka erzählt, eben diese Qualifizierung erhalten.

38 Schmitt, Teleologie und Geschichte bei Aristoteles, 531-536; Arbogast Schmitt, Aristoteles. Poetik. Übersetzung und Kommentar, Darmstadt 2008 (Aristoteles. Werke in deutscher Übersetzung 5), bes. 376-397. 
Odysseus' Geschichte stachelt den Thymos der Seefahrer so sehr an, daß die Lust an der Verwirklichung dessen, was für sie spezifisch ist, über das hinaus, was die Vernunft rät, unmittelbar präsent ist und zum Handlungsmovens wird. Odysseus hatte, wenn er Erfolg haben wollte, keine Wahl: Er konnte nicht versuchen, zu bewirken, daß die Phäaken vergessen, daß ihre Hilfe eine Gefahr für sie selbst darstellt. Er mußte die Situation direkt angehen. Er mußte zeigen, daß in der Lustbilanz die Vollendung der eigenen Arete sogar noch höher steht als das Vermeiden von - auch gottverhängten - Übeln und Strafen. Genau das tut er.

Nachdem Odysseus seine eigene Prüfung siegreich bestanden, seine rednerischen Fähigkeiten und praktische Klugheit bewiesen hat, ${ }^{39}$ will er sich zu

39 Odysseus wartet mit den Gefährten in der Höhle auf die Rückkehr des Polyphem (9.231ff.). Er hat das Gastrecht verletzt, als er ungebeten die Behausung des Riesen betreten und sich an dessen Vorräten gütlich gehalten hat, ein Frevel gegen Zeus Xenios, welcher später das dargereichte Dankopfer nicht annehmen wird (9.550-555). Auch dieses Verfehlen der Gunst des Zeus verschweigt Odysseus nicht, sondern es wird zum Anfang des Todes der Gefährten. Die Szene, die bei der Rückkehr des Kyklopen von Odysseus beschrieben wird, paßt nicht recht ins Bild: es scheint der Teil der Geschichte zu sein, den Odysseus nicht selbst schafft. Polyphem wird als sorgfältig fürsorglicher Hirte dargestellt, er trennt seine Herde nach Altersgruppen, bereitet die Milch und den Käse zu (zu der Frage der Sympathieerweckung mit Polyphem s. Rick M. Newton, Poor Polyphemus. Emotional Ambivalence in Odyssey 9 and 17, in: The Classical World 76.3, 1983, 137-142). Die Szene geht über die Verse 233-251: also fast 30 Verse lang. Hier passiert nichts, was die Peira des Odysseus ankündigen würde. Polyphem ist nicht als Aggressor und Rohling eingeführt, sondern als guter Hirte. Es ist bezeichnenderweise dieses Polyphem-Bild, das in der griechischen Literatur weitergewirkt hat: das bukolische Bild von Polyphem, nicht das Konstrukt des Odysseus, das menschenfressende Ungeheuer Polyphem. Polyphem redet seine „Gäste“, als er sie entdeckt hat, schroff an: fragt direkt nach ihren Namen. Seine Rede klingt dunkel, gefährlich: und dennoch läßt sich Odysseus nicht einschüchtern: die von Odysseus' Dreistigkeit überhaupt erst provozierte Unfreundlichkeit und beginnende Eskalation wird von dem Erzähler im Sinn seiner Fiktion als eine erste Gelegenheit zum Beweis der Außergewöhnlichkeit seines Charakters benutzt. Er beruft sich auf Zeus Xenios und bittet nicht nur um gastliche Aufnahme, sondern auch gleich um Gastgeschenke (9.265-270). Der Kyklop weist dieses Ansinnen - angesichts der Umstände nicht ganz ohne Recht - zurück: beruft sich darauf, daß sie selbst mächtig genug sind und sich nicht um Götter kümmern müssen: Odysseus beschreibt diese Antwort als mit ,tölpelhaftem (neleis) Thymos“" gesprochen (9.272). Tölpelhaft ungeschickt ist Polyphem tatsächlich in seiner Rede und Odysseus ihm in seiner Redegewandtheit weit überlegen. So reagiert der im Rededuell unterlegene und sprachlich gleichsam wehrlose Kyklop mit den schlimmsten Grausamkeiten, die seine körperliche Überlegenheit demonstrieren: Er tötet zwei Gefährten, schneidet sie in Stücke und verzehrt sie zum Abendessen. Nach einigem Überlegen, was zu tun sei, entschließt sich Odysseus zu dem Plan, Polyphem betrunken zu machen und zu blenden, weil dieser ihm der beste zu sein schien (mit einer Formel für richtiges Handeln formuliert, 9.318). Odysseus setzt den Plan ebenso unerbittlich durch wie Polyphem sich zuvor als Menschenfresser erbarmungslos gezeigt hatte. Mit List verhindert er, daß Polyphem Hilfe bei den anderen Riesen ho- 
seiner Tat bekennen, sie mit seinem Namen verbinden, um durch sie ewigen Ruhm zu erlangen. Er provoziert dabei schließlich den Fluch Polyphems, indem er ihm spottet und sich brüstend über die Übermacht des Poseidon erhebt (9.517-525). Polyphem bittet seinen Vater Poseidon daraufhin, Odysseus lange Irrfahren und Leiden auch noch nach seiner Heimkehr zu bereiten (9.526-536). Unheilvoll kündigt die Ablehnung des Dankesopfers, das Odysseus für die Rettung bereitet, durch Zeus die Erfüllung dieses Wunsches an (9.551-555). Der Erzähler Odysseus verschweigt dies nicht. Im Gegenteil: es wird ihm den Phäaken gegenüber zur Begründung für seine langen Irrfahren. Er wird verfolgt von der Rache des Poseidon. Dazu bekennt er sich auch in seiner Erzählung. Doch den Grund dafür hat er selbst erschaffen und in seiner Erzählung in Szene gesetzt. Es ist sein großer Ruhm, seine alles übertreffende und überwindende Findigkeit und Klugheit, die eine solche Strahlkraft besitzt, daß auch Verfehlung und Übermut sie nicht mit einem Schatten zu verdunkeln vermögen. Ein wie großer Lustgewinn dieser Ruhm und die Selbstgewißheit, mehr als alle anderen geleistet zu haben, ist, demonstriert der Erzähler Odysseus durch die Art und Weise, wie er sich zu seiner Verfehlung bekennt, eindrucksvoll.

Wir hatten schon gesehen, daß die Phäaken sich selbst rühmen, die besten Seefahrer $\mathrm{zu}$ sein und anderen freigiebig Geleit zu gewähren (7.555-563). Alkinoos folgt Odysseus' Exempel. Er nimmt die Strafe des Poseidon schließlich zugunsten des Fortschreibens des großen Ruhmes der Phäaken in Kauf: die Versteinerung des Schiffes und die Strafe, daß die Insel hinter einem Berg verborgen wird, d. h. der zivilisierten Welt, der Welt, wo Menschen wohnen, ganz entzogen und endgültig isoliert wird (13.125-187)..$^{40}$ Er tut dies ebenso, wie Odysseus die Gefahr, die ihm durch Poseidon drohte, in Kauf genommen hatte, um seinen eigenen Ruhm zu begründen und zu bewahren. Die Phäaken hätten, so heißt es im 13. Gesang, Poseidon mißachtet, weil sie sichere Führer waren für die Menschen (13.174). Sie haben damit die Gefährdung, die das Meer darstellt, für die, die sie geleiteten, aufgehoben, und die Machtausübung Poseidons behindert. ${ }^{41}$ So wie in Odysseus' selbstgewähltem Abenteuer sein Zwist mit Poseidon dadurch gerechtfertigt erscheint, daß Odysseus seine ihn vor allen anderen Menschen auszeichnenden Fähigkeiten entfaltet und dadurch Ruhm, individuellen Ruhm, erntet, so können sich auch die Phäaken brüsten, sich in ihrer eigentümlichen Arete und mit ihrem Ruhm, Geleiter der Schiffe zu sein, über Poseidon hinwegzusetzen und in diesem Akt Freude an der eigenen Fähigkeit zu gewinnen. Das, was als Frevel erscheinen kann, wird so in

len kann, indem er als seinen Namen „Niemand“ angibt (9.364-367; 387-396). Odysseus genießt seinen Sieg - als Handelnder und als Erzähler (9.413f., 417-424).

40 Vgl. Rainer Friedrich, Zeus and the Phaeacians. Odyssey 13,158, in: The American Journal of Philology 110, 1989, 395-399.

41 Daher soll die Insel vor den Augen der Menschen für immer verborgen sein, und die Phäaken sollen nicht mehr Begleiter sein für Menschen auf See und ihnen helfen. So bleibt die Machtsphäre Poseidons von nun an unangetastet. 
ein anderes Licht gerückt. Dieses Licht, das Odysseus' Erzählung entzündet, suspendiert die Frage nach der Berechtigung des Tuns und ersetzt diese durch die Suche nach dem reinen, exemplarischen Verwirklichen der eigenen Arete.

Den Makel, von Poseidon gehaßt zu sein, kann er so schließlich abschütteln, und dies schließlich selbst bei der umsichtigen Königin Arete:

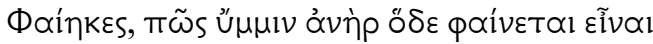

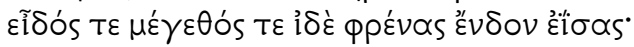

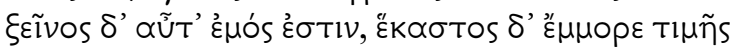

„Phaiaken, wie scheint Euch dieser Mann zu sein?

Achtet auf die schöne Gestalt und seine Größe und auf seine gute Gesinnung (

Gast ist er zudem bei mir; einem jeden aber gebührt sein Anteil an Ehre.“ $(11.336-338)^{42}$

So spricht Arete nach dem Bestehen der Prüfungen im sportlichen Wettkampf und am Ende seiner Erzählungen. Der Erfolg ist damit besiegelt.

\section{Schluß}

Odysseus erschafft und erzählt diese Geschichte. Äußerlich, dem Wort nach ist das Thema der Geschichte das Gastrecht und der kultivierte Grieche Odysseus, der die Barbaren auf ihre Gastfreundschaft testet. Das läßt der Erzähler Odysseus den Handelnden Odysseus immer wieder betonen. Es ist immer wörtliche Rede, in der das Thema Gastrecht angesprochen wird; und es ist immer der handelnde Odysseus, der diese Rede im Munde führt. Diese Technik subjektiviert die Thematik und stellt die Handlungsabsicht als das dar, was sie ist: ein Vorwand, der ganz offenbar auf etwas anderes zielt. Der Erzähler Odysseus inszeniert diese Diskrepanz zwischen Vorwand und tatsächlicher Intention geradezu. Wer die Polyphem-Geschichte also als Exempel schlechter oder pervertierter Gastlichkeit liest, erliegt dieser Inszenierung und verkennt damit den eigentlichen Fokus, in dem es um das Gelingen oder Scheitern riskanten, individualisierten Handelns geht und das unbedingte Streben nach der Verwirklichung des eigenen Kleos.

Wir verstehen in dieser Perspektive der Suche nach der Einheit der Heimkehrerhandlung der Odyssee damit besser, warum Odysseus den Phäaken diese Geschichte erzählt, und warum er sie so erzählt: Er reizt die Phäaken dazu, ihren Ruhm fortzuschreiben, indem sie einen würdigen Gast nach Hause geleiten. Es ist das Ergebnis - und der Erfolg - der Erzählkunst des Odysseus, daß dieses ruhmvolle Handeln als der wahre und wichtigste Grund für alle weiteren Leiden erscheint. Damit verdrängt diese Begründungsstrategie andere alternative Vorstellungen von der Schuld des Odysseus und setzt an deren Stelle

42 Vgl. 8.18-22. 
eine Handlung, die rein und nur das offenbart, was Odysseus zu leisten vermag, was ganz und gar ihm entspricht. Er bekennt selbst, sich dadurch schuldig zu machen. Er bekennt seinen Fehler nicht nur im Sinne einer Schuld, er affirmiert vielmehr das Übertreten des wahrhaft Besten zugunsten der thymetischen Verwirklichung der Lust am eigenen Wagemut, an der eigenen Arete und Einzigartigkeit. Er ist darin erfolgreich, dieses Exempel den Phäaken auch für die gegenwärtige Situation nahezulegen, das Übertreten des Verbotes Poseidons in seinem besonderen Lustaspekt so entfaltend, daß diese der Versuchung nicht zu widerstehen vermögen.

Die besondere Erzählkunst Homers liegt darin, daß Odysseus auch als Erzähler Handelnder bleibt. Das Erzählen wird in der Odyssee nicht zum Medium für die Reflexion auf das Erzählen und die Kunst des Singens. Weil es viel eher Demonstration vollendeter und sich selbst vollendender Individualität ist, müssen auch alle Versuche, diese Erzählung, die eine Handlung ist, auf allgemeine epische Handlungspattern oder Pattern des Dichters der Odyssee zurückzuführen, unzureichend und unspezifisch bleiben. Den Horizont für eine weiter differenzierende Lektüre durch den Blick auf die konkrete Handlungsdimension zu eröffnen, war das Anliegen dieses Beitrags.

\section{Bibliographie}

Austin, N., Archery at the Dark of the Moon. Poetic Problems in Homer's Odyssey (Berkeley 1975).

Fenik, B., Studies in the Odyssey, Hermes-Einzelschriften 30 (Wiesbaden 1974).

Friedrich, R., „Zeus and the Phaeacians. Odyssey 13,158“, in: The American Journal of Philology 110 (1989) 395-399.

Führer, R., „Art. „Nostos‘, begr. von Bruno Snell und hrsg. vom Thesaurus Linguae Graecae“, in: LfrE (2004) Sp. 432-435.

Garvie, A. F., Homer. Odyssey, Books VI - VIII (Cambridge 1994).

Hölscher, U., Die Odyssee. Epos zwischen Märchen und Roman (München ${ }^{2} 1989$ ).

Jong, I. F. de, A narratological commentary on the Odyssey (Cambridge 2001).

Kullmann, W., „Ergebnisse der motivgeschichtlichen Forschung zu Homer (Neoanalyse)“, in: ders., Homerische Motive (Stuttgart 1992) 100-134.

Latacz, J., Homer. Der erste Dichter des Abendlands, 4. überarb. und durchgehend aktualisierte Aufl. (Düsseldorf 2003).

Lexikon des frühgriechischen Epos, begr. von Bruno Snell und hrsg. vom Thesaurus Linguae Graecae (Göttingen 1979 ff.) (= LfrE).

Mattes, W., Odysseus bei den Phäaken. Kritisches zur Homeranalyse, Diss. Frankfurt (Würzburg 1958).

Most, G., „The Structure and Function of Odysseus' Apologoi“, in: Transactions of the American Philological Association 119 (1989) 15-30. 
Newton, R.M., „Poor Polyphemus. Emotional Ambivalence in Odyssey 9 and 17“, in: The Classical World 76.3 (1983) 137-142.

Propp, V., Morphologie des Märchens, dt. von Christel Wendt, hg. von Karl Eisenmacher (München 1972).

Pucci, P., Odysseus Polutropos. Intertextual Readings in the Odyssey and the Iliad, Ithaca: Pietro Pucci, 1987 (Cornell studies in classical philology. The Townsend lectures 46).

—, ,The Proem of the Odyssey“ Arethusa 15 (1982) 39-62.

Radermacher, L., „Die Erzählungen der Odyssee“, in: Sitzungsberichte der Österreichischen Akademie der Wissenschaften Wien / Philosophisch-Historische Klasse 185 (1915).

Radke, G., „Die poetische Souveränität des homerischen Erzählers“, in: Rheinisches Museum 150 (2007) 8-66.

Rengakos, A., „Narrativität, Intertextualität, Selbstreferetialität. Die neue Deutung der Odyssee“, in: M. Reichel und A. Rengakos (Hgg.), Epea pteroenta. Beiträge zur Homerforschung (Stuttgart 2002) 173-191.

Rose, G.P., „Unfriendly Phaeacians“, TAPA 100 (1969) 387-406.

Rutherford, R.B., „At Home and Abroad: Aspects of the Structure of the Odyssey“, in: Proceedings of the Cambridge Philological Society 211: N.S. 31 (1985) 133-50.

-, Homer. Odyssey, Books XIX and XX (Cambridge 1992).

Schmidt, M., „Art. ,Xenos““, in: LfgrE, Bd. 3, 16 (1996) Sp. 463-469.

Schmitt, A., Aristoteles. Poetik. Übersetzung und Kommentar, Aristoteles. Werke in deutscher Übersetzung 5 (Darmstadt 2008).

—, „Homer, Ilias - ein Meisterwerk der Literatur?“, in: Reinhardt Brandt (Hg.), Meisterwerke der Literatur von Homer bis Musil (Leipzig 2001) 9-52.

—, Selbständigkeit und Abhängigkeit menschlichen Handelns bei Homer. Hermeneutische Untersuchungen zur Psychologie Homers, Abhandlungen der Geistes- und Sozialwissenschaftlichen Klasse Akademie der Wissenschaften und der Literatur 5 (Stuttgart 1990).

-, „Teleologie und Geschichte bei Aristoteles oder Wie kommen nach Aristoteles Anfang, Mitte und Ende in die Geschichte?", in: Karlheinz Stierle und Rainer Warning (Hgg.), Das Ende. Figuren einer Denkform, Poetik und Hermeneutik 16 (München 1996), 528-563.

Seeck, G.A., „Homerisches Erzählen und das Problem der Gleichzeitigkeit“, in: Hermes 126 (1988) 131-144.

Segal, C. P., ,The Phaeacians and the Symbolism of Odysseus' Return“, in: Arion 1.4 (1962) 17-64.

Suerbaum, W., „Die Ich-Erzählungen des Odysseus. Überlegungen zur epischen Technik der Odyssee“ Poetica 2 (1968) 150-177.

Tsagarakis, O., „On Simultaneous Actions in Homer“, in: M. Païsi-Apostolopoulou (Hg.), Proceedings of the 9th International Symposium on the Odyssey (2-7 September 2000), (Ithaca 2001) 355-366.

Vries, G. J. de, „Phaeacian Manners“, in: Mnemosyne 30 (1977) 113-121.

Zielinski, T., „Die Behandlung gleichzeitiger Ereignisse im antiken Epos“, in: Philologus Suppl. 8 (1899-1901) 405-449. 


\title{
Bemerkungen zum antiken Homertext
}

\author{
ANTONIOS RENGAKOS
}

In den letzten vier Jahrzehnten hat sich die antike Homerphilologie zweifellos zu einem der am intensivsten erforschten Gegenstände der Klassischen Philologie entwickelt. Textausgaben, Fragmentensammlungen, Spezialuntersuchungen oder Gesamtdarstellungen und nicht zum wenigsten das Lexikon des frügriechischen Epos haben wichtige Resultate erzielen können, aber auch heftige Kontroverse ausgelöst. Trotzdem wird man mit der Behauptung kaum fehlgehen, daß sich in jüngster Zeit in wichtigen Fragen eine communis opinio abzuzeichnen scheint. Das Ziel dieses Beitrags ist die kritische Bestandsaufnahme des Geleisteten, aber auch der Versuch, zu noch ausstehenden Problemen Stellung zu nehmen. Ich werde mich dabei auf zwei Probleme konzentrieren, ein allgemeines, und ein spezielles - beide sind für die Geschichte der Philologie von nicht geringer Bedeutung.

Zuerst das allgemeine Problem: Im Blickpunkt des Forschungsinteresses steht nach wie vor die Kardinalfrage der antiken Homerphilologie, das Problem der Arbeitsweise und der Methode der Alexandriner, konkreter gesagt die Frage, ob die Homerkritiker Handschriften verglichen haben oder ob ihre Lesarten auf Konjektur beruhen; den Anlass zur Behandlung dieser allgemeinen Frage liefert uns ein engstens mit ihr verbundenes spezielles Zetema der antiken Homerkritik, dasjenige der Quellen des Didymos, das jüngst (wieder) kontrovers diskutiert worden ist. Das zweite Spezialproblem, das ich ebenfalls besprechen möchte, ist das Problem der konkreten Gestalt der zenodoteischen Homerausgabe.

1.

Beginnen wir mit der Frage nach der wahren Natur der Lesarten, welche die antiken Zeugen Gelehrten wie Zenodot, Aristophanes von Byzanz oder Aristarch zuschreiben. Mehrheitlich - es genügt die Namen Haslam, Montanari, Nagy, Nickau, Pfeiffer oder Martin Schmidt zu nennen - ist zwar die Forschung von einigen extremen Ansichten abgerückt; ich meine einerseits die frühere, von van der Valk vertretene Theorie, welche die antiken Lesarten 
alexandrinischer Provenienz pauschal als wertlose Konjekturen verwarf, ${ }^{1}$ aber auch die jüngere Theorie van Thiels, nach der die meisten Lesarten der Alexandriner als bloße Hinweise auf Parallelstellen oder Glossen zu interpretieren seien, welche erst Mittelsmänner wie Aristonikos, Didymos usw. als Textvarianten mißverstanden hätten. ${ }^{2}$

Ein wirklicher Konsens ist aber nicht in Sicht: vor einigen Jahren hat nämlich eine gewichtige Stimme, diejenige Martin Wests, eine ebenfalls extreme Theorie aufgestellt, nach welcher einerseits alle zenodoteischen Lesarten urkundlichen Ursprungs seien (ganz einfach weil sie in der ionisch gefärbten Handschrift, welche die Grundlage seines Textes gebildet haben soll, vorhanden waren), andererseits Aristarch für die Konstitution seiner Homerausgabe(n) keine Handschriften verglichen habe. ${ }^{3}$

Mit Wests Ansichten werden wir uns später ausführlicher auseinandersetzen, an dieser Stelle sei jedoch zunächst betont, dass alte und neue Theorien dieser Art von der falschen Voraussetzung ausgehen, dass wir allgemeine Kriterien besitzen, auf Grund deren zuversichtlich zwischen beiden Arten von Lesarten (d.h. zwischen echten [ $=$ durch Handschriften überlieferten] Varianten und Konjekturen) unterschieden werden kann. Wie aber besonders Nickau in seiner Zenodot-Monographie gezeigt hat, ${ }^{4}$ Konjekturen im Homertext als Eigentum eines bestimmten alexandrinischen Kritikers zu erweisen ist unmöglich - man kann nämlich nicht ausschliessen, dass der betreffende Kritiker sie, unwissend über ihren wahren Charakter, in einem älteren Text vorgefunden hat.

Aus diesem Grund ist auch die Faustregel wertlos, die, in verschiedenen Varianten formuliert, besagt, dass die von unserem Vulgatatext abweichenden oder zumindest die durch weitere frühe Zeugnisse nicht unterstützten Lesarten der Alexandriner auf Konjektur beruhen: ${ }^{5}$ erstens ist es nicht möglich, zu jeder alexandrinischen Variante den Nachweis zu erbringen, dass die Variante unse-

1 M. van der Valk, Researches on the Text and Scholia of the Iliad, Leiden 1963.

2 Vgl. H. van Thiel, Zenodot, Aristarch und andere, ZPE 90, 1992, 1-32; Verf., Der Homertext und die hellenistischen Dichter, Stuttgart 1993, 17ff.; M. Schmidt, Variae lectiones oder Parallelstellen: Was notierten Zenodot und Aristarch zu Homer?, ZPE 115, 1997, 1-12; H. van Thiel, Der Homertext in Alexandria, ZPE 115, 1997, 13-36; F. Montanari, Zenodotus, Aristarchus, and the Ekdosis of Homer, in: G. W. Most, Editing Texts - Texte edieren, Göttingen 1998, 4ff.

3 M. L. West, Studies in the Text and Transmission of the Iliad, München-Leipzig 2001; vgl. die Rezensionen von Verf., BMCR 2002.11.15 und G. Nagy, Gnomon 75, 2003, 481-501, sowie Wests Antwort in BMCR 2004.04.17.

4 K. Nickau, Untersuchungen zur textkritischen Methode des Zenodotos von Ephesos, BerlinNew York 1977, 45; 48.

5 R. Janko, The Iliad: A Commentary, vol. IV: Books 13-16, Cambridge 1992, 25: "I agree with van der Valk that most readings where the Alexandrians lack support in the papyri and early codices are conjectures"; vgl. P. Cauer, Grundfragen der Homerkritik, Leipzig 1921-23, 64: "Welche seiner [d.h. Aristarchs] Lesarten sind Konjekturen? Die meisten Chancen haben solche Lesarten, mit denen Aristarch ganz allein steht". 
rer Vulgata voralexandrinisch und somit Zenodot, Aristophanes oder Aristarch auch bekannt gewesen sei, und zweitens können die sogenannten frühen Zeugnisse (z.B. die von den Scholien zitierten antiken Ausgaben oder die vorhandenen frühptolemäischen Papyri) nur mit einer sehr kleinen Zahl alexandrinischer Varianten verglichen werden. Ebenfalls willkürlich ist die Unterscheidung zwischen beiden Arten von Varianten auf Grund ihrer Qualität, d.h. die Annahme, gute Varianten gingen auf die Verwendung älterer Handschriften, schlechte dagegen auf konjekturale Tätigkeit zurück.

Schliesslich, auch Pasquali's Grundsatz ist haltlos, der besagt: "là dove una lezione di Aristarco è contaposta a una del suo maestro Aristofane o più spesso a una di Zenodoto, è estremamente improbabile che tutt'e due siano congetture: al più sarà congettura l'una; anzi quasi sempre, poichè ... gli editori alessandrini erano critici conservatori, non sarà nessuna delle due". ${ }^{6}$ Pasquali's Überzeugung, die Alexandriner seien konservative Kritiker gewesen und deshalb würden beide Lesarten aus zu Rate gezogenen Handschriften stammen, kann natürlich einen stichfesten Beweis nicht ersetzen.

Das Problem läßt sich also nicht auf Grund von diversen Eigenschaften der überlieferten alexandrinischen Varianten pauschal lösen, sondern nur grundsätzlich. Es muss der Beweis geführt werden, daß für die Alexandriner die Verwendung von Handschriften bei der Konstitution ihrer Homerausgaben eine zumindest wahrscheinliche Praxis darstellte. Welche Mittel besitzen wir, um diesen Beweis führen zu können? Es sind dies eine ganze Reihe von Indizien.

Das erste Indiz ist ein Analogieschluss aus den Gepflogenheiten der Schreiber von Papyri. S. West ${ }^{7}$ und Haslam ${ }^{8}$ haben darauf hingewiesen, daß einige frühptolemäische Homer-Papyri Spuren von Kollation mit anderen Homertexten bewahren. Einige Beispiele: im berühmten Ilias-Papyrus 12 aus der Mitte des 3. Jhdts. v.Chr. fügt ein zweiter Schreiber Varianten hinzu; West äußert sogar vorsichtig die Vermutung, daß diese Varianten aus mehreren verglichenen Texten stammen könnten, daß sie eine Art von ,,primitivem apparatus criticus" darstellen. ${ }^{9}$

Dasselbe Bild bieten der Odyssee-Papyrus 31 (2. Hälfte 3. Jhdts. v.Chr.), dessen Schreiber seinen Text mit (nicht besseren) Varianten aus einem anderen Text sowie mit Korrekturen versehen hat, oder der Ilias-Papyrus 51 (1. Jhdt. v. Chr.), zu dem wiederum S. West folgendes bemerkt: ${ }^{10}$ "it looks as if the signs were originally inserted, whether in this papyrus or in an ancestor, by someone

6 G. Pasquali, Storia della tradizione e critica del testo, Firenze 1952, 214.

7 The Ptolemaic Papyri of Homer, Köln-Opladen 1967, 136ff; 223; 263.

8 Homeric Papyri and Transmission of the Text, in: I. Morris-B. Powell, A New Companion to Homer, Leiden 1997, 65 f.

9 S. West, a.a.O. 137.

10 a.a.O. 133. 
who collated his copy with a Vulgate text provided with marginal signs according to the conventional system".

Nur nebenbei sei bemerkt, daß Spuren nachträglicher Korrekturen und Varianten auch in anderen frühptolemäischen, nicht-homerischen Papyri zu finden sind, etwa im Milaneser Posidippus-Papyrus, und daß die Fälle im 2. und 3. Jhdt. n. Chr. sich deutlich vermehren. ${ }^{11}$ Es drängt sich deshalb die Frage auf, die Montanari vor einigen Jahren gestellt hat: ${ }^{12}$ Ist es realistisch anzunehmen, dass eine bei der Herstellung von Kopien geläufige Praxis, die den Vergleich zwischen verschiedenen Vorlagen und die Eintragung von Korrekturen vorsah, den alexandrinischen кpıтıкоí nicht als ein Modell ihrer eigenen Aufgabe erscheinen würde, m.a.W. ist es glaubhaft anzunehmen, dass, wenn der diorthotes eines Scriptoriums den Vergleich von Kopien und deren Korrigierung als Teil seiner Techne betrachtete, diese Methode nicht durch den neuen Typus des diorthotes übernommen wurde, der sich als Gelehrter mit dem Homertext beschäftigte?

Einen zweiten Analogieschluss liefern uns die alexandrinischen DichterGelehrten, insbesondere Apollonios von Rhodos und Kallimachos. Eine stattliche Zahl alexandrinischer Lesarten wurde durch das Zeugnis ihrer Werke, die zahllose Nachahmungen homerischer Ausdrücke, Verse, Motive oder Szenen aufweisen und deshalb eine außerordentlich reiche Sammlung der memoria Homerica darstellen, als urkundlichen Charakters erwiesen. Es werden bezeugt:

- Bindefehler zur älteren homerischen Tradition (die Verse 3.881f. aus den Argonautika des Apollonios sind ein "Zitat" von Od. 6.102ff. in der Version des Peripatetikers Megakleides [4. Jhdt. v. Chr.]),

- die übereinstimmende Verwendung einer homerischen Variante durch einen hellenistischen Dichter, einen frühptolemäischen Papyrus und eine alexandrinische Ausgabe (z.B. ahmt Argon. 4.1571f. Il. 6.4 nach, und zwar in der Version von Pap. Il. 410 [= P. Hibeh 193, ca. 270-230 v.Chr.] und von Pap.

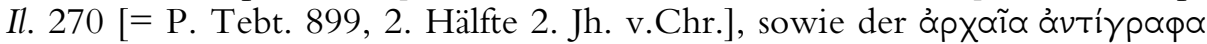
und der ersten Aristarch-Ausgabe),

- das gleichzeitige Vorkommen der Lesart der Vulgata und einer von ihr abweichenden Variante (z.B. Argon. 2.930-45 Il. 2.853-5 in der Version der Vulgata und Strabons),

- die klare Vorwegnahme von Lesarten, die uns bislang unter den Namen späterer Homerkritiker bekannt waren (z.B. Argon. 3.1088f. nach Od. 6.9f. mit Rhianos' Lesart, oder Call. fr. 177.17 Pf. Od. 12.252 mit Kallistratos' Variante). ${ }^{13}$

11 F. Montanari, Ekdosis alessandrina: il libro e il testo, Exemplaria Classica 1, 2009,146ff.

12 Alexandrian Homeric Philology. The Form of the Ekdosis and the Variae Lectiones, in: M. Reichel-A. Rengakos (Hrsg.), Epea pteroenta. Beiträge zur Homerforschung. Festschrift ... W. Kullmann, Stuttgart 2002, 135.

13 Die vier genannten Fälle werden in Verf., Der Homertext..., 128; 154f.; 129; $127 f$. besprochen. 
Wenn also zwei Dichter-Gelehrten der frühptolemäischen Zeit wie Apollonios und Kallimachos für ihre Dichtungen sich nicht mit einer Kopie des Homertextes begnügen, sondern mehrere zu Rate zogen, so dürfen wir wohl annehmen, dass dieselbe Vorgehensweise für die professionellen HomerKritiker selbstverständlich gewesen sein muss.

Ein drittes Mittel, unsere Frage zu lösen, ist der Versuch, die Herkunft alexandrinischer Varianten aus älterer Tradition zu beweisen, m.a.W. echte Bindefehler zur älteren Homerüberlieferung ausfindig zu machen. Seit Wolf, Düntzer und Wecklein gibt es zwar eine Reihe von mehr oder weniger aussagekräftigen, immer wieder genannten Fällen, welche die zenodoteische Ausgabe betreffen, wirklich überzeugend ist jedoch nur eine sehr geringe Anzahl unter ihnen. Es muss gleich hervorgehoben werden, dass dies nicht weiter störend ist, weil es nur auf das Grundsätzliche ankommt: überspitzt formuliert, genügt es nachzuweisen, dass z.B. zwischen den als zenodoteisch überlieferten Lesarten und der älteren Homerüberlieferung ein einziger Bindefehler existiert, um grundsätzlich die Verwendung von Handschriften durch den Ephesier

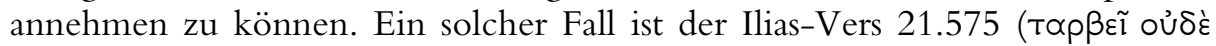

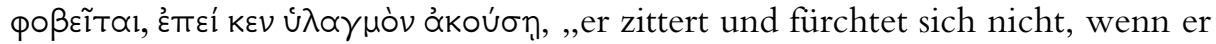
das Gebell hört"), wo unsere handschriftliche (und auch die antike) Vulgata

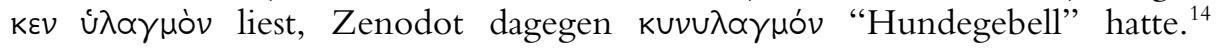

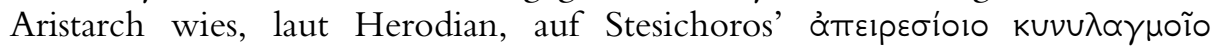
(PMGF 255) hin, d.h. er stellte fest, daß Zenodots Lesart sich respektablen Alters erfreute, und verwarf sie trotzdem aus semasiologischen Gründen.

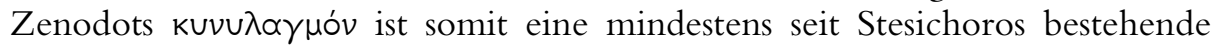
Variante und keine Konjektur des Ephesiers. Auch mit dem vielberufenen

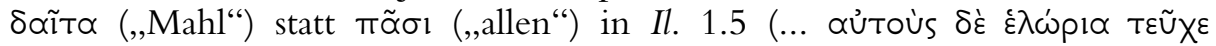

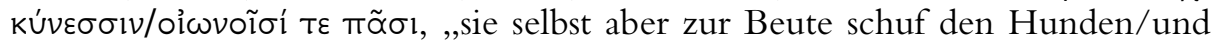
allen Vögeln“ bzw. „den Vögeln zum Mahl“) folgte Zenodot einer Lesart des 5. Jhdts., welche den drei großen Tragikern bekannt gewesen ist (vgl. A. Suppl. 800f., S. Ant. 29-30, E. Ion 504f., Hec. 1078). ${ }^{15}$ Was die Auslassungen von Versen betrifft, so gibt es wiederum mindestens einen sicheren Fall, wo Zenodot älterer Überlieferung gefolgt sein muss. Den Vers Il. 21.195 hat bereits der Peripatetiker Megakleides (4. Jhdt.) nicht berücksichtigt, so daß sich Zenodot, der ihn laut Aristonikos z.St. "nicht schrieb", aller Wahrscheinlichkeit nach auf handschriftlicher Grundlage stützte.

Ausser diesen drei indirekten Indizien gibt es auch ein viertes, diesmal direktes, das die antiken Homerscholien selbst liefern. Sie bezeugen auf unmißverständliche Weise, daß die Alexandriner sowohl Handschriften verglichen als auch Konjekturen vorgenommen haben. Damit sind wir aber bei einem der

14 Nickau, Untersuchungen ... 34f.

15 R. Pfeiffer, Geschichte der Klassischen Philologie. Von den Anfängen bis zum Ende des Hellenismus, München 1978, 142ff.; anders van der Valk, Researches ..., Bd. II, 66ff. und Nickau, Untersuchungen ..., 42, Anm. 32. 
beiden Spezialproblemen gelangt, demjenigen der Quellen des Didymos, das durch das bereits erwähnte Buch von M. West wieder aktuell geworden ist. Es lohnt sich kurz Wests zentrale These in Erinnerung zu rufen, denn, obwohl die Reaktionen auf sie eher negativ ausgefallen sind, ${ }^{16}$ es auch nicht an zustimmenden Urteilen gefehlt hat. ${ }^{17}$

\section{2.}

Wests Theorie über die Quellen des Didymos greift übrigens z.T. eine bereits durch Karl Lehrs vorgetragene Auffassung auf, ${ }^{18}$ der seinerzeit Arthur Ludwich energisch entgegengetreten ist. ${ }^{19}$ West behauptet nun, die Analyse des Wortlauts der didymeischen Scholien führe zu dem Schluss, dass Aristarch außer der zenodoteischen und der aristophanischen (sowie gelegentlich der Lesarten des Philitas, des Apollonios Rhodios und des Eratosthenes) keine weiteren Ausgaben oder Handschriften zu Rate gezogen habe und dass es erst Didymos selbst gewesen sei, der folgende, von ihm zitierte Ausgaben direkt benutzt habe: die Ausgaben des Antimachos, des Rhianos (sei es auf direktem Weg oder über Kallistratos), des Kallistratos (dem er Kenntnis auch der Argolike Ekdosis verdankt), des Aristarch, des Seleukos (dem er Lesarten aus der Kypria, der Kretike und der sogenannten Polystichos verdankt), die Massaliotike, die Chia und vielleicht die Sinopike. Aristarchs ekdoseis und hypomnemata entnimmt Didymos lediglich die Lesarten Zenodots und des Aristophanes. ${ }^{20}$ Aristarch hat also, so die Konsequenz von Wests Theorie, für seine Homerausgabe ausschliesslich innere, Konjektural-, keine äußere, diplomatische Kritik geübt.

Die entscheidende Frage sei sofort gestellt: wird Aristarch in den Didymosoder Aristonikosscholien als andere Ausgaben konsultierend zitiert? Nur nebenbei sei jetzt schon folgendes sich zu fragen erlaubt: wie wahrscheinlich ist es, dass, wie West annimmt, ausgerechnet die drei bedeutendsten Homerkritiker, Zenodot, Aristophanes und Aristarch, keine Handschriften verglichen haben und dass dies als erster eine Nebenfigur der alexandrinischen Homerphilologie wie Kallistratos oder die Kompilatoren der augusteischen Zeit (Didymos) getan haben sollen? Doch zurück zu den Zeugnissen der Scholien.

16 J.-F. Nardelli, Éditer l'Iliade. La transmission et ses débats: perspectives critiques, Gaia 5, 2001, 62f.; R. Janko, Seduta di chiusura, in: F. Montanari (Hrsg.), Omero tremila anni dopo, Roma 2002, 659; G. Nagy, Rez. West, Gnomon a.a.O.; F. Montanari, La filologia omerica antica e la storia del testo omerico, in: A. Bierl-A. Schmitt-A. Willi, Antike Literatur in neuer Deutung (FS Latacz), München-Leipzig 2004, $129 \mathrm{f}$.

17 R. Führer-M. Schmidt, Homerus, Ilias rec. Martin L. West, GGA 253, 2001, 4ff.

18 K. Lehrs, De Aristarchi studiis Homericis, Leipzig 1882, $26 f$.

19 A. Ludwich, Aristarchs homerische Textkritik (nach den Fragmenten des Didymos dargestellt und beurtheilt), Bd. I, Leipzig 1884, 43f.

20 Siehe die zusammenfassende Tabelle West, Studies 84. 
Die Abgrenzung aristarchischer Fragmente in den Homerscholien ist ein notorisches Zetema (nicht von ungefähr besitzen wir immer noch keine Fragmenten-Sammlung Aristarchs!), ich will deshalb zunächst nur die wirklich unumstrittenen Fälle besprechen. Ich lasse deshalb das in Wests sowie Schmidts und Führers Augen zweifelhafte Didymosscholion zu Il. $1.423-424$ beiseite, ${ }^{21}$

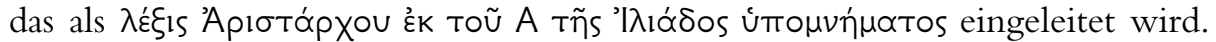

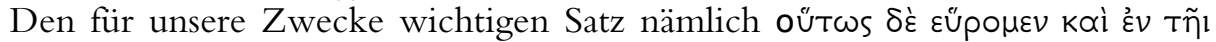

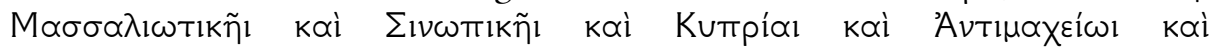

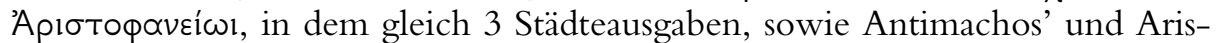
tophanes' Ausgabe zitiert werden, lassen die genannten Forscher nicht als Teil

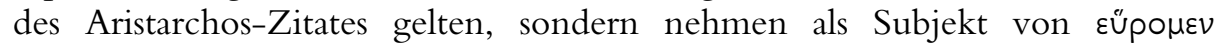
Didymos selbst an - ich finde zu Unrecht, eine detaillierte Diskussion dieses wichtigen Zeugnisses würde aber zu weit führen.

Konzentrieren wir uns auf zwei andere Zeugnisse, in denen auf unmißverständliche Weise davon die Rede ist, daß Aristarch die Wahl seiner Lesart vom Vergleich mehrerer Handschriften abhängig macht:

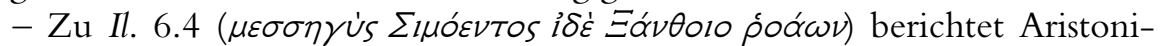

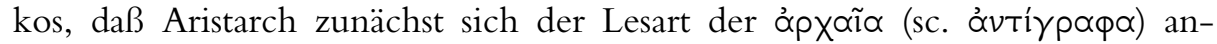

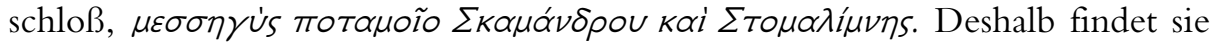

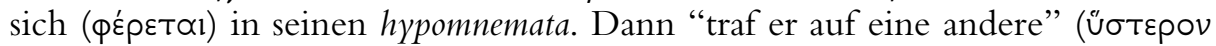

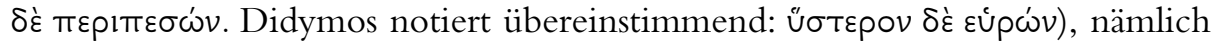

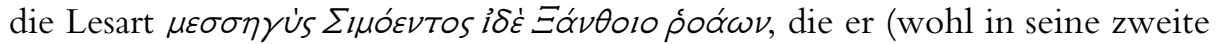
Ausgabe) übernahm ( $\varepsilon \gamma \rho \propto \psi \varepsilon)$.

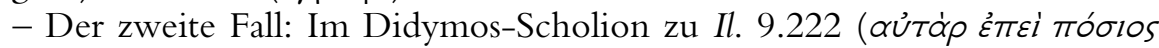

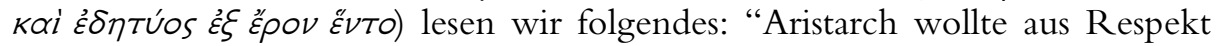
vor der Lesart $\xi^{\xi} \xi \xi \xi \rho \circ \varepsilon^{\prime \prime} \nu T 0$, die er in mehreren Ausgaben vorfand, nichts än-

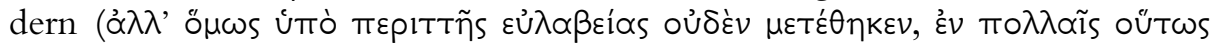

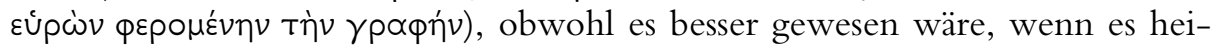

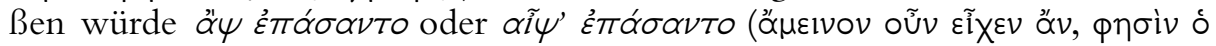

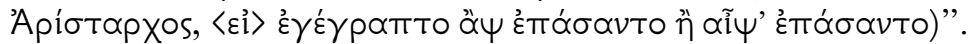

In einer anderen Reihe von Fällen notieren Aristonikos bzw. Didymos, Aristarch berichte ( $(\eta \sigma i)$ ), "einige" Ausgaben (der verwendete Ausdruck ist Tıvย́s oder દ้vıı) würden diese oder jene Lesart bieten; ich zitiere Didymos zu

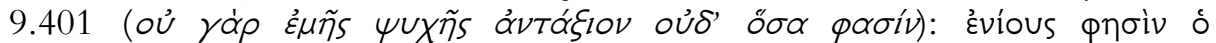

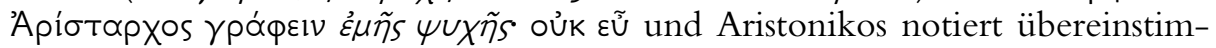

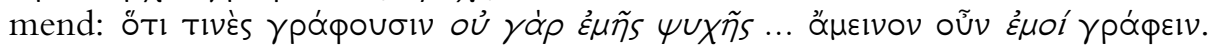
Insgesamt gehören dieser Kategorie fünf Fälle, die Scholien zu den Ilias-Versen 3.230a, 9.159, zum genannten Vers 9.401, zu 11.142 und zu 16.105.

Aus den angeführten Stellen ist nur ein Schluss möglich: nach seinen eigenen Worten berücksichtigt Aristarch bei der Konstitution seines Homertextes Lesarten aus anderen Homerausgaben, die er entweder verwirft oder - was

21 West, Studies 70f.; Führer-Schmidt, GGA 5f. (mit der früheren Literatur). Die Gegenposition: Nagy, Gnomon 490f. 
seltener bezeugt ist - denen er folgt - in einem Fall widerwillig und ausdrücklich nur aus dem Grund, weil die betreffende Lesart von der Mehrheit der ihm zur Verfügung stehenden Handschriften überliefert wurde. Dass die unbestimmten Bezeichnungen tıvés oder हैvıı von Aristarch selbst stammen, wird durch den Zitatcharakter der erwähnten Scholien bewiesen. Wie aber Ludwich gezeigt hat, ${ }^{22}$ ist es bisweilen möglich, durch die Kombination der Didymos- und der Aristonikosscholien eine oder mehrere dieser ungenannten Ausgaben zu identifizieren, was wir hier nicht weiter verfolgen wollen; nur nebenbei sei bemerkt, dass sich unter diesen Ausgaben erwartungsgemäss die

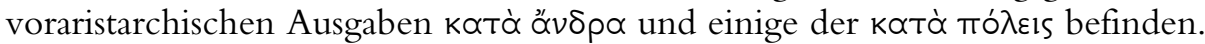
Entgegen Wests Meinung hat also Aristarch ältere Ausgaben - erinnert sei an

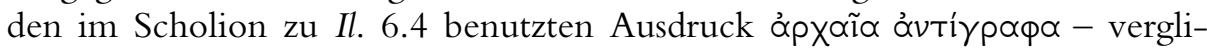
chen.

Bislang haben wir Zeugnisse besprochen, die Aristarch mit der direkten Überlieferung des Homertextes beschäftigt zeigen. Ebenso interessant sind aber diejenigen Scholien, die zeigen, dass die Alexandriner auch die indirekte Überlieferung der Ilias und der Odyssee berücksichtigt haben, d.h. die Homerzitate in der archaischen, der klassischen und besonders der hellenistischen Dichtung. ${ }^{23}$

Einen ersten Fall haben wir bereits kennengelernt: Aristarch weist zum Vers 575 aus Ilias 21 auf Stesichoros hin, dessen Homernachahmung die zenodoteische Lesart bestätigt, die er aber selber (Aristarch) aus semasiologischen Gründen ablehnt.

Einen zweiten Fall stellen die Odyssee-Verse 6.244f. dar (es handelt sich um

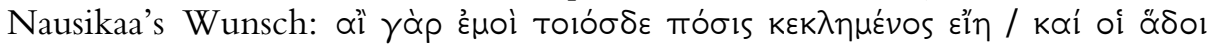
aỦTó $\left.\theta_{1} \mu \dot{i} \mu v \varepsilon ı v\right)$ : laut schol. HQ z.St. hat Aristarch die zwei Verse athetiert, den ersten aber nur zögernd, weil ihn auch Alkman zu benutzen scheint (fr. 81

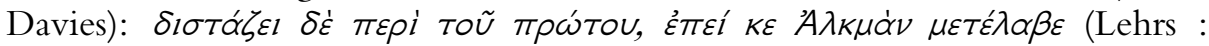

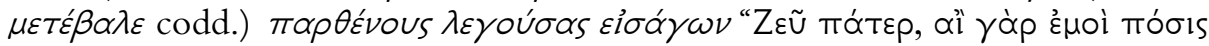
हïn”. Wieder trifft Aristarch eine textkritische Entscheidung unter ausdrücklicher Berücksichtigung der indirekten Überlieferung.

Zwei weitere Dichter zieht Aristarch bei seiner Entscheidung zu Rate, ob

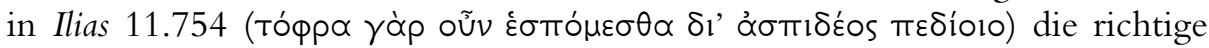
Form des Adjektivs ớ $\sigma \pi \_\delta$ śs oder $\sigma \pi 1 \delta \varepsilon \dot{s}$ ist. In einem wörtlichen Aristarch-

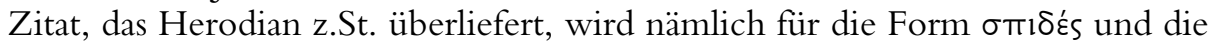

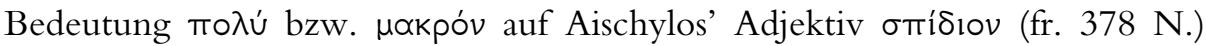

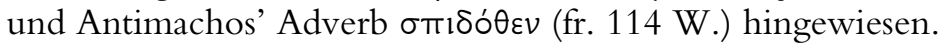

22 Ludwich, Textkritik 2.127f.

23 Weitere Beispiele für die Berücksichtigung von hellenistischen Dichtern durch die alexandrinischen Kritiker bei F. Montanari, Filologi Alessandrini e poeti alessandrini, Aevum Antiquum 8, 1995, 47-63; Verf., Aristarchus and the Hellenistic Poets, Seminari Romani di Cultura Greca 3, 2000, 325-335 und F. Montanari, Callimaco e la filologia, in: Callimaque, Entretiens Hardt 48, Vandoeuvres-Genève 2002, bes. $70 \mathrm{ff}$. 
Das letzte Beispiel betrifft den hellenistischen Epigrammatiker Posidippos

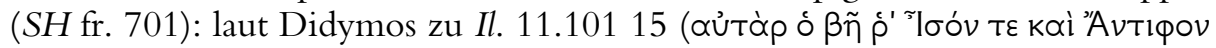
$\dot{\varepsilon} \xi \varepsilon v \propto \rho i \xi \omega v)$ las Zenodot $\beta \tilde{\eta}^{\top}{ }^{\top} \mid \sigma o ́ v$. Aristarch, so Didymos weiter, der der Lesart

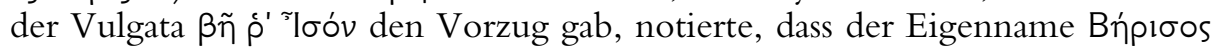
nicht mehr in den Epigrammen des Posidippos überliefert wird, sondern im sogenannten Soros; wahrscheinlich, so fügt Aristarch hinzu, habe Posidippos den Namen eliminiert, nachdem er kritisiert worden ist. M.a.W.: der Epi-

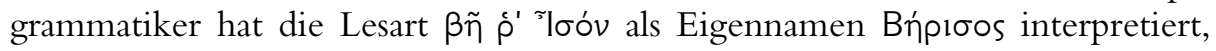
später aber (vielleicht nach der Publikation des zenodoteischen Homertextes Zenodot wird dann derjenige gewesen sein, der Posidippos kritisiert hat) die Lesart verworfen. ${ }^{24}$

Auch Aristarchs Rivale Krates griff auf das Zeugnis der Dichter zurück. In

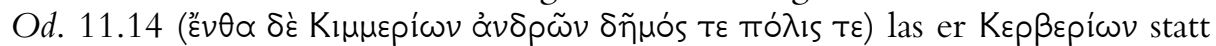
des von der gesamten direkten und indirekten Überlieferung gestützten und

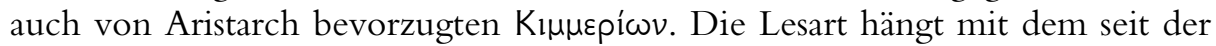
Antike bestehenden Problem der Lokalisation dieses Volkes zusammen. Krates verwarf die Identifizierung mit den historischen Kimmeriern, die ja nicht weit von Griechenland lebten, und lokalisierte sie wahrscheinlich in der Polgegend, wo er auch die Unterwelt wähnte ( K ́⿱㇒㠯 $\beta \varepsilon \rho p o s)$. Eustathios notiert zu Od.

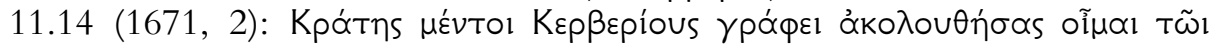

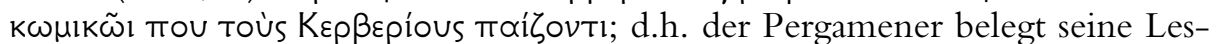
art mit einem Aristophanes- (Ra. 187: in's Kepßepious) und vielleicht auch

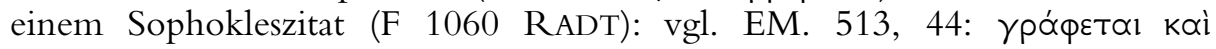

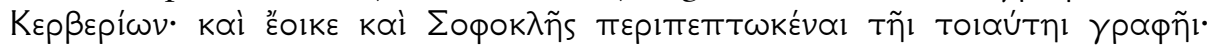

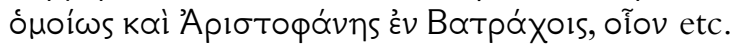

Der Rückgriff der alexandrinischen Philologie auf die direkte und die indirekte Homer-Überlieferung ist also in den Scholien selbt bezeugt. Ausdrückliche Zeugnisse der Konjekturalkritik der Alexandriner sind leider in den Scholien nicht mit Sicherheit zu identifizieren. Es fehlt nämlich eine spezifische

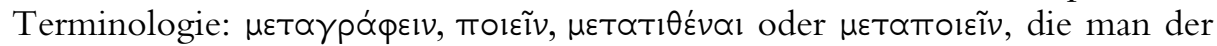
Bedeutung nach als in Frage kommend denken könnte, sind von einfachem

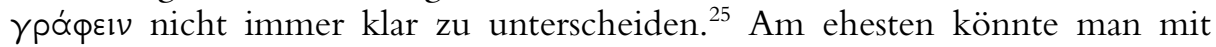
einer gewissen Berechtigung vermuten, dass wir es an Stellen, wo die Wen-

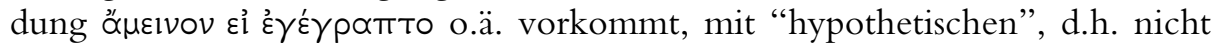
in den Text übernommenen Konjekturen, mit philologischen Gedankenspielen zu tun haben. ${ }^{26}$ Am representativsten ist auch diesmal das Didymos-

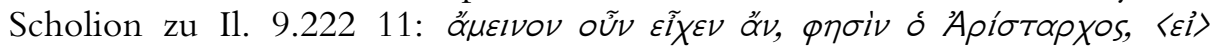

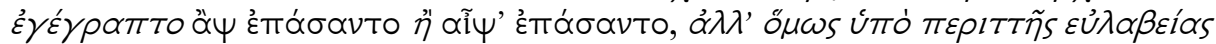

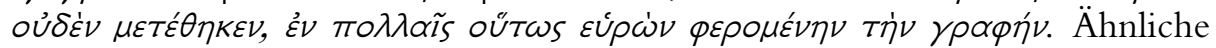

24 Zum Soros vgl. A. Cameron, The Greek Anthology from Meleager to Planudes, Oxford 1993, Appendix V, 369-376; K. Gutzwiller, Poetic Garlands, Berkeley etc., 154ff.

25 Ludwich, Textkritik 2.104f.

26 Pace Ludwich, Textkritik 2.84f. 
Konditionalsätze werden auch in den Didymos-Scholien zu Il. 8.235 oder 16.636 verwendet.

Wir fassen zusammen: nach ausdrücklichem Ausweis Aristarchs - die besprochenen Fälle stammen alle ausnahmsweise aus direkten Aristarch-Zitaten berücksichtigt er bei der Konstitution seines Homertextes sowohl die direkte

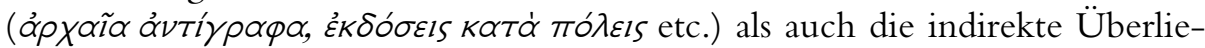
ferung (Homerzitate und -nachahmungen in der archaischen, klassischen und hellenistischen Dichtung). Wie Montanari vor einigen Jahren es formulert hat, handelt es sich bei dieser Vorgehensweise der Alexandriner um einen kulturellen Durchbruch, den Durchbruch von der mechanischen Korrektur eines Textes durch den diorthotes eines Scriptoriums, der Vorlage und Abschrift miteinander verglich, zu der Erkenntnis, dass ein literarischer Text eine Überlieferungsgeschichte hat, während deren er an verschiedenen Stellen entstellt werden könnte, und dass der Originalzustand durch Konjekturen und durch die Auswahl der besseren unter den überlieferten Lesarten wiederhergestellt werden kann.

3.

Kommen wir nun zum zweiten Spezialproblem, das wir untersuchen wollten, der Frage nach der konkreten Gestalt des zenodoteischen Homertextes. Man nahm früher an, ${ }^{27}$ daß es sich um einen fortlaufenden Homertext handelte, der einerseits die zenodoteischen Lesarten enthielt, andererseits an den Rändern Obeloi, das Zeichen für die Athetesen, aufwies; an den Stellen, an denen die Athetesen Zenodots notwendigerweise auch Textveränderungen mit sich zogen, schlug Ludwich vor, daß Zenodot diese Textveränderungen nur supralinear andeutete. Doch beginnend mit Pfeiffer setzte sich eine andere Ansicht durch; Pfeiffer schreibt:28 "Es ist nicht ausgeschlossen, daß Zenodot nach Überprüfung der Handschriften in der Bibliothek einen Homer-Text, der ihm besser als die anderen zu sein schien, als Grundlage auswählte; seine Mängel wird er durch bessere Lesarten in anderen Handschriften oder durch seine eigenen Konjekturen verbessert haben ... Man kann sich kaum ein anderes Vorgehen vorstellen." Und er fährt mit dem Beispiel der italienischen Humanisten fort, die für ihre Ausgabe lateinischer Klassiker einen codex pervetustus zu wählen pflegten, dem sie folgten und den sie gelegentlich durch Vergleich mit anderen Codices sowie durch eigene Konjekturen emendierten. Also: Wahl eines besseren Textes aus den in der Bibliothek zur Verfügung stehenden Handschriften, der durch echte Varianten und Konjekturen emendiert wird -

27 H. Düntzer, De Zenodoti studiis Homericis, Göttingen 1848, 182, Ludwich, Textkritik 2.133f. mit Anm. 113 und G. M. Bolling, The External Evidence for Interpolation in Homer, Oxford 1925, 130.

28 Geschichte 141f. 
Pfeiffer äußert sich leider nicht darüber, wie er sich die konkrete Form vorstellt, in der die Varianten, Athetesen, Auslassungen etc. durch Zenodot in diesen Text eingetragen wurden.

Konkreter sind die Vorstellungen von Nickau:" "dann ist zu fragen, ob Zenodot nicht einen durch Recensio ermittelten Homertext zugrundelegte (der jedoch nicht seinen Vorstellungen von der genuinen Form der Epen entsprach), diesen mit Obeloi versah und $\mathrm{zu}$ ihm Textvorschläge sowie deren Begründung mitteilte". Also wiederum kein autographer Text Zenodots, sondern ein aus den vorhandenen ausgewählter, in dem lediglich die Obeloi eingetragen waren - alle Textvorschläge, Varianten, Auslassungen und Versumstellungen erfolgten mündlich. Nickau führt zwei Gründe an, warum er einen von Zenodot selbst stammenden, fortlaufenden Homertext verwirft, der alle für den Ephesier bezeugten Lesarten enthielt und dem die Obeloi beigegeben waren: zum einen wegen der beiden Stellen (Il. 2.226-228 und 3.334-338a), an denen zenodoteische Athetesen gleichzeitig auch Veränderungen des Kontextes nach sich ziehen, und zum anderen, weil spätere Autoren oft auch über Zenodots Begründüngen seiner Texteingriffe zu berichten in der Lage sind.

Das erste Problem wurde bereits, wie gesagt, durch Ludwich befriedigend gelöst, ${ }^{30}$ der annahm, daß Zenodot solche Texteingriffe "über der betreffenden Zeile durch Überschreiben" andeutete. Zum zweiten Problem läßt sich jetzt schon soviel sagen, daß man zwischen "Begründungen", die natürlich nur mündlich vorgetragen werden konnten, da Zenodot wie bekannt keinen schriftlichen "Kommentar" hinterließ, und Varianten oder Auslassungen unterscheiden muß, die man sich wohl am einfachsten in einem zenodoteischen Homertext eingetragen vorstellen kann. Doch darüber später.

Am gründlichsten hat sich schließlich Franco Montanari mit der Frage der Form der zenodoteischen Ausgabe beschäftigt. In einer Reihe von Arbeiten hat er alle Aspekte des Problems untersucht und ein präzises Bild des zenodoteischen Homertextes entworfen. Für meine weiteren Ausführungen werde ich mich also auf seine kenntnisreiche und besonnene Diskussion stützen.

Auch Montanari nimmt für Zenodots Arbeit einen nicht vom Ephesier selbst stammenden Text, sondern einen mit Sorgfalt ausgewählten, ionisch gefärbten Text als Grundlage (Montanari stimmt hier West zu). Im Gegensatz aber zu Nickau nimmt er - ich glaube zu Recht - an, daß die Texteingriffe schriftlich und nicht mündlich erfolgten: die Athetesen durch die Beigabe des Obelos, die Varianten als Randnotizen und die Versauslassungen durch einen der Mittel, die auch in den literarischen Papyri gängig sind; ich zitiere: "a horizontal or oblique stroke could be drawn above the words or letters to be eliminated, or they could be marked by dots or lines above or below them, or

29 'Zenodotos von Ephesos', RE Xa (1972), 30.

30 Textkritik 2.134; s. auch Düntzer 182 und G. M. Bolling, The Athetized Lines of the Iliad, Baltimore 1944, 73. 
alternatively they could be enclosed within a pair of lines like round parentheses". ${ }^{31}$

Um gleich meine Meinung vorwegzunehmen: ich habe zwei Einwände gegen dieses Bild: einen speziellen, der die Art, mit der Zenodot die Auslassung von Versen markierte, betrifft, und dann einen allgemeineren: warum sollen wir eigentlich nicht an einen unter Zenodots Anleitung gefertigten Text denken, der seine Varianten nicht als Randnotizen, sondern im fortlaufenden Text selbst eingetragen aufwies, und die ausgelassenen Verse nicht als durchgestrichene, unterstrichene oder wie auch immer markierte Verse enthielt, sondern einfach wegließ?

Beginnen wir mit dem Problem der Auslassung von Versen. Die in den Scholien benutzte Terminologie ist wie bekannt schwankend: für diese Art von Texteingriff werden mehrere Ausdrücke verwendet - Nickau hat sie in

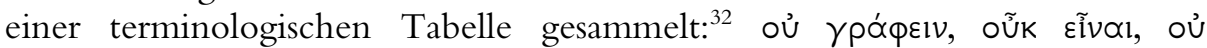

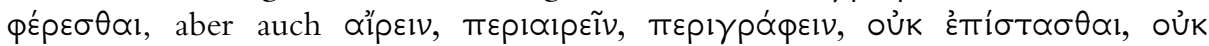

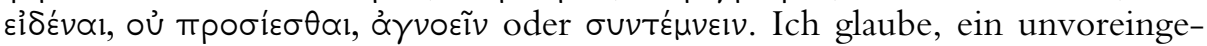
nommener Leser würde gleich zugeben, daß, wie Nickau selbst eingesteht, ${ }^{33}$ diese Ausdrücke den Eindruck vermitteln, "in allen diesen Fällen werde nicht der sozusagen textkritische Apparat Zenodots, sondern sein Homertext beschrieben", m.a.W. sie geben wieder, nicht was aus irgendwelchen Zeichen erschlossen werden könnte, sondern was der Benutzer im zenodoteischen Original oder in dessen Abschriften vorfand bzw. nicht vorfand.

Montanari, der diesen terminologischen Einwand sehr wohl gesehen hat, meint einerseits, dass neben den als auszulassenden markierten Versen ein oủ rpóqsılv oder ähnliches stehen könnte, und andererseits, dass die übrigen Ausdrücke eine vereinfachende und unpräzise Art seien, um diesen Eingriff zu beschreiben. ${ }^{34}$ Ich will zugeben, dass oủ Ypóxpsı gerade noch als Randbemer-

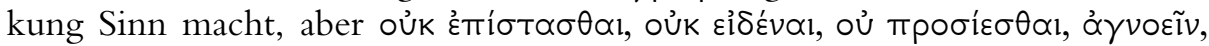

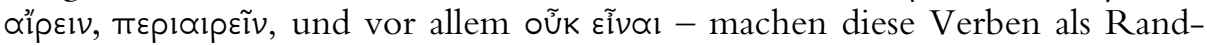
kommentar oder als Beschreibung dessen, was im Text nicht vorhanden ist, mehr Sinn? Sie sind unpräzise und mannigfaltig aus dem einfachen Grund, weil die Auslassung ein "einfacher", direkter und kein raffinierter, indirekter, sozusagen halbherziger Eingriff wie die Athetese ist, und für solch einen Eingriff ist kein spezieller Ausdruck, kein terminus technicus nötig - die Beschreibung des Nicht-Vorhandenseins genügt deshalb vollkommen.

31 Zenodotus, Aristarchus ... 6.

32 Untersuchungen ... 25ff.

33 A.a.O. 13.

34 Zenodotus, Aristarchus ... 7. S. auch F. Montanari, Callimaco e la filologia, in: L. Lehnus-F. Montanari (Hrsg.), Callimaque. Entretiens sur l'antiquité classique 48, Vandoeuvres-Genève 2002, 62ff.. 
Gegen diese wie mir scheint einfachste Lösung könnte man mit Montanari

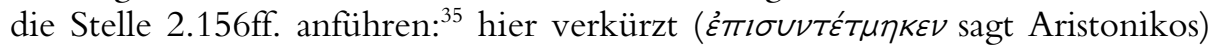

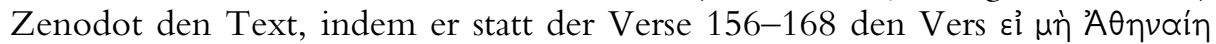

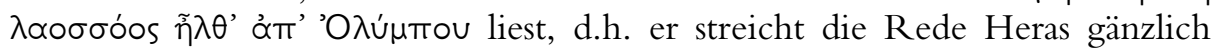

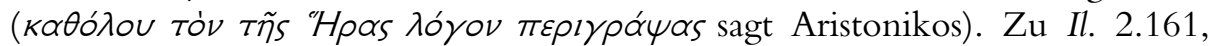
einem also von Zenodot ausgelassenen Vers, wird eine Lesart des Ephesiers

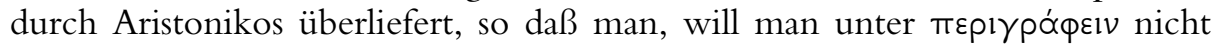
einen speziellen Texteingriff, d.h. den Einsatz von Klammern, verstehen, sich die ausgelassenen Verse als doch im Text vorhanden denken müßte, womit unsere Hypothese von einem Text, in dem die ausgelassenen Verse auch wirklich nicht vorhanden waren, hinfällig würde.

Doch Nickau hat treffend darauf hingewiesen, ${ }^{36}$ daß sowohl hier als auch im zweiten, ähnlich gelegenen Fall der von Zenodot ausgelassenen Verse Il. 2.111-118, wo ebenfalls eine zenodoteische Variante zu einem dieser Verse (111) überliefert wird, es sich um Wiederholungsverse handelt $(2.161=2.177$ und $2.111=9.18$ ) und somit wahrscheinlich sei, dass Aristonikos' Erwähnung der Varianten sich auf das spätere Vorkommen dieser Verse beziehen könnte.

Nichts, so meine Schlußfolgerung, spricht also gegen die Annahme, daß Zenodot die auszulassenden Verse in seinem Text nicht irgendwie graphisch markierte, sondern einfach nicht schrieb. Man bedenke zusätzlich, daß, während Zenodot den Obelos für seine Athetesen einführte, für das Weglassen jedoch von Versen, das gewiß eine viel wichtigere Textentscheidung darstellt, kein kritisches Zeichen überliefert ist. Ließ Zenodot diese Verse in seinem Exemplar einfach stehen und verdammte sie nur mündlich? Und ist es dann wahrscheinlich, daß er ein Zeichen nur für die doch "harmloseren" Athetesen erfunden hätte?

Wenn also die von Zenodot ausgelassenen Verse in seinem Text einfach fehlten, warum sollten seine Varianten als Randnotizen erscheinen und nicht vielmehr im fortlaufenden Text eingetragen sein? Einen Grund dafür kann ich nicht finden. Ich fasse also meine Meinung über das zenodoteische Original zusammen: ein fortlaufender Text, der Obeloi und Varianten enthielt und die eliminierten Verse wirklich ausließ. ${ }^{37}$ Die überlieferten Begründungen dieser Texteeingriffe, darin ist Montanari zuzustimmen, stammen wahrscheinlich aus der mündlichen Tradition seiner Vorträge im Museion. Die bereits zu Aristarchs Zeiten auftretenden Unsicherheiten über einige seiner Varianten sind, ebenfalls mit Montanari, auf die Verwendung von Abschriften der Ausgabe Zenodots zurückzuführen, die wie jede Kopie zuweilen voneinander abwichen.

35 Callimaco 62f. Anm. 10.

36 Untersuchungen 13.

37 M. Haslam, Homeric Papyri and Transmission of the Text, in: I. Morris-B. Powell (Hrsg.), A New Companion to Homer, Leiden 1997, 73. 
Wie anfangs gesagt, ist die alexandrinische Homerphilologie heute dank einer Reihe kommentierter Fragmentsammlungen und spezieller Abhandlungen besser denn je erschlossen. Kontroverse gibt es immer noch, doch alte Probleme dürfen nunmehr als endgültig gelöst gelten - ich erinnere nur an Montanari's elegante Lösung des Zetemas der zwei aristarchischen HomerAusgaben. Das wichtigste ist aber, dass, indem wir in der Lage sind, uns ein genaueres Bild von der alexandrinischen Philologie zu machen und somit sie auch besser zu würdigen, die Homerkritiker nicht mehr subsidiär, als meistens unzuverlässliche Zeugen der Geschichte des Homertextes, sondern um ihrer selbst willen als wichtige Zeugen des kulturellen und intellektuellen Milieus, in dem sie wirkten, erforscht werden. 


\title{
Snells Erben: \\ Zur Geschichte des Lexikons des frühgriechischen Epos ${ }^{\star}$
}

\author{
MARTIN SCHMIDT
}

Martin Schmidt starb am 19. November 2011. Wer das LfgrE benutzt und über die Jahre seine Entstehung verfolgt hat, weiß, wie prägend und inspirierend er im Team der Autoren wirkte. Daß er, der auch nach seiner Pensionierung und zuletzt im Kampf gegen seine Krankheit noch weiter am Lexikon arbeitete, dessen Vollendung noch erlebte, war für ihn eine große Freude.

\section{Archiv für griechische Lexikographie - Thesaurus Linguae Graecae}

Am 3. Mai 1945 besetzte die britische Armee Hamburg und beendete damit die über 12-jährige Hitlerdiktatur. Am 7.Mai wurde in einer turbulenten Fakultätssitzung, die im altphilologischen Seminar stattfand, Bruno Snell als bekannter Gegner der NAZIs zum Dekan der philosophischen Fakultät gewählt. ${ }^{1}$ In dieser Funktion konnte er am 12. Mai dem Direktor des Seminars für klassische Philologie, Prof. Bruno Snell, mitteilen, dass die Staatsverwaltung schon am 3. April die von Snell als Direktor des Seminars am 9. Februar beantragte Einrichtung für griechische Lexikographie als besondere Abteilung des Seminars genehmigt hatte. ${ }^{2}$

Eine „Gründungssitzung“ hatte schon am 13. März mit folgenden fünf Personen stattgefunden: die Professoren Snell und Diller (Hans D. vertrat zu der Zeit den lateinischen Lehrstuhl in Hamburg), der Assistent Dr. Siegmann, Frl. Dr. Eva-Maria Voigt und der Student Walter Jens. Entgegen dieser durch

^ Vorgetragen am 7. Oktober 2010 auf dem Colloquium zum Abschluss der Arbeit am Lexikon; in kürzerer Form bereits am 27. August 2009, auf dem 13.Kongress der FIEC (Féderation internationale des Associations d'etudes classiques) in Berlin im Panel 19 (die deutsche Altertumswisssenschaft). Ich habe den Text um einige interessante Details erweitert

1 Das Protokoll dieser Sitzung ist im Archiv der Universität erhalten. Zu Snells Haltung im 3. Reich s. L.Zieske, „,O', ou' und ,óxl'.75 Jahre BRUNO SNELLS „Das I-Ah des Goldenen Esels““, Hermes 138 (2011), 119-23 mit vielen wichtigen Hinweisen.

2 Die Briefe Snells vom 9. Februar (als Institutsdirektor) und vom 12. Mai 1945 (als Dekan) sind abgedruckt bei W. Beck/ D.Irmer 1996, 51f. 
Protokolle gestützten Datierung hat Snell später ${ }^{3}$ die Gründung des Archivs auf 1944 datiert. Das geschah wohl nur in pectore. ${ }^{4}$

In dem Schreiben vom Februar hatte Snell die Aufgaben des geplanten Archivs beschrieben. Ein Gesamtkatalog der griech. Wörter (große Zettelkasten wie in München) sollte erstellt und einzelne Speziallexika (genannt werden ein Lexikon zu Homer, eins zu den archaischen Lyrikern und eines zu Aischylos) gedruckt werden. „Es würde also mit der Zeit ein THESAURUS LINGUAE GRAECAE heranwachsen“. Damit ist das Stichwort gegeben: der Thesaurus. Die nach der Gründung des THESAURUS LINGUAE LATINAE im Jahre 1894 international geführte Debatte über ein ähnliches Unternehmen für das Griechische hatte kein Ergebnis gebracht ${ }^{5}$ Snell und sein 1937 emigrierter Kollege Ernst Kapp griffen, so Snell, ${ }^{6}$ in den 30er

Jahren Überlegungen von Herrmann Diels auf und entwickelten das Konzept von allgemeiner Verzettelung und Speziallexika, das Snell dann nach dem Zweiten Weltkrieg umzusetzen versuchte. Aber trotz großer internationaler Unterstützung und der Umbenennung des Archivs für griechische Lexikographie in Thesaurus Linguae Graecae ist aus diesem Teil des Vorhabens gar nichts geworden. In den Archivschränken und Regalen in Hamburg finden sich Zettelkästen und viele unaufgeschnittene Teubner-Druckbögen. Es gelang nicht, das nötige Geld zu beschaffen, es gibt keinen Beschluss, diese Arbeit zu beenden, sie hörte einfach auf.

So war es denn folgerichtig, dass Bruno Snell im Jahr 1972 der Bitte von Ted Brunner nachkam, ihm die Nutzung des Namens Thesaurus Linguae Graecae zu gewähren für sein Vorhaben, in Irvine die griechische Literatur der Antike elektronisch zu speichern und verfügbar zu machen.

\section{Das LfgrE}

Dass unter den Speziallexika, die das Archiv hervorbringen sollte, auch ein Homer-Lexikon sein sollte, war für Snell von vornherein klar. Die Arbeiten am Lexikon zu Homer, Hesiod und dem älteren Epos, wie es zunächst intern (bis1954) genannt wurde, begannen im Oktober1947. Nach zwei Jahren wurden an zahlreiche Fachkollegen Probeartikel und Richtlinien verschickt und schon im März 1950 waren über 40 Mitarbeiter gewonnen. Deren Mehrzahl kam von außerhalb, darunter prominente Namen wie Chantraine, H. Fraen-

3 Von 1948 an, siehe Philologus 97, (1948), 320 und Gnomon 21 (1949), 375

4 Laut (mündlicher) Auskunft von E.M.Voigt vom Sommer 2010 gab es vor der Sitzung am 13. März 1945 keinen offiziellen Termin, auf dem sich der Kreis um Snell mit dem "Archiv" befasst hätte.

5 Über diese Debatte informiert kurz Stuart Jones im Vorwort zur 9. Auflage von Liddell-Scott, 1940. Der Text von Diels ist auch abgedruckt bei Beck/Irmer 1996, 34

6 s. Beck/Irmer 1996, 31. 
kel, van Groningen, Leumann, Lloyd-Jones, Risch, Verdenius. 1955 erschien die erste Lieferung, im Jahresabstand die zweite, und 1959 die dritte. Das war ein halbwegs guter Start, und die Resonanz war überaus positiv. Eindrucksvoll ist die Liste der Rezensionen:

Von J.A.Davison und M.Willcock in der Classical Review von 1956 bis 1978, W. J. Verdenius in der Mnemosyne von 1957 bis1989, Alfred Heubeck im Gymnasium von 1957 bis1985 und im Göttingischen gelehrten Anzeiger von 1983 als unseren ständigen Begleitern zu den grossen Einzelrezensionen im Gnomon von Hermann Fränkel (1957), Oswald Szemerenyi (1991), Edzard Visser (2001), im Kratylos 2000 und 2003 von Rudolf Wachter waren alle sehr positiv. Kritischer war Bernhard Forsman in den Indogermanischen Forschungen von 1985 bis 1996 und praktisch ein Verriss war die Rezension von B. Marzullo im Philologus 1957, der zurecht die archaisierende Gestaltung des Homertextes an vielen Stellen monierte.

Aber von 1959 an erschien sechs Jahre lang kein neues Heft, ein deutliches Zeichen der Krise. Es zeigte sich die Schwäche des Systems der Koordination der großen Zahl der oft schon sehr prominenten auswärtigen Mitarbeiter und der jeweils nur kurzen Festanstellung von jungen, oft noch nicht promovierten Nachwuchskräften. Es durften viele Steckenpferde geritten werden. Erst EvaMaria Voigt konnte als (dritte) Redaktorin (nach H.J. Mette u. G. Knebel) ab Mitte der 60er Jahre eine relativ einheitliche Linie durchsetzen. Sie hat nach schwierigen Jahren praktisch das Lexikon neu gegründet, alle langjährigen Mitarbeiter, die das Lexikon dann dreißig Jahre geprägt haben, sind durch ihre Schule gegangen und haben bei ihr gelernt, ordentliche Artikel zu schreiben.

\section{Die Krise}

1976 beschloss die Deutsche Forschungsgemeinschaft, die seit vielen Jahren das Geld zur Bezahlung der Mitarbeiter zur Verfuigung stellte, das scheinbar erfolglose Lexikon, das nach über 20 Jahren noch immer beim Buchstaben A krebste, einzustellen. Und es wäre auch eingestellt worden, wenn nicht ... Bernhard Mader, der Senior unter den Mitarbeitern, seine Kollegen einschließlich der Redaktorin solange genervt hätte, bis sie einsahen, dass man sich da wehren könne und müsse. Dann wurde eine Doppelstrategie verfolgt: Wissenschaft und Arbeitsrecht. Mit Unterstützung der GEW (Gewerkschaft Erziehung und Wissenschaft) gelang es, die Fronten aufzubrechen. Die Universität sah sich zwar nicht als Arbeitgeber, aber die Befristung der Arbeitsverträge auf ein Jahr hielt sie für ungültig. Wenn dieser Standpunkt sich durchgesetzt hätte, dann hätte dies das Ende des Lexikons stark verteuert.

Eine Resolution für die Fortführung des LfgrE wurde verbreitet und von knapp 300 Wissenschaftlern aus der ganzen Welt unterschrieben. Alles, was in der Graezistik Rang und Namen hatte, befand sich darunter (auch Marzullo, 
der Kritiker der 50er Jahre - nur M. West unterschrieb nicht, er brauche das LfgrE nicht, schrieb er seinem Freund Winfried Bühler).

Die DFG gab nach. Zufällig war in diesen Jahren eine Neuregelung der geisteswissenschaftlichen Forschungseinrichtungen in Deutschland fällig. Langfristige Projekte sollten nicht mehr von der DFG, sondern von den Akademien betrieben werden. Und weil Hamburg keine eigene Akademie hatte, kam das Lexikon 1980 in die Obhut der Göttinger Akademie. Damit verbunden war eine Neustrukturierung und Straffung der gesamten Arbeit am Lexikon. Vom Buchstaben B an wurde nach diesem Plan gearbeitet. ${ }^{7}$ Die Rezensenten fanden die damit verbundenen Kürzungen schlecht, aber haben sich im Laufe der Zeit damit versöhnt, zumal das Lexikon kontinuierlich erschien.

Entscheidend dafür war, dass die Mitarbeiter, die in der Krise ihren Arbeitsplatz verteidigt hatten, nun alle fest angestellt wurden ${ }^{8}$ und über zwanzig Jahre beisammen blieben. ${ }^{9}$ Dies Team hat das Lexikon gemacht, erst unter Leitung von Eva Maria Voigt, dann unter Michael Meier-Brügger.

Chronologie der Ereignisse vom 17. Februar bis zum 12. April $1976^{10}$

17. Februar

Letzte Februarwoche März

4. März

5. März

7. März
Der zuständige Ausschuss der DGF empfiehlt dem Hauptausschuss, das scheinbar erfolglose Lexikon einzustellen.

Die Mitarbeiter beschließen, sich zu wehren.

Brief der Mitarbeiter an den Präsidenten der Universität mit der Forderung nach Arbeitsverträgen mit der Universität.

Herausgeber (Prof. Winfried Bühler), Redaktion (EvaMaria Voigt), Mitarbeiter (Bernhard Mader) wenden sich mit einem Brief an die wissenschaftliche Öffentlichkeit und fügen eine Erklärung zur Unterstützung des Lexikons bei, die von 15 prominenten Erstunterzeichnern und bis Mai von knapp 300 Wissenschaftlern aus aller Welt (von Australien über die USA bis zur Sowjetunion) unterzeichnet wird. ${ }^{11}$

Brief der Universität an die Mitarbeiter des Lexikons: Arbeitgeber ist nicht die Universität, sondern Prof. Bühler.

Die Mitarbeiter treten der GEW bei und beantragen Rechtsschutz.

7 s. LfgrE II, 1991, I-V

8 Es dauerte einige Jahre, bis der neue "Dienstherr" dies formell akzeptierte. Bis dahin unterschrieben die meisten Mitarbeiter die ihnen angebotenen befristeten Arbeitsverträge nicht und arbeiteten ohne schriftlichen Vertrag.

9 Dies betrifft die Hauptartikelschreiber William Beck, Rudolf Führer, Bernhard Mader, Georg Markwald, Hans Wilhelm Nordheider, James N. O'Sullivan, Martin Schmidt

10 Quelle sind meine Aufzeichnungen und Sammlungen von Dokumenten

11 Beck/Irmer 1996, 178 f. 
8. März

10. März

16.März

18. März

19.März

21. März

23. März

24. März

30. März

9. April

12. April

Brief des Präsidenten der Universität an den Präsidenten der DFG mit Darlegung des Rechtsstandpunktes der Universität: Forderung eines Sozialplanes, Hinweis auf die Möglichkeit der Übergabe des Lexikons an eine Akademie.

Beschluss des Institutsrates des Seminars für klassische Philologie: Bestürzung über den Einstellungsplan und Hinweis auf die Göttinger Akademie als möglichen Träger des Lexikons.

Brief von C.F. von Weizsäcker an Bruno Snell. ${ }^{12}$

Helmut Flashar, Vorsitzender der Mommsen-Gesellschaft, wendet sich ,,mit großer Sorge um das Schicksal des Lexikons" mit einem Brief an die DFG. ${ }^{13}$

Brief des VizePräsidenten der Universität Hamburg, Prof. Otto, an den Präsidenten der Göttinger Akademie der Wissenschaften. ${ }^{14}$

Das Justitariat der DFG mischt sich mit einem Rechtsgutachten zur Verteidigung de herrschenden Zustände ein.

Brief Prof. Snell an den Präsidenten der DFG. ${ }^{15}$

Mitteilung Eva-Maria Voigts über den Erfolg der Unterschriftensammlung. ${ }^{16}$

Prof. Bühler erklärt, dass die Privatdienstverträge der Mitarbeiter des Lexikons am 31. März auslaufen und spricht vorsorglich eine Kündigung zum 30.6.1976 aus.

Brief der Mitarbeiter an Prof. Bühler: Ablehnung einer Zwischenlösung.

Prof. Bühler versucht vergeblich, die Beschlüsse der DFG zu erfahren.

Mitteilung der DFG an Prof. Bühler über Weiterfinanzierung. ${ }^{15}$

In Zahlen: die Erstellung des ersten Band (der Buchstabe A) dauerte 26 Jahre, von 1952 (ich setze drei Jahre Vorlauf vor 1955) bis 1978. Im gleichen Zeitraum von 26 Jahren wurden von 1978 bis 2004 der 2. und der 3. Band, jeweils ebenso umfangreich wie der 1. Band, fertig gestellt. Der durchschnittliche Output betrug vor 1978 pro Jahr 69, danach 131 Spalten. Soviel zum Thema Befristung von Arbeitsplätzen oder Gewerkschaft und Wissenschaft. ${ }^{17}$

12 Beck / Irmer 1996, 193 f.

13 Beck/Irmer 1996, 188 f.

14 Beck /Irmer 1996, 189ff.

15 Beck / Irmer 1996, $192 \mathrm{f}$.

16 Beck / Irmer 1996, 185

17 Am Lexikon haben nach 1980 auch Theodore Vlachodimitris (seit 1972 bis 2000) und die jeweiligen holländischen Stipendiaten gewirkt. Dazu kamen in verschiedenen 


\section{Snells Thema}

Snell verband mit dem Lexikon eine Erwartung. Er hatte seit vielen Jahren eine historisierende Methode des Nachdenkens über die alten Griechen entwickelt. Er wollte dem Geschichtlichen dessen nachspüren, was die Griechen geleistet haben. Er tat dies besonders, indem er die Distanz zwischen dem Denken Homers bzw. seinen Personen und dem Denken der Griechen nach Homer aufspürte und aufzeichnete. Dass Snell sich dabei in einige unhaltbare und primitivistische Positionen verrannt hat, (die er bis zu seinem Lebensende auch gegen jede Kritik verteidigt hat) ändert nichts an der Bedeutung seines Ansatzes. ${ }^{18}$

Aus philosophischer Sicht hat 1976 C.F. von Weizsäcker Snells Ansatz in einem (aus Anlass der Krise) an Bruno Snell gerichteten Brief beschrieben. ${ }^{19}$ Weizsäcker betonte die Unverzichtbarkeit des Rekurses auf die griechische Philosophie beim philosophischen Nachdenken über die Probleme der modernen Wissenschaftstheorie, Gesellschaftstheorie und Anthropologie und beschrieb, wie sehr der Sprachgebrauch der klassischen griechischen Philosophie sich mit der ,einzigen großen Stilisierung“ auseinandersetze, die den Anfängen der Philosophie (und der Lyrik) vorausliege, eben dem homerischen Epos. Dann, direkt an Snell gerichtet: „Die von Ihnen eingeleitete lexikalische Arbeit an diesem Epos bereitet also philologisch den Boden auf, aus dem sich schließlich der ganze Baum des abendländischen Denkens genährt hat"

Der durch Snells Theorien vorgegebene, von Weizsäcker ausdrücklich betonte relative Wert der Erforschung der homerischen Sprache kann freilich nur relevant werden, wenn es gelingt, die Sprache und die Wörter des frühgriechischen Epos unabhängig von Späterem als Teil einer in sich selbst interessanten Literatur und Kultur zu begreifen und zu erklären.

Deswegen betonte Snell auch von Anfang an die Notwendigkeit der Rückkehr zur klassischen Maxime, die Aristarch zugeschrieben wird: "Ounpov

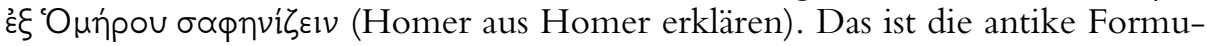
lierung der Notwendigkeit der synchronen Erklärung eines gegebenen Wortschatzes.

Der Snell'sche Ansatz hatte eine unausgesprochene Voraussetzung. Snell folgte in seinem Verstehen des frühgriechischen Epos einer nicht nur in der Altertumswissenschaft weit verbreiteten Ansicht über die "Kulturstufe" des

Hilfsfunktionen verschieden lang Fiorella Grensemann, Reinhard Kranz, Euagoras Kyriakides, Barbara Schönefeld, Anke Seyfart, Natascha Tichá, Volker Yntema.

18 Die Literatur zu Snell ist unübersehbar. Die gründlichste Kritik steht bei A. Schmitt, Selbständigkeit und Abhängigkeit menschlichen Handelns bei Homer. Hermeneutische Untersuchungen zur Psychologie Homers, AAWM 1990/5, Stuttgart 1990. Eine historische Einordnung bei W. Burkert, Mikroskopie der Geistesgeschichte. Bruno Snells ,Entdeckung des Geistes' im kritischen Rückblick Philologus 148 (2004) 168 $182=$ Kleine Schriften 7,277ff.

19 Beck / Irmer 1996, $193 f$. 
homerischen Griechenlands. Spätestens seit dem 19. Jh. war das Archaische erfunden. An seiner Konstruktion wurde allseits gearbeitet, in der Geschichte der Kunst, der Philosophiegeschichte, der Religionsgeschichte, der Rechtsgeschichte, der politischen Geschichte. Ein berühmtes Beispiel: Friedrich Engels entdeckte (in der Nachfolge von L .H. Morgan) im homerischen Griechenland in politisch-gesellschaftlichen Dingen den aktuellen Übergang von der Barbarei in die Zivilisation. Die Entstehung des Staates hatte noch nicht stattgefunden, aber stand grade bevor.

Ganz ähnlich fand Snell im (von ihm nicht thematisierten) Rahmen von Kulturstufen-Theorien und Fortschrittsglauben bei Homer eine Form des (ja angeblich meist sinnlich-konkreten) archaischen, primitiven Denkens. Die „Entdeckung des Geistes“ (so der berühmte Buchtitel von Snells Aufsätzen von 1946) hatte noch nicht stattgefunden, aber stand grade bevor. Die homerischen Menschen hatten, so Snell, keine Vorstellung von der Einheit des menschlichen Körpers, sie hatten kein Bewusstsein von der eigenen psychischgeistigen Funktion beim Entscheiden zwischen Alternativen, und einiges mehr.

Das von Snell durchaus auch in der Hoffnung, dass das alles noch viel genauer dargelegt würde, ins Leben gerufene Lexikon hat sich anders entwickelt. Zwar bemühten sich anfangs einige Autoren, Snell'sche Terminologie beizubehalten, auf dass ja nicht der Eindruck entstünde, ein Held Homers habe sich in irgend einer Sache frei entschieden, ${ }^{20}$ und noch Frau Voigt rief als Redaktorin den Meister beim Verdacht anti-Snellistischer Umtriebe zu Hilfe. Der aber war kein Snellist. Er ließ geschehen, dass sich eine Generation von Wissenschaftlern an seinen Thesen abarbeitete, sie aber letztendlich doch verwarf. In den einschlägigen größeren Artikel über thumos, menos, noos ${ }^{21}$ haben die Snell`schen Thesen ihre Spuren hinterlassen, sie sind aber nicht maßgeblich.

\section{Parry ante portas}

Es gab und gibt auch eine andere Versuchung, das frügriechische Epos und seine Wörter in eine Vor-Zeit zu versetzen, der das LfgrE nicht erlegen ist: Seit den Untersuchungen von Milman Parry spätestens war deutlich, dass das uns vorliegende frühgriechische Epos auf einer langen Tradition mündlicher Dichtung fußt und vieles im Epos, insbesondere die Darstellung typischer Szenen und die Verwendung ständiger Epitheta nur mit dem Rekurs auf diese Tradition erklärt werden kann. Aber schon der alltägliche lexikalische Zwang (und die konservative Resistenz der deutschen Altphilologie gegen diese Theorie) führte dazu, dass ein nahe liegender Fehler vermieden wurde, nämlich das Unterlassen semantischer Untersuchungen und Unterscheidungen

20 K. Mathiessen in den Artikeln bouboul boule, boulomai.

21 Von Rijk van Bennekom/S.R. Van der Mije und R. Führer. 
zugunsten einer Überbewertung einer eindimensionalen Oral-Poetry-Theorie, wonach sich die Wörter mehr oder weniger bedeutungslos aus metrischen Gründen in den Satz drängen. Stattdessen beharrt das LfgrE auf dem Primat der Bedeutung.

Das wird in letzter Zeit auch in Rezensionen anerkannt und gewürdigt, ${ }^{22}$ und hat dazu geführt, dass das LfgrE zur Hauptreferenz für den groß angelegten Basler Kommentar zur Ilias wurde.

\section{Wem nutzt und wer benutzt das Lexikon?}

Um diese Frage korrekt zu beantworten, müsste es einen altphilologischen Citation Index geben. Den gibt es nach meiner Kenntnis noch nicht, aber es gibt Google books und Google scholar. Bei Eingabe der Buchstabenfolge LfgrE (am 3.11.2011) bietet Google books über 19000 und Google scholar 590 nicht damit identische Einträge (zum Vergleich: bei Eingabe von ThLL gibt es bei Google books über 290 000, bei Google scholar 8 400). Diese Einträge sind fast zufällig, sie spiegeln die Bücher wider, die bei Google im Moment erfasst sind. Verbunden mit den eigenen Erfahrungen und Recherchen ergibt sich etwa folgendes Bild:

John Chadwick rechnete noch 1996 das LfgrE zu den Lexika, von denen es heisst: they never got beyond alpha. Nachdem sich langsam herumgesprochen hat, dass das nicht stimmt, nimmt die Benutzung des LfgrE stetig zu und zwar über den engeren Kreis der Homeriker hinaus. Auch Archäologen und Sprachwissenschaftler holen sich da Auskunft. Aber es gibt nationale und fachliche Schranken. Althistoriker benützen das Lexikon sehr selten, und in den USA ist es offenbar, weil überwiegend deutsch geschrieben, nicht benutzbar.

Der wichtigste und bedeutendste Nutzer ist zweifellos der in Arbeit befindliche Basler Kommentar zur Ilias.

Der Verlag will nach Abschluss des Werkes auch eine digitale Ausgabe vorlegen. Das wird die Benutzbarkeit verbessern.

\section{Keine Lexikographie mehr}

Die letzte Lieferung des LfgrE ist vor zwei Monaten erschienen. Im Sinne von Bruno Snell wäre es nahe liegend, jetzt spätestens mit einem zweiten oder, rechnet man den Hippokrates-Index dazu, mit dem dritten der Spezialwörterbücher zu beginnen. Aber beide Institutionen, die mit dem Lexikon verbunden sind, haben sich anders entschieden. Der dritte Nachfolger Bruno Snells auf dem Hamburger Lehrstuhl hat seine Forschungsprioritäten vorgetragen, die

22 z. B Edzard Visser im Gnomon 74 (2002), 97-101; vgl. auch Johannes Haubold in einer Rezension des Basler Ilias - Kommentars in B.M.C.R. 2001.09.01 
Göttinger Akademie hat schon vor über zehn Jahren entschieden, dass mit dem LfgrE die Lexikographie in Hamburg ausläuft. 1998 wurde beschlossen, für die aus Altersgründen ausscheidenden Mitarbeiter keine neuen mehr einzustellen, und lieber die Fertigstellung des Lexikons nach einmal um ein paar Jahre zu verschieben. Also kein Tragiker-Lexikon, kein Lexikon der frühen und klassischen Lyrik, kein Wörterbuch der attischen Prosa, kein Lexikon der Fachschriftsteller. Stattdessen hat die Göttinger Akademie eine Editionsreihe spätantiker Schriften zu Religion und Ethik als neues geisteswissenschaftliches Langzeitvorhaben.

Natürlich ist es keine Werbung, dass das LfgrE über 50 Jahre gebraucht hat, um fertig zu werden. Aber man könnte aus dem Auf und Ab beim LfgrE lernen, dass eine Zeit von 20 bis 30 Jahren bei einem anspruchsvollen Projekt machbar und auch sinnvoll ist.

Wir sind hier auf einem internationalen Kongress. Deswegen soll Hermann Diels mit seiner Utopie das letzte Wort haben. Er spricht von den vielleicht zehn Einzellexika, die seiner Meinung nach den Griechischen Thesaurus bilden sollten. Diese Lexika „könnten dann die verschiedenen Nationen und Akademien unter sich verteilen und einen wissenschaftlichen Riesenagon veranstalten, wer sein Los am raschesten und besten erledigt. Aber das sind alles Zukunftsträume." Soweit Diels 1905. ${ }^{23}$ Dank Bruno Snell ist ein Traum Wirklichkeit.

23 Neue Jahrbücher 8 (1905), 693. 
Bereitgestellt von | SUB Göttingen Angemeldet 


\title{
Vom Gliedergefüge zum handelnden Menschen. Snells entwicklungsgeschichtliche Homerdeutung und ein mögliches Homerbild heute
}

\author{
ARBOGAST SCHMITT
}

1) Snells Anliegen: Rückgewinnung des Europäischen in Europa durch Homer

Snells Plan, ein Lexikon zu Homer in Angriff zu nehmen, hatte neben dem philologisch lexikalischen Interesse zwei weitere, für ihn sehr wichtige Gründe: ${ }^{1}$ Die Situation nach 1945 schien ihm eine Rückbesinnung auf die kulturellen Grundlagen Europas notwendig zu machen, wenn denn nach der Barbarei der vorausgegangenen Jahre Europa wieder zu sich selbst finden können sollte. Diese Rückbesinnung aber konnte für ihn nicht irgendwo einsetzen, sondern musste bis auf Homer zurückgehen. Denn bei ihm fand er die Anfänge derjenigen Entwicklung, die die Besonderheit der europäischen Kultur überhaupt erst hervorgebracht hatte. Ohne diese Besonderheit zu kennen und dadurch lebendig zu halten, konnte Europa nicht seinen Platz unter den Kulturnationen der Welt wiederfinden und sich unter ihnen behaupten. Das Anliegen, das das Lexikon für Snell erfüllen sollte, war deshalb zuerst die Erschließung der Semantik des homerischen Wortschatzes. Geprägt von der Überzeugung Wilhelm von Humboldts, dass die Sprache Ausdruck der Weltanschauung einer Gesellschaft ist, sollte das Lexikon genau diesen Dienst leisten: Es sollte dem heutigen Menschen die Welt Homers erschließen. Die außergewöhnliche Eignung der homerischen Sprache für diesen Dienst gründete für Snell darin, dass die Entwicklung einer natürlichen Sprache zu einer Sprache, die zu wissenschaftlicher Begriffsbildung fähig ist, überhaupt nur an Homer studiert werden konnte. Nur aus dieser - homerischen - Sprache hat sich das moderne, theoretische

1 Beck, William u. Dieter Irmer, Fünfzig Jahre Thesaurus. 1944-1994, v.a. 31-58. s. v.a. auch Schmidt, Martin, Der wissenschaftliche Ort des LfgrE und Beck, William und Hans Wilhelm Nordheider, Arbeitsbericht 2003-2006. 
Bewusstsein“ entwickeln können, alle anderen Sprachen ,zehren hiervon, haben entlehnt, übersetzt, das Empfangene weitergebildet. "2

Homer hat für Snell daher in der,Geistesgeschichte" eine bedeutende und zugleich aufschlussreiche Zwischenstellung: Blickt man von der Entwicklungsstufe, die das moderne Bewusstsein erreicht hat, auf Homer zurück, erscheint er als Anfang, als ein ,Noch-Nicht' des später erst zur Entfaltung Gekommenen. Er ist in dieser Perspektive noch der Stufe zuzuordnen, die einer bewussten, reflexiven Subjektivität vorausliegt. Sein Zugang zur Welt ist von der Anschauung geprägt und mit ihr von einer Erfahrung der Ganzheit, des Eingeordnetseins des Einzelnen in den Kosmos der Natur und der Gemeinschaft.

Betrachtet man Homer dagegen nicht im Blick auf das, was bei ihm noch nicht zu voller, ausdrücklicher Entfaltung gekommen ist, sondern im Blick auf das, was bei ihm angelegt und in ungeschiedener Einheit schon da ist, dann erscheint er gerade umgekehrt, als Inbegriff und ganzheitliche Verkörperung dessen, was Europa zu Europa gemacht hat, genauer: was die besondere Form wissenschaftlicher Aufklärung in Europa möglich gemacht hat. Trotz des Mangels an ausdrücklicher Bewusstheit, die den Menschen erst ganz zu sich selbst bringen kann, verhilft die Beschäftigung mit Homer deshalb auch zu einem einmaligen und bedeutenden Gewinn. Denn sie führt uns zu einem Gegenstand, in dem noch ursprünglich und damit auch unverfälscht und in einem exemplarisch untersuchbaren Zustand da ist, was später in der Entwicklung auseinandergetreten, fragmentiert worden und zum Teil auch verloren gegangen ist.

Snell verweist, um diese Besonderheit Homers sichtbar zu machen, auf den Unterschied anderer, oft primitiver Religionen, in denen das Göttliche als etwas Magisches, unbestimmt und unbestimmbar Numinoses aufgefasst wird, um dagegen die Natürlichkeit der griechischen Götter abzuheben. Diese ,Natürlichkeit' grenzt die griechische Religion aber auch gegen Religionen ab, in denen der Glaube das ,Credo“ an einen transzendenten, der Welt überhobenen Gott verlangt. Im Jenseits muss man die griechischen Götter nicht suchen, sie sind in der empirisch erfahrbaren Welt selbst präsent. Das ist das, was Snell ihre Natürlichkeit nennt. Sie sind natürlich, nicht weil sie da sind wie Wasser und Bäume, sondern weil sie zu eben der (nicht übernatürlichen, sondern) natürlichen Welt gehören, in der wir leben. Es macht keinen Sinn zu fragen, ob es eine Göttin Aphrodite gibt. Denn ihr Wirken ist nicht transzendent, es gibt sie auch nicht nur in bestimmten Nationen oder Kulturen, sondern überall unter Menschen, ja auch unter Tieren. Man kann Aphrodite vernachlässigen, sich nicht um sie kümmern, aber zu sagen, „,ich glaube nicht an Aphrodite“ sei „schlechthin unsinnig“. 3

Die Natürlichkeit der homerischen Götter hat daher für Snell zwei Aspekte: Sie ist ,natürlich', weil sie der Welt der diesseitigen Erfahrung zugänglich

2 Snell, Bruno, Die Entdeckung des Geistes, 207.

3 Snell, Bruno, Die Entdeckung des Geistes, $30 \mathrm{f}$. 
ist, sie ist aber auch ,natürlich', weil sie auf einer Deutung dieser empirischen Welt beruht, die auch für uns Moderne, die eine Emanzipation von der Religion durch die Aufklärung der Vernunft hinter sich haben, noch verstehbar, ja fast selbstverständlich ist.

\section{2) Homer als ,unser` Anfang}

Deshalb betont Snell wiederholt, dass das, was die homerischen Menschen von einer modernen Perspektive aus ,noch nicht' haben, nicht etwa bei ihnen gar nicht vorhanden ist. Es ist vorhanden, aber es ist noch nicht zu Bewusstsein gebracht und deshalb noch nicht zu einer Einheit stiftenden Selbstbestimmung des Menschen geworden. ${ }^{4}$

Auch dieses ,noch nicht' hat daher zwei Aspekte: Es kann den Mangel bezeichnen gegenüber der späteren Entwicklung des Geistes, es kann aber auch die später auseinander getretene Einheit von Sinn und Geist meinen, an die auch das zu sich selbst gekommene Bewusstsein wieder erinnert werden muss, wenn es sich selbst nicht verlieren soll.

Da sich Snell bei der philologischen Durchführung seiner These, die als These ja nicht neu ist, sondern in einer langen neuzeitlichen Tradition steht, vor allem um den Nachweis dessen, was bei Homer aus unserer Sicht noch nicht da ist, bemüht, ist es wichtig, den zweiten Aspekt nicht zu vernachlässigen. Denn er enthält in gewissem Sinn das eigentliche Anliegen Snells, die Bedeutung Homers als richtungweisende Grundlage der europäischen Kultur wieder sichtbar zu machen.

Er kann auch durchgängig bei seinen Untersuchungen nachgewiesen werden, ${ }^{5}$ ja er äußert sich auch in den scheinbar rein negativen Nachweisen von dem, was alles bei Homer, noch nicht' vorhanden ist.

Insbesondere in dem für die Homerdeutung Snells zentralen Bereich, dem Verhältnis von Göttern und Menschen, hat der Nachweis, dass die homerischen Götter eine notwendige Funktion erfüllen, eine wichtige verteidigende Aufgabe. Seit Winckelmann hat man die homerischen Götter immer wieder

4 Snell, Bruno, Die Entdeckung des Geistes, $10 f$.

5 V.a. Snell, Bruno, Die Ausdrücke für den Begriff des Wissens; ders., Aischylos und das Handeln im Drama, Leipzig 1928; ders., Rezension zu Böhme; ders., Gesammelte Schriften; ders., Das Bewußtsein von eigenen Entscheidungen im frühen Griechentum, in: ders., Gesammelte Schriften, 18-31; ders., Göttliche und menschliche Motivation im homerischen Epos, in: ders., Gesammelte Schriften, 55-61; ders., Szenen aus griechischen Dramen; ders., Die Auffassung des Menschen bei Homer, in: ders., Die Entdeckung des Geistes, 13-29; ders., Der Glaube an die olympischen Götter, in: ders., Die Entdeckung des Geistes, 30-44; ders., Das Erwachen der Persönlichkeit in der frühgriechischen Lyrik, in: ders., Die Entdeckung des Geistes, 56-81; ders., Mythos und Wirklichkeit in der griechischen Tragödie, in: ders., Die Entdeckung des Geistes, 95-110; ders., Nachwort 1974, in: ders., Die Entdeckung des Geistes, 283-292. 
wegen ihrer ästhetischen Qualitäten bewundert. ${ }^{6}$ Da bei Homer die Götter oft dann in Aktion treten, wenn ein in modernem Sinn innerer Vorgang in einem Menschen abläuft, scheinen sie in besonderer Weise geeignet, Innerpsychisches in poetisch anschaulicher Weise darzustellen. Vorgänge, die der moderne Beobachter nur abstrakt beschreiben kann, stehen dem Leser Homers konkret vor Augen und entfalten ihre eigene quasi personale Aktivität. Wenn etwa Athene den zu selbständigem Denken herangereiften Telemach ermahnt, nach zu langem Aufenthalt in Sparta endlich wieder an die Situation auf Ithaka zu denken (Odyssee 15, 1ff.), dann spricht in Athene scheinbar nur das eigene Innere Telemachs. Seine Sorgen, seine Beurteilung der Gefährdungen, denen er und sein ganzes Haus in Ithaka ausgesetzt sind, sind in der Darstellung Homers aber nach außen verlegt und gewinnen in den Worten Athenes eine unmittelbar wahrnehmbare Präsenz. Das eigene Innere Telemachs steht in Athene dem Leser konkret vor Augen. $^{7}$

Snell bestreitet diese Deutung nicht, sondern hält an ihr fest, aber er versucht zu zeigen, dass diese ,Externalisierung، von Innerem durch die Götter für Homer keine nur poetische Verfahrensmöglichkeit ist. Sie ist vielmehr, das ist sein Beweisziel, eine Notwendigkeit, die sich aus dem Bewusstseinszustand der homerischen Menschen ergibt. Homer ,braucht' diese Götter, und zwar nicht, weil man durch sie viele und schöne Möglichkeiten poetischer Darstellung gewinnt, sondern weil er sonst das menschliche Handeln nicht verstehen könnte. Was für uns ein selbständiger Akt des Nachdenkens und Entscheidens ist, ist für Homer ein äußerer Eingriff in den Menschen, weil er sich nur so den Vorgang, wie ein Mensch zu einer Entscheidung kommt, erklären kann.

Eine Konsequenz der These, Homer brauche die Götter, um sich menschliches Handeln erklären zu können, war freilich, dass Snell den homerischen Menschen die Fähigkeit zu eigenen Entscheidungen abgesprochen hat. ${ }^{8}$ Diese Bestreitung liegt aber, so sind viele Interpreten überzeugt, im Streit mit den Phänomenen. Denn man findet bei Homer nicht nur einige, sondern sehr viele Indizien, die die Fähigkeit selbständigen Handelns bezeugen.

Überblickt man freilich die Kritik, die an Snell geübt worden ist, ${ }^{9}$ muss man feststellen, dass die Beständigkeit, mit der sich Snell selbst bis zuletzt gegen diese Einwände gewehrt hat, ${ }^{10}$ einen guten Grund in der Sache hat. Denn auch die Gegner Snells bestreiten den Befund, von dem Snell ausgeht, nicht: Homer stellt menschliches Handeln häufig so dar, dass es durch äußere Faktoren, durch Götter, Schicksal, Gemeinschaft, Vererbung, Natur, bestimmt er-

6 Finsler, Georg, Homer in der Neuzeit, 418ff.; s. Schadewaldt, Wolfgang, Winckelmann und Homer.

7 S. zu dieser schon in der Goethezeit vertretenen These (s. Verf., Handeln in Abhängigkeit, 13-17) jetzt wieder Hirschberger, Martina, Die poetische Verwendung der Götter, 287.

8 Z.B. Snell, Bruno, Die Entdeckung des Geistes, 35.

9 S. dazu den Forschungsbericht bei Verf,. Handeln in Abhängigkeit, 13-17.

10 Nachwort 1974 in: Snell, Bruno, Die Entdeckung des Geistes, 283-291. 
scheint. Und nicht nur einzelne Handlungsverläufe, auch das Gesamtgeschehen vor Troja scheint durch den Plan des Zeus, die diós boulé, festgelegt. Dennoch aber macht die Beschreibung der einzelnen Entscheidungen und des Handelns überhaupt der Menschen durch Homer den Eindruck, dass diese Menschen wie selbstverständlich davon ausgehen, dass sie bei ihren Entscheidungen einen Freiraum haben, für den sie ebenso selbstverständlich auch die Verantwortung zu tragen bereit sind. ${ }^{11}$

Die Lösungsvorschläge, die teils gegen Snell, teils auch ohne Bezug auf ihn, zur Erklärung des beschriebenen Befunds gemacht wurden, sind kaum geeignet, Snells These zu entkräften. In der Hauptsache sind es drei Deutungen, die man erwogen hat. Für Albin Lesky ${ }^{12}$ und viele, die ihm gefolgt sind, sind die göttliche Motivation und menschliche Freiheit zwei Seiten ein und derselben ,Medaille‘. Je nach Situation verweise Homer bald auf die eine, bald auf die andere Seite dieses einheitlichen Sachverhalts. Verwandt, aber nicht identisch mit dieser Deutung ist die Annahme, dass göttliches und menschliches Handeln für Homer grundsätzlich in einer noch ungeschiedenen Einheit stehen, die es unmöglich mache, die besondere Leistung eines der beiden Akteure in diesem Gesamtgeschehen herauszukristalliesieren. ${ }^{13}$ Ein dritter, häufig vorgebrachter Lösungsvorschlag ist: Homer motiviere das Handeln seiner Personen oft doppelt. Obwohl er eine Handlung bereits zureichend aus ihren menschlichen Antrieben erklärt habe, lasse er dieselbe Handlung auch noch einmal von einem Gott oder den Göttern ins Werk setzen, etwa wenn Penelope selbst beschließt, die Freier sich am Bogen des Odysseus erproben zu lassen, dann aber Athene ihr diesen Gedanken auch von sich auch noch einmal eingibt (Odyssee 19, 571-586 und 21, 1-4).

Für Snell musste klar sein, dass allen diesen Erklärungen menschlicher Freiheit genau das fehlt, was er als Bedingung bei Homer gesucht hatte: das Bewusstsein davon, dass die Entscheidung für oder gegen etwas allein beim Handelnden selbst liegt. ${ }^{14}$ Jemand, der meint, das, was er selbst beschlossen

11 Janko, Richard, The Gods in Homer, 1-7.

12 Lesky, Albin, Göttliche und menschliche Motivation, 44f.

13 Exemplarisch für diese Interpretation ist Heubeck, Alfred, Der Odyssedichter und die Ilias, 72-81.

14 Da sich Snell selbst zur Charakterisierung des Entwicklungsganges vom homerischen Epos zur frühgriechischen Lyrik und zum attischen Drama v.a. auf Hegel beruft, zitiere ich einige prägnante Äußerungen Hegels, die völlig deutlich machen, dass Hegel das Hauptmoment freier Entscheidung, „daß das Subjekt die Entschließung zu seinem Handeln rein aus sich selbst nimmt", der Antike überhaupt absprach, und zwar im Sinne eben der strikten Alternative, die Snell bei Homer gefordert glaubt: dass nämlich dem Mangel dieses Selbstbewusstseins eine essentielle Fremd- und Außenbestimmtheit entspreche, die zugleich ein Fehlen einer von innen bestimmten Sittlichkeit zur Folge habe. So sagt Hegel z.B. in der Philosophie der Religion: „Weil ... die absolute Reflexion des Selbstbewußtseins in sich, diese Spitze der Subjektivität fehlt [sc. in der klassischen Antike], so ist auch die Moralität als eigene Überzeugung und Einsicht noch nicht entwickelt." In ähnlicher Weise beurteilt er den Standpunkt des griechischen Geistes 
habe, sei zugleich von einem Gott beschlossen worden, oder der nicht fähig ist, seinen eigenen Beschluss auch als seinen eigenen Beschluss festzuhalten, da er ihm irgendwie auch von oben eingegeben erscheint, ist nicht frei, jedenfalls nicht in dem modernen, nachaufgeklärten Sinn, von dem her Snell Freiheit bei Homer zu ermitteln versucht hatte.

\section{3) Zum Rückgang hinter Snell in neuerer Forschung}

Viele neuere Arbeiten zu Homer suchen die Auseinandersetzung mit Snell überhaupt nicht mehr, auch in der internationalen Homerforschung wurde Snell oft nicht rezipiert oder wird es nicht mehr. Die auffallige Leseerfahrung, dass Homer viele menschliche Handlungen mehr oder weniger von göttlichen und anderen äußeren Determinanten beeinflusst sein lässt, wird aber in so gut wie keiner Interpretation ganz übergangen. Man greift vielmehr zur Deutung auf die eben genannten drei Haupterklärungen zurück oder man lässt in postmoderner Pluralität die verschiedenen Motivierungen nebeneinander bestehen, ohne noch einen Versuch zu machen, das Verhältnis zwischen ihnen zu bestimmen. ${ }^{15}$

in der Geschichte der Philosophie: „Der Mensch hatte ein solches Verhältnis noch nicht, sich so in sich zu reflektieren, aus sich sich zu bestimmen ... Dies Moment ist wesentlich, daß ... das Subjekt dies noch nicht auf sich nahm, sondern sich von einem Anderen, Äußeren bestimmen ließ“. Siehe Hegel, Vorlesungen über die Philosophie der Religion II, 129. Oder: „In der klassischen Kunst ... [ist] die menschliche Individualität noch nicht bis zu der Spitze der Innerlichkeit heraufgedrungen ..., auf welcher das Subjekt die Entschließung zu seinem Handeln rein aus sich selbst nimmt. Was wir in unserem Sinne des Worts Gewissen nennen, hat hier noch nicht seinen Platz gefunden. Der griechische Mensch handelt zwar oft aus eigener Leidenschaft ..., das echte Pathos jedoch, das ihn ... beseelt, kommt von den Göttern, deren Inhalt und Macht das Allgemeine solch eines Pathos ist, und die Helden sind entweder unmittelbar davon erfüllt, oder sie fragen die Orakel um Rat, wenn sich ihnen die Götter nicht selber, um die Tat zu befehlen, vor Augen stellen." Siehe Hegel, Vorlesungen über die Geschichte der Philosophie I, 492f.

15 Dieses Vorgehen ist besonders charakteristisch für eine der neuesten Darstellungen der Götter bei Homer von Martina Hirschberger, Die poetische Verwendung der Götter im Homer-Handbuch. In dieser Interpretation haben die Götter eine narrative Funktion (285), sie haben aber auch eine reale Grundlage im Glauben der Gesellschaft (285; 286), die Menschen sind in ihren Entscheidungen frei, und zwar absolut frei (287; im Anschluss an Sarischoulis, Efstratios, Schicksal, Götter und Handlungsfreiheit, v.a. 245273), die Götter greifen aber nach eigenem Belieben in menschliches Handeln ein (286), sie verführen die Menschen zu Handlungen, wie sie es wünschen (288), ob es menschliche Freiheit gibt, bleibt wie im Volksglauben auch bei Homer in der Schwebe, die Menschen verfügen über persönliche Autonomie (288), usw. Man wird nicht bestreiten, dass diese divergierenden, ja widersprüchlichen Verhaltensweisen im homerischen Text beobachtbar sind. Umso mehr muss es die Aufgabe sein, nach einer Erklärung dieses scheinbar nicht Zusammenpassenden zu suchen. 
Die Folge ist eine nur noch die Oberfläche paraphrasierende Beschreibung der unterschiedlichen Erscheinungsweisen menschlichen und göttlichen Handelns. Nicht selten gibt es auch einen erstaunlichen Rückfall hinter Snell.

In dem ,Homer-Handbuch “ von 2011 etwa ist wieder von einer ,poetische(n) Verwendung der Götter im Epos [Götterapparat]“ die Rede: „Die Funktion der Götter im Epos ist eine primär narrative. Ebenso wie die menschlichen Personen sind sie Geschöpfe des Dichters, die sich im Rahmen der epischen Tradition bewegen dürfen. Doch bilden die im realen Kult verehrten Götter die Grundlage für ihre Gestaltung.“ (285) „Häufig müssen sie [sc. die Götter] die Situation retten, wenn diese durch das Handeln der Akteure eine mit den Vorgaben der Tradition nicht vereinbare Wendung zu nehmen droht. Das Wissen des Dichters identifiziert sich so gewissermaßen mit dem Willen der Götter.“ (286)

Wenn Homer z.B. den Streit zwischen Agamemnon und Achill sich so steigern lässt, dass Achill - der Logik der Handlung folgend - gar nicht anders kann, als Agamemnon zu töten, dann wäre die Ilias nach den ersten 200 Versen schon zu Ende. Nur Athene konnte dann Homer retten, die das, was er falsch angelegt hatte, wieder gut macht und Achill im letzten Augenblick vom Schlimmsten abhält. Sie hätte dann zugleich die Funktion, die Vorgabe der Tradition, die von einem Mord Agamemnons durch Achill nicht weiß, wieder herzustellen. Und Homer folgt dieser Vorgabe, weil er in ihr zugleich den Willen der Götter erkennt, dem er seine Erzählung anpasst, auch wenn sie von sich aus eine andere Entwicklung genommen hätte.

Ähnliche Hilfe lassen viele Interpreten Homer durch die Götter zu Teil werden, etwa wenn der wilde, fluchtartige Aufbruch des ganzen achäischen Heeres nach Hause durch Athene gestoppt werden muss (Ilias 2, 155-181), wenn Paris dem Tod durch Menelaos nur dadurch entkommt, dass Aphrodite ihn rettet (ebd. 3, 368-382), wenn Hektor durch Athene, die sich ihm in der Gestalt seines Bruders Deiphobos zeigt, von der (beschämenden) Flucht vor Achill abgehalten wird (ebd. 22, 214-247), usw.

Abgesehen von der kaum denkbaren Vorstellung, man könne von Göttern, die ,real' und - wie die Kultdarstellungen auch in den homerischen Gedichten zeigen - mit Ehrfurcht verehrt wurden, ${ }^{16}$ einen ,narrativen Gebrauch machen, - unterstellt diese ,poetische' Deutung des Götterapparats Homer eine minderwertige literarische Qualität. Mit guten Gründen wehrt sich schon Aristoteles gegen die Meinung, Dichter müssten, um den (oft aus der Traditi-

16 S. v.a. Tsagarakis, Odysseus, Nature and Background; Lateiner, Donald, Homeric Prayer; Dietrich, Bernard Clive, Death, Fate and the Gods. Die Überzeugung, die anthropomorphe Götterwelt Homers entbehre des religiösen Ernstes und müsse deshalb vor allem aus ihrer Erzählfunktion verstanden werden, wird auch von Kennern wie Burkert vertreten. S. Burkert, Walter, Homer's Anthropomorphism. Dass auch die Götter der Ilias den Menschen das jeweils ihnen Zukommende zukommen lassen, und keineswegs nach Lust und Laune (und um der Erzählfunktion willen, für die sie der Dichter gerade brauchen kann) in das Geschehen eingreifen, s. unten Teil III. 
on vorgegebenen) Handlungszusammenhang nicht zu zerstören, eben hin und wieder Inkonsistenzen hinnehmen. Solche Handlungen dürfe man grundsätzlich nicht konstruieren (Poetik 1460a29-35). Dass ausgerechnet Homer, dem Aristoteles eine bestmögliche und dadurch für alle spätere Dichtung vorbildliche Handlungsgestaltung zugeschrieben hat, ${ }^{17}$ nicht in der Lage gewesen sein soll, selbst zu bemerken, dass seine Anlage des Streitverlaufs zwischen Agamemnon und Achill so exzessiv war, dass er ohne einen übernatürlichen Eingriff schon nach wenigen Versen den traditionell vorgegebenen Handlungsverlauf zerstört hätte, ist nicht plausibel. Dazu kommt, dass Homer den Götterapparat in den meisten Fällen gar nicht für diese literarische Hilfestellung benötigt, da die Handlung auch ohne sie konsequent durchgeführt werden konnte. Er ,verwendet' den Apparat ja angeblich nur, um eine schon hinreichend motivierte Handlung noch einmal zu motivieren.

Das ernste Anliegen Snells, die für ein modernes Denken schwierige Leseerfahrung mit den homerischen Gedichten nicht einfach auf sich beruhen und auch nicht als ein bloßes Spiel poetischer Phantasie gelten zu lassen, sondern nach einem verstehbaren Grund der Andersheit Homers zu fragen, macht die Erinnerung an seine Interpretation zu einer weit mehr als nostalgischen Frage. Gerade angesichts der Beliebigkeit, in der postmoderne Interpreten das scheinbar Widersprüchliche oder Unverständliche der homerischen Schilderung menschlichen Handelns einfach stehen lassen, gibt dem Snellschen Verfahren eine neue Aktualität. Auch der nicht philologisch gebildete Leser wird mit den auffälligen Abweichungen von der uns gewohnten Denkweise bei Homer konfrontiert. Mit Recht kann er von der wissenschaftlichen Forschung eine Verständnishilfe erwarten. Diese kann nicht nur darin bestehen, dass sie die Merkwürdigkeiten der homerischen Welt notiert. Die Folge muss sein, dass diese Welt immer fremder erscheint, je mehr man von ihr, genauer: von ihren bloßen Erscheinungsformen, weiß.

Diesem Verfremdungseffekt stellt Snell die Beobachtung entgegen, dass der Mangel, den man von einer selbstbewussten und selbstbestimmten Subjektivität aus bei Homer ermitteln kann, nicht einfach Zeichen einer irgendwie gearteten Andersheit ist, sondern Homer als einen Anfang, als unseren Anfang, den Anfang der Besonderheit der europäischen Kultur ausweist. Mit diesem Anfang sind wir immer noch verbunden, er ist in uns, nicht als etwas Fremdes, sondern als Eigenes.

Snell hat durch seine Interpretationen der mit Homer beginnenden Geschichte der Entdeckung des (europäischen) Geistes weit über die universitäre Philologie hinausgewirkt und auf diese Weise ein Interesse an Homer wieder hergestellt, das über viele Jahrhunderte hin charakteristisch für die Beschäftigung mit Homer war, der nie bloßer Gegenstand von Forschung war, sondern für eine breite Schicht gebildeter Leser und Nachahmer Quelle von Erkenntnis und ästhetischem Vergnügen.

17 S. Verf. Aristoteles. Poetik, 698-700. 


\section{II}

\section{Homer als Teil einer Spätphase in Kultur und Literatur}

\section{1,1) Homer und orientalische Kulturen}

Seit der ersten Auflage von Snells ,Die Entdeckung des Geistes‘ sind mehr als 70 Jahre vergangen, in denen die Homerforschung, unterstützt von einer Reihe von Nachbarwissenschaften, tatsächlich neue, zuvor nicht oder nur wenig bekannte Bereiche erschlossen hat. Die Aufgabe, der sich dieser Beitrag stellen möchte, ist, ob sich von dieser neuen Basis aus das Anliegen Snells, Homer einem modernen Denken verstehbar zu machen, weiterfuhren und in veränderter Form erfüllen lässt.

Auf einen ersten Blick hin scheint eher das Gegenteil der Fall zu sein. Viele der Grundannahmen Snells lassen sich auf Grund einer Vielzahl neuer Erkenntnisse kaum mehr halten. Das gilt gerade für den zentralen Aspekt, dass wir in Homer den Anfang europäischen Denkens zu fassen bekommen.

Homer ist, so muss man von der Position heutiger Kenntnis her feststellen, weder ein Anfang noch der Anfang Europas:

Die Kultur, die Homer beschreibt, d.h. die Zeit, von der er erzählt, ist eingefügt in einen großen Kreis orientalischer Kulturen. Viele ihrer Eigentümlichkeiten lassen sich aus der Zugehörigkeit zu diesem Kreis erklären - in der Religion, der Gesellschaftsordnung, dem Rechtsverständnis, in den Gebrauchsgegenständen und Umgangsformen des Alltagslebens, usw. ${ }^{18}$

Analoges gilt von der Zeit, in der Homer vermutlich seine Werke verfasst hat. Gleichgültig ob man die Entstehung von Ilias und Odyssee ins ausgehende 8. Jahrhundert legt oder ob man sie erst im frühen oder sogar späten 7. Jahrhundert für möglich hält, auch die Kulturen dieser Zeit sind von intensiven Kontakten zum Orient geprägt. ${ }^{19}$

Homer wurde, kaum dass seine beiden großen Epen verfasst waren, zum wirkmächtigen Vorbild für die weitere Literatur, ja für das Denken der Antike insgesamt und wurde durch sie und ihre Rezeption in Mittelalter und Neuzeit tatsächlich zu einer der prägenden Gestalten der europäischen Kultur. ${ }^{20}$ Aber er

18 S. v.a. West, Martin L., The East Face of Helicon; ders., Indo-European Poetry and Myth; Cobet, Justus, Die Ilias, Asien und Europa; Rollinger, Rober, Altorientalische Einflüsse auf die homerischen Epen; Latacz, Joachim, Troia und Homer; Starke, Frank, Troia im Machtgefüge.

19 S. Burkert, Walter, The Orientalizing Revolution; jetzt auch Latacz, Joachim, Zu Homers Person; ders., Homer. Der erste Dichter des Abendlands, 32-88.

20 S. jetzt die einschlägigen Artikel im Homer-Handbuch zu III ,Nachwirkung,, 293435; zur dort völlig ausgesparten Nachwirkung in der philosophisch-theologischen Tradition bis in die Spätantike s. Lamberton, Robert, Homer's Ancient Readers; ders., Homer in Antiquity; ders., Homer. The Theologician; für die im Handbuch fast nicht be- 
ist kulturell kein Ursprung und Anfang, sondern verkörpert einen bestimmten Stand der Rezeption und der Auseinandersetzung mit orientalischen Traditionen. Homer steht in diesen Traditionen, von denen er bewusst vieles übernimmt, anderes auch ohne bewusste Rezeption, in wirkungsgeschichtlicher Abhängigkeit von ihnen.

Die Vorstellung, bei Homer könne man noch einen geistesgeschichtlichen Zustand finden, der der Reflektiertheit des modernen Bewusstseins vorausliegt und uns einen ,mythischen' Horizont eröffnet, in denen der Mensch noch in einer geheimnisvollen Einheit mit der Welt, die ihm unmittelbar durch die Anschauung präsent war, stand, ist angesichts der langen kulturellen Traditionen, die der homerischen Kultur vorausliegen, nicht zu halten. Die Kultur der Zeit Homers und auch die seiner ,Helden“ hat die Charakteristika einer Spätkultur und, im Blick auf ihre Größe, den Charakter eines eher kleinen Anhangs.

\section{1,2) Homer und die Tradition mündlicher Dichtung vor ihm}

Genauso deutlich wird der Charakter einer reflektierten Spätphase, zu der Homer gehört, wenn man die Besonderheit der homerischen Dichtweise beachtet. Dass Homer in einer mündlichen Dichtungstradition stand, wusste auch Snell. Die Vorstellung einer mündlichen Dichtung als Charakteristikum der Dichtung der Vorzeit bzw. einer naiven Dichtweise, die in der Gegenwart weiterbestand, ist romantisch. Natürlich kannte Snell diese Theorien und auch ihre Übernahme in die Homerphilologie. Dennoch ist es berechtigt festzustellen, dass die Übernahme der Ergebnisse der sogenannten oral poetry theory bei Snell eher gering ausgeprägt ist, und vor allem, dass die Erforschung der Besonderheiten dieser Art Dichtung seit Snell große Fortschritte gemacht hat und dass viele dieser Fortschritte erst langsam auch in der deutschen Forschung rezipiert wurden.

Die um Vieles genauere und umfangreichere Kenntnis der Techniken mündlichen Erzählens, die die oral poetry-Analysen gebracht haben ${ }^{21}$ macht klar, dass diese Art des Erzählens nichts mit einer dichtenden Volksseele zu tun hat, die sich unmittelbar und untechnisch ausspricht. ${ }^{22}$ Im Gegenteil, dieses

handelte Frage nach der Deutung Homers in den jeweiligen Rezeptionsphasen ist immer noch wichtig Finsler, Georg, Homer in der Neuzeit.

21 S. v.a. Latacz, Joachim (Hg.), Homer. Tradition und Neuerung; Holoka, James P., Homer, Oral Poetry Theory, and Comparative Literature; Kirk, G. S., Homer and the Oral Tradition; Scodel, Ruth, Listening to Homer; Danek, Georg, Epos und Zitat; Schmitz, Thomas, Homerische Poetik.

22 Zwar nicht mehr im Blick auf eine dichtende Volksseele wie in der Romantik gibt es aber auch heute noch die Position, die formelhaften Erzählstrategien Homers entstammten einem ,ordinary speech', d.h. sie seien dem üblichen Sprachgebrauch entnommen und von seinem Usus geprägt. S. z.B. Minchin, Elizabeth, Homer and the Resources of Memory. Diese These ist nicht ganz von der Hand zu weisen. Aristoteles lobt 
Dichten musste gelernt sein. Auch wenn wir die Überlieferungs- und Schulungsvorgänge nicht kennen - denkbar ist die Weitergabe des Gelernten vom Vater auf den Sohn, eher aber wohl durch das Lernen bei einem Meister oder in einer Gilde -, das, was gelernt sein musste, bevor man überhaupt ein Aoidós sein konnte, ist gut aus den homerischen Texten selbst - und auch durch Ergänzungen aus den Verfahrensweisen anderer mündlicher Dichtung - ermittelbar. Das Wissen über die Besonderheiten dieser Verfahrensweisen ist gerade durch Snells ,Lexikon des Frühgriechischen Epos" bedeutend gefördert worde. ${ }^{23}$ Die von Snell selbst noch formulierte Aufgabe, aus der Verwendung der Sprache die Bedeutung der einzelnen Wörter im Gesamt des überlieferten Sprachgebrauchs zu ermitteln, hat sich als sehr fruchtbar erwiesen und zu vielen Einsichten in die - keineswegs nur formalen, sondern von Inhalten gelenkten - Techniken des Erzählens geführt.

Diese Techniken (von der Schulung in der Bildung des Hexameters aus bestimmten variablen Grundelementen, ${ }^{24}$ über die Erlernung der - zur Person oder Situation - passenden Beiwörter, den Formelversen, der typischen Szene bis zur Strukturanlage einer ganzen Erzähleinheit) waren jedenfalls zur Zeit Homers über Jahrhunderte tradiert. Auch hier steht Homer in einer langen Tradition, die er kennt und beherrscht, d.h. in einer Tradition, die er nicht naiv, sondern reflektiert fortsetzt. Auch als Dichter also ist Homer kein Anfang, sondern verkörpert ein Spätstadium, und zwar offenkundig ein Spätstadium der Vollendung.

Das Bild, das die Forschung heute von Homer zeichnen kann, das ihn in eine lange orientalische Kulturtradition einordnet und ihn als Dichter als Vertreter einer Spätphase, in der er früher Angelegtes zur Vollendung führt, ausweist, reicht zwar nicht hin, um Snells Homerbild als Ganzes in Frage zu stellen, aber es nimmt ihm eine wichtige Säule: die Vorstellung, wir könnten in Homer eine Ursprungsphase der Menschheit zu fassen bekommen, eine mythische Dichtung, durch die wir ,etwas von fernen Zeiten und anderen Menschen, die sahen und sagten und wußten, was uns - durch unser bewußtes,

z.B. an Euripides, dass seine hohe Kunst gerade darin bestanden habe, die Alltagssprache so zu komponieren, dass sie ganz ohne, poetische' Wörter einen poetischen Charakter bekommen habe. Es ist aber klar, dass der Kunstcharakter nicht aus dem Material der ordinary speech kommt, sondern aus seiner neuen Formung. Das gilt sicher auch für Homers Umgang mit dem Material der oral poetry. Hier geht es um technisch Gelerntes oder Lernbares (auch wenn man sich das selbst beibringt, wie Phemios, Odyssee 22, 347f.).

23 Ein vorzügliches Beispiel für die Qualität dieser Lexikonarbeit, durch die nicht nur eine allgemeine Technik des Erzählens, sondern gerade die je individuelle Einpassung des richtigen Worts an die richtige Stelle nachgewiesen werden kann, bietet Führer, Rudolf, Worte im Kontext. S. den Beitrag in diesem Band.

24 S. dazu die grundlegende Studie von Visser, Edzard, Homerische Versifikationstechnik. 
distanziertes Verhältnis zur Wirklichkeit - abhanden gekommen ist“",25 erfahren.

Das ehrwürdige Alter dieser Vorstellung, an der Snell durchaus einige Korrekturen vorgenommen hat, hat sicher dazu beigetragen, dass er gar nicht auf den Gedanken kam, es grundsätzlich in Frage zu stellen (und viele tun dies trotz der neuen Forschungsergebnisse - bis heute nicht). Denn sie stammt nicht aus der Klassik und Romantik, auf die Snell sich vor allem stützt, auch nicht aus dem 17., 16. oder 15. Jahrhundert, sondern ist bekanntlich in diesen frühneuzeitlichen Rezeptionsphasen neu aus der hellenistisch-römischen Antike übernommen worden. Wir finden sie z.B. bei dem Stoiker Chrysipp (der seinerseits über Platon und Aristoteles hinweg auf die Vorsokratiker zurückgreift, ${ }^{26}$ oder etwa - an einer für die Neuzeit besonders einflussreichen Stelle bei Horaz. ${ }^{27}$ Für Horaz sind die Dichter zugleich Seher, Künder einer ursprünglichen Weisheit (sapientia quondam, v. 396), in Zeiten, als die Menschen noch in Wäldern lebten (silvestris homines, v. 391) und zur Kultur erst durch die Dichter, deren mythischer Heros Orpheus ist, gebildet werden mussten. Homer ist für Horaz - ganz ähnlich wie noch für Snell - nicht Vertreter dieser allerersten Urform, aber er folgt ihr unmittelbar und ragt über die Späteren hinaus (insignis Homerus, v. 401).

Einer solchen Vor- und Urform der Kultur - und schon gar nicht einer spezifisch europäischen Urform - gehört Homer, das kann man mit einiger Sicherheit heute sagen, nicht an.

Dass man in Gegensatz dazu heute Homer in lange kulturelle und literarische Traditionen einordnet, muss freilich nicht bedeuten, ihn darin aufgehen zu lassen. Diese letztere Tendenz, die vor allem für die oral poetry-Forschung in ihren Anfängen (mit Ausläufern bis heute) charakteristisch war, war vielmehr ihrerseits Folge der Übernahme romantischer Vorstellungen von Dichtung. Der vielfältig geführte und berechtigte Nachweis, dass Homer Teil einer mündlichen Dichtweise ist, war ja für viele Anlass, auch die Ilias und die Odyssee ganz als Produkte eines spontanen, unartifiziellen und sich im mündlichen Vortrag immer neu formierenden Singens auszugeben. Die Ordnungselemente, die die mündliche Dichtweise bot, fasste man nur als Hilfsmittel für die Möglichkeit, unmittelbar und improvisierend erzählen zu können, auf.

25 Burkert, Walter, Antiker Mythos - Begriff und Funktion, 20.

26 S. Cicero, De natura deorum I, 41

27 S. Horaz, Ars poetica, 391-407. 


\section{1,2a) Das ,Griechische“ bei Homer ist nicht griechisch, sondern homerisch}

Von vielen verschiedenen Aspekten her konnte aber inzwischen die Besonderheit der homerischen Dichtungen herausgearbeitet werden. ${ }^{28}$ Dass Homer sich von dem, was man allgemein über mündliches Dichten weiß, in vielem unterscheidet, - insbesondere durch die je individuelle Art der Anwendung des ,Formelhaften' und durch die außergewöhnlich durchkomponierte Bauweise seiner Epen - kann inzwischen als ein weitgehender Konsens der Forschung gelten. ${ }^{29}$

Im Einzelnen gibt es aber noch viele umstrittene Deutungsprobleme, manches ist ganz ungeklärt.

Auf einige Probleme aus diesen Bereichen möchte ich etwas genauer eingehen, teils weil sie zu einer Korrektur der Thesen von Snell beitragen, teils weil sie besonders geeignet sind, sein zentrales Anliegen, Homer nicht nur aus historischem oder ästhetischem Interesse zu lesen, sondern in seiner Bedeutung für eine immer noch relevante Kulturtradition zurückzugewinnen, ein Stück weiter zu erfüllen.

Was das Verhältnis Homers zur mündlichen Dichtung angeht: Der sogenannte epische Kyklos bietet, auch wenn das, was an schriftlicher Überlieferung von ihm noch erhalten ist, in spätere Zeiten gehört, vielfache Beispiele für mündlich entstandene Erzählungen im Umkreis Homers. Diese Erzählungen unterscheiden sich aber in mehrfacher Hinsicht deutlich von den homerischen, und zwar sowohl in der inhaltlichen Deutung des berichteten Geschehens als auch in der formalen Gestaltung der Erzählungen.

Auch wenn man selbst in neuesten Behandlungen der homerischen Poetik lesen kann, es sei ,schwer, klare Unterscheidungen [zu treffen], zwischen für das gesamte archaische Epos typischen Elementen und spezifischen Besonderheiten von Ilias und Odyssee ", ${ }^{30}$ bereits die Inhalte der kyklischen Epen und der beiden Epen Homers unterscheiden sich erheblich. In Anlehnung und konsequenter Fortführung älterer Forschungen hat Jasper Griffin zusammenge-

28 Grundlegend für viele neuere Forschungen zur Kompositionstechnik Homers ist Schadewaldt, Wolfgang, Iliasstudien; s. jetzt v.a. Latacz, Joachim, Die Erforschung der IliasStruktur; zur Geschichte der Homerforschung von der Antike bis in die Gegenwart; s. die ausgezeichnete Darstellung und Analyse bei Schwinge, E.-R., Homerische Epen und Erzählforschung; eine vorzügliche Darstellung der Forschungsgeschichte bietet Nesselrath, Heinz-Günther, Geschichte der Homerforschung. Da es Snell besonders um die Herausarbeitung des ,Griechischen' geht, behalte ich auch bei der Benennung der homerischen ,Achäer' öfter die Bezeichnung 'Griechen' bei und nehme eine kleine Ungenauigkeit im Kauf.

$29 \mathrm{Zu}$ einer neueren Tendenz, trotz einer Ablehnung der früheren Homeranalyse wieder die Frage nach der Genese der homerischen Werke ins Zentrum zu stellen (dieses Mal unter der Voraussetzung, dass es sich um den Arbeitsprozess eines Dichters handle), s. das Folgende.

30 S. Schmitz, Thomas, Homerische Poetik, 64. 
stellt, wie viel an Phantastischem, Mirakulösem, Romantischem, an magischen Praktiken, an unbestimmten Vorstellungen über das unberechenbare und die natürlichen Gesetze aufhebenden Wirken der Götter im Kyklos enthalten ist, von dem man keine oder nur noch marginale Spuren bei Homer findet. ${ }^{31}$

Analoges gilt für die Behandlung der Charaktere der Personen. Insbesondere Achill und Odysseus sind bei Homer trotz mancher Charakterschwächen als gute Charaktere gezeichnet. Dasselbe gilt für Homers Menschenbild und die Darstellung der Lebens- und Denkweise der meisten Personen vor Troja, während in den kyklischen Epen von einer großen Zahl schlimmer Vergehungen, ja Verbrechen berichtet wird.

Im Blick auf Snell sind diese Beobachtungen besonders bemerkenswert, denn sie dokumentieren, dass gerade das, was Snell für das typisch Griechische bei Homer gehalten hat, ${ }^{32}$ nicht griechisch, sondern homerisch ist. Dass das Göttliche den Menschen als etwas Unheimliches, Magisches, als Schauder Erregendes entgegentrete, findet man nicht nur bei den sogenannten ,Primitiven', es ist auch für viele griechische Vorstellungen von Religion zutreffend, nur eben nicht für Homer.

Da auch Snell von dem ,,von Homer geschaffenen Glauben an die olympischen Götter"333 spricht, kann man an seiner Deutung auch mit einer Einschränkung festhalten: Das, was man bei Homer vorfindet, ist nicht etwas typisch Griechisches, das er in prägnanter Weise dargestellt und zusammengefasst hat, sondern es ist die deutende Leistung des Dichters (oder der Dichter - dazu unten mehr) der Ilias und Odyssee.

Diese Abgrenzung gilt dann allerdings auch gegenüber anderen Einflüssen, auch den orientalischen, die man in den homerischen Epen nachweisen kann. Auch bei ihnen muss zumindest geprüft werden, wie die funktionale Einordnung in die Geschehensdeutung, die diese Epen bieten, auch die übernommenen Elemente umgeformt hat.

\section{1,2b) Die Besonderheit der Handlungsanlage und der Zeitgestaltung bei Homer gegenüber dem Kyklos}

Wichtiger und noch konsequenzenreicher als die eben behandelten Unterschiede ist ein Unterschied in der Handlungsdarstellung selbst, der sowohl einen formalen wie einen inhaltlichen Aspekt hat.

Aristoteles, der seine Konzeption von guter Dichtung bekanntlich weitgehend von Homer bereits erfüllt glaubt, verweist in seiner Poetik mehrfach

31 S. Griffin, Jasper, The Epic Cycle and the Uniqueness of Homer; s. auch Kullmann, Wolfgang, Ilias, 81: „,in der Ilias ... ist alles Märchenhafte und Fabulöse ausgeklammert.“ Inhalte des Kyklos und die Forschungssituation sind gut zusammengefasst bei Latacz, Joachim, Artikel ,Epischer Zyklus".

32 S. Snell, Bruno, Die Entdeckung des Geistes, 30f.

33 S. ebd. 30. 
darauf, dass Homer grundlegend anders erzählt habe als die anderen epischen Dichter (23, 1459a30ff.; 26, 1462b10f.; 8, 1451a22ff.) und leitet aus diesem Unterschied ab, Homer habe als einziger genau gewusst, welche Aufgabe einem Dichter als Dichter gestellt ist (24, 1460b5-11). Die meisten Dichter versuchten nämlich, die Ordnung ihrer Erzählung aus einer Ordnung der Zeit zu gewinnen. Die Einheit einer Biographie mit ihrer Aufeinanderfolge der Ereignisse eines Lebens, oder die Einheit eines Zeitabschnitts, mit der kausalen Aufeinanderfolge von geschichtlichen Ereignissen böten in Wahrheit keine einheitlichen Gestaltungsvorgaben, an denen sich ein Dichter orientieren könne.

Homer müsse im Vergleich mit den anderen als ,thespesios' gelten, als ein Dichter, dessen Werke wie ,von Gott gesprochen ${ }^{634}$ erscheinen. Denn obwohl der trojanische Krieg einen Anfang und ein Ende habe, habe er nicht versucht, den ganzen Kriegsverlauf darzustellen. Eine diesem Verlauf folgende Handlungskomposition hätte niemals ,gut überschaubar“ sein können, entweder wegen der schieren Masse oder wegen der Komplexität der Stoffvielfalt. Stattdessen habe er einen Teil herausgegriffen, und zwar, wie man aus dem 8. Kapitel ergänzen kann, eine Handlung, ,wie wir sie meinen“ (8, 1451a28-30), und habe das andere in darauf bezogenen Einzelszenen dargestellt, wie den Schiffskatalog und anderes, und habe so seine Darstellung strukturiert (23, 1459a31-37).

Man kann sich fragen, weshalb Aristoteles der bloßen Handlungsanlage eine so außergewöhnlich hohe poetische Bedeutung zumisst. Auch in modernen Interpretationen beachtet man, dass die homerischen Epen eine meisterhafte, hochkomplexe Komposition aufweisen, für deren Qualität die außergewöhnliche Darstellungsweise, ein zehnjähriges Geschehen in einer Handlung, die nur wenige Tage umfasst, zu erzählen, eine große Rolle spiele. ${ }^{35}$ Aber Aristoteles scheint gerade auf diesen letzten Aspekt, auf die kurze, überschaubare Handlungsanlage, das ganze Gewicht seines Urteils zu legen, während die neuere und neueste Forschung in der Haupthandlung, etwa der ,Achilleis' in der Ilias (wieder) nur eine Art Grundstock sieht, der später durch eine Fülle von Erweiterungen, Retardationen usw. erst $\mathrm{zu}$ dem uns heute überlieferten Großepos geworden sei. ${ }^{36}$

34 S. die Erklärung durch Nordheider im Lexikon des Frühgriechischen Epos, Nordheider, H. W., Artikel ,thespésios' (LfgrE).

35 Vor allem Joachim Latacz hat den aristotelischen Hinweis auf die Strukturanlage der homerischen Epen aufgegriffen und grundsätzlich für die Interpretation fruchtbar gemacht. Auf seinen Ergebnissen baut das Folgende in Vielem auf. S. v.a. Latacz, Joachim, Homer. Der erste Dichter der Abendlands, v.a. 89-166; ders., Die Erforschung der Iliassstruktur; ders., Artikel ,Homerische Frage; s. auch die wichtige Analyse bei Schwinge, E.-R., Homerische Epen und Erzählforschung.

36 Hauptvertreter dieser neueren Tendenz, die in mancher Hinsicht einen Rückgang hinter die Ergebnisse der Forschung des Baus der Ilias von Schadewaldt bis Latacz mit sich bringt, sind v.a. Reichel, Michael, Fernbeziehungen in der Ilias; Kullmann, Wolfgang, Ilias, 79-119; West, Martin, The Making of the Iliad. In diesen Arbeiten wird die 
Da gerade, wenn man Homer mit den Augen Snells zu betrachten versucht, der handelnde Mensch im Zentrum stehen muss, scheint es sinnvoll, der hohen Bewertung der Handlung in Ilias und Odyssee durch Aristoteles, der ja ihretwegen Homer das Attribut ,göttlich' gegeben hat, eine noch etwas genauere Beachtung zu geben.

Aristoteles sagt mit Blick auf die Ilias, sie enthalte mehrere Handlungseinheiten (18, 456a11-19). Das dürfe man bei der Abfassung einer Tragödie nicht nachahmen. Aischylos und Euripides z.B. hätten mit Erfolg einzelne Handlungen aus der Gesamtdarstellung der Ilias herausgegriffen, andere, die das Ganze in eine Tragödienhandlung zusammenzuziehen versucht hätten, seien gescheitert.

An späterer Stelle sagt er dagegen, aus der Ilias könne man nur eine Tragödienhandlung machen. Das unterscheide sie von den kyklischen Epen. In der Kleinen Ilias etwa könne man 8 Tragödienhandlungen unterbringen, z.B. Die Entscheidung über die Waffen, den Philoktet, den Neoptolemos, ... Die Zerstörung Trojas, usw. Diese Dichtungen kreisten um einen Menschen oder um einen Zeitraum und ihre Handlungen seien dem ,unbestimmt Vielen', das in einem Zeitraum geschehen könne, entsprechend, vielteilig (23, 1459b1-8).

Beide Aussagen des Aristoteles widersprechen sich nicht, sondern machen etwas über seinen Handlungsbegriff deutlich: Ein kyklisches Epos wie die Kleine Ilias behandelt ein Geschehen, das sich über einen gewissen Zeitraum erstreckt. Es beginnt mit dem Geschehen nach dem Tod Achills und führt über die Eroberung und Zerstörung Trojas bis zur Abfahrt der Griechen nach Hause. In diesem Geschehen ,passiert' viel, es gibt darin auch mehrere Handlungen, wenn unter Handlung vorläufig verstanden werden soll, dass in ihr von handelnden Personen ein subjektives Ziel angestrebt wird. Diese Handlungen aber sind für sich je selbstständig, sie sind nicht Teil einer Handlung, sondern folgen lediglich als Ereignisse aufeinander. So ist mit der Übergabe der Waffen Achills und dem Selbstmord des Aias die erste Handlung abgeschlossen. Die Rückholung des zur Tötung des Paris nötigen Philoktet ist eine neue Handlung. Ihr Ziel ist erreicht, wenn es gelungen ist, Philoktet nach Troja zurückzubringen und mit seiner Hilfe Paris getötet ist. Wenn Odysseus danach Neoptolemos zurückholt und ihm die Waffen seines Vaters Achill übergibt, ist das wieder eine neue Handlung, die ihren eigenen Anfang und ihr eigenes Ende hat, usw.

Eine Erzählung, die das Geschehen der Kleinen Ilias zum Gegenstand hat, muss die Ordnung ihrer Struktur aus der Kausalität der Ereignisse füreinander

Homer-Analyse einerseits nicht aufgegriffen. Die alte Annahme von einer aus vielen, oft unindividuellen Quellen entstandenen Ilias findet keine Erneuerung, im Gegenteil: gerade im Nachvollzug der verschiedenen Bauphasen soll die Genialität eines individuellen Dichters dokumentiert werden. Die Methoden andererseits, diese Phasen zu unterscheiden, sind aber in wesentlicher Hinsicht analytisch im alten Sinn. Deshalb versucht das Folgende die Einheit des Bauplans der Ilias von den neuen Einwänden her neu zu ermitteln. 
gewinnen: Was war nötig, damit Troja zerstört werden konnte, usw.? Der Bericht orientiert sich demgemäß an der Abfolge der Ereignisse in der Zeit. Er kann linear verlaufen und den Geschehnissen folgen, wie sie stattgefunden haben, er kann aber auch irgendwo einsetzen und in Vor- und/oder Rückblenden erzählen, ,wie es gekommen ist, dass ...', oder ,wie es kommen wird, dass ...'. Entscheidend ist, dass der Leser oder Hörer am Ende das Gesamtgeschehen und die Bedingungen, wie es im Verlauf der Zeit sich entwickelt hat, kennt.

Viele neuere Interpreten halten mit Horaz den Unterschied in der Zeitgestaltung, ob der Erzähler dem Gang der Ereignisse in der Zeit linear folgt, oder ob er ,,in medias res“ (Ars Poetica, v. 148) springt, um von dort durch ,Analepsen“ und ,Prolepsen“, durch Raffung und Dehnung der Zeit, je nach der Wichtigkeit des Geschehens (usw.) eine eigene narrative Ordnung zu finden, für den Unterschied, der Homer vom Kyklos trennt.

Das ist aber vermutlich nicht die Meinung des Aristoteles und entspricht auch nicht dem Befund, den man bei Homer beobachten kann. Zwar springt Homer tatsächlich irgendwo in die Mitte, genauer: ans Ende des Geschehens, wenn er mit seiner Erzählung beginnt. In der Odyssee spielt er geradezu auf die von einem mündlich erzählenden Dichter offenbar erwartete Fähigkeit an, ,irgendwo' beginnen und doch eine ganze, runde Geschichte erzählen zu können: „Davon (von den Geschichten des Odysseus und seiner Gefährten) fang irgendwo an und erzähle auch uns“, bittet er die Muse (v. 10).

Aber man erfährt über den Verlauf der Geschehnisse in der Zeit fast nie etwas vom Erzähler selbst, sondern immer von seinen Personen. ${ }^{37}$ Der Grund für dieses Verfahren ist aber kaum zuerst narratologisch, d.h. er hat nicht die Zielsetzung eines Erzählers, um durch den Vor- oder Rückgriff auf anderes Geschehen das jetzige Geschehen in den richtigen Zusammenhang zu bringen. Der Grund ist immer, dass der Bericht von etwas Vergangenem oder Zukünftigen (oder auch nur der Hinweis darauf) der gerade agierenden Person zur Motivation ihres Handelns dient: Sie benötigt das Vergangene oder Zukünftige für die Handlungsziele, die sie gerade verfolgt. Da dieser Aspekt in der Homerforschung seltener und kaum konsequent verfolgt ist, muss er etwas ausführlicher behandelt werden.

Man hat immer wieder bewundernd festgestellt, dass es Homer gelungen ist, zwei Zeitebenen miteinander zu verbinden, die Ebene der von ihm ausdrücklich dargestellten (Achill-)Handlung und die Ebene des Gesamtgeschehens. ${ }^{38}$ Wer die Ilias aus der Hand legt, weiß nicht nur, weshalb Achill in Zorn geraten ist und wie er sich wieder beruhigt hat, er kennt (fast) die ganze Trojageschichte.

$37 \mathrm{Zu}$ diesem Verfahren bei Homer s. Nünlist, René und Jong, Irene de, Homerische Poetik in Stichwörtern, 159f. Dort auch weitere Literatur.

38 S. dazu die immer noch wichtige Erklärung bei Lesky, Albin, Homeros, Kap. VII. Ilias, 3. Frage der Einheit, v.a. 91-98. 
Um diese Geschichte zu kennen, muss man z.B. auch wissen, wie denn der Auszug nach Troja in Aulis begonnen hat und unter welchen günstigen oder ungünstigen Vorzeichen er stand. Davon erfährt man in der Ilias durch Odysseus. Das Heer, von Agamemnon auf die Probe gestellt, stürmt zu den Schiffen, um nach Hause abzusegeln. Da braucht Odysseus starke Argumente, um die wild gewordene Truppe zur Umkehr zu überreden. Dazu dient ihm die Erinnerung an Aulis, wie dort der Seher Kalchas gerade für dieses zehnte Jahr den endlichen, aber sicheren Sieg in Aussicht gestellt hat (2, 299-330). In über 30 Versen lässt ihn Homer deshalb die damalige Situation in Erinnerung rufen, um damit zu enden: Das erfüllt sich gerade, ${ }^{39}$ also bleibt alle, bis wir die Stadt des Priamos eingenommen haben (2, 330-33).

Die Einspiegelung der Vergangenheit hat also keine, jedenfalls keine direkt oder gar ausdrücklich vorgebrachte narrative Funktion. Nicht für den Gang der Erzählung, sondern für die Motivation der Handlung ist die Erinnerung an die Vergangenheit nötig.

Ganz ähnlich ist es, wenn es um die Frage geht, was denn in den 9 Jahren, in denen die Griechen vor Troja lagen, geschehen ist. Das erfährt man z.B. von Achill während der sogenannten Bittgesandtschaft im 9. Buch der Ilias, weil er sich gegen den Vorwurf, er sei um seine Kameraden und deren Leid nicht bekümmert, verteidigen will. Wie eine Vogelmutter, so sagt er, habe er sich immer um alle gekümmert, habe gekämpft und gelitten. Zwölf Städte habe er zu Schiff, elf zu Land erobert, usw. (9, 316-319). Nun weiß der Leser oder Hörer, womit die Griechen vor Troja beschäftigt waren, sie haben die Städte rund um Troja erobert, um es zu schwächen und um Beute zu machen.

Von der ersten Verhandlung der Griechen mit den Trojanern, um wenigstens noch ein Beispiel anzuführen, erfährt man in der Ilias, als sich während der sogenannten Mauerschau Priamos über die gedrungene Gestalt des Odysseus, den Helena ihm gezeigt hatte, wundert. Da berichtet Antenor davon (3, 203-227), dass sich die Trojaner über das merkwürdige Aussehen des Odysseus auch schon damals gewundert hätten, als er nach der Ankunft der Griechen zusammen mit Menelaos in die Stadt gekommen sei, um über die Rückgabe Helenas zu verhandeln. ${ }^{40}$

Die Geschichtszeit ist für Homer offenbar weder in ihrem eigenen Ereignisverlauf noch bei ihrer Wiedergabe durch den Erzähler Gestaltungsprinzip.

$39 \mathrm{Zu}$ dieser Übersetzung und Deutung der Stelle s. Latacz, Joachim (Hg.) Homers Ilias. Gesamtkommentar. Bd. II, 2: Kommentar, $99 \mathrm{f}$.

40 Viele weitere Beispiele für die Einspiegelung der Trojageschichte in die Achilleushandlung bei Schwinge, E.-R., Homerische Epen und Erzählforschung, 488-492; Kullmann, Die Quellen der Ilias, 5-11 hat nicht weniger als 60 solcher Anspielungen auf die Trojageschichte zusammengestellt. S. auch Latacz, Joachim, Zur Struktur der Ilias 157. Die Art der Einbettung dieser ,Exkurse“ in die Handlung gilt natürlich auch für andere Sagenkomplexe, die in die Ilias übernommen sind, etwa für die Meleagergeschichte, die Phoinix als Exempel zur Ermahnung Achills dient. S. Schwinge, ebd. 488-498. 
Die Ordnung der Erzählung und die objektive oder subjektive Ordnung der Zeit stehen in keinem Zusammenhang miteinander.

Die Stelle, an der man etwas über den geschichtlichen Verlauf des Krieges erfährt, ist in der Ilias durch die Rolle bestimmt, die ein geschichtliches Moment innerhalb der Handlung einer Person hat.

Das bedeutet, und das ist schon eine erste wichtige Erklärung für die Aristotelische These, dass die Ordnung der Erzählung in der Ilias aus der Ordnung der Handlung kommt, genauer: aus der einen, überschaubaren Handlung, die Ursache dafür ist, dass man aus der Ilias nur eine Tragödie hätte gewinnen können.

Tatsächlich stehen die Einzelhandlungen, die man in der Ilias isolieren kann, in einem anderen Verhältnis zueinander und zum Ganzen als etwa in der Kleinen Ilias. Die Patrokloshandlung z.B. verläuft nicht neben der Handlung des Achill, sie ergibt sich vielmehr unmittelbar aus dem Handeln Achills selbst. Achills überlanges Zögern, selbst wieder helfend in den Kampf einzugreifen, führt Patroklos zu der Bitte, an Stelle des Achill die Kameraden zu retten. Obwohl dieses Ziel ein eigenes, eigenständiges Ziel des Patroklos ist, das für sein Handeln bestimmend ist, so dass man zu Recht von einer eigenen Handlung bei ihm sprechen kann, bedeutet das Ende dieser Handlung, d.h. sein Tod, andererseits nicht nur das Ende seiner Rettungshandlung, sondern ist zugleich der Anfang eines neuen Teils der Achillhandlung. Für Achill, der schon nach der Rede des Aias am liebsten zugestimmt hätte, wieder mitzukämpfen (9, 644f.), der danach sich neu und intensiv für das Schicksal der kämpfenden Freunde interessiert $(11,599 f f$.$) und schließlich sogar Patroklos als$ eine Art Stellvertreter in den Kampf schickt (16, 47ff.), bedeutet der Tod des Freundes den letzten Schritt, seinen Zorn zu überwinden und wieder selbst am Kampf teilzunehmen.

Ohne die Patrokloshandlung gäbe es , die eine Tragödie‘, die die Ilias darstellt, überhaupt nicht, sie ist ein notwendiger Teil dieser Handlung. Auch der Ort, an dem sie im Gesamt des erzählten Ganzen steht, ist durch ihre Funktion für die Achillhandlung festgelegt. Man könnte sie weder wegnehmen noch umstellen, ohne dass das Ganze sich wesentlich ändern würde (Aristoteles, Poetik 8, 1451a30-35). ${ }^{41}$

41 Die ganz andere ,Erzähltheorie', die Aristoteles konzipiert und an Homer mit guten Gründen und Belegen verifiziert hat (s. Verf., Aristoteles. Poetik, 92-127), wird gerade an der unterschiedlichen Zeitbehandlung in besonderer Weise erkennbar. Die Zeit hat für die heutigen Erzähltheorien eine grundlegende Bedeutung (s. Ricoeur, Paul, Zeit und Erzählung. Band II: Zeit und literarische Erzählung; Genette, Gérard, Die Erzählung. Die Erzählweise bei Homer, aber auch in der griechischen Tragödie, kann demgegenüber fast als antitemporal bezeichnet werden. Deshalb ist es in den homerischen Epen nicht der Erzähler, der die Ordnung bestimmt, indem er die Zeit rafft oder dehnt, indem er vor- oder zurückgreift, und auch nicht irgendwelche Personen als ,Fokalisatoren'. Bei der Ordnung aus der Handlung, wie man sie bei Homer findet, ist auch das Vergangene wie das Zukünftige immer dann präsent, wenn es für den Handelnden 


\section{2) Zur ,poetischen Verfahrensweise' bei der Darstellung einer Handlung} und eines Geschehensverlaufs

\section{2a) Der Anfang der Menis-Handlung und die Geschichte des trojanischen Kriegs}

Es ergibt sich als eine direkte Konsequenz aus dieser Einbettung der Einzelhandlungen in die Achillhandlung und durch die Ordnungs- und Gestaltungsfunktion, die diese Handlung dadurch für die Gesamtkomposition bekommt, dass sie kaum nur einen Grundstock der Ilias bilden konnte, den zur Erzeugung von Spannung und zur Anreicherung der Inhaltsfülle oder um wichtige Teile der Trojageschichte unterzubringen, ein oder mehrere Dichter durch Retardationen und Einschübe mancherlei Art erweitert haben sollten.

Vielleicht ist es gut, sich zur Klärung an eine Kritik des Aristoteles an einer fehlerhaften Weise der Feststellung von Widersprüchen in einer Dichtung zu erinnern. Viele, so sagt er, gehen mit einer festen Vorstellung von dem, was in einer Dichtung dargestellt sein müsse, an die Kritik des Werks und kritisieren dann den Dichter, wenn das, was er sagt, ihrem Vorurteil widerspricht. ${ }^{42}$

Setzt man bei der Ilias voraus, ihr Hauptthema, das Homer über die Erzählung der Achillhandlung habe behandeln wollen, sei der trojanische Krieg, ${ }^{43}$ dann erscheint die Ilias in vieler Hinsicht ergänzungsbedürftig, unvollständig, sogar widersprüchlich oder ungereimt.

Vor allem aber liegt es in der Konsequenz dieser Vorerwartung, dass man viele bei Homer der Handlungsdarstellung unmittelbar dienende Erklärungen - mit Vor- oder Rückverweisen, Hinweisen auf andere Teile der Trojageschichte oder auf andere Sagenkreise usw. - als verdeckte Zusätze, die die temporale Ganzheit der Trojageschichte herstellen sollen, auffasst. Das ist so bei dem eben diskutierten Hinweisen auf die Situation in Aulis und beim Schiffskatalog, bei den ersten beiden Kriegstagen, von denen die Bücher 3 bis 8 berichten, insgesamt, darunter wieder besonders bei der Mauerschau, ja selbst bei der neuen Ver- und Entführung Helenas durch Paris,${ }^{44}$ die Homer nach

präsent ist. In diesem Punkt richten sich auch die griechischen Tragiker in vielem nach Homer. Die Vorgeschichte des Königs Ödipus etwa wird dann erzählt, wenn sie für die Handlungsgegenwart des Ödipus unmittelbar relevant ist: In einer Situation höchster Beunruhigung darüber, er könne selbst der gesuchte Mörder des Laios sein, berichtet Ödipus seiner Frau von seiner Vorgeschichte, die ihm diese gegenwärtige Beunruhigung verursacht (Sophokles, König Ödipus vv. 726-833).

42 S. Aristoteles, Poetik 25, 1461b1-4. S. dazu Verf., Aristoteles. Poetik, 720-722.

$43 \mathrm{Zu}$ diesem Ergebnis kommt auch Schwinge, Homerische Epen und Erzählforschung, 509511, in einer vielfach überzeugenden Gesamtdeutung des Bauplans der homerischen Epen.

44 Ebd. 510. 
der Rettung des Paris von Menelaos gewissermaßen nachspielen lasse, und bei vielem anderen mehr. ${ }^{45}$

Homers Thema aber ist ausdrücklich die ,Menis‘ des Achill, und sein Epos endet auch mit dem Ende der Empörtheit Achills (s. dazu gleich das Folgende), ohne Rücksicht darauf, dass die Trojageschichte noch nicht zu Ende erzählt, ist. Nicht einmal der Tod Achills ist behandelt.

Auch wenn es Homer gelungen ist, in diese Handlungsdarstellung alles das einzublenden, was man aus den Gesamtereignissen des trojanischen Kriegs wissen muss, und darüber hinaus auch noch vieles, was aus anderen ,mythologischen' Erzählungen zum Verständnis dieser Handlung benötigt wird, das alles ist nicht sein Thema. Es muss also auch nicht vollständig oder gar in der richtigen Reihenfolge der Ereignisse dargestellt sein, es hat seine Aufgabe nur in der Erklärung der Zornhandlung.

Das also muss Gegenstand einer literarkritischen Prüfung sein, ob die Darstellung alles das enthält, was die Zornhandlung verstehbar macht, und ob die dazu nötigen Einblendungen diese Aufgabe an der richtigen Stelle richtig erfüllen.

Dass der Anfang zur Erklärung der Zornhandlung von Homer gut gelungen ist, wird allgemein und mit großer Bewunderung bestätigt. ${ }^{46}$ Fraglich aber scheint sehr vielen der Fortgang der Handlung, nachdem sich Achill verletzt und beleidigt zurückgezogen hat. Und er ist beleidigt, das muss vielleicht wegen mancher Missverständnisse beachtet werden, nicht weil ihm Briseis weggenommen wird, sondern weil Agamemnon ihm, der als ,Zerstörer Trojas“ (ptolíporthos) mitgekommen ist, ${ }^{47}$ gesagt hat, er brauche ihn nicht, er könne nach Hause fahren (1, 172-175). Die Bitte, die Achill über die Vermittlung seiner Mutter Thetis an Zeus richtet, ist auf diese Verletztheit bezogen: Zeus soll dafür sorgen, dass die Griechen so schwere Niederlagen erleiden, dass sie sehen, wie wenig sie ohne Achill erreichen können (1, 350-412, v.a. 408412).

45 S. die Liste der ,Rückbezüge“ auf die Vorgeschichte bei Kullmann, Wolfgang, Ilias, 89. Die Frage ist nicht, ob es Rückbezüge bei Homer gibt, die Frage ist, ob diese Rückbezüge sozusagen verdeckt und unausdrücklich, ja vielleicht sogar ungewollt in den Text gekommen sind. Wenn die Art, wie Aphrodite Helena zu Paris schickt (3, 448-461) eine Einspiegelung der Verkuppelung von Helena und Paris, wie wir sie aus den Kyprien $(\$ 11)$ kennen, ist, dann steht sie bei Homer in gewissem Sinn an der falschen Stelle und macht zumindest die Frage nötig, ob es Homer gelungen ist, diese nicht zu seiner eigentlichen Handlungskonzeption gehörende Partie gut einzufügen.

46 S. Kullmann, Wolfgang, Ilias, 91: „Die psychologische Feinzeichnung, die Schilderung der allmählichen Eskalation des Gesprächs heben sich aus allem, was wir über die mythologische Überlieferung wissen oder aus der orientalischen Dichtung kennen, aufgrund ihrer poetischen Qualität heraus und sind Zeichen eines bedeutenden Dichters und können nicht die Leistung eines Kollektivs oder einer Tradition sein.“

47 Dass dies das Hauptmotiv für Achill war, am Zug gegen Troja teilzunehmen, zeigt gut Oka, Michio, Achill, der Zerstörer der Stadt. 
Da Zeus dieser Bitte Achills zustimmt (1, 502-530) und ihre Erfüllung von Homer sogar als ,Diós boulé, als Plan des Zeus bezeichnet wird, der sich im folgenden Handeln der Menschen erfüllen werde, erwarten viele, dass Agamemnon, dem Zeus einen schnellen Sieg vorgaukelt, gleich beim ersten Ausrücken seines Heers in schlimme Bedrängnis geraten müsse. Da an Stelle dieser Bedrängnis erst einmal eine Reihe von Siegen und ,Aristien“ (v.a. die des Diomedes, Buch 5) der Griechen dargestellt werden, glaubt man, Homer habe in diese ersten Bücher (Buch 3 bis 8) in nicht ganz passender Weise die ersten Kriegsereignisse, die eigentlich schon neun Jahre vor der Situation, die er in seiner Erzählung voraussetzt, stattgefunden haben, eingefügt (er oder ein Bearbeiter). Seine Leser sollten auf diese Weise an den Anfang des Kriegs erinnert werden, damit ihnen das ganze Geschehen präsent sein konnte. Die MenisHandlung werde in Wahrheit erst mit der Kriegswende in Buch 8 oder, wie manche meinen, ${ }^{48}$ sogar erst mit Buch 11 fortgeführt.

Bleibt man konsequent dabei, dass Homer (oder der Bearbeiter der Endfassung der Ilias) seinen Lesern (oder Hörern) auch in den Büchern drei bis sieben vom Fortgang der Zornhandlung berichten und also auch bei Ihnen diesen Eindruck erzeugen wollte, muss man fragen, wieso ihm dies - anders als vielen Philologen - plausibel erscheinen konnte. Stellt man diese Frage in dieser Weise, kehrt sich die Beweislast beinahe um. Weshalb sollte Homer seinen Leser, die auf die Erfüllung der Zeuszusage für Achill warteten, ohne es auszusprechen, nur durch die Art der Beschreibung der Vorgänge, einen „Rückbezug auf die Vorgeschichte“"49 bieten wollen? Den damaligen Hörern oder Lesern war aus langer Überlieferung der ganze trojanische Krieg und also auch sein Anfang bekannt. Für sie wäre eine (Pseudo-)Wiederholung des Anfangsgeschehens im zehnten Kriegsjahr unglaubwürdig gewesen. ${ }^{50}$

Von der Beschreibung des Kampfgeschehens, wie sie die Ilias bietet, her, ist außerdem ein Kriegsanfang in der Weise, wie er in den Büchern 3 bis 7 vorgeführt wird, ziemlich sicher ausgeschlossen. Die uns bekannte Überlieferung aus den Kyprien beschreibt den Kriegsanfang in einer Weise, die auch als Voraussetzung der Ilias plausibel ist. ${ }^{51}$ Die Trojaner versuchen, die Griechen,

48 S. Kullmann, Wolfgang, Ilias, 87; s. West, Martin, The Making of the Iliad, 51.

49 S. Kullmann, Wolfgang, Ilias, 89. Die These ist hier nicht neu, sondern sehr verbreitet.

50 Aristoteles, der den Dichtern viel freie Erfindung zugesteht, schränkt diese Freiheit allerdings ein, wenn sich ein Dichter einen geschichtlichen Gegenstand gewählt hat (Poetik 24, 1460b26f.; s. dazu Verf., Aristoteles. Poetik 698f.). Dann nämlich dürfe man keine Erfindungen machen, die im dargestellten geschichtlichen Geschehen gar nicht vorkommen könnten. Aristoteles' Beispiel ist aus der Sophokleischen Elektra entnommen. Dort lässt Sophokles dem Erzieher von Orest den Auftrag geben, im Palast zu berichten, Orest sei bei den pythischen Spielen ums Leben gekommen (v. 44-50). Da es solche Spiele zur Lebenszeit des Orest noch gar nicht gegeben habe, könne man nicht glaubwürdig einem Publikum, dem die Geschichte bekannt ist, eine solche Fehlinformation geben. Das Gleiche gilt für Homers antike Leser.

51 S. Burgess, S. Jonathan, The Tradition of the Trojan War. 
als sie aus den Schiffen aussteigen, daran zu hindern, an Land zu gehen. Protesilaos, der als erster an Land geht, findet dabei den vorhergesagten Tod. Daraufhin tötet Achill einen der Trojaner, die unter großen Verlusten in die Stadt zurück getrieben werden (Kyprien $\ 35-38$ ). Danach schicken die Griechen eine Gesandtschaft nach Troja $(\$ 39)$, von der auch die Ilias berichtet $(3,203-$ 227).

Seit dieser Zeit herrscht zwischen den beiden Kampfparteien in der Ilias bekanntlich ein Patt. Die Mauern Trojas sind von Apollon und Hephaist gebaut und für die Griechen uneinnehmbar, die Griechen sind im offenen Kampf der Heere von den Trojanern nicht zu besiegen, weil Achill unüberwindlich ist. Auf diese Situation reagiert Hektor mit kluger Kampftechnik, indem er sich einem offenen Kampf nicht stellt. Die Griechen liegen vergeblich vor Troja (deshalb möchte das ganze Heer auch sofort nach Hause segeln, als Agamemnon es anbietet), und zwar offenkundig von Anfang an.

Als Achill nach dem Tod des Patroklos wieder mitkämpfen will, erinnert der kluge Ratgeber der Trojaner Poulydamas ausdrücklich daran, dass die Möglichkeit, gegen die Achäer Krieg zu führen, eine Ausnahmesituation war (18, 254-283). Nur durch den Streit der Könige konnten die Trojaner es wagen, aus der Stadt auszufallen. Poulydamas' Schilderung, wie ganz ausgeschlossen es sei, sich außerhalb der sicheren Mauern gegen Achill zu schützen, und seine Aufforderung, die Stadt wieder von den Türmen aus zu verteidigen und von hier aus Achill sich vergeblich abkämpfen zu lassen, bis er von selbst ermüdet zu den Schiffen zurückkehre, beschreibt deutlich die Grundposition der beiden Kriegsparteien vor Troja.

Das in den Büchern 3 bis 7 geschilderte Kampfgeschehen gehört, wie die Ilias es darstellt, ins zehnte Kriegsjahr. Erst durch den Streit der Könige ist eine Situation entstanden, in der die beiden Heere einander gegenüber treten konnten, - und in der sie ja auch ohne Achill kämpfen. ${ }^{52}$

Dass diese Fortführung der Handlung in der Ilias vielen nicht glaubwürdig erscheint, liegt auch an einer weiteren Vorerwartung. Diese Vorerwartung ist: Zeus hätte den ohne Achill kämpfenden Agamemnon gleich eine Niederlage bereiten müssen. Da dies erst im Buch 8 oder 11 geschieht, scheinen die Bücher 3-8 (Mitte) eine nicht passende Zutat.

Nimmt man die Handlungsführung im Sinn der ersten beiden Bücher der Ilias zum Ausgangspunkt, ist allerdings eine andere Vorerwartung näher liegend. Agamemnon hat sich gegenüber Achill hochmütig auf seine Unterstützung durch Zeus berufen. Zeus verführt Agamemnon mit genau diesem

52 Den der (vom Dichter gemeinten) Wirklichkeit gemäßen Anfang hört man aus dem Mund des alten Antenor, der während der Mauerschau von der ersten Verhandlungsabordnung der Griechen nach der Landung berichtet. Damals seien Menelaos und Odysseus nach Troja gekommen und hätten ihr Anliegen vorgebracht. (3, 203-224). Hier wird ausdrücklich vom Anfang berichtet, nicht in der Hoffnung, allein aus dem Bericht über eine Verhandlung fühlten sich die Leser an den Kriegsanfang erinnert. 
Hochmut $^{53}$ und täuscht ihm im Traum einen schnellen Sieg vor. Damit Agamemnon eine reale Erfahrung von dieser Täuschung bekommt, muss er tatsächlich ausrücken, und der Kampf muss so verlaufen, dass er die Erreichung des Siegs auch für glaubwürdig halten kann. Der Kampf muss ,natürlich' beginnen und eine berechtigte Hoffnung auf die Einlösung des Versprechens durch Zeus bieten.

Genau auf diese Weise lässt Homer den Kampf beginnen. Noch am Tag nach dem (Trug-)Traum versucht Agamemnon sein Heer und führt es zum Angriff gegen die auch ihrerseits vom Gerücht um das ausrückende Heer der Griechen aufgescheuchten Trojaner $(2,786-806) .{ }^{54}$ Gleich zuerst trifft Menelaos auf Paris, der sofort die Flucht ergreift, sich aber schließlich von Hektor dazu bringen lässt, sich Menelaos zu stellen. Diese erste schnelle Siegchance für die Griechen wird verstärkt durch einen heilig beschworenen Vertrag, dass über Sieg und Niederlage der ganzen Heere der Ausgang des Kampfes zwischen den beiden entscheiden solle. Der folgende Eidbruch durch die Trojaner macht Agamemnon - im (dieses Mal) berechtigten Vertrauen auf Zeus - ganz sicher, dass dieser ihm den endgültigen Sieg gewähren werde (4, 231-239). Zeus wird ihm diesen Sieg auch gewähren. Agamemnon aber glaubt

53 Zeus lässt Agamemnon ja vom Traum sagen, er sorge sich sehr um ihn und fühle mit ihm: 2, 26f. Er nimmt damit auf Agamemnons Hybris 1, 174 direkt Bezug; Agamemnon verfällt dieser Täuschung und stützt sich auf Zeus' vermeintliches Versprechen: 2, $63 \mathrm{f}$.

54 Dass Iris Priamos nicht darauf aufmerksam macht, dass die Achäer ohne Achill kämpfen, ist merkwürdig, da man davon ausgehen muss, dass die Trojaner ohne dieses Wissen niemals die Tore geöffnet und ihre Heere formatiert hätten. Dennoch ist der Schluss, Iris' Meldung sei „nach dem Muster einer Meldung über die Landung der Achäer zu Beginn des Krieges nachgestaltet" (Kullmann, Ilias, 94) kaum richtig. Denn Polites, aus dessen Perspektive Homer ja Iris berichten lässt, sagt, obwohl er schon in viele Kriege gezogen sei, habe er noch nie ein so großes Heer gesehen, zahlreich wie Sand am Meer und wie die Blätter an den Bäumen, das über die Ebene gegen die Stadt hinziehe (2, 798-800). Das ist genau die Situation, die im 2. Buch der Ilias beschrieben wird, nicht aber eine mögliche Wiederaufnahme der Beschreibung, wie die Troer bei der Landung der Schiffe vergeblich versucht hatten, zu verhindern, dass die Griechen an Land gehen. Auch Polites' Hinweis, dass jetzt die Zeit des Friedens vorbei sei (2, 797), muss nicht auf die Zeit vor der Ankunft der Griechen bezogen werden. Denn auch seit dieser Ankunft herrscht eine Art Frieden in Troja selbst, der nun durch den Aufbruch der ungeheuren Massen, den Polites als Späher beobachtet hat, wie Iris behauptet, jäh und gewaltsam unterbrochen ist. Sinn macht die Rede des Polites, wenn man voraussetzt, dass die Trojaner vom Rückzug Achills schon wussten, nicht aber davon, dass ausgerechnet jetzt die Griechen mit einem so riesigen Heer einen Angriff vorbereiteten, und dass es dieser Aufbruch des Heeres ist, von dem er berichtet. Dann musste die folgerichtige Reaktion Hektors sein, dass er auch seine Mannschaften aufstellt. Eine Erklärung, weshalb Homer auf den Rückzug Achills nicht hinweisen lässt, findet man dadurch nicht, wohl aber eine Begründung dafür, dass Homer hier nicht den Kriegsanfang einspiegeln kann. 
sich an dieser Stelle in seinem Vertrauen auf das Traumversprechen des Zeus bestätigt und verstrickt sich so tiefer in seine hybride Verblendung.

So beginnt der Kampf von neuem und wieder scheint sich Agamemnons Zuversicht zu bestätigen. Es ist vor allem Diomedes, einer der Tapfersten nach Achill, der siegreich ist, aber schon am Ende dieses Tags kommt es zwischen Hektor und Aias zu einem unentschiedenen Abbruch des Kampfes (7, 182321). Sie sind die beiden einander am meisten gewachsenen Kämpfer auf den beiden Seiten. So gibt der Abbruch des Kampfes, von dem das 8. Buch berichtet, einen ersten wichtigen Hinweis darauf, dass ohne Achill die Trojaner kaum geschlagen werden können.

Schon am zweiten Kampftag wendet sich das Blatt so endgültig, dass Agamemnon am Abend weinend vor seinem Heer steht, seine Täuschung durch Zeus beklagt und zur Heimkehr aufruft (9, 8-29).

Lässt man sich von der Länge der Erzählzeit (die sich über sechs Bücher erstreckt) nicht ablenken, dann sieht man, dass Zeus sein Versprechen bereits am zweiten Kampftag zu einem guten Teil bereits erfüllt hat.

Auch die nun folgende vermeintliche ,Erweiterung' oder ,Retardation", von der das neunte Buch berichtet, ist in der Handlung gut motiviert und ist zum Verständnis der inneren Entwicklung in Achill, der sich langsam, in mehreren Schritten, von seinem Zorn wegbewegt, nötig.

Zunächst aber trägt die Erzählung des neunten Buches viel zur Charakteristik von Agamemnon, dem Gegenspieler des Achill, bei. Er muss sich von tapfereren Kriegern wie Diomedes zum Durchhalten auffordern lassen (9, 3149), ist aber bereit, sein Fehlverhalten gegenüber Achill vor der Gemeinschaft einzugestehen $(9,115-120)$ und Achill (wie es diesem Athene vorhergesagt hatte) überreiche Geschenke als Versöhnungsgabe anzubieten $(9,121-156)$, er verzichtet aber nicht darauf, Achill aufzufordern, er solle sich bezähmen und sich ihm unterordnen $(9,157-161)$.

Dieses prägnant und in seiner charakteristischen Mischung von Eigenschaften gut motivierte Handeln des Agamemnon hat zugleich eine wichtige Funktion für das weitere Handeln des Achill. Denn dieser beschäftigt sich die ganze Zeit über schon mit großen Heldentaten (die er offenbar sehr ungern entbehrt, s. 1, 492), er zeigt sich gegenüber den Freunden, die ihn um Hilfe bitten, sehr freundschaftlich $(9,193-220)$ und ist nach den Reden des Odysseus, Phoinix und Ajas jedesmal ein wenig milder gestimmt. Dass Ajas ihm aus der Seele gesprochen habe, sagt er selbst $(9,644-648)$. Wenn er dennoch noch nicht nachgibt, liegt das auch an dem fordernden Ton Agamemnons, der dadurch auch ein Motiv für das zu späte Einlenken des Achill liefert.

Davon also, dass das neunte Buch eine mögliche spätere Ergänzung sei, die der Iliasdichter aus irgendeinem Grund für eine aufnahmewürdige Zutat gehalten hat, kann, wenn man die Handlungsanlage der Ilias betrachtet, keine Rede sein. Es liefert die notwendigen Bedingungen für das tragische Unglück Achills, der zu lange braucht, um sich ,umbiegen` zu lassen. 
Dies wird auch durch das folgende elfte Buch bestätigt, das zugleich die Auffassung widerlegt, Achill habe bis zum Tod des Patroklos unverändert in seinem Groll verharrt. Ganz im Gegenteil sieht man auch im elften Buch, wie Achill, der äußerlich unverändert bei seiner Ablehnung jeder Hilfe beharrt, sich auf seine endgültige Umwendung hin weiter entwickelt. Denn nach dem Weggang der Freunde sitzt er nicht mehr im Zelt und singt von den Heldentaten anderer, - so haben die Freunde Achill bei ihrem Bittgang angetroffen (9, 186-191) -, sondern steht auf dem Deck seines Schiffes und nimmt mit groBen Gefühlen an der Not seiner Kameraden teil (11, 599ff).

\section{Exkurs zur Darstellung innerer Vorgänge bei Homer}

Vielleicht ist es gut, an dieser Stelle die Verfolgung der Handlungsdarstellung kurz zu unterbrechen und zu beachten, wie Homer innere Vorgänge darstellt. Offenbar ist auch in dieser Hinsicht Aristoteles im Recht, der sagt, dass Homer nicht über das Handeln seiner Personen (sc. mit reflektierenden Kommentaren) rede, sondern dieses Handeln durch die prägnante charakteristische Aktivität, in der sich ein innerer Zustand äußere, unmittelbar vorführe. ${ }^{55} \mathrm{Im}$ Sinn dessen, was Schiller bei der Glaukos-Diomedes-Szene vermisst, ${ }^{56}$ könnte man auch in der Situation nach den Bitten der Freunde vermissen, dass man von Homer nichts über den inneren Zustand Achills erfährt. Es gibt keinen auktorialen Kommentar darüber, dass er innerlich zerrissen sei, dass die Tendenz, nachzugeben und wieder mitzuhelfen, langsam stärker in ihm wird und fast das Übergewicht gewinnt, usw., geschweige denn dass Homer irgendein Gefühl der mitempfindenden Teilnahme an Achills innerer Not äußert. Nichts von dieser Art steht bei Homer, aber der mitdenkende Leser erfährt es sehr wohl, nur eben durch die Handlung selbst, die diese inneren Motive zum Ausdruck bringt. Wenn Achill auf dem Deck seines Schiffes steht, dann bedeutet das für den, der sein früheres Verhalten in Erinnerung hat, dass er sich geändert und neue Empathie für die Freunde gewonnen hat.

Unter Berücksichtigung dieser Darstellungsweise kann man wohl auch verstehen, weshalb Homer Zeus nichts über die Weise, wie er seinen Plan gegen Agamemnon durchführen will, sagen lässt. Zeus führt genau das, was dazu nötig ist, durch. Es bleibt dem Leser überlassen, an der Art der Durchführung des Plans seine Motivierung zu erkennen.

Dass Achill sich nach dem scheinbar ganz vergeblichen Bittgang seiner Freunde wieder geöffnet hat für die Not des ohne ihn kämpfenden griechischen Heeres (11, 599ff), ist die innere Voraussetzung dafür, dass er sich zu einer ersten wirklichen Hilfe drängen lässt: Er schickt Patroklos an seiner Stelle mit seiner Rüstung in den Kampf (16, 48-100). Dieses nur halbe Entgegen-

55 S. Verf. Aristoteles. Poetik 694-697; s. ders., Anschauung und Anschaulichkeit, v.a. 130137.

56 S. Schiller, Friedrich, Über naive und sentimentalische Dichtung, 713-715. 
kommen muss er bitter büßen, denn Patroklos fällt in seinem Einsatz für die Kameraden, weil er im Siegesrausch die Grenzen, die ihm Achill nachdrücklich gesetzt hatte, nicht mehr sehen konnte und wollte.

Dieser Tod bewegt Achill so stark, dass er an seinen Streit mit Agamemnon überhaupt nicht mehr denken kann. Er versöhnt sich mit Agamemnon und kann es fast nicht erwarten, endlich wieder einzugreifen, den Tod des Patroklos zu rächen und so viel wie möglich von dem wieder gutzumachen, was er durch sein Fernbleiben den Kameraden zugefügt hatte $(19,56-73)$.

\section{2b) Zur Einbettung der ,Rachehandlung in die Menis-Handlung nach der Versöhnung Achills mit Agamemnon}

Im Sinn vieler Interpreten hat die Menis-Handlung der Ilias an dieser Stelle ihr eigentliches Ende bereits gefunden, denn Achills Zorn auf Agamemnon ist endgültig geschwunden. Die Frage, weshalb Homer als Thema seines Gedichtes die Menis Achills angibt, nach der endgültigen Absage an diese Menis durch Achill aber noch fünf weitere Bücher folgen lässt, die dann nicht einmal mit der Zerstörung Trojas, sondern mit der Übergabe Hektors an seinen Vater und seine Beerdigung enden, diese Frage bewegt freilich wohl nicht nur die wissenschaftliche Forschung, sondern jeden Leser.

Bevor man aber Homer eine falsche Themenangabe unterstellt und folgert, nach der Beendigung der Menis-Handlung habe er oder ein Bearbeiter irgendwann das Bedürfnis empfunden, die Geschichte noch bis zum Tod des Hektor weiterzuerzählen, muss man allerdings das Handlungskonzept der Ilias noch etwas genauer beachten.

Wenn man in den modernen westlichen Sprachen von Handlung (plot, story line, acte, action, azione) spricht, meint man in der Regel den Geschehensverlauf, die Reihenfolge, in der Ereignisse ablaufen und zu einem bestimmten Ergebnis führen. Dass dies nicht unqualifiziert die Auffassung von Handlung sein kann, die man in der Ilias findet, hat schon der Unterschied zwischen ihrer Handlungskomposition und der Komposition der kyklischen Epen nahegelegt. Nicht alles, was geschieht oder geschehen musste, damit Troja zerstört wurde, ist Thema der Ilias, - wie etwa in der Kleinen Ilias erst das hölzerne Pferd gebaut sein, das Heer abgefahren, das Pferd in die Stadt gezogen sein musste, bevor die Eroberung beginnen konnte. Die Ilias dagegen gibt nicht nur als Thema die Menis des Achill an, sie exponiert im ersten Buch die komplexen Entstehungsgründe dieses - zugleich heftigen und anhaltenden - Zorns, der in Achill entsteht und ihm ein neues Ziel seines Handelns setzt. Und dieses Ziel ist ein inneres, ein subjektives Ziel, auf das hin die weiteren Handlungsschritte (im modernen Sinn des Wortes) Achills ausgerichtet sind, und das so zugleich die Organisation der Struktur der Erzählung in der Ilias bestimmt. 
Der Beginn ist Achills Mitgefühl mit dem Leid des Heers, das ihn bewegt, eine Versammlung einzuberufen. Erregt wird es in ihm (und nicht in einem anderen - das ist eine Auszeichnung für Achill ${ }^{57}$ - von Hera, die um die Danaer besorgt ist, deren Erfolg vor Troja ihr Anliegen ist (1, 53-56). Auch ohne dass ein auktorialer Erzähler das aussprechen muss, ist Achill dadurch als zu tätigem Mitleid fähig charakterisiert, und es ist zugleich deutlich, dass auch ihm der Sieg der Griechen ein großes Anliegen ist. Dass Kalchas, bevor er auf Agamemnons Schuld hinzuweisen bereit ist, sich an Achill mit der Bitte um Schutz wendet (1, 74-83), bringt einen weiteren Aspekt hinzu: An Achill kann man sich auch in schwieriger Situation um Hilfe wenden. Im weiteren Verlauf des Streits setzt sich Achill einem Agamemnon gegenüber, der sich einer privaten Liebe wegen weigert, eine gerechte Forderung der Gemeinschaft zu erfuillen - vor allem für einen gerechten Ausgleich zwischen Leistung und Lohn ein (1, 121-171). Den Höhepunkt des Streits bildet, dass Agamemnon behauptet, er brauche Achill, der seit neun Jahren die Hauptlast des Kriegs trägt, gar nicht, da er von vielen anderen und vor allem von Zeus geehrt werde (1, 172-175). Diese Entwertung seiner Leistung ist es, die Achill aufs tiefste schmerzt (áchos) und empört, so sehr, dass er erst im Augenblick, da er zur Tat übergehen und Agamemnon töten will, sich von Athene umwenden und seinem Zorn ein anderes Ziel setzen lässt (1, 188-218). Dieses Ziel ist, wie Achill selbst sagt, Agamemnon solle dazu gebracht werden, seine Verblendung zu erkennen, in der er den Besten der Achäer entehrt hat (1, 411f.). Damit es erreicht werden kann, müssen, wie er sagt, die Achäer von den Trojanern bis ans Meer zurückgedrängt werden, damit sie alle ,in den Genuss ihres Königs kommen'. ${ }^{8}$

Wie bereits diese kurze Rekapitulation zeigt, hat der Wille, den Achill auf Grund seines Streits mit Agamemnon am Ende fasst, nicht ein einfaches, pauschales Ziel, sondern enthält in sich mehrere Komponenten. Auf keinen Fall geht es ihm nur um die Wiederherstellung seiner Ehre, so große Bedeutung sie auch für ihn hat. Es geht ihm auch nicht nur, wie manchmal behauptet wird, um den Verlust seiner ,Ehrengabe“ Briseis. Das zeigt sich daran, dass er sie zwar sehr ungern, aber widerstandslos an Agamemnon übergeben lässt. Er selbst hat sich ja deshalb dafür eingesetzt, dass Agamemnon seine Geliebte Chryseis zurückgeben muss, damit das gemeinsame Unternehmen nicht scheitert. Das will er offenbar auch nach dem Streit nicht und dokumentiert das mit der Übergabe der Briseis. Er dokumentiert das auch dadurch, dass er seinem Ziel eine Grenze setzt. Er will nicht die Vernichtung des griechischen Heeres, sondern nur, dass es so weit zurückgedrängt wird, dass es ohne seine, Achills, Hilfe keinen Ausweg für Agamemnon mehr gibt.

Für dieses Ziel aber nimmt er größtes Unglück seiner Kameraden in Kauf. Erstaunlicherweise stimmt sogar Zeus selbst diesem Wollen Achills zu. Die Art

57 S. unten Abschnitt III.

58 S. Ilias, 1, 410; s. dazu die vorzügliche Erklärung von ,epaurisko‘, ,epaureo“ durch Führer, R., Artikel ,epaurisko, epaureo' (LfgrE) 
und Weise, in der er seinen Plan, Achill zu unterstützen, enden lässt, ist allerding so, dass Achill keine Freude an dieser Erfüllung empfinden kann (18, 79f.: „Alles hat der Olympier erfüllt, aber was für eine Freude bleibt mir davon?“). Er hat seinen besten Freund Patroklos verloren und muss sich sagen: ,Jetzt aber kehre ich nicht mehr zurück in das geliebte väterliche Land, und weder dem Patroklos war ich ein Licht noch den anderen Freunden, von denen so viele dem Hektor erlagen." (18, 101-103). Und: Er muss sich Vorwürfe machen: „als eine unnütze Last der Erde sitze ich bei den Schiffen“, obwohl er der Beste zum Schutz der Freunde hätte sein können, hätte er sich nicht durch den Streit zu einem so großen Zorn (chólos) verleiten lassen (18, 104-111).

Homer greift, wie er es oft tut, am Ende einer Entwicklung (nicht am absoluten Ende) - über die Mitte - auf den Anfang zurück: Achills Streit mit Agamemnon begann, weil er die Not des Heeres nicht mehr mitansehen konnte. Auf dem Höhepunkt seines ,Grolls' weist er die Ermahnung, er solle doch des Heeres sich erbarmen (eléaire 9, 302) als ganz unangemessen zurück: Wie eine Vogelmutter habe er sich immer für alle eingesetzt (9, 323-327). Und nun, nach der für ihn unerwartet tragischen Erfüllung der ,Diós Boulé, ist es zuerst die Reue und das Bedauern über die versäumte Hilfeleistung, die ihn zu neuem Handeln bewegt.

Dieses neue Handeln ist kein Neubeginn einer eigenständigen Handlung, die, nachdem die Menis-Handlung abgeschlossen ist, mit dem neuen Ziel, Rache an Hektor zu üben, einsetzt. Achill will natürlich wegen des Tods des Patroklos Rache an Hektor üben, aber er tut das aus einem Impuls seines bisherigen Handlungsziels heraus: Er kann erst dann wieder (innere) Ruhe finden, wenn er wieder gut gemacht hat, was er an Schlimmem durch sein Fernbleiben von der Schlacht für die Achäer verursacht hat. ${ }^{59}$

Dass sein Wüten gegen die Troer, das ihn tatsächlich zu einem ,Berserker“ macht, nicht zuerst blanke Rachewut, sondern eine Art Tollwut des Wiedergutmachens ist, sieht man am deutlichsten an seinem Verhalten gegenüber Hektor. Zwar könnte ihn, wie er selbst zu Hektor sagt, die Wut so packen, dass er ihn eigenhändig zerfleischte (22, 345-354), aber bei der Durchführung seiner Rache an Hektor verfährt er geradezu zeremoniell. Er lässt seine Männer nach der Schlacht nicht auseinander gehen, sondern verlangt, dass sie alle erst auf die Mahlzeit verzichten und erst noch Patroklos die Ehre der - rituellen - Beweinung geben, damit er Patroklos alles das erfülle, was er ihm versprochen habe $(23,6-23)$.

Auch wenn Achill beim Erweis dieser Ehre weit übers Ziel hinausschießt, der Impuls zu diesem Tun ist sehr stark von dem Wunsch geprägt, wieder zu dem zu werden, der er immer gewesen ist: der „mächtige Schutz aller Achäer“ (1, 283f.: méga pásin hérkos achaioísin), der die Hauptlast des Krieges für alle

59 Das erklärt Achill selbst auch noch einmal einem unterlegenen Kämpfer (Lykaon), den er früher schon einmal geschont hat, dem er jetzt aber keine Gnade mehr gewähren will. S. Ilias 21, 133-135. 
trägt. Um das durch seinen, Groll' Versäumte wieder gut zu machen, ist er sogar ohne Zögern bereit, sein eigenes Leben zu opfern: „Gleich möchte ich sterben, da ich dem getöteten Freunde keine Hilfe gebracht habe“ (18, 98f.; 114-126).

Auch wenn mit dem Tod des Patroklos Achills Zorn auf Agamemnon mit einem Schlag verschwunden ist, die von diesem Zorn ausgelöste innere Bewegung in Achill ist nicht am Ende. Empört über Agamemnon war er, weil diesem die ganz private Liebe zu Chryseis wichtiger war als der Erfolg des gemeinsamen Unternehmens. Diese Empörung über die Gefährdung des gemeinsamen, mit so vielen Leiden verbundenen Kampfes besteht in Achill auch nach der Versöhnung mit Agamemnon weiter. Ihr Gegenstand ist jetzt aber er selbst. Und es ist diese Empörung, die ihn in die Rachewut gegen die Trojaner und vor allem Hektor treibt: Viele der Troerfrauen, so sagt er, sollen weinend erkennen, „dass ich lange genug mich vom Kampf zurückgehalten habe" $(18,125)$.

Ähnlich wie die Patrokloshandlung ein funktionaler Teil der MenisHandlung Achills ist, ist auch die ,Rachehandlung' nach der Versöhnung mit Agamemnon keine neue Handlung, sondern ist auch ihrerseits wieder ein funktionaler Teil der Menis-Handlung.

Ihr Ende findet diese eine - einzige - Handlung der Ilias erst, als Achill sich auch noch vom Zwang der Wiedergutmachung gegenüber Patroklos (auch durch die Leichenspiele) befreit hat und sich in den Zustand einer milden Hilfsbereitschaft zurückverwandelt hat, der ihn befähigt, mit Priamos mitzuleiden und ihm seinen Sohn zurückzugeben (24, 477-676).

\section{3) Die poetische Bedeutung der Darstellung von Handlung bei Aristoteles und Homer}

Im Sinn der aristotelischen Forderung an eine einheitliche Handlung, dass man keinen Teil wegnehmen oder hinzufügen, keinen umstellen oder ändern können dürfe, ohne dass das Ganze sich ändert (Aristoteles, Poetik 8, 1451a30-35), kann man von der Handlung der Ilias sagen, dass sie genau diese Bedingungen erfüllt:

Sie ist eine Handlung im aristotelischen Sinn.

Denn ,Handeln' ist nach Aristoteles immer die Verfolgung eines subjektiven Gutes, die Verfolgung einer Lust oder das Meiden einer Unlust, und es hat seinen Erfolg auch in dem innerlich erfahrenen Glück im Genuss der erreichten Lust und hat seinen Misserfolg in der Verfehlung dieser Lust. ${ }^{60}$ Die einzelnen Stationen der Handlung der Ilias sind, wie ein knapper Überblick zur Erinnerung bringt, alle innerlich. Es beginnt mit dem Mitleid Achills, seiner Empörung, Verletztheit, seinem Groll, es geht weiter mit den Folgen der Hybris Agamemnons gegenüber Achill, mit der Täuschung und Verblendung

60 Belege und Begründung bei Verf., Aristoteles. Poetik, 92-127. 
Agamemnons, mit seiner jämmerlichen Verzagtheit und Zerknirschtheit, mit der Not der Freunde, mit Achills allmählicher empathischer Hinwendung zur Not der anderen, mit seiner Trauer und Reue nach dem Tod des Patroklos, mit seiner Wut, alles wieder gutzumachen, und endet mit seinem Mitleid mit dem Vater seines Feindes.

Bereits dies, dass man die Handlung der Ilias in so wenigen Worten erzählen kann, macht verständlich, weshalb Aristoteles der Handlung, ,wie wir sie meinen“" (Poetik 8, 1451a28f.) ${ }^{61}$ einen so hohen poetischen Wert zumisst. Die Art der Handlungskomposition, wie sie in der Ilias erkennbar ist, hat offenbar nichts mit Handlungsführung in dem uns gewohnten Sinn zu tun. Wenn man unter Handlung die kausal schlüssige Ereignisfolge versteht, ist von Aristoteles her klar, dass die geschichtliche Wirklichkeit wegen ihrer komplexen Mischung aus Regel und Zufall eine solche Geschehensfolge nicht oder nur in Ausnahmefällen bietet (Poetik 8, 1451a16-22; 23, 1459a17-30). ${ }^{62}$

Die subjektive, vom Dichter machbare Ordnung eines solchen in der Zeit verlaufenden Geschehens ist daher entweder von den Auswahlkriterien abhängig, durch die er das einheitlich Zusammengehörende aussondert, oder von der Fähigkeit, eine Handlung zu erfinden, in der Anfang, Mitte und Ende entwickelt werden aus einer konkreten Verwirklichung der generellen Tendenzen eines Charakters, Bestimmtes vorzuziehen oder zu meiden (Poetik 9, 1451b 8-10; 1454a33-36). ${ }^{63}$ Die möglichen Ordnungsfunktionen, die narrative Techniken bieten könnten, ${ }^{64}$ sind allein für sich nicht geeignet, den Grund-

61 S. ebd. 365-371.

62 S. ebd. 674-682.

63 S. ebd. 381-397; 534-536.

64 Die Anwendung neuerer Erzähltheorien auf die Interpretation der Erzählweise Homers hat viele fruchtbare Ergebnisse gebracht, v.a. in den klugen Deutungen durch Irene de Jong. S. grundlegend Jong, Irene de, Narrators and Focalizers. So ist es eine das Verständnis fördernde Beobachtung, dass Homer das "Schweigen der Arete in der Phaiakengeschichte der Odyssee zwar als Erzähler selbst, aber mit den Augen der Arete berichtet, d.h. als eine ,embedded focalization'. S. Jong, Irene de, Homer as Literature. Auf die Möglichkeit dieser Art der Darstellung aufmerksam zu sein, schärft den Blick für die Besonderheit und Qualität der homerischen Darstellungsweise. Es ist aber andererseits nicht eine ,typische“ Technik, durch die man den Text und seine Qualität richtig versteht. Das ist erst möglich, wenn man erfasst, dass diese Technik an dieser Stelle aus diesem oder jenem Grund der richtige Ausdruck für das zu erzählende Geschehen war. So begreift man als Leser auch, das Schweigen der Arete'. Arete hat bemerkt, dass Odysseus Gewänder trägt, die er nur von Nausikaa erhalten haben kann. Deshalb schweigt sie so lange, bis sie Odysseus gefahrlos darauf ansprechen kann. Platon macht im Phaidros die Bemerkung, dass die formale Kenntnis rhetorischer Techniken, auf die die zeitgenössischen Redner besonders stolz waren, nur ,ta pro tes téchnes ", d.h. nur eine notwendige Voraussetzung einer technischen Beherrschung der Redekunst seien, nicht aber bereits hinreichend für diese Kunst. Man müsse nämlich über die bloß technischen Mittel (etwa der Emotionserregung) hinaus auch noch wissen, wann, in welchem Maß, wem gegenüber usw. man diese Mittel anwenden müsse. Vor allem aber müsse man sich um die Einheit der Handlung, bei der wie bei einem Lebewesen die 
defekt einer an der Geschichtszeit orientierten Darstellung aufzuheben. Die vielen Bemühungen philologischer Interpreten, eine Ordnung der Ereignisfolge zu finden, an der die Darstellung Homers orientiert gewesen sein könnte, sind in gewissem Sinn notwendig zum Scheitern, d.h. zur Feststellung genötigt, Homer habe eine einheitliche Konzeption nicht durchhalten und bestenfalls in mehreren, nie ganz kongruenten Schritten erreicht.

Die Ordnungsleistung einer Handlungsdarstellung kommt für Aristoteles immer aus dem subjektiven Charakter des Handelns. Deshalb unterscheidet er streng zwischen Handeln (práxis) und Machen, Herstellen (poíesis). Die Dichtung ist gerade keine ,poíesis', denn eine poiesis muss sich nach den äußeren Bedingungen dessen richten, was sie herstellen will.

Wenn Achill erreichen will, dass Zeus den Trojanern solange Siege über die Griechen gewährt, bis diese zu den Schiffen zurückgetrieben sind, muss er nach Mitteln, die dafür geeignet sind, suchen und mit ihnen so umgehen, wie es ihnen gemäß ist. Diese Mittel liegen nicht in seiner Hand. Er muss sich nach den Bedingungen richten, die zu ihrer Gewinnung nötig sind.

Das gelingt ihm erfolgreich. Alles das, was ,gemacht' werden muss, damit Agamemnon gewaltige Niederlagen erleidet, geschieht auch. Aber sein subjektives Ziel, um dessentwillen er dies alles ins Werk gesetzt hat, hat er nicht erreicht. Diese beiden Ziele sind also nicht dieselben: Das objektive Ziel des Tuns und Machens ist die Niederlage Agamemnons. Das subjektive Ziel aber ist die Freude über die dadurch wiederhergestellte Ehre. Dieses Ziel hat er nicht erreicht, sondern muss sich im Gegenteil fragen, was er denn nun von dem erfolgreichen ,Machen' gehabt habe (18, 79f.).

Nimmt man diesen strengen Handlungsbegriff, für den das, was um des Handelns willen gemacht, getan werden muss, Hilfsmittel, aber nicht Ordnungsprinzip ist, zum Maßstab, wird ein ganz anderer Maßstab für die Gestaltung oder das Verstehen einer Handlungskomposition sichtbar.

Für eine am geschichtlichen Geschehen orientierte Handlungsdarstellung ist es wichtig, dass die Ereignisse ,kausal notwendig' oder wenigstens wahrscheinlich aufeinander folgen. Wenn die Griechen absegeln, ist es wahrscheinlich, dass sich die Trojaner in Sicherheit fühlen und die Tore öffnen. Wenn Hektor vor den Mauern Trojas bleibt, ist es fast unvermeidlich, dass er sich am nächsten Tag Achill stellen muss.

Diese Art der Handlungslogik soll ein Dichter auch nach Aristoteles beachten. Für den Dichter als Dichter aber zählt eine andere. ${ }^{65}$ Wenn Ödipus auf

Teile zueinander und zum Ganzen zusammenstimmen müssen, bemühen. Aristoteles ist Platon in diesem Punkt gefolgt. S. Platon, Phaidros 266d-269a. Zur Rezeption dieser Position bei Aristoteles s. Verf., Aristoteles. Poetik, 365-371. Eine sachliche ähnliche Anmerkung zur Ergänzungsbedürftigkeit der Kenntnis ,allgemeiner Erzähltechniken“ macht Schwinge, Homerische Epen und Erzählforschung, 511.

65 Zur Unterscheidung der Kriterien, die zur Dichtung als Dichtung gehören, an denen man daher ihre Qualität beurteilen muss, von Kriterien, deren Richtigkeit von nichtpoetischen Bedingungen abhängt, z.B. von einer Kenntnis der Kampftaktik, von me- 
dem Weg von Delphi nach Theben ist, ist es weder wahrscheinlich noch notwendig, dass er seinem Vater begegnet. Und wenn ein Vater sich aufmacht, um den größten Gegner seines Sohnes um Mitleid zu bitten, kann er dieses Handeln nicht auf die Wahrscheinlichkeit gründen, dass feindliche Krieger in dieser Weise mit den Vätern ihrer Gegner mitfühlen.

Wenn hier von Wahrscheinlichkeit die Rede sein kann, muss es sich um eine individuelle Wahrscheinlichkeit handeln. Ist es wahrscheinlich, dass dieser Achill, der gerade Hektor zur Strafe mitleidlos um die Stadt geschleift hat, Mitleid mit seinem Vater entwickeln wird?

Stellt man diese Frage so, ist es erforderlich, sich die Iliashandlung als Ganze vor Augen zu stellen, um sie beantworten zu können. Denn diese Antwort muss als Antwort auf die Frage gegeben werden: Ist es wahrscheinlich, dass Achill, wenn er sich der allgemeinen Beschaffenheit seines Charakters gemäß in seinem Reden und Tun verhält, mit Wahrscheinlichkeit Priamos erhören wird?

Tatsächlich scheint Homer unter diesem Gesichtspunkt unter den vielen möglichen Reden und Taten eines Achill ausgewählt und genau die dargestellt zu haben, in denen sich die allgemeinen charakterlichen Tendenzen Achills im Verlauf einer bestimmten Handlung äußern und sich deshalb konsequent auseinander ergeben und sich zu einer Einheit fügen.

In einer großen Notsituation der Gemeinschaft zeigt er sein Mitgefühl (1, 53-67), seine Hilfsbereitschaft und Courage (1, 84-91), zugleich seine Heftigkeit und seine zu schnellem Zorn führende Ehrverletzlichkeit (1,121ff.), er kann aber in höchster Wut noch auf die Vernunft hören (1, 193-218); kann zwischen Boten und Botschaft unterscheiden (als Agamemnon die Herolde schickt, seine Briseis zu holen; 1, 327-347), leidet selbst sofort unter den Folgen seines Zorns, die ihn am Mitkämpfen hindern (1, 488-492), erweist sich trotz großer Verbitterung als Freund seiner Freunde (9, 185-220), lässt sich nur schwer, aber in verstehbaren Schritten umwenden (9, 221-16, 100; 19, 40ff.), usw., bis er schließlich sogar wieder zum Mitleid mit dem Vater seines größten Gegners fähig wird (24, 477ff.).

Dies ist, wie Aristoteles zu Recht feststellt, eine gut überschaubare Handlung, die man zugleich gut im Gedächtnis behalten kann, weil jeder ihrer Teile konsequent aus dem anderen hervorgeht. Wer z.B. begreift, wie Achill durch die Rede des Ajas schon fast umgestimmt ist $(9,644 f$.) -, begreift auch, dass die Folge sein muss, dass er nicht mehr im Zelt sitzt (9, 186-190), sondern auf dem Deck seines Schiffes steht und wegen des Leids der Freunde bekümmert ist (11, 599ff.), usw.

In diese gut überschaubare und durch ihre innere Konsequenz wohl verstehbare Handlung sind an jeweils den Stellen, an denen die Handlungsmotivation dies erforderlich macht, diejenigen Informationen eingefügt, die man

dizinischen Verfahren usw., s. Aristoteles, Poetik 25, 1460b16-23; s. Dazu Verf. Aristoteles. Poetik 707-711. 
braucht, um die Stellung der Handlung im geschichtlichen Ganzen, zu dem sie gehört, zu verstehen: Achill verteidigt sich gegen seine angebliche Mitleidlosigkeit mit dem Hinweis auf die vielen Kämpfe rund um Troja, bei denen er seit neun Jahren für alle ,wie eine Vogelmutter gesorgt hat (9, 321-331). Odysseus erinnert an die Vorhersagen des Kalchas in Aulis, weil er dadurch die fliehende Truppe zum Halten bringen will (2, 299-332), usw. Diese ,Einschübe' sind auch je nach dem Bedarf an Handlungsbeeinflussung oder Handlungserklärung länger oder kürzer, etwa wenn Phoinix in langer Rede den verstockten Achill durch eine Parallelgeschichte die Tragik seines augenblicklichen Handelns aufzeigen will (9, 430-605), während Achill wenige Sätze genügen, um an seine allen wohlbekannte Hilfsbereitschaft zu erinnern.

Entscheidend ist, dass durch diese Einfügungen an der jeweils durch die Handlungslogik erforderlichen Stelle auch eine Ordnung haben, die bewirkt, dass man sie gut begreifen und erinnern kann.

Auch diese Ordnung aber ist nicht die Ordnung der Zeit, sondern die Ordnung der Handlung. Dass dies eine ganz außergewöhnliche Weise ist, die Komposition einer Erzählung anzulegen, fällt zwar unmittelbar auf, wenn man beachtet, dass Homer ein Geschehen von zehn Jahren in einer Handlung von ca. zwei Wochen darstellt, ein differenzierteres und angemessenes Bild von dieser Kompositionsweise kann man aber erst gewinnen, wenn man das besondere Handlungsverständnis selbst in Rechnung stellt, an dem sich Homer als Erzähler orientiert.

Dieser subjektive Begriff von Handlung, für den Handeln durch das erstrebte Glück oder das vermiedene Unglück charakterisiert ist, führt den, der sich an ihm orientiert dazu, dass er die wahrscheinlichen oder notwendigen Schritte, die jemand braucht, um sein Ziel zu erreichen, aus dem Gesamt des möglichen Verhaltens eines Handelnden auswählt und in ihrer Abfolge darstellt. So entsteht eine durchgängige Struktur der Darstellung, eine Zusammenstimmung der Teile untereinander und zum Ganzen.

Da es bei der Darstellung von Handeln in diesem Sinn nicht um die Erklärung eines rein kognitiven Sachgehalts geht, sondern darum, am konkreten Reden und Tun eines Menschen verstehbar zu machen, weshalb er dabei und dadurch glücklich oder unglücklich wird, ist dieses Verstehen immer auch von Gefühlen begleitet. Wer mit Achill die Gründe, die ihn gegen Agamemnon aufbringen, durchdenkt, wird sich mit ihm mitempören. Der Dichter seinerseits, der diese Gründe finden und ihre Äußerung darstellen muss, muss die sie begleitenden Lust- und Unlustgefühle mitempfinden können, sonst wüsste er gar nicht, welche Gründe er Achill vorbringen lassen muss, um die Entstehung seines außergewöhnlichen Zorns verstehbar zu machen. ${ }^{66}$

Die Art der Handlungsdarstellung, wie man sie in der Ilias vorfindet, hat daher sowohl eine hohe Relevanz für die strukturelle Ordnung der Erzählung

66 S. dazu Aristoteles, Poetik 17, 1455a29-35; s. dazu Verf., Aristoteles. Poetik, 547f.; 551553. 
als auch für ihre stilistische Formung. Die Art und Weise, wie ein Handelnder beschrieben wird oder selbst redet, wird, wenn es gelingt, wirklich das aktuelle Handeln eines bestimmten Charakters auszuwählen oder zu erfinden, immer auch eine solche Form haben, dass sie die jeweiligen Gefühle, die mit den äußeren oder inneren Tätigkeiten verbunden sind, mit darstellt.

So wird verstehbar, weshalb Aristoteles der Darstellung einer Handlung einen so hohen poetischen Wert beimisst, und zugleich, weshalb er der Auffassung ist, Homer habe die Aufgabe einer solchen Handlungsdarstellung in beinahe göttlicher Weise erfüllt, die weit über das hinaus ging, was alle anderen epischen Dichter geleistet hatten. Da wir das Aristotelische Urteil zwar nicht unmittelbar an den Texten dieser ,kyklischen ${ }^{6}$ Epen $^{67}$ überprüfen können, wohl aber an den überlieferten Inhaltsangaben, die tatsächlich auf die von Aristoteles charakterisierte Darstellungsweise hindeuten, spricht viel dafür, dass dieses Urteil auch historisch zutrifft.

Von der Sache wie von der historischen Situation her ist es daher wahrscheinlich, dass die Darstellungsweise, die wir in Ilias (und Odyssee) vorfinden, singulär ist. Die hohe Vollendung, in denen in diesen Epen in einer wohl charakterisierten Haupthandlung jeder Schritt eine konsequente Folge des vorhergehenden ist, und in denen zugleich eine ganze geschichtliche Welt gedeutet und miterklärt ist, muss als ein Produkt, das sich einem einheitlichen Plan verdankt, begriffen werden.

\section{Ist die Ilias ,gemacht'?}

Wenn man nach einer möglichen Entwicklung des Aufbaus der Ilias fragt, etwa von einem einfachen, einsträngigen Geschehenskern zu einem komplexen Großepos, ist die Frage nicht, ob die Komposition der Ilias eine Genese haben konnte oder musste. Natürlich kann die Konzeption wie die Durchführung eines solchen Plans lange Zeit in Anspruch nehmen und auch geändert werden. Entscheidend aber ist, dass die zuletzt vollendete Fassung einem einheitlichen Plan folgen muss, der vom ersten Anfang der Darstellung an konsequent über die dazu notwendigen Schritte (der Mitte) auf das Ende der Erzählung (wie es in der Endfassung vorliegt) zulaufen muss.

Auch wenn man zu Recht davon ausgehen kann, dass eine solche Endfassung bei der konkreten Durchführung des Handlungsplans immer wieder neue Konturen bekommen kann, diese Änderungen im Lauf der Durchführung müssen gewählt sein, um die Handlung noch besser zu motivieren, um einen Handlungsschritt noch funktionaler in das Ganze einzupassen. Dass die Ände-

67 Diese Epen heißen nach Aristoteles nicht kyklisch, weil sie einen Sagenkreis um Troja oder Theben bilden, sondern weil ihre Darstellungsweise von der Art ist, dass sie um eine Person oder einen historischen Zeitabschnitt - statt um eine Handlung - kreist. S. Poetik 23.,1459b1-b8; s. dazu Verf., Aristoteles, Poetik, 680682 . 
rungen im Gegenteil aus den Diskrepanzen, Ungereimtheiten, Widersprüchen, aus versehentlich Stehen- Gebliebenem, aus der Freude an Anspielungen oder einfach aus Fabulierlust usw. erschlossen werden können, würde bedeuten, dass diese Änderung nicht mit Blick auf die geplante ,sýstasis ton pragmáton“ gewählt sind, sondern aus ihr äußerlichen Gründen, um eine Erinnerung an die ersten Kriegsphase einzufügen oder andere Details aus der zehnjährigen Kriegsgeschichte und um anderer Anreicherungen willen. Im Bezug auf das, was Aristoteles das ,Poetische' nennt und von dem er behauptet, Homer habe als Einziger gewusst, wie man es verwirklichen müsse, würden diese Bereicherungen zwingend eine Verschlechterung bedeuten und könnten kaum als Zeichen des Reifens des dichterischen Genies Homers verstanden werden. ${ }^{68}$

Auf solche Defizite stützen sich viele philologische Argumente, die belegen sollen, dass eine bestimmte Partie nicht im Ursprungsplan der Ilias enthalten sein konnte. So sind z.B. viele überzeugt, der Schiffskatalog sei in die Ilias nur eingefügt, weil Homer irgendwann die Streitmacht der Achäer beschreiben musste. Eine solche Beschreibung gehöre aber an den Anfang der Trojageschichte, unmittelbar nach der Ankunft des Heeres. Also stehe der jetzt in die Ilias aufgenommene Schiffskatalog an einer ,eigentlich ' falschen Stelle. ${ }^{69}$

Die Vorerwartung dieser Argumentation ist, der Anfang des Kriegs um Troja müsse auch den Anfang der Erzählung Homers bilden. Diese Vorerwartung wird im Text der Ilias aber, wie ich zu zeigen versucht habe, nicht nur ein oder zwei Mal, sondern fast nie erfüllt. Die Ordnung der Erzählung ist nicht an der Geschichte des Kriegs, sondern an der Menis-Handlung Achills orientiert. Nimmt man diese Themenangabe als Kriterium für die Ausführung des Themas, erweist sich die Stellung des Schiffskatalogs als perfekte Einfügung in den Gesamtplan dieser Handlung: ${ }^{70}$

Das zweite Buch beginnt mit der Täuschung Agamemnons, er könne auch ohne Achill siegen, wenn er jetzt mit der ganzen Heeresmacht $(2,28 f .)^{71}$ ausrücke. Von dieser verwegenen Hoffnung berichtet er den Anführern (2, 65f.) und schreitet, um seinen Plan durchzuführen zu einer Versuchung seines Heeres $(2,100 f f$.$) . Diese Versuchung wäre auf keinen Fall am Beginn des Kriegs$ möglich, denn Agamemnon begründet sie mit der Enttäuschung über die langen sieglosen Jahre, in denen Zeus ihm die in Aulis versprochene Eroberung Trojas versagt habe $(2,110-120 ; 134-138)$. Sie bildet aber einen passenden Auftakt für die Mobilisierung des ganzen Heeres. Die riesigen Massenbewegungen schildert Homer ausführlich und in vielen Gleichnissen. Sie demonst-

68 S. West, Martin, The Making of the Iliad, 67.

69 S. ebd. 55-58.

70 Die Gegenargumente sind gut zusammengefasst und um neue erweitert bei Kullmann, Wolfgang, Poesie, Mythos und Realität. Kullmanns Argumentation wird im Folgenden vorausgesetzt, s. jetzt aber auch West, Martin, The Making of the Iliad, 55-58.

$71 \mathrm{Zu}$ den möglichen Bedeutungen von ,pansydie' s. Beck, William, Artikel ,pansydie (LfgrE). 
rieren, was Agamemnon selbst in seiner Versuchung des Heeres gesagt hat: die der Zahl nach große Übermacht der Achäer über die Trojaner, so dass selbst spätere Generationen noch darüber erstaunen werden, weshalb dieses mächtige Volk nicht längst gesiegt habe (2, 119-130). Als diese Massen dann endlich von ihren Anführern geordnet aufgestellt werden, da habe Agamemnon Zeus, Ares und Poseidon gleichend - unter ihnen herausgeragt, wie ein Stier unter Rinderherden. So habe ihn Zeus herausgehoben aus der Masse der Heroen $(2,477-483)$.

Dieses Auftreten Agamemnons passt vorzüglich zu seiner ersten Reaktion auf den Zeustraum. So wie er sich da mit allen Insignien seiner Macht eingekleidet hat (2, 42-51) und vor die Anführer seines Heeres getreten ist, (2, 52ff.) so steht er nun mit eben dieser Machtsymbolik vor dem ganzen Heer (2, 101-109; 477-484), dessen Anblick ihn noch tiefer in die verblendete Hoffnung auf einen schnellen Sieg treibt. Der nun folgende ,Schiffskatalog' bietet die Vergewisserung der realen Basis für diese Siegeshoffnung. Er bestätigt in konkreter anschaulicher Aufzählung die Überlegenheit des achäischen Heeres. Unter der Bewegung dieses Heeres erdröhnte die Erde wie unter dem Groll des Blitze schleudernden Zeus (2, 779-782), heißt es am Ende des ,Katalogs'. Das hat sicher eine ähnliche Wirkung auf Agamemnon wie die Heeresschau und Heereszählung, die Xerxes vor seinem Zug gegen die Griechen abhält: ${ }^{72}$ Sie erweckt den Eindruck der Unüberwindlichkeit, ein Eindruck, zu dem Zeus in der homerischen Darstellung das Seine beiträgt.

Im Sinn der Handlung der Ilias hat der Schiffskatalog eine wichtige Funktion und er hat sie an der richtigen Stelle.

Als Erinnerung an den Beginn des Kriegs, d.h. als Teil einer Erzählung vom Krieg um Troja, wäre er nicht nur unpassend und möglicherweise eingeschoben, er hätte von Homer überhaupt nicht in seine Erzählung aufgenommen werden können. Denn entweder gab es zu Beginn des Kriegs einen solchen Heeresaufmarsch gar nicht, sondern lediglich vergebliche Einzelangriffe gegen die Verteidigung der Mauern durch die Trojaner, die sich diesem durch Achill unüberwindlichen Heer nicht gestellt haben, so dass die Griechen ohne die Möglichkeit, den Feind im Kampf zu stellen, vor Troja lagen, oder es gab diesen Aufmarsch, bzw. Homer hätte in einem narrativen Rückgriff an die Heeresversammlung in Aulis erinnern wollen, dann hätte auch ein geringerer Erzähler mit Leichtigkeit den Katalog vor dem neuen Aufmarsch des Heeres im 10. Kriegsjahr als eine ,Analepse' gestaltet und so die Neuformierung des Heers mit der Erinnerung an die Ankunft vor Troja verbunden.

Wenn Homer das nicht getan hat, dann folgt daraus, dass ihm die jetzige Anordnung sinnvoller erschien. Sie hat ihre Plausibilität von dem Gegenstand her, von dem die Ilias berichten will. Denn es ist zwar im Blick auf übliche Kriegsverläufe unwahrscheinlich, dass ein Heer sich erst nach vielen Jahren zum Kampf aufstellt, nicht aber in der in der Ilias vorausgesetzten Pattsituation,

72 Herodot, Historien VII, 44, 45 und 59-100. 
die erst durch den Streit der Könige aufgebrochen werden konnte. Von diesem Streit her aber ist die Fortsetzung der Hybris Agamemnons gegenüber Achill wahrscheinlich. Ihre Umsetzung in die konkrete Kriegshandlung durch Agamemnon ist konsequent.

Dass diese gewaltige Exposition der Heeresmacht der Achäer, durch die die Verblendung Agamemnons ebenso gewaltige Nahrung erhalten hat, in realistischer Weiterführung erste Siegeseffekte bringt und Agamemnon in seiner Hoffnung auf den Sieg so sicher zu macht, dass er nach der Wende des Kriegsglück aus großer Höhe tragisch abstürzt, wie es die Bücher 3 bis 8 darstellen, ist im Sinn des Handlungskonzepts der Ilias folgerichtig und von innerer Wahrscheinlichkeit. Einen Grund, diese Handlungsbewegung für die Zutat einer anderen Hand oder wenigstens für eine spätere Zutat desselben Dichters zu halten, gibt es daher nicht.

Auch wenn hier die Auseinandersetzung mit der Annahme einer schrittweisen genetischen Erweiterung einer zunächst einfachen zu einer am Ende hochkomplexen Iliashandlung nur exemplarisch und ohne Bezug auf eine große Vielzahl weiterer kleinerer Ungereimtheiten in den Details der Darstellung, aus denen sich das Wachsen der Ilias ableiten lassen soll, geführt werden konnte, in einem positiven Sinn kann man mit Grund davon ausgehen, dass die Ilias das Werk eines Dichters ist, der in ihr einen einheitlichen Gesamtplan verwirklicht hat, und zwar auf eine so besondere und außergewöhnliche Weise, dass sie dadurch nicht nur von ihren mündlichen Vorgängern, sondern von dem meisten epischen Werken auch der späteren Antike, ja bis in die Gegenwart unterschieden ist.

\section{III}

\section{Welche Art von Handeln gibt es bei den Menschen Homers?}

Snells Homerdeutung ist in ihren verschiedenen Aspekten auf den handelnden Menschen konzentriert gewesen. Diese Fokussierung zeugt von dem richtigen Blick Snells auf die Aufgabe, die eine Homerdeutung leisten muss. Nimmt man zu seinem Urteil noch das Urteil des Aristoteles, der sicher einer der besten Homerkenner der Antike war, hinzu, wird die poetische Bedeutung dieser Fokussierung noch klarer. Für Snell stand die Frage, ob ein eigenständiges, subjektives Handeln der Menschen bei Homer überhaupt möglich ist, im Vordergrund. Diese Frage wird sogar noch wichtiger, wenn man die große Bedeutung selbständigen Handelns für die Komposition der homerischen Epen mitbedenkt. Dann allerdings steht nicht die Frage nach dem bloßen, $\mathrm{Ob}^{\text {‘ }}$ zur Debatte, sondern es geht um ein möglichst genaues und konkretes Verständnis der besonderen Art dieses Handelns.

Wenn Snell mit seiner viel diskutierten These, dass menschliches Handeln keinen wirklichen und eigenständigen Anfang habe und so auch nicht zu sei- 
nem eigenen Ende komme, ${ }^{73}$ ganz im Recht wäre, könnte die aristotelische Behauptung, bei Homer sei in vorbildlicher Weise erfüllt, was ein Dichter als Dichter zu leisten habe, nur als eine grandiose Überformung durch die philosophische Theorie gelten.

Man muss aber nicht von Aristoteles ausgehen, um Snells Bestreitung selbständigen Handelns bei den homerischen Menschen für problematisch zu halten. Man kann sogar sagen, dass ihm fast keiner der bedeutenden Homerphilologen in dieser Bestreitung gefolgt ist. Vermutlich legt auch kaum ein Leser der Ilias oder der Odyssee diese Bücher aus der Hand mit dem Eindruck, von Marionetten der Götter oder des Schicksals gelesen zu haben.

Dennoch muss man sich dem besonderen Befund bei Homer stellen. Denn auch wenn man zu Recht die Überzeugung gewinnt, dass es Freiheit und Verantwortung und auch ein Bewusstsein davon bei Homer gibt, es kann nicht dieselbe Vorstellung von freier Entscheidung vorliegen, wie sie einem aufgeklärten, modernen Bewusstsein vertraut ist. Wenn Achill sich entscheidet, das gegen Agamemnon schon gezogene Schwert wieder in die Scheide zu stecken (1, 193-214), wenn Helena von Aphrodite zu Paris getrieben wird (3, 383448), wenn Athene Telemach dringend rät, nach zu langem Aufenthalt bei Menelaos und Helena in Sparta endlich an die Heimfahrt zu denken (Odyssee 15, 10-42), dann handeln diese Personen nicht allein aus sich selbst, sondern sind von Göttern beeinflusst und zum Teil sogar sehr massiv beeinflusst.

Die besondere, ,natürliche ' Weise dieses göttlichen (Mit-)Wirkens an menschlichem Handeln hat allerdings schon seit Langem dazu beigetragen, diesem göttlichen Wirken nicht dieselbe Bedeutung und schon gar nicht dieselbe religiöse Bedeutung zu geben, wie sie einem heutigen Denken naheliegt.

Man muss dabei gar nicht an Denkgewohnheiten des christlichen Abendlands denken. Auch in der Aeneis Vergils etwa findet man eine ganz andere Art göttlichen Wirkens. Aeneas ist von sich aus damit beschäftigt, seiner geliebten Dido beim Aufbau Karthagos zu helfen. Er muss von Merkur, dem Boten Juppiters, ,angedonnert' (Aeneis 4, 282) und zu einer Wende seines Verhaltens gebracht werden, damit das Fatum, das ihn zur Gründung Roms bestimmt hat, sich erfüllen kann (Aeneis 4, 219-282).

Das ist bei Homer anders. Achill weicht in dem Moment, in dem er zur Tat schreitet, vor dem Königsmord zurück und versucht, sich auf andere Weise Genugtuung zu verschaffen. Helena lässt sich von Paris wieder anziehen, obwohl sie seine Schwäche im Kampf verachtet. Telemach erinnert sich an die Probleme zu Hause, die er zu lange vernachlässigt hat. Für diese Entscheidungen braucht man in unserem Verständnis keine Gottheit, ein neuerer Erzähler könnte für derartige innere Vorgänge gar keine Götter verantwortlich machen, denn es sind eigene menschliche Aktivitäten.

73 S. Snell, Bruno, Die Entdeckung des Geistes, 35 
Das war der Grund, weshalb man lange Zeit den homerischen Göttern nur eine narrative Funktion geben wollte. Sie bieten die Möglichkeit, ,innerpsychische Vorgänge der epischen Personen selbst" zu ,externalisieren' ${ }^{74}$

Das ist auch der Grund, weshalb man das Handeln der Götter bei Homer für ,natürlich ' (und nicht für wunderbar und übernatürlich) hält, und weshalb man auch dann, wenn man Snells These ablehnt, Homer habe sich dieses natürliche Handeln noch nicht erklären können, bei einer Art Nichtunterscheidung von Göttlichem und Menschlichem bleibt: Für Homer scheint es einfach noch keinen Unterschied ausgemacht zu haben, ob er ein Handeln im Menschen selbst beginnen oder durch einen Gott einleiten lässt.

Auch wenn man dieses Nichtunterscheiden auf die Spitze treibt und, die Snellsche These einfach umkehrend, behauptet, alles Handeln der Menschen wie der Götter bei Homer sei absolut frei, ${ }^{75}$ kommt man an einer Erklärung

74 So jetzt wieder Hirschberger, Martina, Die poetische Verwendung der Götter im Epos, 287.

75 Das ist die Hauptthese von Sarischoulis, Efstratios, Schicksal, Götter und Handlungsfreiheit. Sarischoulis zeigt in einem Durchgang durch die Semantik der wichtigsten Wörter für das, was oft mit ,Schicksal' übersetzt wurde, dass diese Begriffe an keiner Stelle eine durchgängige Bestimmtheit des Menschen oder des Weltenlaufs durch ein im Voraus festgesetztes Schicksal bezeichnen. Dies ist ein richtiges und wichtiges negatives Ergebnis, und auch die positive Erklärung dieser Begriffe, deren Grundbedeutung in einer angemessenen Zuteilung des einem Menschen Zustehenden liege, trifft in vielem das Richtige (auch wenn das öfter zitierte, aber kaum in seinen Ergebnissen benutzte Lexikon des Frühgriechischen Epos ähnliche Deutungen bereits vorgelegt und dokumentiert hat). Mit Grund betont er auch, dass die Menschen bei Homer Verantwortung für ihr Handeln tragen, für das sie sich selbst entscheiden können. Erstaunlich ist, dass er zum Erweis dieser Freiheit die These Snells einfach umkehrt. Hatte Snell behauptet, an Stelle eigener Entscheidung bestimmten Götter die Wenden im menschlichen Handeln, behauptet Sarischoulis, gleichgültig von wem oder durch was ein Mensch beeinflusst wird, es liege am Ende immer allein an ihm, wozu er sich in seiner von nichts eingeschränkten Freiheit entscheidet. Einen Unterschied in der Freiheit des Willens zwischen den heutigen Menschen und den Menschen Homers gebe es nicht. Bei Homer findet man dagegen sehr große Unterschiede in der Intensität der Beeinflussung eines Menschen durch die Götter und dementsprechend auch eine größere oder geringere Freiheit diesen Beeinflussungen gegenüber. Sarischoulis macht von seinen eigenen Ergebnissen zu wenig Gebrauch. Wenn es kein absolut determiniertes Schicksal gibt, braucht man auch keine absolute Freiheit, um dennoch selbstbestimmt zu sein. Ein durchgängig bestimmtes Schicksal, das von göttlicher Providenz zeugt, gibt es in der Antike erst in der Stoa (darauf findet man keinen Hinweis in der Arbeit von Sarischoulis). Dass man nicht in anachronistischer Weise dieses stoische Fatumkonzept auf Homer zurückübertragen sollte, bedeutet auch, dass man auch den stoischen Freiheitsbegriff nicht bei Homer suchen sollte. Hier liegt ein Grundwiderspruch in der Arbeit von Sarischoulis. Er zeigt, dass es keinen Schicksalsbegriff im Sinne des Fatums bei Homer gibt, sucht aber gleichwohl einen Freiheitsbegriff bei ihm nachzuweisen, der überhaupt nur einer solchen Fatumvorstellung gegenüber Sinn macht.

Die homerischen Menschen sind nicht deshalb frei, weil sie jede Art von Beeinflussung einfach dadurch zu der ihren machen, dass sie ihr zustimmen oder nicht zustimmen, sondern dass sie gegenüber Einwirkungen, denen sie ausgesetzt sind, den Bereich su- 
nicht vorbei, weshalb dann Homer überhaupt Götter an menschlichem Handeln beteiligt sein lässt. Diese Frage ist umso dringender, da man heute kaum mehr bezweifeln kann, dass die Götter bei Homer, denen die Menschen auch in seinen Epen in vielfältiger Weise in Ehrfurcht, mit Gebeten und rituellen Zeremonien begegnen, keine Geschöpfe seiner Phantasie, sondern Gegenstand realer religiöser Verehrung waren.

Die Antwort scheint mir, wie ich in mehreren Untersuchungen schon ausführlicher zu begründen versucht habe,$^{76}$ darin zu liegen, dass der Anteil an menschlichem Handeln, der bei Homer den Göttern zugeschrieben wird, nicht derselbe ist wie der Anteil, den die Menschen selbst für ihr Handeln haben.

Offenbar sah Homer der menschlichen Selbständigkeit andere Grenzen gesetzt, als dies uns als seinen heutigen Interpreten der Fall zu sein scheint.

Die These, die im Folgenden noch einmal von einigen Aspekten her begründet werden soll, ist, dass Homer mit dieser Grenzziehung nicht ein Beispiel eines archaischen, noch unentwickelten Denkens bietet, sondern - beinahe im Gegenteil - einem überzogenen Glauben an die uneingeschränkte Selbstbestimmtheit des Menschen eine nachdenkenswerte Kritik.

Für Snell bot die Göttin Aphrodite nicht nur das erste Beispiel für die ,Natürlichkeit' des griechischen Götterglaubens, sie war ihm auch Zeugnis dafür, dass der Glaube an sie kaum zu einem Zweifel Anlass gebe: „Wer wollte etwa leugnen, dass Aphrodite existiert? Sie wirkt offenbar in jedem anderen Volk genau wie unter den Griechen ja, selbst unter Tieren." ${ }^{\text {"77 }}$

In ähnlicher Weise lässt Platon im Symposion die Priesterin Diotima argumentieren. Beim Menschen, so sagt sie, könne man meinen, es sei seine eigene Planung, wenn er in Liebe einen anderen Menschen begehrt, sich um ihn sorgt, sich aufopfernd für ihn einsetzt, Kinder zeugt, sie pflegt und aufzieht, usw. Bei den Tieren aber könne man sehen, dass sie von dem gleichen erotischen Drang heftig umgetrieben werden. Eros also (mit dem man auf den Liebreiz der Schönheit, die von Aphrodite ausgeht, antwortet) sei nicht etwas, was wir nach unserem Wollen machen, sondern das eine Kraft über uns ausübt, mit der wir uns auseinandersetzen müssen. ${ }^{78}$

An Eros und Aphrodite zu glauben, ist in diesem Sinn Anerkennung der Tatsache, dass sie nicht durch uns in der Welt sind, sondern Mächte, deren Einfluss wir ausgesetzt, wenn auch nicht ausgeliefert sind.

Diese Denkweise ist auch einem modernen Denken nicht fremd. Auch wir sprechen von der Liebe als einer Macht und entschuldigen z.B. das Fehlverhal-

chen, der - in größerem oder geringerem Maß - genau diesen Einwirkungen gegenüber in ihrer Verfügung bleibt. S. das Folgende.

76 S. v.a. Verf., Selbständigkeit und Abhängigkeit menschlichen Handelns; ders., Handeln in Abhängigkeit.

77 S. Snell, Bruno, Die Entdeckung des Geistes, 31.

78 S. Platon, Symposion 207a-d. 
ten eines Menschen mit der Begründung, es sei die Liebe gewesen, von der er verführt gewesen sei.

Im Unterschied zu Homer nennen wir eine solche Macht nicht mehr göttlich, höchstens metaphorisch.

Festhalten kann man aber wohl, dass auch wir in ihr eine Einschränkung menschlicher Selbständigkeit erkennen, und auch, dass wir die Liebe nicht für etwas willkürlich und immer wieder anders Wirkendes ansehen, sondern ihr eine bestimmte Wirkweise zuschreiben und die Varianten innerhalb dieses Bereichs suchen.

Dass Homer solche Wirkungen nicht auf abstrakte Mächte, sondern auf persönliche Götter zurückführt, liegt zuerst an den religiösen Traditionen, in denen er steht. Dass er diese Traditionen nicht einfach übernommen hat, zeigt z.B. der Vergleich mit der ganz anderen, weit irrationaleren Religiosität, die man in den kyklischen Epen findet. Herodot schreibt ihm zusammen mit Hesiod zu, er habe den Göttern ihre Beinamen (d.h. wofür sie zuständig sind) gegeben, habe die Bereiche, in denen ihnen Ehren erwiesen wurden, und ihre ,technai', ihr je besonderes Können und ihre Tätigkeiten umschrieben. ${ }^{79}$ Es sind Deutungsleistungen (keine poetischen Fiktionen), um derentwillen er Homer rühmt.

Verfolgt man unter diesem Gesichtspunkt die Darstellung des Agierens der Götter in Ilias und Odyssee, kann man feststellen, dass dieser Darstellung eine bestimmt konturierbare Auffassung von den Göttern zugrunde liegt.

Differenzierter noch als bei Aphrodite kann man diese Gottesvorstellung an Athenes Wirken nachvollziehen.

Athene nimmt bei Homer in extrem unterschiedlicher Weise Einfluss auf menschliches Handeln.

Gegenüber Odysseus verhält sich Athene beinahe wie von Gleich zu Gleich. Sie zeigt sich ihm als die Göttin, die sie ist, und steht ihm in vielfältiger Weise bei. Sie gibt auch einen Grund für diese Hilfe an: Weil er unter den Menschen bei weitem der Beste an klugem Denken und Reden sei, so wie sie unter den Göttern gerühmt sei wegen ihrer auf den klugen Vorteil bedachten Denkens (13, 296-299). Deshalb könne sie ihn nicht in Stich lassen, weil er auf das Gute bedacht sei, geistesgegenwärtig und im Besitz seines Verstandes (13, 331f.).

Nimmt man diese Begründung als Hinweis auf die Ursache für die Unterschiedlichkeit ihres Verhaltens gegenüber den Menschen, zeigt sich eine Art Skala, die von uneingeschränkter Unterstützung zu einer eingeschränkteren Hilfe führt bis hin zu einer Verweigerung der Hilfe, ja der schweren Schädigung.

Auch Telemach erfährt vielfache Unterstützung durch Athene. Ihm zeigt sie sich aber nicht direkt als sie selbst, sondern erscheint ihm in verwandelter Form, als Gastfreund, Ratgeber oder als Traumbild. Anders als Odysseus of-

79 S. Herodot, Historien II, 53. 
fenbart sie ihm auch nicht ihre eigenen Gedanken. Sie verbirgt ihm sogar, was sie selbst weiß. So ermahnt sie ihn z.B., damit zu rechnen, dass Penelope bald einen Freier heiraten könne, er wisse doch wie die Frauen sind (15, 17-23). Das sagt sie, obwohl sie gerade Odysseus der unerschütterlichen Treue seiner Frau versichert hat $(13,379-381)$. Mit der Verwandlung geht offenbar eine Angleichung an denjenigen, dem sie sich zuwendet, einher. Sie spricht mit Telemach so, wie dieser, der gerade zu selbständigem Denken sich hin entwickelt, mit sich selbst sprechen könnte oder sollte.

Ein ähnliches Vorgehen kann man auch bei ihrem Mitwirken an der - begrenzten - Selbstbeherrschung des Achill beobachten (1, 202-214). Sie zeigt sich Achill zwar als sie selbst und spricht vertraut mit ihm. Das, was sie ihm rät aber, entspricht weder ihrem ,auf den wahren Vorteil bedachten Denken“ (Odyssee 13, 298f.) im Allgemeinen noch dem wahren Vorteil, den sie zusammen mit Hera für die Griechen erhalten und verwirklichen möchte. Denn sie rät Achill zwar von der Tötung des Königs ab, aber sie bittet ihn nicht wie etwa wenig später Nestor, er solle von seinem Zorn lassen (1, 274-284), sondern stachelt ihn sogar noch an, Agamemnon verbal herabzusetzen, ${ }^{80}$ so viel er wolle $(1,211)$, ja sie gibt ihm einen für ihn wie für die Griechen verhängnisvollen Wink, er könne sich auch auf andere, bessere Weise Genugtuung verschaffen $(1,212-214)$.

Dem Leser, der die exzessive Steigerung des Streits zwischen Achill und Agamemnon mitverfolgt hat, dürfte der Grund für diese Beschränkung der Vernünftigkeit des Rats deutlich sein: Achill, von höchstem Schmerz (áchos) über die Unverschämtheit Agamemnons getroffen, wäre an dieser Stelle nicht zu einer völligen Aufgabe seiner Wut bewegbar. Dazu bedarf es einer langen, mit viel Leid verbundenen Entwicklung.

Aber es ist für Achill in seinem gesamten in der Ilias dargestellten Verhalten charakteristisch, dass er sich nicht völlig an seine Leidenschaft verliert. ${ }^{81} \mathrm{Er}$ kann bei den Herolden, die seine Briseis holen, zwischen Boten und Botschaft unterscheiden $(1,327-344)$, er bleibt seinen bittenden Kameraden in größter Freundschaft verbunden $(9,185-221)$, obwohl er ihrem Anliegen gegenüber ganz und gar verbittert ist. Am Ende ist er sogar zum Mitleid mit dem Vater Hektors, den er in beinahe wahnsinniger Wut geschändet hat, imstande (24, 471-676). Diese Fähigkeit, auch in der höchsten leidenschaftlichen Erregung der Vernunft nicht völlig verschlossen zu sein, zeigt Achill auch gegenüber Athene. Er hört auf ihren Rat (1, 215-218), dieser Rat aber ist von Athene so gegeben, dass er ihn - als der Charakter, der er ist, und in der inneren Verfassung, in der er ist, - auch annehmen kann. Das Maß an Vernunft, an dem ihm Athene Teil gibt, ist er selbst. So viel, wie er von Athene anzunehmen in der Lage ist, so viel erhält er von ihr.

80 S. Nordheider, H. W., Artikel ,oneidízo‘ (LfgrE).

81 S. Verf., Achill - ein Held. 
Auch Hektor gegenüber erweist sich Athene als eine Göttin, die ihm zu dem Vorteil zu verhelfen versucht, der ihm angemessen ist. Zwar sagt Homer von Hektor, Athene habe ihm den Verstand genommen, als er nach Achills Wiedereintritt in den Kampf dem klugen Rat des Poulydamas nicht folgt, mit dem Heer wieder Schutz hinter den Mauern der Stadt zu suchen (18, 310313). Aber Hektor ist nicht so verblendet, dass er diesen Fehler nicht selbst einsehen würde (22, 99-110). So hilft ihm Athene wenigstens dabei, seine Folgen zu mindern. Als Hektor außer sich vor Angst vor Achill flieht, verwandelt sie sich in seinen Bruder Deiphobos und täuscht Hektor dadurch, dass sie vorgibt, sich mit ihm gemeinsam Achill zu stellen (22, 214-259). Dieses Vorgehen Athenes wird von den meisten neueren Interpreten als Zeichen der moralischen Minderwertigkeit der homerischen Götter (oder auch nur der Götter der Ilias) ausgelegt. Tatsächlich will Athene vor allem Achill zu einem ehrenvollen Sieg über Hektor verhelfen. Es steht aber außer Frage, dass Hektor in dieser Situation nur die Wahl hatte, auf feiger Flucht von Achill getötet zu werden oder sich Achill zu stellen und so wenigstens in einem ehrenvollen Kampf zu fallen. Dazu verhilft ihm Athene. Auch hier ist für ihr Verhalten, d.h. für die Täuschung, nicht ihr göttliches Wollen im Allgemeinen verantwortlich, sondern das, was für Hektor in dieser Situation der noch beste Vorteil war.

In gar keiner Weise vorteilhaft verhält sich Athene gegenüber Pandaros, dem sie, ohne dass er auch nur ahnt, mit wem er es zu tun hat, rät, den heilig geschworenen Eid zwischen den beiden Heeren zu brechen und auf Menelaos zu schießen. Das werde ihm großen materiellen Gewinn und Ansehen bei Paris einbringen (4, 86-104).

Diese sogar von Zeus selbst beschlossene ,Versuchung' des Pandaros gilt als das Hauptbeispiel für das willkürliche Wirken der homerischen Götter, die den Menschen auch noch die Verantwortung für etwas aufbürden, was sie selbst beschlossen und ins Werk gesetzt haben. Selbst ein Rebell gegen die Gelehrten-Philologie spricht von ,zynischen“ und ,voyeuristischen“ Göttern und zeigt sich überzeugt, dass es eine Idee von Schuld bei Homer nicht gebe: „Fluch und Segen werden jedem je nach Laune der Götter zuteil.“"82

Ein solches moralisch vernichtendes Urteil hatte das auf seine Erfolge in einer neuen Physik und seine christliche Kultiviertheit stolze Frankreich am Ende des 17. Jahrhunderts (in der berühmten querelle des anciens et des modernes $^{83}$ ) über Homer gefällt. Dass wir immer noch daran festhalten, zeugt nicht von einer sorgfältigen Lektüre.

Homer lässt Pandaros von einer Athene verführt werden, die dieser überhaupt nicht erkennt - er hat nicht einmal eine Ahnung, dass er von einem Gott beeinflusst sein könnte. Zu ihm kommt kein Bote des Zeus, der ihn andonnert. Er wird von einem vermeintlichen Kameraden ,überredet' (4, 93).

82 S. Schrott, Raoul, Homer. Ilias, XV.

83 S. Verf., Artikel, Querelle des anciens et des modernes'. 
Dass er sich davon zu einem verbrecherischen Handeln bewegen lässt, kommentiert der Erzähler Homer: „Dem Dummkopf beredete sie die Sinne.“ Schrott übersetzt vom gemeinten Sinn her nicht schlecht: „Er war Narr genug, sich überreden zu lassen."

Das ist richtig. Der Narr, der zugleich süchtig nach Reichtum und Anerkennung ist, ist Pandaros. Und Athenes Worte sind an ihn gerichtet, weil er ein solcher Charakter ist. Auch er erhält von der Göttin des wahren Vorteils das, was er davon aufzufassen in der Lage ist. Und das ist etwas nur scheinbar Vorteilhaftes. Es durch ein ungeheures Verbrechen zu erkaufen, stimmt er bereitwillig, gleichsam von aller Vernunft verlassen, zu.

Man kann und muss sich freilich fragen, weshalb Homer für ein so unvernünftiges Verhalten eine Göttin der Vernunft zuständig sein lässt. Die Antwort auf diese Frage setzt die weitere Frage voraus, weshalb Homer überhaupt für das kluge Bedachtsein auf den tatsächlichen Vorteil eine Göttin zuständig sein lässt. ${ }^{84}$ Das kann im besten Fall allegorisch gedeutet werden: eine Gottheit als bloß anschauliche Verkörperung eines abstrakten Vermögens.

Ähnlich wie bei Aphrodite wird man auf jeden Fall auch von dieser praktischen Vernunft sagen können, dass sie nicht in der Welt ist, weil wir sie jedesmal neu erschaffen. Heraklit hat bekanntlich die Feststellung an den Anfang seines Werks gestellt: Die Vernunft ist für alle ein und dieselbe, aber die meisten leben so, als habe jeder seine Privatvernunft. ${ }^{85}$ Ohne die Orientierung an ein und derselben Rationalität kann es keine Verständigung geben. Selbst der, der bestreitet, dass es eine einheitliche Vernunft für alle geben kann, muss dafür gute Argumente vorlegen, von denen er erwarten kann, dass alle sie akzeptieren. Auch in der Bestreitung der einen Vernunft muss man sich auf sie stützen.

Auch wenn dieser kurze Hinweis in keiner Weise als Begründung ausreicht, er kann immerhin daran erinnern, dass die Annahme einer Vernunft, an der alle partizipieren müssen, die miteinander argumentieren und reden wollen, kein Relikt einer mythischen Vorzeit ist, sondern eine diskussionswürdige Annahme.

Selbst bei Pandaros kann man auf etwas Gemeinsames von dieser Art hinweisen. Denn der Gedanke, durch einen Bruch des Eids und eine Hilfestellung für Paris aus dem Hintergrund sich Vorteile und Anerkennung zu verschaffen, ist kein privater Gedanke, der nur für Pandaros möglich war, sondern er ist ein

84 Es soll hier nicht die These aufgestellt werden, Athene sei für Homer eine Verkörperung des abstrakten Begriffs der Vernunft. Dass Athene Person ist, hat bei Homer andere Gründe, als sie in der vorsokratisch-stoischen Allegorese zur Erklärung gegeben werden. Außerdem vereinigt Athene wie die anderen Götter, wie aber auch menschliche Charaktere wie etwa Achill, verschiedene Züge in sich. Ob und wie diese sich zu einer Einheit fügen, kann hier nicht verfolgt werden. Ohne Zweifel aber ist Athenes Kompetenz in praktischer, den wirklich zuträglichen Erfolg bedenkender Klugheit bei Homer ein wichtiger, vielleicht der grundlegende Zug ihres Wesens. S. das Folgende.

85 S. Diels, Hermann, Die Fragmente der Vorsokratiker, 151 (Fragm. B2). 
denkbares Angebot, auf das jeder in dieser Situation aufmerksam sein und eingehen konnte. Der Neuplatonische Philosoph Proklos betont allerdings, dass eine so verbrecherische Natur, die eine solche denkbare Möglichkeit auch zu verwirklichen suchte, im ganzen trojanischen Heer außer bei Pandaros nicht zu finden gewesen sei. ${ }^{86}$

Die Frage, weshalb Homer diese eine gemeinsame Vernunft, die er zudem eher als eine Art Phronesis, eine praktische Vernunft, die auf das kluge Bedenken des wahren Vorteils gerichtet ist, deutet, als Person auffasst, kann hier nicht zureichend erörtert werden. In der späteren Philosophie, z.B. bei Platon, gibt es den Gedanken, dass es erstaunlich wäre, wenn wir als Menschen unsere Selbstständigkeit und Personalität zwar vom Besitz der Vernunft her hätten, diese Vernunft selbst aber, die von sich selbst her ist, was sie ist, unpersönlich gedacht werden müsste. ${ }^{87}$

Sicher ist auch bei Homer, dass die Vorstellung, Götter handelten als Personen, mit der Erfahrung der eigenständig aktiven Wirkung, die man von ihnen machen kann, zusammenhängt. Bei Aphrodite ist dies besonders deutlich, aber auch bei Athene ist klar, dass sie dort, wo sie auftritt, als etwas von sich aus Aktives erfahren wird.

Dass die Wirkungen, die Homer von Athene ausgehen lässt, von heutigen Lesern nicht als göttlich begriffen werden, liegt zu einem guten Teil an den Verwandlungen, durch die sich die homerische Athene den Personen, auf die sie wirkt, angleicht. Dass Athene Achill auf den Gedanken bringt, sich Genugtuung von Agamemnon zu verschaffen, indem er ihn spüren lässt, was er für ihn wert ist, ist natürlich kein Gedanke einer göttlichen Vernunft. Aber es ist ein Gedanke, der nicht nur für Achill denkbar war, selbst wir heute können ihn ohne Weiteres verstehen. Dass er von Athenes eigentlichem Denken und Wollen abweicht, liegt an Achills Aufnahmefähigkeit in seiner individuellen Situation - aber auch diese Einschränkung kann von den unterschiedlichsten Lesern nachvollzogen werden.

Obwohl er also ein typisch Achilleischer, für Achill charakteristischer Gedanke ist, ist er nicht ein nur privates Produkt Achills, sondern hat einen all-

86 Proklos, In Platonis rem publicam commentarii, I, 104f.

87 Siehe Platon, Sophistes 248e6-249a2; siehe dazu v.a. die Ausführungen von Cornelia de Vogel, What was God for Plato?, v.a. 210, 241. De Vogel macht nicht nur vom Gedanken her, sondern durch schlagende philologische Belege unzweifelhaft deutlich, dass die Ideen für Platon nicht abstrakte „Seinsheiten“ sind, sondern in philosophisch gereinigter Form die Funktionen der alten olympischen Götter übernommen haben. $\mathrm{Zu}$ dieser Frage siehe auch D. Bremer, Die Epiphanie des Gottes (mit Diskussion der Literatur). Bremers These allerdings, dass die ,höchste Idee ' ein unpersönlich vorgestelltes Göttliches bei Platon sei, kann schwerlich zutreffen, nicht nur wegen vieler (z.B. von Cornelia de Vogel gesammelter) Gegenbelege bei Platon selbst (v.a. Sophistes 248f.), sondern v.a. wegen der in der Geschichte des Platonismus und Neuplatonismus bis ins Mittelalter (v.a. über Dionysius Areopagita) vermittelten Überzeugung von der Personalität der Götter, die vorsorgen, wollen, ins Werk setzen und vieles mehr. Siehe dazu v.a. Bernard, W., Spätantike Dichtungstheorien, v.a. 107-164. 
gemeinen Aspekt an sich. Diese verstehbare Möglichkeit ist ein Angebot an Achill - auch in einem modernen Sinn des Wortes -, das verstanden und dann angenommen oder nicht angenommen werden kann.

Der Schein, die Götter, vor allem die Götter der Ilias, griffen nach Willkür und Laune in menschliches Leben ein, ${ }^{88}$ sollte von dem, der die Entstehung der Unterschiede in der Art ihres Wirkens beachtet, auch als Schein, d.h. als ein pauschaler Eindruck der Oberfläche, durchschaut werden. Wenn Athene Hektor den Verstand nimmt, dann deshalb, weil er dem Rat des Poulydamas, der ,nach vorne und hinten zu sehen in der Lage ist' $(18,250)$, d.h. der den allgemeinen, wirklichen Vorteil im Auge hat, im verblendeten Siegesrausch nicht zu folgen in der Lage war. Und wenn sie Odysseus beim Wettlauf mit Aias hilft, dann deshalb, weil er einen erkennbaren Vorteil, der sich ihm darbot (einen Misthaufen auf der Endstrecke, über den er Aias durch einen Spurt täuschen konnte), geistesgegenwärtig erfasst hat. ${ }^{89}$

Der Liebling eines Gottes zu sein, ist daher eine Auszeichnung, es heißt, fähig zu sein, sich ihm gemäß zu verhalten und sich das zu erschließen, was in der Potenz dieses Gottes steht. Eine solche Auszeichnung zu haben, muss nicht

88 S. Siehe Lesky, Albin, Göttliche und menschliche Motivation, 43f.; siehe dagegen aber die bedenkenswerten Ausführungen W. Kullmanns, Die Quellen der Ilias, v.a. 252; ders., Das Wirken der Götter in der Ilias, 106f. Die These, die Götter gewährten Huld und Strafe nach ,Lust und Laune', ist auch übernommen von Muth, Robert, Einführung in die griechische und römische Religion, 60. „Göttliche Willkür“, die „,das Handeln der Aristokraten“" spiegele, ist auch nach Reucher, Th., Die situative Weltsicht Homers, 85f., die Ursache für den Eidbruch durch Pandaros (auch sonst zeichnet sich Reuchers Homerdeutung dadurch aus, dass sie in neuen Begriffen alte Vorurteile tradiert). Von der Tendenz, göttliches Eingreifen in das menschliche Schicksal als einen Willkürakt zu deuten und dafür gerade die Pandaros-Szene zum Zeugnis zu nehmen, ist aber auch K. Reinhardts Homerinterpretation nicht frei. Siehe z.B. Das Parisurteil, 26; und ders., Die Ilias und ihr Dichter, 118f. Dieser angeblichen Götterwillkür setzt W. Nicolai zu Recht entgegen, dass Homer aristokratische Willkürakte in erster Linie an seinen menschlichen Figuren demonstriert. Siehe Nicolai, W., Wirkungsabsichten des Iliasdichters, 90, 94f., 96-101; ders., Rezeptionssteuerung in der Ilias, 10-12. Kullmann sieht einen bedeutenden Unterschied zwischen der Göttervorstellung der Ilias und der der Odyssee. Erst in der Odyssee gebe es die Vorstellung einer göttlichen Gerechtigkeit, in der Ilias solle man eher von einem ,aufgeklärten Polytheismus‘ sprechen. Die Aufgeklärtheit bestehe in einer „totalen Nichtbeziehung zwischen Gott und Mensch“ (Kullmann, Wolfgang, Kapitel Ilias, 101, mit Hinweisen auf weitere eigene Arbeiten), die die menschliche Tragik krass sichtbar mache. Diese Auslegung ist nahegelegt durch die unterschiedliche Deutlichkeit, in der die göttliche Gerechtigkeit in Odyssee und Ilias sichtbar werden. Ursache ist vor allem der jeweilige Gegenstand. In der Odyssee geht es primär um das Verhältnis von Odysseus und Athene, in der Ilias dagegen findet man ein vielfach differenziertes Verhältnis der verschiedenen Personen zu den Göttern. Es ist nicht verwunderlich, dass sich Athene gegenüber Pandaros anders verhält als gegenüber Odysseus. Das ist aber nicht Zeichen ihrer Willkür, sondern gerade dafür, dass sie in ihrem Verhalten das menschliche Verhalten angemessen berücksichtigt. 
immer einen endgültigen Vorteil für jemanden bedeuten. Ein Liebling Athenes wie Odysseus, der sich auch in einer hocherregten Situation, etwa wenn er die untreuen Dienerinnen zu den Freieren seiner Frau schleichen sieht, nicht vom Blick auf seinen wahren Vorteil abbringen lässt, erreicht durch sein Athene gemäßes Verhalten auch ein glückliches Ende. Ein Liebling Aphrodites oder des Ares zu sein, hat den Kompetenzen dieser Götter gemäß nicht dieselbe Wirkung.

Für die Ordnung unter diesen Einflüssen auf den Menschen ist Zeus zuständig. ${ }^{90}$ Er verteilt die Ehren (von denen Herodot sagt, Homer habe ihre Zuordnungen richtig erkannt und den Griechen mitgeteilt, Historien II, 53) und ist für das Gesamtgeschehen verantwortlich. Aber auch die sogenannte Diós boulé wirkt in der Ilias nicht als Schicksal, und schon gar nicht als ein zufälliges, den Einzelnen mehr oder weniger kontingent zufallendes Schicksal. ${ }^{91}$

Wie auch bei den einzelnen Einflussnahmen der Götter auf Menschen braucht man von einem modernen Verständnis her diese göttliche Lenkung nicht. Das Geschehen würde auch ohne Zeusplan nicht anders ablaufen. Achill zieht sich zurück, das verschafft den Trojanern Vorteile und bringt Agamemnon zur einsichtigen Reue. Achill aber lässt sich zu spät umstimmen und endet so tragisch.

Dass Homer dieses Geschehen für einen Plan des Zeus hält, muss bedeuten, dass er die Überzeugung hat, es sei alles so verlaufen, wie es dem menschlichen Handeln gemäß verlaufen musste, d.h. wie es gerecht war. So wie die

90 Dazu grundlegend noch immer: Lloyd-Jones, Hugh, The Justice of Zeus.

91 Das ist die Grundthese von Jonas Grethlein, Das Geschichtsbild der Ilias; ders., The Greeks and Their Past. Diese These, die Grethlein unter Zuhilfenahme neuerer philosophisch hermeneutischer Ansätze bei Homer zu belegen versucht, ist nicht nur vom Begriff der sog. ,Schicksalkontingenz' her problematisch. Ein Schicksal trifft den einzelnen Menschen oft kontingent. Das liegt aber, wenn man den Glauben an ein (alles durchwaltendes) Schicksal voraussetzt, an der begrenzten Perspektive des Menschen (so die stoische Deutung der Kontingenz). Bei Homer gibt es zwar oft auch Äußerungen aus dieser Perspektive, bemerkenswerter Weise aber selten von den Hauptfiguren. Agamemnon weiß, dass die Verblendung, die ihn ins Unglück geführt hat, zu einem guten Teil ihre Ursache in ihm hat. So ist es auch bei Achill, der sich sogar bittere Vorwürfe macht, dass er zu sehr seinem Zorn nachgegeben hat und so selbst Verantwortung dafür trägt, dass ihn das schlimme Schicksal des Todes seines besten Freundes ereilt hat. Auch Hektor klagt sich selbst an, in jener ,unglückseligen Nacht', als Poulydamas ihn zum Rückzug in die Stadt aufgefordert hat, seiner Verblendung gefolgt zu sein. Bei Patroklos gibt es ein solches Wissen um eine eigene Verfehlung nicht, es ist aber in der homerischen Darstellung klar, dass er deutliche Gebote und nachdrückliche Bitten Achills übergangen hat und nur dadurch ins Unglück geraten ist, usw. Das Geschichtsbild Homers ist sicher nicht vom Glauben an ein kontingent den Menschen treffendes Schicksal geprägt, gegen das sich die Menschen Verteidigungsstrategien ausdenken müssten. 
Menschen gehandelt haben, ein solches Schicksal ist ihnen auch zuteil geworden.

Zum Verständnis kann die Unterscheidung viel beitragen, die man bei der menschlichen Beeinflussung durch einzelne Götter zwischen dem göttlichen und dem menschlichen Anteil treffen kann.

Offenbar ist für Homer vieles, was uns als Produkt des eigenen Inneren gilt, etwas von diesem Inneren Verschiedenes, Äußeres. Nicht deshalb, weil etwas in mir vorgeht, ist es auch in meiner selbständigen Verfuggung und in diesem Sinn meine eigene Aktivität.

Die einleuchtende Kraft, die ein Gedanke von sich aus auf das Denken auszuüben vermag; die Verlockung, die die Vorstellung von Geld und Ruhm auf das Denken ausübt; das Überredende, Verführende oder auch logisch Zwingende, das ein Gedanke in sich selbst hat; aber auch die Liebreiz wirkende Macht der Schönheit; die Verblendung, die vom Besitz der Macht ausgeht; die Kampfeswut oder der Siegestaumel, die die Menschen zu erfassen vermögen, all das wirkt in der Darstellung Homers von außen auf den Menschen ein.

Dies bedeutet aber nicht, dass die homerischen Menschen überhaupt nicht von einem in ihnen selbst liegenden Vermögen wüssten, durch das sie selbst bestimmen, wozu sie sich entscheiden oder was sie planen. Dieses Vermögen ist lediglich nicht auf die inneren Vorgänge des Menschen als ganze bezogen, so als ob die Liebe, die ich fühle, einfach mein Gefühl, der Gedanke, den ich denke, als ganzer mein Gedanke sei, sondern ist auf das wirklich in der subjektiven Macht des Einzelnen Liegende eingeschränkt, d.h. auf die Art und Weise, wie jemand einen Gedanken aufnimmt, wie er von sich aus sich ihn erschließt oder vorstellt, was für ein Gedanke es ist, der ihn zu überzeugen vermag, wie er Liebreiz, Macht, Bedrohliches usw. überhaupt wahrzunehmen in der Lage ist, und wie er dem, was er davon in sich aufgenommen hat, widersteht oder verfällt.

Die Unterscheidung zwischen menschlichem und göttlichem Anteil folgt bei Homer offenbar anderen Kriterien als denen, die wir anlegen, wenn wir uns der eigenen Selbstbestimmung vergewissern. Die Frage, wie sie etwa Bruno Snell formuliert, lautet: Weiß ich, dass ich es bin, der gerade einen Gedanken fasst, eine Liebe empfindet, eine Entscheidung trifft, usw.? Auf diese Frage kann man nur mit ,Ja' oder ,Nein' antworten.

Bei Homer müsste die Frage lauten: Ist der Gedanke, den ich gerade denke, als Ganzer mein Produkt, oder gibt es etwas an ihm, was nicht von mir stammt, sondern wo ich nur der Aufnehmende, Erschließende bin? Oder: Ist die Liebe, die ich empfinde, etwas, das ganz aus mir kommt und ganz in meiner Verfügung liegt, oder gibt es hier etwas, was schon von sich selbst her etwas ist und eine eigene Verfügungsmacht ausübt, die ich erkennen kann, von der ich getroffen, ja verwundet, um meine eigenen Möglichkeiten gebracht werden, der ich aber auch widerstehen kann?

Die Grenze zwischen dem Eigenen und Fremden geht im Sinn dieser Auffassung mitten durch das Innere des Menschen selbst. Das Kriterium der Un- 
terscheidung ist, ob etwas in meiner Verfügung steht oder nicht oder nur teilweise. Die Aufforderung über dem Apollon-Tempel in Delphi lautete: ,Erkenne dich selbst'. Ihre Bedeutung ist, wie Rudolf Pfeiffer überzeugend gezeigt hat ${ }^{92}$ nicht: ,Bespiegele dich in allem reflexiv selbst!', sondern: ,Erkenne deine Grenzen!

Diese Aufforderung hat man oft nur im Sinn einer Aufforderung zur Bescheidenheit ausgelegt. Sie schließt aber selbst bei dieser Deutung ein, dass man sich nur dann selbst erkennen kann, wenn man zwischen Eigenem und Fremdem, zwischen dem, was in der eigenen Macht steht und was nicht in ihr liegt, unterscheiden kann. Nur dann ist es überhaupt möglich, im Geflecht der Ursachen, die auf einen einwirken, sozusagen den Faden herauszufinden, den man selbst in der Hand hat und mit dem man selbst Einfluss auf sein Handeln nehmen kann.

Platon lässt im Symposion aufgeklärte Sophisten auftreten, die das göttliche Gefühl des Eros im Menschen als Quelle seiner Souveränität preisen: Wer sich ihm hingibt, wird zum idealen Kämpfer in der Schlacht (Phaidros), wer ihn richtig einsetzt, entfaltet eine Kultur des Zusammenlebens (Pausanias), wer ihn kennt und richtig nutzt, wird alle Bedürfnisse des Menschen technisch, mit Methode befriedigen können (Erixymachos). Aber der Dichter Aristophanes widerspricht: Dass wir Eros haben, ist kein Zeichen unserer Souveränität, sondern unseres Mangels. Wir sehnen uns nach einer verlorenen Ganzheit. Und die Priesterin Diotima ergänzt: Der Mangel, um dessentwillen wir Eros haben, ist nicht das Ganze, sondern das für uns rundum Gute. ${ }^{93}$

Die Kritik, die Dichter und Priesterin an den aufgeklärten Sophisten üben, ist der homerischen Form der Selbsterkenntnis verwandt: Es gibt kein Wissen des Menschen um sich selbst, der seine Abhängigkeiten nicht zuvor bedenkt. Erst daraus entsteht die Möglichkeit, sich selbst aus dem heraus, was in der eigenen Macht steht, zu verwirklichen.

Dieses Wissen ist nicht das bei jedem Entscheidungsakt gleiche Bewusstsein: ,Es kommt - allein - auf mich an, wie ich mich entscheide', wie es Snell für den modernen und eine neuere Arbeit sogar für den homerischen Menschen $^{94}$ in Anspruch genommen hat. Es entwickelt sich vielmehr nur durch kritische Prüfung der eigenen Erfahrungen, durch die man eine konkrete Fähigkeit gewinnt zu unterscheiden zwischen dem, was in der eigenen Macht liegt und was nicht. Da diese Unterscheidung jedem Einfluss gegenüber anders ist, entsteht dadurch eine persönliche Freiheitskompetenz. Sie wird dadurch zu

92 S. Pfeiffer, Rudolph, Ausgewählte Schriften, 80ff.

93 Zur Deutung dieser Tendenz im Symposion s. Thiel, Rainer, Irrtum und Wahrheitsfindung.

94 S. Sarischolulis, Efstratios, Schicksal, Götter und Handlungfreiheit, v.a. 161ff.; z.B. von Telemach: „,... der Held allein bestimmt, welche Beweggründe seinem Handeln zugrundeliegen. Telemachos, der die unterschiedlichen Antriebe, sei es von einem Gott, sei es von seinem eigenen Inneren, empfängt und auswertet, ist Träger und Bestimmer des eigenen Handelns.“ (205). 
einem Signum des Charakters, den man hat. Von ihm, d.h. von den aus vielen Erfahrungen gewonnenen Tendenzen, Bestimmtes vorzuziehen oder zu meiden, hängt das Handeln des Menschen ab. Dadurch hat es eine bestimmte Kontur, durch die ein Mensch nicht beliebig auf Äußeres reagiert, sondern so, dass seine Ziele verstanden werden können und die Schritte, in denen er sie verfolgt, eine Ordnung haben. Diese Ordnung gibt dann die Ordnung der Darstellung dieses Handelns vor.

\section{Literatur}

\section{Antike Autoren:}

Aristotelis De arte poetica liber, rec. R. Kassel (Oxford 1965).

M. Tulli Ciceronis scripta quae manserunt omnia, Fasc. 45: De natura deorum, rec. Wilhelm Ax (Stuttgart 1968).

Diels, Hermann, Die Fragmente der Vorsokratiker. Griechisch und Deutsch, hrsg. v. Kranz, Walther, Bd. 1 (Berlin 1951).

Herodoti Historiae, rec. C. Hude, 2 Bde. (Oxford $\left.{ }^{3} 1927\right)$.

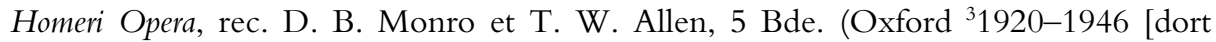
auch in Bd. 5 Ilia parva und Cypria]).

Q. Horati Flacci opera, rec. F. Klingner (Leipzig ${ }^{3} 1959$ ).

Platonis Opera, rec. J. Burnet, 5 Bde. (Oxford 1900-07).

Procli Diadochi In Platonis rem publicam commentarii, ed. W. Kroll, 2 Bde. (Leipzig 1899/1901).

Sophoclis Tragoediae, ed. R. D. Dawe, 2 Bde. (Leipzig 1975/79).

P. Vergili Maronis opera, rec. R. A. B. Mynors (Oxford 1969).

\section{Sekundärliteratur}

Beck, W. - Irmer, D., Fünfzig Jahre Thesaurus. 1944-1994, (Hamburg 1996).

Beck, W. - Nordheider, H. W., Arbeitsbericht 2003-2006: http://www1.unihamburg.de/Thesaurus

Beck, W., Artikel ,pansydie“, in: Lexikon des Frühgriechischen Epos Bd. 4 (Göttingen 2004), 964-965.

Bernard, W., Spätantike Dichtungstheorien. Untersuchungen zu Proklos, Herakleitos, Plutarch (Stuttgart 1990).

Bremer, D., Die Epiphanie des Gottes in den homerischen Hymnen und Platons Gottesbegriff, Zeitschrift für Religions- und Geistesgeschichte 27 (1975) 1-2.

Burgess, J. S., The Tradition of the Trojan War in Homer and the Epic Cycle (Baltimore/London 2001).

Burkert, W., The Orientalizing Revolution. Near Eastern Influence on Greek Culture in the Archaic Age (Cambridge 1992). 
—, „Antiker Mythos - Begriff und Funktion“, in: H. Hofmann, Antike Mythen in der europäischen Tradition (Tübingen 1999) 11-26.

-, „Homer's Anthropomorphism: Narrativ and Ritual“, in: ders., Kleine Schriften I: Homerica (Göttingen 2001) 80-94.

Cobet, J., „Die Ilias, Asien und Europa“, in: Ch. Ulf, - R. Rollinger, Lag Troia in Kilikien? Der aktuelle Streit um Homers Ilias (Darmstadt 2011) 425-441.

Danek, G., Epos und Zitat. Studien zu den Quellen der Odyssee (Wien 1998).

Dietrich, B. C., Death, Fate and the Gods: The Development of a Religious Idea in Greek Popular Believe and in Homer (London 1977).

Finsler, G., Homer in der Neuzeit. Von Dante bis Goethe (Leipzig/Berlin 1912).

Führer, R., Artikel ,epaurisko, epaureo', in: Lexikon des Frühgriechischen Epos Bd. 2, (Göttingen 1991) 626.

Genette, G., Die Erzählung (München ${ }^{2} 2010$ ).

Grethlein, J., Das Geschichtsbild der Ilias. Eine Untersuchung des Geschichtsbildes der Ilias aus phänomenologischer und narratologischer Perspektive, Hypomnemata 163 (Göttingen 2006).

- The Greeks and Their Past. Poetry, Oratory and History in the Fifth Century BCE (Cambridge 2010).

Griffin, J., „The Epic Cycle and the Uniqueness of Homer“, in: D. L. Cairns (Hg.), Oxford Readings in Homer's Iliad (Oxford 2004) 365-384.

Hegel, G. W. F., Vorlesungen über die Philosophie der Religion II, Theorie-Werkausgabe 17 (Frankfurt/Main 1969).

-, Vorlesungen über die Geschichte der Philosophie I, Theorie-Werkausgabe 18 (Frankfurt/Main 1971).

Heubeck, A., Der Odysseedichter und die Ilias (Erlangen 1954).

Hirschberger, M., „Die poetische Verwendung der Götter im Epos (,Götterapparat') (Kap. III,5)“, in: A. Rengakos - B. Zimmermann, (Hgg.), Homer-Handbuch. Leben - Werk - Wirkung (Stuttgart/Weimar 2011).

Holoka, J. P., „Homer, Oral Poetry Theory, and Comparative Literature“, in: J. Latacz, Zweihundert Jahre Homerforschung. Rückblick und Ausblick (Stuttgart/Leipzig 1991) 465-481.

Janko, R., „The Gods in Homer: Further Considerations“, in: R. Janko, The Iliad. A Commentary. Vol. IV, Books 13-16 (Cambridge 1995) 1-7.

Jong, I. de, Narrators and Focalizers. The Presentation of the Story in the Iliad (Amsterdam 1989 [=1987]).

—, „Homer as Literature: Some Current Areas of Research“, in: J. P. Crieland, (Hg.), Homeric Questions (Amsterdam 1995) 127-146.

Kirk, G. S., Homer and the Oral Tradition (Cambridge 1976).

Köhnken, A., „Der Endspurt des Odysseus. Wettkampfdarstellung bei Homer und Vergil“", Hermes 109 (1981) 129-148.

Kullmann, Wolfgang, Das Wirken der Götter in der Ilias. Untersuchungen zur Frage der Entstehung des homerischen „Götterapparats“ (Berlin 1956).

—, Die Quellen der Ilias (Wiesbaden 1960).

—, „Poesie, Mythos und Realität im Schiffskatalog der Ilias“, Hermes 137 (2009) 1-20. 
—, Ilias (Kap. I, 6), in: Rengakos, Antonios u. Zimmermann, Bernhard (Hgg.), HomerHandbuch, Stuttgart/Weimar 2011, 78-119.

Lamberton, R., Homer. The Theologician. Neoplatonist Allegorical Reading and the Growth of the Epic Tradition (Berkeley/Los Angeles/London 1986).

-, Homer's Ancient Readers (Princeton 1992).

-, „Homer in Antiquity“, in: Ian Morris - Barry B. Powell (Hg.), A New Companion to Homer (Leiden u.a. 1997) 33-54.

Latacz, J. (Hg.), Homer. Tradition und Neuerung (Darmstadt 1979).

Latacz, J., „Die Erforschung der Iliassstruktur“, in: ders. (Hg.), Zweihundert Jahre Homer-Forschung. Rückblick und Ausblick (Stuttgart/Leipzig 1991) 381-414.

- Artikel ,Epischer Zyklus', in: Der Neue Pauly Bd. 3, (Stuttgart 1997) 1154-1156.

- Artikel ,Homerische Frage‘, in: Der Neue Pauly Bd. I, 4, (Stuttgart 2000) 501-511.

—, Homer. Der erste Dichter des Abendlands (Düsseldorf/Zürich 2003).

Latacz, J. (Hg.) Homers Ilias. Gesamtkommentar. Band II: Zweiter Gesang (B). Faszikel 2: Kommentar (München/Leipzig 2003).

Latacz, J, Troia und Homer. Der Weg zur Lösung eines alten Rätsels (München/Berlin $\left.{ }^{5} 2005\right)$.

—, „Zu Homers Person (Kap. I,1)“, in: A. Rengakos - B. Zimmermann, HomerHandbuch (Stuttgart/Weimar 2011) 1-25.

—, „Zur Struktur der Ilias“, in: J. Latacz. (Hg.), Homers Ilias. Gesamtkommentar. Prolegomena (München/Leipzig 2000) 146-157.

Lateiner, D., „Homeric Prayer“, Arethusa 30 (1977) 241-272.

Lesky, A., Göttliche und menschliche Motivation im homerischen Epos, Sitzungsberichte der Akademie Heidelberg (1961).

—, Homeros, (Stuttgart 1967) (= Realenzyklopädie Supplement Band XI).

Lloyd-Jones, H., The Justice of Zeus (Berkeley/Los Angeles - London 1971).

Minchin, E., Homer and the Resources of Memory: Some Applications of Cognitive Theory to the Iliad and the Odyssey (Oxford 2001).

Muth, R., Einführung in die griechische und römische Religion (Darmstadt 1998).

Nesselrath, H.-G., ,Geschichte der Homerforschung (Kap. I,11)“, in: A. Rengakos B. Zimmermann, Homer-Handbuch (Stuttgart/Weimar 2011) 175-199.

Nicolai, W., „Wirkungsabsichten des Iliasdichters“, in: G. Kurz - D. Müller - W. Nicolai (Hgg.), Gnomosyne. Menschliches Denken und Handeln in der frühgriechischen Literatur (München 1981) 81-101.

—, ,Rezeptionssteuerung in der Ilias“, Philologus 127 (1983) 1-12.

Nordheider, H. W., Artikel ,thespésios‘, in: Lexikon des Frühgriechischen Epos Bd. 2 (Göttingen 1991) 1023-1024.

—, Artikel ,oneidízo‘, in: Lexikon des Frühgriechischen Epos Bd. 3 (Göttingen 2004) 709.

Nünlist, R. - Jong, I. de, „Homerische Poetik in Stichwörtern“, in: J. Latacz (Hg.), Homers Ilias. Gesamtkommentar. Prolegomena (München/Leipzig 2000) 159-171.

Oka, M., „Achill, der Zerstörer der Stadt (,ptolíporthos') - eine Neuerung des Iliasdichters", Antike und Abendland 36 (1990) 18-36.

Pfeiffer, R., Ausgewählte Schriften (München 1960). 
Reichel, M., Fernbeziehungen in der Ilias (Tübingen 1994).

Reinhardt, K., „Das Parisurteil“, in: ders. Tradition und Geist (Göttingen 1960) 16-36.

-, Die Ilias und ihr Dichter, aus dem Nachlaß hrsg. von Uvo Hölscher (Göttingen 1961).

Rengakos, A. - Zimmermann, B. (Hgg.), Homer-Handbuch. Leben - Werk - Wirkung (Stuttgart/Weimar 2011).

Reucher, Th., Die situative Weltsicht Homers (Darmstadt 1983).

Ricoeur, P., Zeit und Erzählung. Band II: Zeit und literarische Erzählung (München 1989 [frz. 1984]).

Rollinger, R., ,Altorientalische Einflüsse auf die homerischen Epen“, in: A. Rengakos - B. Zimmermann, Homer Handbuch (Stuttgart/Weimar 2011) 213-227.

Sarischoulis, E., Schicksal, Götter und Handlungsfreiheit in den Epen Homers (Göttingen 2008).

Schadewaldt, W., „Winckelmann und Homer“, in: ders., Hellas und Hesperien. Gesammelte Schriften zur Antike und zur neueren Literatur (Stuttgart/Zürich 1960) 600-636.

—, Iliasstudien (Darmstadt 1966 [=Berlin 1938]).

Schiller, F., „Über naive und sentimentalische Dichtung“, in: F. Schiller, Sämtliche Werke Bd. 5, Erzählungen. Theoretische Schriften, hg. v. Wolfgang Riedel (München 2004) 713-715.

Schmidt, M., Der wissenschaftliche Ort des LfgrE: http://www1.unihamburg.de/Thesaurus.

Schmitt, A., Selbständigkeit und Abhängigkeit menschlichen Handelns bei Homer. Hermeneutische Untersuchungen zur Psychologie Homers, Akademie der Wissenschaften und der Literatur in Mainz, Abhandlungen der geistes- und sozialwissenschaftlichen Klasse; 1990, 5 (Mainz/Stuttgart 1990).

—, „Handeln in Abhängigkeit. Determination und Freiheit im Verhältnis von Mensch und Gott bei Homer", in: D. Ingenschay, - H. Pfeiffer, Werk und Diskurs (München 1999) 11-32.

- Artikel ,Querelle des anciens et des modernes‘, in: Der Neue Pauly, hg. v. H. Cancik (u.a.), Bd. 15,2 (Stuttgart 2002) 607-622.

-, „Achill - ein Held?“, in: Heldengedenken. Über das heroische Phantasma. Sonderheft Merkur hg. v K.-H. Bohrer - K. Scheel (Berlin 2009) 860-870.

-, „Anschauung und Anschaulichkeit in der Erkenntnis- und Literaturtheorie des Aristoteles", in: A. Schmitt - G.. Radke-Uhlmann (Hgg.), Anschaulichkeit in Kunst und Literatur. Wege bildlicher Visualisierung in der europäischen Geschichte (München/Leipzig 2011) 91-152.

—, Aristoteles. Poetik, übers. u. erl. (Berlin $\left.{ }^{2} 2011\right)$.

Schmitz, Th., „Homerische Poetik (Kap. I,5)“, in: A. Rengakos - B. Zimmermann, Homer-Handbuch (Stuttgart/Weimar 2011) 64-78.

Schrott, R., Homer. Ilias, übertragen v. Raoul Schrott, kommentiert v. Peter Mauritsch (München 2008).

Schwinge, E.-R., „Homerische Epen und Erzählforschung“, in: J. Latacz, Zweihundert Jahre Homerforschung. Rückblick und Ausblick (Stuttgart/Leipzig 1991) 482-512. 
Scodel, R., Listening to Homer. Tradition, Narrative, and Audience (Ann Arbor 2002).

Snell, B., Die Ausdrücke für den Begriff des Wissens in der vorplatonischen Philosophie, Diss. Göttingen 1922 (Berlin 1924).

_, Aischylos und das Handeln im Drama, Philologus, Suppl. 20,1 (Leipzig 1928).

—, Rezension zu Böhme, Die Seele und das Ich im homerischen Epos, Gnomon 7 (1931) 74-86.

-, Gesammelte Schriften (Göttingen 1966).

—, Szenen aus griechischen Dramen (Berlin 1971).

-, Die Entdeckung des Geistes. Studien zur Entstehung des europäischen Denkens bei den Griechen (Göttingen ${ }^{6} 1986$ ).

Starke, F., „Troia im Machtgefüge des zweiten Jahrtausends vor Christus“, in: Arch. Landesmuseum Bad. Württ. et al. (Hg.), Troia. Traum und Wirklichkeit. Begleitband zur Ausstellung (Stuttgart 2001) 34-45.

Thiel, R., „Irrtum und Wahrheitsfindung. Zur Argumentationsstruktur von Platons Symposion“, in: S. Matuschek (Hg.): Wo das philosophische Gespräch ganz in Dichtung übergeht. Platons Symposion und seine Wirkung in der Renaissance, Romantik und Moderne, Jenaer Germanistische Forschungen, N.F. 13 (Heidelberg 2002) 516.

Tsagarakis, O., Nature and Background of Major Concepts of Divine Power in Homer (Amsterdam 1977).

Visser, E., Homerische Versifikationstechnik. Versuch einer Rekonstruktion (Frankfurt/Main u.a. 1987).

Vogel, C. J. de, „What was God for Plato?“, in: dies. Philosophia I, Studies in Greek Philosophy (Assen 1969) 210-242.

West, M. L., The East Face of Helicon. West Asiatic Elements in Greek Poetry and Myth (Oxford 1997).

-, Indo-European Poetry and Myth (Oxford 2007).

-, The Making of the Iliad. Disquisition and Analytical Commentary (Oxford 2011). 
Bereitgestellt von | SUB Göttingen Angemeldet 


\title{
$\tilde{\eta}$ and Theory of Mind in the Iliad
}

\author{
RUTH SCODEL
}

This paper addresses a word for which the $L f g E$ article provides little actual guidance, particle requiring such extended and independent treatment. The lexicon is valuable, however, for its bibliography. ${ }^{1}$ This study honors the project in a different way, by looking at a single word that may help us understand how Homeric characters think, the particle $\tilde{\eta}$.

The aspect of Homeric psychology with which this paper will mainly concern itself is Theory of Mind (abbreviated ToM): the understanding of the self and others as beings who have beliefs, emotions, desires, the understanding that the mental states of others are often different from one's own at a particular moment, and the capacity to interact with others by making inferences about those mental states. Since a celebrated article in 1978 asked whether chimpanzees possess ToM, questions surrounding ToM have been important in developmental psychology, cognitive science, philosophy, and primatology. ${ }^{2}$ Within the field there is ongoing debate about the nature of ToM, the two main branches being Theory Theory and Simulation Theory (Theory Theory holds that we use folk psychology to infer the mental states of others, Simulation Theory that we imagine what our mental states would be in another's situation). ${ }^{3}$ However, experiment has brought consensus about some issues. Although there are both individual and cross-cultural differences in the development of ToM, these represent variation within a human universal: for example, everywhere, at roughly four years old, children acquire the ability to recognize that others may have false beliefs.

Homeric psychology has long been a significant question in Homeric studies, especially since Snell's famous argument that Homeric characters do not possess what moderns would call "minds." ${ }^{4}$ Scholars have pursued this debate through two main issues. First, they have discussed how we should understand the decisions of characters and their responsibility for them, given how frequently the gods directly intervene in the characters' mental processes or are

\footnotetext{
$1 \quad$ LfgE 12 (1987), (R. von Bennekom).

2 Permack and Woodruff 1978.

3 Doherty 2009 is a recent introduction; Carruthers/Smith 1996 includes essays from a wide range of fields.

4 Snell 1975, influenced by Voigt 1934.
} 
said to do so. ${ }^{5}$ The psychological literature on behavior attribution, how people explain their own and others' behavior, might be useful for this discussion, especially since attribution appears to be subject to significant cultural variation. ${ }^{6}$ However, this paper will not discuss the specific attributions made by Homeric characters. Classicists have also discussed the language of the various mental organs in the Homeric epics and the extent to which they are distinct. ${ }^{7}$ While contemporary classical scholarship rejects the Snell-Voigt view of the Homeric mind, there is no consensus about whether Homer's separate organs anticipate Plato's divisions of the soul or not. ${ }^{8}$ Outside the field, the SnellVoigt model continues to be influential. ${ }^{9}$

ToM has also been one of the concerns of a new subfield in the study of literature, cognitive poetics or cognitive literary studies. ${ }^{10}$ While Homer does not provide the complex levels of ToM found in modern fiction, a consideration of ToM provides a way to look at Homeric psychology from a new perspective. Instead of asking how the poet depicts mental activity, it invites us to ask how the characters within the epic consider the mental activity of other characters. The Homeric poems are not subtle explorations of how one character's complex interiority imagines another's, but they are very rich in representations of people as they draw inferences, right or wrong, about the mental activity of others.

Of course, there are many representations in Homer of ToM where $\tilde{\eta}$ does not appear, while not all uses of the particle can be connected with ToM. In two famous examples, है $\gamma v \omega$ and vósl are used where a character-Achilles at Il. 1.333 and Alcinous at Od.6.67-recognizes and responds to the unspoken thoughts or feeling of an interlocutor whose speech has been inhibited by aidos. Achilles reads the external behavior of the heralds. ${ }^{11}$ Alcinous knows his daughter and realizes that she is thinking about her marriage. He has perhaps been thinking about it himself-but the poet does not tell the audience this.

Although the particle offers only a very partial approach to Homeric ToM, it is a potentially useful one, and a consideration of how characters think about others' thoughts may help clarify some uses of the particle. For this paper, examples will be drawn from the Iliad, except where I am looking at word combinations for which it is necessary to collect all possible examples. $\tilde{\eta}$ 's uses are

5 Critiques of the Snell/Voigt model include Harrison 1960, Gaskin 1990, and especially Schmitt 1990.

6 Lillard 2006 summarizes studies of cultural difference.

7 Sullivan 1988; Jahn 1987 argues that the formulaic system is the main determinant of which terms are used. Clarke 1999, especially 53-69, is helpful.

8 So the analysis of Pelliccia 1995 is very different from that of Williams 1993.

9 For example, Taylor 1989, 118 (a very important book in moral philosophy).

10 The New York Times of March 30, 2010 had an article on the subject, with the headline "The Next Big Thing in English: Knowing They Know That You Know." See especially Zunshine 2006 and Leverage et al. 2011.

11 Kirk 1985-1993 on Il. 1.334-5. 
customarily divided into affirmative and interrogative, though these are not entirely straightforward categories, and the interrogative is a specialized use of the affirmative. It is straightforward that $\tilde{\eta}$ is a word of character-speech. There are only a handful of examples of uncombined $\tilde{\eta}$ from the Iliad's narrator. ${ }^{12}$

Ruijgh proposed that $\tilde{\eta}$ works in opposition to ou. ${ }^{13}$ It affirms what a listener might be inclined to doubt or deny. Wakker (examining tragedy, however, not Homer) sets $\tilde{\eta}$ in contrast to $\mu \eta \dot{\eta} v$ : $\mu$ 'v affirms the sincerity of the speaker, while $\tilde{\eta}$ insists on the external truth of the speaker's claims. ${ }^{14}$ If $\tilde{\eta}$ tends to be used where the listener might be inclined to doubt, it indicates that the speaker senses the likelihood of doubt. The particle therefore has a basic connection with ToM. Yet a speaker can use affirmative $\tilde{\eta}$ when speaking to himself- the doubt can be his own.

$\tilde{\eta}$ often appears in questions or statements that involve ToM claims, and is also found with inferences, evaluations, statements about the future, and promises. It is only rarely used when knowable facts, such as past events, as at issue.

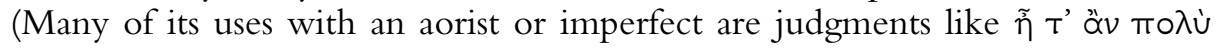

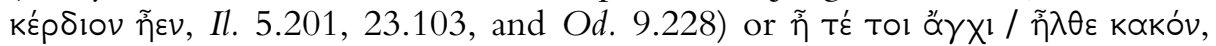
$11.362,20.449$, where a speaker interprets events.) Rather it points to the external realities that justify the speaker's perception or judgment; hence it often appears with $\mu \alpha^{\prime} \lambda \alpha, \mu \dot{\varepsilon} \gamma \alpha$, or To $\lambda_{u}$. The reality itself is not open to doubt, but the speaker's evaluation of it is. The particle only rarely affirms the truth of what could actually be known, but insists on the rightness of inferences, pre-

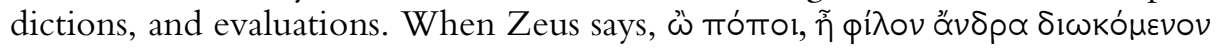

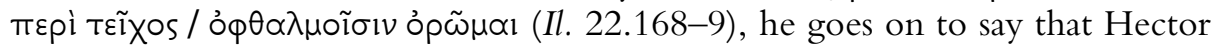
offered many sacrifices. ${ }^{15}$ Zeus does not emphasize the truth of what he says because he worries that anyone will doubt that he cares about Hector, but he asserts that his feeling is based on good reasons. Hector is not only dear to Zeus, but deserves to be. Similarly, the combination $\tilde{\eta} \tau \varepsilon$ is used mainly apodotically or in sentences that, in Ruijgh's formulation, "exprime un fait plus ou moins hypothétique."16

Homeric speakers use the combination $\tilde{\eta}$ i $v \propto$ to follow a question about another's motives by proposing an answer. These proposed answers (which are normally punctuated and understood as rhetorical questions) make mindreading claims. The epic corpus presents five examples of $\tilde{\eta}$ ívo. All belong to a recognized category for interrogative $\tilde{\eta}$ - the pattern in which a speaker asks

12 This is not true of all its combinations, such as $\tilde{\eta}$ Tol, which indicates that they are appropriately treated separately. Frazer 1981 examines $\tilde{\eta}$ tol in self-corrections. This paper will not consider $\tilde{\eta}$ Tol.

13 Ruijgh 194-5 (paragraph 187).

14 Wakker 1997.

15 Richardson in Kirk 1985-1993 ad loc (p. 126) points out that $\varphi^{i} \lambda \circ v$ ö $v \delta \rho \alpha$ is a unique expression with strong emotional weight.

16 Ruijgh 1971, 798, (paragraph 655). 
about someone's motives, and then proposes an answer to the question. ${ }^{17}$ All are sarcastic, but the sarcasm is of different kinds. ${ }^{18}$ When Odysseus asks Athena why she sent Telemachus to look for his father instead of telling him the truth, he asks:

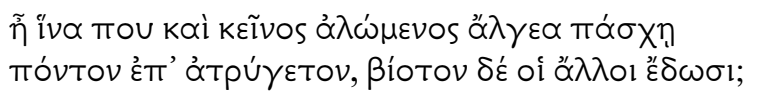

(Od. 13.418)

Odysseus surely does not believe that Athena sent Telemachus abroad for these reasons- rebuking Athena, implying that a neutral observer would think she had sent Telemachus to travel in order to make him suffer and cause further damage to his property, and that her real motive was inadequate. He has already pointed out that she did not help him during the Adventures (Od. 13.316-19), and she has excused herself by saying that she did not want to fight with Poseidon (Od. 13.341-3). Odysseus may not be fully satisfied by her explanation. Similarly,

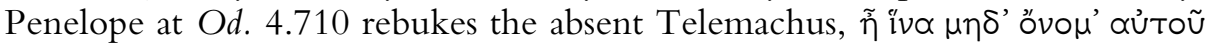

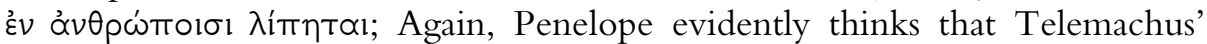
actual motive cannot have been adequate. Here, Athena's motive for having him travel is exactly the opposite of Penelope's sarcastic guess. Zeus, remarkably, speaks similarly of his own motives for giving immortal horses to Peleus at

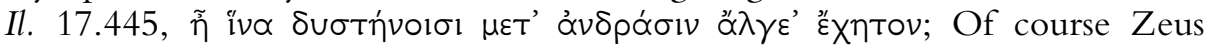
knows that he acted to honor Peleus, not to cause suffering to the horses, but he expresses his dismay at the consequences that he failed adequately to consider. ${ }^{19}$ At Il. 1.203 when Achilles asks why Athena has come from Olympus-

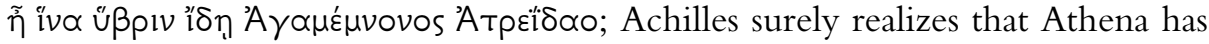
not pulled his hair and spun him around because she has come to see Agamemnon's hybris. He, like Odysseus, uses the formula in (subtle) rebuke, but in this instance he implies that the motive he names ought to be her reason, although it is not.

Finally, Apollo asks Athena why she has come from Olympus to the Trojan battlefield:

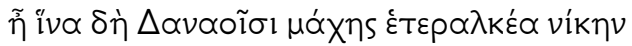

$\delta \tilde{\omega}$ s;

(Il. 7.26-7)

Athena has indeed come to help the Danaans, and Apollo is sincere in stating what he infers about her motives. However, he is, like the other speakers,

17 Denniston 1954, 283.

18 BK on Il. 1. 203. says "nicht selten ironisch."

19 Griffin 1980, 190, points out that Zeus seems to be more distressed for the horses than for Patroclus. 
criticizing the motive, as he makes clear-Athena should pity the Trojans, but does not.

A speaker who makes a rhetorical point by imputing a false motive to the interlocutor is very confident, since the speech would badly misfire if the real motive were accidentally named. There is real ToM behind the false allegations. Still, Odysseus' and Achilles' implied rebukes of Athena, and Penelope's of Telemachus, are not just unfair, but say more about the speakers than about those who motives appear to be in question. Penelope is resisting Telemachus' new maturity, while Achilles does not want Athena to interfere with his decision whether to kill Agamemnon. Odysseus may or may not know Athena's real motives, but he attributes the desire to make Telemachus suffer to Athena not only as a complaint about this action, but because he resents her failure to

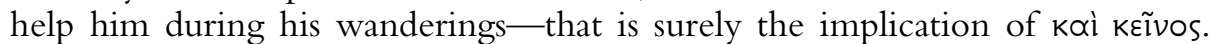
Odysseus has just overtly complained about her earlier absence. She has excused herself, explaining that she did not want to fight with Poseidon (Od. 13.314-28, 338-43). Odysseus, evidently, is still (not surprisingly) resentful. In all these instances, the characters protest from a limited and local viewpoint. Apollo is correct about Athena's desire to help the Danaans, but she could just as fairly have complained that he pities only the Trojans. Only a few lines later, he implies that Troy is doomed only because "you two goddesses" wish it to be (30-32), with no acknowledgment of the will of Zeus.

$\tilde{\eta}$ is also found in other examples that show the Homeric characters' ToM in action. Some, like the cases with iv $v$, ironically impute motives that the speaker knows are false. Achilles angrily asks Odysseus during the Embassy:

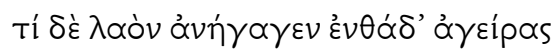

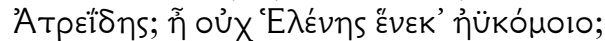

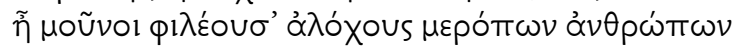

Aттеїठळl;

$$
\text { (Il. 9.338-40) }
$$

The first $\tilde{\eta}$ introduces a straightforward and sincere alleged motive. The second is more complex. At least one other premise is assumed between the two questions: ["Why did he take away my wife?] However, since the point at issue is the inconsistency in Agamemnon's actions, Achilles must be aiming his second question too at Agamemnon's motives: he is not really asking whether only the Atreidae love their wives, but whether Agamemnon believes this to be true (and of course he knows that Agamemnon does not believe this).

Questions often precede such imputations of false motives. For instance, Agamemnon asks the Achaeans at Il. 4.242-6 why they are not fighting, and compares them to fawns. Then he complains:

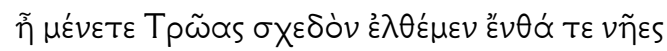

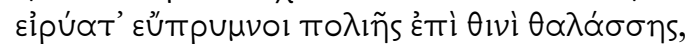

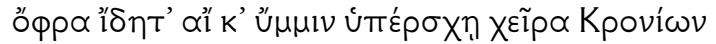

$$
\text { (Il. 4.247-9) }
$$


Similarly, Athena first asks Ares if he has not heard what Hera has just said (Il. 15.130-31) and then rebukes him at 15.132-3:

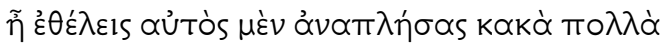

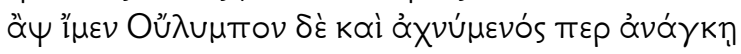

A question is not the only way to introduce this kind of speech, however. For example, Aias exhorts the Achaeans to valor, and then complains to them at Il. 15.504-5:

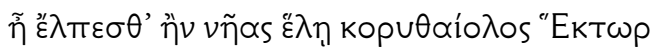

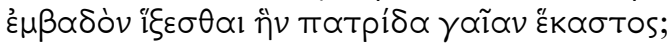

All these beliefs and intentions are absurd, but Homeric rebukes are not supposed to be "fair." Here the false and absurd suggestions about the interlocutors' intentions are not expressions of the speaker's beliefs about the others' thoughts. Instead, they express the speaker's own anxieties. Athena, for example, continues her rebuke of Ares:

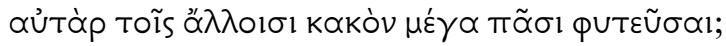

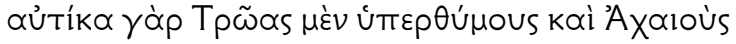

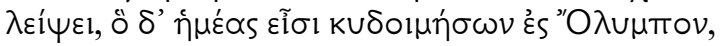

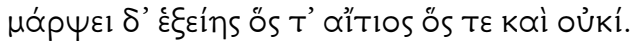

Unmistakably, Athena is more concerned for herself than for Ares, putting into his mind as a possible desire ( $(\dot{\varepsilon} \theta \dot{\varepsilon} \lambda \varepsilon 15)$ the consequence she hopes to avoid. While Athena does not say anything explicitly about what Zeus will think or feel, she can predict how he will act if Ares intervenes. She may be relying simply on past experience, not claiming any insight into Zeus' mental life but inferring future behavior from a pattern that she perceives.

$\tilde{\eta}$ also, as we have seen at Il. 7.26-7, introduces sincere Theory-of-Mind claims. Agamemnon at Il. 1.131-2 accuses Achilles of trying to trick him with the proposal that Agamemnon wait for the capture of Troy to obtain a replacement prize, but that he will then receive three or four times as much (Il. 1.122-9). He continues:

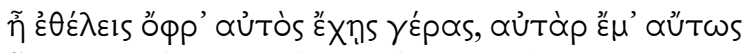

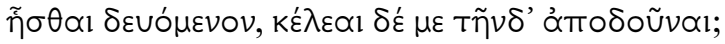

(Il. 1.133-4)

This is surely what Agamemnon believes Achilles wants, and he is, in a sense, right. The solution Achilles is proposing would leave Agamemnon with no prize, while Achilles still had his. Agamemnon's formulation, however, is highly emotional, marked by the contrast between Achilles and himself in aưtóp

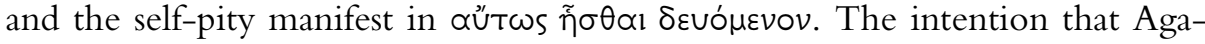
memnon attributes to Achilles is not just a particular policy, but a wish to humiliate Agamemnon. Because he would find the outcome of this proposal humiliating, he assumes that it was Achilles' intention that he should be humil- 
iated. There is no reason to think that Achilles actually intends his suggestion this way, or that he anticipated Agamemnon's response; Achilles presumably assumes that the promise of multiple recompense later is a sufficient counterweight to immediate loss. Agamemnon fails to read Achilles' mind adequately, but his failure also hints that Achilles has failed to read Agamemnon's mind adequately.

Sometimes, this emotional component in Theory-of-Mind passages fully

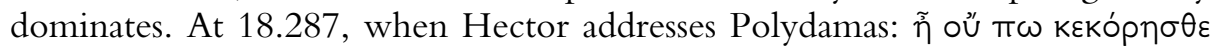

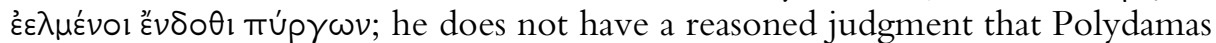
finds the siege less frustrating than others, nor is he falsely suggesting that he thinks this. In his anger that Polydamas disagrees with his plans, he finds it impossible to imagine that anyone who shares his experience of the siege can be opposed to his attempt to end it. Here, again, no question precedes 287, but instead we have the statement that Hector is unhappy with Polydamas' advice (Il. 18.285-6. The most extreme example of such pseudo-Theory-ofmind is Priam's hysterical treatment of the Trojans who come to comfort him:

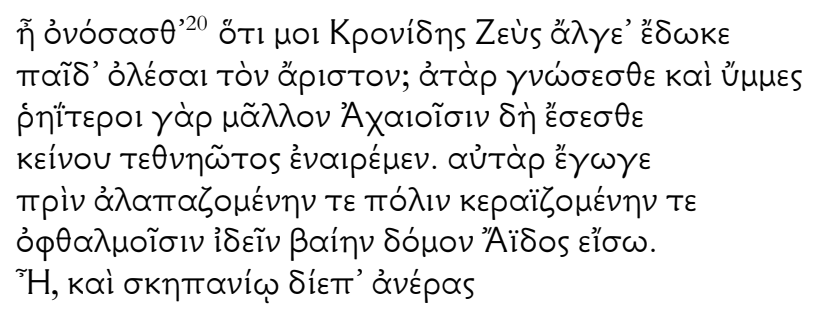

$$
\text { (Il. 24.241-7) }
$$

Priam, of course, knows that the Trojans know all this as well as he does. He is simply using criticism of the Trojans as a focus for his undirected anger and fear.

Even when a guess at another's intentions is almost accurate, it is colored by the speaker's own attitudes. Hecuba uses the $\tilde{\eta}$ of suggested response when she sees Hector in the city:

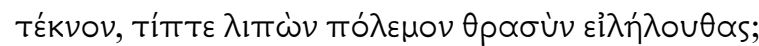

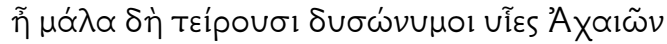

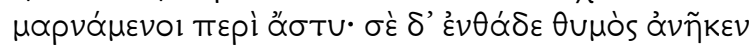

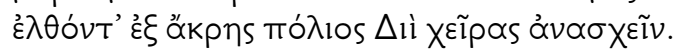

$$
\text { (Il. 6.254-7) }
$$

This is not punctuated as a question, but it is not really distinguishable from the suggested responses that editors treat as questions. Hecuba clearly believes that she understands why Hector has left battle, since she offers her son wine as

20 This is the reading of Aristarchus; the paradosis is oü $v \varepsilon \sigma \theta^{\prime}$. West daggers (see West 2001, 278); $B K$ ad loc. follows the analogy with $O d$. 17. 378-9, which is similarly sarcastic. 


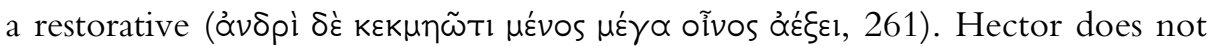
actually seem to feel especially tired (and he disagrees with her about the effects of wine, 264-5). The listener knows that Hecuba has generally the right idea, but is wrong in detail, Hector's own thymos has not inspired his visit to Troy, but rather advice from Helenus. He does not intend to go himself to the acropolis to pray, but to send the women. The prayer is not to be directed to Zeus, but to Athena. We may guess that Hecuba assumes that Hector is tired because she is his mother. As in other examples, the speaker's own situation influences how that person considers the mental lives of others. Her other errors of detail are even more subtle reflections of how one person's understanding of both other individuals and of the broader situation affect the operations of theory-of-mind. Hecuba knows Hector well enough to realize that a need for prayer is the likeliest cause of his departure from the battlefield, since he is too responsible a leader to come to the city for any less important a concern. She has no way, however, of knowing about Helenus' advice to Hector. Because she has such respect for her son, she automatically assumes that his decision to come into Troy was spontaneously and entirely his own, and she automatically assumes that he will want to pray to the greatest of the gods.

We can see the same technique in passages where editors place affirmative rather than interrogative $\tilde{\eta}$ at the introduction of a a theory-of-mind assertion. For example, Hector's famous false assumption about Patroclus:

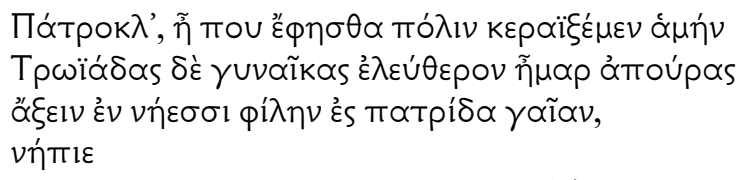

(Il. 16.830-33)

Striking here, as in the earlier examples, is how Hector describes what Patroclus expected in terms that are obviously those of his own imagination. Hector says that Patroclus imagined enslaving the Trojan women because that is his own worst fear; Patroclus himself might have amplified the basic idea "take Troy" very differently.

If, in Iliad 1, Agamemnon distorts what Achilles desires, Achilles is not conscientious in his reconstruction of Agamemnon's thinking, either. He says that Agamemnon has "the heart of a deer"—-that is, that he is cowardly—and claims that Agamemnon avoids going into battle or joining ambushes with the other Achaean leaders (Il. 1.225-8). He then adds a motive for Agamemnon's avoidance of danger:

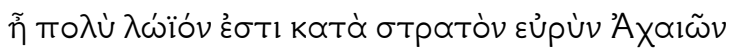

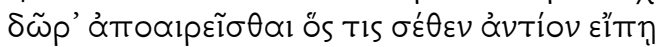

(Il. 1.229-30)

Affirmative $\tilde{\eta}$ is often found with adjectives or adverbs, like moגu here. But there can be little doubt that Achilles is not making a general statement about 
the best course of action for anyone, but asserting that he understands how Agamemnon thinks. He connects Agamemnon's alleged cowardice with his alleged greed and his behavior now, implying a coherent strategy that Agamemnon follows. While others increase their booty by themselves fighting to win it, Agamemnon has realized that he can more easily obtain goods by taking them away from anyone who opposes him. Since such a strategy would be imaginable only for Agamemnon, Achilles is engaging in ToM. He probably is not seriously proposing that Agamemnon has such a strategy, however. The rest of the poem will prove that the accusation of cowardice is, at best, exaggerated. Instead, he wants to emphasize that Agamemnon's threat to take his prize belongs in such a strategy. Whether or not Agamemnon actually thinks this way, he is acting as if he did. Affirmative $\tilde{\eta}$ does not indicate genuine belief in the truth of what is asserted, but directs the audiences (internal and external), to the speaker's irony.

When Helen again pretends to imagine Aphrodite's intentions, the situation is slightly different, but again the function of ToM, even when it is accurate, is to reveal the speaker's concerns. Aphrodite, in disguise, has urged Helen to go to Paris, so Helen knows exactly what her immediate intentions are. Helen uses the $\tilde{\eta}$ of a proposed motive:

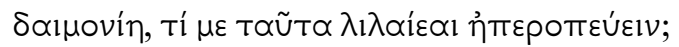

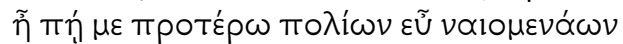

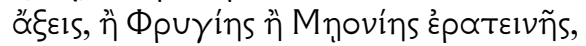

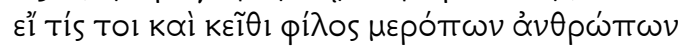

$$
\text { (Il. 3.400-402) }
$$

Indeed, she continues by proposing a true answer to her question:

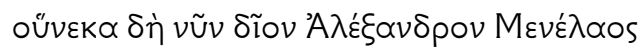

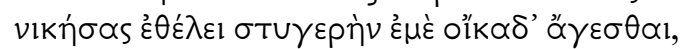

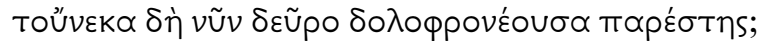

$$
\text { (Il. 3.403-5) }
$$

The falsely imputed intention expresses Helen's broader frustration at being a tool for Aphrodite.

When Hector rebukes Paris for retreating before Menelaus, he reconstructs the likely Achaean reaction:

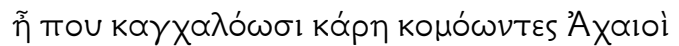

фóv

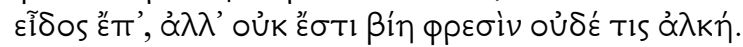

(Il. 3.43-5)

The audience has no way of knowing whether the Achaeans have indeed been brought to laugh out loud at the absurdity of selecting a leader for his good looks. The bad behavior of Paris is probably more salient to Hector than it is to the Achaeans, but Hector is not really talking about what the Achaeans 
actually think, but what he would think if he were in their position, and what Paris is giving them the opportunity to think.

This pseudo-theory-of-mind can be somewhat more complex. Nestor, speaking to Patroclus, issues a rebuke to Achilles that sounds very much like the just-cited examples from the battlefield, but in the third person:

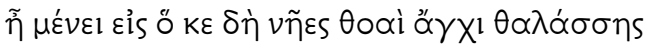

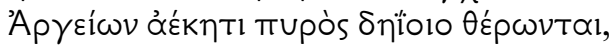

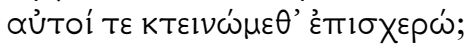

$$
\text { (Il. 11.666-8) }
$$

Nestor surely intends this complaint in the same spirit as Agamemnon and Aias mean theirs. From his point of view, this is a reductio ad absurdum of Achilles' behavior. Achilles, however, has announced to the Embassy that this is precisely what he intends, since he will fight only when Hector reaches his own ships (Il. 9.650-53). Nestor, however, does not know that Achilles said this, since Odysseus reported only his first speech. Achilles himself refers back to his earlier statement at 16.61-3. So Nestor thinks he is falsely attributing an intention to Achilles when he is describing his intentions fairly accurately. After his narrative, he will propose the exchange of armor to Patroclus in the case that Achilles wants to help the Achaeans but is prevented by a prophecy (11.794803). The condition does not apply, but Achilles will apply the suggestion for his own purposes. Nestor seems to find Achilles incomprehensible.

Sometimes it is hard to judge's a character's speculations about another character's thoughts. Achilles addresses Aeneas on the battlefield, using the $\tilde{\eta}$ of a suggested reply:

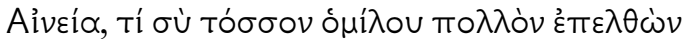

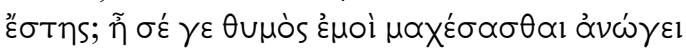

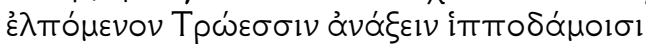

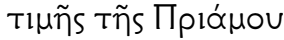

$$
\text { (Il. 20.178-81) }
$$

Since Achilles continues by arguing that such an expectation would be utterly unrealistic, he seems actually to believe that Aeneas could have such a hope. He continues with the alternate possibility that Aeneas is motivated by the hope of an exceptionally fine temenos if he kills Achilles; he responds to this possibility by arguing that Aeneas will not find it easy to kill Achilles. Achilles seems to realize that he simply does not understand why Aeneas would fight him. He has, of course, no idea that Apollo in disguise has prompted Aeneas (and that Aeneas expressed his reluctance before being persuaded, Il. 20.79111). At the end of the episode, Achilles uses a doubled $\tilde{\eta}$ to express his perplexity at Aeneas' rescue: Aeneas' disappearance is truly a great wonder (20.344) and, contrary to Achilles' assumptions, Aeneas turns to be truly dear to the gods (20.347-8 of). There are limits on Achiles' understanding of other people and of the world. 
Both affirmative and interrogative $\tilde{\eta}$, then, appear regularly in theory-ofmind passages - but these passages suggest that Iliadic characters are either not very interested in accurately commenting on the mental lives or others, or they are more concerned with their own purposes-probably the latter. However, sometimes speakers use expressions with $\tilde{\eta}$ to offer support for their theory-ofmind inferences. Nestor, for example, uses the particle twice when he considers the consequences of the quarrel between Achilles and Agamemnon:

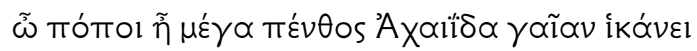

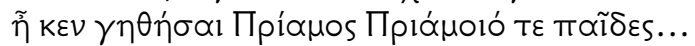

(Il.1.254-55)

Nestor can have no direct knowledge of how the news of the quarrel will be received at home, and indeed he speaks as if the information were being transmitted instantaneously. In contrast, he uses the optative to distance the

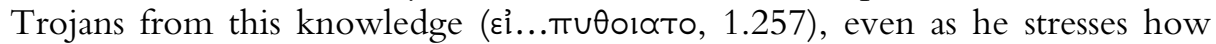
precisely he can predict their response. However, this inference about the Trojans justifies the claim that grief is coming to Achaea. Then, by pointing out that Agamemnon and Achilles are pre-eminent in both fighting and counsel (258), he explains why he is so certain that the news of the quarrel would please the Trojan rulers, and this explanation then further justifies his claim that great grief is coming to Achaea.

Nestor repeats this structure in his rebuke to the Achaeans for failing to respond to Hector's challenge:

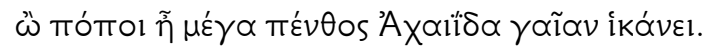

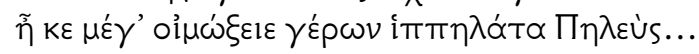

$$
\text { (Il. 7.124-5) }
$$

The optative speculation about Peleus' response justifies the statement that great grief is reaching Achaea. He then explains that he has personal knowledge from which he can judge Peleus' likely reaction to the leaders' failure to answer Hector's challenge (7.126-8), having witnessed Peleus' delight in asking about the ancestry of the Argives participating in the Trojan expedition.

$\tilde{\eta}$, even when the sentence it introduces does not make a theory-of-mind claim or conjecture, most often appear at this boundary where an individual, internal judgment meets the external world-or the judgments of others. Only occasionally does it insist on a fact. Affirmative $\tilde{\eta}$ frequently follows $\ddot{\omega}$ Tómol, as it does in the lines just cited, where it insists on the speaker's accuracy in insisting not just that grief is coming to Achaea, but that this grief is great. In another example of sequential $\tilde{\eta}$, Aias addresses Hector:

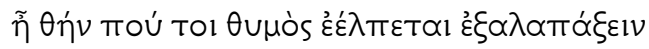

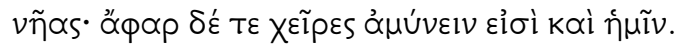

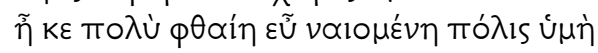

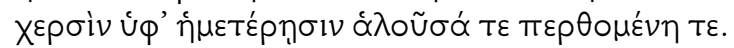

(Il. 13. 813-6) 
The first $\tilde{\eta}$ introduces a sincere and accurate theory-of-mind statement about Hector's beliefs, the second the speaker's evaluation of the likely outcome. Achilles greets the embassy with two $\tilde{\eta}$-statements:

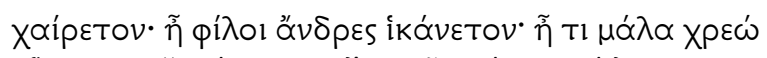

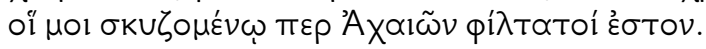

(Il. 9.197-8)

The first $\tilde{\eta}$-statement reassures the visitors that Achilles recognizes their status as his friends. It indicates his understanding that they are uncertain of his attitude. The second marks his judgment of their action in coming to see him, and suggests that he shares the view that he believes they have themselves.

Interrogative $\tilde{\eta}$ is likewise closely associated with issues of mind, even outside the "suggested motive" use. It typically attempts to establish a shared understanding between speaker and interlocutor in a situation where the basis for such shared understanding already exists, but a shared interpretation needs to be established. When Athena urges Pandarus to shoot Menelaus and Helenus

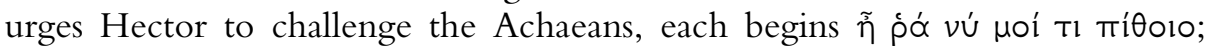
$(4.93,7.48)$. Each follows the initial request with a reason why the interlocutor

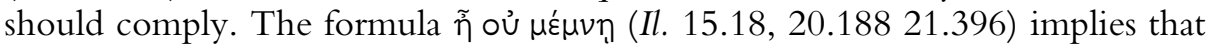
the interlocutor does and should remember a relevant episode in the past. Nestor says to Diomedes:

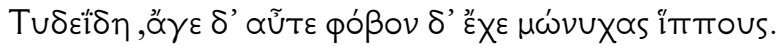

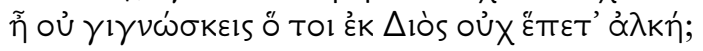

(Il. 8.139-40)

Nestor, of course, knows that Diomedes can recognize Zeus' hostilitythunderbolts have fallen directly in front of his chariot - but he needs to overcome Diomedes' resistance to retreating.

Epeius, boasting that he will win the boxing match, complains:

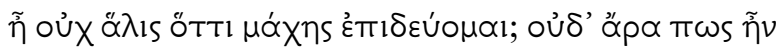

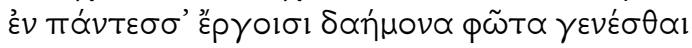

$$
\text { (Il. 23.670-71) }
$$

He appeals to common knowledge that he is not a warrior of the first rank. $\mathrm{He}$ knows that they all know. His implied argument seems to be:

Major premise: Nobody is good at everything (but, by implication, everyone is good at something)

Minor premise: I am not good in battle, as everyone knows

Conclusion: I am good at something else (namely, boxing). $\tilde{\eta}$ marks this essential shared knowledge.

In other passages, the particle demands an interlocutor's agreement to an unhappy speaker's resentful interpretation of events. Agamemnon complains to Zeus: 


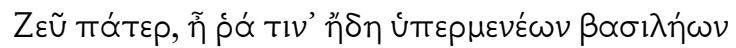

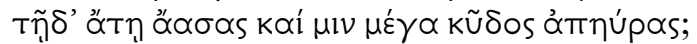

$$
\text { (Il. 8.236-7) }
$$

This is closely comparable to Thetis' complaint to Hephaestus:

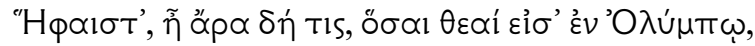

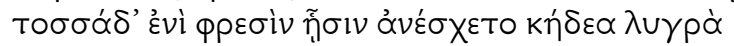

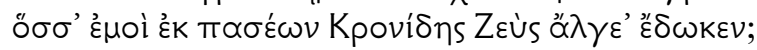

(Il.18.429-31)

Agamemnon goes on to remind Zeus of his many sacrifices and to pray that he save the Achaeans, if not the ships; Thetis catalogues her miseries. These are not real questions, of course, but complaints and requests for sympathy. This interrogative $\tilde{\eta}$ is very close to the affirmative, since the speaker seeks agreement not about what has taken place, but about his interpretation of it as worse than what has happened in any comparable case. These questions could not be called theory-of-mind claims, but they indicate that the speaker expects a certain receptivity from the interlocutor, a receptivity that $\tilde{\eta}$ seems to demand.

\section{Addendum:}

Finally, there are the cases in which the narrator uses the particle: 13.354, 16.362 and 16.46 , as well as the two where he uses $\tilde{\eta} \tau \varepsilon$. In two of the examples, the particle appears to have been borrowed from the character, and the phenomenon is close to free indirect discourse. At 16.362-3, Hector realizes that battle has turned in favor of the Achaeans, but fights in order to let the other Trojans retreat:

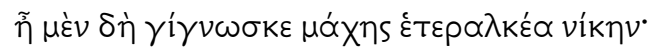

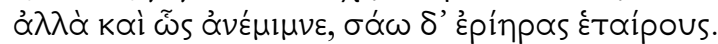

The lines are about his mental state, and $\sigma \alpha \dot{\alpha} \omega$ is surely conative. At 13. 353-6, Poseidon intervenes against Zeus' will:

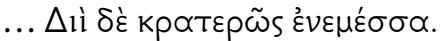

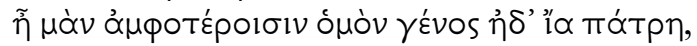

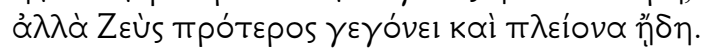

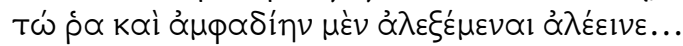

These lines anticipate 15.185-204, when Poseidon complains that Zeus is arrogating too much power (in effect expanding 13.354), while Iris reminds him that Zeus is older (echoing 13.356). The $\tilde{\eta}$-statement follows a description of Poseidon's emotional state and is followed by a line from which it is explicit that this view of Zeus explains why Poseidon acts as he does. Yet would Po- 
seidon express his awareness of Zeus' greater power as an admission that Zeus "knows more" than he? In both these passages, there is evidently some contamination between the narrator's voice and the character's thoughts-it is FID, although the language is the narrator's. ${ }^{21}$ I would not call it characterfocalization, but $\tilde{\eta}$ is as much Hector's and Poseidon's word as the narrator's.

The other examples, however, indicate a very different situation in which the narrator uses the particle of character-speech.

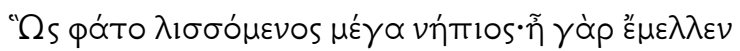

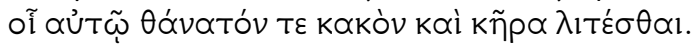

$$
\text { (Il. 16.46-7). }
$$

Here the narrator is commenting precisely on what the character does not know but the narrator does; if, as I am arguing, $\tilde{\eta}$ affirms the truth of speech mainly when genuine proof is not possible, this would seem to be an extraordinary exception.

This is the only Iliadic example of the particle with a form of $\mu \dot{\varepsilon} \lambda \lambda \omega \omega$. The Odyssey has parallels, however. Although it uses $\tilde{\eta}$ Tol, Od. 22.98 may help explain the usage at $I l .16 .46^{22}$. The narrator first informs the audience that Antinous expected to be able to succeed in the bow-contest (Od. 22.96-97), and then explains how wrong he was:

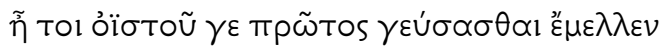

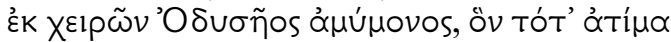

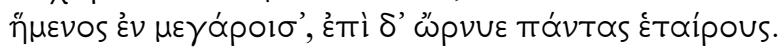

(Od. 22.98-100)

As in the comment on Patroclus, the narrator here notes the character's inability to foresee the consequences of his action. The narrator of the Odyssey does not use the word $v$ ńmios here, because Antinous has just introduced it into the hearer's mind by saying that as a small child, he saw Odysseus, móiis $\delta$ ' हैं $v \eta \dot{n} \pi$ los $\tilde{\eta} \alpha(O d .22 .95)$. The irony is obvious, and the narrator does not need to repeat the word in his own voice.

Two of the narrator's uses of $\tilde{\eta}$ with है $\mu \varepsilon \lambda \lambda \varepsilon v$, then, explain why the character is a vímios. Even though the sentence in which the particle is used appears to be a statement about past facts, it serves to defend the narrator's evaluation of the character. The Homeric narrator never calls a character vímios without an explanation of why the judgment is justified, which suggests that these evaluations do not belong to the objective knowledge bestowed by the Muses. ${ }^{23}$

21 For the problems of FID, see Fludernik 1993, 398-414.

22 In four of the five, the form of $\mu \dot{\varepsilon} \lambda \lambda \omega$ stands at verse-end, as it does in the formula

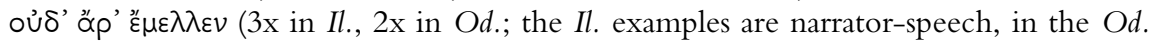
Odysseus comments with hindsight). See de Jong 2001, 251.

23 Fränkel 1976, 41 note 31, claims that this is objective knowledge. 
They express the narrator's pity for mortal ignorance. ${ }^{24}$ Even an $\varepsilon$ है $\mu \lambda \lambda \lambda_{\varepsilon v-}$ statement of this kind is not necessarily spoken with the poet's special authority. As a prolepsis, it depends on the poet's knowledge of the plot. However, these passages stress a character's ignorance, implying that the outcome was already a real possibility, not beyond the power of the character to foresee, had the character not been, as mortals characteristically are, unaware of the wider context of his choices.

We can compare the instances with $\tilde{\eta} \tau \varepsilon$ in the narrator's voice: Il. 16.687 and 17.236. 16.687 again concerns Patroclus. He was a vímıs (16.686), for he

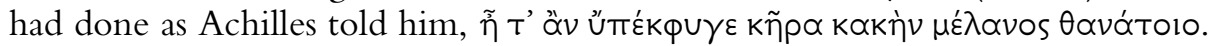
In Il. 17.236, the narrator is commenting on the folly of the Trojans, who fully expected to be able to take the corpse of Patroclus from Aias, vทंmiol; instead he killed many of them. Although this line provides one of the relatively rare instances of the particle to mark an indubitable past fact, the line is still close to a condition-if the Trojans had been wise, these men would not have died.

\section{Bibliographie}

BK: Latacz, J., Homers Ilias: Gesamtkommentar. Auf der Grundlage der Ausgabe von AmeisHentze-Cauer (1868-1913) (München2000)

Clarke, M., Flesh and Spirit in the Songs of Homer: a study of words and myths (Oxford 1999).

Denniston, J. D., The Greek Particles. (Oxford ${ }^{2} 1954$ ).

Doherty, M. J., Theory of Mind: how Children Understand Others' Thoughts and Feelings (Hove 2009).

Fludernik, M., The Fictions of Language and the Languages of Fiction. The lingustic representation of speech and consciousness. (London - New York 1993).

Fränkel, H., Dichtung und Philosophie des frühen Griechentums: eine Geschichte der griechischen Epik, Lyrik und Prosa bis zur Mitte des fünften Jahrhunderts (München 1976/1962).

Frazer, R. M., „Corrective ฑैтol in Homer and Hesiod.“ Mnemosyne 34 (1981) 265271.

de Jong, I. F., A Narratological Commentary on the Odyssey (Cambridge, UK 2001).

—, Narrators and Focalizers: the presentation of the story in the Iliad. (Amsterdam 1987).

Gaskin, R., „Do Homeric Heroes Make Real Decisions?“ CQ 40 (1990) 1-15.

Griffin, J., Homer on Life and Death. (Oxford 1980).

—, „Homeric Words and Speakers“. JHS 106 (1986) 36-57.

Harrison, E. L., „Notes on Homeric Psychology“, Phoenix 14 (1960) 63-80.

Jahn, T., Zum Wortfeld ,Seele-Geist’ in der Sprache Homers (München 1987).

24 Griffin 1986, 40; de Jong 1987, 86-7. Griffin thinks that the narrator can use the word in this unusually evaluative way because it can also be used to mean "small child." 
Kirk, G. S. et al., The Iliad, a commentary (Cambridge 1985).

Leverage, M. et al., Theory of Mind and Literature (Purdue 2010).

Liliard, A., „The Socialization of Theory of Mind: Cultural and Social Class Differences in Behavior Explanation." In A. Antoniette, O. Liverta-Sempio, and A. Marchetti, eds. Theory of Mind and Language in Developmental Contexts (New York 2006).

Mumford, D. B. „Somatic Symptoms and Psychological Distress in the Iliad of Homer." Journal of Psychosomatic Research 41 (1996) 139-48.

Pelliccia, H., Mind, body, and speech in Homer and Pindar. Hypomenmata 107 (Göttingen 1995).

Premack, D. G. / Woodruff, G., „Does the chimpanzee have a theory of mind?“ Behavioral and Brain Sciences 1 (1978) 515-26.

Ruijgh, C. J., Autour de te épique: études sur la syntaxe grecque. (Amsterdam 1971).

Schmitt, A., Selbständigkeit und Abhängigkeit menschlichen Handelns bei Homer: hermeneutische Untersuchungen zur Psychologie Homers (Mainz 1990).

Snell, B., Die Entdeckung des Geistes: Studien z. Entstehung d. europ. Denkens bei d. Griechen. 4., neubearb. Aufl. (Göttingen: ${ }^{4} 1975$, first edition 1948).

Snell, B.. Lexikon des frühgriechischen Epos. (Göttingen 1955-2010).

Sullivan, S. D., Psychological Activity in Homer: a study of phrēn (Ottawa 1988).

Taylor, C., Sources of the Self: the making of the modern identity (Cambridge, Mass. 1989).

Voigt, C., Überlegung und Entscheidung: Studien zur Selbstauffassung des Menschen bei Homer (Berlin-Charlottenburg 1934).

Wakker, Gerry., „Emphasis and Affirmation. Some Aspects of $\mu \dot{v}^{\nu}$ in Tragedy“ in: A. Rijksbaron, New Approachs to Greek Particles. (Amsterdam 1997).

West, M. L., Studies in the text and transmission of the Iliad (München 2001).

Williams, B., Shame and necessity (Berkeley 1993).

Zunshine, L., Why We Read Fiction: theory of mind and the novel (Columbus 2006). 


\title{
Ilias diachronica: \\ Zur sprach- und versgeschichtlichen Analyse des $\Xi$
}

\author{
EVA TICHY
}

Für Christoph Michel

Der Beitrag will zweierlei zeigen: erstens, warum es gut ist, für die Erklärung der Ilias außer dem (weitgehend) gesicherten sprachhistorischen Wissen auch noch eine metrische Entwicklungshypothese zur Hand zu haben, und zweitens, wie sich mit einer kombinierten sprach- und versgeschichtlichen Methode empirische Homeranalyse betreiben lässt.

1. Unter Homerforschern ist man sich darin einig, dass die Ilias Altes und Junges enthält, ob man dabei nun eher Sprachformen oder eher Erzählmotive und das Heldenpersonal im Blick hat. Zum einen überlagern sich zwei Sprachsysteme (vom Lautlichen bis hin zur Syntax der Partikeln), ein altepisches, äolisch gefärbtes und ein deutlich jüngeres, das Ionische des 8 . Jahrhunderts, wobei das alte dominiert. Altes und Junges stehen aber auch inhaltlich nebeneinander und durchdringen sich gegenseitig, was sich in sachlichen Unschärfen und einzelnen Widersprüchen äußern kann; derartige Beobachtungen gaben den Anstoß zur Homeranalyse und sind, soweit diese noch in der einen oder anderen Form betrieben wird, auch weiter ihre Grundlage. Mit etwas gutem Willen und dem nötigen Vorwissen sollte sich, möchte man meinen, doch wohl das eine mit dem anderen verbinden lassen. Keine philologische Analyse macht jedoch von der sprachhistorischen Evidenz Gebrauch ${ }^{1}$; warum nicht? Der Grund liegt sicher nicht nur in mangelnder Kenntnis, wie sie bis 1850 entschuldbar war und auch heute wieder gern zugegeben wird, denn in der Zwischenzeit gab es nicht wenige Philologen, die mit der Sprachentwicklung hinreichend vertraut waren. Falls - wie man ebenfalls argwöhnen könnte - eine philologische Schule oder Richtung sich der sprachhistorischen Argumentation verschlossen hätte, um ihr eigenes Homerbild zu bewahren, hätte sich wohl irgendwann ein junger Kopf an einem zeitgemäßen Neuentwurf versucht. Der Grund ist schlicht und einfach der: Es geht nicht.

1 In diese Tradition stellt sich auch Martin West mit seinem 'analytischen Kommentar' (2011, V: ,it does not deal with such matters as the language, metre, or material culture“). Zum Schiffskatalog heißt es später allerdings doch (a.a.O. 112): „Many of the ship lines use the Ionian reduced form véєs and for that reason cannot be very old." 
Die Ilias enthält nicht nur auf weite Strecken, sondern überall Altes, was in traditioneller Dichtung auch nicht auffällt. Zugleich enthält sie aber auch überall Junges: Auf eine sprachlich durchgehend alt wirkende Partie von drei, selten auch einmal fünf oder sechs Versen folgt regelmäßig mindestens ein junger Vers, der entweder den ionischen Digammaschwund voraussetzt oder (als ein Beispiel von vielen) den Genetivausgang -ov in einer Position enthält, wo man man ihn nicht, wie immer vor Vokal, als elidiertes -010 oder ${ }^{+}-\infty$ lesen kann.

Junge Ionismen oder die Vernachlässigung von anlautendem Digamma sind im Hexameter so gut wie immer metrisch notwendig; aus dem Homertext lassen sie sich deshalb nicht eliminieren. Zum Teil sind sie auch offensichtlich durch die Regeln des Hexameters erzwungen; in diesem Punkt verhalten sich homerische Ionismen wie epische Kunstbildungen, von denen sie auch nicht in jedem Fall klar unterscheidbar sind.

Das heißt: Die uns erhaltene homerische Ilias stammt in allen ihren Teilen von Homer, verstanden als ionischer Dichter des 8. Jahrhunderts, der ihr die innere und äußere Struktur verliehen hat. Älteres Material muss er in großem Umfang gekannt haben, doch hat er - außer Einzelversen, hie und da auch Gruppen weniger Verse - nichts davon unverändert übernommen und in sein eigenes Großepos integriert. Eine unitarische Grundhaltung ist also unvermeidlich, auch und gerade im Hinblick auf die Sprachform.

Mit dieser Haltung steht man allerdings wieder vor dem Problem, dessen sprachliche Seite auch die Analyse nicht gelöst, sondern nur ausgeblendet hat: der Frage der historischen Vermittlung aller alten Formen und Inhalte. Wie kann die Ilias so viele mythologische, genealogische, geographische, sachgeschichtliche und nicht zuletzt auch sprachhistorische Informationen bieten, wenn traditionelles Versmaterial, das diese Informationen über die Zeiten transportiert hat, darin gar nicht oder höchstens in kleinen Bruchstücken verwendet ist?

Im Hexameter ist das Übermittlungsproblem nicht lösbar; wegen der überall eingestreuten, metrisch notwendigen Ionismen ist der Hexametertext der Ilias (wie auch der Odyssee) ohne Zweifel als Ganzes jung. Ein Ausweg bietet sich an ungewohnter Stelle: Statt den Hexameter mit den Griechen selbst als gottgegebene, feststehende metrische Grundlage zu betrachten, sollte man zusätzlich zur sprachgeschichtlichen Dimension auch eine versgeschichtliche Dimension mit einbeziehen, genauer gesagt: die sprachhistorischen Erfahrungstatsachen mit einer metrischen Entwicklungshypothese kombinieren.

2. Wer geisteswissenschaftlich zu argumentieren gewohnt ist, wird weder erwarten noch verlangen, dass sich die kombinierte sprach- und versgeschichtliche Hypothese im strengen Sinn beweisen lässt. Sie ist jedoch in eine Methode umsetzbar, bei deren praktischer Anwendung deutlich wird, wieweit sie sich in Fragen des Homertexts und der homerischen Sprache bewährt. 
Den Ausgangspunkt für alles Folgende liefert Nils Berg (1978), der seinerseits auf Wilamowitz' (1921) Erkenntnissen und Sammlungen zu den choriambischen Dimetern aufbaut und über die Hexameter-Diskussion des 19. Jahrhunderts, auch Usener ${ }^{2}$, dadurch schon im Ansatz hinausgelangt. Das silbenzählende Dikolon, von dem er ausgeht - der katalektische choriambische Tetrameter, genannt Priapeus - ist, anders als früher herangezogene Vorläuferverse, von der archaischen Zeit bis zum Hellenismus in allen lyrischen Gattungen belegt. Im Zentrum steht bei Berg die schwierige Frage, wie auf dieser Grundlage der takt- und morenzählende Hexameter zustande kommen konnte. Den anzunehmenden Prozess nennt er Katametronisierung (ich ziehe 'Katametrisierung' vor).

Was mit dem Terminus gemeint ist, zeigt ein einfaches Beispiel. Die Kombination des indogermanischen Achtsilblers $\mathrm{x} \times \mathrm{x} \times \mid \cup-\cup \mathrm{x} \|$ (der durch den Sprachvergleich als grundsprachlich erwiesen ist) mit seiner katalektischen Variante ergibt, wenn der iambische Rhythmus auch außerhalb der Kadenzen überwiegt, ein fünfzehnsilbiges Dikolon der Form:

$$
\bullet-\nabla-|\cup-\cup-\|\nabla-\nabla-\mid \cup-\mathrm{x}\| \text {. }
$$

Durch taktmäßige Gliederung und den wechselseitigen Ausgleich der Freiheitsgrade zwischen den ersten drei Takten - d.h. durch Katametrisierung wird aus diesem lyrischen Vers ein Sprechvers, der katalektische iambische Tetrameter:

$$
\nabla-\cup-|\nabla-\cup-\|\nabla-\cup-\mid \cup-\mathrm{x}\| \text {. }
$$

Die historische Erklärung des Hexameters verläuft nach dem gleichen Prinzip, nur ist von Varianten des lyrischen Dikolons auszugehen, in deren beiden Hälften jeweils ein Choriambus auftrat - den belegten Varianten des Priapeus. In diesen Fällen (oder zumindest einem davon, nach Berg Variante $3 \mathrm{~b}$ ) führte die Katametrisierung zum homerischen Hexameter:

$$
\begin{aligned}
& \text { 1a }|-\cup \cup-|^{-}-\nabla-\|-\cup \cup-\mid \cup-x\| \\
& 2 \mathrm{a} \cup \cup|-\cup \cup-| \cup-\|-\cup \cup-\mid \cup-\mathrm{x}\| \\
& \text { 3a } \square \underline{\cup} \cup-|-\cup \cup-\|-\cup \cup-\mid \cup-\mathrm{x}\| \\
& 1 \mathrm{~b}|-\cup \cup-| \cup-\cup-\| \underline{\cup} \cup|-\cup \cup-| \mathrm{x}|| \\
& 2 \mathrm{~b} \underline{\cup} \cup|-\cup \cup-| \cup-\| \underline{\cup} \cup|-\cup \cup-| \mathrm{x}|| \\
& 3 b-\nabla-\cup|-\cup \cup-\quad\|\underline{\cup} \nabla|-\cup \cup-| x\| \\
& \overrightarrow{{ }^{1}-\underline{U}{ }^{2}{ }^{2}-\left.\underline{U}\right|^{3}-\left.U\right|^{4}-\left.\left.U\right|^{5} \circlearrowleft\right|^{6} \mathrm{x} \|} \text {. }
\end{aligned}
$$

Beim Hexameter ist der Vorgang nicht so leicht nachvollziehbar wie beim iambischen Tetrameter, weil, wie es scheint, die Katametrisierung der in Grenzen variablen Grundlage einen Vers von noch größerer Variationsbreite

2 Die (Bergk-)Usenersche Hypothese kennt man heute eher unter dem Namen Wests (zuletzt wohl 1987, 19). 
ergeben hat. Um ein Verständnis dieser Zusammenhänge wollen wir uns hier gar nicht erst bemühen, sondern lieber ein paar konkrete Beispiele zu Hilfe nehmen. Ein Priapeus vom Typ 2b, den man sich wie alle lyrischen Verse dieser Zeit gesungen vorzustellen hat, steht gleich zu Anfang bei Pindar:

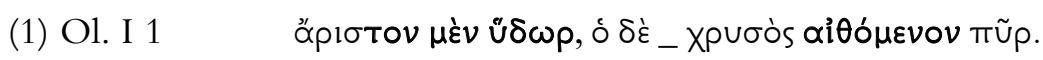

Der Priapeus zeigt, wie man unter anderem an diesem Beispiel sieht, außer den beiden charakteristischen Choriamben (in Fettdruck) auch noch zwei weitere, selten ganz fehlende Strukturmerkmale: erstens die Tendenz, die alte innere Versgrenze (bezeichnet durch Tiefstrich) als Wortgrenze zu bewahren, und zweitens die Tendenz zur ein- oder beidseitigen Abgrenzung der Choriamben gegenüber ihrer Umgebung. ${ }^{3}$

Homerische Hexameter haben im Durchschnitt 15 3\% Silben. Fünfzehnsilbige Verse, in der Ilias immerhin $30 \%$, lassen sich meist unverändert als Priapeen oder, da das Ergebnis mit dem lyrischen Vers nicht völlig übereinstimmt ${ }^{4}$, epische Fünfzehnsilbler lesen, wie z.B. die zweite Zeile an folgender Stelle:

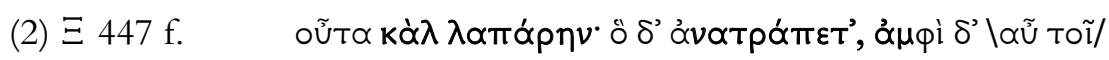

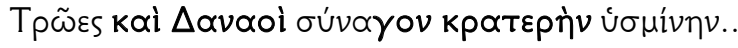

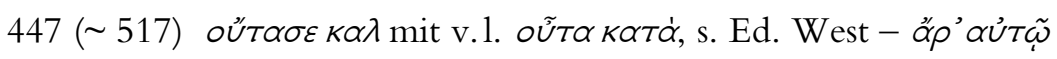

Bei sechzehnsilbigen Hexametern und Holodaktyloi kann oft eine Partikel oder Pronominalform wegbleiben, vgl. Vers 1, 3 und 4 im nächsten Beispiel:
(3) $\Xi 16-20$

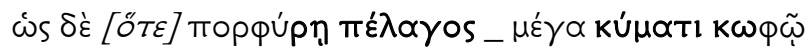

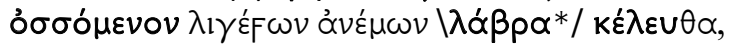

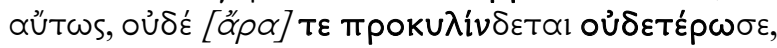

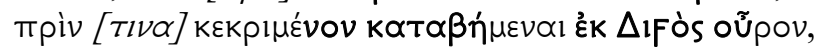

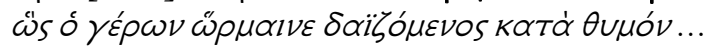

\section{$17 \lambda \alpha \imath \psi \eta \rho \dot{\alpha}$}

Das soeben in aller Kürze vorgeführte Restitutionsverfahren, mit dem sich homerische Hexameter in epische Fünfzehnsilbler zurückverwandeln lassen, ist keineswegs auf alle Verse anwendbar (nicht etwa auf $\Xi 20$, was oben die Kur-

3 Wenn ein Sänger vor oder nach dem Choriambus kurz absetzte oder verzögerte, konnte wortschließender Konsonant auch vor Vokal gleichzeitig silbenschließend sein. Dies erklärt, wenn man homerische Hexameter im Sinne der Hypothese betrachtet,

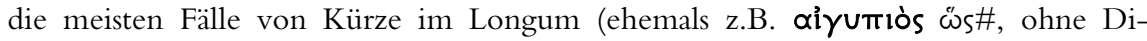

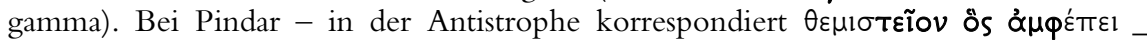

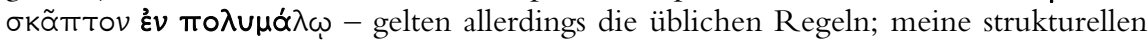
Abgrenzungen decken sich also nur zur Hälfte mit den Silbengrenzen.

4 Der Unterschied liegt in der freieren Besetzung der Ancipitia, besonders der zwei oder vier Silben vor der alten inneren Versgrenze. Diese epische Lizenz lässt sich zum einen aus der Restitutionspraxis ableiten, zum andern bildet sie eine wesentliche Voraussetzung für die historische Erklärung des Hexameters (Tichy 2010, 134 unter e). 
sive anzeigt). Wenn überhaupt, lässt sich die Restitution aber in drei Vierteln der Fälle ohne Schwierigkeiten durchführen. Ein Viertel der Verse kann, wie am Beispiel von $\Xi 448$ (= П 764) gesehen, unverändert übernommen werden; bei der Hälfte genügen leichte Änderungen, die Wortschatz und Semantik nicht betreffen, s. Beispiel (3) mit Ausnahme der zweiten Zeile. Bei dem verbleibenden Viertel muss mit unterschiedlichem Aufwand und Risiko nach plausiblen Lösungen gesucht werden; nicht selten hilft ein Austausch des Epithetons. Obige Restitution von $\Xi 17$ setzt beispielsweise die Annahme

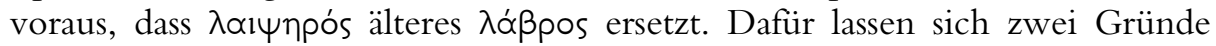
anführen: Erstens ist $\lambda \alpha ́ \beta p o s$ in entsprechender Verwendung für die Ilias belegt

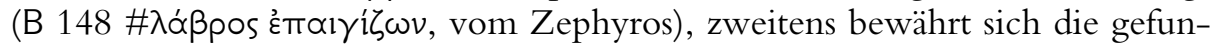

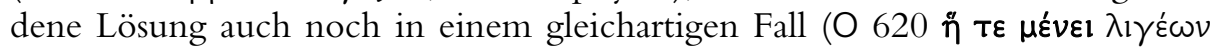

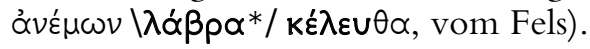

3. Nur weil sich etwas als machbar erweist, muss man es allerdings nicht machen; es kommt immer darauf an, was man damit gewinnt. In diesem Fall entscheiden die Vorteile für die Erklärung des Homertexts und seiner oft uralten sprachlichen Detailprobleme, die es auch nach Abschluss des großen Lexikons noch reichlich gibt. Sehen wir uns die letzten beiden Beispiele daraufhin noch einmal an.

In Beispiel (3), Zeile 3 erscheint őp a als sekundärer, durch die Umstellung auf den Hexameter bedingter Zusatz, der dort das 2. Biceps komplettiert. Für metrisch bedingt hält man hier őp $\propto$ wohl schon immer; jetzt lässt sich konkret angeben, weshalb das (in diesem Fall) semantisch leere Element überhaupt in den Vers gelangt ist.

Weniger harmlos ist ein anderer Fall: In der ersten Zeile von Beispiel (2) darf man, ebenso wie $\Xi 517$, bei sprach- und versgeschichtlicher Restitution

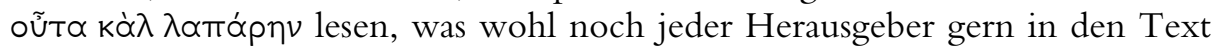
der Ilias gesetzt hätte. Im Hexameter muss man sich jedoch für eine der überlieferten Varianten entscheiden, entweder oũt $\propto$ k $\propto$ tà (so einhellig an der drit-

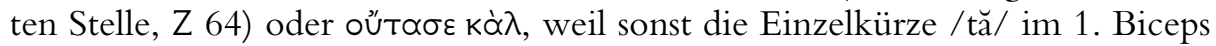
stünde.

Beispiel (4), s.u., braucht eine Vorbemerkung zum Thema Zäsuren. Die strukturierenden Zäsuren des Hexameters liegen mit einer Ausnahme noch an denselben Stellen, auf die im epischen Fünfzehnsilbler entweder die alte Versgrenze fiel oder - im Ergebnis viel wichtiger - die Abgrenzung des ersten oder zweiten Choriambus, jeweils in Richtung auf die Versmitte. Aus den bisherigen Beispielen lässt sich ablesen, wie es zu vier der fünf Zäsuren

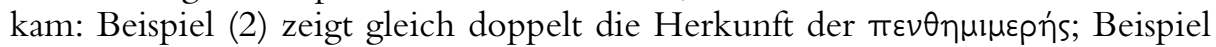

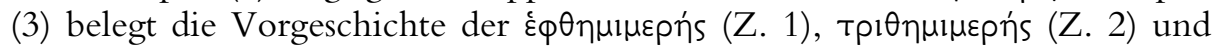
der bukolischen Diärese (Z. 1-4).

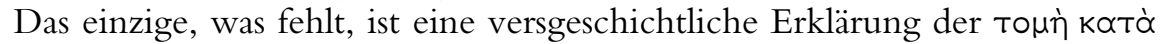
трі́тоv троххі̃ov. Diese Zäsur muss im Hexameter zu den vier anderen hinzugekommen sein, im wesentlichen wohl durch Vorverlegung der alten Vers- 
grenze. Man vergleiche den folgenden, im wesentlichen sicher restituierten Fünfzehnsilbler ${ }^{5}$ mit dem überlieferten Hexameter (kursiv), der den Herausgebern wegen des adverbiellen ơ $\lambda \lambda_{0}$ (?) - hier nicht wie tò ơ $\lambda \lambda_{0}$ 'im übrigen' schon seit jeher Probleme macht.
(4) $\Xi 249$

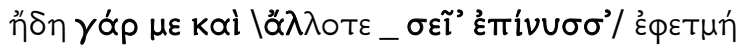
$\rightarrow$

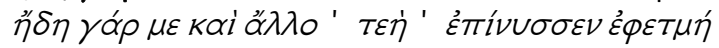

Hypnos zu Hera: 'Schon ein andermal hat mich dein Auftrag zu Verstand gebracht.'

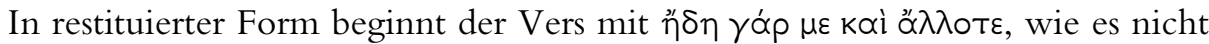
nur der homerischen Norm entspricht, sondern auch durch einen Parallelvers

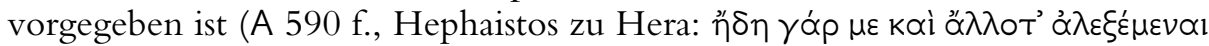

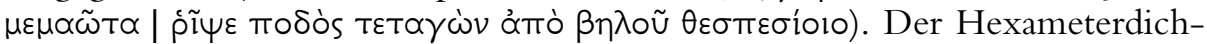
ter musste $\alpha^{\prime \prime} \lambda \lambda$ от $\varepsilon$ hier um die letzte Silbe kürzen, damit der Vers nicht in zwei gleiche Hälften zerfiel. Zum Ersatz verwendete er das zweisilbige, dichtersprachliche Possessivpronomen $T \varepsilon(F) o ́-$. Resultat dieser Verschiebung der

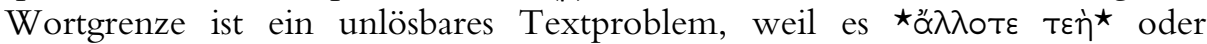

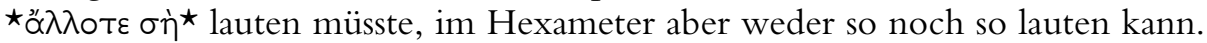
Einen eigenen neuen Vers hätte der ionische Hexameterdichter (es muss nicht Homer selbst gewesen sein) wohl anders formuliert; bei der metrischen Anpassung bereits tradierten Wortlauts, die allem Anschein nach improvisierend erfolgt ist, konnte jedoch dies und noch mehr dergleichen unterlaufen. ${ }^{6}$

Beispiel (2) ist einer Kampfszene entnommen, das Gleichnis (3) steht im Erzähltext, Satz (4) fällt in einem Göttergespräch. Wenn man das $\Xi$ inhaltlich dreiteilt, stammt jedes Beispiel außerdem aus einem anderen Teil, das heißt: Alle drei Teile enthalten Altes, konkret gesprochen alte Verse. Das ist, in nuce und auf winziger Materialbasis, schon eine erste Aussage zur sprach- und versgeschichtlichen Analyse des $\Xi$.

4. Einer der größten Vorzüge des Restitutionsverfahrens liegt paradoxerweise darin, dass es scheitern kann. Das sollte allerdings auch so sein, denn die Ilias als Ganzes ist und bleibt ein ionischer Text des 8. Jahrhunderts, enthält also ganz ohne Zweifel Verse, die von vornherein im Hexameter gedichtet sind. Solche Verse als epische Fünfzehnsilbler restituieren zu wollen, ist offenkundig sinnlos - und im allgemeinen hat man damit auch keinen Erfolg, wenn ein Hexameter nicht gerade fünfzehnsilbig ist und zufällig auch die andere metrische Analyse erlaubt.

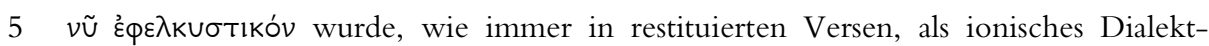

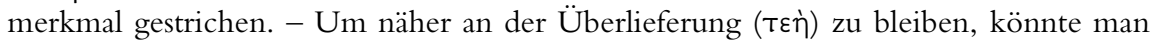
statt des elidierten $\sigma \varepsilon \tilde{\imath}$ ’ auch $\sigma \grave{\eta}$ schreiben und den Hiat (wie im Hexameter) in Kauf nehmen.

6 Für weitere Beispiele vgl. Tichy 2010, 85 ff., 118 f., 135. 
Homerischen Hexametern, die auf epische Fünfzehnsilbler zurückgehen und die altepischen Sprachmerkmale zeigen, stehen Hexameter mit jungen ionischen Dialektmerkmalen gegenüber, die schon von Anfang an in dieser Form gedichtet sind. Der Anteil originärer Hexameter - unter denen sich die Originalverse des Ioniers Homer befinden müssen - lässt sich nach Abschluss der Restitution leicht auszählen; im $\Xi$ beträgt er ein gutes Viertel (27,6 \%) und liegt damit zwischen $\mathrm{N}(24,7 \%)$ und $\mathrm{O}(31,2 \%) .^{7}$ Wenn man den Mittelteil des $\Xi$, die eigentliche $\Delta$ iòs åmát $\eta$, für sich nimmt und seiner Textumgebung gegenüberstellt, erhält man weitere, um einiges interessantere Zahlen:

1. Teil mit Überleitung (1-158):

54 originäre Hexameter $=34,2 \%$;

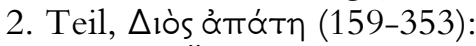

29 originäre Hexameter $=14,9 \%$;

3. Teil mit Überleitung (354-522): 61 originäre Hexameter $=36,1 \%$.

Diese Zahlen kann, wer will, so interpretieren: Teil 1 und 3, die jeweils den Erzählstrang fortsetzen, hat Homer nach seinem eigenen Plan neugedichtet und dabei nach Möglichkeit auf altes Material zurückgegriffen. Teil 2, die retardierende Einlage über Heras weibliche List, hat er dagegen als Ganzes übernommen und in die eigene Erzählung eingebaut. Es war ein bekanntes und beliebtes Einzelstück, wie das Lied von Ares und Aphrodite, das Demodokos am Phaiakenhof zur Unterhaltung des Gastes Odysseus singt. ${ }^{8}$

5. Lässt sich diese Interpretation des statistischen Befunds auch inhaltlich bestätigen? Was ist in den erzählenden, zu einem Drittel neugedichteten Teilen an altem Versmaterial eingebaut, und was ist in dem zu sechs Siebteln alten Mittelteil in den tradierten Text neu eingefügt?

Im insgesamt jungen ersten Teil (bis 158) sind sprach- und versgeschichtlich alt oder können zumindest alt sein':

- ein Gleichnis, unser drittes Beispiel (16-19);

7 Die bearbeiteten Texte sind, mit Hinweisen zur Auswertung und weiteren Vorbemerkungen (Ilias diachronica N: Grundlagen, Verhältnis zu Rudolf Borchardt; Ilias diachronica O: praktische Durchführung, Realitätswert, nochmals zu Borchardt), als Preprint digital publiziert und international frei zugänglich (Tichy 2010-). Dort angegebene Zahlen können sich mit jeder Aktualisierung ändern, bisher lag die Differenz aber noch immer niedriger als $2 \%$.

8 Inzwischen neige ich dazu, in mehreren, sämtlich im epischen Fünfzehnsilbler restituierbaren Stücken aus N $\Xi O$ die tragenden Teile eines alten Kurzepos zu sehen, deren Reihenfolge in der Ilias nicht mehr die alte ist (N 345-357; $\Xi 159-353$; N 43-125, 206-239; $138-151 ;$ O 4-235). Es bleibt aber wahrscheinlich, dass das furr sich wirkungsvolle Stück zu passender Gelegenheit auch einzeln vorgetragen wurde.

9 Sprachlich unauffällige Verse können auch als fünfzehnsilbige Hexameter gedichtet worden sein; in solchen Fällen entscheidet entweder der Kontext oder erkennbar alte (eindeutig junge) Parallelstellen. - Der Hexameterdichter kann alte Verse an einer Stelle verändert haben, ohne dass sich das metrisch oder sprachlich auswirkt, vor allem durch den Austausch strukturgleicher Namen und Namensformeln. 
- alle direkten Reden, abgesehen von Einzelversen und situationsbezogenen Partien im Gespräch zwischen Agamemnon und Nestor (42, 51, 54-59, 61, 67 f., 71 ff.) und vier weiteren Versen (93 f., 108, 120);

- fünf der acht Redeeinleitungen (64, 82, 103, 109, 138);

- sonstige, mehr oder weniger formelhafte Einzelverse (1, 14, 37, 134 ff., 152);

- Poseidons Schrei (147-150);

- die Szene, in der Hera Poseidon erblickt (155 f.), nicht aber deren unmittelbare Umgebung (153 f.: Hera hält Ausschau vom Olymp; 157 f.: Hera sieht auch Zeus).

Im insgesamt jungen dritten Teil (ab 354) sind alt oder können doch alt sein:

- ein Gleichnis (414-417) und ein Parallelenbündel negierter Vergleiche, in letzterem Fall mit Kontext (394-401);

- alle Reden bis auf Poseidons Anregung zum Waffentausch, der dann auch stattfindet (364-377, ausgenommen $370=74)$;

- alle Redeeinleitungen (355 f., 363, 453, 469, 478, 500);

- sonstige, mehr oder weniger formelhafte Einzelverse (361 f., 378, 426, 444);

- Teile von Kampfszenen (404-408, 409-412, 421 f.; 428-439: Versorgung des Ohnmächtigen; 440 ff., 447 ff., 465-468, 476 f., 490-493) und Einzelverse entsprechenden Inhalts (379, 383 f., 391, 402, $458=486,461,488$, 506);

- ein Katalog achaiischer Siege (511-519), jedoch ohne den vorangestellten Musenanruf und den Hinweis auf die Situation.

Im sonst vollständig alten Mittelteil sind jung:

- Heras Entschluss, gut angezogen zum Ida zu gehen (161 f.);

- sieben Einzelverse (168: Zimmerschlüssel; 180: Gewandnadel; 213, von Aristophanes und Aristarch athetiert; 224: Aphrodite geht wieder hinein; 231: Hera trifft Hypnos; 269 [ 276], interpoliert; 336);

- der zweite Teil der Lügengeschichte ${ }^{10}$, die Hera zuerst Aphrodite und dann, am Schluss verkürzt, auch Zeus erzählt (205ff. = 304 ff., 209 f.);

- Heras Weg über Thrakien bis zum Meer (225-229);

- Heras erstes Bestechungsangebot (239 ff.), das Hypnos mit Schweigen übergeht, als Folie des zweiten, dem er nicht widerstehen kann (vgl. 267 f.);

10 Den Bezug auf ein anderes Ehepaar der Götterwelt muss ein ionischer Dichter hergestellt haben, der eine Spiegelszene gestalten wollte. Wie der fast durchgängig (außer 208, v.l.) statt des Duals verwendete Plural zeigt, sprach Hera in der alten Fassung von drei oder mehr Verwandten. 
- der poetisch überhöhte Schluss: Die Erde lässt unter dem Götterpaar Klee, Krokus und v́ókıv $\theta$ os wachsen, die sie vom Boden hochheben (347-351, darin 348 als alter Einzelvers).

Es spricht viel dafür, dass die textkritisch unverdächtigen Einschübe und Änderungen im Mittelteil von Homer selbst stammen. Das ins Übernatürliche gesteigerte Motiv der reagierenden Natur erscheint jedenfalls auch am Anfang des $\mathrm{N}$ - ebenfalls in einer originären Hexameterpartie (27-34) -, als Poseidons Ausfahrt von freudespringenden Meerestieren begleitet wird. Mit Sicherheit original homerisch sind außerdem der erste und der dritte Teil, in denen die Iliashandlung voranschreitet, und der darin verfolgte dichterische Handlungsplan.

6. Das Ergebnis der sprach- und versgeschichtlichen Analyse des $\Xi$ scheint klar, wird aber manchen enttäuschen. Vieles, gerade auch Schönes und Elaboriertes, hat Homer nicht selbst gedichtet, sondern letztlich - über äolische, teilweise auch bereits ionische Vermittlung - aus altepischer, äolisch geprägter Dichtung übernommen. Auf dem Übermittlungsweg wurden die fünfzehnsilbigen, aus einem lyrischen Versmaß hervorgegangenen und der Lyrik immer noch nahestehenden Gesangsverse an den durchlaufend rhythmisierten, innerhalb seiner sechs Metren äußerst variablen Sprechvers angeglichen, der in ionischer Dichtung den epischen Fünfzehnsilbler ablöst.

Bei der Enttäuschung sollte es jedoch nicht bleiben: Die auf eine Hypothese gegründete, im weiteren aber rein empirisch verlaufende Untersuchung bestätigt das Bild Homers als eines überlegen planenden Dichters, der immer dann, wenn sich nicht gerade ein längst geprägtes und „wirkungsbewiesene[s] "11 Stück zur Verwendung anbot, eigene Hexameter improvisierte. Einen Redaktor hat die Ilias zu keiner Zeit gebraucht.

11 Borchardt 1959, 53 [Ende 1944]. - Rudolf Borchardt hat in seinen letzten beiden Lebensjahren (unter kläglichsten Arbeitsbedingungen, gestützt auf ein phänomenales Gedächtnis) ein Bild der Ilias und Homers entworfen, das mein Ergebnis bis in die Formulierungen hinein vorwegnimmt. Über mir nebensächlich scheinende Unterschiede, etwa die Entscheidung für oder gegen Schriftlichkeit, sehe ich dabei hinweg. [Korrekturnachtrag: Ilias diachronica $\lambda$ stimmt zu Schadewaldts analysierender Interpretation, Iliasstudien 1-94.]. 


\section{Anhang: Ilias diachronica $\Xi$}

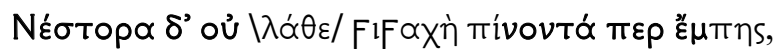

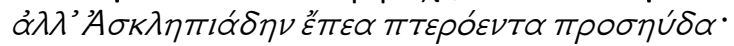

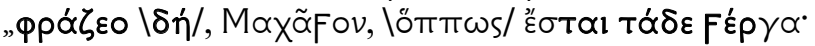

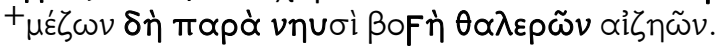

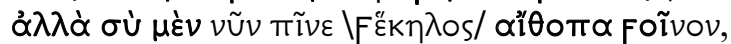

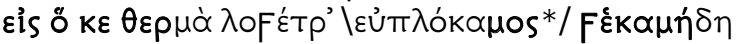

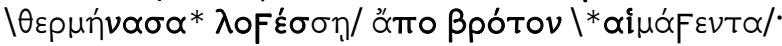

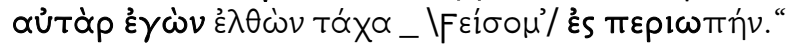

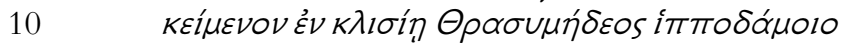

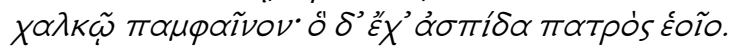

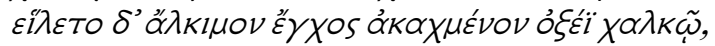

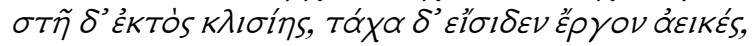

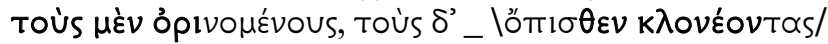

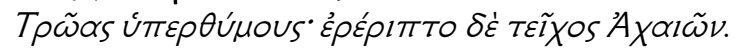

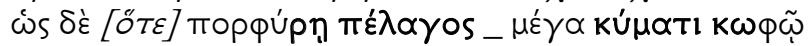

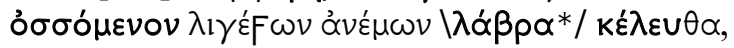

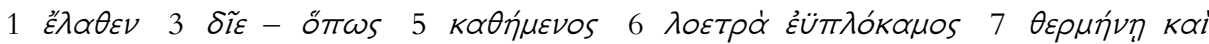

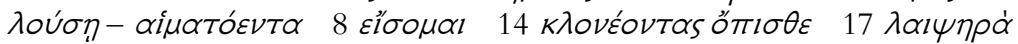

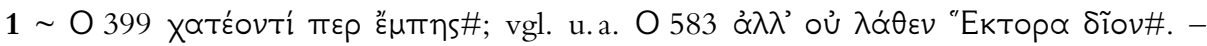
Fortsetzung des Handlungsstrangs, der $\wedge 805$ verlassen wurde. 2 Variabler Formelvers,

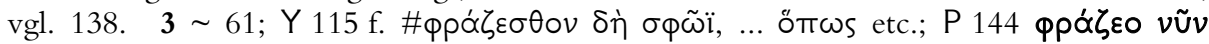

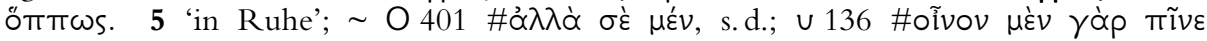

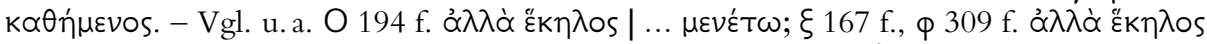

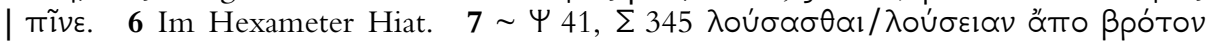

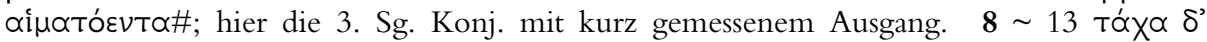

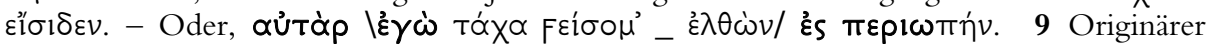

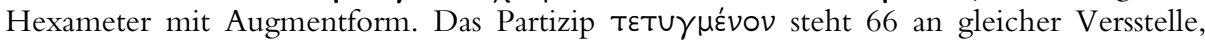

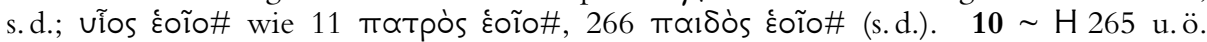

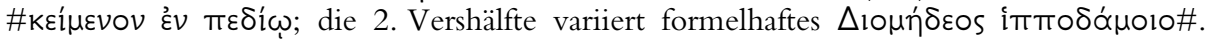

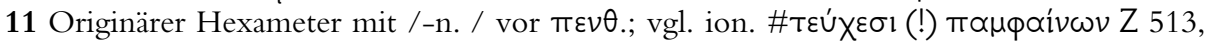

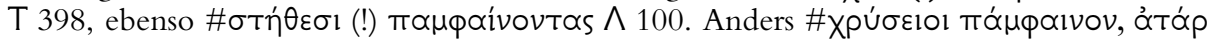
$\wedge 30$ mit regulärer Behandlung der 3. Plural. $12=\mathrm{K} 135$, O 482; Hexametervariante zu

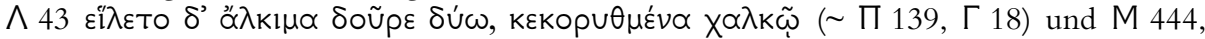

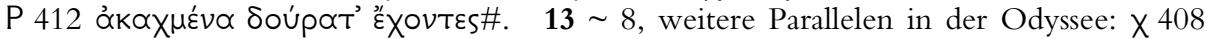

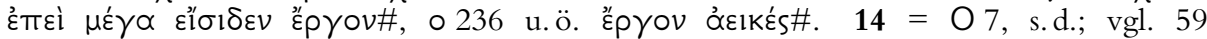

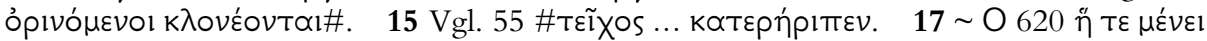

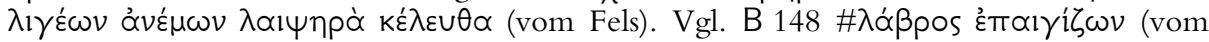

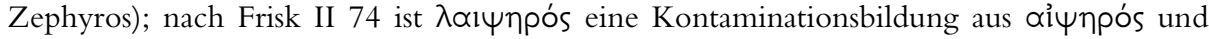
$\lambda \alpha \dot{\beta} \beta$ pos. 


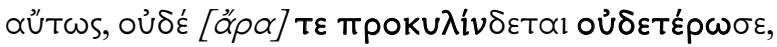

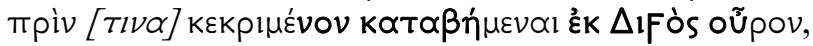

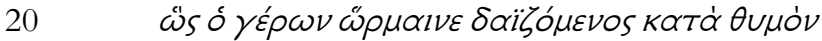

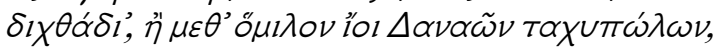

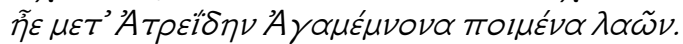

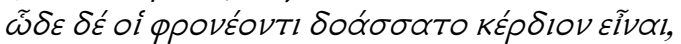

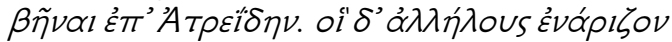

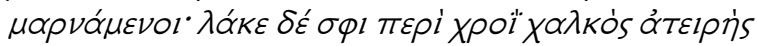

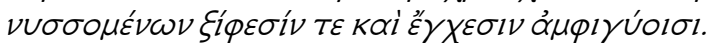

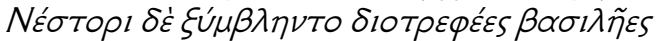

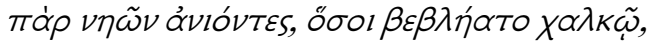

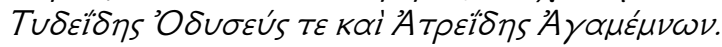

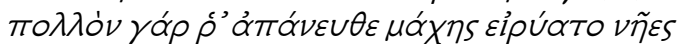

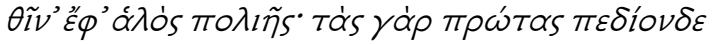

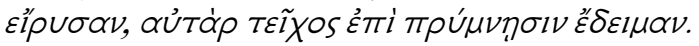

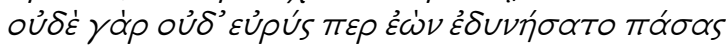

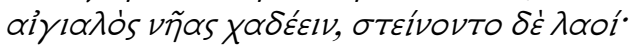

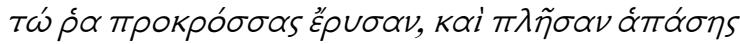

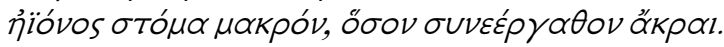

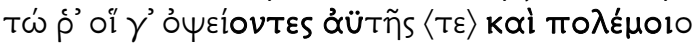

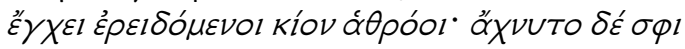

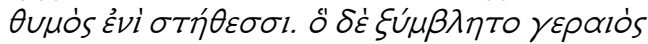

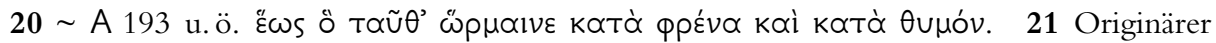

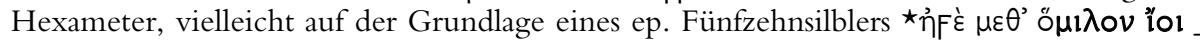

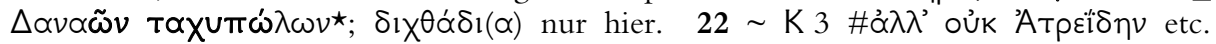

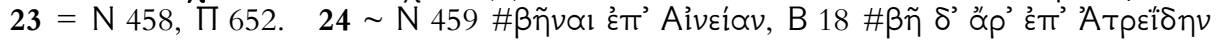

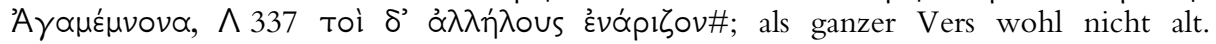

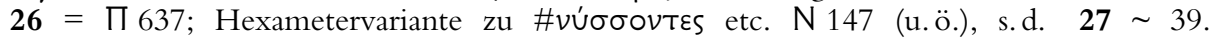

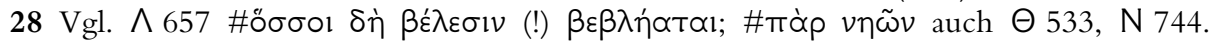

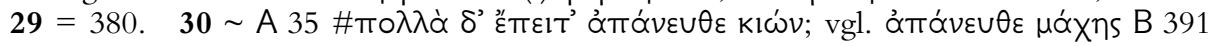

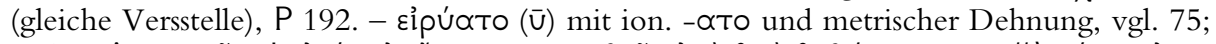

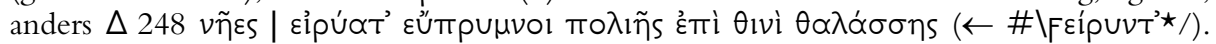

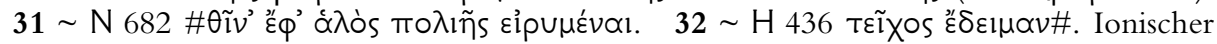

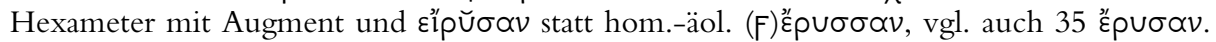
33 Wegen des Augments wohl kein alter Vers, auch wenn die 1. Hälfte leicht restituierbar

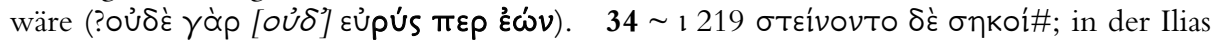

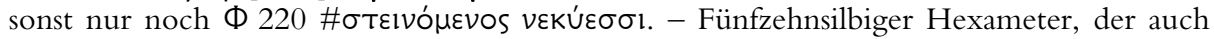

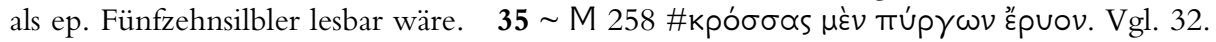

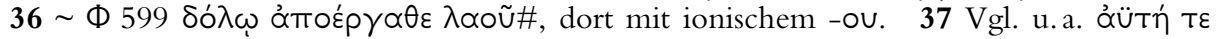

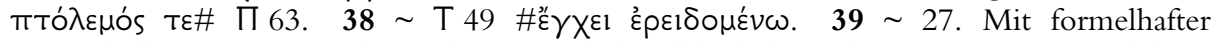
1. Vershälfte und (wie auch 40) als ep. Fünfzehnsilbler lesbar, aber dem Kontext nach kein alter Vers. 


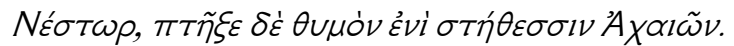

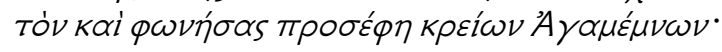

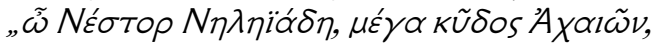

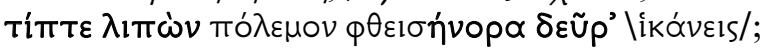

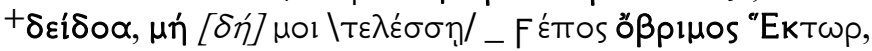

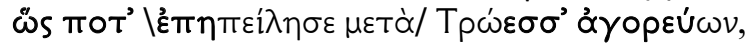

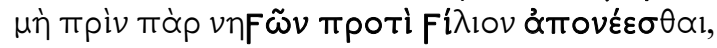

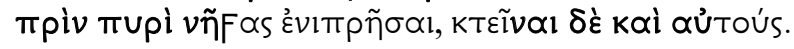

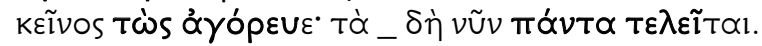

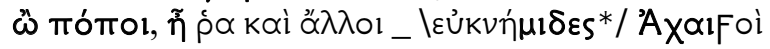

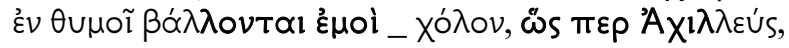

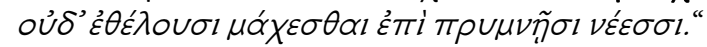

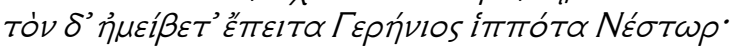

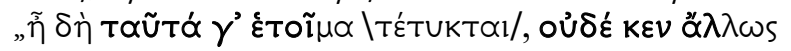

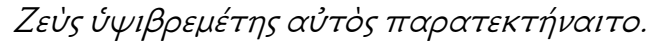

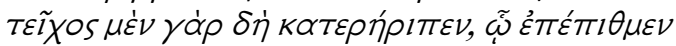

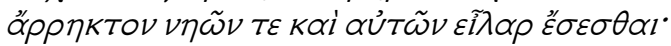
ol' $\delta$ '

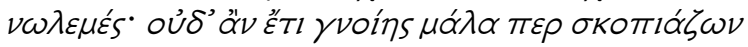

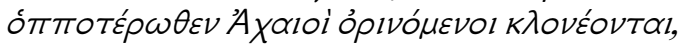

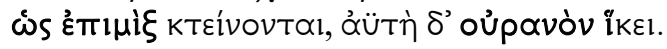

$40 \sim \mathrm{N}$ 808; gilt seit Aristarch als interpoliert. 41 Abwandlung des Formelverses kaí $\mu \mathrm{l} v$

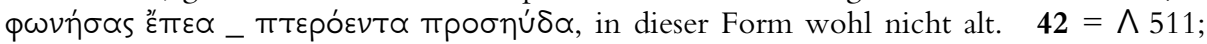
fünfzehnsilbiger Hexameter mit suffixal gestrecktem Patronymikon (statt $\star N \eta \lambda \eta \hat{i} \delta \eta$ oder

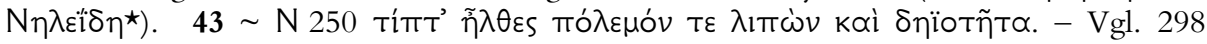

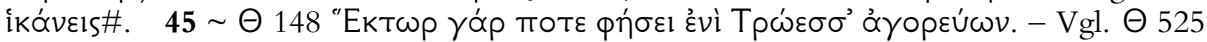

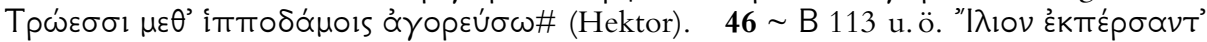

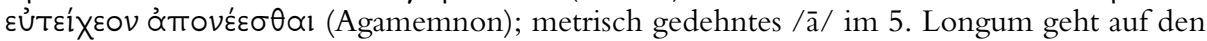

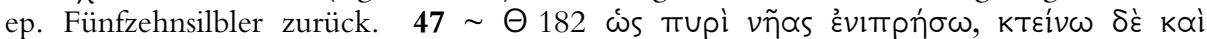

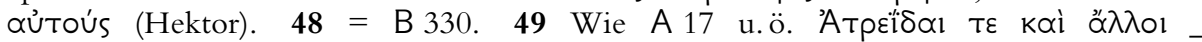

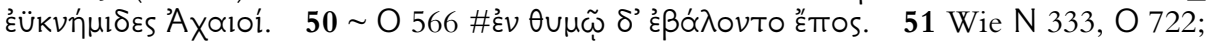
vgl. dagegen 65.52 Aus alten Vershälften zusammengesetzter, sechzehnsilbiger Iteratvers;

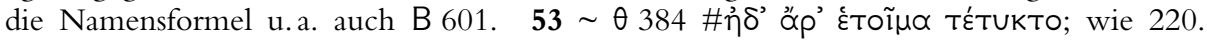

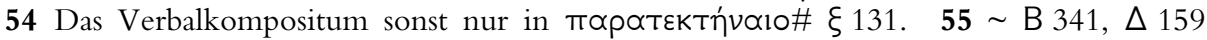

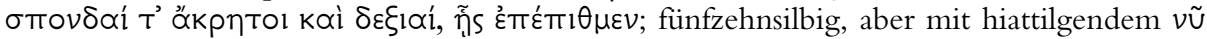

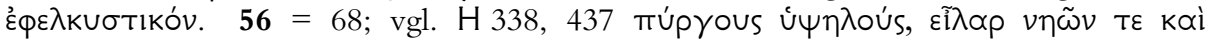

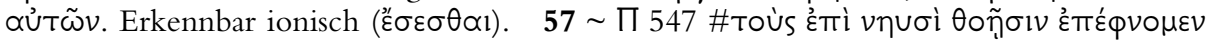

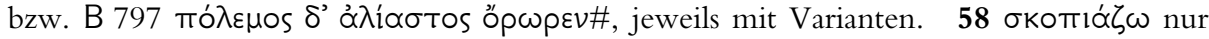
hier und K 40, K 260. $\quad 59 \sim 14 . \quad 60 \sim$ B 153, M 338 åütì $\delta$ oủpavòv ĩkev\#. 


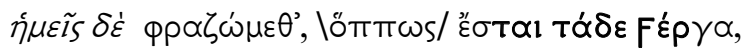

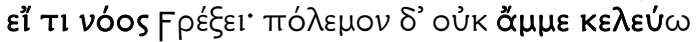

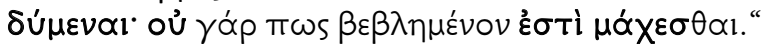

65

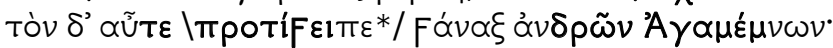

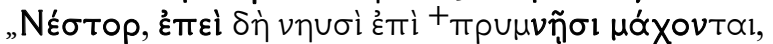

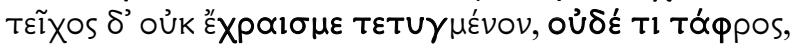

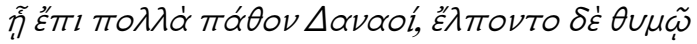

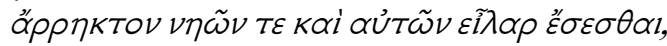

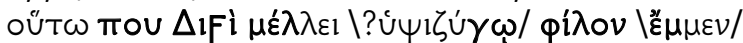

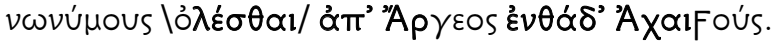

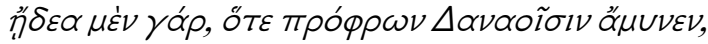

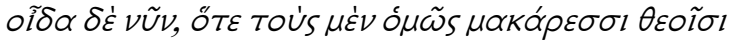

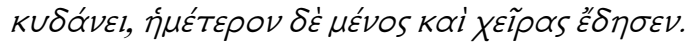

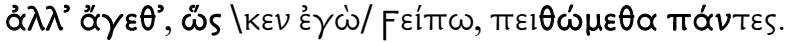

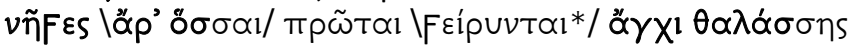

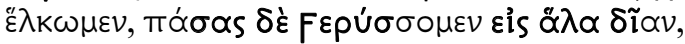

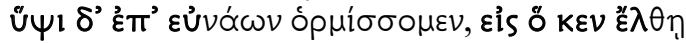

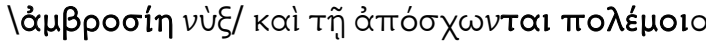

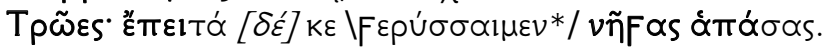

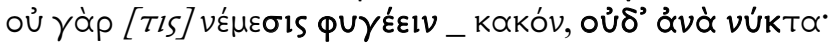

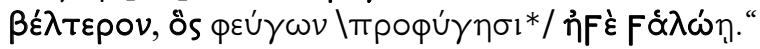

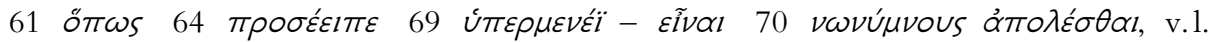

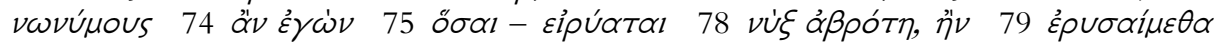

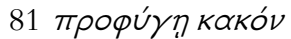

$61 \sim 3$, wie hier auch $\Delta 14$. Im Hexameter ist ohne metrischen Grund der 1 . Choriambus

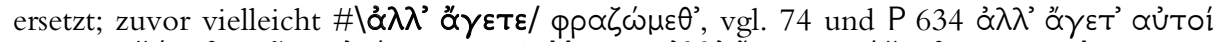

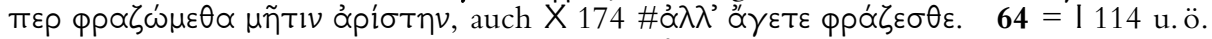

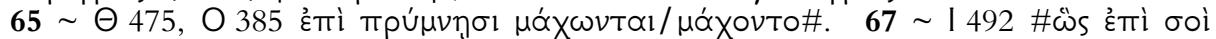

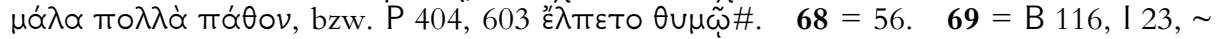

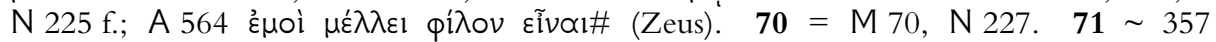

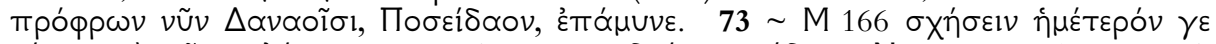

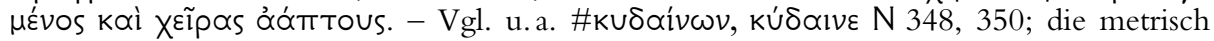

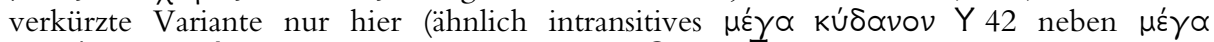

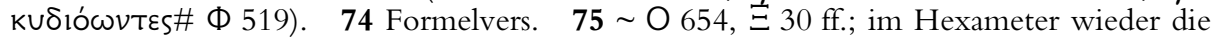
ion. Perfektform mit metrischer Dehnung. Zur Syntax vgl. $371 . \quad 78$ Vgl. $\Sigma 267$ f. vن̀ $\xi \ldots \mid$

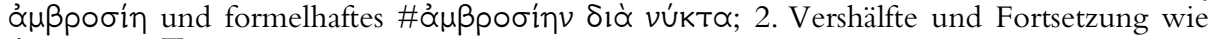
$\wedge 799 \mathrm{f}$. $\sim ~ \Pi 41 \mathrm{f}$. Im Hexameter ist die Diärese nach dem zweiten Fuß vermieden, das

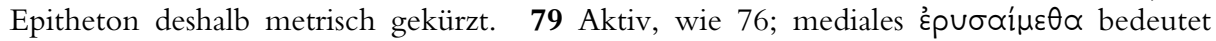
sonst '(einen Gefallenen) auf die eigene Seite ziehen, retten'. Die Medialendung ergibt ein

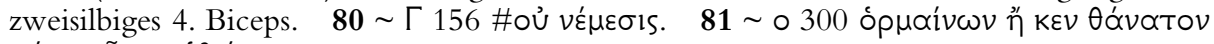

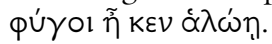




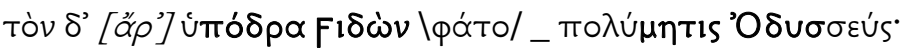

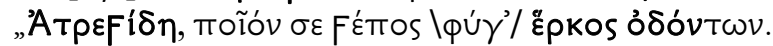

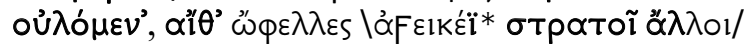

85

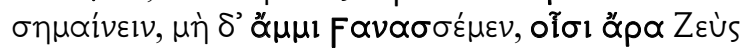

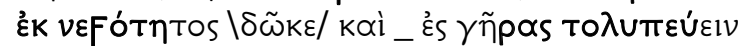

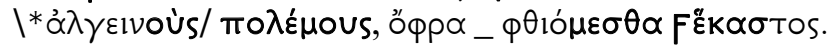

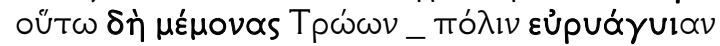

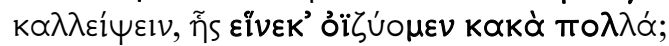

90

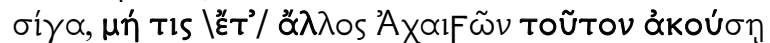

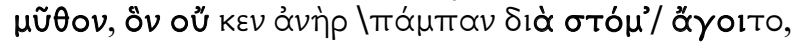

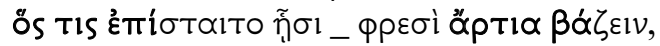

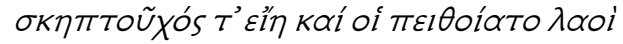

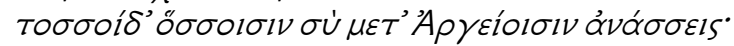

95

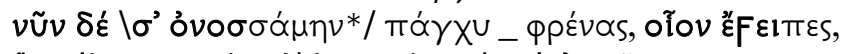

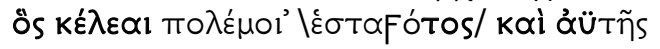

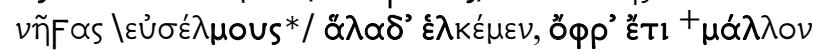

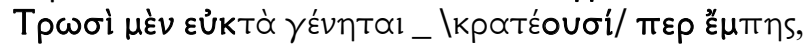

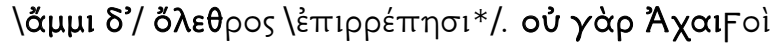

100

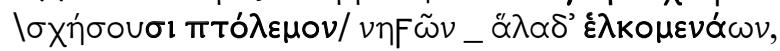

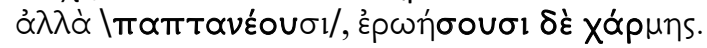

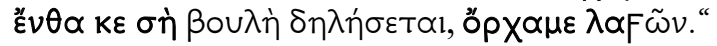

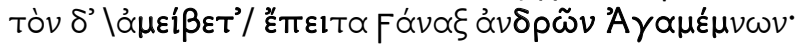

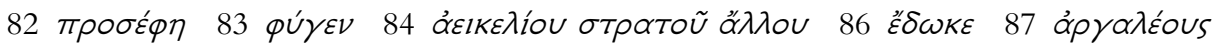

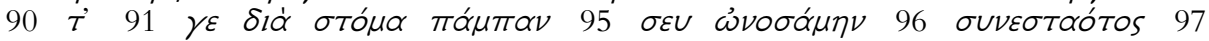

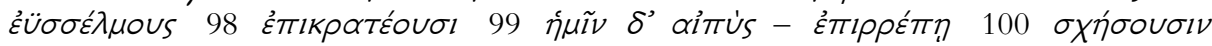

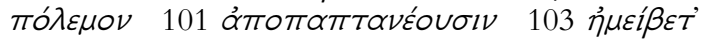

$\mathbf{8 2}=\Delta 349$; variabler Formelvers. $\quad \mathbf{8 3}=\Delta 350 . \quad \mathbf{8 4}$ 'bei einem anderen Heer'; vgl.

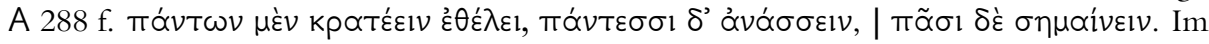
Hexameter hier statt des Lokativs (!) der ionische Genetiv auf -ou. Die suffixale Streckbil-

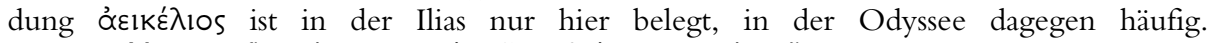

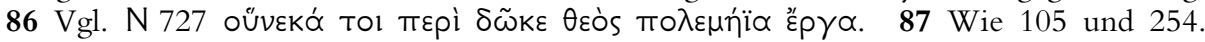

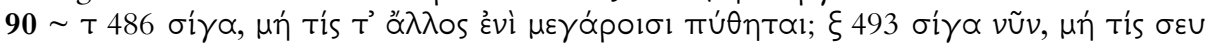

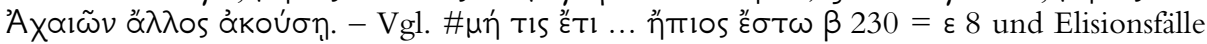

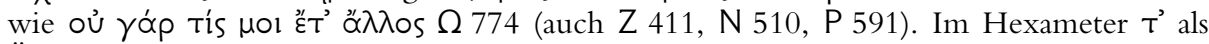
Äquivalent von kói. $93 \mathbf{f}$. Einschub in originären ionischen Hexametern. $\quad 93 \sim$ M 229

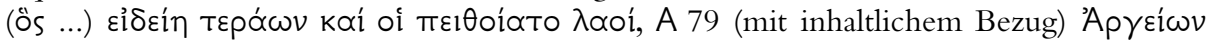

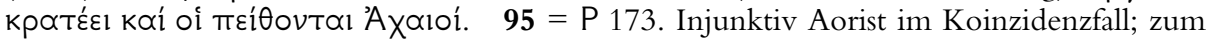

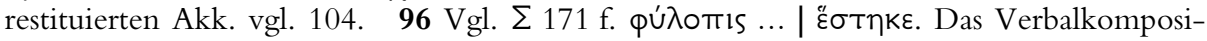

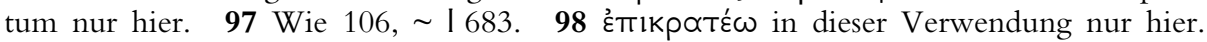

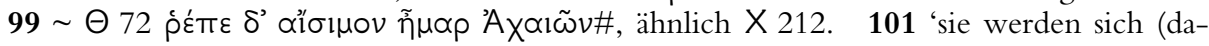
nach) umsehen'; das Verbalkompositum nur hier. $\mathbf{1 0 3}=$ A 172. 


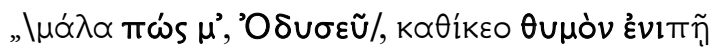

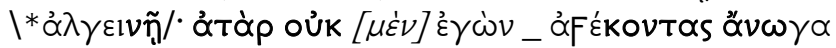

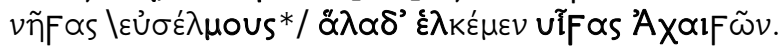

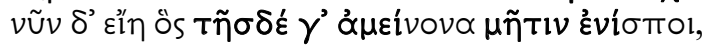

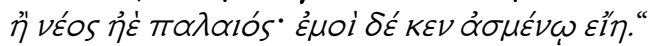

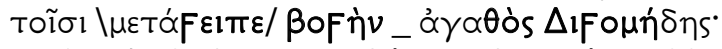

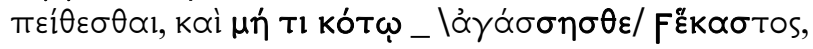

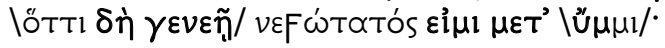

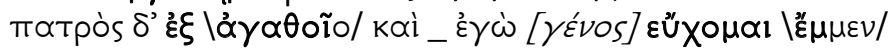

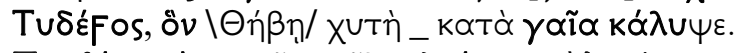

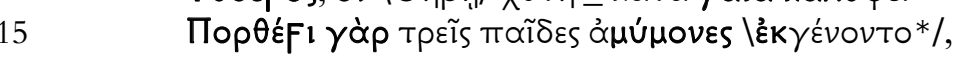

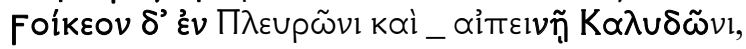
"A

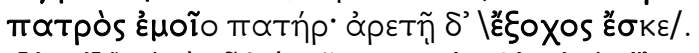

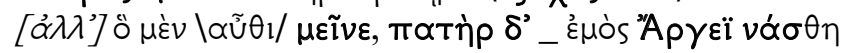

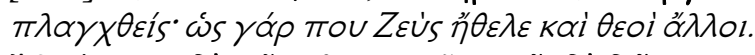

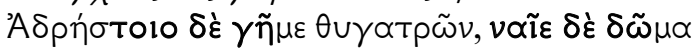

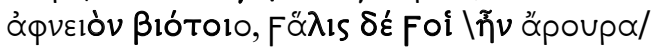

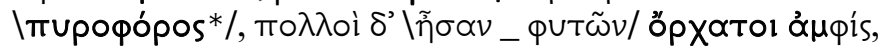

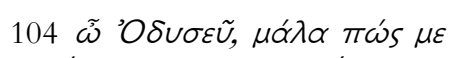
$\mu \varepsilon \tau \dot{\varepsilon} \varepsilon l \pi \varepsilon \quad 110 \mu \alpha \tau \varepsilon \dot{\sigma} \sigma \mathrm{\mu} \mu \mathrm{v}$ 113 á $\gamma \alpha \theta \circ \tilde{u}-\varepsilon \tilde{v} \alpha \alpha 1114$

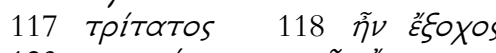

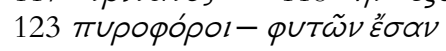
$105 \dot{\alpha} \rho \gamma \alpha \lambda \dot{\varepsilon} \eta$ $111 \stackrel{\alpha}{\gamma} \gamma \alpha \dot{\alpha} \sigma \eta \sigma \theta \varepsilon$

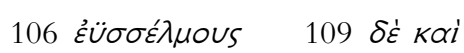

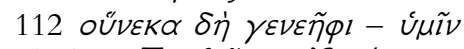

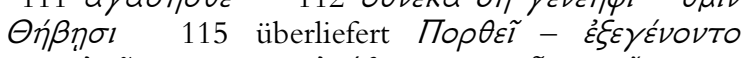

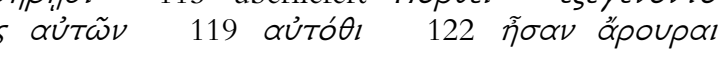

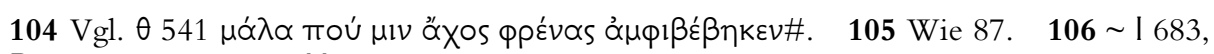
B $165=181 . \quad 107 \sim$ H 446 f. 108 Dativ des Rezipienten; kurzgemessenes $-\omega$ verrät den ionischen Dichter, wie auch kontrahiertes \# $\eta_{\eta}$ statt des ersten $\eta(F) \dot{\varepsilon} . \quad 109 \sim \Gamma 96$; variabler

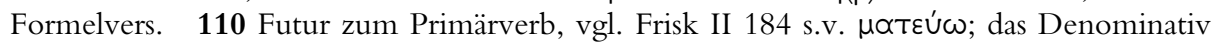

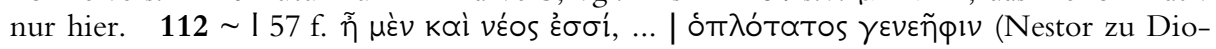

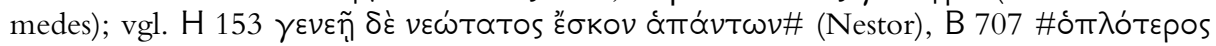

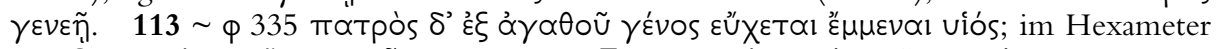

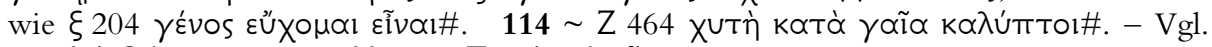

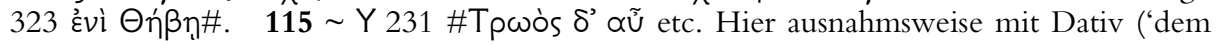

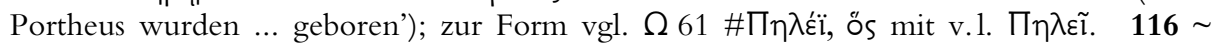

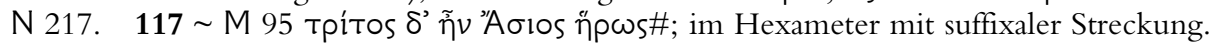

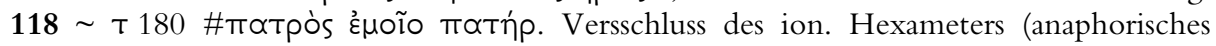

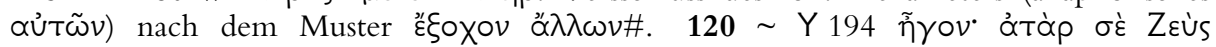

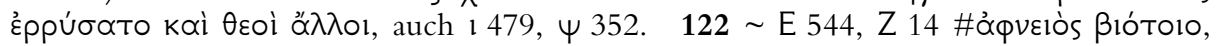

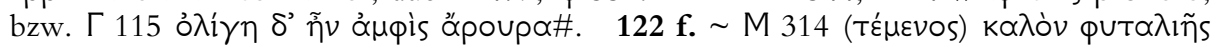

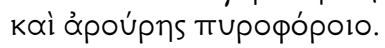




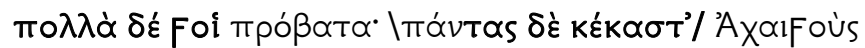

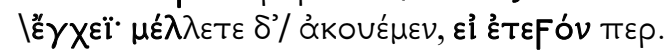

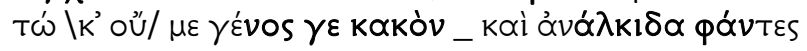

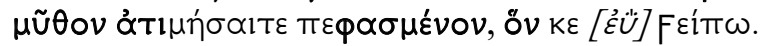

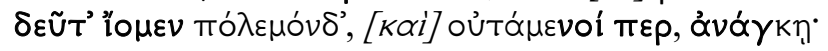

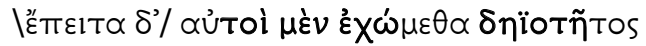

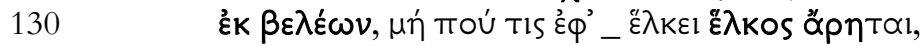

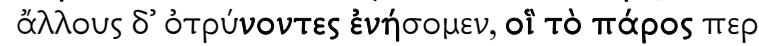

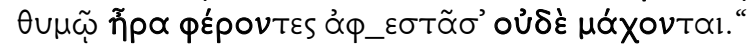

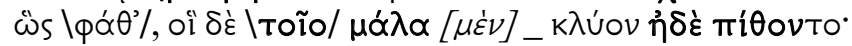

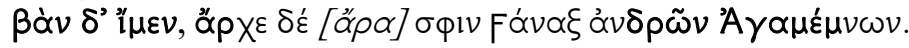

135

140

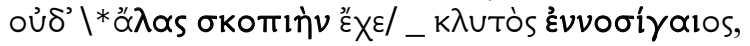

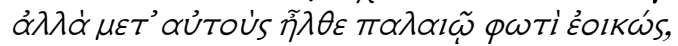

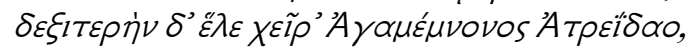

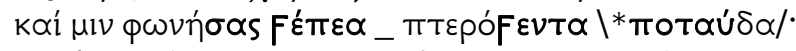

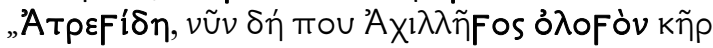

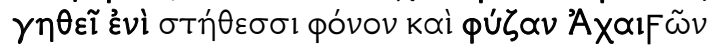

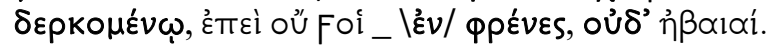

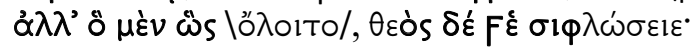

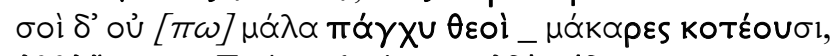

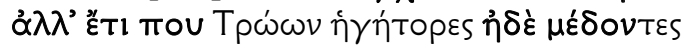

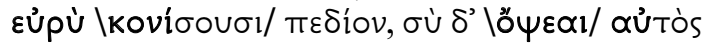

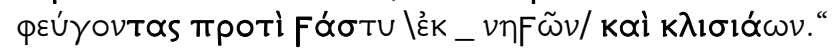

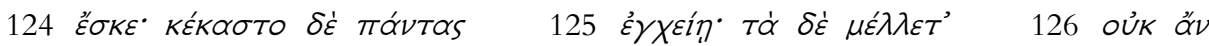

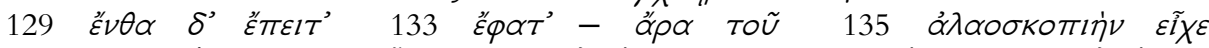

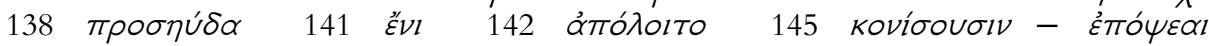
$146 \nu \varepsilon \tilde{\omega} \nu$ ơ $\pi 0$

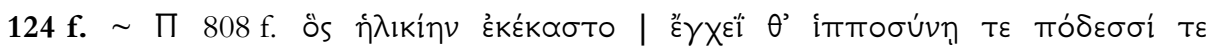

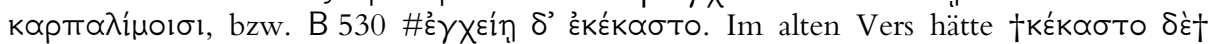

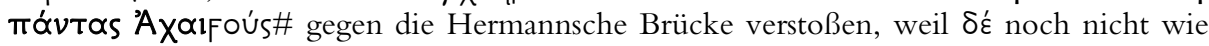
$\tau \varepsilon$ behandelt wurde. 125 In dem formelhaften Versschluss zählt Kurzdiphthong vor Vo-

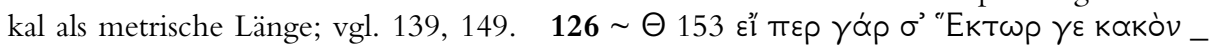

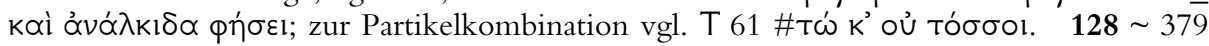

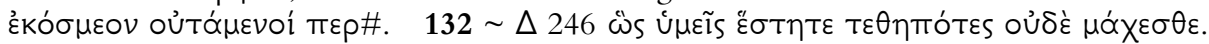
133 Formelvers. $134 \sim 384$, dort im Hexameter mit $\sigma \phi 1.135 \sim$ N 10, s.d.

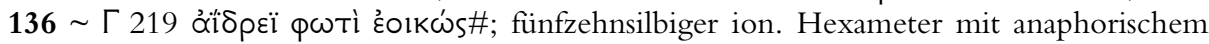

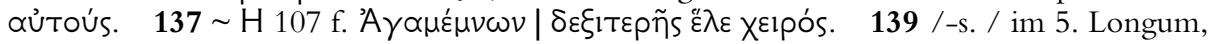
bzw. in der ersten Länge des Choriambus. 140 Wegen Undeutlichkeit der Doppelkürze

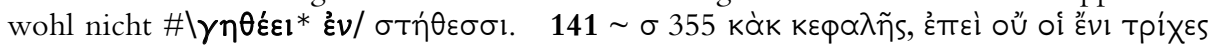

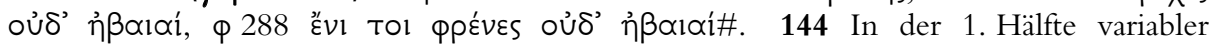
Formelvers. 145 f. 'wirst sie fliehen sehen'; das Futur mit Präverb nur hier. $146 \sim \Pi 45$

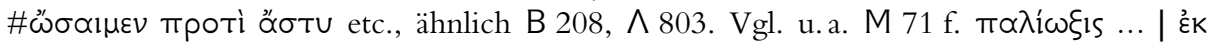
$\nu \eta \tilde{\omega} v$. 


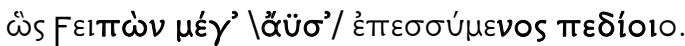

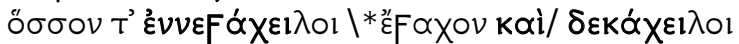

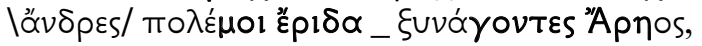

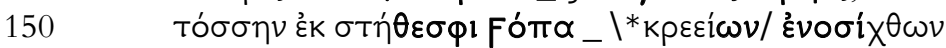

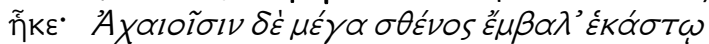

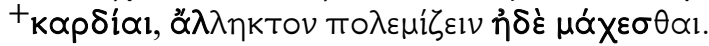

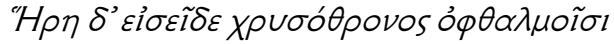

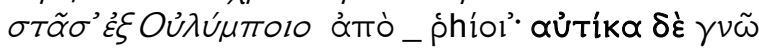

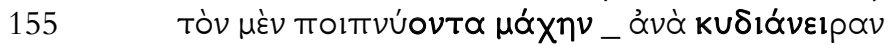

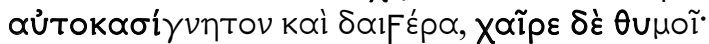

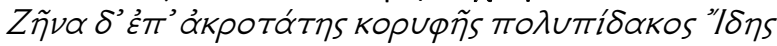

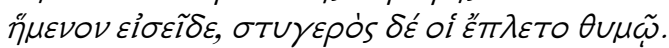

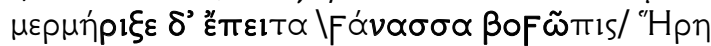

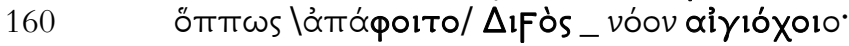

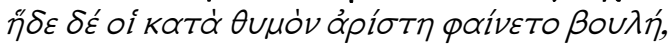

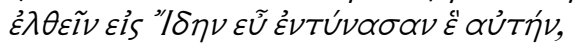

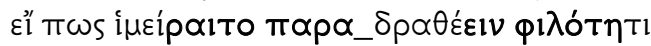

F

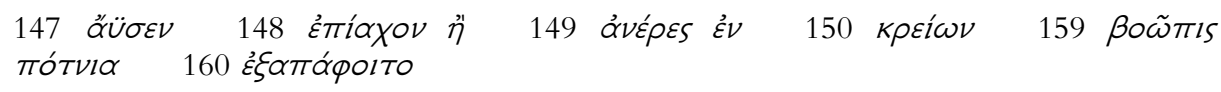

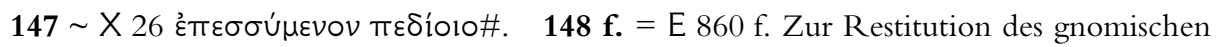

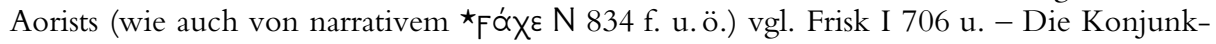

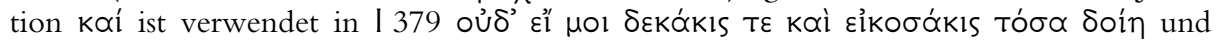

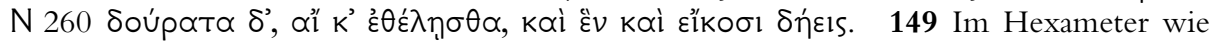

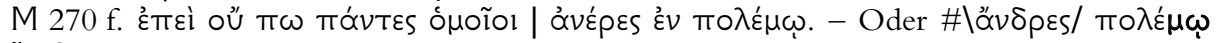
हैpı $\delta \alpha$ etc. 'die zum Kampf den Streit des Ares zusammenführen'. Der finale Dativ wäre

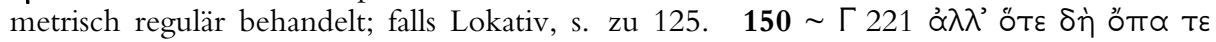

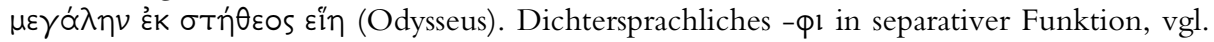

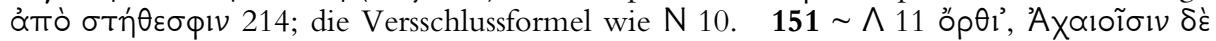

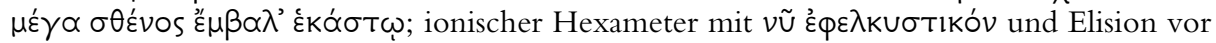
ehemaligem Digamma. $152=$ B 452, $\wedge$ 12; Lokativ des $a$-Stamms mit kurz gemessenem Ausgang. $\quad 153 \sim 158$ \#

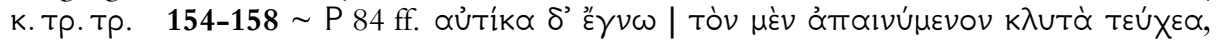

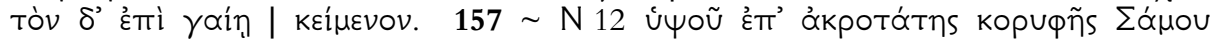

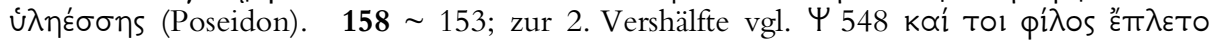

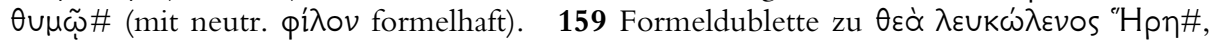

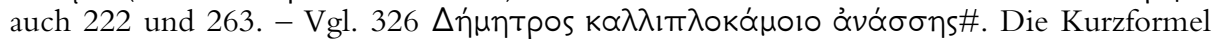

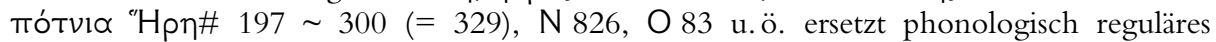

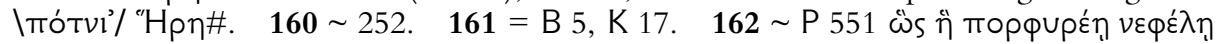

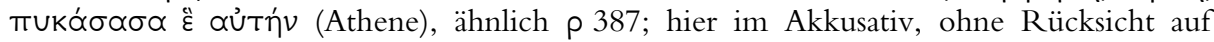
ehemaliges Digamma in $(F) \dot{\varepsilon}$. 
165

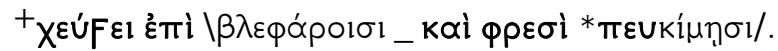

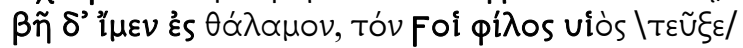

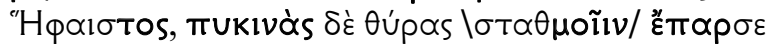

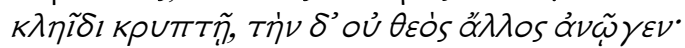

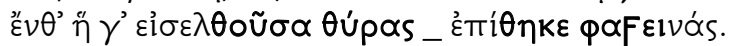

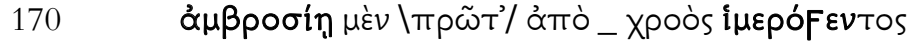

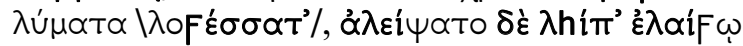

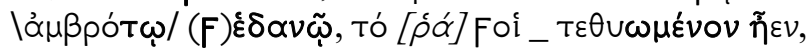

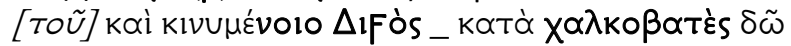

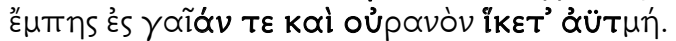

175

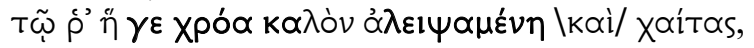

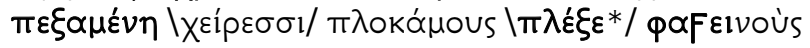

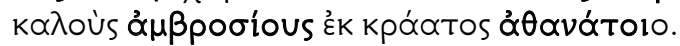

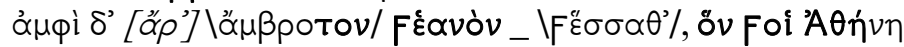

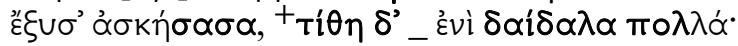

180

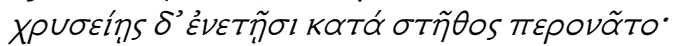

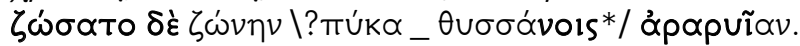

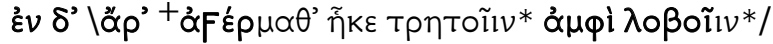

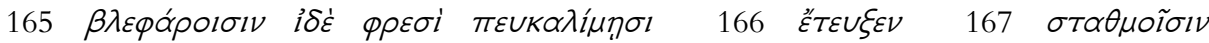

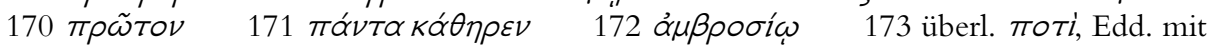

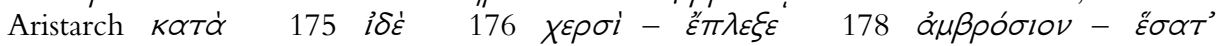

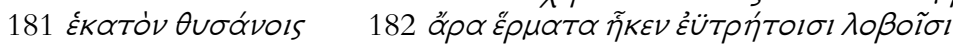

165 Xยún mit kurz gemessenem Konjunktivausgang. -

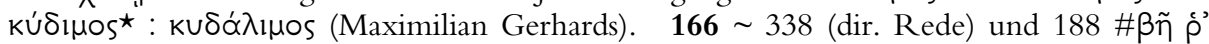

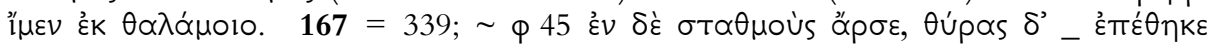

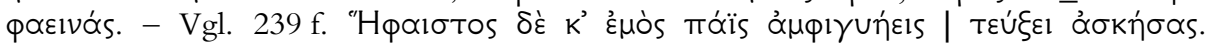
168 Originärer Hexameter, der nach $338 \mathrm{f}$. nicht wiederkehrt; darin ion. ơ $v \tilde{\omega} \gamma \varepsilon v$ gegen-

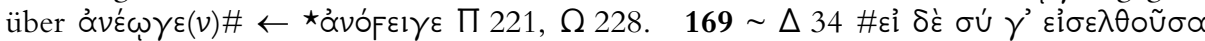

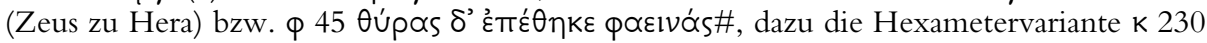

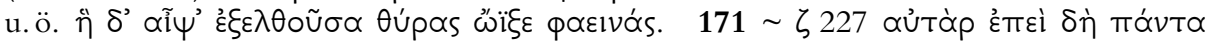

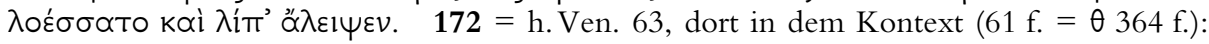

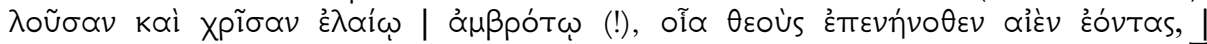

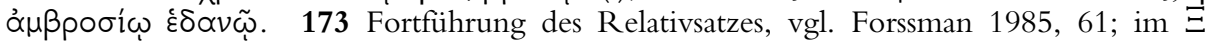

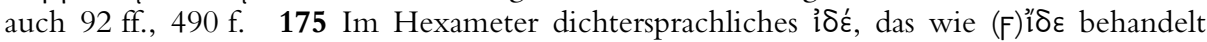

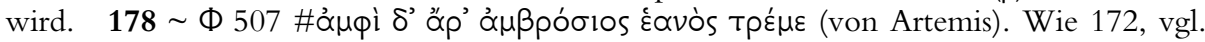

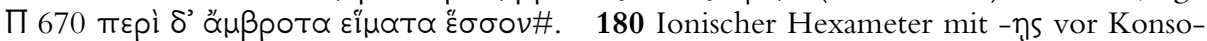

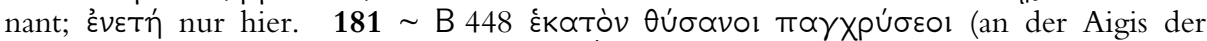

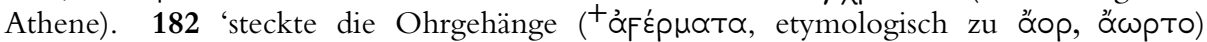

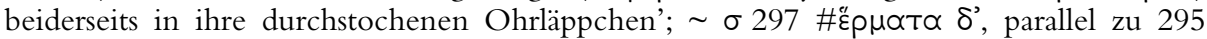

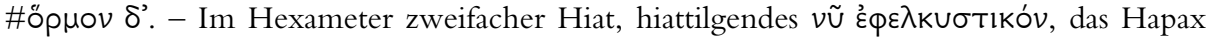

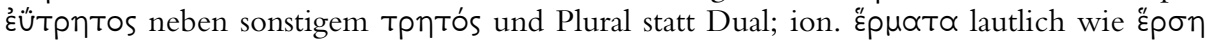

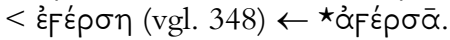




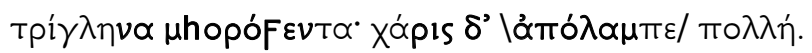

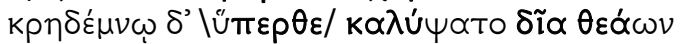

185

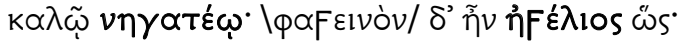

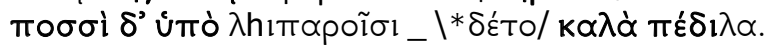

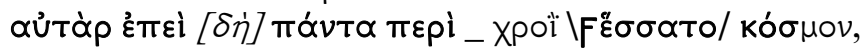

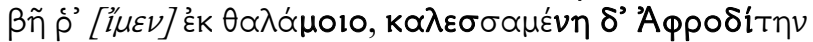

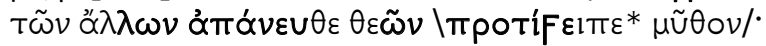

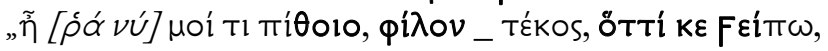

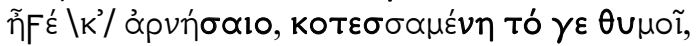

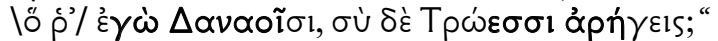

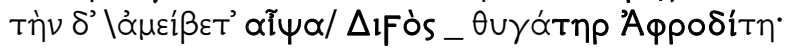

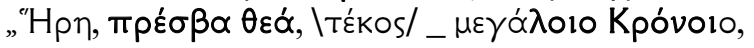

195

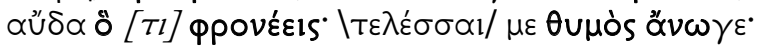

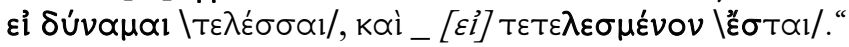

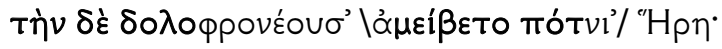

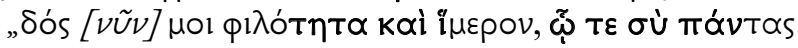

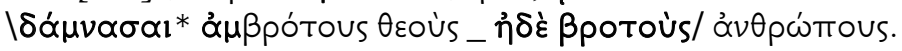

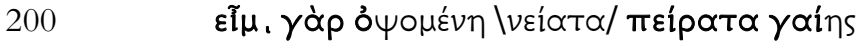

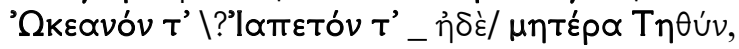

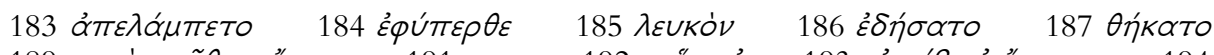

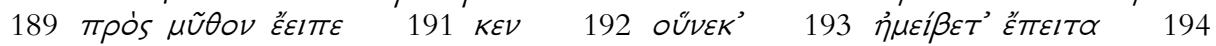

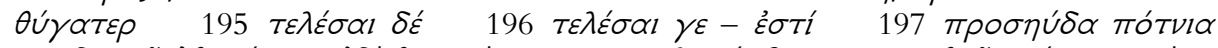

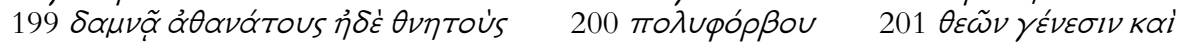

$183=\sigma 298$; mediales o̊mо入а́ $\mu \pi \varepsilon$ - nur hier. $186=$ B 44 u. ö., sonst von Männern. Der mediale Wurzelaorist zu $\delta \varepsilon \dot{\epsilon}$ bzw. $\delta i \delta \eta \mu$ ist nicht bezeugt, aber vorauszusetzen, vgl. LIV

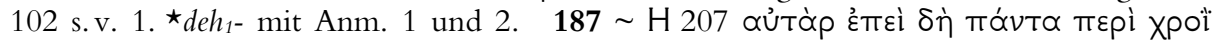

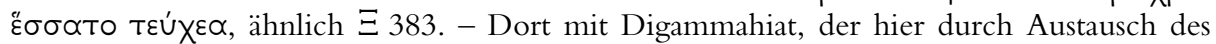
Verbs beseitigt ist; die Kunstbildung $\theta$ ந́k $\propto$ тo sonst nur in der Dolonie (K 31, Versanfang).

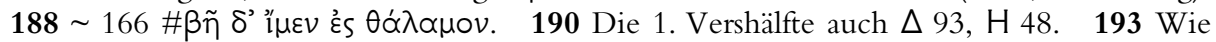
O 471. $194=243, \sim$ E 721, Ө 383 (Nom.). 195 f. = $=426$ f., \& 89 f.; 'wenn ich (den Wunsch) erfüllen kann, wird er auch in Erfüllung gehen'. Im Hexameter mit ungewöhn-

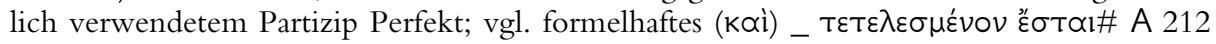

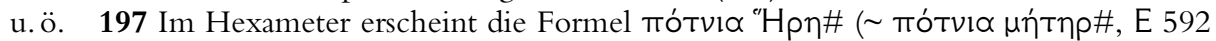

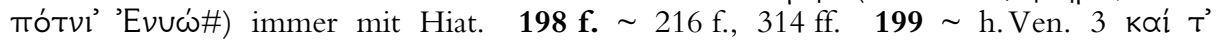

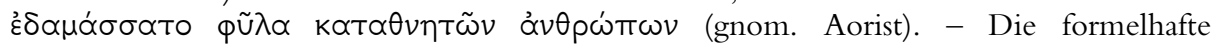
2. Vershälfte $\theta \nu \eta \tau \tilde{\omega} \nu ~ \alpha ُ v \theta \rho \omega ́ \pi \omega \nu \#$ (u. ä.) gibt es erst im Hexameter. 200 f. Vgl.

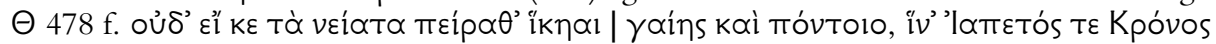
$\tau \varepsilon$... (Zeus zu Hera). Der Plural in Vers $202 \mathrm{ff}$. setzt voraus, dass Hera ursprünglich von mehr als zwei Verwandten sprach. $200 \sim 301$, wiederaufgenommen $205=304$. Vgl.

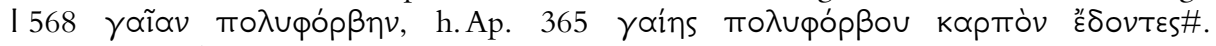
$201=302$, vgl. 246 . 


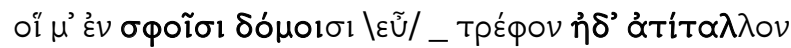

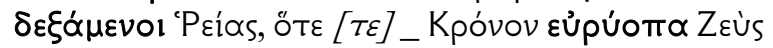

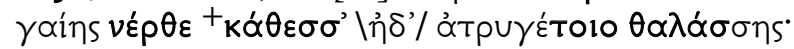

205

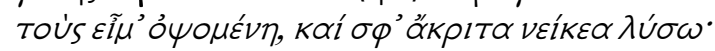

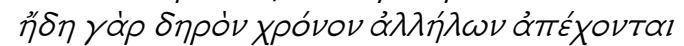

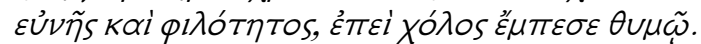

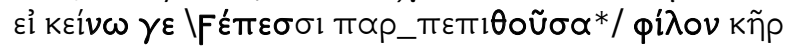

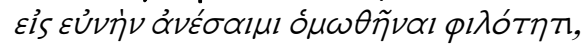

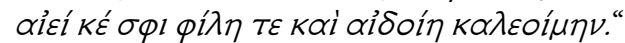

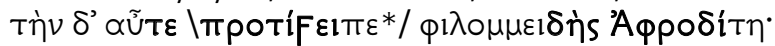

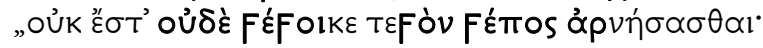

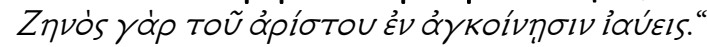

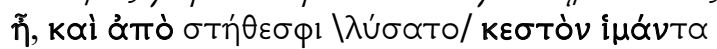

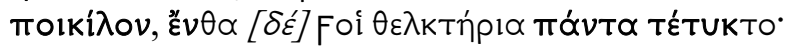

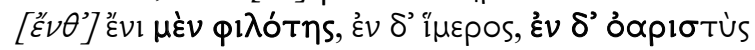

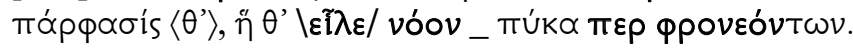

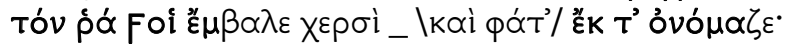

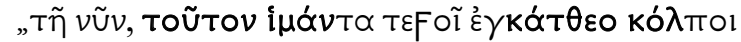

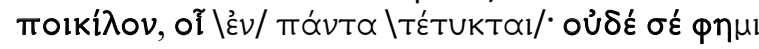

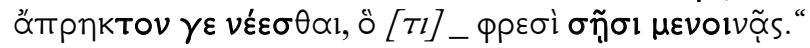

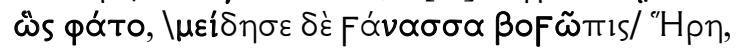

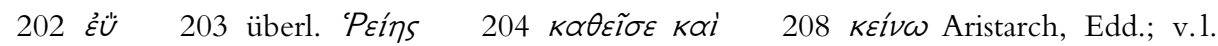

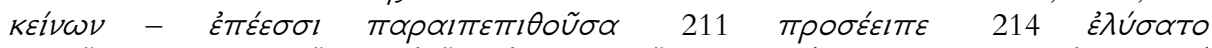

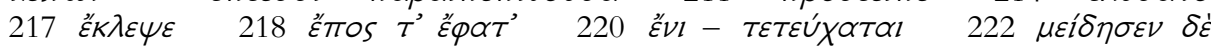

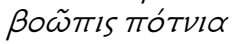

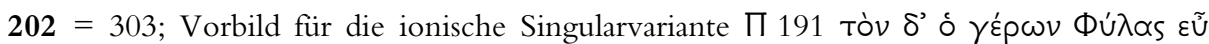

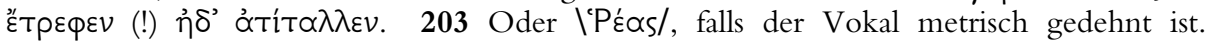

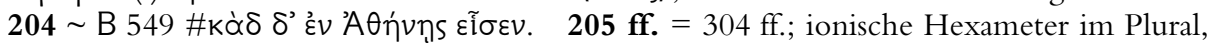
die sich auf Okeanos und Tethys als Paar beziehen. 205 (304) Als ep. Fünfzehnsilbler

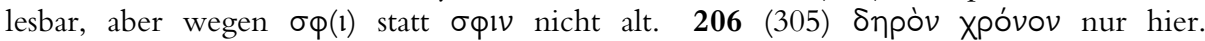
207 (306) Г 445, Z 25 фı

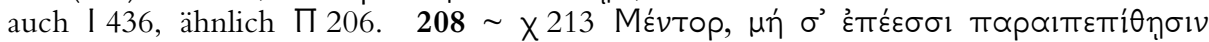

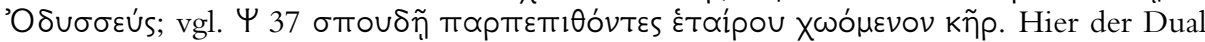

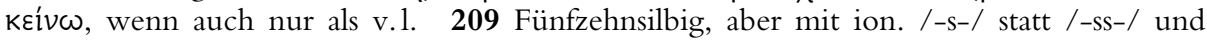

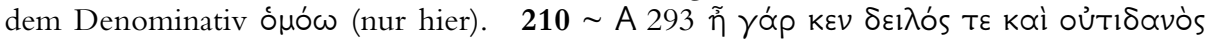

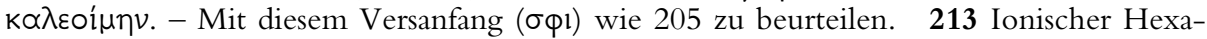

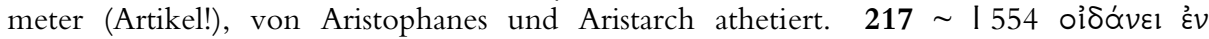

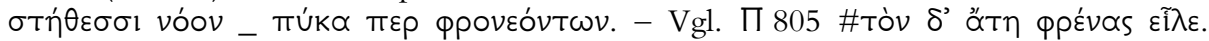

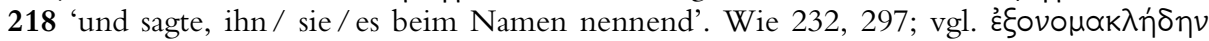

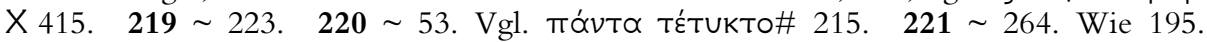

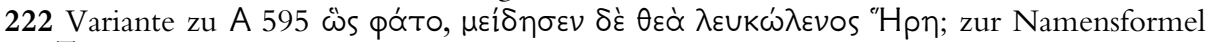
des $\Xi$ vgl. 159. 


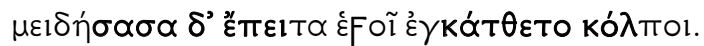

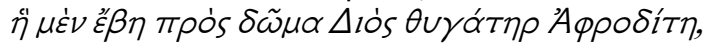

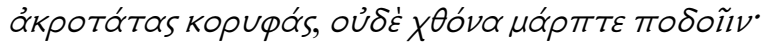

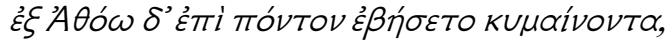

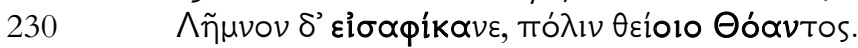

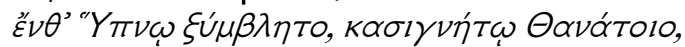

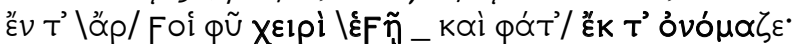

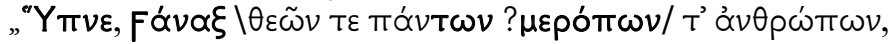

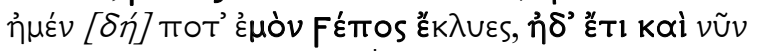

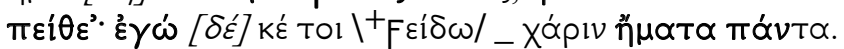

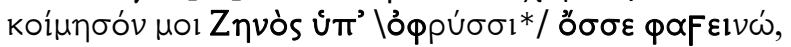

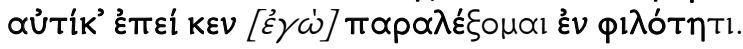

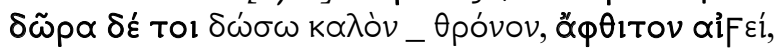

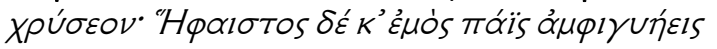

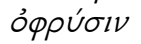

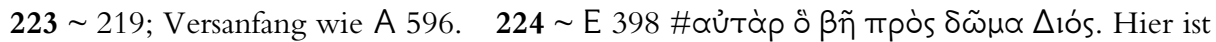

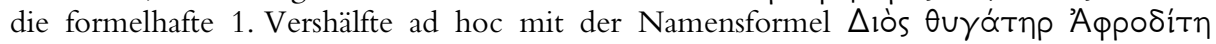
kombiniert, wobei $\Delta$ lós nur einmal steht. $\mathbf{2 2 5}=\mathrm{T}$ 114; originärer Hexameter.

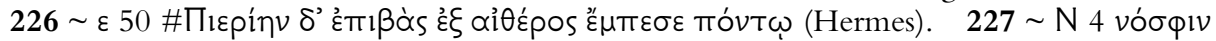

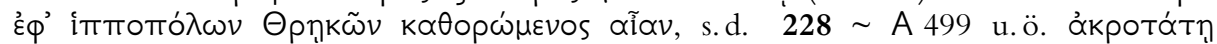

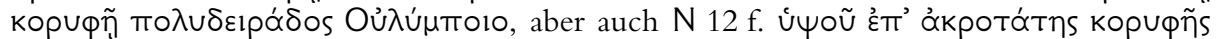

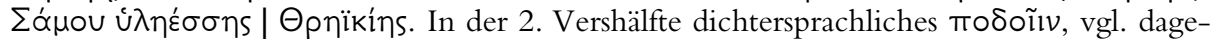

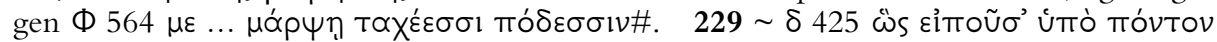

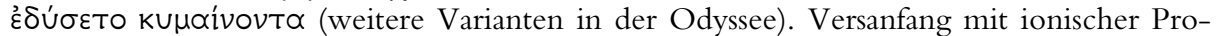
klise: $\delta(\dot{\varepsilon})$ nach dem Präpositionalausdruck statt nach dem ersten Wort; zur Namensform

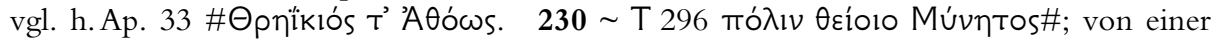

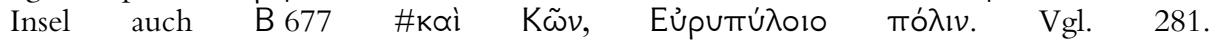

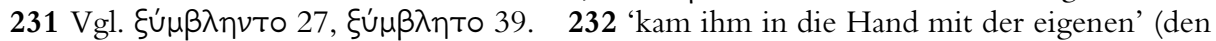
Regeln der deutschen Wortstellung entspräche: 'kam ihm mit der Hand in die seine'). Zur

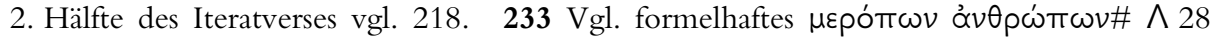
u. ö.; die Stilfigur des Hexameters war im alten Vers nicht realisierbar. 234 f. $\sim$ П 236

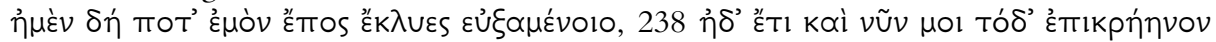

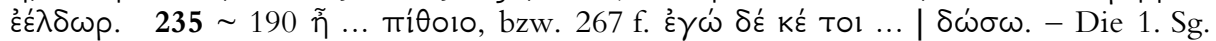

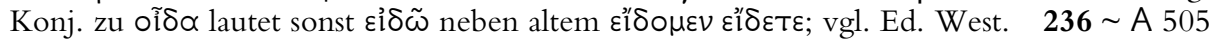

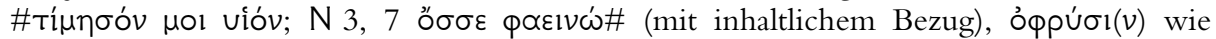

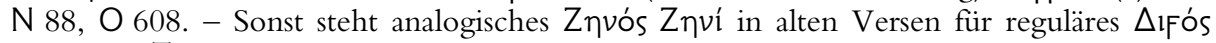
$\Delta \mathrm{l}$ í, vgl. $\Xi 247$ gegenüber 250 und $\mathrm{N}$ 449, O 104, 131. 238 Dichtersprachlicher Vers unbestimmbaren Alters. 
240

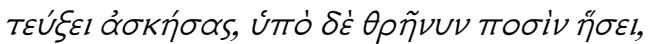

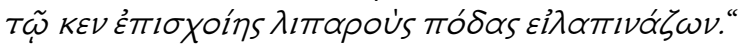

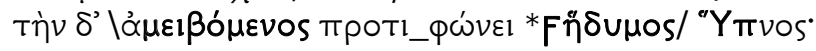

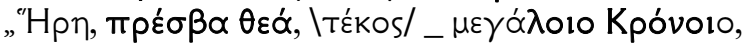

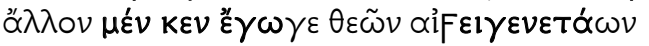

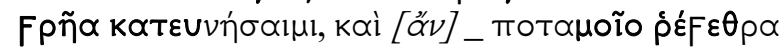

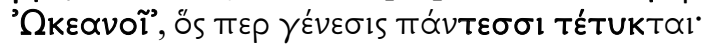

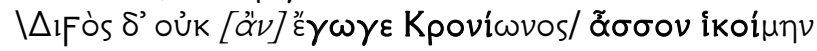

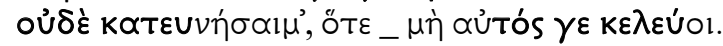

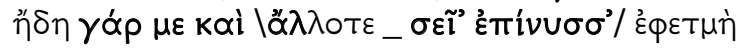

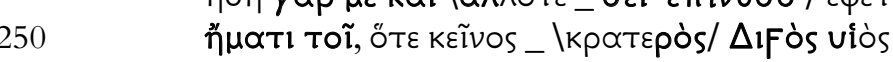

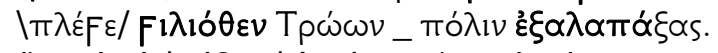

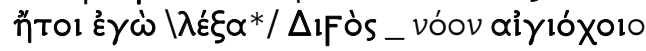

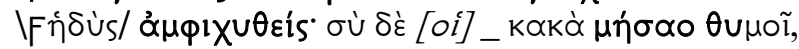

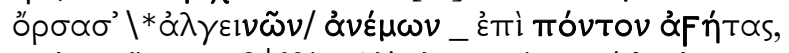

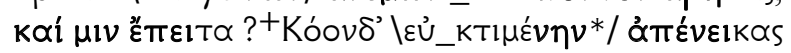

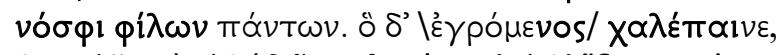

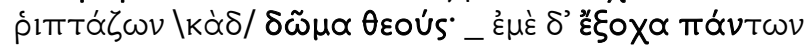

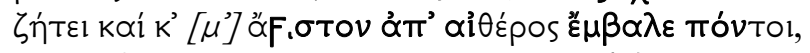

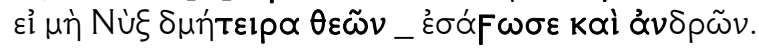

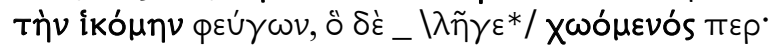

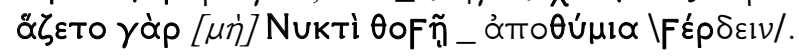

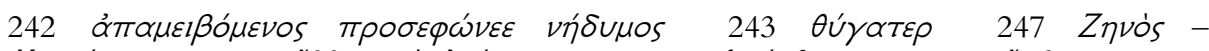

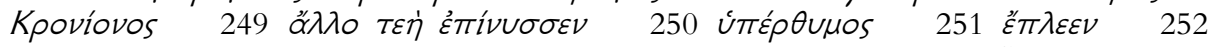

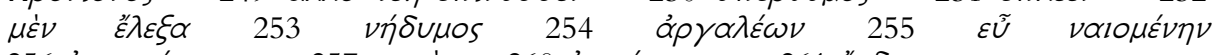

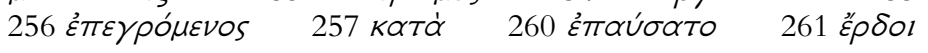

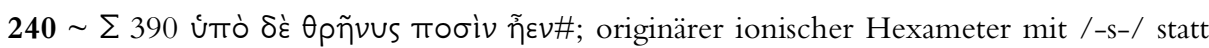

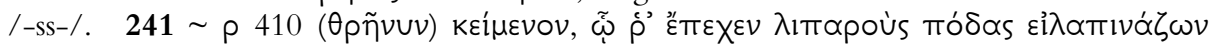

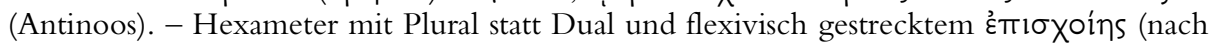

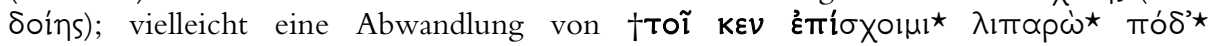

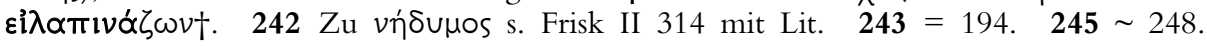

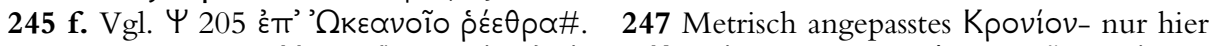

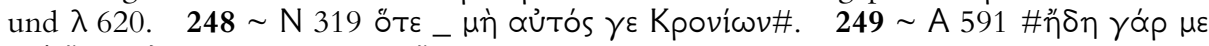

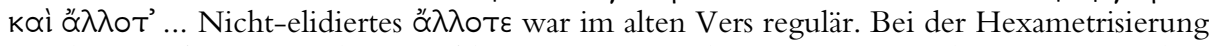
wurde es verkürzt, um die Mitteldiärese zu vermeiden; zur Auseinandersetzung mit dem Ergebnis vgl. Ed. West. - тєท́ nach к. тр. тр. (mit Langvokal im Hiat vor $\varepsilon \phi \theta$.) ersetzt

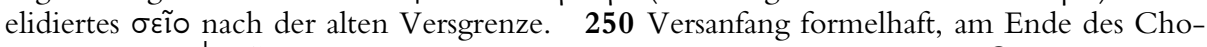
riambus gilt ${ }_{\text {To ̃ }}$ als geschlossene Silbe. - Zur Restitution (wie O 25) vgl. 324

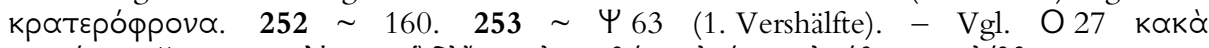

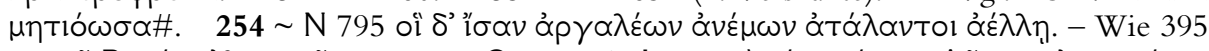

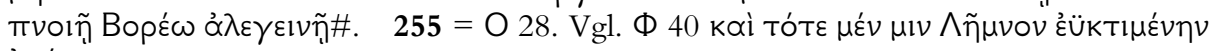

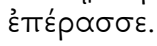




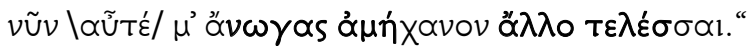

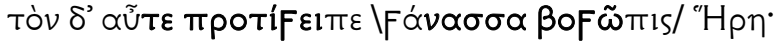

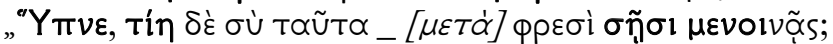

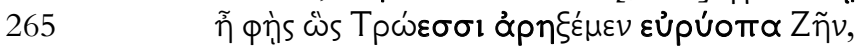

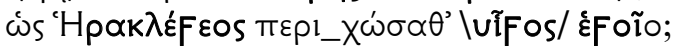

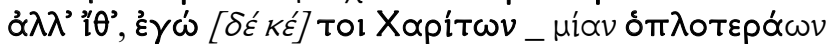

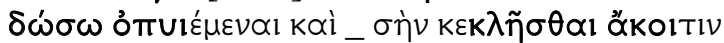

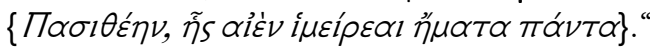

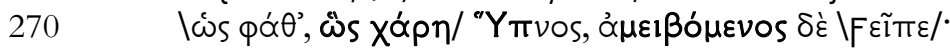

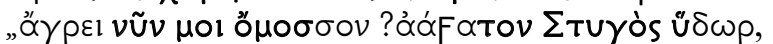

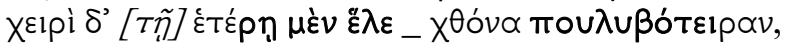

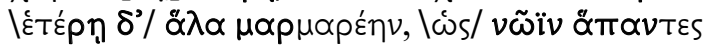

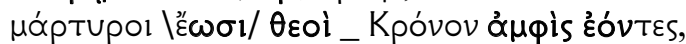

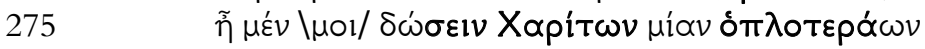

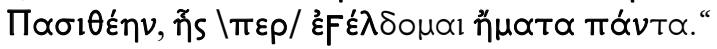

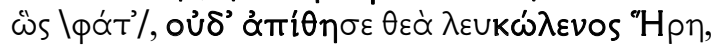

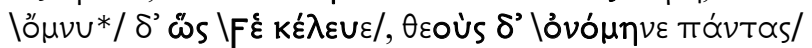

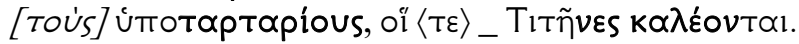

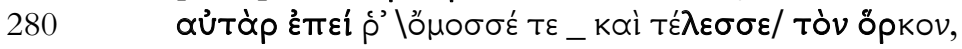

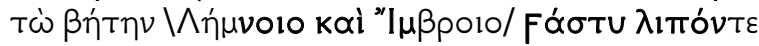

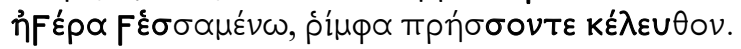

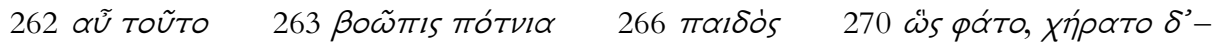

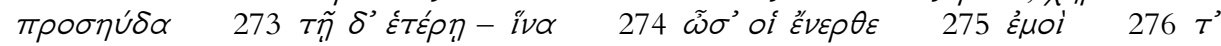

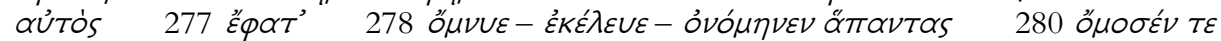

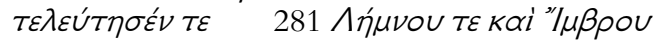

262 Vgl. $v \tilde{U} v \propto$ $\cup \tilde{T} \varepsilon \varepsilon$ $\mu$ 252, 303 u. ö. 263 Erste Vershälfte formelhaft; im übrigen wie

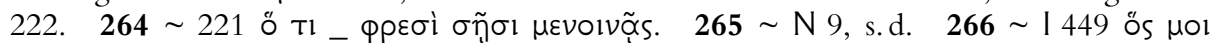

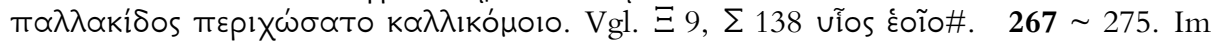

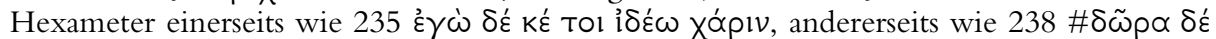

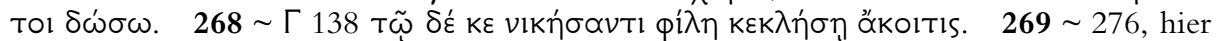

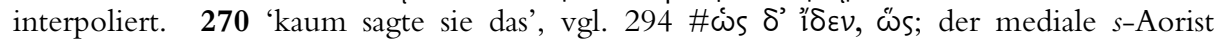

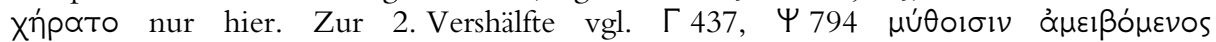

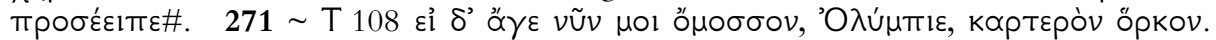

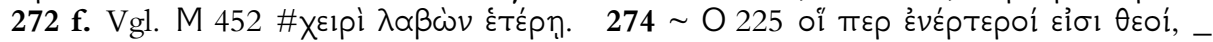

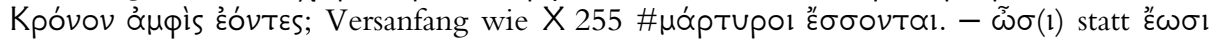
nur hier und $\omega 491 . \quad 275 \sim 267 \mathrm{f} . \quad 277=078$ u. ö.; variabler Formelvers. $\quad 278 \sim$ B 11

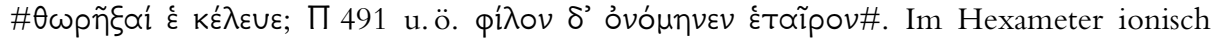
modernisiert. 280 'den verlangten Eid' (anaphorisch); $=\beta$ 378, к 346, $\mu$ 304, ○ 438,

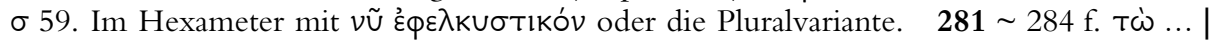

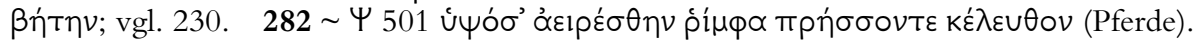




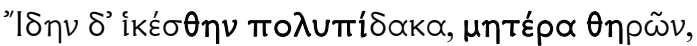

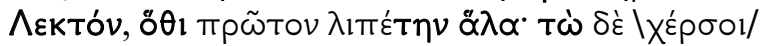

285

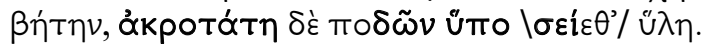

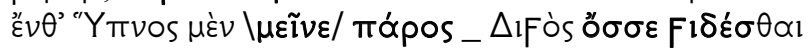

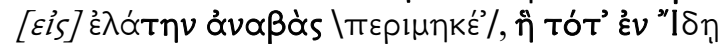

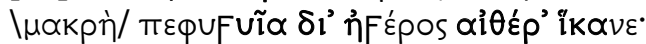

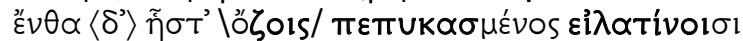

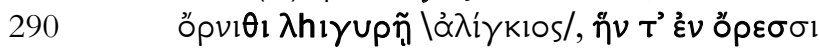

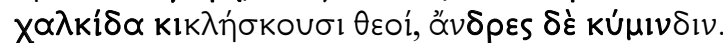

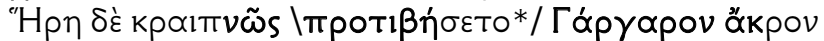

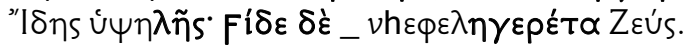

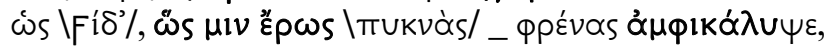

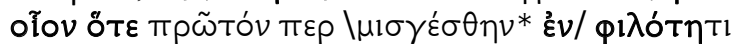

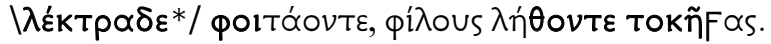

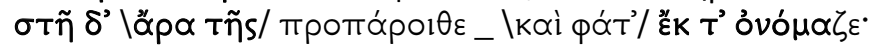

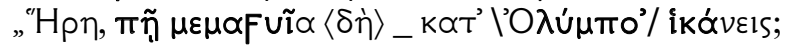

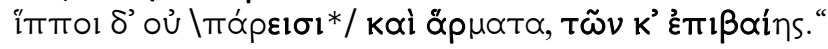

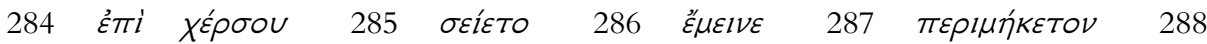

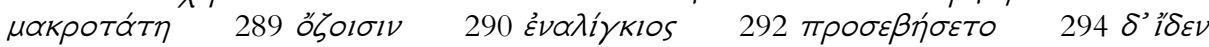

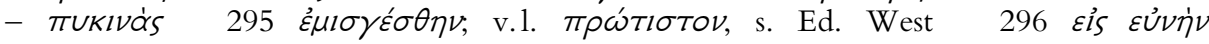

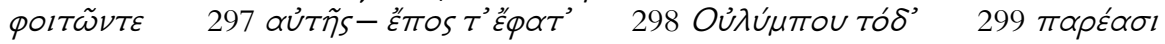

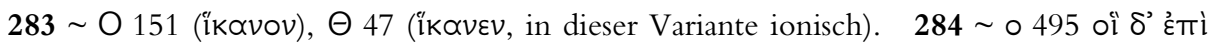
Xépoou\#, in der Odyssee auch weitere Parallelen. 285 Hiat im 5. Biceps des

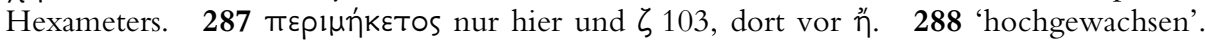

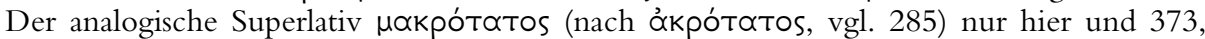

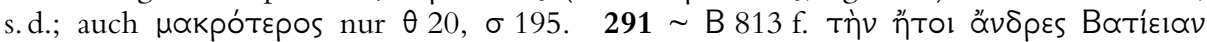
Kıк

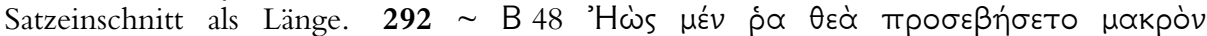
"O

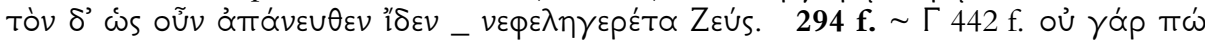

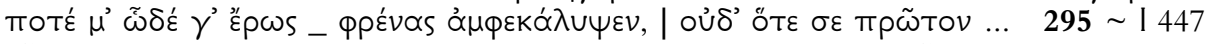

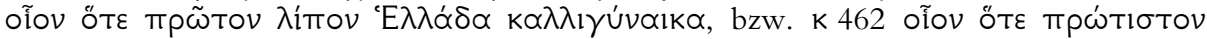

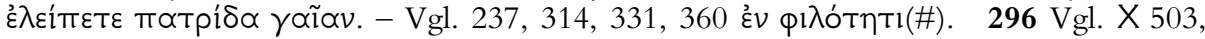

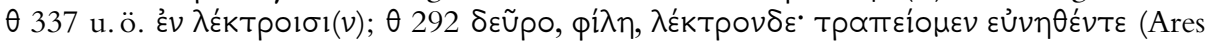

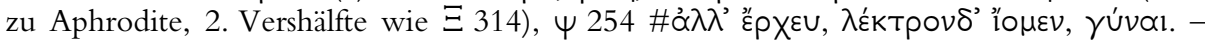

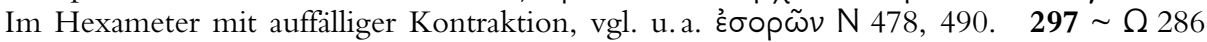

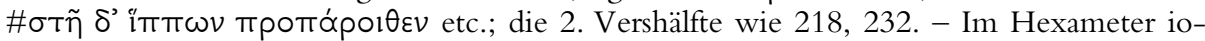

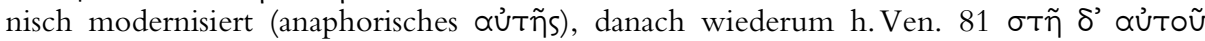

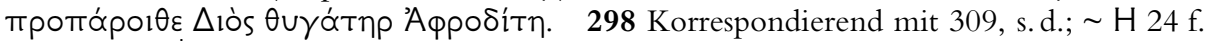

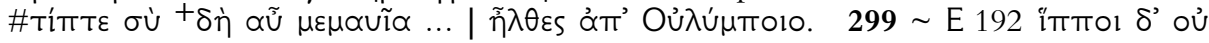

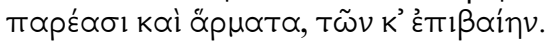


300

305

310

320

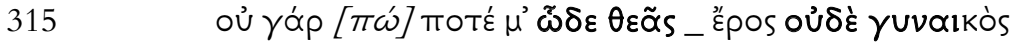

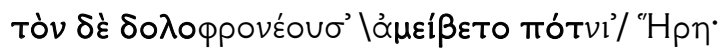

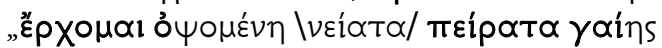

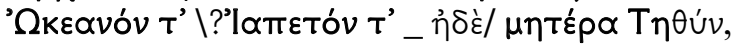

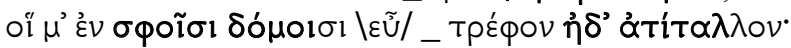

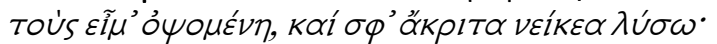

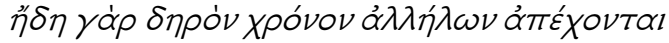

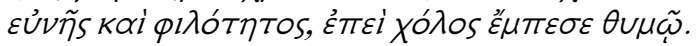

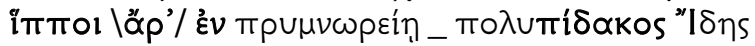

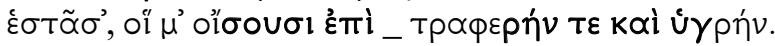

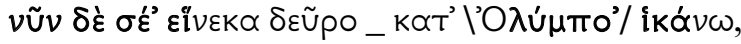

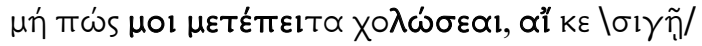

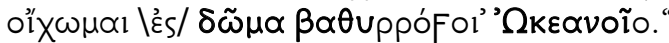

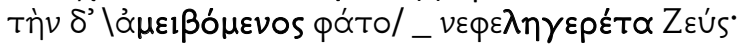

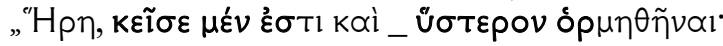

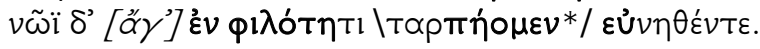

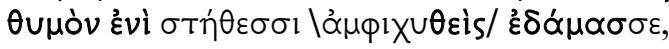

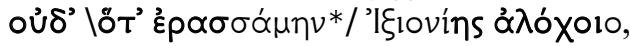

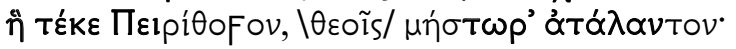

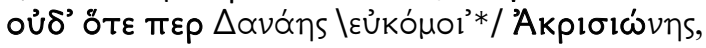

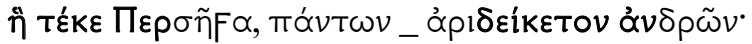

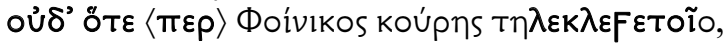

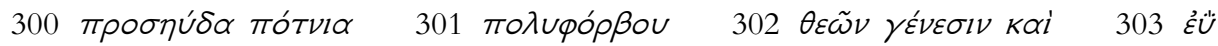

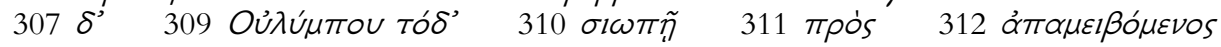

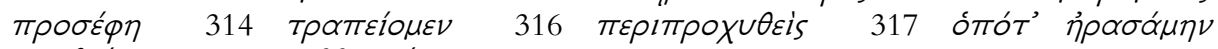

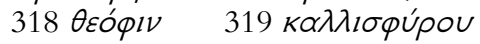

$\mathbf{3 0 0}=329, \sim 197 . \quad 301 \sim 200$, s.d. $\quad 302-306=201$ f., 205 ff., s. d. 307 Die Konjunktion $\delta \varepsilon$ war wohl entbehrlich, weil Hera ihre Antwort auf Zeus' Frage (298) hier durch die Antwort auf seine Nebenbemerkung (299) unterbricht, eingeschoben zwischen 304 \#тoùs

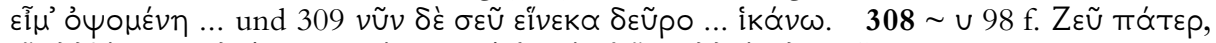

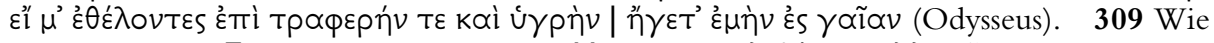

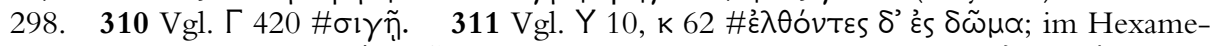

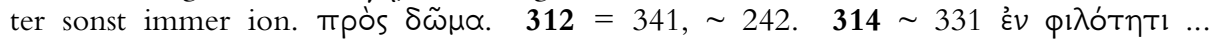

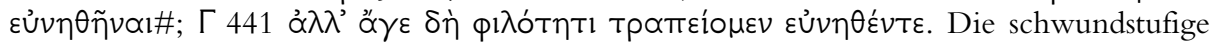

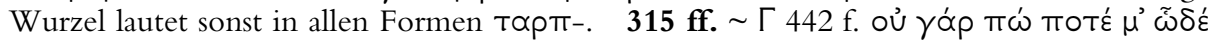

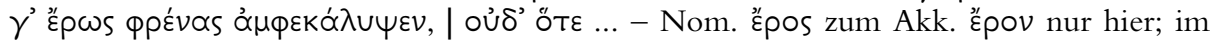
ep. Fünfzehnsilbler könnte stattdessen हैpws gestanden haben, vgl. außer der Parallelstelle

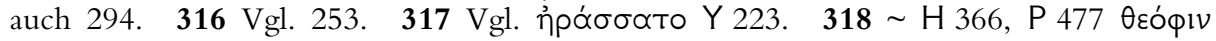

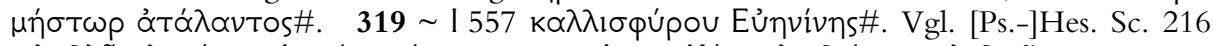

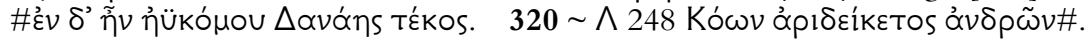




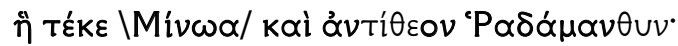

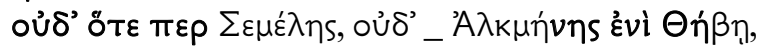

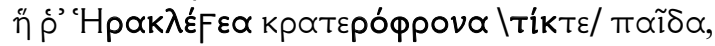

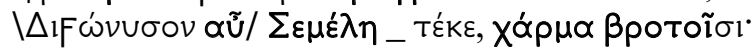

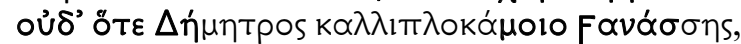

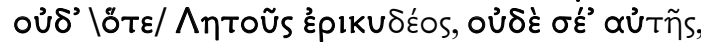

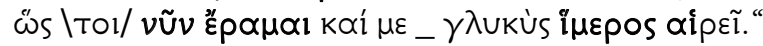

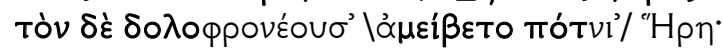

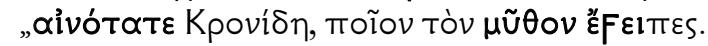

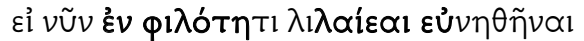

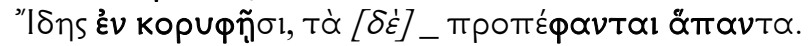

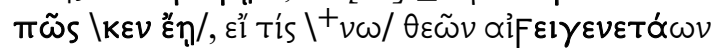

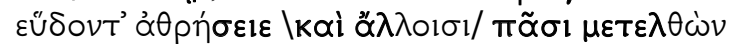

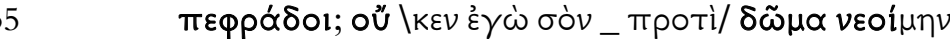

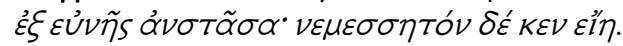

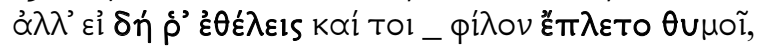

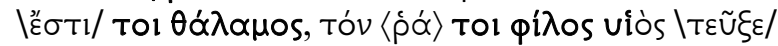

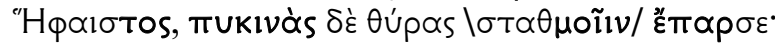

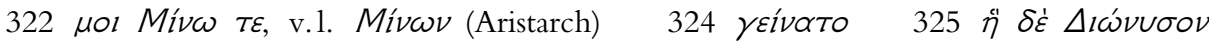

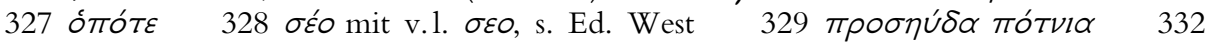

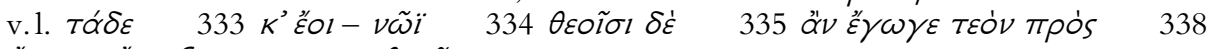

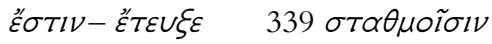

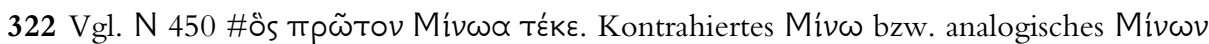

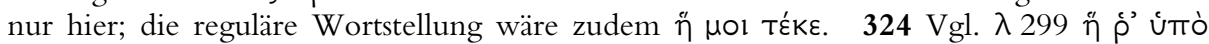

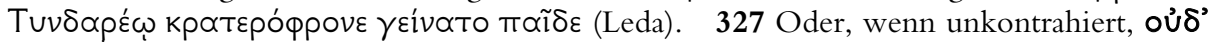

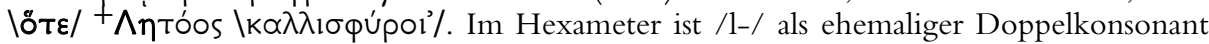

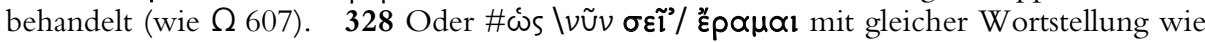

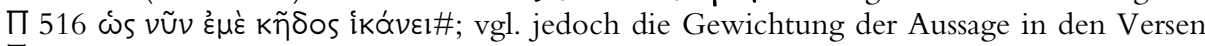
$\Xi 315 \mathrm{ff}$. Der Anfang des Hexameters ist in jedem Fall, ohne metrischen Anlass, ionisch modernisiert. $\mathbf{3 2 9}=300 . \quad 330$ Iteratvers der Ilias. $\mathbf{3 3 1} \sim 314,360 . \quad 331$ f. $\sim$ O 4 f.

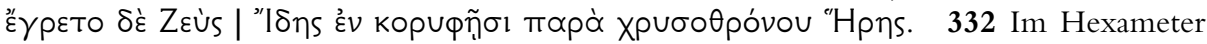

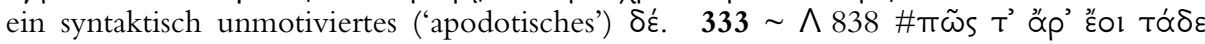

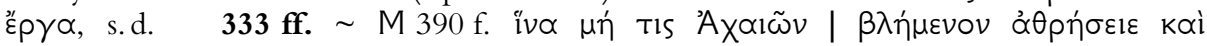

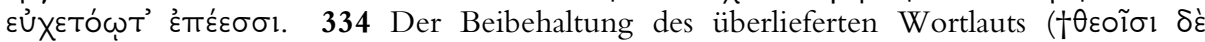
$\pi \tilde{\alpha} \sigma \mathfrak{l} \mu \varepsilon \tau \varepsilon \lambda \theta \omega \dot{v} \# \dagger)$ steht der Vorläufer der Hermannschen Brücke entgegen; $\delta \varepsilon \dot{\varepsilon}$ wird erst im Hexameter wie $T \varepsilon$ behandelt. 335-353 Am Schluss der Episode häufen sich 'Idealverse' mit dreifacher metrischer Binnengliederung (11 von 14 alten Versen, unterbrochen durch 5 neue). $\quad 336 \sim$ o 58, 96 \#a̛v zu Aphrodite) und $\Omega$ 463. Wohl ein eingeschobener dichtersprachlicher Hexameter. 337

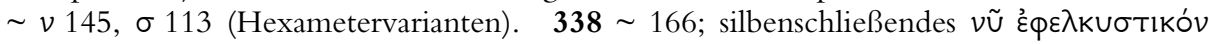
im 1. Biceps. $\quad 339=167$. 


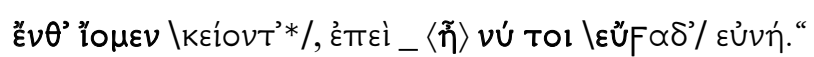

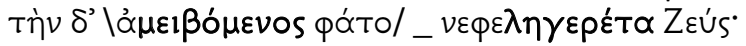

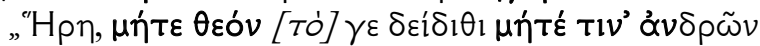

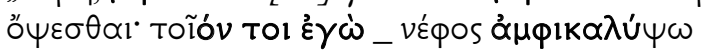

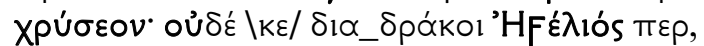

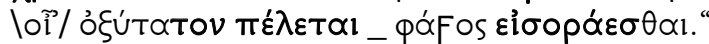

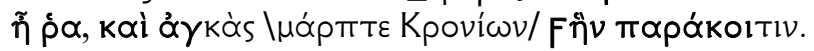

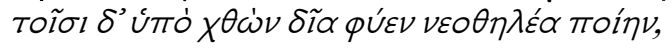

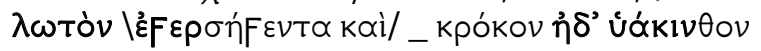

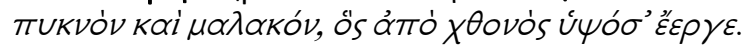

350

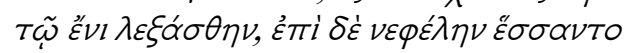

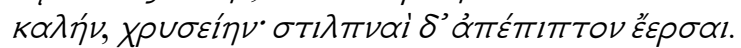

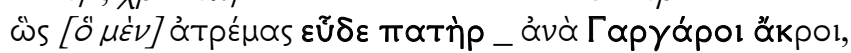

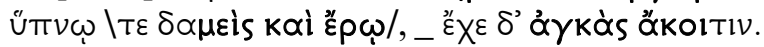

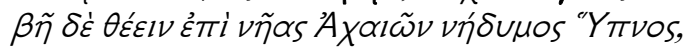

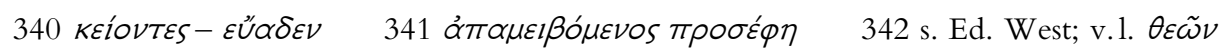

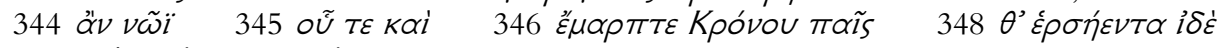

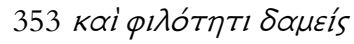

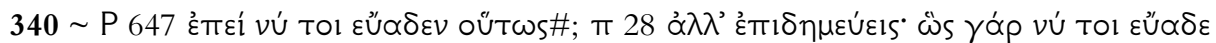

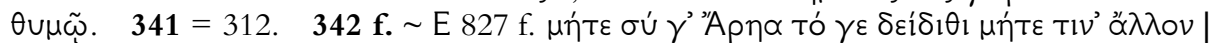

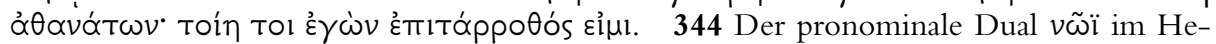

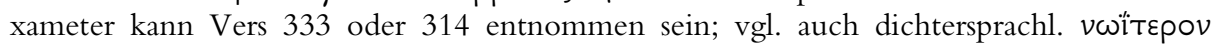

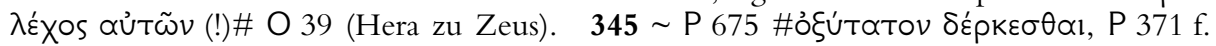

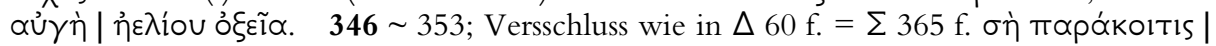

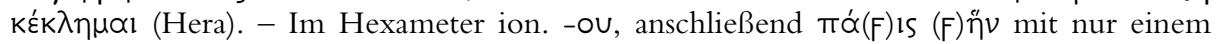
Digammareflex. 347-351 Ein übernommener alter Vers (348) inmitten originärer Hexameter, die den ionischen Dichter verraten. 347 Plural statt Dual, silbenschließendes vũ

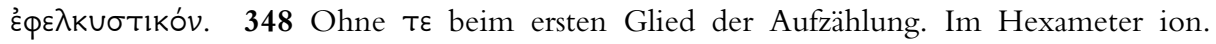

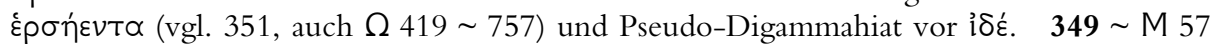

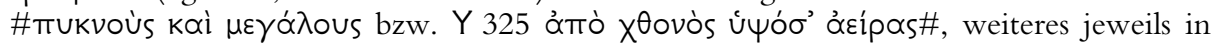
der Odyssee. 350 T $\tilde{\omega}$ है है l (mit lang gemessenem $-\omega \leftarrow-0$, vgl. 149 und 250) nur hier und $\varepsilon 57, \zeta 46$, beidemal in ähnlichem Kontext. - Die Dualform $\lambda \varepsilon \xi \alpha ́ \sigma \theta \eta v$ erweist keinen alten Vers, sondern dient als dichtersprachliche Variante zu $\lambda \varepsilon \dot{\varepsilon} \xi \alpha \nu 0^{\star}$ (wie $\varepsilon \sigma \sigma \sigma \alpha \nu$ to\#). In

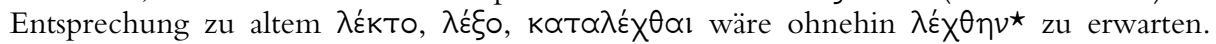

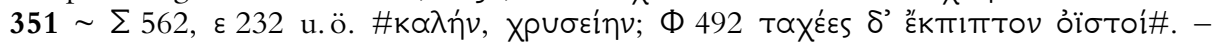
$\sigma \tau \imath \lambda \pi v$ ós erscheint erst wieder bei Aristoteles. $352 \sim 292$, O 152. Das überleitende $\mu \varepsilon \dot{v}$

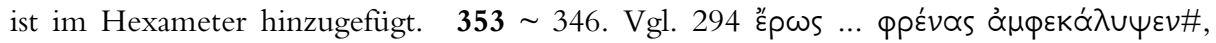

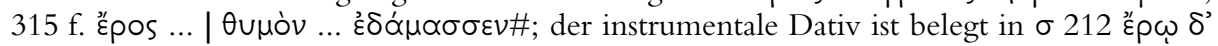

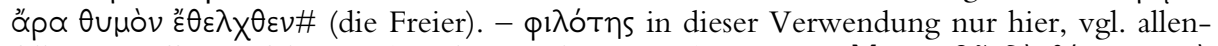

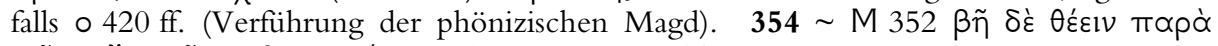

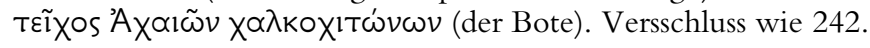




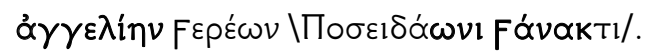

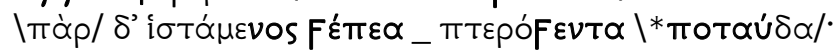

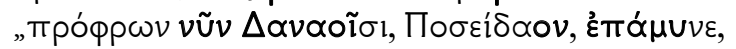

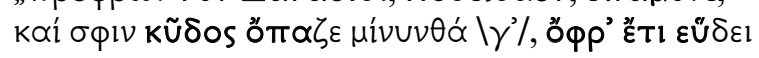

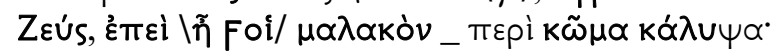

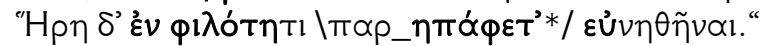

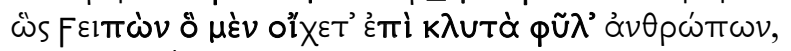

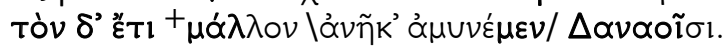

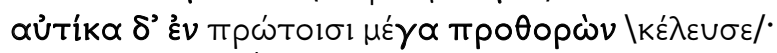

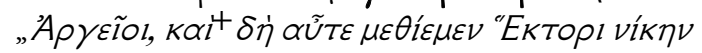

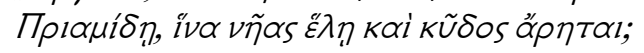

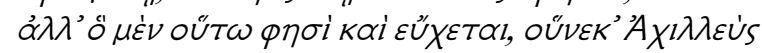

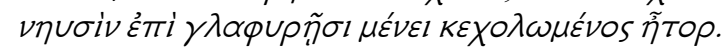

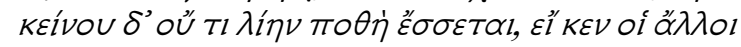

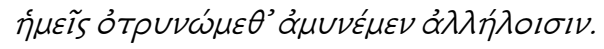

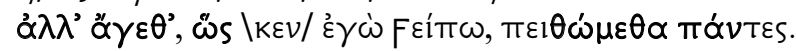

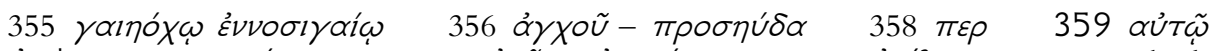

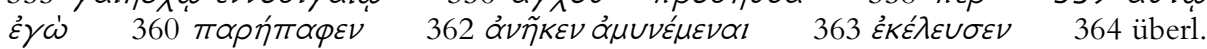 $\delta^{\prime} \alpha \tilde{U} T \varepsilon$, s. Ed. West 370 ờ $\nu$

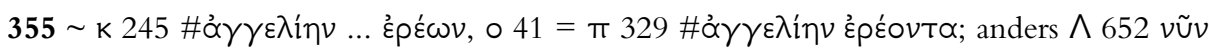

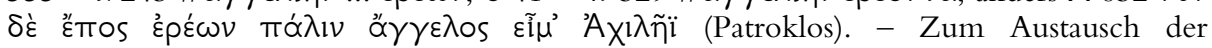

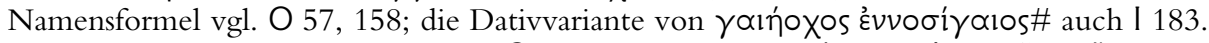

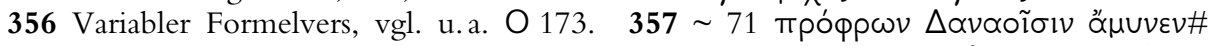

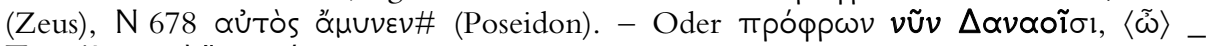

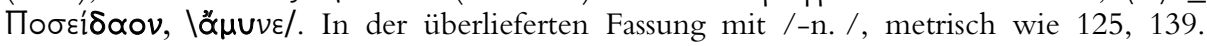

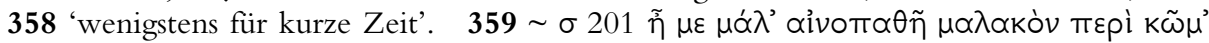

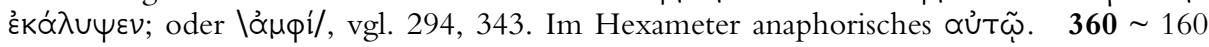

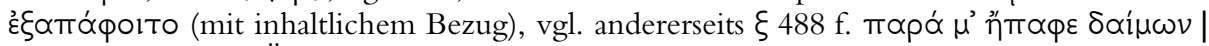

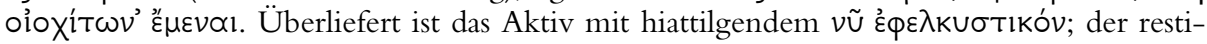
tuierte Vers besitzt die zusätzliche Bedeutungskomponente 'im eigenen Interesse'. 361

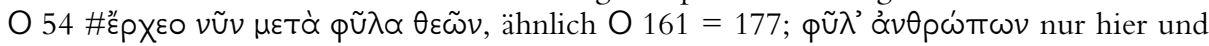

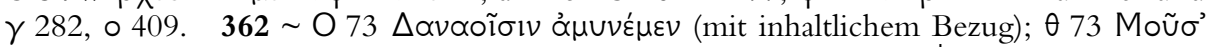

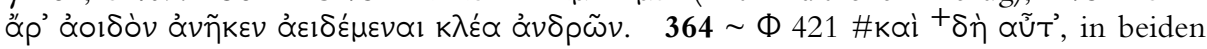
Fällen mit Synizese. - $\mu \varepsilon \theta i ́ \eta \mu$ ist auffallend anders verwendet als in Poseidons erster Parainese an die Argeier (N 97, 108, 114, 116, 118, 121 als Leitmotiv 'im Kampf nachlassen',

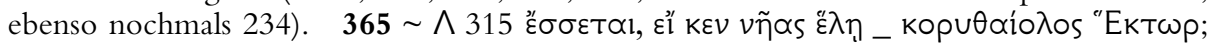

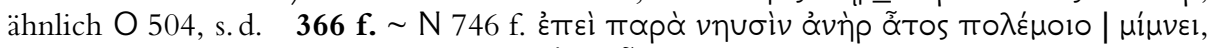

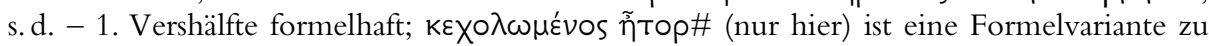

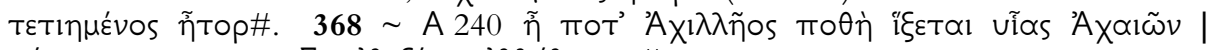
бúf 


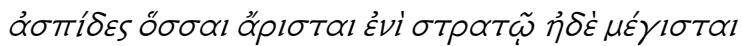

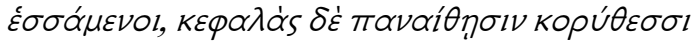

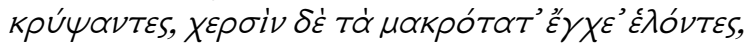

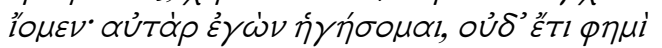

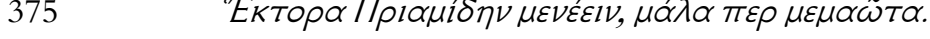

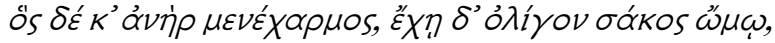

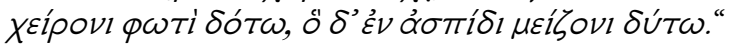

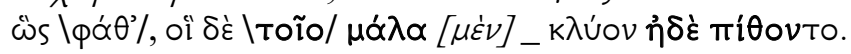

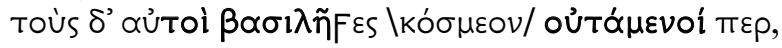

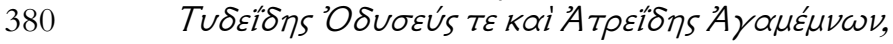

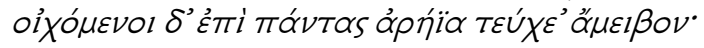

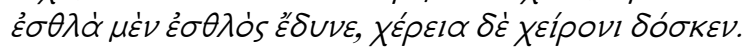

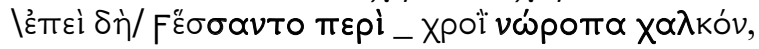

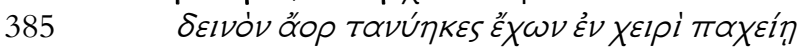

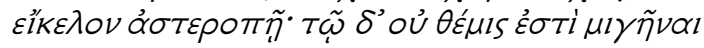

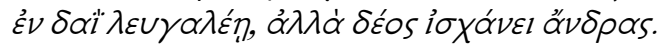

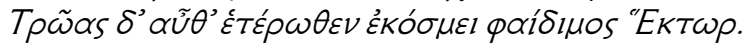

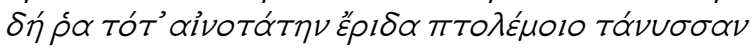

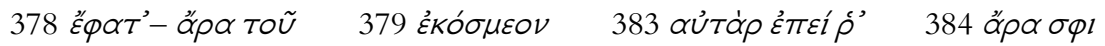

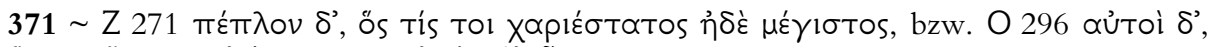

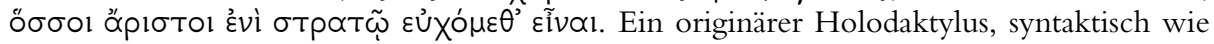

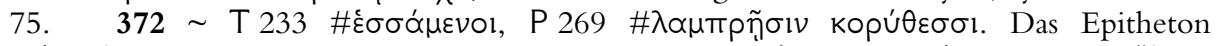

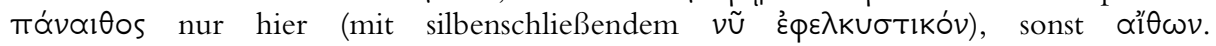

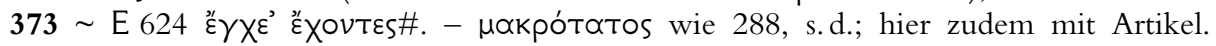

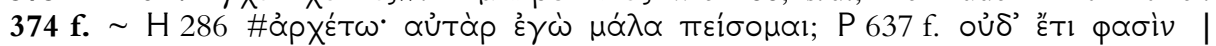

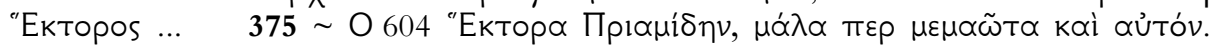

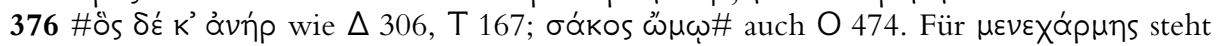

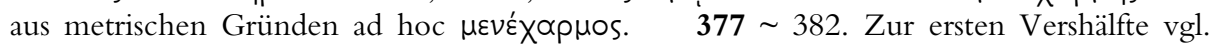

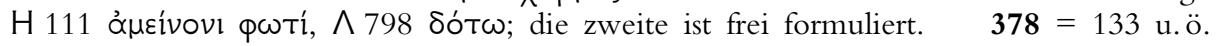
$\mathbf{3 7 9} \sim$ 128; die inhaltliche Entsprechung folgt $388 . \quad 380=29 . \quad 381$ f. $\sim Z 235$ òs

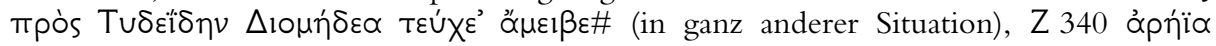

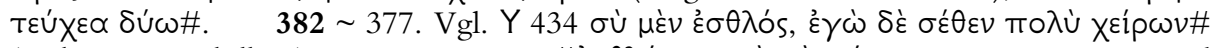

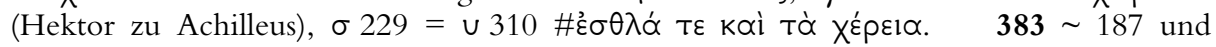

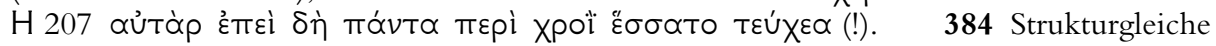

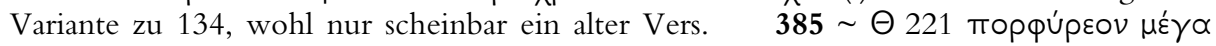

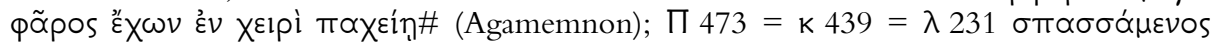

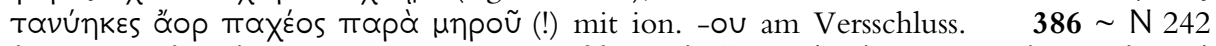

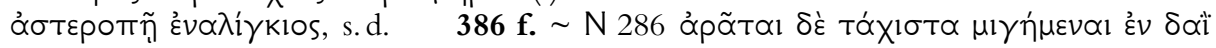

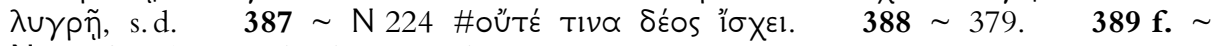
N 358 f., s. d.; ion. Plural statt Dual. 
390

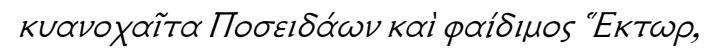

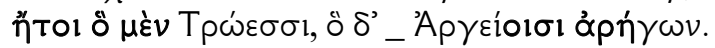

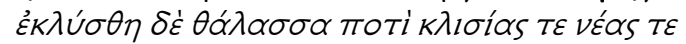

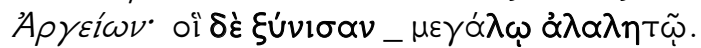

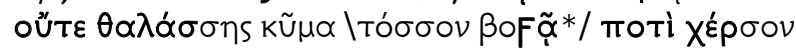

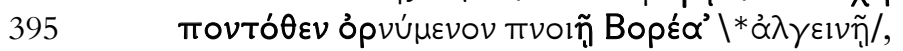

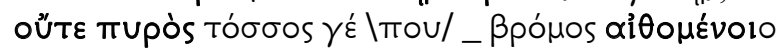

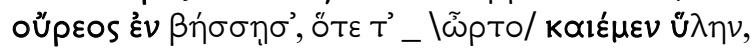

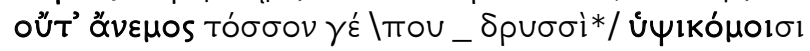

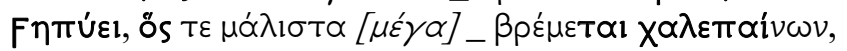
400

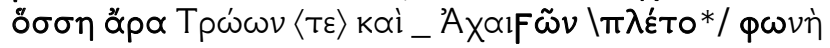

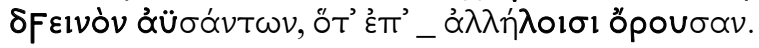

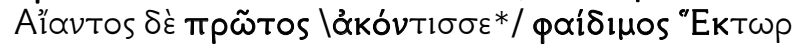

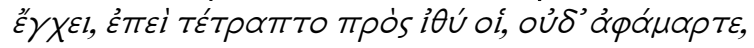

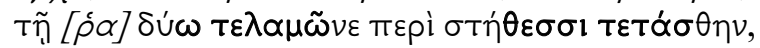
405

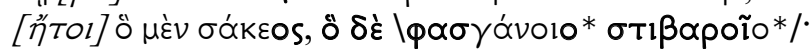

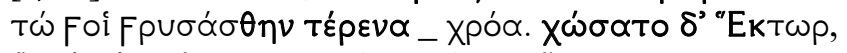

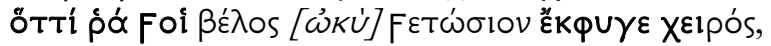

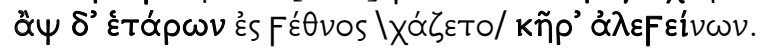

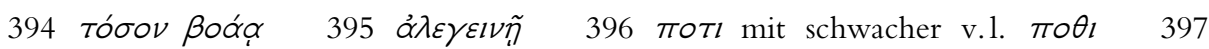

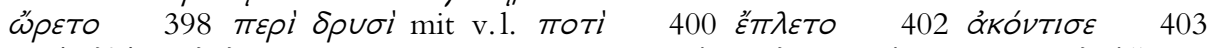

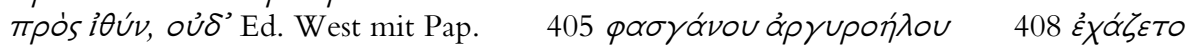

$390 \sim$ N 563, s. d.; Kombination zweier Namensformeln, die auch als epischer Fünfzehn-

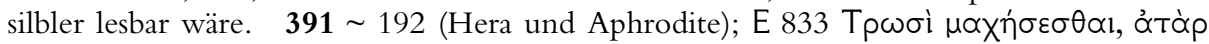

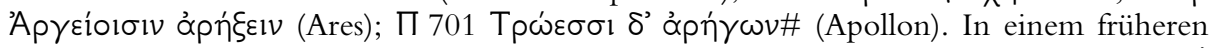
Kontext auf zwei Götter bezogen, vgl. Friedrich 1956, 38 Anm. 3. $392 \sim 394$ тоті

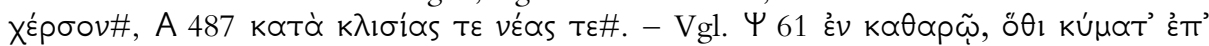

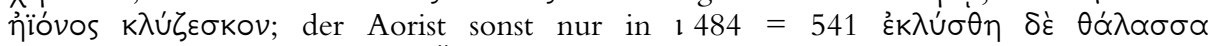

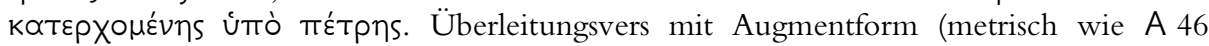

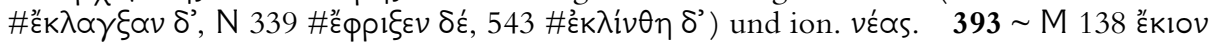

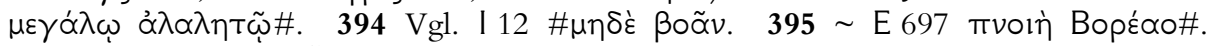

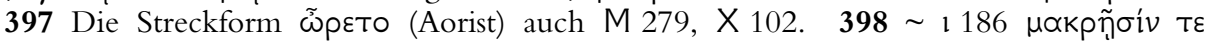

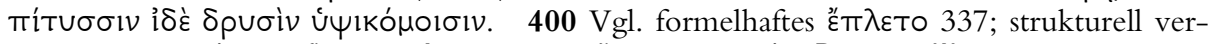

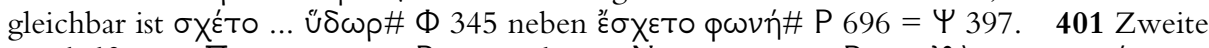

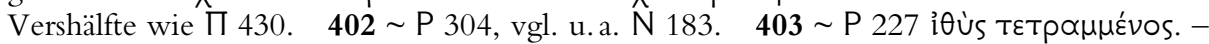
Dichtersprachl. Hexameter mit Enjambement, oi in der Stellung von ion. $\propto \cup ̉ T \tilde{\omega}$ und ion.

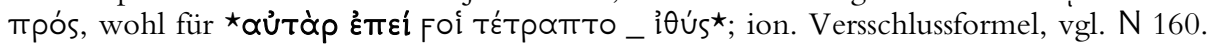

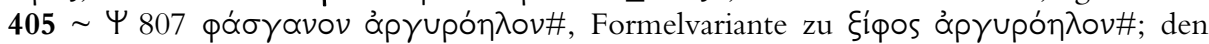

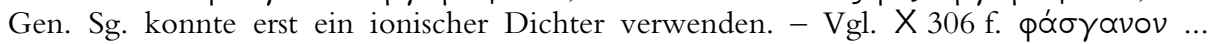
бтıßарóv. Metrisch wie 357. 406 Versschluss wie X 291. $407=X 292 . \quad 408$ Formelvers, u.a. N 566. 


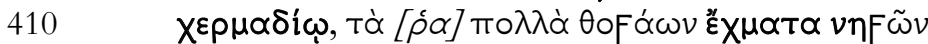

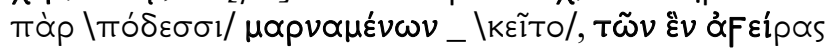

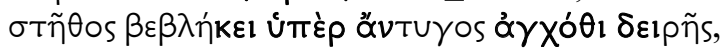

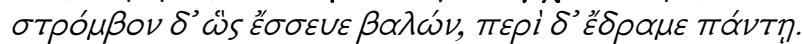

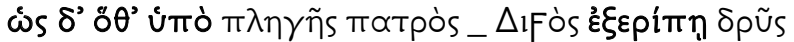

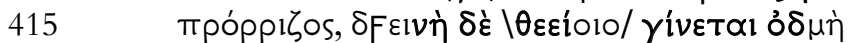

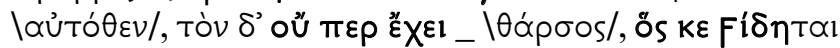

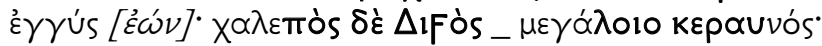

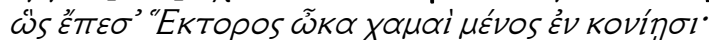

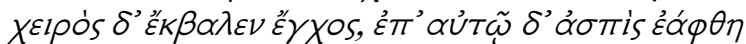

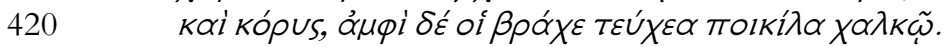

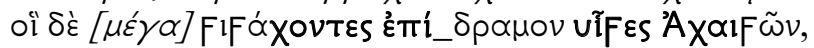

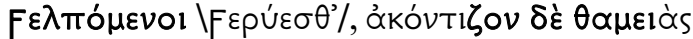

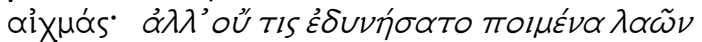

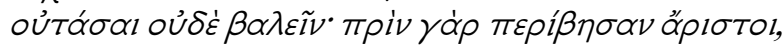

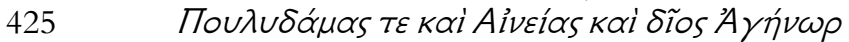

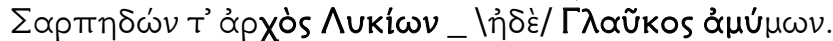

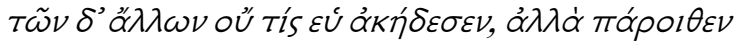

411 тоо

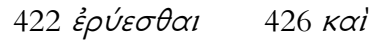

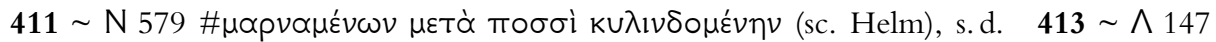

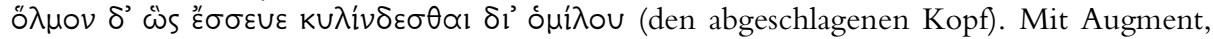

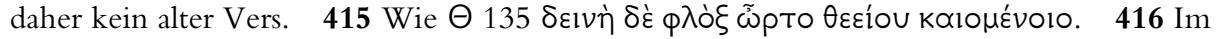

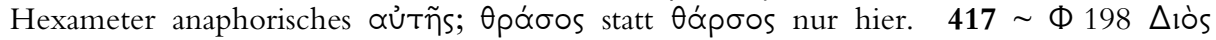

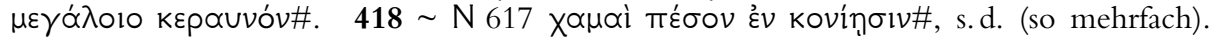

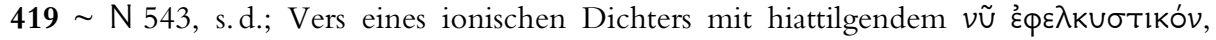
anaphorischem $\propto \cup \mathcal{T} T \tilde{\omega}$ und $\delta(\dot{\varepsilon})$ nach dem Präpositionalausdruck statt an zweiter Stelle nach

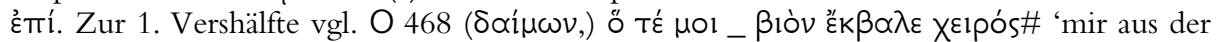

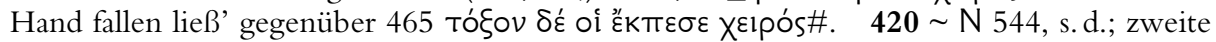
Vershälfte wie N 181, M 396. 421 Im Hexameter mit Kürze im 2. Longum.

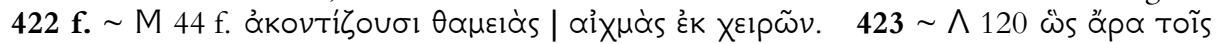

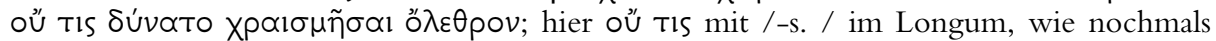
427, doch nirgends sonst. Ursache dieser metrischen Irregularität ist das syllabische Aug-

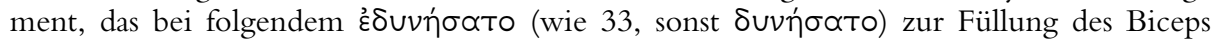
benötigt wird. 424 Hexameter auf ionischer Dialektbasis (\#oủTóool statt \#oủTó $\mu \varepsilon v \alpha l,-\beta \eta \sigma \alpha v$ statt $-\beta \alpha v)$. 425 Als ep. Fünfzehnsilbler lesbar, aber wohl eine ad hoc zusammengestellte Namenreihe. $\quad 426 \sim$ B 876 (Troerkatalog). $\quad 427 \sim \psi 70$ o ่ $\mu \varepsilon ́ v$

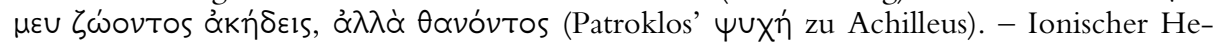

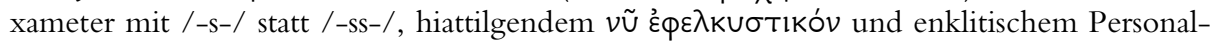
pronomen an später Stelle vor dem Verb; oü Tis wie 423. 


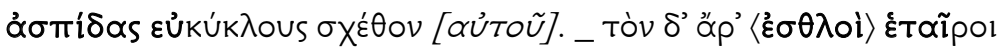

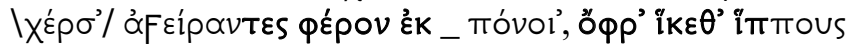

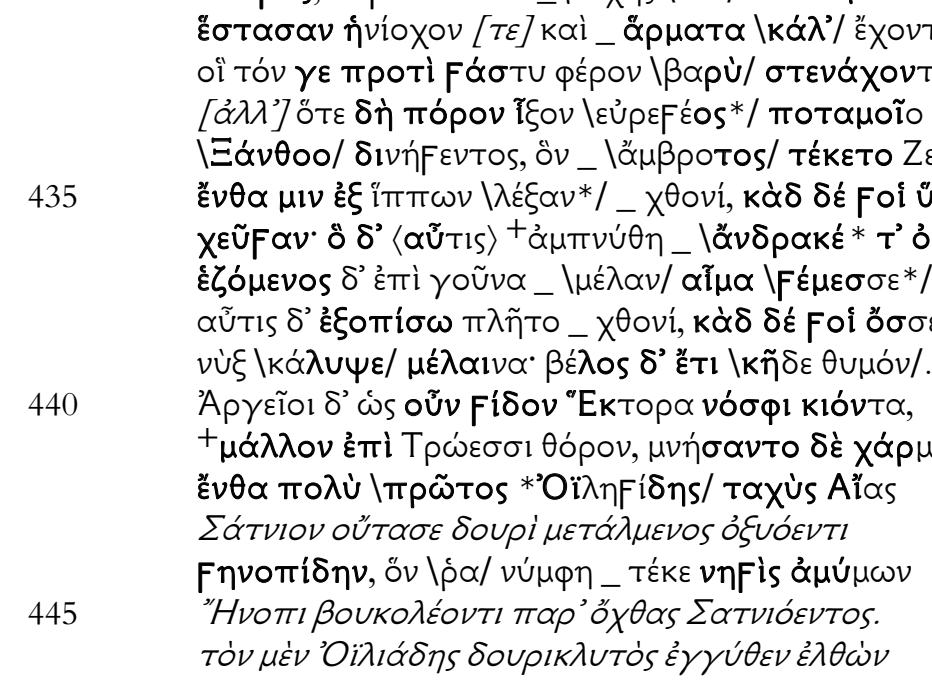

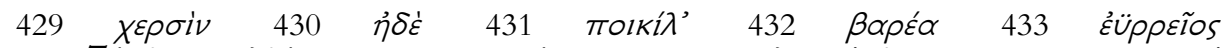

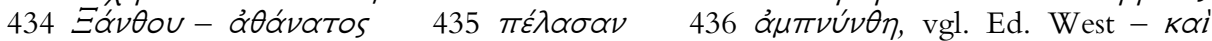

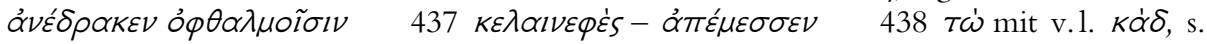

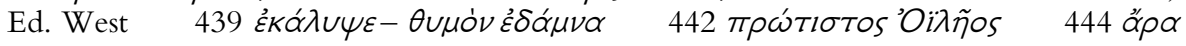

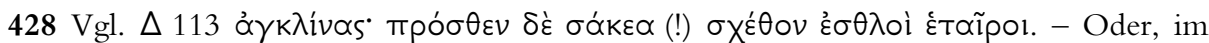

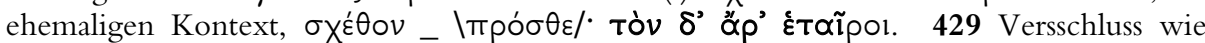
$\mathrm{N} 535.430$ ff. $=$ N 536 ff. $\overline{433} \mathbf{f}$. $=\Phi 1$ f., auch dort fortgesetzt durch \#हैv $\theta \propto$. Zweite Vershälfte von 434 wie B $741 . \mathbf{4 3 5}$ 'betteten ihn auf die Erde'. Im Hexameter angegli-

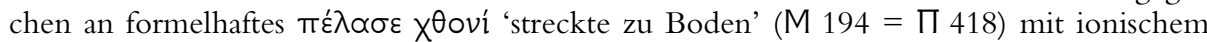

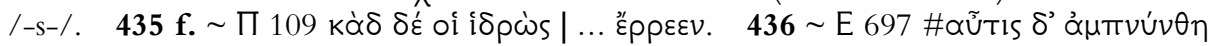

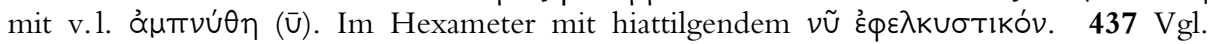

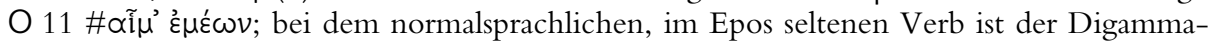

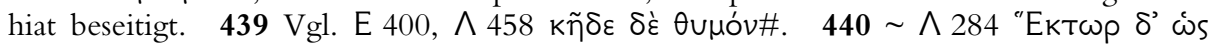

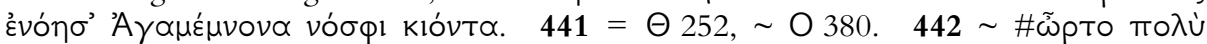

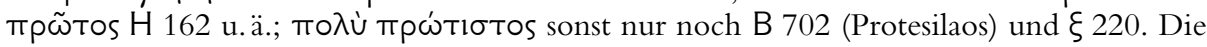

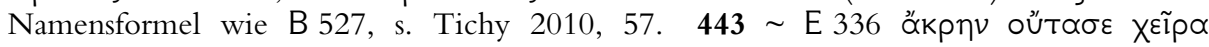

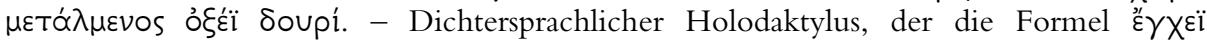

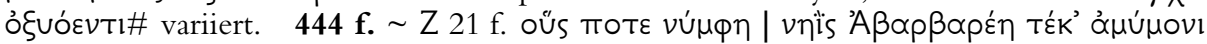

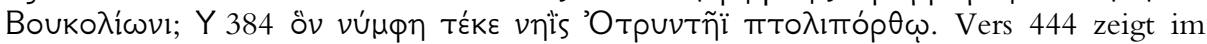

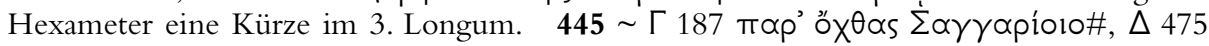

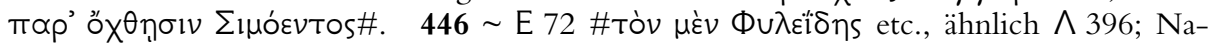
mensvariante im Hexameter. 


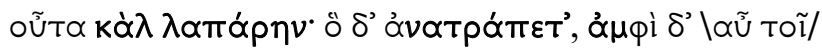

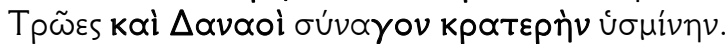

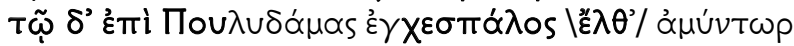

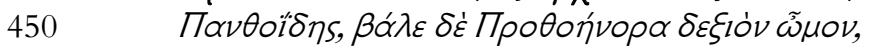

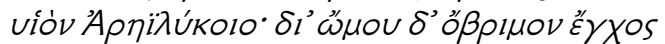

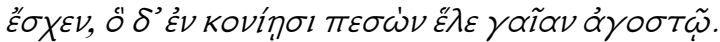

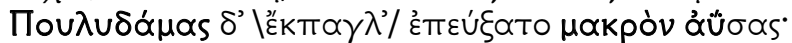

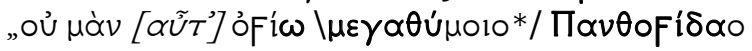

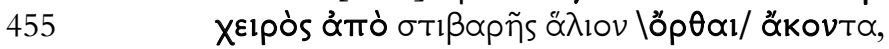

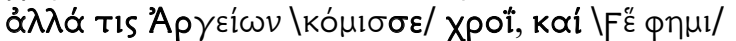

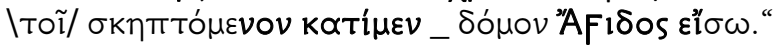

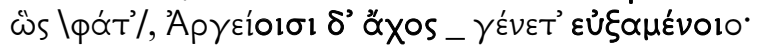

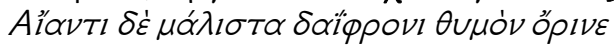

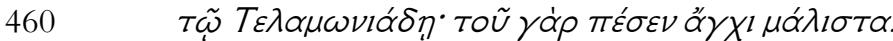

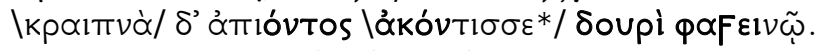

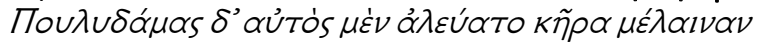

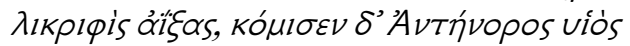

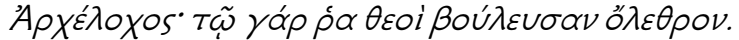

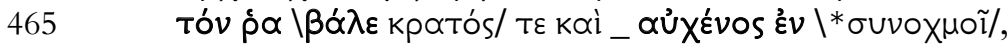

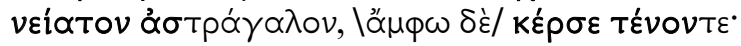

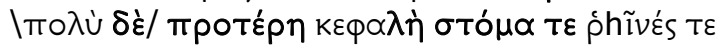

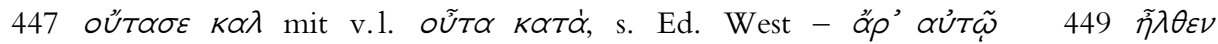

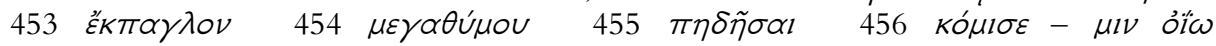

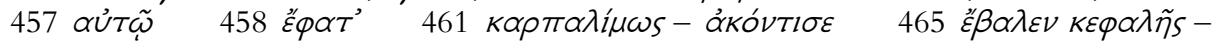

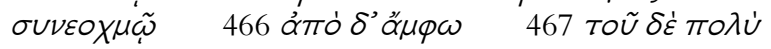

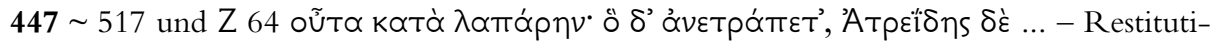
on des Versschlusses wie O 449, s.d. $448=\Pi 764.449 \sim \mathrm{N} 384$, O 540.

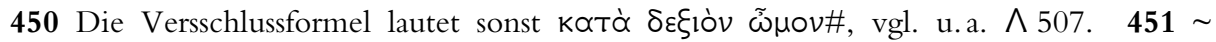
N 519 (Namensvariante). $\quad \mathbf{4 5 2}=$ N 520, s.d. $\quad \mathbf{4 5 3} \sim 478$ und N 413, 445, letztere reine

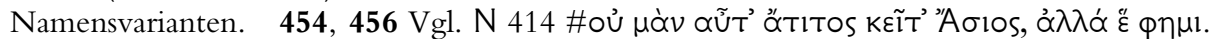

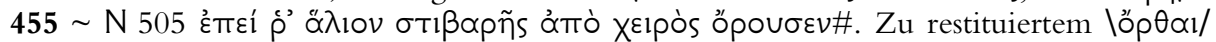

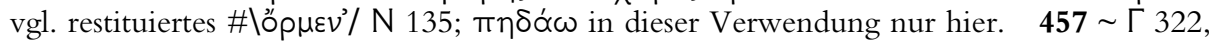

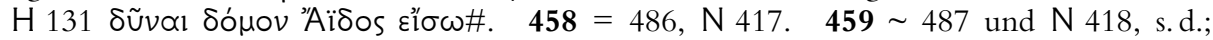

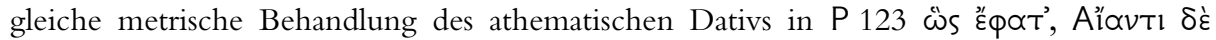

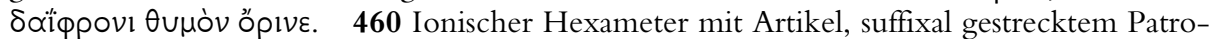

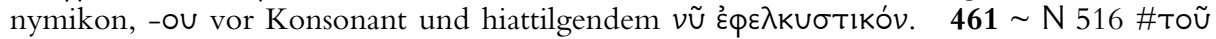

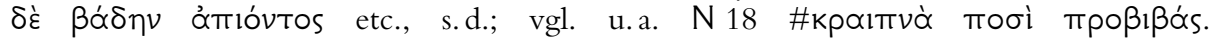
462 Zweite Vershälfte formelhaft. 463 Kein alter Vers, weil restituiertes \кó $\mu$ $\sigma \varepsilon /$ (wie 456) hier gegen die vorhexametrische Hermannsche Brücke verstoßen würde. 464 Als

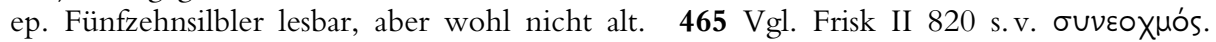

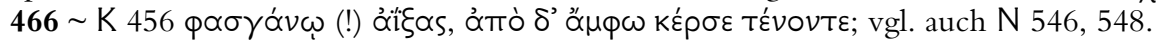




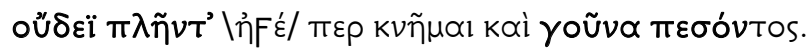

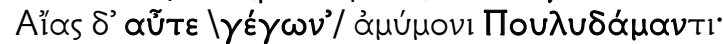

\begin{tabular}{|c|c|}
\hline 470 & 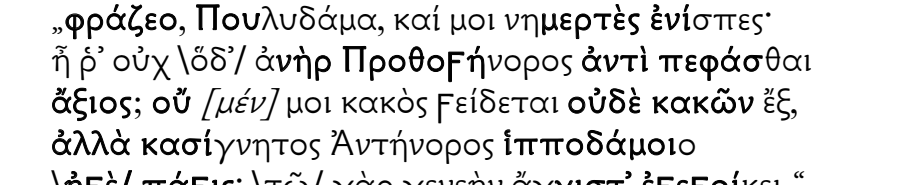 \\
\hline 475 & 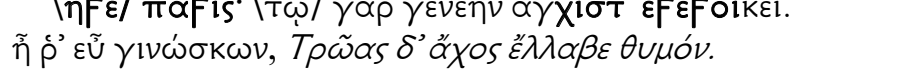 \\
\hline & 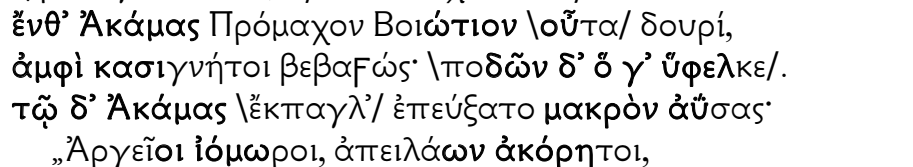 \\
\hline 480 & 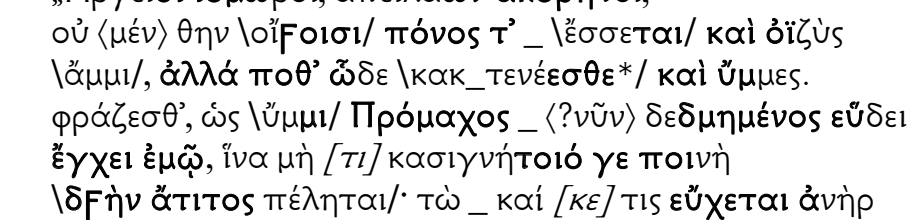 \\
\hline 485 & 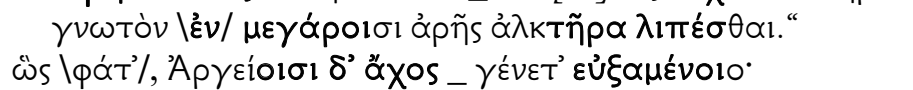 \\
\hline
\end{tabular}

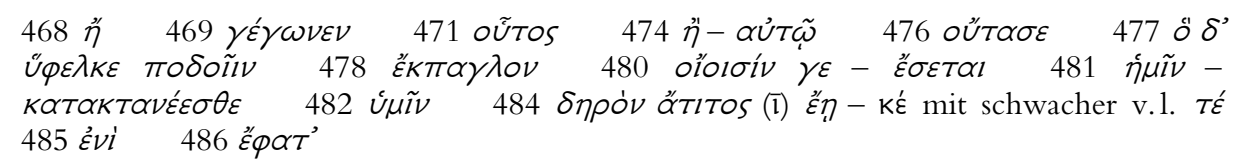

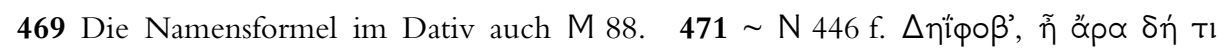

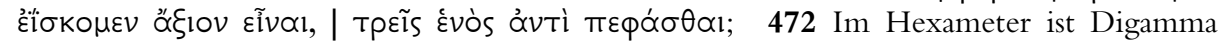

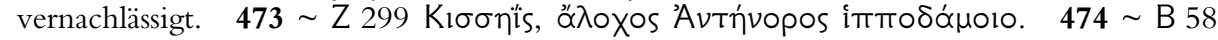

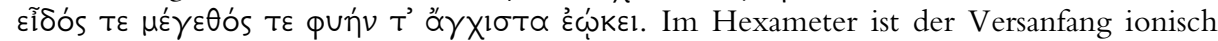

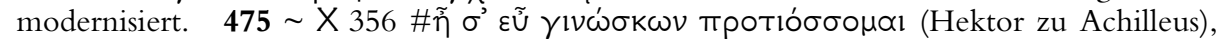

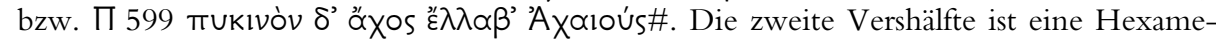

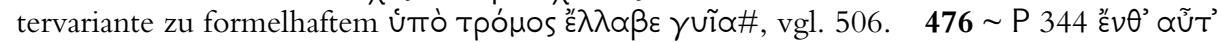

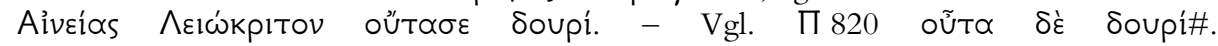

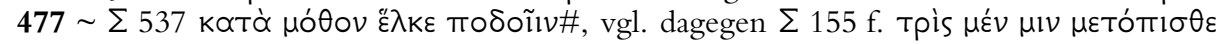

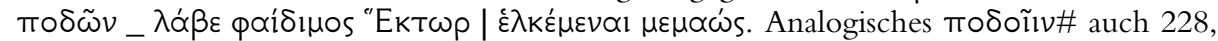

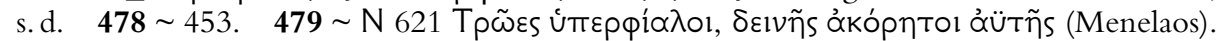

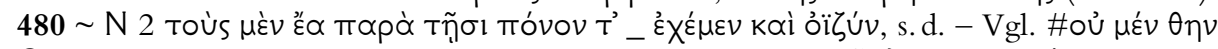

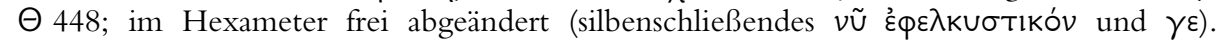

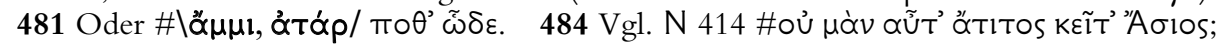
das Verbaladjektiv gehört hier wie dort zu tívw 'Buße zahlen', nicht tíw 'ehren'. Im He-

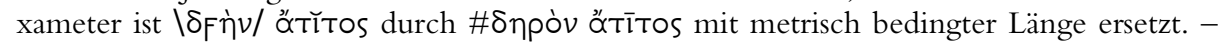

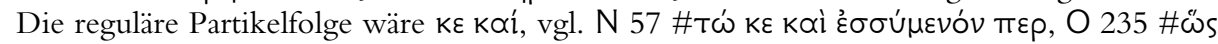

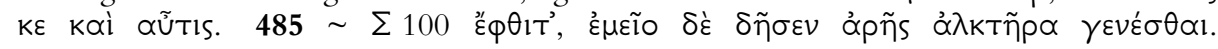
$486=458$. 


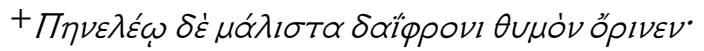

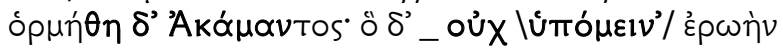

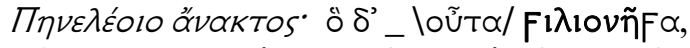

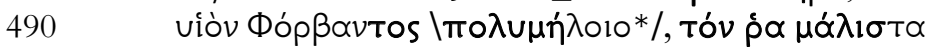

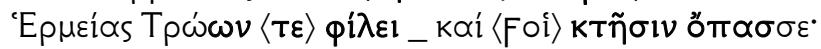

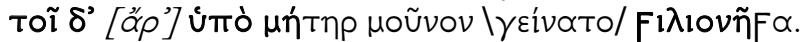

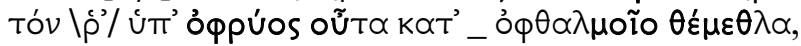

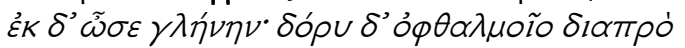

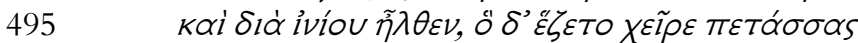

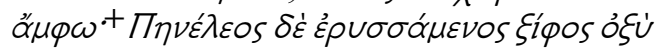

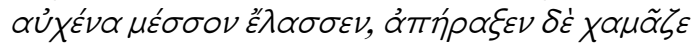

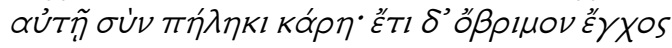

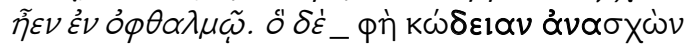

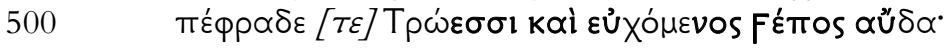

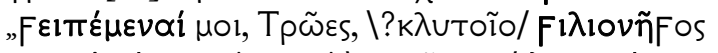

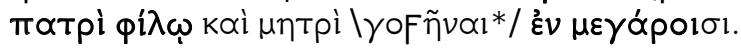

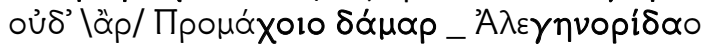

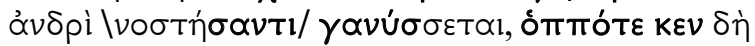

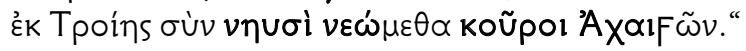

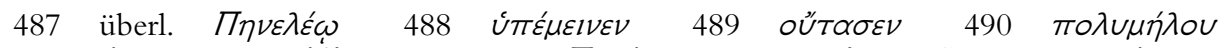

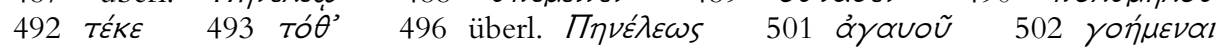

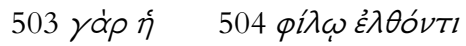

$487 \sim 459$ (Namensvariante). - Vgl. 489, 496, auch B 494. Der Name des Boioters ist kein etymologisch durchsichtiges Kompositum auf ion. $-\lambda \varepsilon \omega \varsigma$ statt des allein homerischen $-\lambda \bar{\alpha} o \varsigma$ (Ausnahme: phonologisch gekürztes 'A $\gamma \dot{\varepsilon} \lambda \varepsilon \omega$ s mit Synizese $\chi 131,247)$, vgl. Frisk II 529

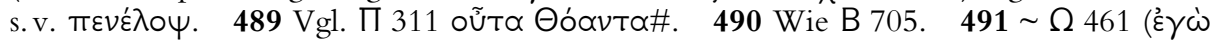

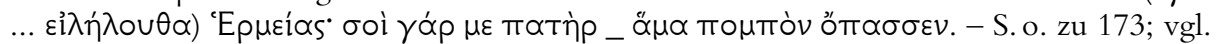

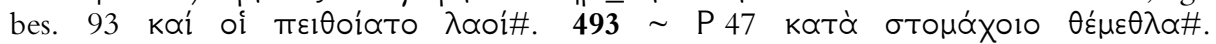
494-499 Originäre Hexameter, in denen altes Material verwendet ist. 494 Gen.

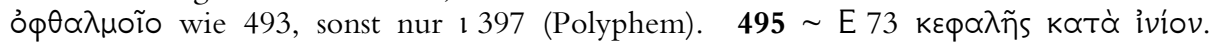

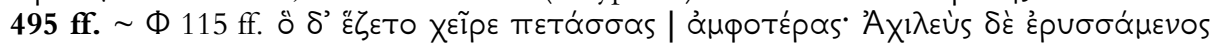

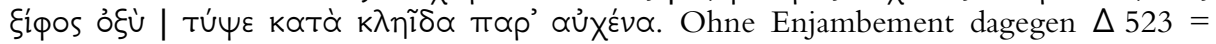

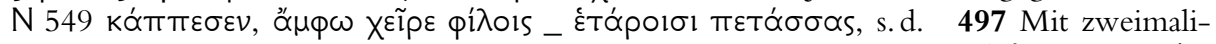
gem /-ss-/, aber erkennbar ionisch (hiattilgendes und silbenschließendes $\nu \tilde{u}$ દ̇ $\phi \varepsilon \lambda \kappa \cup \sigma \tau ı$ тóv,

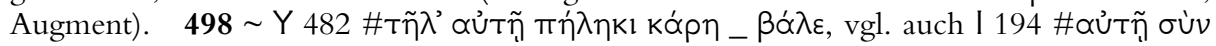
фó $\mu ı \gamma \gamma l$; Versschluss formelhaft. Wie der folgende Vers als ep. Fünfzehnsilbler lesbar,

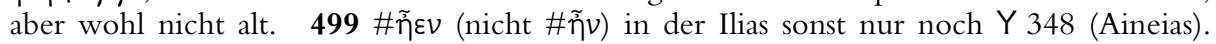

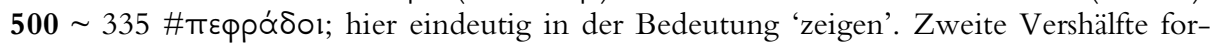

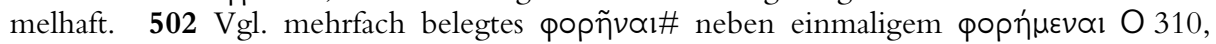

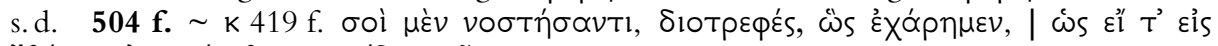
' 


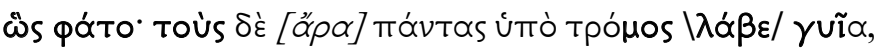

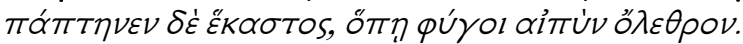

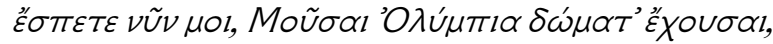

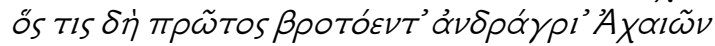

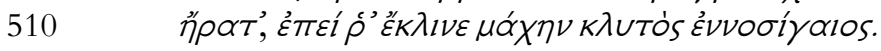

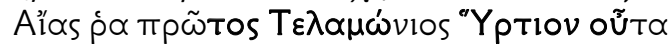

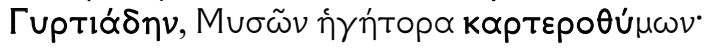

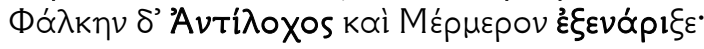

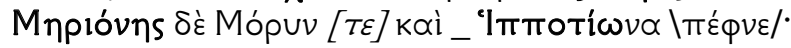

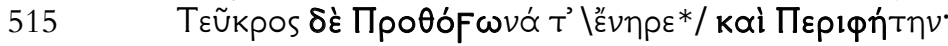

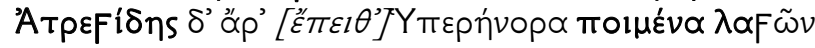

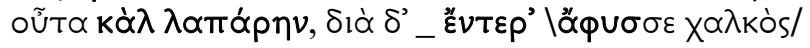

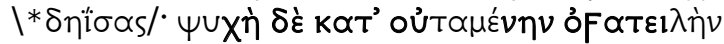

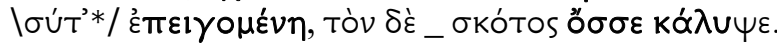

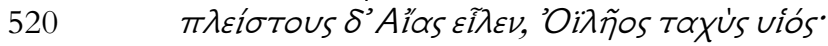

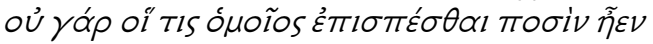

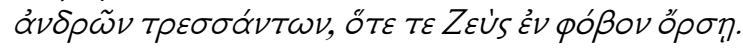

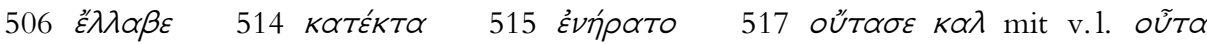

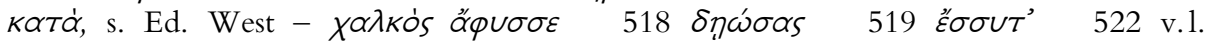

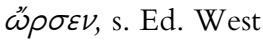

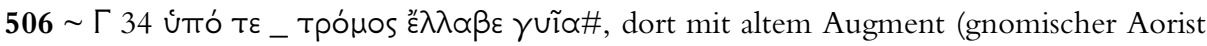

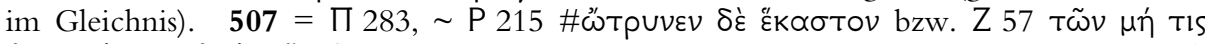

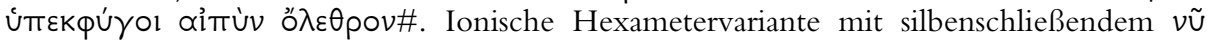

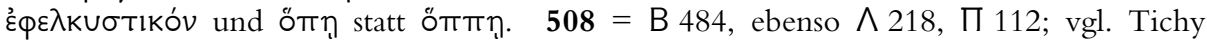

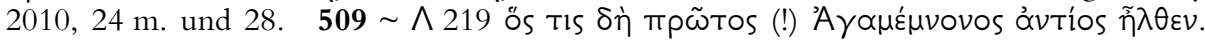

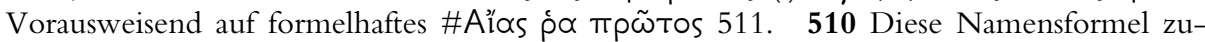
letzt 135, dann nochmals O 173, 184 im Gespräch mit Iris. $\mathbf{5 1 1} \sim$ Z 5, M 378, N 809

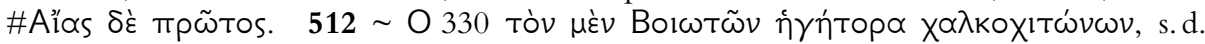

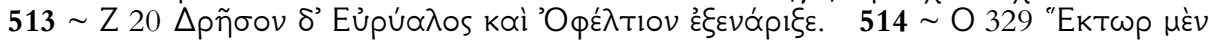

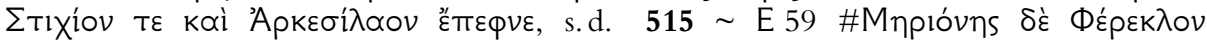

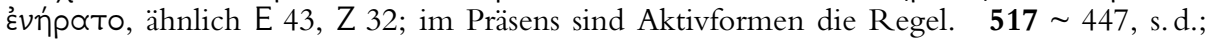

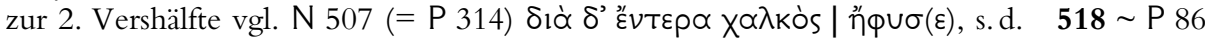

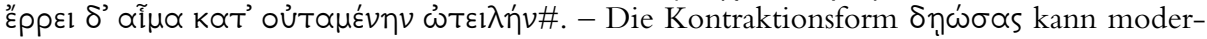

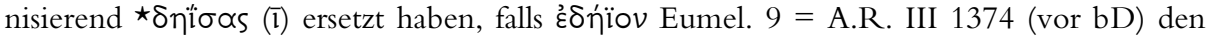

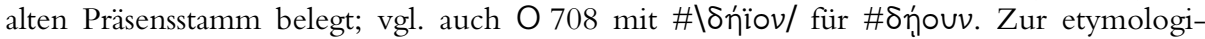
schen Problematik s. Chantraine, DELG 271. 520 Originärer Hexameter mit Augment-

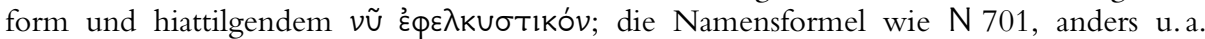

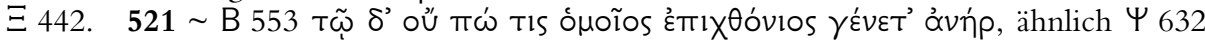

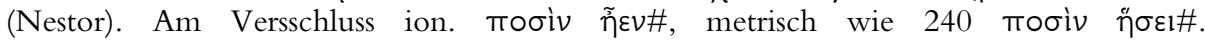

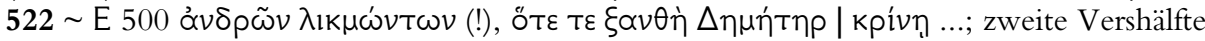
formelhaft. 


\section{Zeichen und Notation}

Metrum: epischer Fünfzehnsilbler (= katalektischer choriambischer Tetrameter, freiere Form des Priapeus) - Hexameter

Sprache: $\quad$ homerisches Äolisch in ionischer Aussprache - Ionisch des 8. Jahrhunderts mit konventionellen Äolismen

$\alpha \beta \gamma \delta$ griechische Kursive: überlieferter homerischer Wortlaut, der in den restituierten Text nicht aufgenommen wurde, bzw. sich der sprach- und versgeschichtlichen Restitution entzieht

$[\alpha \beta \gamma \delta] \quad$ Teil des Hexameters, im restituierten Vers gestrichen

$\mid \alpha \beta \gamma \delta / \quad$ im restituierten Vers ersetzt (das Überlieferte im oberen Apparat)

$\langle\alpha \beta \gamma \delta\rangle \quad$ in den restituierten Vers eingefügt

$\{\ldots\} \quad$ interpolierter Vers

fett Choriambus

$\square_{-} \square \quad$ Tiefstrich mit Abstand: alte Versgrenze nach der 8. Silbe, die mit einer Wortgrenze zusammenfällt

﹎ Tiefstrich ohne Abstand: alte Versgrenze, die in eine unechte (!) Kom-

$\begin{array}{ll} & \text { positionsfuge fällt (bei Univerbierungen, besonders } \\ +_{\square} & \text { bei der Restitution korrigiert, z.T. mit Ed. West }\end{array}$

$\star_{\square} \quad$ (in Ilias und Odyssee) unbezeugt, rekonstruiert

$\square^{\star} \quad$ Wortform (in Ilias und Odyssee) unbezeugt, aber durch sprachliche Regeln eindeutig vorgegeben; bei Flexionsformen, aber z.B. auch bei restituiertem Verbum simplex gegenüber bezeugtem Verbalkompositum /-s. / silbenschließendes -s (-s) vor vokalischem Anlaut.

Der obere Apparat korrespondiert im wesentlichen mit $\mid \alpha \beta \gamma \delta /$ und bietet in griechischer Kursive den überlieferten Text.

Der untere Apparat dient dazu, die Restitution bzw. den Verzicht auf eine solche zu begründen und erwägenswerte Alternativen zu nennen. Vollständigkeit der Textparallelen ist nicht angestrebt.

Wenn eine restituierte 1. Vershälfte ausnahmsweise zwei Choriamben umfasst, sind beide - insgesamt also drei - im Druck hervorgehoben. 


\section{Verzeichnis der zitierten Literatur}

Berg, Nils, „Parergon metricum: der Ursprung des griechischen Hexameters“. Münchener Studien zur Sprachwissenschaft 37, 1978, 11-36.

Borchardt, Rudolf, Prosa II. Nachworte und Abhandlungen. Hrsg. v. Marie Luise Borchardt unter Mitarb. v. Ernst Zinn. Stuttgart 1959. - S. 7-108: „Grundriß zu Epilegomena zu Homeros und Homer“ [1944/45].

Forssman, Bernhard, „Fortführung von Relativsätzen im Avestischen“. Münchener Studien zur Sprachwissenschaft 45, 1985, 55-67.

Friedrich, Wolf-Hartmut, Verwundung und Tod in der Ilias. Göttingen 1956.

LIV = Rix, Helmut, Martin Kümmel, Lexikon der indogermanischen Verben. Die Wurzeln und ihre Primärstammbildungen. 2. Auflage. Wiesbaden 2001.

Schadewaldt, Wolfgang, Iliasstudien. 3. Auflage. Darmstadt 1966. - 1. Auflage Leipzig 1938

Tichy, Eva, Älter als der Hexameter? Schiffskatalog, Troerkatalog und vier Einzelszenen der Ilias. Bremen 2010.

Tichy, Eva, Ilias diachronica. Preprint. Universitätsbibliothek Freiburg 2010-, Dokumentenserver http://www.freidok.uni-freiburg.de/volltexte. - Bisher verfügbar: Ny, /7620; Ksi, /7735; Omikron, /8017; Iota, /8282; Kappa, /8333; Lamb$\mathrm{da}, / 8615$.

West, Martin L., Introduction to Greek Metre. Oxford 1987.

West, Martin L., Homeri Ilias. I. Stuttgart/Leipzig. II. München / Leipzig 1998-2000. $[=$ Ed. West $]$

West, Martin L., The Making of the Iliad. Disquisition and Analytical Commentary. Oxford 2011.

Wilamowitz-Moellendorff, Ulrich v., Griechische Verskunst. Berlin 1921. 


\section{Kleines Sach- und Wortregister}

Archaeologia Homerica X

Aristarch s. Homertext

Aristoteles s. Homerbild und

Kulturentwicklung

Bremer Stadtmusikanten 188ff.

Bronzezeit s. Griechenland

Double deixis in Homeric Speech: hóde und hóutos 63ff.

Etymologie zu pérthō und eáphthe $119 f$.

Griechenland und Kleinasien in der Spätbronzezeit

Ahhijawa 149

Hethiter, Hetthitisch $147 f$.

Homer 170

Kolb gegen Korfmann 143

Schliemann H. $143 f$.

Spätbronzezeit $141 \mathrm{ff}$.

Troia 141ff.

Schrott R. widerlegt 142

Tawagalawa-Brief 166

Homerbild, Homerdeutung 263ff.

Aristoteles 269

Arten von Handeln 300

Geschichtszeit 280

Handlung bei Aristoteles 292

Handlung bei Homer 292

Ilias gemacht? 297

Innere Vorgänge 288

Menis-Handlung 282

Motivation des Handelns 279

Poetische Verfahrensweise 280

Homerische Hymnen $1 \mathrm{ff}$.

als Opfergabe 23
Homertext in der Antike 239ff.

Aristarch 193ff., 245

Didymos 244

Zenodots Homertext 248

Ilias diachronica $335 \mathrm{ff}$.

Analyse des Xi 335

Homer 336

metrische Entwicklung 335

Kulturentwicklung in Europa

Aristoteles 100

Athen 99f.

Deutsche Klassik 109

Homerbestimmtheit 89, 102,

115

Hom.-Diskurs in Ostionien 91

Ionische Wende, Milet 96

Livius Andronicus 104

Moderne Literatur 115

Troia-Literatur im MA 105

Xenophanes von Kolophon $97 \mathrm{f}$.

Lexikon des frühgriech.

Epos (LfgrE) V

Geschichte LfgrE 253ff.

Gründung durch Snell 253

Krise ab 1976255

Latacz J. 89

Parry ante portas 259

Snells Thema 258

Međedović A.

,jugoslawischer Homer ${ }^{6}$ 27ff.

Lord A. $29 \mathrm{ff}$.

oral theory 30

Parry M. 27ff. 
Odysseus bei den Phäaken

Apologoi des Odysseus 217, 220

Heimkehrerhandlung $215 \mathrm{ff}$.

Kyklopen 227

Nostos 215

Poseidon 226

xénos 223

Patroklos und Phoinix 181ff.

Patroklos, s. Wörter

Präpositionalausdrücke,

Lokalpartikeln bei Hom. 45ff.

im Vedischen 48 zur Verwendung mit Gen. 54ff.

Tmesis 45

Scholia omerici

Glosse dialettali 123ff.

Cipro 129

Creta 131

Theory of mind 319ff.

$\bar{e} 319 \mathrm{ff}$.

Snell B. V, X, 253, 263, 319

Wörter im Kontext 85ff.

Sprecherpersönlichkeit 85

,naming Patroclus‘ 86 


\section{Abhandlungen der Akademie der Wissenschaften zu Göttingen Neue Folge}

Wer kauft Liebesgötter? Metastasen eines Motivs

Dietrich Gerhardt, Berlin/New York 2008

ISBN 978-3-11-020291-5

Abhandlungen der Akademie der Wissenschaften zu Göttingen. Neue Folge 1

Römisches Zentrum und kirchliche Peripherie. Das universale Papsttum als Bezugspunkt der Kirchen von den Reformpäpsten bis zu Innozenz III

Hrsg. von Jochen Johrendt und Harald Müller, Berlin/New York 2008

ISBN 978-3-11-020223-6

Abhandlungen der Akademie der Wissenschaften zu Göttingen. Neue Folge 2

Gesetzgebung, Menschenbild und Sozialmodell im Familien- und Sozialrecht

Hrsg. von Okko Behrends und Eva Schumann, Berlin/New York 2008

ISBN 978-3-11-020777-4

Abhandlungen der Akademie der Wissenschaften zu Göttingen. Neue Folge 3

Wechselseitige Wahrnehmung der Religionen im Spätmittelalter und in der Frühen Neuzeit

I. Konzeptionelle Grundfragen und Fallstudien (Heiden, Barbaren, Juden)

Hrsg. von Ludger Grenzmann, Thomas Haye, Nikolaus Henkel

u. Thomas Kaufmann, Berlin/New York 2009

ISBN 978-3-11-021352-2

Abhandlungen der Akademie der Wissenschaften zu Göttingen. Neue Folge 4/I

Wechselseitige Wahrnehmung der Religionen im Spätmittelalter und in der Frühen Neuzeit.

II. Kulturelle Konkretionen (Literatur, Mythographie, Wissenschaft und Kunst)

Hrsg. von Ludger Grenzmann, Thomas Haye, Nikolaus Henkel

u. Thomas Kaufmann, Berlin/Boston 2012

ISBN 978-3-11-028519-2

Abhandlungen der Akademie der Wissenschaften zu Göttingen. Neue Folge 4/II

Das Papsttum und das vielgestaltige Italien. Hundert Jahre Italia Pontificia

Hrsg. von Klaus Herbers und Jochen Johrendt, Berlin/New York 2009

ISBN 978-3-11-021467-3

Abhandlungen der Akademie der Wissenschaften zu Göttingen. Neue Folge 5

Die Grundlagen der slowenischen Kultur

Hrsg. von France Bernik und Reinhard Lauer, Berlin/New York 2010

ISBN 978-3-11-022076-6

Abhandlungen der Akademie der Wissenschaften zu Göttingen. Neue Folge 6 
Studien zur Philologie und zur Musikwissenschaft

Hrsg. von der Akademie der Wissenschaften zu Göttingen, Berlin/New York 2009. ISBN 978-3-11-021763-6

Abhandlungen der Akademie der Wissenschaften zu Göttingen. Neue Folge 7

Perspektiven der Modernisierung. Die Pariser Weltausstellung, die Arbeiterbewegung, das koloniale China in europäischen und amerikanischen Kulturzeitschriften um 1900 Hrsg. von Ulrich Mölk und Heinrich Detering, in Zusammenarb. mit Christoph Jürgensen, Berlin/New York 2010

ISBN 978-3-11-023425-1

Abhandlungen der Akademie der Wissenschaften zu Göttingen. Neue Folge 8

Das strafende Gesetz im sozialen Rechtsstaat. 15. Symposion der Kommission:

„Die Funktion des Gesetzes in Geschichte und Gegenwart"

Hrsg. von Eva Schumann, Berlin/New York 2010

ISBN 978-3-11-023477-0

Abhandlungen der Akademie der Wissenschaften zu Göttingen. Neue Folge 9

Studien zur Wissenschafts- und zur Religionsgeschichte

Hrsg. von der Akademie der Wissenschaften zu Göttingen, Berlin/New York 2011 ISBN 978-3-11-025175-3

Abhandlungen der Akademie der Wissenschaften zu Göttingen. Neue Folge 10

Erinnerung - Niederschrift - Nutzung.

Das Papsttum und die Schriftlichkeit im mittelalterlichen Westeuropa

Hrsg. von Klaus Herbers und Ingo Fleisch, Berlin/New York 2011

ISBN 978-3-11-025370-2

Abhandlungen der Akademie der Wissenschaften zu Göttingen. Neue Folge 11

Erinnerungskultur in Südosteuropa

Hrsg. von Reinhard Lauer, Berlin/Boston 2011

ISBN 978-3-11-025304-7

Abhandlungen der Akademie der Wissenschaften zu Göttingen. Neue Folge 12

Old Avestan Syntax and Stylistics

Hrsg. von Martin West, Berlin/Boston 2011

ISBN 978-3-11-025308-5

Abhandlungen der Akademie der Wissenschaften zu Göttingen. Neue Folge 13

Edmund Husserl 1859-2009. Beiträge aus Anlass der 150. Wiederkehr des Geburtstages des Philosophen

Hrsg. von Konrad Cramer und Christian Beyer, Berlin/Boston 2011

ISBN 978-3-11-026060-1

Abhandlungen der Akademie der Wissenschaften zu Göttingen. Neue Folge 14 
Kleinüberlieferungen mehrstimmiger Musik vor 1550 in deutschem Sprachgebiet.

Neue Quellen des Spätmittelalters aus Deutschland und der Schweiz

Hrsg. von Martin Staehelin, Berlin/Boston 2011

ISBN 978-3-11-026138-7

Abhandlungen der Akademie der Wissenschaften zu Göttingen. Neue Folge 15

Carl Friedrich Gauß und Russland.

Sein Briefwechsel mit in Russland wirkenden Wissenschaftlern

Hrsg. von Karin Reich und Elena Roussanova, unter Mitwirkung von Werner Lehfeldt, Berlin/Boston 2011

ISBN 978-3-11-025306-1

Abhandlungen der Akademie der Wissenschaften zu Göttingen. Neue Folge 16

Der östliche Manichäismus - Gattungs- und Werksgeschichte.

Vorträge des Göttinger Symposiums vom 4./5. März 2010

Hrsg. von Zekine Özertural und Jens Wilkens, Berlin/Boston 2011

ISBN 978-3-11- 026137-0

Abhandlungen der Akademie der Wissenschaften zu Göttingen. Neue Folge 17

Studien zu Geschichte, Theologie und Wissenschaftsgeschichte

Hrsg. von der Akademie der Wissenschaften zu Göttingen, Berlin/Boston 2012 ISBN 978-3-11- 028513-0

Abhandlungen der Akademie der Wissenschaften zu Göttingen. Neue Folge 18

Rom und die Regionen. Studien zur Homogenisierung der lateinischen Kirche im Hochmittelalter Hrsg. von Jochen Johrendt und Harald Müller, Berlin/Boston 2012

ISBN 978-3-11- 028514-7

Abhandlungen der Akademie der Wissenschaften zu Göttingen. Neue Folge 19

Die orientalistische Gelehrtenrepublik am Vorabend des Ersten Weltkrieges. Der Briefwechsel zwischen Willi Bang(-Kaup) und Friedrich Carl Andreas aus den Jahren 1889 bis 1914 Hrsg. von Michael Knüppel und Aloïs van Tongerloo, Berlin/Boston 2012 ISBN 978-3-11- 028517-8

Abhandlungen der Akademie der Wissenschaften zu Göttingen. Neue Folge 20 
Bereitgestellt von | SUB Göttingen Angemeldet

Heruntergeladen am | 27.10.14 12:39 
Bereitgestellt von | SUB Göttingen Angemeldet

Heruntergeladen am | 27.10.14 12:39 
Bereitgestellt von | SUB Göttingen Angemeldet

Heruntergeladen am | 27.10.14 12:39 